Please do not destroy or throw away this publication. If you have no for it, with to the Geological Survey at Washington and ask for a from treturn it

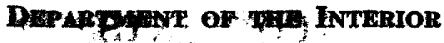
Eubert Work, Seviotary

U. S. GgOLOGICAL BÜRVT Geore Oth Smith, Director

Water-Supply Paper 596-A

\title{
METHODS OF EXPLORING AND REPAIRING LEAKY ARTESIAN WELLS
}

\author{
PAPERS BY
}

JOHN McCOMBS AND ALBERT G. FIEDLER

WITH A PREFACE BY

OSCAR E. MEINZER

JAN 7 S 3 ig

\author{
Contribations to the hydrology of the United States, 1927 \\ (Pages 1-32) \\ Pablished April 2, 1927
}

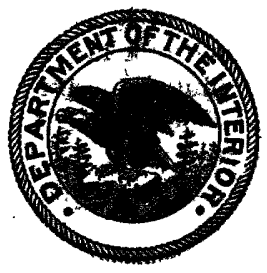

UNITED STAFES

GOVERNMENT PRINTING OFEICE

, WABHINGTON

1927 


\section{CONTENTS}

Preface, by Oscar E. Meinzer.

Methods of exploring and repairing leaky artesian wells on the island of

Oahu, Hawaii, by John McCombs.

Introduction.

Oahu artesian basins

Historical sketch

Geology and hydrology

Methods of drilling wells

Determination of underground leakage

Methods of repairing leaky wells

Recasing

Plugging or sealing

Laws relating to artesian wells

The Au deep-well current meter and its use in the Roswell artesian

basin, New Mexico, by Albert G. Fiedler

Description of the meter and accessories_._._._._.

Rating the meter

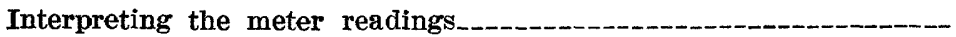

Tests of specimen wells

Platw 1. Flowing wells in the Roswell artesian basin, New Mexico: $A$, Well of Oasis Cotton Co.; $B$, Well of H. D. King

2. Old type of dump bucket used in plugging wells : $A$, Bucket with ball-shaped valve pulled up, ready to be charged; $B$, Enlarged view of lower end of bucket with valve pulled up; $O$, Bucket with rod forced down, so that it has released the valve and engaged the umbrella latch; $D$, Enlarged view of upper end of bucket with umbrella latch engaged

3. $A$, Swedge used in cleaning defective wells before recasing them and the subend to which dump bucket is attached; $B, A u$ deep-well current meter

4. A, Apparatus for using $\mathrm{Au}$ deep-well current meter in exploring wells; $B$, Same apparatus set up

5. A, Automobile truck on which reel is permanently mounted; $B$, Cable passing over odometer to well

Figure 1. Section of the island of Norderney, Germany, showing the application of the Badon Ghyben-Herzberg theory

2. Section of the Waikiki artesian area, Honolulu

3. Diagram showing head of Oahu College well, Honolulu, from 1899 to 1925

4. Latest type of 3-inch dump bucket used in plugging wells_...-

5. Section of well 34, on Young Street, Honolulu, showing method of plugging. 


\title{
CONTRIBUTIONS TO THE HYDROLOGY OF THE UNITED STATES, 1927
}

\author{
N. C. Grovkr, Chief Hydraulic Engineer
}

\section{METHODS OF EXPLORING AND REPAIRING LEAKY ARTESIAN WELLS}

\section{PREFACE}

By Oscar E. Metnzer

The use of a current meter to explore wells, as described in the following papers by McCombs and Fiedler, is a distinct advance in methods both of hydrologic research and of practical well management. So far as I am informed, this method was first used successfully in 1918, by R. D. Klise, of the United States Geological Survey, in a study of the artesian wells of Honolulu.

The principle involved is very simple. The meter is let down into the well, where it records the velocity of the water at any depth desired; with the velocity and the diameter of the well known, the rate of flow at any point can be determined. Hence, a series of measurements taken at successive levels from the bottom to the top of the well will show just where the water enters and in what amounts, where it leaks out and in what amounts, and how much is delivered at the surface. For certain investigations it may be necessary to devise apparatus for measuring the diameter of a well at any depth, but thus far no serious difficulties have arisen on account of uncertainty as to the diameter.

This method has now been successfully used in the main artesian areas on the island of Oahu and in the Roswell artesian basin, in the Pecos Valley, N. Mex. In both of these areas the problem has been to ascertain the quantity of artesian water that is wasted by leakage from the wells at nonartesian horizons. The exploration of an artesian well is of immediate practical value to the well owner in giving 
him definite and reliable information as to whether any leaks occur in his well; if so, at what depths and in what amounts and about how much the yield can be increased by recasing. Moreover, the exploration of all or a considerable proportion of the wells of an artesian basin furnishes essential data to the investigator who is charged with the duty of making an inventory of the artesian water supply of the basin for the purpose of bringing about the maximum beneficial use without harmful overdevelopment.

I believe the current meter will eventually be used also in exploring pump wells to determine the horizons at which water enters the wells. In wells that extend through beds permeated with salt water it may, however, be more practicable to detect leaks of salt water into the wells by chemical or electrolytic methods.

The value of the current meter in exploring wells has been impressed on me by my experience in the Roswell artesian basin of New Mexico. In 1916 I spent about 10 days in the Pecos Valley near Roswell planning an investigation of its artesian-water supply. At that time the artesian pressure had already declined greatly, and many ranches along the margin of the original area of artesian flow had been abandoned because the water level in the wells had gone too low for profitable pumping. There was much local discussion and difference of opinion as to whether the decline in artesian pressure was due to overdevelopment or to subterranean leakage out of the wells through corroded or defective casings, but almost no definite information was available concerning this very vital question. I had taken with me a Price current meter and some equipment for inserting it into flowing wells. In the preliminary tests which I was able to make I did not succeed in getting any information as to leakage, but $I$ was convinced that with more substantial equipment it would be feasible to explore flowing wells for underground leakage with a current meter.

On account of the World War and other conditions, the investigation in the Roswell artesian basin had to be postponed until 1925, when it was taken up by Mr. Fiedler. He was provided with a current meter designed especially by Carl $H$. Au for use in exploring deep wells. (See p. 24.) The first flowing well to be explored was an old well 932 feet deep that was suspected of leaking. The meter was let down about 25 feet at a time and readings were made at. each level. The readings showed that the current increased from the bottom to about the 785-foot level, and that from this level to the top it was nearly constant at about 3.80 feet a second, or 605 gallons a minute, proving that the casing was not leaking at any point. In other wells, as described by Mr. Fiedler in this report, leaks of various kinds were found, the position of each leak was determined. 
and the quantity of artesian water wasted through it was measured or estimated. Thus the underground waste of artesian water need no longer be a matter of mere opinion, as the facts can be definitely determined by exploring each well.

For the work in Honolulu the Price current meter was used, although it was recognized that this meter was not designed for this purpose. (See p. 12.) For the work in New Mexico, however, the special deep-well meter constructed by $\mathrm{Mr}$. $\mathrm{Au}$ is giving good service. The outer jacket of this meter is a 3-inch pipe, but $\mathrm{Mr}$. Au is at present working on a meter of still smaller diameter. The methods of lowering the meter in the New Mexico work are more rapid than those used in the Honolulu work. Where large leaks are encountered special precautions have to be taken to prevent the meter from being carried out of the well by the outward current.

On account of the great value of the artesian-water supply in the Honolulu district it was wise public policy to carry out a somewhat expensive program of thorough recasing or plugging all leaky artesian wells. Great credit is due to the governor and the legislature for authorizing this vital program of conservation and to $\mathbf{M r}$. MeCombs and his colaborers for carrying it out so effectively. The value of the work already completed is indicated by the fact that the leakage which has been stopped is equal to more than one-fourth of the total quantity of artesian water used for the public supply of Honolulu. The experience on this project has shown that recasing and plugging leaky wells are difficult and expensive operations that require the services of a skillful driller with adequate drilling equipment, working under the instruction of a competent hydraulic engineer. It is indeed fortunate that the experience gained and the methods developed through the expensive and difficult work done in the Honolulu district have been recorded by Mr. McCombs in the paper presented for the benefit of other operators in various parts of the world who will have to meet similar problems.

The investigation in the Roswell artesian basin may show that the water there is not sufficiently valuable to justify a program of conservation similar to that followed in Honolulu, but Mr. McCombs's paper will help materially in presenting the problem to the people of this basin in tangible form, and their decisions in regard to their future artesian-water policy will be based on sounder information than would otherwise have been available. Plate 1 shows two very strong flowing wells recently drilled in the Roswell artesian basin. Obviously a well that will produce so much water by artesian pressure is very valuable while it is in good condition, but may become a great liability to the community if its casing becomes leaky. 


\section{METHODS OF EXPLORING AND REPAIRING LEAKY ARTESIAN WELLS ON THE ISLAND OF OAHU, HAW AII}

\section{By JoHN MоСомвs}

\section{INTRODUCTION}

This paper is intended primarily to present certain methods of testing and repairing artesian wells which have been devised and used on the island of Oahu. These methods are so completely dependent on the geology and hydrology of the coastal plain and on the well-drilling procedure that a brief discussion of these subjects is also necessary.

The writer is indebted to Mr. M. H. Carson, district engineer, who, as chief hydrographer for the Territory, is in charge of artesian investigations. and who has reviewed this report and given many valuable suggestions; to Dr. H. S. Palmer, of the University of Hawaii, and Mr. A. H. Hobart, who reviewed the report from the standpoint of geologist and well driller, respectively; and to Mr. B. L. Bigwood, who read the manuscript. Dr. H. L. Lyon, of the Hawaiian Sugar Planters' Association, has assisted materially in the investigations and has furnished information of much value. Special acknowledgments are due to the pioneer well drillers, Messrs. John A., James S., and Lincoln L. McCandless, who have given freely of the information acquired in more than 40 years of well drilling in Honolulu.

\section{OAHU ARTESIAN BASINS}

\section{HISTORICAL SKETCH}

The only island of the Hawaiian group on which artesian water has been extensively developed is Oahu. The first flowing well was drilled on this island in 1879 , and up to the end of 1925 about 600 wells had been drilled. In 1925 the maximum daily draft on these wells was more than $350,000,000$ gallons, and the average more than $250,000,000$ gallons. This water is the main source of domestic supply for 100,000 people and is used also to irrigate sugar-cane land which produces annually about 140,000 tons of sugar, worth over $\$ 11,000,000$. Artesian water was early recognized as being of much value, and in 1884 a bill was passed by the legislature and signed by King Kalakaua providing for "mechanical appliances to arrest the flow" and providing also that artesian water might not be used solely to drive machinery.

Detailed logs of formations were kept for the earlier wells, and some were published at the time in the newspapers, but the first attempt to preserve records systematically was made by employees 
of the Hawaiian Government Survey Office, under the direction of W. D. Alexander, who was surveyor successively for the Kingdom, the provisional government, the Republic, and the Territory. These records, though incomplete, have been of the greatest value in all subsequent work; in fact, they comprise most of the records available for the period 1879 to 1910 , both well logs and readings of static head.

In 1909 W. C. Mendenhall, then in charge of ground-water investigations for the United States Geological Survey, visited Hawaii, and as a result of conferences with Governor Frear and others arranged with Marston Campbell, then superintendent of public works, to have T. F. Sedgwick, an employee of the public works department, carry out certain investigations as outlined by Mr. Mendenhall. Mr. Sedgwick located most of the wells then in existence, made systematic monthly readings of static head on a considerable number of wells distributed about the island, and determined the salt content of a large number of samples of well water. This work was continued until 1916, and the data so collected have been essential in all subsequent investigations.

The Territorial Legislature of 1915 authorized the appointment of a commission to investigate and report on the water resources of Hawaii. This commission consisted of $K$. G. Larrison, then district engineer in the United States Geological Survey, as chairman, and Arthur G. Smith and Mr. Sedgwick as the other members. It conducted detailed investigations in the Honolulu district between Diamond Head and Red Hill and as a result of its recommendations ${ }^{1 .}$ the legislature of 1917 passed an act which defines waste of artesian water and gives the chief hydrographer authority to investigate and prevent it. This law, as amended by further legislative enactment, is given on pages $22-24$.

Since 1917 the artesian investigations have been conducted by the division of hydrography of the office of the commissioner of public lands, Territory of Hawaii. The successive chief hydrographers of the division have also been district engineers in the United States Geological Survey.

\section{GEOLOGY AND HYDROLOGY}

The artesian water on the island of Oahu occurs in a highly pervious vesicular basalt, locally known as "pukapuka" (Hawaiian, puka $=$ hole). This rock is extensively fissured, but no large cavities are encountered in drilling in it. The rock is, however, rather

\footnotetext{
1 Report of the water commission of the Territory of Hawail to His Excellency, the Governor of Hawaii, 1917. This report is now out of print, but copies are available for consultation at the U. S. Geological Survey, Washington, D. C., and at most of the district offices.
} 
weak and has a tendency to cave under the action of the drill. The upper surface of the water-bearing pukapuka rock in most places slopes $10^{\circ}$ or more toward the sea. It is overlain by a clayey confining bed, above which lie coral limestone, coral mud, coral sand, gravel, recent lava flows, pyroclastic material, and soil. The waterbearing formation or aquifer is very thick. Several wells have been drilled into it 400 feet or more, without passing through it or finding any marked change in the character of the material. In the Honolulu district the confining bed extends up the slope as an effective cover over the aquifer to a height of about 40 feet above sea level. The upper part of the aquifer is exposed and permits entry of fresh water from rain during storms and perhaps from streams at all times.

There is evidence that the lower seaward part of the aquifer is exposed to the sea, so that artesian water can pass freely into the sea, around the lower edge of the confining bed, or sea water can move in the opposite direction into the aquifer. If, before any wells were drilled, the island had been in a lake of fresh water instead of in the sea the rain water that entered the aquifer at the upper end would have passed under the confining bed and would eventually have reached the lake. On account of the extreme permeability of the pukapuka the head of the artesian water would, under those conditions, have been only slightly above the lake level and would have been due entirely to the frictional resistance of the aquifer. The static head on the first wells drilled in the central Honolulu area was, however, more than 42 feet above sea level. It is believed that this static head was due only in small part to frictional resistance in this aquifer but mainly to the difference in specific gravity of the sea water and the fresh artesian water.

The theory of the behavior of fresh water in contact with salt water in a pervious formation, known as the theory of Badon Ghyben and Herzberg, is stated by Brown ${ }^{2}$ as follows:

Wherever a coast is formed of pervious rocks containing ground water that receives continual additions from rainfall, this ground water must move downward and laterally toward the shore and mingle ultimately with the salt water of the sea. Such movements have long been a matter of common knowledge. Even on small porous, sandy islands fresh water can generally be found at an altitude slightly above mean sea level. It might be supposed that in such places the salt water surrounding the island would penetrate the sand to mean sea level and immediately absorb all the fresh water that might percolate downward to its surface. For several physical reasons this does not happen. Such islands are found, in reality to contain a dome-shaped lens of fresh water floating upon a concave surface of salt water. The fresh water is enabled to float upon the salt water because it has a considerably smaller density. This principle was apparently first applied to the hydrology of sea-

${ }^{2}$ Brown. J. S., A study of coastal ground water, with special reference to Connecticut: U. S. Geol. Survey Water-Supply Paper 537, pp. 16-17, fig. 2, 1925. 
coasts by Badon Ghyben, ${ }^{3}$ a Dutch captain of engineers, as the result of investigations made in Holland in 1887 , but gained little notice from hydrologists at that time. It was also published about 1900 by Herzberg, of Berlin, who apparently had no knowledge of the work of Badon Ghyben. Herzberg found in drilling wells on the island of Norderney, one of the East Friesian islands off the coast of Germany, that the depth to the salt water was roughly a function of the height of the water table above mean sea level and of the density of the water of the North Sea. Figure 1 shows the application of his theory.

Let $\mathbf{H}=$ total thickness of fresh water.

$h=$ depth of fresh water below sea level.

$t=$ height of fresh water above mean sea level.

$$
\text { Then } \mathbf{H}=\boldsymbol{h}+\boldsymbol{t} \text {. }
$$

But the column of fresh water $H$ must be balanced by a column of salt water $h$ in order to maintain equilibrium. Wherefore, if $g$ is the specific gravity of sea water and the specific gravity of fresh water is assumed to be 1 ,

whence

$$
\begin{gathered}
\mathrm{H}=h+t=h g \\
h=\frac{t}{g-1} .
\end{gathered}
$$

In any case $g-1$ will be the difference in specific gravity between the fresh water and the salt water. Herzberg gives the specific gravity of the North Sea as 1.027, whence $h=37 t$.

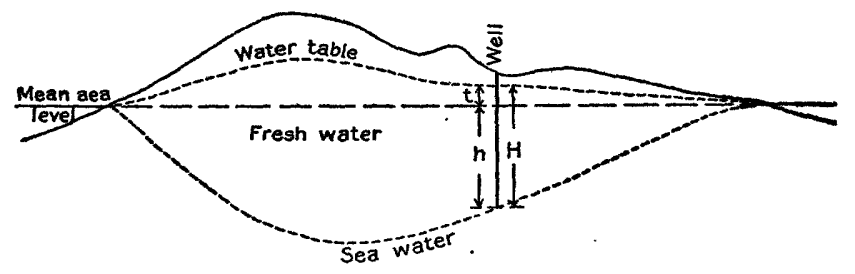

Fraund 1.-Section of the island of Norderney, Germany, showing the application of the Baden Ghyben-Herzberg theory. (From Herzberg)

The action of the water beneath the confining bed on the island of Oahu follows this principle, but the effect is not the same as is shown in Figure 1 for an island with uniform permeability. Consider an ideal section of a permeable formation along a seacoast, with an impervious vertical wall at the shore line extending to a depth of 1,500 feet below sea level but not to the bottom of the permeable formation. Assume further that the water in the permeable formation on the landward side of the wall is as salty as sea water and is standing at sea level. If water is pumped from the landward side, sea water will at once flow under the wall, and the water level on the landward side will, except for friction, remain the same. If fresh water is added by rainfall on the land, the balance will be maintained, but the levels will not be the same; an

Badon Ghyben, W., Nota in verband met de voorgenomen put boring nabij Amsterdam : K. Inst. Ing. Tijdschr., 1888-89, p. 21, The Hague, 1889.

* Herzberg, Baurat, Die Wasserversorgung einiger Nordseebäder : Jour. Gasbeleuchtung und Wasserversorgung, Jahrg. 44, Munich, 1901. 
amount of sea water equal in weight to the added fresh water but smaller in volume will be forced out under the wall, leaving the fresh-water level inside the wall higher than the sea-water level on the outside. As the process of adding fresh water continues the zone of contact between the fresh and the salt water will sink lower and lower until one of two things happens-either the upper surface of the fresh water will reach the top of the wall and thenceforth any water added by rainfall will flow over the wall, or else the zone of contact between fresh and salt water will reach the bottom of the wall and fresh water will begin to flow out under the wall. In either case the zone of contact will thereafter remain stationary.

An actual section in the Waikiki area is shown in Figure 2. It illustrates conditions equivalent in their effect to those discussed above. The wall is present, not as a thin vertical structure but as a sloping sheet of impervious clay. This clay wall is overlain with many other materials, which, except for their weight, do not affect the result.

The average specific gravity of sea water at the surface off the coast of Oahu has been reported by Lyon ${ }^{5}$ as 1.024 , if that of ordinary artesian water is rated as 1 . At greater depth the specific gravity may be somewhat higher. With sea water 1.024 times as heavy as fresh water, the difference in level between the fresh water in the aquifer and the salt water in the sea will increase about 1 foot for each 43 feet of fresh water added. If the wall extends 1,500 feet below sea level the fresh water will stand about 36 feet above sea level, provided the wall rises to that height.

The change in conditions behind this actual wall of impervious clay has gone much farther than in the ideal case outlined above. In 1883, when well 54 (see fig. 2) was drilled, the water in this well rose to a height of 36 feet above sea level and had a very low salt content. It is reasonable to suppose that at that time the fresh water was either flowing out under the confining bed or was flowing over the top of it. As there are no physical evidences of large springs near the 36-foot level, the former supposition is more probably the correct one. By 1892 the head had declined to about 30 feet above sea level, and the water in well 54 had become too salty to drink. In September, 1925, the head was less than 19 feet above sea level and salt water had risen until it began to affect well 37 , at a higher level.

The experience with these wells indicates that salt begins to appear in a well when the theoretical zone of contact between the fresh and salt water is still at a considerable depth below the bottom of the well. This condition may be due in part to the width of the actual

-Lyon, H. L. (botanist, Hawaiian Sugar Planters Association), oral communication. 

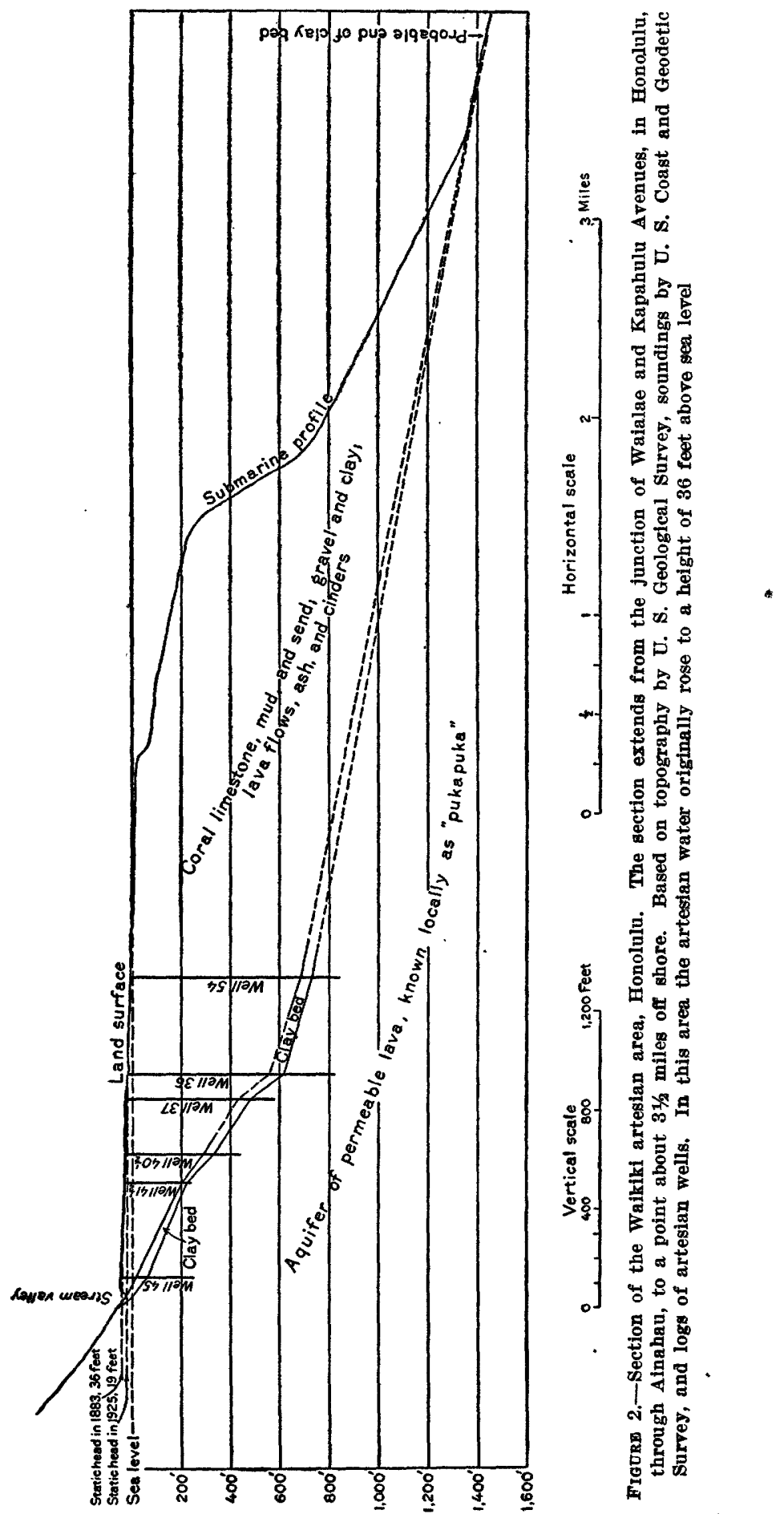


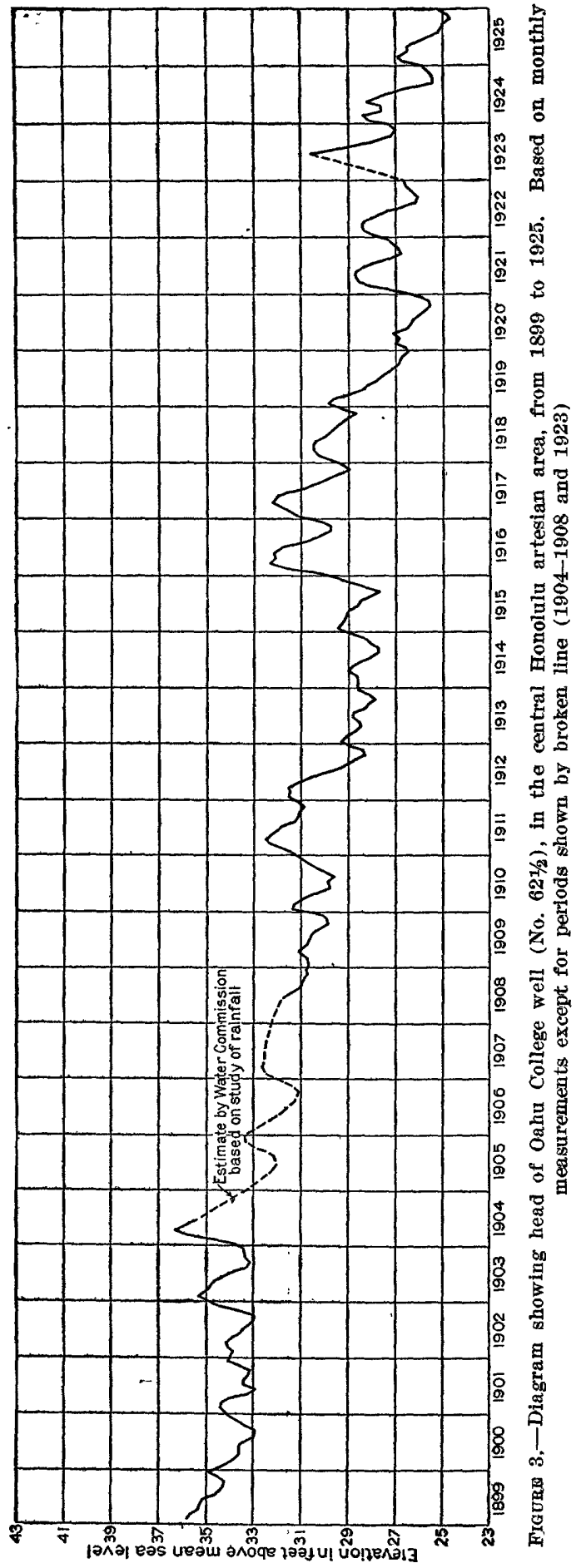

contact zone and in part to the doming up of the salt water under a well that is discharging. Obviously there must be a contact zone of considerable width in which the water contains more salt than normal artesian water but less than sea water. Such an intermediate condition is undoubtedly developed by diffusion of the dissolved salt and by the mixing of salt and fresh water due to the alternate up and down movements of the water in the aquifer, as fluctuations in the head are caused by variations in rainfall, draft, and tide. At the upper limit of this zone the salt content is only slightly greater than that of normal fresh water, but it increases progressively with depth until at the lower limit it is equal to that of sea water. If the specific gravity of the sea water is greater than has been assumed, the contact between fresh and salt water will be theoretically higher and the transition zone correspondingly thinner.

The relation of pumpage to loss of static head and invasion by sea water, as outlined above, is the basis for the rather extensive 
conservation which has been planned and enforced by the division of hydrography. Most artesian basins in the United States have been overdeveloped and have suffered large losses in head. In most. of them, however, the process of decline in artesian head is selflimiting, and the principal damage that results from 'overdevelopment and waste of artesian water is in making pumping necessary. On the island of Oahu the drop in artesian head produces more serious results. As the head is due to an equilibrium between fresh and salt water, a loss of 1 foot in artesian head will be accompanied. by a rise of the salt water of about 42 feet. Thus the decline of head becomes of great significance, as it indicates loss of storage.

The diagram given in Figure 3 shows the head of a well at Oahu College since 1899. It shows annual and secular fluctuations due to variations in rainfall but with a persistent net decline through the period of 26 years, due to heavy withdrawal of water through wells. This well is in the central artesian area, which is adjacent to the Waikiki artesian area referred to in the preceding discussion and shown in Figure 2. The exceptionally long and continuous record. of the Oahu College well, however, shows conditions that are typical of all the artesian areas in Honolulu.

\section{METHODS OF DRTLING WELLS}

The wells on Oahu are always drilled with cable tools. The usual practice is to "spud in" the hole through the loose surface materials, to introduce, if necessary, a short section of large pipe to prevent caving, and to drill to the aquifer with a bit slightly larger than the size of casing that is to be used. When the first flow is encountered the hole is cased throughout, and the casing landed at the bottom by allowing it to drop a few inches. A bit that will just clear the casing is then used, and the hole is usually extended 60 to 100 feet into the aquifer. The clay cap, being slightly plastic, probably flows around the lower end of the casing and makes a tight seal.

In some wells, where gravel or other loose material is encountered, it is necessary to reduce the casing. The string of larger casing is run down to the caving material and driven into it as far as possible by use of a sand bucket and drive blocks. The drilling is then continued with a smaller bit, and when the aquifer is reached enough casing to extend above the bottom of the larger string is dropped in. This practice is not commendable but is nearly always followed when caving formations are encountered. It is worthy of note that reduced wells in general become defective sooner than those which are not reduced.

\section{DETERMINATION OF UNDERGROUND IEAKAGE}

It was observed early in the history of well drilling on Oahu that flowing wells can be obtained only in certain definite areas on the 
coastal plain. These areas are separated by other areas where no artesian water is found. It was also observed that within a given area the water in all wells has the same static head but that in general the head in the different areas is not the same. This observation was confirmed by the investigations of the water commission in 1916. The head fluctuates with draft and rainfall, and also to a less extent with barometric pressure and perhaps with tide, but almost uniformly in each area.

These isopiestic areas or areas of equal static head are unique and their existence has made the discovery of underground leakage simple. Levels have been run to nearly all the 149 wells in the Honolulu city area, and static heads are determined periodically. Wells on which the head is found to be noticeably low are at once known to be leaking.

A number of wells that have been found deficient in static head have been further examined by use of a current meter equipped to be lowered into the well. The meter used until recently is a Price meter, of the kind used by the Geological Survey in gaging streams. ${ }^{\circ}$ It is equipped with a wire guard to protect the cups, and the end of the yoke is fastened rigidly to a length of $3 / 8$-inch pipe. This adaptation of the Price meter was made by R. D. Klise in 1918. This meter is, however, not wholly satisfactory for this purpose. It is made to run with the axis vertical, but when it is used in a well the axis is horizontal and the friction is thereby increased, with consequent loss of sensitiveness and accuracy. Another disadvantage is that the meter is too large to go into a well that is less than 6 inches in inside diameter. An Au meter is now used. (See p. 24.) In early tests the meter was lowered into the wells on a wire, but high velocities were found, and where large leaks were encountered the meter was carried out through the holes in the casing. It therefore became necessary to have a more rigid support. The process used at present is the result of changes and modifications made over a period of seven years.

If the well that is to be tested flows at the surface the casing is extended above the static level, and all surface flow is thereby stopped. Any current then observed is due to leaks in the casing. It is highly desirable to stop the surface flow before testing wherever the head is low enough to permit, because velocity ascertained from a single reading with a current meter is more nearly accurate than velocity determined as the difference of two readings. In wells whose casing is reduced in size underground the resulting increase in velocity obscures the result if surface flow is permitted. For

- For a description of the Price current meter see manual of the manufacturers, W. \& I. E. Gurley, Troy, N. Y., or Hoyt, J. C., and Grover, N. C., River discharge, 4th ed., pp. 6-22, John Wiley \& Sons, 1920. 
low heads-that is, less than 20 feet-the extended casing does not need to be very heavy. The easiest method of making a tight joint between the well casing and the extension is to use for the extension a pipe about 2 inches larger in diameter, slip it over the casing, and calk between with oakum or rope yarn.

The equipment necessary consists of the meter, a tripod sufficiently high and strong to support two men at the height of the extended casing, a single sheave block, a coil of $5 / 8$-inch rope long enough to reach to the bottom of the well, a reel of insulated twostrand copper wire somewhat longer than the rope, 200 feet of $3 / 8$-inch pipe in 10-foot lengths, two pipe wrenches, a roll of friction tape, steel tape, telephone receiver, dry battery, and stop watch.

The meter is lowered into the well on the pipe, a length at a time, electrical connection is made by means of the insulated wire, and the weight is supported on the rope. It is advisable to tape the wire to the pipe at each joint in the pipe and to slip a half hitch in the rope over the pipe at close intervals. In these tests 200 feet of pipe has always been found sufficient, and frequently 50 feet is enough, but care must be taken not to lower the top end of the pipe below the first large leaks, because it may be pulled to the side of the casing by the outward current and become fastened in the openings. Observations for velocity can be made as each length of pipe is being screwed on. Observations made as the pipe is lowered will reveal breaks in the wiring. If the meter fails to register at least twice as it is lowered 10 feet, something is wrong.

The following table gives results of a number of complete examinations for leakage. The total underground leakage discovered in Honolulu to 1925 is approximately 7,750,000 gallons a day, of which $5,900,000$ gallons a day has been stopped by suitable repairs. The conservation effected in thus saving artesian water that would otherwise have been wasted by flowing into the sea through underground passages will be better appreciated if the quantity is compared with the total quantity of artesian water consumed from the Honolulu waterworks, which in 1925 averaged $22,000,000$ gallons a day.

As most of the artesian water is comparatively noncorrosive, few leaks originate inside the casing. The coral is the trouble maker, as it is more or less pervious and being below sea level frequently carries water which is very salty; it is also somewhat soluble and is easily eroded. Probably the first step toward the formation of a leak is corrosion of the pipe from the outside, probably by salt water. As soon as leaks are formed the process changes, and fresh water under considerable pressure from inside dissolves and erodes the coral until the support is gradually removed from around the casing. It has been noted that the head on a well that is at first only slightly 
defective will drop abruptly later, indicating a large waste of water. This sudden decrease in head probably indicates the change from a number of small leaks to a general collapse of the casing, allowing free flow of the water through large solution passages in the coral.

A leak of another type is that which occurs around the bottom of an improperly seated casing. A leak of a third type, which is less common, occurs in a well that is not cased throughout. If the log of the well being tested is available or even known approximately, the type of leak can be determined with the current meter. If it is of the first type mentioned above, a current will be indicated and the velocity will increase suddenly at a definite depth, always in a pervious formation, and will not increase below that formation. If the leak is caused by an improperly seated casing, a current will first be indicated near the bottom of the well, at the top of the aquifer, and the velocity will at once reach its maximum and will decrease almost to zero at the bottom. Leaks of the third type will usually be recognized by a gradual increase in velocity, followed in some wells by a decrease due to the enlarged cross section that results from caving.

\section{Defective wells in the Honolulu district}

\begin{tabular}{|c|c|c|c|c|c|c|c|}
\hline \multirow{2}{*}{ Well No. } & \multirow{2}{*}{$\begin{array}{l}\text { Depth } \\
\text { (feet) }\end{array}$} & \multirow{2}{*}{$\begin{array}{c}\text { Diameter } \\
\text { (inches) }\end{array}$} & \multicolumn{2}{|c|}{$\begin{array}{l}\text { Static head (feet } \\
\text { above mean sea } \\
\text { level) }\end{array}$} & \multicolumn{2}{|c|}{$\begin{array}{c}\text { Leakage (gallons } \\
\text { a day) }\end{array}$} & \multirow{2}{*}{ Remarks } \\
\hline & & & Normal a & Observed & $\begin{array}{c}\text { Esti- } \\
\text { mated b }\end{array}$ & $\begin{array}{l}\text { Meas- } \\
\text { ured }\end{array}$ & \\
\hline $\begin{array}{l}2 \\
3 \\
3 \\
22\end{array}$ & $\begin{array}{r}740 \\
850 \\
300 \\
700 \\
500 \\
495 \\
775 \\
650 \\
762 \\
497 \\
830 \\
573 \\
734 \\
1,152 \\
765 \\
600\end{array}$ & $\begin{array}{c}55 / 8 \\
55 / 8 \\
55 / 8 \\
55 / 8 \\
55 / 8 \\
55 / 8 \\
95 / 8 \\
55 / 8 \\
55 / 8 \\
75 / 8 \\
75 / 8 \\
4 \\
75 / 8 \\
95 / 8 \\
95 / 8 \\
95 / 8 \\
12 \\
10 \\
75 / 8\end{array}$ & $\begin{array}{l}22.2 \\
22.2 \\
20.7 \\
29.3 \\
32.0 \\
27.6 \\
28.0 \\
28.0 \\
27.5 \\
27.5 \\
27.5 \\
23.0 \\
20.1 \\
27.1 \\
32.0 \\
27.0 \\
30.8 \\
27.6 \\
30.8\end{array}$ & $\begin{array}{r}6.4 \\
6.2 \\
19.2 \\
24.0 \\
18 \\
17.5 \\
12.2 \\
23.4 \\
26.0 \\
23.6 \\
9.1 \\
19.3 \\
11.8 \\
23.0 \\
13.5 \\
7 \\
21 \\
25.6 \\
13.3\end{array}$ & $\begin{array}{r}250,000 \\
250,000 \\
100,000 \\
500,000 \\
500,000 \\
100,000 \\
50,000 \\
50,000 \\
100,000 \\
200,000 \\
100,000 \\
\end{array}$ & $\begin{array}{c}(c) \\
(c) \\
750,000 \\
(f) \\
(f) \\
(c) \\
600,000 \\
(f) \\
550,000 \\
(h) \\
650,000 \\
500,000 \\
(i) \\
200,000 \\
\end{array}$ & $\begin{array}{l}\text { Sealed. } \\
\text { Do. } \\
\text { Recased. } \\
\text { Obstructed. } \\
\text { Obstructed. } \\
\text { Recased. } \\
\text { To be recased.॰ } \\
\text { Sealed. } \\
\text { To be recased. } \\
\text { Sealed. } \\
\text { Do. } \\
\text { Recased. } \\
\text { Do. } \\
\text { Do. } \\
\text { Do. } \\
\text { Do. } \\
\text { Do. } \\
\text { Obstructed.• }\end{array}$ \\
\hline
\end{tabular}

a Normal head is the head on a near-by well known to be in good condition.

6 The method of estimating leakage from a defective well is based on observed loss of head, depth, and diameter. The water from any leak will be discharging into a pervious formation, and the external head will be virtually sea level. The observed loss of head is then that part of the total head above sea level which is lost in aquifer and well casing together. Varying assumptions based on experience are made as to distribution of this loss between aquifer and casing. The estimates are regarded as accurate within 25 per cent.

- The meter can not be used because the well has a short length of 6-inch casing at the top.

- The owner, on being notified to repair his well, engaged a building contractor to dothe work. Concrete was poured in and bridged at a depth of about 100 feet, or just above the leak. The well at present is probably leaking to capacity. Will probably cost $\$ 5,000$ to clean out and recase.

- Obstruction is soil and rubbish only.

$f$ Too small to admit Price meter.

- Government well; funds to repair it are now available.

Owner recased the well without requiring a meter test.

- Recased in 1917 before the meter came into use 


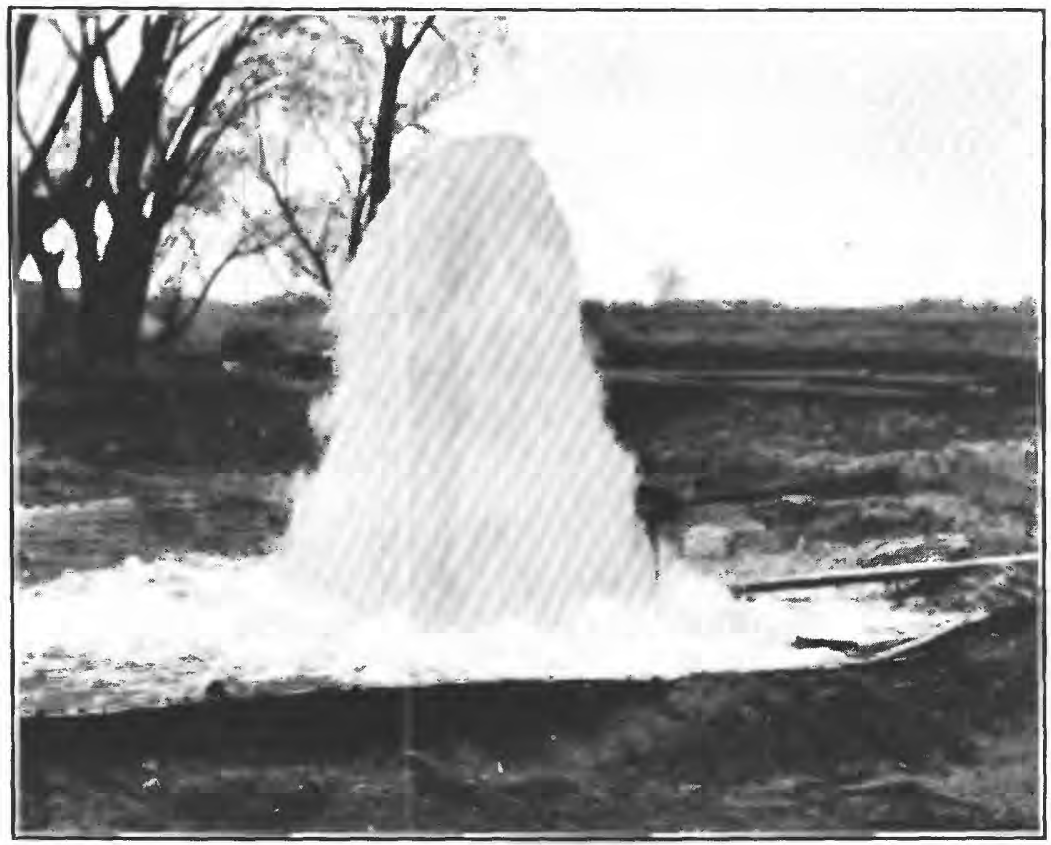

A. WELL OF OASIS COTTON CO., IN THE NW. 1/4 SEC. 22, T. 11 S., R. 25 E.

This well is 780 feet deep and $121 / 2$ inches in diameter. On April 21, 1926, it had a flow of 5,710 gallons a minute

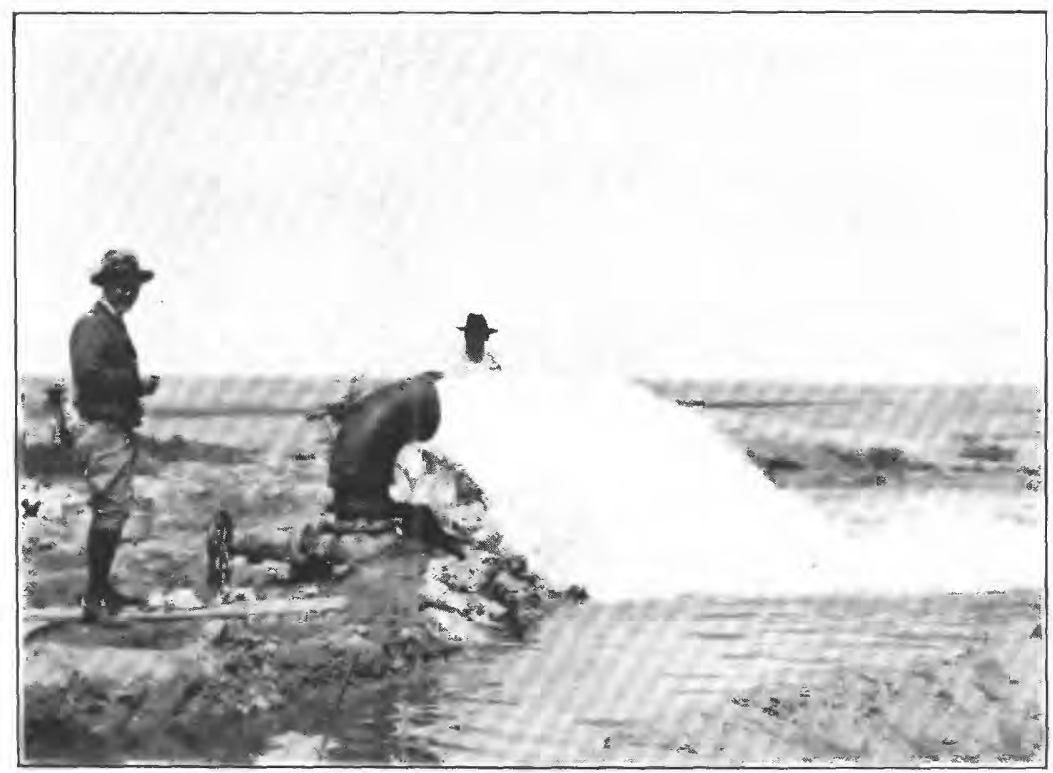

B. WELL OF H. D. KING, IN THE SW. 1/4 SEC. 14, T. 11 S., R. 25 E.

This well is 845 feet deep and 10 inches in diameter. On April 21, 1926, it had a flow of 3,190 gallons a minute

Flowing Wells in the Roswell Artesian Basin, New Mexico 


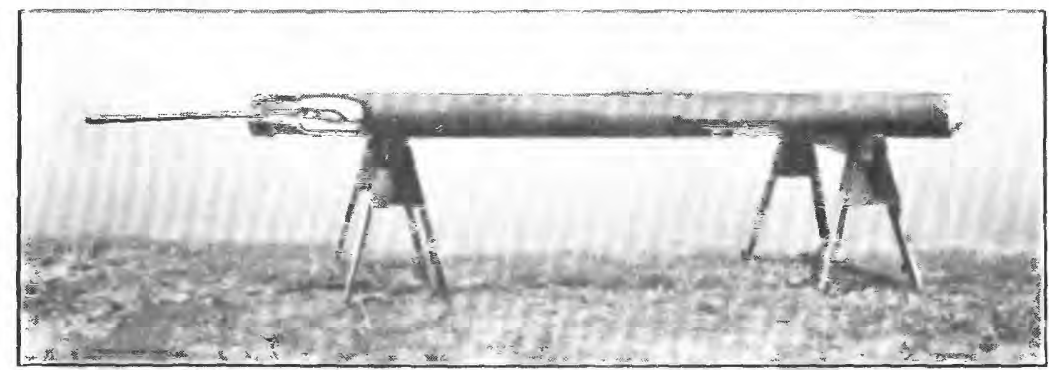

A. BUCKET WITH BALL-SHAPED VALVE PULLED UP, READY TO BE CHARGED

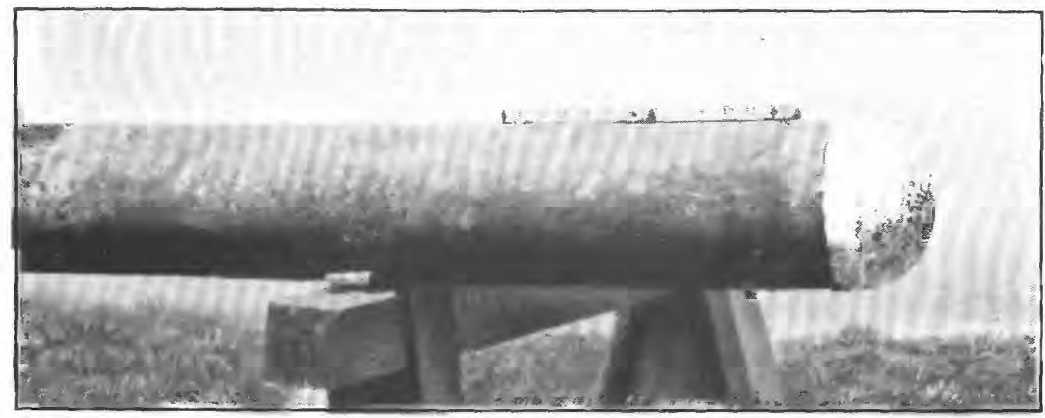

B. ENLARGED VIEW OF LOWER END OF BUCKET WITH VALVE PULLED UP

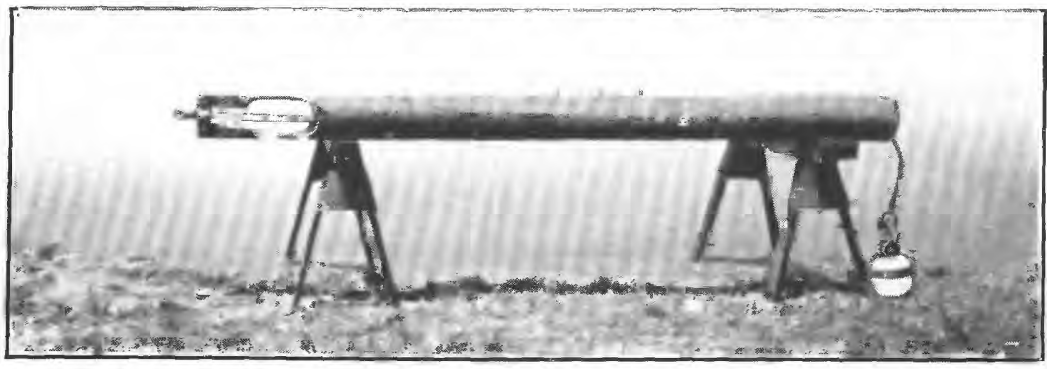

C. BUCKET WITH ROD FORCED DOWN, SO THAT IT HAS RELEASED THE VALVE AND ENGAGED THE UMBRELLA LATCH

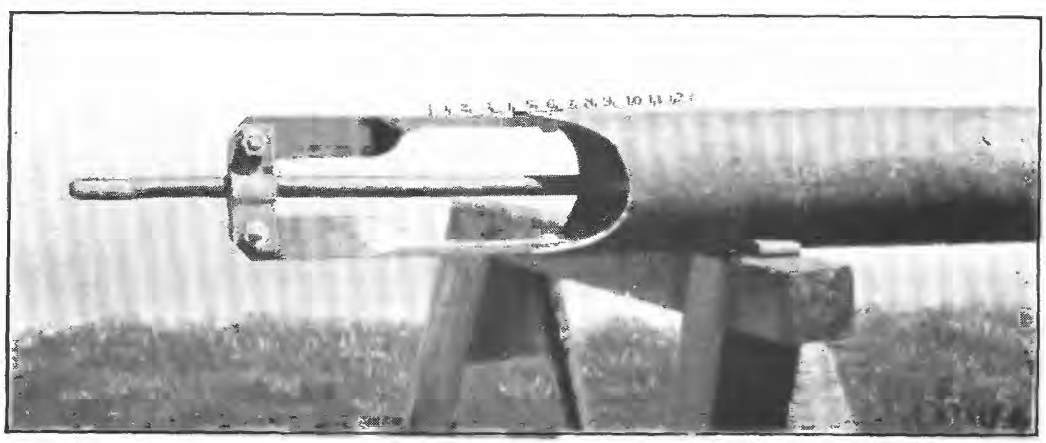

D. ENLARGED VIEW OF UPPER END OF BUCKET WITH UMBRELLA LATCH ENGAGED

Old Type of Dump Bucket Used in Plugging Wells 


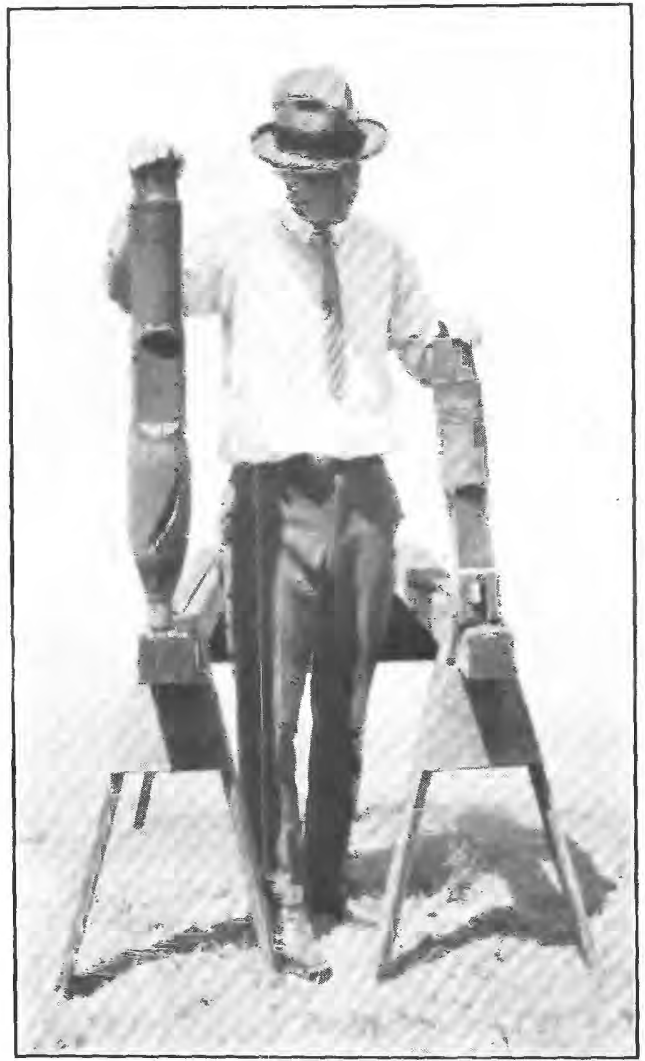

A. SWEDGE USED IN CLEANING DEFECTIVE WELLS BEFORE RECASING THEM AND THE SUBEND TO WHICH DUMP BUCKET IS ATTACHED

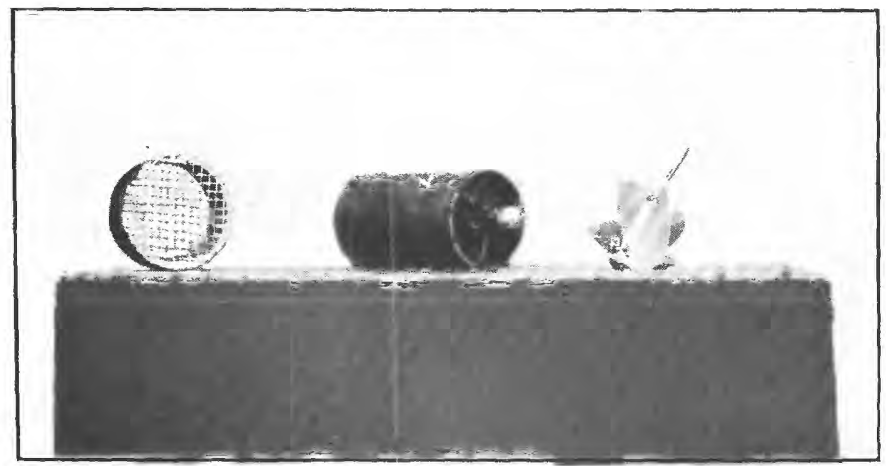

B. AU DEEP-WELL CURRENT METER

The turbine wheel has been removed from the meter to be shown in the view. The screen at the left is attached to the bottom of the meter pipe shown in Plate 4, $A$ 


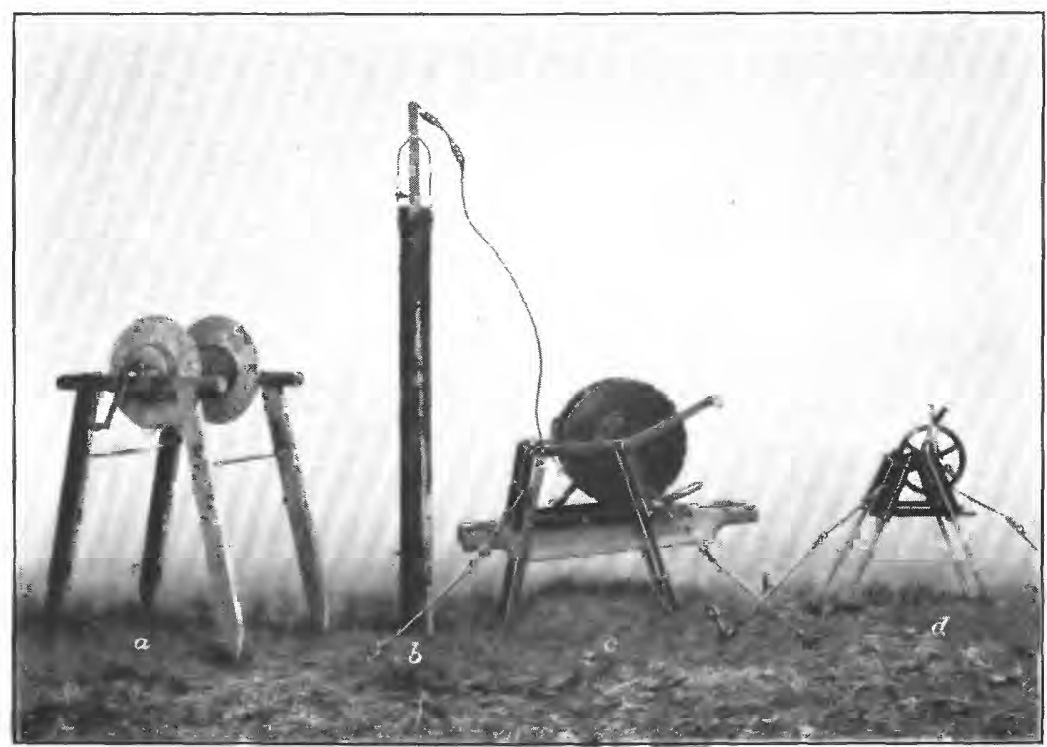

A. APPARATUS FOR USING AU DEEP-WELL CURRENT METER IN EXPLORING WELLS

$a$, Reel for holling insulated electric wire, to which the head phone and battery are attached; $b$, upper 4-foot section of the 3-inch meter pipe; $c$, reel for holding cable to which the meter pipe is attached; $d$, odometer for recording depth

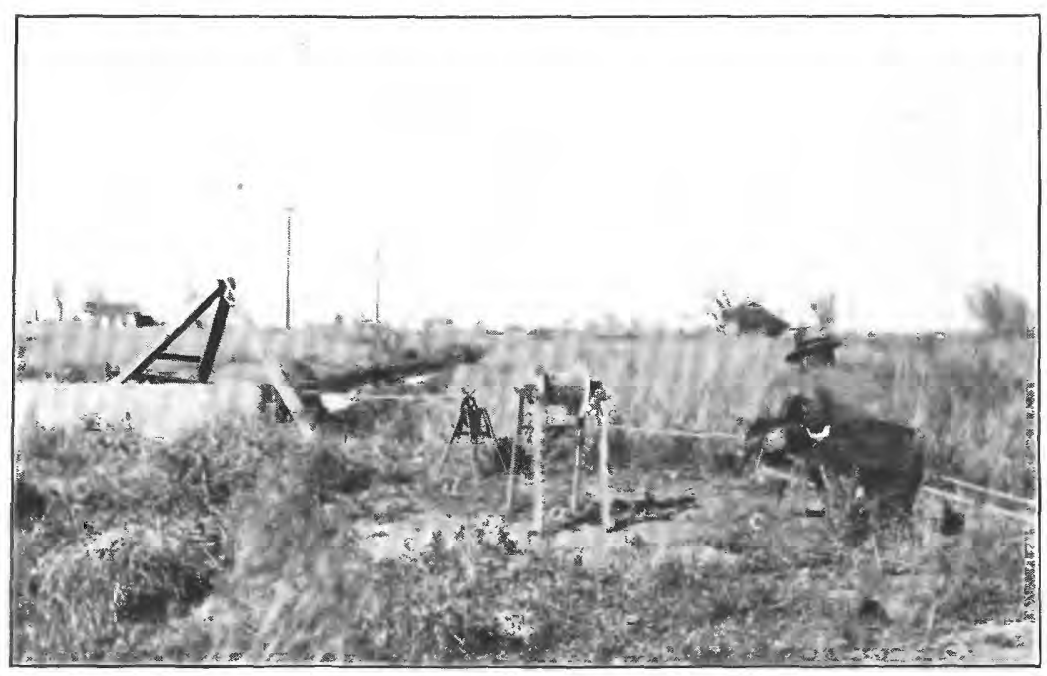

$B$. SAME APPARATUS SET UP

For explanation of letters see $A$ 


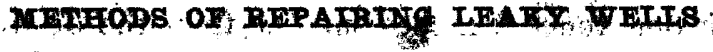

\section{RECASING}

The older wells are usually lined with well casing, but the most common practice at present is to use steam pipe both for new jobs: and for recasing, as it is more easily obtained and is believed to be of better qualifity. Galvanized pipe is now. being used to some extent. for recasing, but in the writer's opinion it is of little additional: value, although it costs more. The sizes of well casings are defined by giving the outside diameter; whereas the sizes of steam piper are defined by giving the inside diameter. The proper sizes to use in recasing for the more common sizes of original casing are given in the following table:

Sizes of pipe to be used in recasing wells

[Comprited on basis of pipe tables in catalogue of Oil Well Supply Co. All diameteqs are giventa inabes]

\begin{tabular}{|c|c|c|c|c|c|c|c|c|c|}
\hline \multicolumn{3}{|c|}{ Original casing } & \multicolumn{3}{|c|}{$\begin{array}{l}\text { Diameter of largest } \\
\text { well casing to fit }\end{array}$} & \multicolumn{3}{|c|}{$\begin{array}{l}\text { Diameter of largest } \\
\text { steam pipe to fit }\end{array}$} & \multirow{3}{*}{ Remarks. } \\
\hline \multirow{2}{*}{ Nominal desig- } & \multicolumn{2}{|c|}{$\begin{array}{l}\text { Actual di- } \\
\text { ameter }\end{array}$} & \multirow{2}{*}{$\begin{array}{l}\text { In- } \\
\text { side }\end{array}$} & \multirow{2}{*}{$\begin{array}{l}\text { Out- } \\
\text { side }\end{array}$} & \multirow{2}{*}{$\begin{array}{l}\text { Over } \\
\text { coup- } \\
\text { ling }\end{array}$} & \multirow{2}{*}{$\begin{array}{l}\text { In- } \\
\text { side }\end{array}$} & \multirow{2}{*}{$\begin{array}{l}\text { Out- } \\
\text { side }\end{array}$} & \multirow{2}{*}{$\begin{array}{l}\text { Over } \\
\text { coup- } \\
\text { ling }\end{array}$} & \\
\hline & $\operatorname{In*}_{\text {side }}$ & $\begin{array}{l}\text { Out- } \\
\text { stde }\end{array}$ & & & & & & & \\
\hline \multirow{2}{*}{$\begin{array}{l}\text { 12-inch steam pipe- } \\
\text { 12-inch casing } \\
\text { 10-... } \\
\text { 10-inch steam pipe- } \\
\text { 8-inch casing } \\
\text { 8-inch casing } \\
\text { 6-inch steam pipe-... } \\
\text { 6-inch casing }\end{array}$} & $\begin{array}{l}12.00 \\
11.514\end{array}$ & $\begin{array}{l}12.75 \\
12.000\end{array}$ & $\begin{array}{l}9,582 \\
9.582\end{array}$ & $\begin{array}{l}10.000 \\
10.000\end{array}$ & $\begin{array}{l}10.911 \\
10.911\end{array}$ & $\begin{array}{r}10.192 \\
10.192\end{array}$ & $\begin{array}{r}10.750 \\
10.750\end{array}$ & $\begin{array}{l}11.721 \\
11.721\end{array}$ & \multirow{2}{*}{$\begin{array}{l}\text { Usually necessany } \\
\text { turn dowh conplings } \\
\text { on steam pipe. } \\
\text { Necessary to turn down } \\
\text { couplings on steam } \\
\text { pipe. } \\
\text { very tight. } \\
\text { Very tight. } \\
\text { Very tight. }\end{array}$} \\
\hline & $\begin{array}{r}10.102 \\
9.582 \\
8.071 \\
7.628 \\
6.063 \\
5.672\end{array}$ & $\begin{array}{r}10.75 \\
10.000 \\
8.628 \\
8.000 \\
6.622 \\
6.000\end{array}$ & $\begin{array}{l}5.672 \\
\text { 4. } 696 \\
\text { 3. } 733\end{array}$ & $\begin{array}{l}6.000 \\
5.000 \\
4.000\end{array}$ & $\begin{array}{l}6.664 \\
5.621 \\
4.521\end{array}$ & $\begin{array}{l}\text { 8. } 071 \\
\text { 8.071 } \\
\text { 6.065 } \\
6.065 \\
4.026 \\
4.026\end{array}$ & $\begin{array}{l}\text { 8. } 625 \\
8.625 \\
6.625 \\
\text { 6. } 625 \\
4.500 \\
\text { 4.500 }\end{array}$ & $\begin{array}{l}9.358 \\
9.358 \\
7.358 \\
7.358 \\
5.091 \\
5.091\end{array}$ & \\
\hline
\end{tabular}

Recasing in Hawaii is always done by experienced well drillers with adequate equipment. It can not be too strongly emphasized that work of this kind requires experience, skill, and intelligence. The tools and equipment required are about the same as for drilling, and include derrick, power plant, either bull wheel or hoisting drums, walking beam, drills, jars, bailers or sand buckets, swedges, spudding. line and shoe, pipe wrenches, and minor equipment. The power plant is driven by either steam or gasoline, and must develop enough: power to lift a full string of casing when hanging clear.

After the equipment is assembled on the ground and the derrick and power plant set up, the first step is to clean out the well casing. to the diameter of the outside of the new pipe. This is usually done by runing a series of swedges (see pl. $3, A$ ) through the casing, 
starting with one about 2 inches smaller than the desired diameter and ending with the exact size. These swedges should be used with jars and a short drill stem or sinker bar, in order. to insure removal if they stick, and should be given an up and down motion as they are lowered, by use of either the spudding line and shoe or the walking beam with or without temper screw. These, swedges will remove scale and also open the pipe to full diameter if it is not too. badly collapsed.

Many of the older wells have been abandoned by their owners and allowed to stand open for years, and as a result they have had rubbish of every sort thrown into them. Some wells have been obstructed with rock and soil dumped in with the intention of filling. them completely. Several of these wells were known to be defective, but it was at first believed that it would be very difficult to repair them. Experience has shown, however, that these plugs or obstructions were never complete, but at most were only a few feet thick. The material introduced, whatever its nature, seems to bridge in the casing.

The tool that has been used with uniform success in cleaning out such obstructions is the wash rod or jetting drill, such as is used for drilling wells and test holes in unconsolidated material: In cleaning wells a drill with a cutting edge $17 / 8$ inches in length is used. This drill is suspended on 1-inch wrought-iron pipe, and the drill casing is 2 -inch pipe. The 2-inch casing is lowered into the well until it rests on the obstruction. The drill is then introduced, drilling is started, and the 2-inch casing is made to follow the drili as closely as possible by turning and driving it. Most of the fine material will flow out with the wash water, and the drill and casing will usually go down rapidly. When an obstruction has been drilled through the drill and casing may be lifted and a new hole started. Usually the obstruction will fall free after being drilled through once or twice, but the dislodged material may bridge again farther down, where the process may have to be repeated. Ultimately such material as has not been washed out will reach the bottom of the hole, where if necessary it may be drilled up and removed with the regular well tools. The wash-rod method has been used successfully to a depth of 300 feet but is not recommended for much greater depths on account of the weight of the apparatus.

When cleaning is completed the casing is lowered into the well a joint at a time. It is handled with the so-called elevators, which are clamped around just below the couplings. The casing already in the well is supported on clamps. The threads of each joint are carefully covered with red lead and are screwed up till the ends of the pipe abut. Usually the bottom end of the string is provided 
with a coupling or a steel shbe. If the string of casing binds in the holle it may be driven, either with a maul or by putting a wooden clamp of the string of drill tools and driving with the bull wheel. If the swedging is property done, however, the amount of binding that will occur is slight unless the hole is crooked. Rarely it may be necessary to drill out caving material that has lodged below the end of the new string. Turning the string in the hole is often helpful in passing tight places.

The new casing may stop at or just beyond the end of the old; as the original hole is reduced here. It is the usual practice to put a metal clamp around the top of the new casing and to rest it on the old casing to prevent possible falling after the job is done. There seems to be little need of any further elosing of the small annular space between the two casings. As the new casing is lowered the couplings pick up scale and make a tight seal. A thin cement grout is sometimes poured between the two casings, and this undoubtedly helps to form a seal, but numerous wells recased without it have been perfectly satisfactory for years. The usual test for a satisfactory recasing is the full recovery of the static head for the particular locality, and the: writer knows of no well recased in the manner described that did not recover and keep the full head. When-a job is completed it is always advisable to run the sand bucket or even the drill to make sure that no obstructions are left either in the pipe or in the open hole in the rock below.

No: recased well in Honolulu has continued to leak except where the new casing did not go deep enough. As a general rule, nothing smaller than an 8-inch well is considered worth recasing. The smaller :wells should be plugged. In a few places where a small amount of water was needed for some definite local use, wells as small as 6 inches have been recased, but this practice is only making trouble for some one in the future, because special equipment will be required to explore and repair wells of small diameter.

\section{PLUgGiNg OR SeaLING}

The law of the Territory of Hawaii provides that no well shall be made inaccessible for inspection unless it has been sealed in a manner approved by the superintendent of hydrography. This law, as long as funds are available for its enforcement, operates to keep unskilled, malicious, or ignorant persons from obstructing well casings in an attempt to plug the well, to evade the law, or to do damage intentionally. All recent plugging jobs have been supervised by the writer or some other engineer from the division of hydrography.

The permanent seal is made with concrete, which must be placed as a plug several feet thick at the top of the aquifer and in the cap 


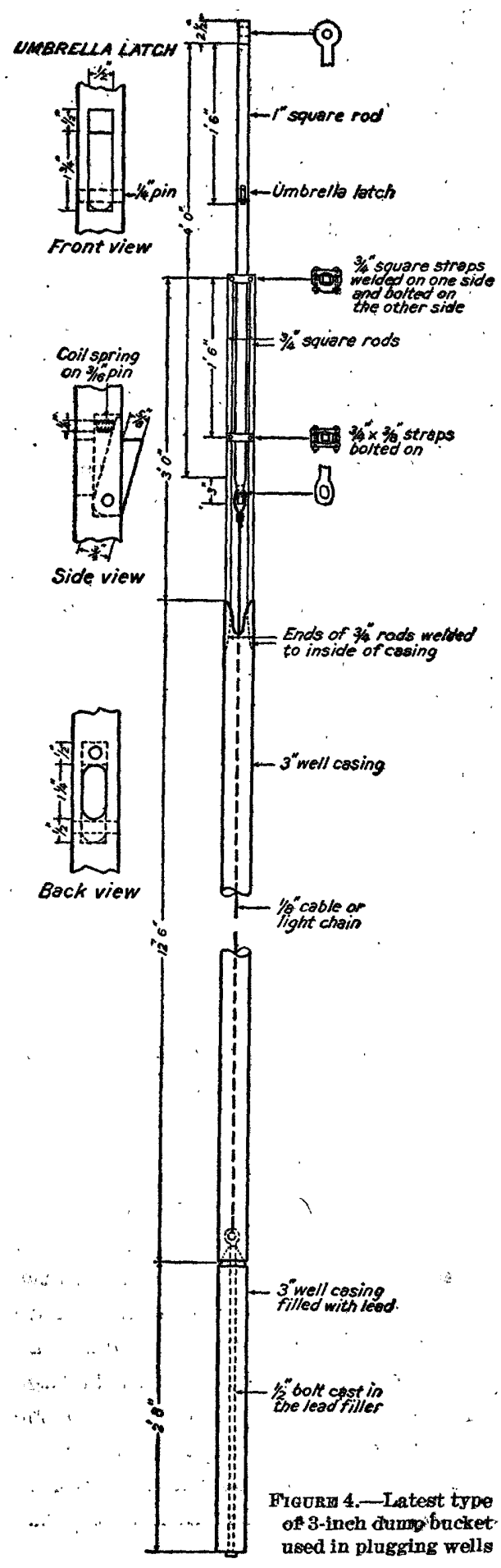

rock. It is obvious, however, that concrete can not be poured into a long column of water, as this would result in a complete separation of the aggregate. To avoid this separation two methods have been used. In one the concrete is let down in bags; and in the other a bucket. is used that dumps when it reaches the bottom and releases the concrete in $\mathbf{a}$ mass. The second method is by far the more satisfactory'. The dump buckets used are patterned after that recommended by the United. States Bureau of Mines ${ }^{7}$ but have been redesigned and adapted to water-well conditions by A. H. Hobart; an engineer and well driller in Honolulu. The most important modifications : of the Bureau of Mines pattern are the use of a square rod at the top : and a lead-filled. cylinder instead of an iron ball at the bottom. The square rod has remedied the trouble previously encountered with the umbrella latch, and the heavy lead cylinder insures complete and certain dumping, as. its greater weight is sufficient- to pull the suspending chain through material of any sort. Plate 2 shows a dump bucket of the type originally used; Figure 4 shows an improved dump bucket of the most recent pattern, with the square shaft and extra weight.

7 Tough, F, B., Methods of shutting off water in oil and gas wells : U. S. Bur. Mines-Bull. 163, pl. 2, 1918. 
In use, when the bucket is loaded and ready to be lowered, the total weight is on the plug at the bottom, the rod is up, and the umbrella latch is disengaged. When the bucket has been lowered to the bottom and raised slightly, the tools above have forced the umbrella rod and latch down until the latch has passed the ring at the top of the bucket yoke and has sprung out. The weight of the bucket is then on the latch, and there is about 2 feet of slack in the line to the plug. The concrete flows out as the bucket is slowly raised. The umbrella latch is the weak point of this device. It should be as large as possible, should be provided with a strong coil spring, and should also be easily removable for adjustment and cleaning. The shell of the bucket may be of fairly light material and should be at least 2 inches smaller in diameter than the well casing it is to enter in order to provide enough waterway around the sides for quick operation. It is most rapidly handled on the sand line, provided there is sufficient power to lift it, but in wells where there is danger of caving it is advisable never to use any line except the drill line and to use jars above every tool that is lowered.

A well that has a strong flow, either at the surface or through subsurface leaks, presents a difficult problem. The concrete will be washed and separated by the water, no matter how it is put in, unless the flow is first shut off with other material. The most successful plugs have been made with iron turnings and filings. These can be purchased in Honolulu at a low price and are as a rule heavy enough to stay in the well. Crushed rock has also been used, but is too light. for high velocities.

The method used is to clean out the well and fill from the bottom with iron turnings, using the dump bucket. These turnings may be tamped occasionally, either with the weight on the end of the bucket or better with a "sub-end" or blunt drill on a string of tools. When the height of material increases at a regular rate as each bucket is added little tamping is needed, but when there is little or no increase, as in large cavities, thorough tamping is useful. The turnings shut off the flow a little at a time and will either plug the well completely or reduce the flow so much that concrete will set. When the depth of the leak is known the height at which the water surface should stand in a sealed well in the area is easily computed. The well water flows out into salt water that is under sea-level head, and when a static condition is reached the head above sea level on the well will be $0.024 h$, in which $h$ equals the depth of the leak below sea level. The theory of this balance is discussed in the section headed "Geology and hydrology." (See pp. 5-11.) In general, when a leaking well is closed off in the aquifer the water surface will fall to the level of the ground water in the formation that is car- 
rying the leakage. When it appears from the behavior of the water surface and from the amount of material placed that the

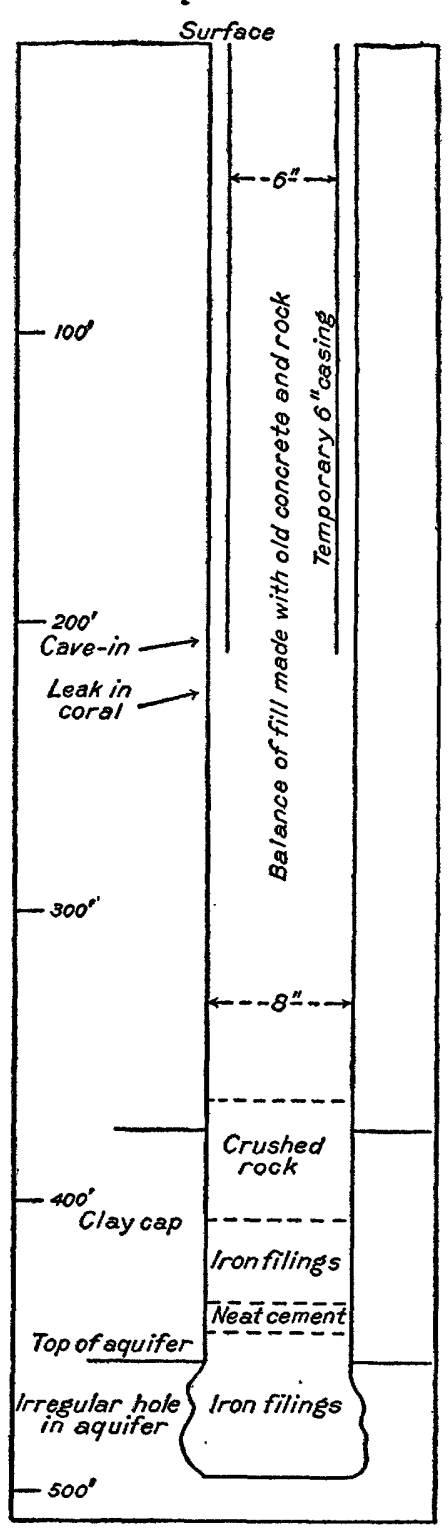

Figuni 5.- - Section of well 34, on Young Street, Honolulu, showing method of plugging. The upper layer of iron turnings was used in this well but is not required iron plug is complete the current meter should be let down into the well, and if no measurable flow exists it is safe to put in concrete. This method has been used to seal wells ranging in diameter from 4 to 10 inches and in depth from 200 to 850 feet. It might not give as good results in other regions where larger unbalanced pressures exist.

The general procedure on a job of this sort is exemplified by well 34, on Young Street, Honolulu. (See fig. 5.) This well was drilled in 1887 to supply an ice plant. It was 8 inches in diameter and 497 feet deep and penetrated the aquifer about 40 feet. It was found to be defective in 1918 , and readings of static head in 1924 showed the water surface about 17 feet below the average for the locality, or only 10 feet above sea level. A test with the current meter showed a flow of over 600,000 gallons daily through a leak in the casing about 250 feet below the surface. The observed velocity below the leak was more than 5 feet a second.

A local well driller was engaged by the owners to seal this well, and the writer inspected the work throughout. The well was opened and swedged out, and the depth was accurately determined. An attempt was then made to fill up the water-bearing stratum by dumping in No. 2 crushed rock, which runs from half an inch to $11 / 2$ inches in diameter. A cubic yard of this rock was poured in, but soundings showed that none of it reached the bottom. The driller then poured in No. 1 rock, which runs as large as $2 \frac{1}{2}$ inches in diameter; even this material would not sink but was carried out through the leak. A cave-in then occurred at a depth of 184 feet, 
due probably to the friction of the large rock. This was drilled through with a 2-inch wash-rod outfit, followed by a 6 -inch casing, the cavings being knocked down the well and passing out at the leak. The 6-inch casing was forced down to 205 feet, the caving stopped, and the well was again open.

Iron filings and turnings were then placed with a 4-inch dump bucket. The well was filled up 51 feet with this material, bringing the top of the iron above the top of the aquifer. No difficulty was found in making the iron stay in the hole, but about twice as much was put in as the computed volume indicated. Probably the hole had been enlarged by caving in. The static head fell to 5 feet above sea level and the well meter showed no flow. A concrete cap was then placed on top of the iron turnings by use of the dump bucket and was given time to set. The remainder of the well was filled with stone, sand, etc. The 6-inch temporary casing was withdrawn without difficulty. The total cost of this job was $\$ 2,600$, of which $\$ 950$ was due to the cave-in.

A few wells of small diameter having large leaks have required a heavier material. In these wells the aquifer was filled with iron turnings until only a small space remained. The water entering this confined space had so great a velocity that the turnings would not settle. The last few feet was then filled with lead shot, which was heavy enough to stop the flow and to permit concrete to set. Owing to the high cost of lead every effort should be made to fill with iron as high as possible.

A thin grout is used for the concrete cap because thicker mixtures will clog the bucket. This grout works well for the first two buckets, but it piles up in the bottom in a soft semiliquid mass, and great difficulty has been encountered in dumping other loads, as the bucket sinks into the soft material already in place. This difficulty led to the use of precast concrete cores, which are made about 5 feet long and 2 or 3 inches smaller in diameter than the hole in which they are placed and have a wire loop at the upper end. One of these cores is placed after each two buckets of grout. They are suspended from the sand line with a thin piece of rope yarn, which must be just strong enough to carry the weight. The plugs will settle into the soft grout, and the rope yarn can then be broken by a quick jerk.

One essential step in sealing that must be emphasized is careful measurement of the depths. The operator must know how much fill he is getting with each load of material placed and must keep accurate and complete notes. The "feel" of the line is as important in sealing as in drilling, and an experienced operator will be able to tell the height of his plug within an inch or two at any time. 
Recently two wells that had caved so badly that the dump bucket could not be used were sealed by first dropping iron turnings through a 2-inch pipe and then pumping in cement grout.

The cost of sealing varies greatly. Most of the jobs done under the inspection of the division of hydrography have been done by contract on the basis of a daily rate for furnishing equipment and crew, and the cost varied with the difficulties encountered. Wells 4 or 6 inches in diameter cost more to seal than larger wells of equal depth, on account of the small tools and careful handling required.

The methods of recasing and sealing outlined are those which have been and are being used with success on the island of Oahu, and the writer is convinced that they will work anywhere under similar conditions. There are three essentials for good well work-experience, intelligence, and money. Good drilling and repairing are not cheap, and good well men are not to be found everywhere nor made overnight from unskilled labor. The high value of water in Hawaii has made it practicable to spend money rather freely on wells, and wherever the work has been intrusted to competent drillers the results have justified the expenditure.

\section{LAWS RELATING TO ARTESIAN WELIS}

The law of the Territory of Hawaii that is now in effect in regard to artesian wells is given below.

\section{Revised laws of Hawaii, 1925, ohapter 291-Artesian wells}

Stc. 4500. Defined.-An artesian well, for the purposes of this chapter, is defined to be an artificial well or shaft which is sunk or driven to an artesian stratum or basin, and through which water is raised or carried to or above the surface of the ground by natural pressure or gravity, or through which water is or may be raised or carried to or above the surface of the ground by artificial means. (Laws of 1917, chap. 156, sec. 1.)

SEC. 4501. Uncapped and fowing a public nuisance; persons responsible therefor.-An artesian well which is not capped, cased, equipped, or furnished with such mechanical appliance as will readily and effectively arrest and prevent the flow of any water from such well is declared to be a public nuisance. The owner, tenant, or occupant of the land upon which such a well is situated; or any person in charge of such a well, who causes, suffers, or permits such public nuisance, or suffers or permits it to remain or continue, is guilty of a misdemeanor; and any person owning, possessing or occupying any land upon which is situated an artesian well, or any person in charge of such a well, who causes, suffers, or permits the water to unnecessarily flow from such well, or to go to waste, is guilty of a misdemeanor. (Laws of 1917, chap. 156, sec. 2.)

SEC. 4502. Waste from, defined.-For the purposes of this chapter, waste is defined to be causing, suffering, or permitting the water in any artesian well to reach any porous substratum before coming to the surface of the ground; or to fiow from such well upon any land or directly into any stream or other natural water course or channel or into the sea or any bay, lake, or pond; or into any street, road, or highway, uniess to be used for beneficial purposes; 
provided, that this section shall not be so construed as to prevent the beneficial use of water by direct flow or from storage reservoirs served by wells for irrigation, domestic, and other useful purposes, except for driving machinery; provided, however, that water may be used for driving machinery, in case it be utilized afterwards for irrigation or other useful purposes. The extent to which water of any artesian well may be devoted to useful or beneficial purposes shall be subject to regulation by the superintendent of hydrography, Division of Hydrography, to such quantities as may be necessary for the purposes for which the well is used. (Laws of 1917, chap. 156, sec. 3 ; amended by Laws of 1923 , chap. 228 , sec. 1.)

SEC. 4503. Inspection of.-Every artesian well shall be maintained by the owner, tenant, or occupant of the land upon which the well is situated or the person in charge of the well so as to provide access at all times for purposes of inspection unless the well has been sealed just above the water-bearing stratum in a manner approved by the superintendent of hydrography. (Laws of 1917 , chap. 156, sec. 4 ; amended by Laws of 1923 , chap. 228, sec. 2.)

SEC. 4504. Drilling, notice of.-No artesian well shall be drilled without first notifying, in writing the superintendent of hydrography, which notice shall state the exact location of the proposed well, the owner's name, the well driller's name and the proposed use of the water. (Laws of 1923, chap. 228, sec. 3.)

SEC. 4505. Boring of, record to be kept and filed-Any person boring, or causing to be bored, an artesian well shall keep a complete and accurate record of the depth and thickness of the different strata penetrated, and within ninety days after the last day of boring shall file the record in the office of the superintendent of hydrography. (Laws of 1917, chap. 156, sec. 5.)

SEc. 4506. Violations; penalties.-Any person violating any of the provisions of this chapter shall be guilty of a misdemeanor and shall, for each offense, upon conviction thereof, be fined not more than fifty dollars; and where continuance of waste, as defined in this chapter, is under immediate control, each day's continuance of the same, after written notice from the superintendent of hydrography, shall constitute a separate offense; provided, however, that when the continuance of the waste is not under immediate control, as where recasing or sealing is necessary, each day's continuance of the same shall constitute a separate offense after sixty days have elapsed from the time of receiving written notice to prevent waste from the superintendent of hydrography. (Laws of 1917, chap. 156, sec. 6; amended by Laws of 1923, chap. 228, sec. 4.)

SEC. 4507. Inspection of by police and superintendent of hydrography.-For the more effectual carrying out of the provisions of this chapter, the high sheriff and deputy high sheriff, the sheriff and deputy sheriff of any county or city and county, all police officers, and any authorized representative of any city or county or city and county or of the superintendent of hydrography may at all times enter without warrant the premises where an artesian well is situated or whereon or wherein artesian water is used in order to procure such information or for such other purposes as may be necessary. (Laws of 1917, chap. 156, sec. 7.)

SEC. 4508. Appeals from decisions of superintendent of hydrography.-Any person, firm, copartnership, or corporation adversely affected thereby may appeal to the board of appeals from any ruling of the superintendent of hydrography regulating the fiow, manner of sealing, or manner of repairing of any artesian well by filing in writing a notice of appeal within ten days after the date of the ruling with the superintendent. The appeal shall be 
heard by the attorney general, the commissioner. of public lands, and the superintendent of public works, sitting together, who, while so sitting together, for the purposes of this chapter, shall constitute a board of appeals. The vote of one member of this board, disapproving the ruling appealed from, shall operate to sustain the appeal and abrogate the ruling. (Laws of 1923, chap. 228, sec. 5.)

SEc. 4509. Partial invalidity; effect of.-If any section, subsection, sentence, clause, or phrase of this chapter, is for any reason held to be unconstitutional, that decision shall not affect the validity of the remaining portions of this chapter. The legislature declares that it would have passed this chapter, and each section subsection, sentence, clause, and phrase thereof, irrespective of the fact that any one or more other sections, subsections, sentences, clauses or phrases be declared unconstitutional. (Laws of 1917, chap. 156, sec. 9.)

\section{Act 120, Session Laws, 1925}

AN ACT To amend chapter 291 of the Revised laws of Hawaii, 1925, relating to artesian wells

Section 1. Chapter 291 of the Revised laws of Hawaii, 1925, is hereby amended by adding thereto a new section to be known as section $4506 \mathrm{~A}$, to read as follows :

“Sxc. 4506A. Person may relieve himself of liability.-Any person owning an artesian well may relieve himself of further responsibility therefor by transferring to the county or city and county in which it is situated said well and the exclusive right to develop the artesian water on or under any property owned by him in the district in which such well is situated and the right to enter said property for the purpose of capping or plugging such well. It shall be the duty of the county or city and county to accept such well and such right and to cap or properly plug such well. The said county or city and county shall have the right to use the well and to lay and maintain pipes to draw water therefrom, provided that such use and the laying and maintenance of such pipes be made in such manner as to cause a minimum inconvenience to the person owning said well before its transfer as provided herein."

SEc. 2. This act shall take effect upon its approval.

Approved April 28, 1925.

\section{THE AU DEEP-WELL CURRENT METER AND ITS USE IN THE ROSWELL ARTESIAN BASIN, NEW MEXICO}

By Albert G. Fiedlek

\section{DESCRIPTION OF THE METER AND ACCESSORIES}

In view of the renewed interest in the conservation of artesian water, the United States Geological Survey has long realized the need for an instrument by which leakage in artesian wells might be detected, the location of the leak determined, and the quantity of leakage measured. The Price current meter, which is used by the Geological Survey in gaging streams, was constructed for use in surface streams. Although it has given valuable results as used in exploring artesian wells in Hawaii, it is not properly designed for most effective use in wells. (See p. 12.) In an endeavor to over- 
come the limitations of the Price meter and of other current meters made for measuring surface streams, Mr. Carl H. Au, technician, of the Geological Survey, designed and constructed a new meter that has proved to be adapted for use in wells and is now being used successfully by the writer in an investigation of the Roswell artesian basin in the Pecos Valley of New Mexico.

The principles involved in the use of the apparatus for the determination of leakage are very simple. The fundamental hydraulic expression is $q=a v$, an equation in which $q$ equals the quantity of water per unit of time, $a$ equals the cross-section area, and $v$ equals the velocity of the water passing the section. It is apparent that a given quantity of water flowing from a pipe in a given unit of time has a certain mean velocity. Any increase in the quantity of water discharged per unit of time from the pipe must be due to an increase in the mean velocity of the water. The water passing upward in an artesian well that is in good condition has a comparatively uniform velocity at all points where the well casing is of the same nominal diameter, although minor variations are caused by slight irregularities in the cross-section area of the casing. Should a leak occur in the casing the velocity of the water above this point will be decreased because a part of the flow will be leaving the casing and wasting into a permeable stratum that is not filled with water or that contains water under low head.

The current meter is used to determine variations in velocity at different depths in an artesian well and thereby to locate underground leaks from the well. The same principle is involved in the exploration of the uncased lower part of the well to determine whether the casing has been inserted to a sufficient depth to prevent waste of water from the well into a permeable stratum that contains water under low head.

The Au deep-well current meter is essentially a turbine wheel mounted within a cylindrical brass case, which is suspended in a 3inch pipe and is lowered into the well and removed from the well by means of a cable and reel. (See pls. 3, $B$, and 4.) Near the lower end of the brass meter case, on the inside, is mounted a pointed bearing upon which the wheel revolves. This pointed bearing is provided with a movable nut which is turned up when the meter is not in use, thereby removing the turbine wheel from the bearing and preventing it from being damaged. At the upper end of the brass cylinder there is a removable frame which supports a single or a pentapoint commutator head like those used in the Price current meter. These commutator heads are interchangeable, and either may be used according to the velocity of the water in the well. The vanes of the turbine wheel are made of aluminum; their shape is shown in 
Plate 3, $B$. The lower bearing of the wheel is a pivot cup of hard steel, and the upper shaft is made of unhardened tool steel. The upper shaft is drilled and tapped to accommodate the standard Price cam and worm screw to be used with the single and pentapoint heads, respectively. The turbine wheel revolves very freely, as is indicated by the fact that at a velocity of about 4 feet per second it rotates three times as fast as the cups on a Price current meter.

The cylindrical brass case that contains the working parts is supported in the upper end of the 3-inch iron pipe by means of a $1 / 4$-inch cap screw which projects inside the pipe about three-eighths of an inch. A brass spring clip, which is fastened by means of a cap screw to one arm of the cage at the top of the pipe, rests upon the commutator head and holds the meter in place. One arm of the cage at the top of the pipe is movable around a bolt at its upper end and has a slot near its lower end, so that by merely loosening the cap screw in the slot the arm may be swung to one side and after removing the spring clip the meter may be readily taken out for cleaning or inspection.

The 3-inch pipe in which the meter is placed (see pl. 4, A) is made in two 4 -foot sections which can be connected by means of a standard collar. In flowing wells with small head one section furnishes sufficient weight to carry the meter to the bottom of the hole. In addition to furnishing the necessary weight and protecting the meter, the pipe also prevents the meter from being carried outside of the well casing when passing a large leak. A fourfingered cage of spring brass is fastened near the lower end of the pipe to assist in keeping the pipe centered and in passing minor irregularities in the casing or in the uncased hole. Pieces of scale are sometimes scraped from the well casing by the meter pipe, and pebbles may be jarred loose in the uncased portion of the hole. To prevent this material from obstructing the meter, screens are provided for use in the ends of the pipe. (See pl. 3, B.) Whenever the screens are used a correction must be applied to the recorded velocity to reduce it to the normal velocity for unobstructed flow.

The rest of the equipment (see pl. 4) consists of a reel upon which is wound the $\frac{3}{16}$-inch wire cable used for lowering the meter into the well, an odometer for measuring the depth of the meter in the well, a reel for the stranded insulated electric wire cable, and minor accessories.

The odometer consists of a grooved brass wheel, the circumference of which is 2 feet. Two pins are fastened upon the spokes of the wheel, and at every half revolution one of them trips a counting device, thereby recording the number of feet that the meter has been lowered into the well. In removing the meter from a well the 


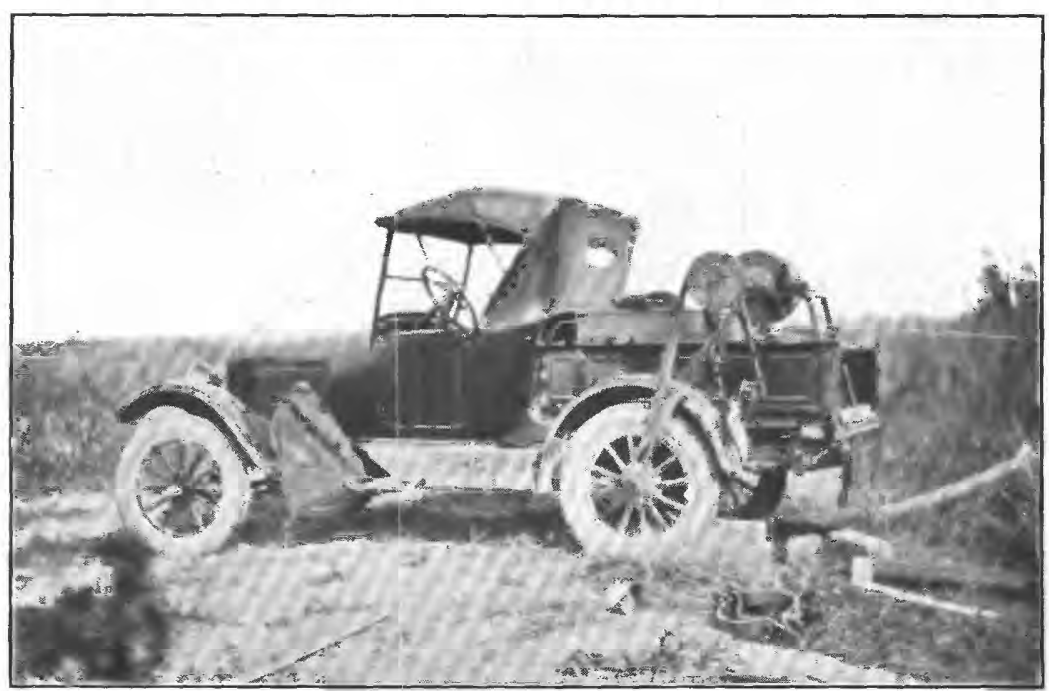

A. AUTOMOBILE TRUCK ON WHICH REEL IS PERMANENTLY MOUNTED

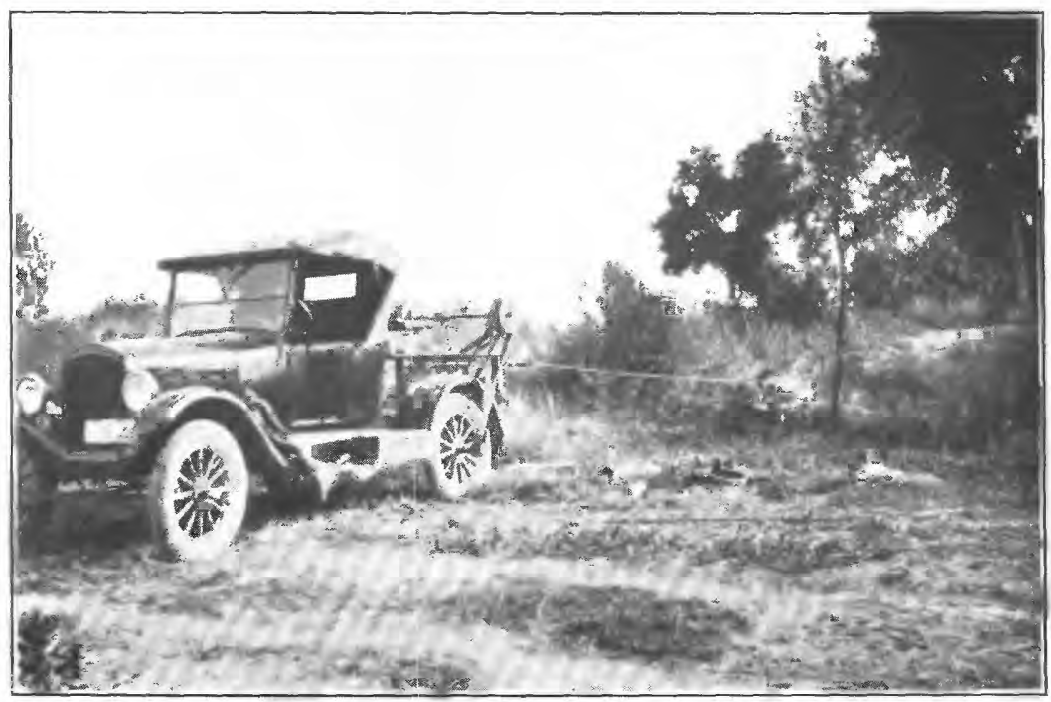

B. CABLE PASSING OVER ODOMETER TO WELL 

operation of the counter reverses so that it is possible to know at all times the depth of the meter in the well.

The electric circuit of the equipment is simple. The wire cable is used for one side of the circuit, and the insulated electric wire, wound on a separate reel, is attached to the meter commutator head and forms the other side. A small dry-cell battery and a 75-ohm head phone are used in a manner similar to that with an ordinary current meter. The revolutions of the turbine wheel are timed with a stop watch.

The cable reel and the odometer shown in Plate 4 are those originally used by Van Orstrand in his measurements of deep-well temperatures. ${ }^{8}$ They became available for this investigation because an improved set of apparatus is now used by Van Orstrand. ${ }^{9}$

The examination for leakage of an average artesian well 1,000 feet in depth requires almost a day's time, using the equipment that has been described. If the well has an elbow and discharge pipe, these must be removed so that the meter can be inserted in the well. In removing the meter from the well two men are required to operate the main cable reel and one man to operate the reel upon which the insulated electric cable is wound. Although the apparatus is somewhat bulky it can readily be completely disassembled and packed into a Ford car for transportation from well to well.

Just before this paper was sent to press a small automobile truck was purchased and the main reel was permanently mounted on it, as is shown in Plate 5. The old cable was replaced with a new one that has the insulated electric wire on the inside of it, and thus the extra reel for the electric wire is no longer needed. The new cable is onefourth inch in diameter and consists of six strands of seven wires each surrounding the insulated wire. These improvements promise to save much labor and to expedite the work. It is not yet known how long the insulation will last when the cable is used in this way.

\section{RATING THE METER}

The $\mathrm{Au}$ deep-well current meter is rated by inserting it in a well, measuring the stream that flows from the well with an ordinary current meter or by some other method, and timing the revolutions of the turbine wheel. If the diameter of the casing and the discharge of the well are known, the mean velocity of the water can readily be computed and be correlated with the number of revolutions of the turbine wheel per second. Wells with different rates of discharge and different sizes of casing are tested in this manner, and from the

\footnotetext{
${ }^{8}$ Van Orstrand, C. F., Temperature measurements: West Virginia Geol. Survey County Repts., Barbour and Upshur Counties and western portion of Randolph County, pp. 47-48, pls. 51, 52, 1918.

- Van Orstrand, C. E., Apparatus for the measurement of temperatures in deep wells by means of maximum thermometers: Econ. Geology, vol. 19, pp. 229-248, April-May, 1924.
} 
information obtained velocity curves are drawn and a rating table is computed. Although it is known that the velocity of water issuing from a pipe is not uniform throughout the cross section, the meter records showed that the difference between the velocity at the center of the casing and that at the side is negligible. This is due to the fact that the variations in velocity throughout the cross section are more or less equalized by the frictional resistance that the 3-inch meter pipe offers to the water passing through the meter,

\section{INTERPRETING THE METER RATINGS}

In exploring a well the meter is let down a little at a time, and velocity observations are made at regular intervals to determine when a leak is passed. In a nonflowing well no current will be noted. until a leak is encountered, whereas in a flowing well a leak is indicated by an increase in velocity. If a water-bearing stratum that supplies water to the well is passed the speed of the turbine wheel will decrease. After the meter has passed below the end of the casing variations in the velocity will occur, owing to the irregularities in the size of the uncased hole. As long as no consistent change is noted these variations are disregarded.

The leaks usually occurring in wells may be classified as of four general types:

1. General disintegration of casing producing innumerable holes.This condition is indicated by a gradual inerease in velocity in both flowing and nonflowing wells.

2. One or more large leaks.-Such leaks are indicated by an abrupt appearance of current in nonflowing wells and an abrupt increase in its velocity in flowing wells.

3. Improperly seated casing.-In nonflowing wells movement of the water begins to be recorded at the end of the casing near the top of the aquifer, reaches its maximum velocity immediately; and decreases as the water-bearing strata are passed and the bottom of the hole is reached. In flowing wells an increase in velocity occurs in like manner, followed by a decrease.

4. Insufficient casing.-In nonflowing wells movement of the water begins to be recorded after the meter has passed the end of the ćasing, reaches its maximum velocity as the meter passes through the uppermost water-bearing stratum, and then decreases until the bottom of the hole is reached. In flowing wells there is likewise an increase in velocity after the meter has passed the end of the casing until the first water-bearing stratum is reached, then a decrease below the last water-bearing stratum to the bottom of the hole.

In the inspection of a well in which the diameter of the casing has been reduced or in which the uncased portion of the hole has not been 
drilled with the same size bit throughout it is possible that an increase in velocity due merely to a reduction in section may be interpreted erroneously as an indication of a leak. This mistake can be avoided by computing the discharge at the point where the diameter of the casing is known, using the velocity indicated by the meter at that point, and then making a like computation for the point where the velocity increased, using the next smaller regular size of hole or casing. Should the discharge as computed for the two points agree within fairly close limits it is reasonably certain that the increase in velocity is caused by a reduction in section. A condition such as this is shown in the tests of wells 2 and 3 given herewith.

\section{TESTS OF SPECIMEN WELLS}

Results of tests made on several wells in the Roswell artesian basin, in Chaves and Eddy Counties, N. Mex., are given below.

Well 1 is an 8-inch well that yields a flow of sulphur water. The casing was covered with a slimy growth of algæ. Only 20 gallons a minute was flowing from the well casing, and at a short distance from the well water was issuing from a hole in the ground.

Record of velocity in well 1

\begin{tabular}{|c|c|c|c|c|c|c|c|}
\hline$\therefore \quad$ Depth & $\begin{array}{l}\text { Velocity } \\
\text { (feet per } \\
\text { second) }\end{array}$ & Depth & $\begin{array}{l}\text { Velocity } \\
\text { (feet per } \\
\text { second) }\end{array}$ & $\underset{\text { (feet) }}{\text { Depth }}$ & $\begin{array}{l}\text { Velocity } \\
\text { (feet per } \\
\text { second) }\end{array}$ & $\begin{array}{l}\text { Depth } \\
\text { (feet) }\end{array}$ & $\begin{array}{l}\text { Velocity } \\
\text { (feet per } \\
\text { second) }\end{array}$ \\
\hline $\begin{array}{l}5 \\
10 \\
11 \\
12 \\
12 \\
15 \\
20 \\
25 \\
50 \\
75 \\
100\end{array}$ & $\begin{array}{r}0.10 \\
.29 \\
.35 \\
.46 \\
.81 \\
.82 \\
.81 \\
.88 \\
.89 \\
.89 \\
.89 \\
1.00\end{array}$ & $\begin{array}{l}150 \\
175 \\
200 \\
225 \\
250 \\
275 \\
300 \\
325 \\
350 \\
375 \\
400 \\
425\end{array}$ & $\begin{array}{r}1.05 \\
1.05 \\
.89 \\
.89 \\
.89 \\
.89 \\
1.01 \\
.95 \\
.95 \\
.89 \\
.89 \\
.89\end{array}$ & $\begin{array}{l}450 \\
475 \\
500 \\
525 \\
550 \\
575 \\
600 \\
620 \\
625 \\
627 \\
650 \\
675\end{array}$ & $\begin{array}{r}0.89 \\
.89 \\
.89 \\
.89 \\
.85 \\
.89 \\
.89 \\
1.35 \\
2.15 \\
2.46 \\
2.15 \\
2.30\end{array}$ & $\begin{array}{l}690 \\
700 \\
725 \\
750 \\
775 \\
800 \\
810 \\
817 \\
818 \\
819 \\
820\end{array}$ & $\begin{array}{l}2.46 \\
2.24 \\
2.46 \\
2.46 \\
2.30 \\
2.46 \\
2.46 \\
1.47 \\
.07 \\
.04 \\
.00\end{array}$ \\
\hline
\end{tabular}

A study of the velocities show two major leaks, one at a depth of less than 15 feet and another between 600 and 625 feet. The water represented by the increase in velocity above the 15-foot level was issuing from the hole in the ground, while the water passing out at the lower leaks was wasting into a deeper permeable stratum. The meter passed the water-bearing strata between 810 and 818 feet, as is shown by the decrease in velocity. The end of the casing was at 696 feet, and the drop in velocity at 700 feet was doubtless caused by an enlargement of the hole due to eddy currents created as the water passed through the cap rock into the casing. It will be noticed that there was an increase in velocity between the 100-foot and 200-foot levels. This is undoubtedly caused by the condition of the casing and is disregarded, as the velocity again drops to its former rate. 
At the time of the inspection 20 gallons per minute was flowing from the well and 120 gallons per minute from the hole in the ground. It is conservatively estimated that if this well were put in good condition its flow at the surface would be increased to 400 gallons per minute.

Well 2 is an 8-inch well drilled in 1911. It yields salty water. At the time that it was inspected no water was flowing from the casing, but 1,000 gallons 'per minute was issuing from a hole around the casing.

Record of velocity in well 2

\begin{tabular}{|c|c|c|c|c|c|c|c|}
\hline $\begin{array}{l}\text { Depth } \\
\text { (feet) }\end{array}$ & $\begin{array}{l}\text { Velocity } \\
\text { (feet per } \\
\text { second) }\end{array}$ & $\begin{array}{l}\text { Depth } \\
\text { (feet) }\end{array}$ & $\begin{array}{l}\text { Velocity } \\
\text { (feet per } \\
\text { second) }\end{array}$ & $\underset{\text { (feet) }}{\text { Depth }}$ & $\begin{array}{l}\text { Velocity } \\
\text { (feet per } \\
\text { second) }\end{array}$ & $\begin{array}{c}\text { Depth } \\
\text { (feet) }\end{array}$ & $\begin{array}{l}\text { Velocity } \\
\text { (feot per } \\
\text { second) }\end{array}$ \\
\hline $\begin{array}{l}0 \\
25 \\
38 \\
39 \\
42 \\
55 \\
75 \\
1050 \\
155 \\
180 \\
210\end{array}$ & $\begin{array}{l}0 \\
0 \\
0 \\
1.24 \\
6.54 \\
6.71 \\
6.71 \\
6.54 \\
6.54 \\
6.37 \\
6.71 \\
6.71 \\
6.88\end{array}$ & $\begin{array}{l}260 \\
285 \\
310 \\
340 \\
365 \\
390 \\
415 \\
440 \\
465 \\
490 \\
520 \\
545 \\
570\end{array}$ & $\begin{array}{l}6.37 \\
6.37 \\
6.20 \\
5.86 \\
6.37 \\
6.54 \\
6.37 \\
6.20 \\
6.20 \\
6.54 \\
6.37 \\
6.03 \\
6.37\end{array}$ & $\begin{array}{l}600 \\
625 \\
650 \\
675 \\
700 \\
725 \\
752 \\
763 \\
775 \\
805 \\
830 \\
855 \\
880\end{array}$ & $\begin{array}{r}6.20 \\
6.20 \\
6.37 \\
6.37 \\
6.88 \\
6.54 \\
7.05 \\
12.65 \\
13.16 \\
11.87 \\
11.87 \\
11.87 \\
13.33\end{array}$ & $\begin{array}{l}903 \\
908 \\
913 \\
922 \\
925 \\
934 \\
945 \\
985 \\
1,000 \\
1,100\end{array}$ & $\begin{array}{r}12.48 \\
11.87 \\
10.78 \\
11.87 \\
5.86 \\
1.59 \\
.06 \\
.00 \\
.00\end{array}$ \\
\hline
\end{tabular}

A marked increase in velocity occurred between the depths of 38 and 42 feet. A computation of the discharge at the 42-foot level, using the area of an 8-inch casing, showed a discharge of about 1,000 gallons per minute. This corresponds to the discharge from the hole around the casing and indicates that practically all the water was finding its way to the surface through the hole. During the examination of the well it was interesting to note that whenever the meter passed the 42-foot level about 400 to 500 gallons per minute flowed out of the casing, probably because the meter would temporarily span the leak and partly close it. Minor variations in velocity were noted from the 5-foot level to the 725-foot level, but the average was consistently the same, showing that there was no other leak. A marked increase occurred between 752 and 763 feet, a depth at which according to the driller's $\log$, the well had been reduced to 6 inches in diameter by means of a perforated liner. As a means of checking this the following computations were made:

8-inch portion:

Cross-section area of casing, 0.35 square foot.

Velocity at 725-foot level, 6.54 feet per second.

Discharge, $0.35 \times 6.54=2.29$ second-feet.

6-inch portion:

Cross-section area of casing, 0.19 square foot.

Velocity at 763-foot level, 12.65 feet.per second.

Discharge, $0.19 \times 12.65=2.40$ second-feet. 
Thus the computed discharges check within 0.11 second-foot, or 50 gallons per minute, which is as near as could reasonably be expected. The recorded log gives the bottom of the liner at a depth of 917 feet. It will be noted that from 922 to 945 feet the velocity decreases almost to zero, showing that this is the horizon of the principal water-bearing strata. Only a little water enters the well from lower levels.

Well 3 at the time the examination was made had been only recently completed, and therefore accurate information was available concerning the size and depth of the hole and the casing that was inserted. The well was drilled 10 inches in diameter to a depth of 304 feet, and 10-inch casing was set to this depth. Drilling was continued with an 8-inch bit to a depth of 710 feet, and the hole was then reamed 10 inches in diameter to 650 feet. Before the hole was reamed the water level in the well was several feet below the ground surface, but after reaming the well flowed several hundred gallons per minute. As the depth of the hole had not been changed and no additional casing had been set, it is believed that the flow was caused by the reamings filling the interstices of open strata into which the artesian water was leaking. A study of the logs of other wells in this vicinity also indicates that there was insufficient casing in the well: To determine the location of the open strata and the approximate amount of the leakage the well was examined with the mefer.

Record of velocity in well 3

\begin{tabular}{|c|c|c|c|c|c|c|c|}
\hline $\begin{array}{l}\text { Depth' } \\
\text { (feet) }\end{array}$ & $\begin{array}{l}\text { Velocity } \\
\text { (feet per } \\
\text { second) }\end{array}$ & $\begin{array}{l}\text { Depth } \\
\text { (feet) }\end{array}$ & $\begin{array}{l}\text { Velocity } \\
\text { (feet per } \\
\text { second) }\end{array}$ & $\begin{array}{l}\text { Depth } \\
\text { (feet) }\end{array}$ & $\begin{array}{l}\text { Velocity } \\
\text { (feet per } \\
\text { second) }\end{array}$ & $\begin{array}{l}\text { Depth } \\
\text { (feet) }\end{array}$ & $\begin{array}{l}\text { Velocity } \\
\text { (feet per } \\
\text { second) }\end{array}$ \\
\hline $\begin{array}{l}0 \\
100 \\
\mathbf{3} 85 \\
360 \\
390\end{array}$ & $\begin{array}{r}1.38 \\
1.42 \\
1.46 \\
.82 \\
.82 \\
.88\end{array}$ & $\begin{array}{l}415 \\
440 \\
470 \\
495 \\
520 \\
530\end{array}$ & $\begin{array}{r}0.82 \\
.82 \\
.92 \\
.88 \\
.78 \\
1.00\end{array}$ & $\begin{array}{l}545 \\
555 \\
570 \\
600 \\
625 \\
650\end{array}$ & $\begin{array}{l}1.64 \\
2.09 \\
2.09 \\
3.05 \\
2.62 \\
4.80\end{array}$ & $\begin{array}{l}675 \\
685 \\
700 \\
711\end{array}$ & $\begin{array}{r}4.25 \\
3.92 \\
1.54 \\
.25 \\
.00\end{array}$ \\
\hline
\end{tabular}

The observations to a depth of 285 feet were within the cased part of the hole. Below the end of the casing the velocity decreased, doubtless because the uncased hole was somewhat larger than the 10-inch casing. The velocity remained comparatively uniform from 320 to 520 feet, indicating that the size of the uncased hole remained fairly uniform and that there was no appreciable leakage. From 520 to 625 feet, however, there was in general a progressive increase in velocity until at 625 feet it was nearly twice that in the cased part of the hole and about three times that in the part between 320 and 520 feet. As this part of the hole was drilled to the same diameter as the uncased hole above 520 feet, the increase in velocity was almost certainly due to water wasting into permeable strata between 520 and 
625 feet. The increase in velocity between 625 and 650 feet was evidently caused by a reduction in the diameter of the hole to 8 inches.

Computations checking this interpretation of the velocity readings are as follows:

Cross-section area of 10-inch casing, 0.54 square foot.

Average velocity in casing, 1.40 feet per second.

Flow in casing, $0.54 \times 1.40=0.76$ second-foot, or 340 gallons per minute.

The hole below the casing to 650 feet was reamed to a diameter of 10 inches, but it had evidently been enlarged by erosion and caving. $A$ coefficient was applied to express this enlargement and also other differences that may exist between the character of the flow in the cased and uncased parts of the hole.

The average velocity between 320 and 520 feet was about 0.85 foot per second. If the flow remained the same, as is altogether probable, the coefficient to be applied is the ratio of the two velocities-that is, $1.40 \div 0.85=1.65$.

Using this coefficient, the flow below the leak, near the bottom of the 10 -inch hole ( 625 feet), is computed as $0.54 \times 2.62 \times 1.65=2.33$ second-feet.

At the depth of 650 feet the hole was reduced to a diameter of 8 inches. Using the same coefficient the flow at this level is computed as $0.35 \times 4.80 \times 1.65=2.77$ second-feet.

The computed flows agree within 0.44 second-foot, which is as near as can be expected in view of the fact that the enlargement of the hole is doubtless irregular, differing with the character of the strata penetrated and with the original diameter. The velocity decreased at or above the 675 -foot level and continued to decrease to the bottom, indicating the passing of the water-bearing strata.

It is estimated that with proper casing the discharge of this well could be increased from 340 to 800 or 900 gallons per minute.

\footnotetext{
ADDITIONAL COPIES

OY THIS PUBLICATION MAT BE PROCURED HROM

THE SUPERINTENDENT OF DOCUMENTS

GOVERNMENT PRINTING OFFICE

WASHINGTON, D. C.

15 CENTS PER COPY

$\nabla$
} 

I 


\section{LABRARY CODY

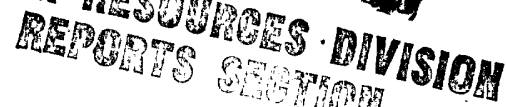

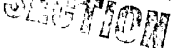





\section{Department of The INTerior \\ Hubert Work, Secretary}

U. S. GEOLOGICAL SURVEY

George Otis Smith, Direetor

Water-Supply Paper 596

\section{CONTRIBUTIONS TO THE HYDROLOGY OF THE UNITED STATES}

\section{7}

NATHAN C. GROVER, Chief Hydraulic Engineer

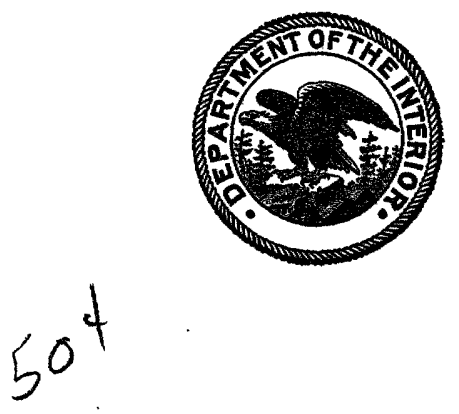

UNITED STATES

GOVERNMENT PRINTING OFFICE

WASHINGTON

1928 



\section{CONTENTS}

(The letters in parentheses preceding the titles are those used to designate the papers for advance publication]

(A) Methods of exploring and repairing leaky artesian wells, papers by John McCombs and A. G. Fledler, with a preface by 0 . W. Metnzer (published April 2, 1927)

Page

Quality of water of Colorado River in 1925-26, by W. D. Collins and

C. \$. Howard (published June 15, 1927)

(C) Ground water in the Ordovician rocks near Woodstock, Va., by

G. M. Fall (published August 22, 1927)

(D) Quality of water of Pecos River in Texas, by W. D. Collins and

H. B. Riffenburg (published August 24, 1927)

(E) Quality of the surface waters of New Jersey, by W. D. Collins and

C. S. Howard (published September 30, 1927) _._. $(1,4 \leq 4)$

(E) Laboratory tests on physical propertfes of water-bearing materials, by N. D. Stearns (published November 3, 1927)

(G) Chemical character of waters of Florida, by W. D. Collins and C. S. Howard (published February 17, 1928) (lio 4 S

(H) Notes on practical water analysis, by W. D. Collins (putished February 21, 1928) 10.9

\section{IILUSTRATIONS}

Pratw 1. Flowing - wells in the Roswell artesian basin, New Mexico: A, Well of Oasis Cotton Co.; B, Well of H. D. King

2. Old type of dump bucket used in plugging wells: $A$, Bucket with

t... ball-shaped valve pulled up, ready to be charged; $B$, Fin-

- larged view of lowe end of buclet with valve pulled up; $\sigma$, W 3 ucket with rod forced down, so that it has relitased the valve Thithd engaged the umbrella latch; $D$, Enlarged vlew of upper it end of bueket with umbrella latch engaged.

8. A, Swedge nsed in cleaning defective wells before recasing them and the subend to which dump bucket is attached; $B, A u$ deep-well current meter

4. 4, Apparatus for using Au deep-well current meter in exploring wells; $B$, Same apparatus set up

5. A, Automobile truck on which reel is permanently mounted; $B$, Cable passing over odometer to well

6) Composition of river waters in Arizona and California

7. Generallzed geologic map of the vicinity of Woodstock, Va...... 
Puate 8. Monthly precipitation at Woodstock, Va., from January, 1920, to August, 1924, compared with the mean monthly precipitation for the period 1897 to 1923

9. Dissolved mineral matter and discharge of Pecos River at Angeles and at Grandfalls, Tex

10. Map showing location of sampling points for surface waters of New Jersey

11. Shakers used in making mechanical analysis_

12. Apparatus used in determining porosity by the pycnometer method

13. Permeability apparatus, including the long cylinder used for

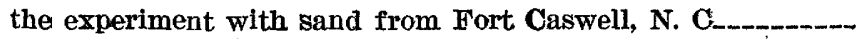

14. Composition of natural and treated waters.

Frgurm 1. Section of the island of Norderney, Germany, showing the application of the Badon Ghyben-Herzberg theory

2. Section of the Waikiki artesian area, Honolulu._._._._.

3. Diagram showing head of Oahu College well, Honolulu, from 1899 to 1925

4. Latest type of 3-inch dump bucket used in plugging wells_-_..-

5. Section of well 34, on Young Street, Honolulu, showing method of plugging.

6. Map of Colorado River drainage basin showing sampling points

7. Dissolved solids in Colorado River at Grand Canyon and at Topock, Ariz., and discharge at Grand Canyon.

9. Monthly distribution of precipitation at Woodstock, Va., 18971923, and 1921-1923.

10. Diagrammatic cross section of the rocks in the vicinity of the Chapin-Sacks well, Woodstock, Va

11. Graphic representation of analyses of well waters from vicinity of Woodstock, Va.

12. Composition of water from Pecos River and tributaries in New Mexico

13. Composition of water from Pecos River in Texas___._-__-_-

14. Analyses of water from Pecos River at Angeles, Tex.._-_._-

15. Analyses of water from Pecos River at Grandfalls, Tex

16. Range in composition of samples of water from rivers in New Jersey.

17. Analyses of surface waters of New Jersey

18. Apparatus used for obtaining volumetric samples in the field_-

19. Diagram showing distribution curves of mechanical composition of typical materials

20. Diagram showing accumulative curves of mechanical composition of typical materials.

21. Diagram showing relation between the uniformity coefficients and the porosities. in the materials tested.

22. Diagram showing relation between the moisture equivalents and the 10 per cent sizes of the materials tested.

23. Diagram of long-cylinder permeability apparatus

24. Diagram showing relation of rate of flow to hydraulic gradient in the experiment in which a 1,000-millimeter column of sand from Fort Caswell, N. C., was used. 
Fravkm 25. Diagram showing on an enlarged scale a part of the data shown in Figure 24

26. Diagram showing relation of rate of flow to hydraulic gradient in the experiment in which a 100-millimeter column of

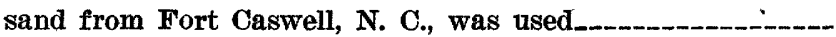

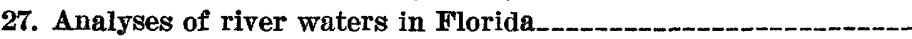

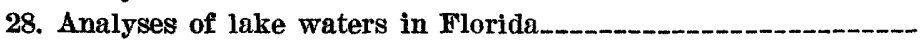

29. Analyses of ground waters in western Florida

30. Analyses of ground waters in northern and central Florida_-.--

31. Analyses of ground waters in southern Florida

32. Analyses of natural and softened waters at Daytona Beach, Fla

33. Analyses of waters from public supplies in Florida, before and after treatment.

34. County lines in Florida at time of compilation of table of

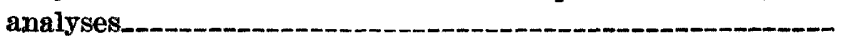





\title{
CONTRIBUTIONS TO THE HYDROLOGY OF THE UNITED STATES, 1927
}

\author{
N. C. Grovar, Chief Hydraulic Engineer
}

\section{METHODS OF EXPLORING AND REPAIRING LEAKY ARTESIAN WELLS}

\section{PREFACE}

By Ogoar E. Mhtnzer

The use of a current meter to explore wells, as described in the following papers by McCombs and Fiedler, is a distinct advance in methods both of hydrologic research and of practical well management. So far as I am informed, this method was first used successfully in 1918, by R. D. Klise, of the United States Geological Survey, in a study of the artesian wells of Honolulu.

The principle involved is very simple. The meter is let down into the well, where it records the velocity of the water at any depth desired; with the velocity and the diameter of the well known, the rate of flow at any point can be determined. Hence, a series of measurements taken at successive levels from the bottom to the top of the well will show just where the water enters and in what amounts, where it leaks out and in what amounts, and how much is delivered at the surface. For certain investigations it may be necessary to devise apparatus for measuring the diameter of a well at any depth, but thus far no serious difficulties have arisen on account of uncertainty as to the diameter.

This method has now been successfully used in the main artesian areas on the island of Oahu and in the Roswell artesian basin, in the Pecos Valley, N. Mex. In both of these areas the problem has been to ascertain the quantity of artesian water that is wasted by leakage from the wells at nonartesian horizons. The exploration of an artesian well is of immediate practical value to the well owner in giving 
him definite and reliable information as to whether any leaks occur in his well; if so, at what depths and in what amounts and about how much the yield can be increased by recasing. Moreover, the exploration of all or a considerable proportion of the wells of an artesian basin furnishes essential data to the investigator who is charged with the duty of making an inventory of the artesian water supply of the basin for the purpose of bringing about the maximum beneficial use without harmful overdevelopment.

I believe the current meter will eventually be used also in exploring pump wells to determine the horizons at which water enters the wells. In wells that extend through beds permeated with salt water it may, however, be more practicable to detect leaks of salt water into the wells by chemical or electrolytic methods.

The value of the current meter in exploring wells has been impressed on me by my experience in the Roswell artesian basin of New Mexico. In 1916 I spent about 10 days in the Pecos Valley near Roswell planning an investigation of its artesian-water supply. At that time the artesian pressure had already declined greatly, and many ranches along the margin of the original area of artesian flow had been abandoned because the water level in the wells had gone too low for profitable pumping. There was much local discussion and difference of opinion as to whether the decline in artesian pressure was due to overdevelopment or to subterranean leakage out of the wells through corroded or defective casings, but almost no definite information was available concerning this very vital question. I had taken with me a Price current meter and some equipment for inserting it into flowing wells. In the preliminary tests which I was able to make I did not succeed in getting any information as to leakage, but $I$ was convinced that with more substantial equipment it would be feasible to explore flowing wells for underground leakage with a current meter.

On account of the World War and other conditions, the investigation in the Roswell artesian basin had to be postponed until 1925, when it was taken up by Mr. Fiedler. He was provided with a current meter designed especially by Carl H. Au for use in exploring deep wells. (See p. 24.) The first flowing well to be explored was an old well 932 feet deep that was suspected of leaking. The meter was let down about 25 feet at a time and readings were made at each level. The readings showed that the current increased from the bottom to about the 785-foot level, and that from this level to the top it was nearly constant at about 3.80 feet a second, or 605 gallons a minute, proving that the casing was not leaking at any point. In other wells, as described by $\mathrm{Mr}$. Fiedler in this report, leaks of various kinds were found, the position of each leak was determined, 
and the quantity of artesian water wasted through it was mieasured or estimated. Thus the underground waste of artesian water need no longer be a matter of mere opinion, as the facts can be definitely determined by exploring each well.

For the work in Honolulu the Price current meter was used, although it was recognized that this meter was not designed for this purpose. (See p. 12.) For the work in New Mexico, however, the special deep-well meter constructed by $\mathrm{Mr}$. Au is giving good service. The outer jacket of this meter is a 3-inch pipe, but' Mr. Au is at present working on a meter of still smaller diameter. The methods of lowering the meter in the New Mexico work are more rapid than those used in the Honolulu work. Where large leaks are encountered special precautions have to be taken to prevent the meter from being carried out of the well by the outward current.

On account of the great value of the artesian-water supply in the Honolulu district it was wise public policy to carry out a somewhat expensive program of thorough recasing or plugging all leaky artesian wells. Great credit is due to the governor and the legislature for authorizing this vital program of conservation and to $\mathrm{Mr}$. McCombs and his colaborers for carrying it out so effectively. The value of the work already completed is indicated by the fact that the leakage which has been stopped is equal to more than one-fourth of the total quantity of artesian water used for the public supply of Honolulu. The experience on this project has shown that recasing and plugging leaky wells are difficult and expensive operations that require the services of a skillful driller with adequate drilling equipment, working under the instruction of a competent hydraulic engineer. It is indeed fortunate that the experience gained and the methods developed through the expensive and difficult work done in the Honolulu district have been recorded by $\mathrm{Mr}$. McCombs in the paper presented for the benefit of other operators in various parts of the world who will have to meet similar problems.

The investigation in the Roswell artesian basin may show that the water there is not sufficiently valuable to justify a program of conservation similar to that followed in Honolulu, but Mr. McCombs's paper will help materially in presenting the problem to the people of this basin in tangible form, and their decisions in regard to their future artesian-water policy will be based on sounder information than would otherwise have been available. Plate 1 shows two very strong flowing wells recently drilled in the Roswell artesian basin. Obviously a well that will produce so much water by artesian pressure is very valuable while it is in good condition, but may become a great liability to the community if its casing becomes leaky. 


\section{METHODS OF EXPLORING AND REPAIRING IEAKY ARTESIAN WELLS ON THE ISLAND OF OAHU, HA W AII}

\section{By JoHN MoCombs}

\section{INTRODUCTION}

This paper is intended primarily to present certain methods of testing and repairing artesian wells which have been devised and used on the island of Oahu. These methods are so completely dependent on the geology and hydrology of the coastal plain and on the well-drilling procedure that a brief discussion of these subjects is also necessary.

The writer is indebted to Mr. M. H. Carson, district engineer, who, as chief hydrographer for the Territory, is in charge of artesian investigations and who has reviewed this report and given many valuable suggestions; to Dr. H. S. Palmer, of the University of Hawaii, and Mr. A. H. Hobart, who reviewed the report from the standpoint of geologist and well driller, respectively; and to $\mathrm{Mr}$. B. L. Bigwood, who read the manuscript. Dr. H. L. Lyon, of the Hawaiian Sugar Planters' Association, has assisted materially in the investigations and has furnished information of much value. Special acknowledgments are due to the pioneer well drillers, Messrs. John A., James S., and Lincoln L. McCandless, who have given freely of the information acquired in more than 40 years of well drilling in Honolulu.

\section{OAHU ARTESIAN BASINS}

\section{HISTORICAL SKWTCH}

The only island of the Hawaiian group on which artesian water has been extensively developed is Oahu. The first flowing well was drilled on this island in 1879 , and up to the end of 1925 about 600 wells had been drilled. In 1925 the maximum daily draft on these wells was more than $350,000,000$ gallons, and the average more than $250,000,000$ gallons. This water is the main source of domestic supply for 100,000 people and is used also to irrigate sugar-cane land which produces annually about 140,000 tons of sugar, worth over $\$ 11,000,000$. Artesian water was early recognized as being of much value, and in 1884 a bill was passed by the legislature and signed by King Kalakaua providing for "mechanical appliances to arrest the flow" and providing also that artesian water might not be used solely to drive machinery.

Detailed logs of formations were kept for the earlier wells, and some were published at the time in the newspapers, but the first attempt to preserve records systematically was made by employees 
of the Hawaiian Government Survey Office, under the direction of W.D. Alexander, who was surveyor successively for the Kingdom, the provisional government, the Republic, and the Territory. These records, though incomplete, have been of the greatest value in all subsequent work; in fact, they comprise most of the records available for the period 1879 to 1910 , both well logs and readings of static head.

In 1909 W. C. Mendenhall, then in charge of ground-water investigations for the United States Geological Survey, visited Hawaii, and as a result of conferences with Governor Frear and others arranged with Marston Campbell, then superintendent of public works, to have T. F. Sedgwick, an employee of the public works department, carry out certain investigations as outlined by Mr. Mendenhall. Mr. Sedgwick located most of the wells then in existence, made systematic monthly readings of static head on a considerable number of wells distributed about the island, and determined the salt content of a large number of samples of well water. This work was continued until 1916, and the data so collected have been essential in all subsequent investigations.

The Territorial Legislature of 1915 authorized the appointment of a commission to investigate and report on the water resources of Hawaii. This commission consisted of $\mathbf{K}$. G. Larrison, then district engineer in the United States Geological Survey, as chairman, and Arthur G. Smith and Mr. Sedgwick as the other members. It conducted detailed investigations in the Honolulu district between Diamond Head and Red Hill and as a result of its recommendations ${ }^{1}$ the legislature of 1917 passed an act which defines waste of artesian water and gives the chief hydrographer authority to investigate and prevent it. This law, as amended by further legislative enactment, is given on pages $22-24$.

Since 1917 the artesian investigations have been conducted by the division of hydrography of the office of the commissioner of public lands, Territory of Hawaii. The successive chief hydrographers of the division have also been district engineers in the United States Geological Survey.

\section{GEOLOGY AND HYDROLOGY}

The artesian water on the island of Oahu occurs in a highly pervious vesicular basalt, locally known as "pukapuka" (Hawaiian, puka=hole). This rock is extensively fissured, but no large cavities are encountered in drilling in it. The rock is, however, rather

\footnotetext{
${ }^{1}$ Report of the water commission of the Territory of Hawail to His Excellency, the Governor of Hawail, 1917. This report is now out of print, but copies are available for consultation at the U. S. Geological Survey, Washington, D. C., and at most of the district offleen.
} 
weak and has a tendency to cave under the action of the drill. The upper surface of the water-bearing pukapuka rock in most places slopes $10^{\circ}$ or more toward the sea. It is overlain by a clayey con-: fining bed, above which lie coral limestone, coral mud, coral sand, gravel, recent lava flows, pyroclastic material, and soil. The waterbearing formation or aquifer is very thick. Several wells have been drilled into it 400 feet or more, without passing through it or finding any marked change in the character of the material. In the Honolulu district the confining bed extends up the slope as an effective cover over the aquifer to a height of about 40 feet above sea level. The upper part of the aquifer is exposed and permits entry of fresh water from rain during storms and perhaps from streams at all times.

There is evidence that the lower seaward part of the aquifer is exposed to the sea, so that artesian water can pass freely into the sea, around the lower edge of the confining bed, or sea water can move in the opposite direction into the aquifer. If, before any wells were drilled, the island had been in a lake of fresh water instead of in the sea the rain water that entered the aquifer at the upper end would have passed under the confining bed and would eventually have reached the lake. On account of the extreme permeability of the pukapuka the head of the artesian water would, under those conditions, have been only slightly above the lake level and would have been due entirely to the frictional resistance of the aquifer. The static head on the first wells drilled in the central Honolulu area was, however, more than 42 feet above sea level. It is believed that this static head was due only in small part to frictional resistance in this aquifer but mainly to the difference in specific gravity of the sea water and the fresh artesian water.

The theory of the behavior of fresh water in contact with salt water in a pervious formation, known as the theory of Badon Ghyben and Herzberg, is stated by Brown ${ }^{2}$ as follows:

Wherever a coast is formed of pervious rocks containing ground water that receives continual additions from rainfall, this ground water must mote downward and laterally toward the shore and mingle ultimately with the salt water of the sea. Such movements have long been a matter of common knowledge. Even on small porous, sandy islands fresh water can generally be found at an altitude slightly above mean sea level. It might be supposed that in such places the salt water surrounding the island would penetrate the sand to mean sea level and immediately absorb all the fresh water that might percolate downward to its surface. For several physical reasons this does not happen. Such islands are found, in reality to contain a dome-shaped lens of fresh water floating upon a concave surface of salt water. The fresh water is enabled to float upon the salt water because it has a considerably smaller density. This principle was apparently first applied to the hydrology of sea-

2 Brown. J. S., A study of coastal ground water, with special reference to Connecticut: U. S. Geol. Survey Water-Supply Paper 537, pp. 16-17, fig. 2, 1925. 
coasts - by Badion Ghyber, a Dutch captain of engineers, as the result of investigations made in Holland in 1887 , but gained little notice from hydrologists at that time. It was also published about 1900 by Herzberg, of Berlin, who apparently had no knowledge of the work of Badon Ghyben. Herzberg found in drilling wells on the island of Norderney; one of the East Friesian islands off the coast of Germany, that the depth to the salt water was roughly a function of the height of the water table above mean sea level and of the density of the water of the North Sea. Figure 1 shows the application of his theory.

Let $\mathbf{H}=$ total thickness of fresh water.

$h=$ depth of fresh water below sea level.

$t=$ height of fresh water above mean sea level.

Then

$$
\mathrm{H}=\boldsymbol{h}+\boldsymbol{t} \text {. }
$$

But the column of fresh water $H$ must be balanced by a column of salt water $h$ in order to maintain equilibrium. Wherefore, if $g$ is the specific gravity of sea water and the specific gravity of fresh water is assumed to be 1,

whence

$$
\begin{gathered}
\mathrm{H}=h+t=h g \\
h=\frac{t}{g-1} .
\end{gathered}
$$

In any case $g-1$ will be the difference in specific gravity between the fresh water and the salt water. Herzberg gives the specific gravity of the North Seá as 1.027, whence $h=37 t$.

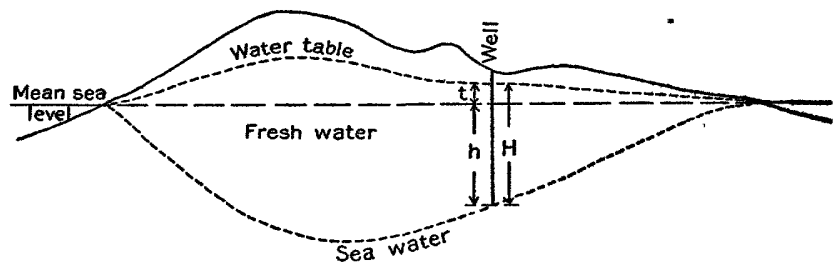

FlaUnm 1.-Section of the island of Norderney, Germany, showing the application of the Baden Ghyben-Herzberg theory. (From Herzberg)

The action of the water beneath the confining bed on the island of Oahu follows this principle, but the effect is not the same as is shown in Figure 1 for an island with uniform permeability. Consider an ideal section of a permeable formation along a seacoast, with an impervious vertical wall at the shore line extending to a depth of 1,500 feet below sea level but not to the bottom of the permeable formation. Assume further that the water in the permeable formation on the landward side of the wall is as salty as sea water and is standing at sea level. If water is pumped from the landward side, sea water will at once flow under the wall, and the water level on the landward side will, except for friction, remain the same. If fresh water is added by rainfall on the land, the balance. will be maintained, but the levels will not be the same; an

${ }^{3}$ Badon Ghyben, W., Nota in verband met de voorgenomen put boring nabij Amsterdam : K: Inst. Ing. Tijdschr., 1888-89, p. 21, The Hague, 1889.

- Herzberg, Baurat, Die Wasserversorgung einiger Nordseebäder: Jour. Gasbeleuchtung und Wasserversorgung, Jahrg. 44, Munich, 1901. 
amount of sea water equal in weight to the added fresh water but smaller in volume will be forced out under the wall, leaving the fresh-water level inside the wall higher than the sea-water level on the outside. As the process of adding fresh water continues the zone of contact between the fresh and the salt water will sink lower and lower until one of two things happens-either the upper surface of the fresh water will reach the top of the wall and thenceforth any water added by rainfall will flow over the wall, or else the zone of contact between fresh and salt water will reach the bottom of the wall and fresh water will begin to flow out under the wall. In either case the zone of contact will thereafter remain stationary.

An actual section in the Waikiki area is shown in Figure 2. It illustrates conditions equivalent in their effect to those discussed above. The wall is present, not as a thin vertical structure but as a sloping sheet of impervious clay. This clay wall is overlain with many other materials, which, except for their weight, do not affect the result.

The average specific gravity of sea water at the surface off the coast of Oahu has been reported by Lyon ${ }^{5}$ as 1.024, if that of ordinary artesian water is rated as 1 . At greater depth the specific gravity may be somewhat higher. With sea water 1.024 times as heavy as fresh water, the difference in level between the fresh water in the aquifer and the salt water in the sea will increase about 1 foot for each 43 feet of fresh water added. If the wall extends 1,500 feet below sea level the fresh water will stand about 36 feet above sea level, provided the wall rises to that height.

The change in conditions behind this actual wall of impervious clay has gone much farther than in the ideal case outlined above. In 1883, when well 54 (see fig. 2) was drilled, the water in this well rose to a height of 36 feet above sea level and had a very low salt content. It is reasonable to suppose that at that time the fresh water was either flowing out under the confining bed or was flowing over the top of it. As there are no physical evidences of large springs near the 36-foot level, the former supposition is more probably the correct one. By 1892 the head had declined to about 30 feet above sea level, and the water in well 54 had become too salty to drink. In September, 1925, the head was less than 19 feet above sea level and salt water had risen until it began to affect well 37 , at a higher level.

The experience with these wells indicates that salt begins to appear in a well when the theoretical zone of contact between the fresh and salt water is still at a considerable depth below the bottom of the well. This condition may be due in part to the width of the actual

E Lyon, H. L. (botanist, Hawailan Sugar Planters Association), oral communication. 


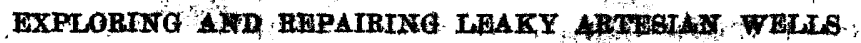

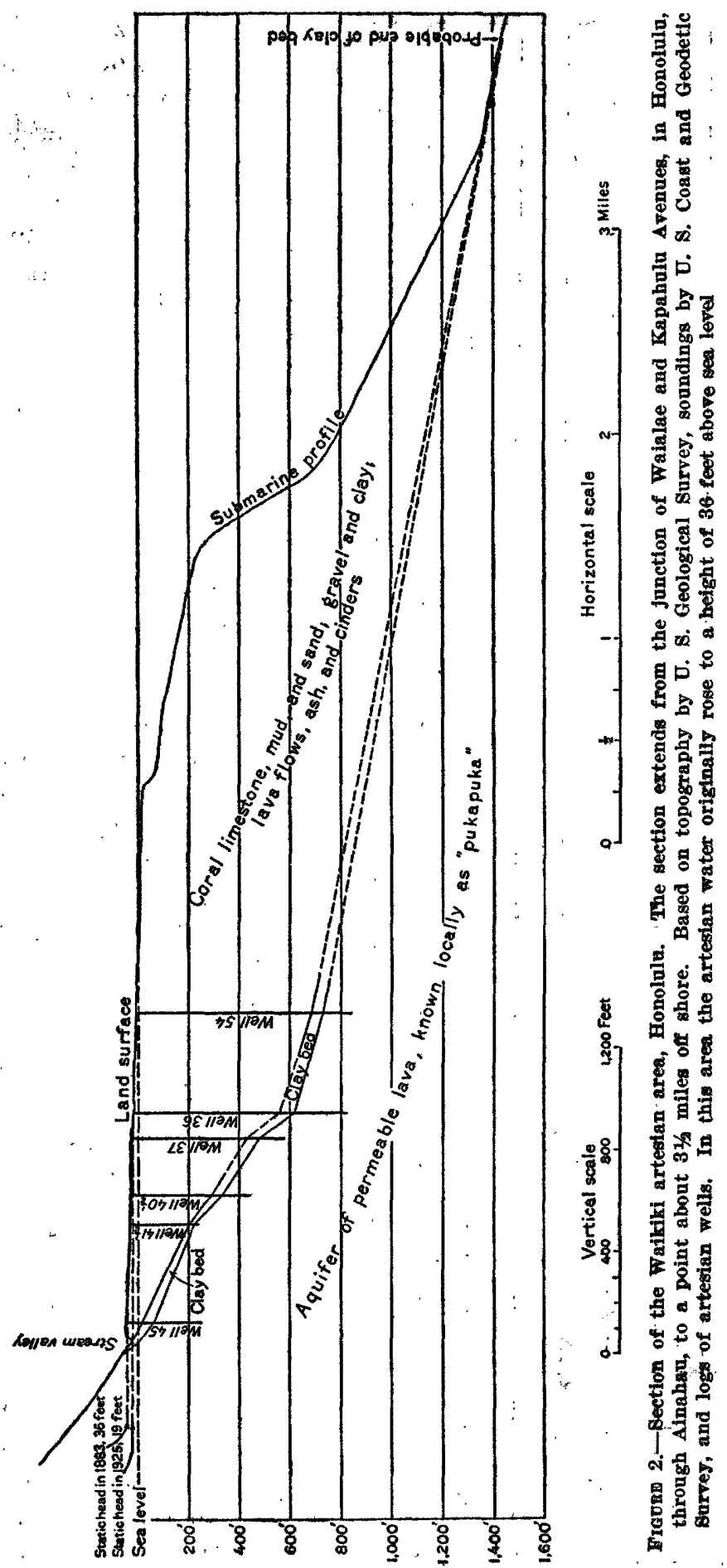




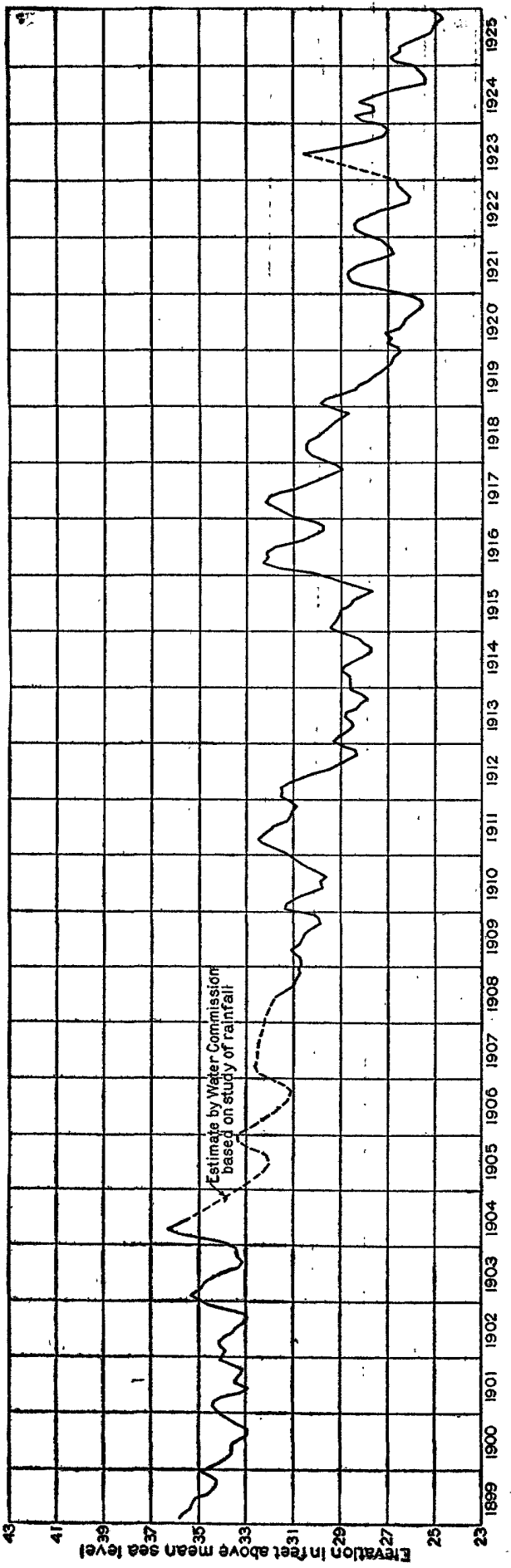

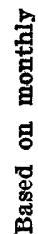

งิ่

욤

운

\&

론

รั

\$

สำ

댏

要告

क

퉁

덤

응

田:

焉

焉

을

$\Rightarrow$

푱

竞

बำ

.

4

范

政

要

星

롱

ธํํㄴ

प्र

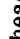

ह contact zone and in part to the doming up of the salt water under a well that is discharging. Obviously there must be a contact zone of considerable : width in which the water contains more salt than normal artesian water but less than sea water. Such an intermediate condition is undoubtedly developed by diffusion of the dissolved salt and by the mixing of salt and fresh water due to the alternate up and down movements of the water in the aquifer, as fluctuations in the head are caused by variations in rainfall, draft, and tide. At the upper limit of this zone the salt content is only slightly greater than that of normal fresh water, but it increases progressively with depth until at the lower limit it is equal to that of sea water. If the specific gravity of the sea water is greater than has been assumed, the contact between fresh and salt water will be theoretically higher and the transition zone correspondingly thinner.

The relation of pumpage to loss of static head and invasion by sea water, as outlined above, is the basis for the rather extensive 
conservation which has been planned and enforced by the division of hydrography. Most artesian basins in the United States have been overdeveloped and have suffered large losses in head. In most of them, however, the process of decline in artesian head is selflimiting; and the principal damage that results from overdevelopment and waste of artesian water is in making pumping necessary. On the island of Oahu the drop in artesian head produces more serious results. As the head is due to an equilibrium between fresh and salt water, a loss of 1 foot in artesian head will be accompanied by a rise of the salt water of about 42 feet. Thus the decline of head becomes of great significance, as it indicates loss of storage.

The diagram given in Figure 3 shows the head of a well at Oahu College since 1899. It shows annual and secular fluctuations due to variations in rainfall but with a persistent net decline through the period of 26 years, due to heavy withdrawal of water through wells. This well is in the central artesian area, which is adjacent to the Waikiki artesian area referred to in the preceding discussion and shown in Figure 2. The exceptionally long and continuous record of the Oahu College well, however, shows conditions that are typical of all the artesian areas in Honolulu.

\section{METHODS OF DRILIING WELLS}

The wells on Oahu are always drilled with cable tools. The usual practice is to "spud in" the hole through the loose surface materials, to introduce, if necessary, $\dot{a}$ short section of large pipe to prevent caving, and to drill to the aquifer with a bit slightly larger than the size of casing that is to be used. When the first flow is encountered the hole is cased throughout, and the casing landed at the bottom by allowing it to drop a few inches. A bit that will just clear the casing is then used, and the hole is usually extended 60 to 100 feet into the aquifer. The clay cap, being slightly plastic, probably flows around the lower end of the casing and makes a tight seal.

In some wells, where gravel or other loose material is encountered, it is necessary to reduce the casing. The string of larger casing is run down to the caving material and driven into it as far as possible by use of a sand bucket and drive blocks. The drilling is then continued with a smaller bit, and when the aquifer is reached enough casing to extend above the bottom of the larger string is dropped in. This practice is not commendable but is nearly always followed when caving formations are encountered. It is worthy of note that reduced wells in general become defective sooner than those which are not reduced.

\section{DFTERMINATION OF UNDERGROUNT IEAKAGE}

It was abserved early in the history of well drilling on Oahu that flowing wells can be obtained only in certain definite areas on the $95221^{\circ}-28-2$ 
coastal plain. These areas are separated by. other areas where no artesian water is found. It was also observed that within a given area the water in all wells has the same static head but that in general the head in the different areas is not the same. This observation was confirmed by the investigations of the water commission in 1916. The head fluctuates with draft and rainfall, and also to a less extent with barometric pressure and perhaps with tide, but almost uniformly in each area.

These isopiestic areas or areas of equal static head are unique and their existence has made the discovery of underground leakage simple. Levels have been run to nearly all the 149 wells in the Honolulu city area, and static heads are determined periodically. Wells on which the head is found to be noticeably low are at once known to be leaking.

A number of wells that have been found deficient in static head have been further examined by use of a current meter equipped to be lowered into the well. The meter used until recently is a Price meter, of the kind used by the Geological Survey in gaging streams, ${ }^{\circ}$ It is equipped with a wire guard to protect the cups, and the end of the yoke is fastened rigidly to a length of $3 / 8$-inch pipe. This adaptation of the Price meter was made by R. D. Klise in 1918. This meter is, however, not wholly satisfactory for this purpose. It is made to run with the axis vertical, but when it is used in a well the axis is horizontal and the friction is thereby increased, with consequent loss of sensitiveness and accuracy. Another disadvantage is that the meter is too large to go into a well that is less than 6 inches in inside diameter. An $\mathrm{Au}$ meter is now used. (See p. 24.) In early tests the meter was lowered into the wells on a wire, but high velocities were found, and where large leaks were encountered the meter was carried out through the holes in the casing. It therefore became necessary to have a more rigid support. The process used at present is the result of changes and modifications made over a period of seven years.

If the well that is to be tested flows at the surface the casing is extended above the static level, and all surface flow is thereby stopped. Any current then observed is due to leaks in the casing. It is highly desirable to stop the surface flow before testing wherever the head is low enough to permit, because velocity ascertained from a single reading with a curfent meter is more nearly accurate than velocity determined as the difference of two readings. In wells whose casing is reduced in size underground the resulting increase in velocity obscures the result if surface flow is permitted: For

${ }^{6}$ For a description of the Price current meter see manual of the manufacturers, $W$. L. E. Gurley, Troy, N. Y., or Hoyt, J. C., and Grover, N. C., Hiver diseharge, 4th ed., pp. 6-22, John Wiley \&ons, 1920. 
low heads-that is, less than 20 feet-the extended casing does not need to be very heary. The easiest method of making a tight joint between the well casing and the extension is to use for the extension a pipe about 2 inches larger in diameter, slip it over the casing, and call between with oakum or rope yarn.

The equipment necessary consists of the meter, a tripod suffciently high and strong to support two men at the height of the extended casing, a single sheave block, a coil of $5 / 8$-inch rope long enough to reach to the bottom of the well, a reel of insulated twostrand copper wire somewhat longer than the rope, 200 feet of $3 / 8$-inch pipe in 10-foot lengths, two pipe wrenches; a roll of friction tape, steel tape, telephone receiver, dry battery, and stop watch.

The meter is lowered into the well on the pipe, a length at a time, electrical connection is made by means of the insulated wire, and the weight is supported on the rope. It is advisable to tape the wire to the pipe at each joint in the pipe and to slip a half hitch in the rope over the pipe at close intervals. In these tests 200 feet of pipe has always been found sufficient, and frequently 50 feet is enough, but care must be taken not to lower the top end of the pipe below the first large leaks, because it may be pulled to the side of the casing by the outward current and become fastened in the openings. $\mathrm{Ob}$ servations for velocity can be made as each length of pipe is being screwed on. Observations made as the pipe is lowered will reveal breaks in the wiring. If the meter fails to register at least twice as it is lowered 10 feet, something is wrong.

The following table gives results of a number of complete examinations for leakage. The total underground leakage discovered in Honolulu to 1925 is approximately 7,750,000 gallons a day, of which $5,900,000$ gallons a day has been stopped by suitable repairs. The conservation effected in thus saving artesian water that would otherwise have been wasted by flowing into the sea through underground passages will be better appreciated if the quantity is compared with the total quantity of artesian water consumed from the Honolulu waterworks, which in 1925 averaged $22,000,000$ gallons a day.

As most of the artesian water is comparatively noncorrosive, few leaks originate inside the casing. The coral is the trouble maker, as it is more or less pervious and being below sea level frequently carries water which is very salty; it is also somewhat soluble and is easily eroded. Probably the first step toward the formation of a leak is corrosion of the pipe from the outside, probably by salt water. As soon as leaks are formed the process changes, and fresh water under considerable pressure from inside dissolves and erodes the coral until the support is gradually removed from around the casing. It has been noted that the head on a well that is at first only slightly 
defective will drop abruptly later, indicating a large waste of water. This sudden decrease in head probably indicates the change from a number of small leaks to a general collapse of the casing, allowing free flow of the water through large solution passages in the coral.

A leak of another type is that which occurs around the bottom of an improperly seated casing. A leak of a third type, which is. tess common, occurs in a well that is not cased throughout. If the log of the well being tested is available or even known approximately, the type of leak can be determined with the current meter. If it is of the first type mentioned above, a current will be indicated and the velocity will increase suddenly at a definite depth, always in a pervious formation, and will not increase below that formation. If the leak is caused by an improperly seated casing, a current will first be indicated near the bottom of the well, at the top of the aquifer, and the velocity will at once reach its maximum and will decrease almost to zero at the bottom. Leaks of the third type will usually be recognized by a gradual increase in velocity, followed in some wells by a decrease due to the enlarged cross section that results from caving.

Defective wells in the Honolulu district

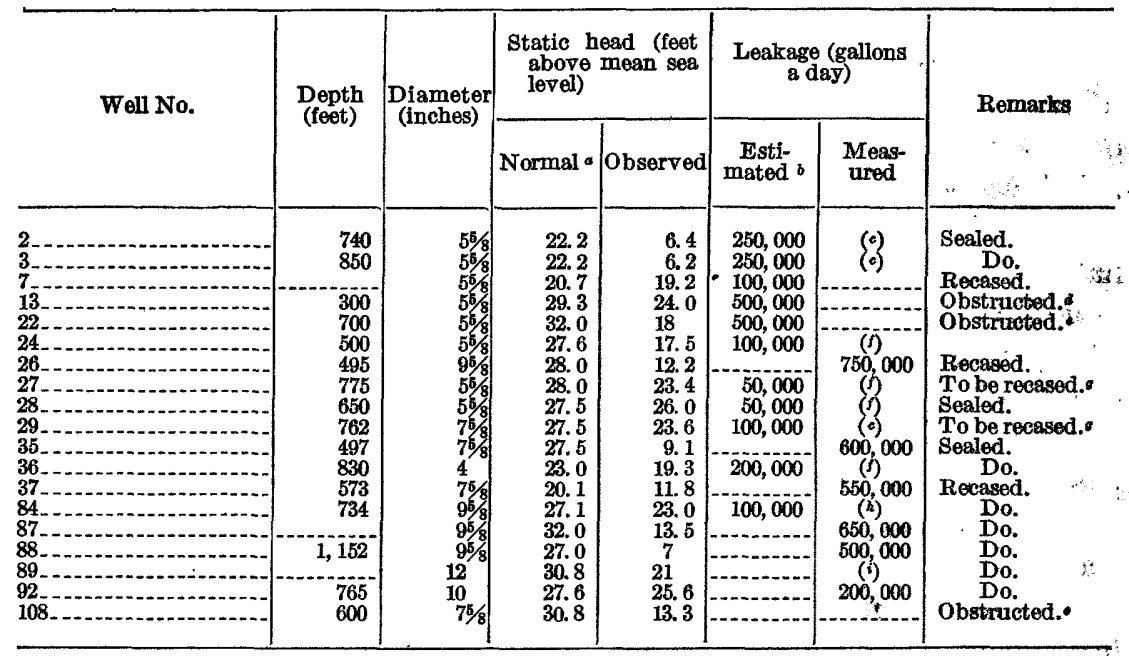

a Normal head is the head on a near-by well known to be in good condition.

- The method of estimating leakage from a defective well is based on observed loss of head, depth, and diameter. The water from any leak will be discharging into a pervious formation, and the exteraal head will be virtually sea level. The observed loss of head is then that part of the total head abote level which is lost in aquifer and well casing together. Varying assumptions based on experience are made as to distribution of this loss between aquifer and casing. The estimates are regarded as accurate within 25 per cent.

The meter can not be-used because the well has a short length of 6-inch casing at the top.

a The owner, on being notified to repair his well, engaged a building contractor to dothework. Concrete was poured in and bridged at a depth of about 100 feet, or just above the leak. The well at present is probably leaking to capacity. Will probably cost $\$ 5,000$ to clean out and recase.

Obstruction is soil and rubbish only.

$f$ Too small to admit Price meter.

- Government well; funds to repair it are now available.

h Owner recased the well without requiring a meter test.

- Recased in 1917 before the meter came into use 


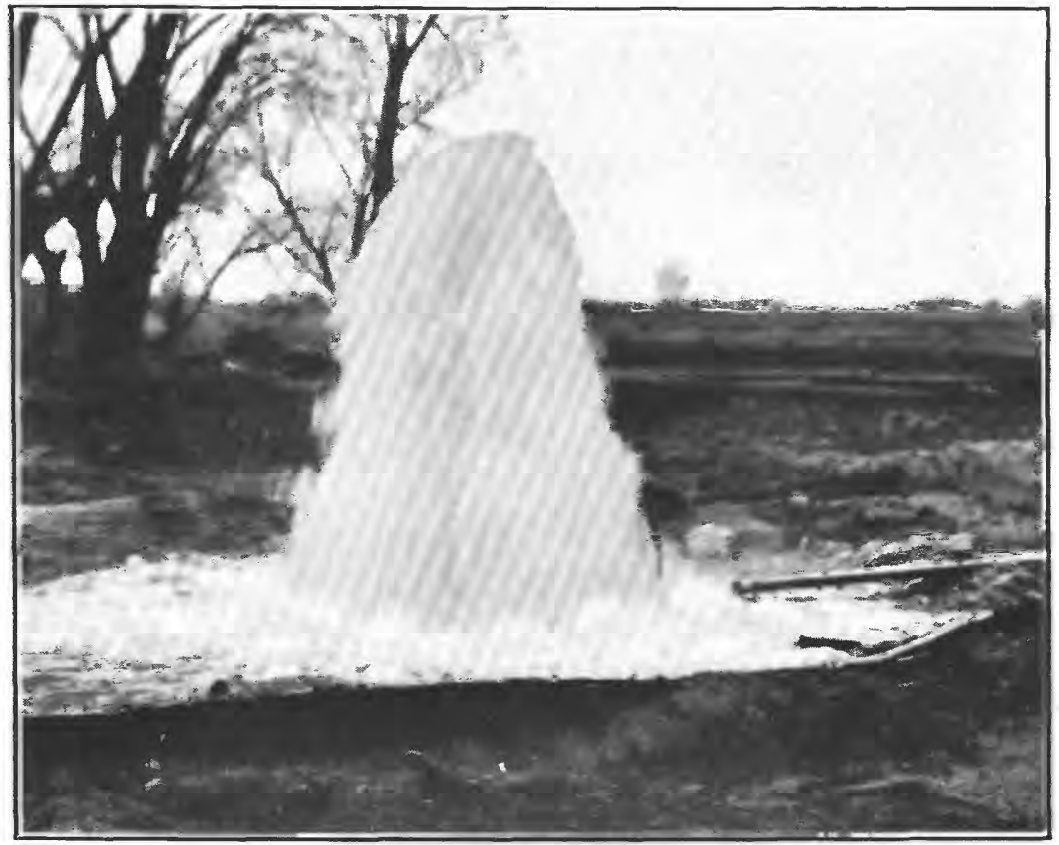

A. WELL OF OASIS COTTON CO., IN THE NW. 1/4 SEC. 22, T. 11 S., R. 25 E.

This well is 780 feet deep and 121/2 inches in diameter. On April 21, 1926, it had a flow of 5,710 gallons a minute

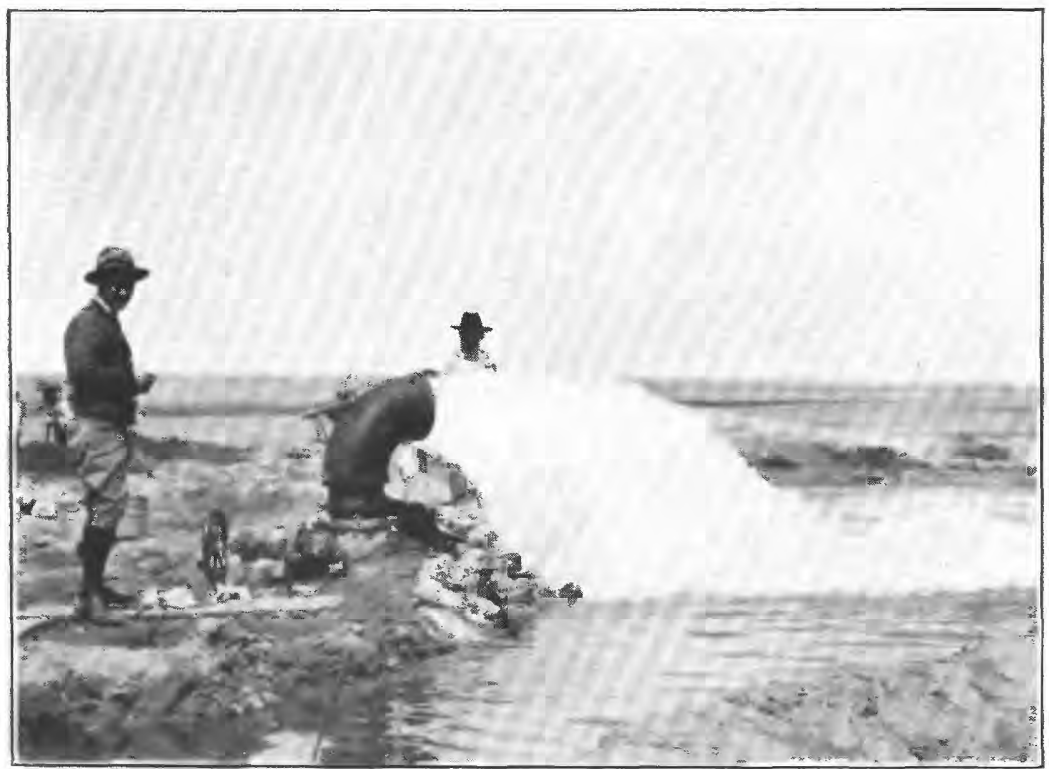

B. WELL OF H. D. KING, IN THE SW. 1/4 SEC. 14, T. 11 S., R. 25 E.

This well is 845 feet deep and 10 inches in diameter. On April 21, 1926, it had a flow of 3,190 gallons a minute

Flowing Wells in the Roswell Artesian Basin, New Mexico 


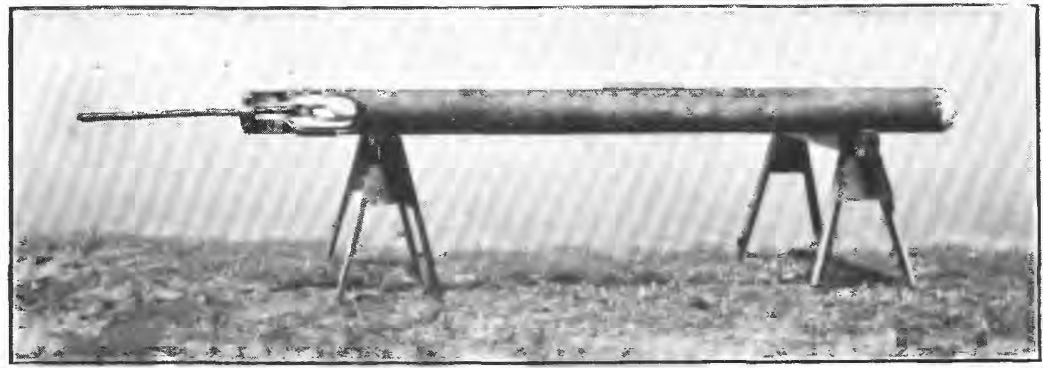

A. BUCKET WITH BALL-SHAPED VALVE PULLED UP, READY TO BE CHARGED

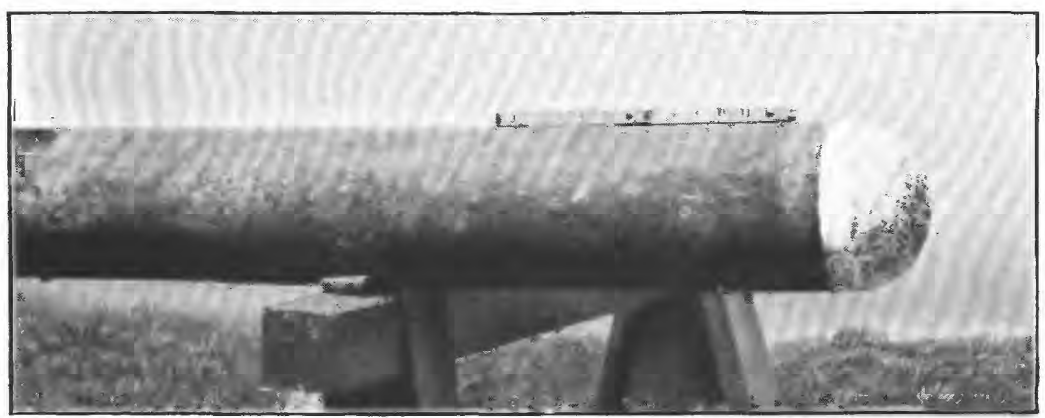

B. ENLARGED VIEW OF LOWER END OF BUCKET WITH VALVE PULLED UP

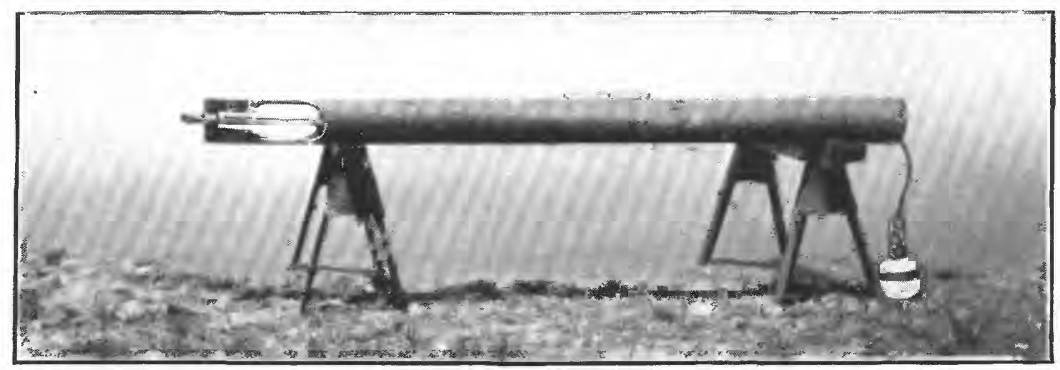

C. BUCKET WITH ROD FORCED DOWN, SO THAT IT HAS RELEASED THE VALVE AND ENGAGED THE UMBRELLA LATCH

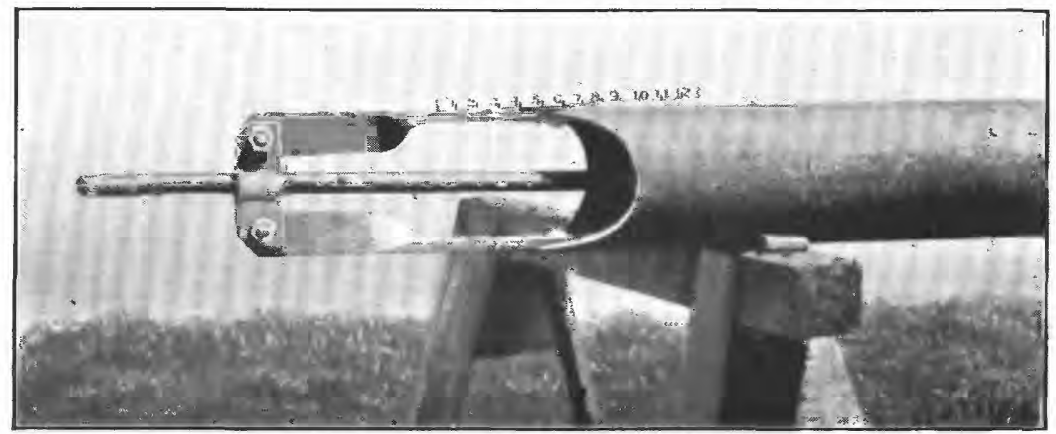

D. ENLARGED VIEW OF UPPER END OF BUCKET WITH UMBRELLA LATCH ENGAGED

Old Type of Dump Bucket Used in Plugging Wells 


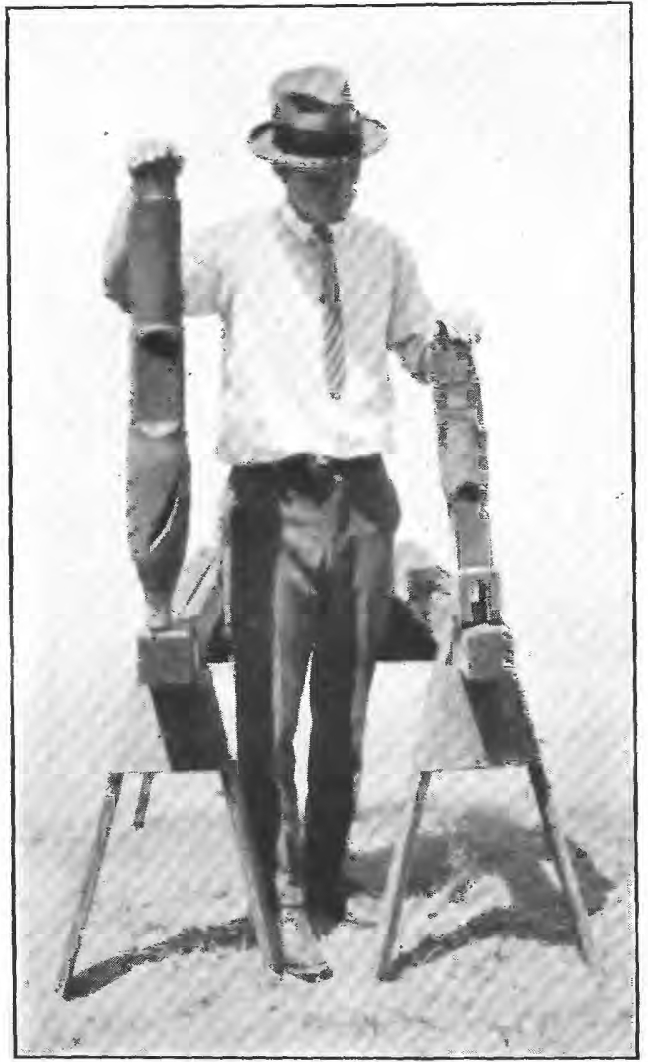

A. SWEDGE USED IN GLEANING DEFECTIVE WELIS BEFORE RECASING THEM AND THE SUBEND TO WHICH DUMP BUCKET IS ATTACHED

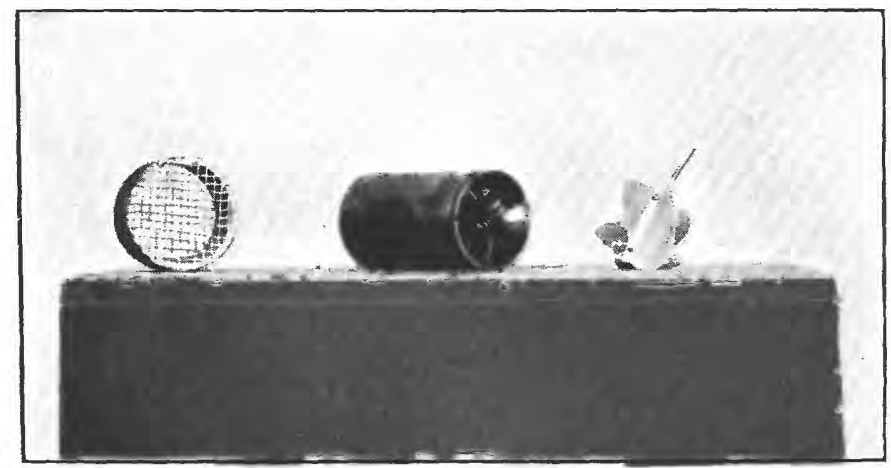

B. AU DEEP-WELL CURRENT METER

The turbine wheel has been removed from the meter to be shown in the view. The screen at the left is attached to the bottom of the meter pipe shown in Plate 4, $A$ 


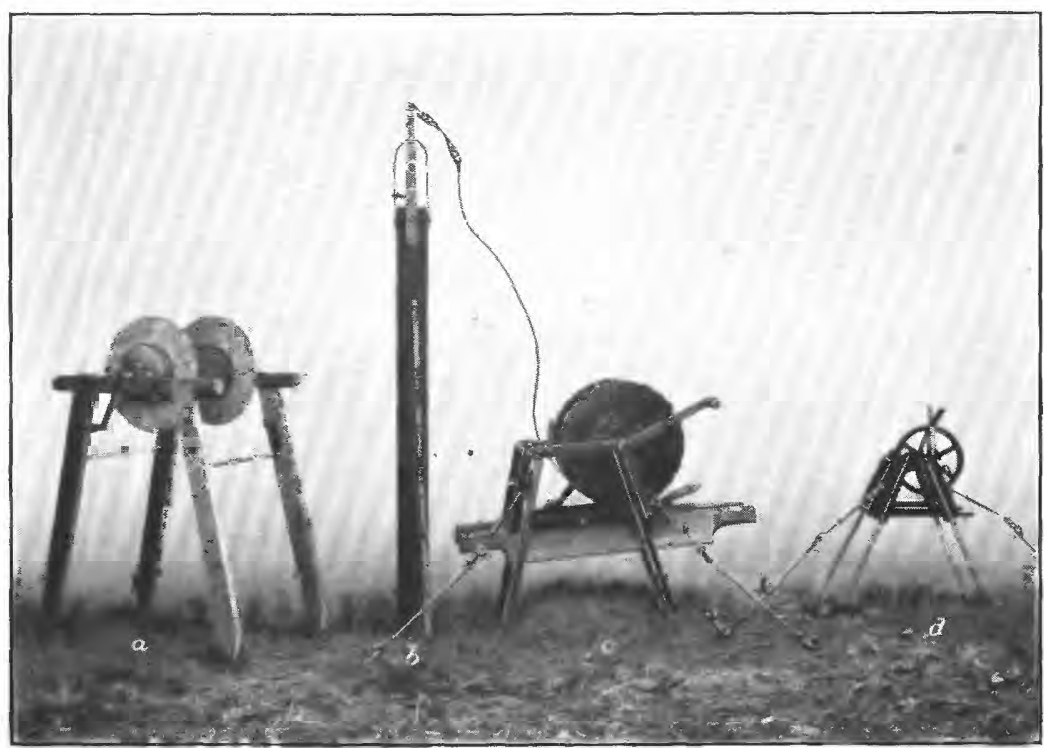

A. APPARATUS FOR USING AU DEEP-WELL CURRENT METER IN EXPLORING WELLS

$a$, Reel for holling insulated electric wire, to which the head phone and battery are attached; $b$, upper 4-foot section of the 3 -inch meter pipe; $c$, reel for holding cable to which the meter pipe is attached; $d$, odometer for recording depth

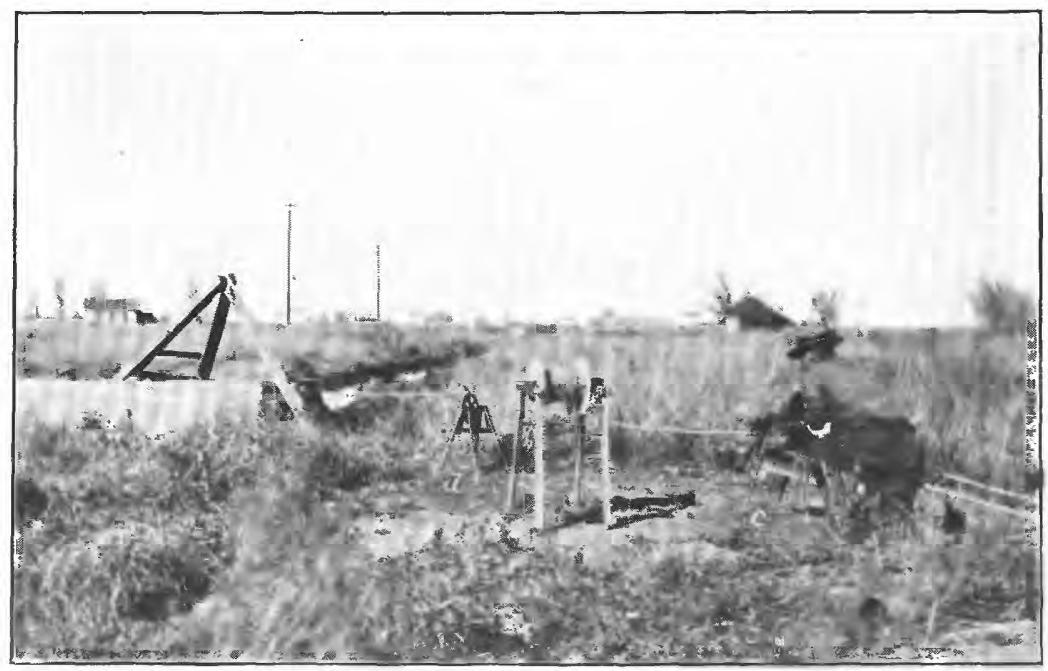

$B$. SAME APPARATUS SET UP

For explanation of letter's see $A$ 


\section{MHTHODS OF RHPATRENG LEAKY WEILS}

\section{RECASING}

The older wells are usually lined with well casing, but the most common practice at present is to use steam pipe both for new jobs and for recasing, as it is more easily obtained and is believed to be of better quality. Galvanized pipe is now being used to some extent for recasing, but in the writer's opinion it is of little additional value, although it costs more. The sizes of well casings are defined by giving the outside diameter, whereas the sizes of steam pipe are defined by giving the inside diameter. The proper sizes to use in recasing for the more common sizes of original casing are given in the following table:

Sizes of pipe to be used in recasing wells

[Computed on basis of pipe tables in catalogue of Qil Well Supply Co. All diameters are given in inches]

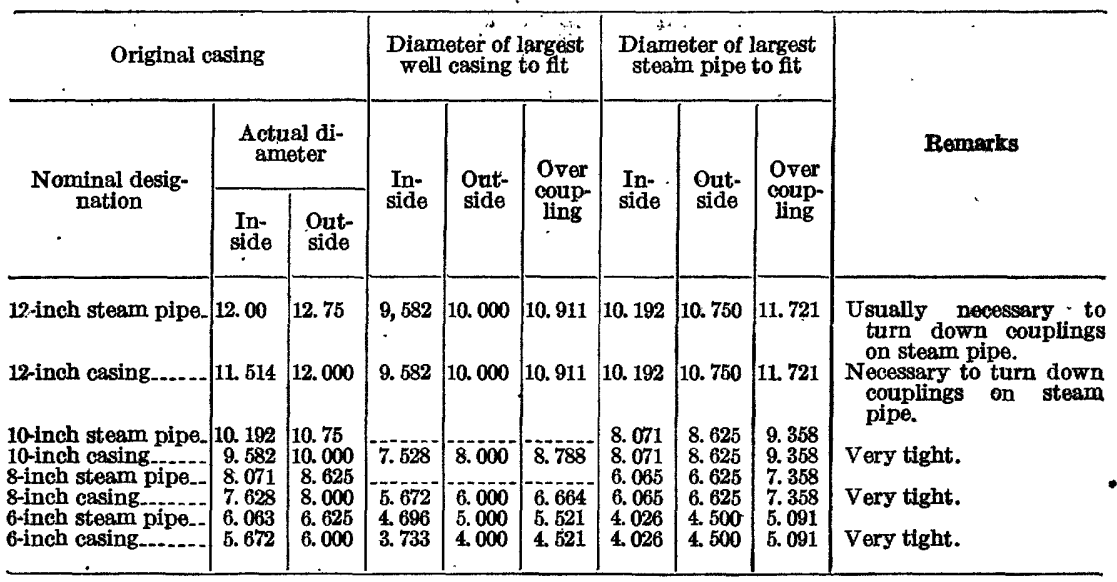

Recasing in Hawaii is always done by experienced well drillers with adequate equipment. It can not be too strongly emphasized that work of this kind requires experience, skill, and intelligence. The tools and equipment required are about the same as for drilling, and include derrick, power plant, either bull wheel or hoisting drums, walking beam, drills, jars, bailers or sand buckets, swedges, spudding line and shoe, pipe wrenches, and minor equipment. The power plant is driven by either steam or gasoline, and must develop enough power to lift a full string of casing when hanging clear.

After the equipment is assembled on the ground and the derrick and power plant set up, the first step is to clean out the well casing to the diameter of the outside of the new pipe. This is usually done by running a series of swedges (see pl. $3, A$ ) through the casing, 
starting with one about 2 inches smaller than the desired diameter and ending with the exact size. These swedges should be used with jars and a short drill stem or sinker bar, in order to insure removal if they stick, and should be given an up and down motion as they are lowered, by use of either the spudding line and shoe or the walking beam with or without temper screw. These swedges will remove scale and also open the pipe to full diameter if it is not too badly collapsed.

Many of the older wells have been abandoned by their owners and allowed to stand open for years, and as a result they have had rubbish of every sort thrown into them. Some wells have been obstructed with rock and soil dumped in with the intention of filling them completely. Several of these wells were known to be defective, but it was at first believed that it would be very difficult to repair them. Experience has shown, however, that these plugs or obstructions were never complete, but at most were only a few feet thick. The material introduced, whatever its nature, seems to bridge in the casing.

The tool that has been used with uniform success in cleaning out such obstructions is the wash rod or jetting drill, such as is used for drilling wells and test holes in unconsolidated material. In cleaning wells a drill with a cutting edge $17 / 8$ inches in length is used. This drill is suspended on 1-inch wrought-iron pipe, and the drill casing is 2-inch pipe. The 2-inch casing is lowered into the well until it rests on the obstruction. The drill is then introduced, drilling is started, and the 2-inch casing is made to follow the drill as closely as possible by turning and driving it. Most of the fine material will flow out with the wash water, and the drill and casing will usually go down rapidly. When an obstruction has been drilled through the drill and casing may be lifted and a new hole started. Usually the obstruction will fall free after being drilled through once or twice, but the dislodged material may bridge again farther down, where the process may have to be repeated. Ultimately such material as has not been washed out will reach the bottom of the hole, where if necessary it may be drilled up and removed with the regular well tools. The wash-rod method has been used successfully to a depth of 300 feet but is not recommended for much greater depths on account of the weight of the apparatus.

When cleaning is completed the casing is lowered into the well a joint at a time. It is handled with the so-called elevators, which are clamped around just below the couplings. The casing already in the well is supported on clamps. The threads of each joint are carefully covered with red lead and are screwed up till the ends of the pipe abut. Usually the bottom end of the string is provided 
with a coupling or a steel shoe. If the string of casing binds in the hole it may be driven, either with a maul or by putting a wooden clamp on the string of drill tools and driving with the bull wheel. If the swedging is properly done, however, the amount of binding that will occur is slight unless the hole is crooked. Rarely it may be necessary to drill out caving material that has lodged below the end of the new. string. Turning the string in the hole is often helpful in passing tight places.

The new casing may stop at or just beyond the end of the old, as the original hole is reduced here. It is the usual practice to put a metal clamp around the top of the new casing and to rest it on the old casing to prevent possible falling after the job is done, There seems to be little need of any further elosing of the small annular space between the two casings. As the new casing is lowered the couplings pick up scale and make a tight seal. A thin cement grout is sometimes poured between the two casings, and this undoubtedly helps to form a seal, but numerous wells recased without it have been perfectly satisfactory for years. The usual test for a satisfactory recasing is the full recovery of the static head for the particular locality, and the writer knows of no well recased in the manner described that did not recover and keep the full head. When a job is completed it is always advisable to run the sand bucket or even the drill to make sure that no obstructions are left either in the pipe or in the open hole in the rock below.

No recased well in Honolulu has continued to leak except where the new casing did not go deep enough. As a general rule, nothing smaller than an 8-inch well is considered worth recasing. The smaller wells should be plugged. In a few places where a small amount of water was needed for some definite local use, wells as small as 6 inches have been recased, but this practice is only making trouble for some one in the future, because special equipment will be required to explore and repair wells of small diameter.

\section{PLUGGING OR SEALING}

The law of the Territory of Hawaii provides that no well shall be made inaccessible for inspection unless it has been sealed in a manner approved by the superintendent of hydrography. This law, as long as funds are available for its enforcement, operates to keep unskilled, malicious, or ignorant persons from obstructing well casings in an attempt to plug the well, to evade the law, or to do damage intentionally. All recent plugging jobs have been supervised by the writer or some other engineer from the division of hydrography.

The permanent seal is made with concrete, which must be placed as a plug several feet thick at the top of the aquifer and in the cap 


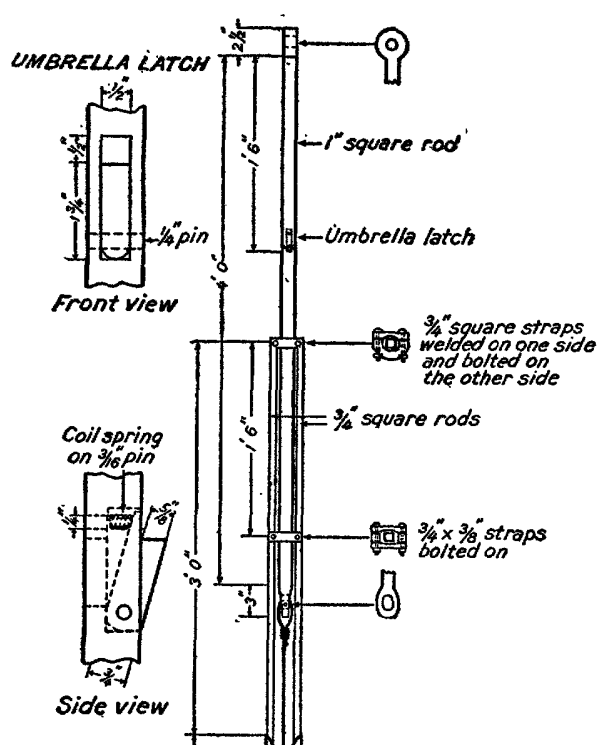

rock. It is obvious, however, that concrete can not be poured into a long column of water, as this would result in a complete separation of the aggregate. To avoid this separation two methods have been used. In one the concrete is let down in bags, and in the other a bucket is used that dumps when it reaches the bottom and releases the concrete in a mass. The second method is by far the more satisfactory. The dump buckets used are patterned after that recommended by the United States Bureau of Mines ${ }^{7}$ but have been redesigned and adapted to water-well conditions by A. H. Hobart, an engineer and well driller in Honolulu. The most important modifications of the Bureau of Mines pattern are the use of a square rod at the top and a lead-filled cylinder instead of an iron ball at the bottom. The square rod has remedied the trouble previously encountered with the umbrella latch, and the heavy lead cylinder insures complete and certain dumping, as its greater weight is sufficient to pull the suspending chain through material of any sort. Plate 2 shows a dump bucket of the type originally used; Figure 4 shows an improved dump bucket of the most recent pattern, with the square shaft and extra weight.

7 Tough, F. B., Methods of shutting of 3-inch dump bucket used in plugging wells 
In use, when the bucket is loaded and ready to be lowered, the tetal weight is on the plug at the bottom, the rod is up, and the umbrella latch is disengaged. When the bucket has been lowered to the bottom and raised slightly, the tools above have forced the umbrella rod and latch down until. the latch has passed the ring at the top of the bucket yoke and has sprung out. The weight of the bucket is then on the latch, and there is about 2 feet of slack in the line to the plug. The concrete flows out as the bucket is slowly raised. The umbrella latch is the weak point of this device. It should be as large as possible, should be provided with a strong coil spring, and should also be easily removable for adjustment and cleaning. The shell of the bucket may be of fairly light material and should be at least 2 inches smaller in diameter than the well casing it is to enter in order to provide enough waterway around the sides for quick operation. It is most rapidly handled on the sand line, provided there is sufficient power to lift it, but in wells where there is danger of caving it is advisable never to use any line except the drill line and to use jars above every tool that is lowered.

A well that has a strong flow, either at the surface or through subsurface leaks, presents a difficult problem. The concrete will be washed and separated by the water, no matter how it is put in, unless the flow is first shut off with other material. The most successful plugs have been made with iron turnings and filings. These can be purchased in Honolulu at a low price and are as a rule heavy enough to stay in the well. Crushed rock has also been used, but is too light for high velocities.

The method used is to clean out the well and fill from the bottom with iron turnings, using the dump bucket. These turnings may be tamped occasionally, either with the weight on the end of the bucket or better with a "sub-end" or blunt drill on a string of tools. When the height of material increases at a regular rate as each bucket is added little tamping is needed, but when there is little or no increase, as in large cavities, thorough tamping is useful. The turnings shut off the flow a little at a time and will either plug the well completely or reduce the flow so much that concrete will set. When the depth of the leak is known the height at which the water surface should stand in a sealed well in the area is easily computed. The well water flows out into salt water that is under sea-level head, and when a static condition is reached the head above sea level on the well will be $0.024 h$, in which $h$ equals the depth of the leak below sea level. The theory of this balance is discussed in the section headed "Geology and hydrology." (See pp. 5-11.) In general, when a leaking well is closed off in the aquifer the water surface will fall to the level of the ground water in the formation that is car- 
rying the leakage. When it appears from the behavior of the water surface and from the amount of material placed that the

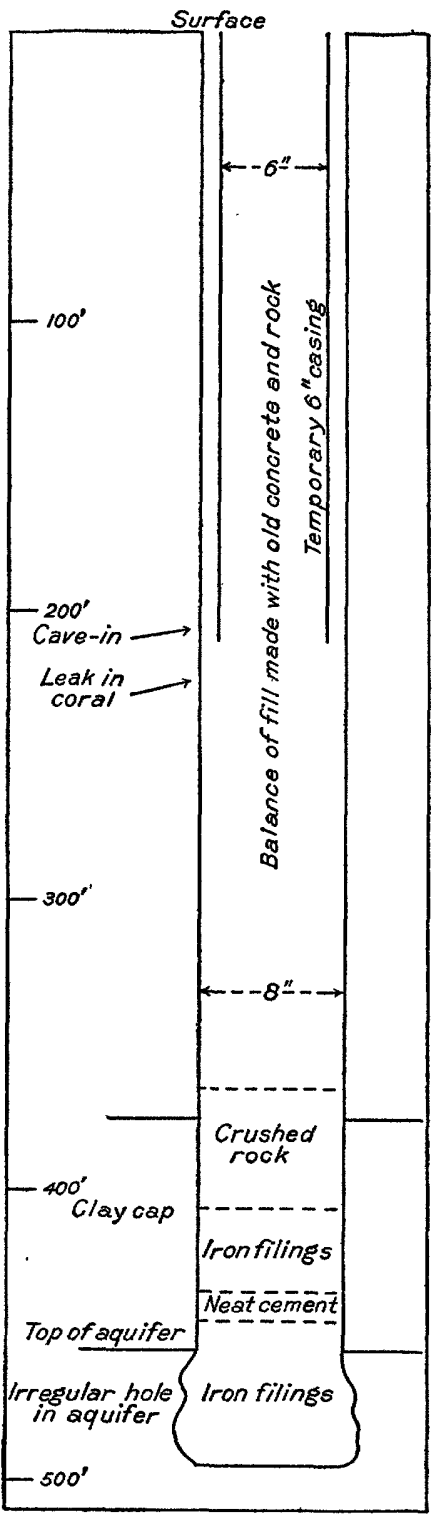

FigURE 5.-Section of well 34, on Young Street, Honolulu, showing method of plugging. The upper hyer of iron turnings was used in this well but is not required iron plug is complete the current meter should be let down into the well, and if no measurable flow exists it is safe to put in concrete. This method has been used to seal wells ranging in diameter from 4 to 10 inches and in depth from 200 to 850 feet. It might not give as good results in other regions where larger unbalanced pressures exist.

The general procedure on a job of this sort is exemplified by well 34, on Young Street, Honolulu. (See fig. 5.) This well was drilled in 1887 to supply an ice plant. It was 8 inches in diameter and 497 feet deep and penetrated the aquifer about 40 feet. It was found to be defective in 1918, and readings of static head in 1924 showed the water surface about 17 feet below the average for the locality, or only 10 feet above sea level. A test with the current meter showed a flow of over 600,000 gallons daily through a leak in the casing about 250 feet below the surface. The observed velocity below the leak was more than 5 feet a second.

A local well driller was engaged by the owners to seal this well, and the writer inspected the work throughout. The well was opened and swedged out, and the depth was accurately determined. An attempt was then made to fill up the water-bearing stratum by dumping in No. 2 crushed rock, which runs from half an inch to $1 \frac{1}{2}$ inches in diameter. A cubic yard of this rock was poured in, but soundings showed that none of it reached the bottom. The driller then poured in No. 1 rock, which runs as large as $21 / 2$ inches in diameter; even this material would not sink but was carried out through the leak. A cave-in then occurred at a depth of 184 feet, 
due probably to the friction of the large rock. This was drilled through with a 2-inch wash-rod outfit, followed by a 6 -inch casing, the cavings being knocked down the well and passing. out at the leak. The 6-inch casing was forced down to 205 feet, the caving stopped, and the well was again open.

Iron filings and turnings were then placed with a 4-inch dump bucket. The well was filled up 51 feet with this material, bringing the top of the iron above the top of the aquifer. No difficulty was found in making the iron stay in the hole, but about twice as much was put in as the computed volume indicated. Probably the hole had been enlarged by caving in. The static head fell to 5 feet above sea level and the well meter showed no flow. A concrete cap was then placed on top of the iron turnings by use of the dump bucket and was given time to set. The remainder of the well was filled with stone, sand, etc. The 6-inch temporary casing was withdrawn without difficulty. The total cost of this job was $\$ 2,600$, of which $\$ 950$ was due to the cave-in.

A few wells of small diameter having large leaks have required a heavier material. In these wells the aquifer was filled with iron turnings until only a small space remained. The water entering this confined space had so great a velocity that the turnings would not settle. The last few feet was then filled with lead shot, which was heavy enough to stop the flow and to permit concrete to set. Owing to the high cost of lead every effort should be made to fill with iron as high as possible.

A thin grout is used for the concrete cap because thicker mixtures will clog the bucket. This grout works well for the first two buckets, but it piles up in the bottom in a soft semiliquid mass, and great difficulty has been encountered in dumping other loads, as the bucket sinks into the soft material already in place. This difficulty led to the use of precast concrete cores, which are made about 5 feet long and 2 or 3 inches smaller in diameter than the hole in which they are placed and have a wire loop at the upper end. One of these cores is placed after each two buckets of grout. They are suspended from the sand line with a thin piece of rope yarn, which must be just strong enough to carry the weight. The plugs will settle into the soft grout, and the rope yarn can then be broken by a quick jerk.

One essential step in sealing that must be emphasized is careful measurement of the depths. The operator must know how much fill he is getting with each load of material placed and must keep accurate and complete notes. The "feel" of the line is as important in sealing as in drilling, and an experienced operator will be able to tell the height of his plug within an inch or two at any time. 
Recently two wells that had caved so badly that the dump bucket could not be used were sealed by first dropping iron turnings through a 2-inch pipe and then pumping in cement grout.

The cost of sealing varies greatly. Most of the jobs done under the inspection of the division of hydrography have been done by contract on the basis of a daily rate for furnishing equipment and erew, and the cost varied with the difficulties encountered. Wells 4 or 6 inches in diameter cost more to seal than larger wells of equal depth, on account of the small tools and eareful handling required.

The methods of recasing and sealing outlined are those which have been and are being used with success on the island of Oahu, and the writer is convinced that they will work anywhere under similar conditions. There are three essentials for good well work-experience, intelligence, and money. Good drilling and repairing are not cheap, and good well men are not to be found everywhere nor made overnight from unskilled labor. The high value of water in Hawaii has made it practicable to spend money rather freely on wells, and wherever the work has been intrusted to competent drillers the results have justified the expenditure.

\section{IAWS RELATING TO ARTESIAN WELIS}

The law of the Territory of Hawaii that is now in effect in regard to artesian wells is given below.

\section{Revised laws of Hawaii, 1925, ohapter 291-Artesian wells}

SEC. 4500. Defined-An artesian well, for the purposes of this chapter, is defined to be an artificial well or shaft which is sunk or driven to an artesian stratum or basin, and through which water is raised or carried to or above the surface of the ground by natural pressure or gravity, or through which water is or may be raised or carried to or above the surface of the ground by artificial means. (Laws of 1917, chap. 156, sec. 1.)

SEc. 4501. Unoapped and flowing a public nuisance; persons responsible therefor.-An artesian well which is not capped, cased, equipped, or furnished with such mechanical appliance as will readily and effectively arrest and prevent the flow of any water from such well is declared to be a public nuisance. The owner, tenant, or occupant of the land upon which such a well is situated, or any person in charge of such a well, who causes, suffers, or permits such public nuisance, or suffers or permits it to remain or continue, is guilty of a misdemeanor; and any person owning, possessing or occupying any land upon which is situated an artesian well, or any person in charge of such a well, who causes, suffers, or permits the water to unnecessarily flow from such well, or to go to waste, is guilty of a misdemeanor. (Laws of 1917, chap. 156, sec. 2.)

SEc. 4502. Waste from, defined.-For the purposes of this chapter, waste is defined to be causing, suffering, or permitting the water in any artesian well to reach any porous substratum before coming to the surface of the ground, or to flow from such well upon any land or directly into any stream or other natural water course or channel or into the sea or any bay, lake, or pond; or into any street, road, or highway, unless to be used for beneficial purposes; 
provided, that this section shall not be so construed as to prevent the beneficial use of water by direct flow or from storage reservoirs served by wells for irrigation, domestic, and other useful purposes, except for driving machinery; provided, however, that water may be used for driving machinery, in case it be utilized afterwards for irrigation or other useful purposes. The extent to which water of any artesian well may be devoted to useful or beneficial purposes shall be subject to regulation by the superintendent of hydrography, Division of Hydrography, to such quantities as may be necessary for the purposes for which the well is used. (Laws of 1917, chap. 156, sec. 3 ; amended by Laws of 1923, chap. 228, sec. 1.)

Stc. 4503. Inspection of.-Every artesian well shall be maintained by the owner, tenant, or occupant of the land upon which the well is situated or the person in charge of the well so as to provide access at all times for purposes of inspection unless the well has been sealed just above the water-bearing stratum in a manner approved by the superintendent of hydrography. (Laws of 1917 , chap. 156, sec. 4 ; amended by Laws of 1928 , chap. 228, sec. 2.)

SEc. 4504. Drilling, notice of.-No artesian well shall be drilled without first notifying, in writing the superintendent of hydrography, which notice shall state the exact location of the proposed well, the owner's name, the well driller's name and the proposed use of the water. (Laws of 1923, chap. 228, sec. 3.)

SEC. 4505. Boring of, record to be kept and fled-Any person boring, or causing to be bored, an artesian well shall keep a complete and accurate record of the depth and thickness of the different strata penetrated, and within ninety days after the last day of boring shall file the record in the office of the superintendent of hydrography. (Laws of 1917, chap. 156, sec. 5.)

SEc. 4506. Violations; penalties.-Any person violating any of the provisions of this chapter shall be guilty of a misdemeanor and shall, for each offense, upon conviction thereof, be fined not more than fifty dollars; and where continuance of waste, as defined in this chapter, is under immediate control, each day's continuance of the same, after written notice from the superintendent of hydrography, shall constitute a separate offense; provided, however, that when the continuance of the waste is not under immediate control, as where recasing or sealing is necessary, each day's continuance of the same shall constitute a separate offense after sixty days have elapsed from the time of receiving written notice to prevent waste from the superintendent of hydrography. (Laws of 1917, chap. 156, sec. 6; amended by Laws of 1923, chap. 228, sec. 4.)

Stc. 4507. Inspection of by police and superintendent of hydrography.-For the more effectual carrying out of the provisions of this chapter, the high sheriff and deputy high sheriff, the sheriff and deputy sheriff of any county or city and county, all police officers, and any authorized representative of any city or county or city and county or of the superintendent of hydrography may at all times enter without warrant the premises where an artesian well is situated or whereon or wherein artesian water is used in order to procure such information or for such other purposes as may be necessary. (Laws of 1917, chap. 156, sec. 7.)

SEC. 4508. Appeals from decisions of superintendent of hydrography.-Any person, firm, copartnership, or corporation adversely affected thereby may appeal to the board of appeals from any ruling of the superintendent of hydrography regulating the flow, manner of sealing, or manner of repairing of any artesian well by filing in writing a notice of appeal within ten days after the date of the ruling with the superintendent. The appeal shall be 
heard by the attorney general, the commissioner of publie lands, and the superintendent of public works, sitting together, who, while, so sitting together, for the purposes of this chapter, shall constitute a board of appeals. The vote of one member of this board, disapproving the ruling appealed from. shall operate to sustain the appeal and abrogate the ruling. (Laws of 1923. chap. 228, sec. 5.)

SEC. 4509. Partial invalidity; effect of.-If any section, subsection, sentence, clause, or phrase of this chapter, is for any reason held to be unconstitutional. that decision shall not affect the validity of the remaining portions of this chapter. The legislature declares that it would have passed this chapter, and each section subsection, sentence, clause, and phrase thereof, irrespective of the fact that any one or more other sections, subsections, sentences, clauses on phrases be declared unconstitutional. (Laws of 1917, chap. 156, sec. 9,)

\section{Act 120, Session Laws, 1925}

AN ACT To amend chapter 291 of the Revised laws of Hawaii, 1925, relating to artesiay wells

SECTION 1. Chapter 291 of the Revised laws of Hawaii, 1925, is herebr amended by adding thereto a new section to be known as section 4506A; to read as follows :

"Sec. 4506A. Person may relieve himself of liability.-Any person owning an artesian well may relieve himself of further responsibility therefor by transferring to the county or city and county in which it is situated said wel and the exclusive right to develop the artesian water on or under any propert: owned by him in the district in which such well is situated and the right: to enter said property for the purpose of capping or plugging such well. It shall be the duty of the county or city and county to accept such well and such right and to cap or properly plug such well. The said county or city and count? shall have the right to use the well and to lay and maintain pipes to drav water therefrom, provided that such use and the laying and maintenance of sucl pipes be made in such manner as to cause a minimum inconvenience to the person owning said well before its transfer as provided herein."

SEc. 2. This act shall take effect upon its approval.

Approved April 28, 1925.

\section{THE AU DEEP-WELL CURRENT METER AND ITS USE IN THE ROSWELL ARTESIAN BASIN, NEW MEXICO}

\section{By ALbert G. FIEDLer}

\section{DESCRIPTION OF THE METER AND ACCESSORIES}

In view of the renewed interest in the conservation of artesiar water, the United States Geological Survey has long realized the need for an instrument by which leakage in artesian, wells might, be detected, the location of the leak determined, and the quantity of leakage measured. The Price current meter, which is used by the Geological Survey in gaging streams, was constructed for use ir surface streams. Although it has given valuable results as usec. in exploring artesian wells in Hawaii, it is not properly designed for most effective use in wells. (See p. 12.) In an endeavor to over- 
come the limitations of the Price meter and of other current meters made for measuring surface streams, Mr. Carl H. Au, technician, of the Geological Survey, designed and constructed a new meter that has proved to be adapted for use in wells and is now being used successfully by the writer in an investigation of the Roswell artesian basin in the Pecos Valley of New Mexico.

The principles involved in the use of the apparatus for the determination of leakage are very simple. The fundamental hydraulic expression is $q=a v$, an equation in which $q$ equals the quantity of water per unit of time, $a$ equals the cross-section area, and $v$ equals the velocity of the water passing the section. It is apparent that a given quantity of water flowing from a pipe in a given unit of time has a certain mean velocity. Any increase in the quantity of water discharged per unit of time from the pipe must be due to an increase in the mean velocity of the water. The water passing upward in an artesian well that is in good condition has a comparatively uniform velocity at all points where the well casing is of the same nominal diameter, although minor variations are caused by slight irregularities in the cross-section area of the casing. Should a leak occur in the casing the velocity of the water above this point will be decreased because a part of the flow will be leaving the casing and wasting into a permeable stratum that is not filled with water or that contains water under low head.

The current meter is used to determine variations in velocity at different depths in an artesian well and thereby to locate underground leaks from the well. The same principle is involved in the exploration of the uncased lower part of the well to determine whether the casing has been inserted to a sufficient depth to prevent waste of water from the well into a permeable stratum that contains water under low head.

The Au deep-well current meter is essentially a turbine wheel mounted within a cylindrical brass case, which is suspended in a 3inch pipe and is lowered into the well and removed from the well by means of a cable and reel. (See pls. 3, $B$, and 4.) Near the lower end of the brass meter case, on the inside, is mounted a pointed bearing upon which the wheel revolves. This pointed bearing is provided with a movable nut which is turned up when the meter is not in use, thereby removing the turbine wheel from the bearing and preventing it from being damaged. At the upper end of the brass cylinder there is a removable frame which supports a single or a pentapoint commutator head like those used in the Price current meter. These commutator heads are interchangeable, and either may be used according to the velocity of the water in the well. The vanes of the turbine wheel are made of aluminum; their shape is shown in 
Plate 3, $B$. The lower bearing of the wheel is a pivot cup of hard steel, and the upper shaft is made of unhardened tool steel. The upper shaft is drilled and tapped to accommodate the standard Price cam and worm screw to be used with the single and pentapoint heads, respectively. The turbine wheel revolves very freely, as is indicated by the fact that at a velocity of about 4 feet per second it rotates three times as fast as the cups on a Price current meter.

The cylindrical brass case that contains the working parts is supported in the upper end of the 3-inch iron pipe by means of a $1 / 4$-inch cap screw which projects inside the pipe about three-eighths of an inch. A brass spring clip, which is fastened by means of a cap screw to one arm of the cage at the top of the pipe, rests upon the commutator head and holds the meter in place. One arm of the cage at the top of the pipe is movable around a bolt at its upper end and has a slot near its lower end, so that by merely loosening the cap screw in the slot the arm may be swung to one side and after removing the spring clip the meter may be readily taken out for cleaning or inspection.

The 3-inch pipe in which the meter is placed (see pl. 4, $A$ ) is made in two 4-foot sections which can be connected by means of a standard collar. In flowing wells with small head one section furnishes sufficient weight to carry the meter to the bottom of the hole. In addition to furnishing the necessary weight and protecting the meter, the pipe also prevents the meter from being carried outside of the well casing when passing a large leak. A fourfingered cage of spring brass is fastened near the lower end of the pipe to assist in keeping the pipe centered and in passing minor irregularities in the casing or in the uncased hole. Pieces of scale are sometimes scraped from the well casing by the meter pipe, and pebbles may be jarred loose in the uncased portion of the hole. To prevent this material from obstructing the meter, screens are provided for use in the ends of the pipe. (See pl. 3, B.) Whenever the screens are used a correction must be applied to the recorded velocity to reduce it to the normal velocity for unobstructed flow.

The rest of the equipment (see pl. 4) consists of a reel upon which, is wound the $\frac{3}{16}$-inch wire cable used for lowering the meter into the well, an odometer for measuring the depth of the meter in the well, a reel for the stranded insulated electric wire cable, and minor accessories.

The odometer consists of a grooved brass wheel, the circumference of which is 2 feet. Two pins are fastened upon the spokes of the wheel, and at every half revolution one of them trips a counting device, thereby recording the number of feet that the meter has been lowered into the well. In removing the meter from a well the 


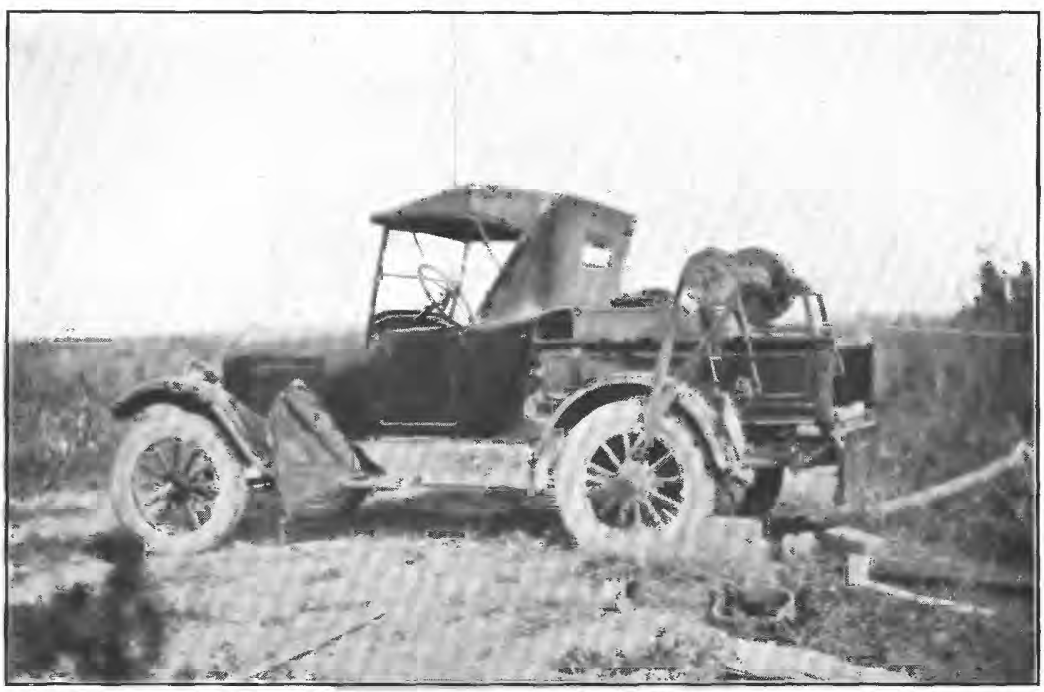

A. AUTOMUBILE TRUCK ON WHICH REEL IS PERMANENTLY MOUNTED

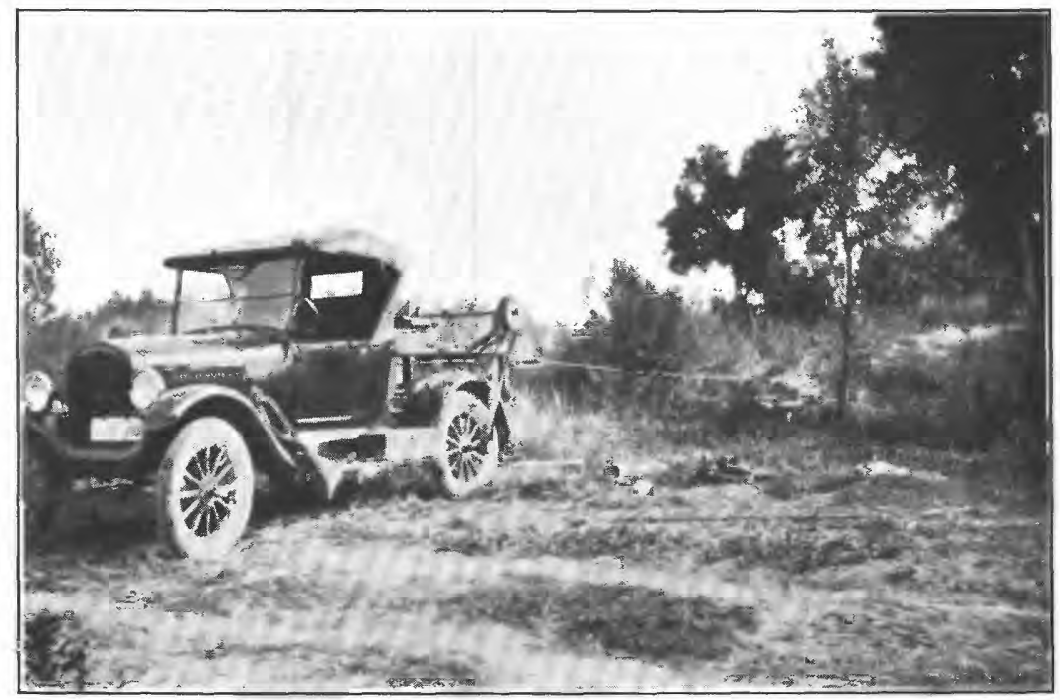

B. CABLE PASSING OVER ODOMETER TO WELL 

operation of the counter reverses so that it is possible to know at all times the depth of the meter in the well:

The electric circuit of the equipment is simple. The wire cable is used for one side of the circuit, and the insulated electric wire, wound on a separate reel, is attached to the meter commutator head and forms the other side. A small dry-cell battery and a 75-ohm head phone are used in a manner similar to that with an ordinary current meter. The revolutions of the turbine wheel are timed with a stop watch.

The cable reel and the odometer shown in Plate 4 are those originally used by Van Orstrand in his measurements of deep-well temperatures. $^{8}$ They became available for this investigation because an improved set of apparatus is now used by Van Orstrand. ${ }^{9}$

The examination for leakage of an average artesian well 1,000 feet in depth requires almost a day's time, using the equipment that has been described. If the well has an elbow and discharge pipe, these must be removed so that the meter can be inserted in the well. In removing the meter from the well two men are required to operate the main cable reel and one man to operate the reel upon which the insulated electric cable is wound. Although the apparatus is somewhat bulky it can readily be completely disassembled and packed into a Ford car for transportation from well to well.

Just before this paper was sent to press a small automobile truck was purchased and the main reel was permanently mounted on it, as is shown in Plate 5. The old cable was replaced with a new one that has the insulated electric wire on the inside of it, and thus the extra reel for the electric wire is no longer needed. The new cable is onefourth inch in diameter and consists of six strands of seven wires each surrounding the insulated wire. These improvements promise to save much labor and to expedite the work. It is not yet known how long the insulation will last when the cable is used in this way.

\section{RATING THE METER}

The Au deep-well current meter is rated by inserting it in a well, measuring the stream that flows from the well with an ordinary current meter or by some other method, and timing the revolutions of the turbine wheel. If the diameter of the casing and the discharge of the well are known, the mean velocity of the water can readily be computed and be correlated with the number of revolutions of the turbine wheel per second. Wells with different rates of discharge and different sizes of casing are tested in this manner, and from the

\& Van Orstrand, C. E., Temperature measurements : West Virginia Geol. Survey Connty Repts., Barbour and Upihur Counties and western portion of Randolph Connty, pp. 47-48, pls. 51, 52, 1918.

- Van Orstrand, C. E., Apparatus for the measurement of temperatures in deep wells by means of maximum thermometers: Econ. Geology, vol. 19, pp. 220-248, April-May, 1924. $95221^{\circ}-28-3$ 
information obtained velocity curves are drawn and a rating table is computed. Although it is known that the velocity of water issuing from a pipe is not uniform throughout the cross section, the meter records showed that the difference between the velocity at the center of the casing. and that at the side is negligible. This is due to the fact that the variations in velocity throughout the cross section are more or less equalized by the frictional resistance that the 3-inch meter pipe offers to the water passing through the meter.

\section{INTERPRETING THE METER READINGS}

In exploring a well the meter is let down a little at a time, and velocity observations are made at regular intervals to determine when a leak is passed. In a nonflowing well no current will be noted. until a leak is encountered, whereas in a flowing well a leak is indicated by an increase in velocity. If a water-bearing stratum that supplies water to the well is passed the speed of the turbine wheel will decrease. After the meter has passed below the end of the casing variations in the velocity will occur, owing to the irregularities in the size of the uncased hole. As long as no consistent change is noted these variations are disregarded.

The leaks usually occurring in wells may be classified as of four general types:

1. General disintegration of casing producing innumerable holes.This condition is indicated by a gradual increase in velocity in both flowing and nonflowing wells.

2. One or more large leaks.-Such leaks are indicated by an abrupt appearance of current in nonflowing wells and an abrupt increase in its velocity in flowing wells.

3. Improperly seated casing.-In nonflowing wells movement of the water begins to be recorded at the end of the casing near the top of the aquifer, reaches its maximum velocity immediately, and decreases as the water-bearing strata are passed and the bottom of the hole is reached. In flowing wells an increase in velocity occurs in like manner, followed by a decrease.

4. Insuffcient casing.-In nonflowing wells movement of the water begins to be recorded after the meter has passed the end of the casing, reaches its maximum velocity as the meter passes through the uppermost water-bearing stratum, and then decreases until the bottom of the hole is reached. In flowing wells there is likewise an increase in velocity after the meter has passed the end of the casing until the first water-bearing stratum is reached, then a decrease below the last water-bearing stratum to the bottom of the hole.

In the inspection of a well in which the diameter of the casing has been reduced or in which the uncased portion of the hole has not been 
drilled with the same size bit throughout it is possible that an increase in velocity due merely to a reduction in section may be interpreted erroneously as an indication of a leak. This mistake can be avoided by computing the discharge at the point where the diameter of the casing is known, using the velocity indicated by the meter at that point, and then making a like computation for the point where the velocity increased, using the next smaller regular size of hole or casing. Should the discharge as computed for the two points agree within fairly close limits it is reasonably certain that the increase in velocity is caused by a reduction in section. A condition such as this is shown in the tests of wells 2 and 3 given herewith.

\section{TESTS OF SPECIMEN WELLS}

Results of tests made on several wells in the Roswell artesian basin, in Chaves and Eddy Counties, N. Mex., are given below.

Well 1 is an 8-inch well that yields a flow of sulphur water. The casing was covered with a slimy growth of algæ. Only 20 gallons a minute was flowing from the well casing, and at a short distance from the well water was issuing from a hole in the ground.

Record of velocity in well 1

\begin{tabular}{|c|c|c|c|c|c|c|c|}
\hline $\begin{array}{l}\text { Depth } \\
\text { (feet) }\end{array}$ & $\begin{array}{l}\text { Velocity } \\
\text { (feet per } \\
\text { second) }\end{array}$ & $\underset{\text { (feet) }}{\text { Depth }}$ & $\begin{array}{l}\text { Velocity } \\
\text { (feet per } \\
\text { second) }\end{array}$ & $\begin{array}{c}\text { Depth } \\
\text { (feet) }\end{array}$ & $\begin{array}{l}\text { Velocity } \\
\text { (feet per } \\
\text { second) }\end{array}$ & $\begin{array}{l}\text { Depth } \\
\text { (feet) }\end{array}$ & $\begin{array}{l}\text { Velocity } \\
\text { (feet per } \\
\text { second) }\end{array}$ \\
\hline $\begin{array}{l}5 \\
10 \\
11 \\
12 \\
13 \\
15 \\
20 \\
25 \\
50 \\
75 \\
100\end{array}$ & $\begin{array}{r}0.10 \\
.29 \\
.35 \\
.46 \\
.81 \\
.82 \\
.81 \\
.88 \\
.89 \\
.89 \\
.89 \\
1.00\end{array}$ & $\begin{array}{l}150 \\
175 \\
200 \\
2250 \\
250 \\
300 \\
325 \\
350 \\
375 \\
400 \\
425\end{array}$ & $\begin{array}{r}1.05 \\
1.05 \\
.89 \\
.89 \\
.89 \\
.89 \\
1.01 \\
.95 \\
.95 \\
.89 \\
.89 \\
.89\end{array}$ & $\begin{array}{l}450 \\
475 \\
500 \\
525 \\
550 \\
575 \\
600 \\
620 \\
625 \\
627 \\
675\end{array}$ & $\begin{array}{r}0.89 \\
.89 \\
.89 \\
.89 \\
.85 \\
.89 \\
.89 \\
1.35 \\
2.15 \\
2.46 \\
2.15 \\
2.30\end{array}$ & $\begin{array}{l}690 \\
700 \\
725 \\
\mathbf{7 5 0} \\
\mathbf{7 7 5} \\
\mathbf{8 0 0} \\
810 \\
817 \\
818 \\
819 \\
820\end{array}$ & $\begin{array}{l}2.46 \\
2.24 \\
2.46 \\
2.46 \\
2.30 \\
2.46 \\
2.46 \\
1.47 \\
.07 \\
.04 \\
.00\end{array}$ \\
\hline
\end{tabular}

A study of the velocities show two major leaks, one at a depth of less than 15 feet and another between 600 and 625 feet. The water represented by the increase in velocity above the 15-foot level was issuing from the hole in the ground, while the water passing out at the lower leaks was wasting into a deeper permeable stratum. The meter passed the water-bearing strata between 810 and 818 feet, as is shown by the decrease in velocity. The end of the casing was at 696 feet, and the drop in velocity at 700 feet was doubtless caused by an enlargement of the hole due to eddy currents created as the water passed through the cap rock into the casing. It will be noticed that there was an increase in velocity between the 100-foot and 200-foot levels. This is undoubtedly caused by the condition of the casing and is disregarded, as the velocity again drops to its former rate. 
At the time of the inspection 20 gallons per minute was flowing from the well and 120 gallons per minute from the hole in the ground. It is conservatively estimated that if this well were put in good condition its flow at the surface would be increased to 400 gallons per minute.

Well 2 is an 8-inch well drilled in 1911. It yields salty water. At the time that it was inspected no water was flowing from the casing, but 1,000 gallons per minute was issuing from a hole around the casing.

Record of velocity in well 2

\begin{tabular}{|c|c|c|c|c|c|c|c|}
\hline $\begin{array}{c}\text { Depth } \\
\text { (feet) }\end{array}$ & $\begin{array}{l}\text { Velocity } \\
\text { (feet per } \\
\text { second) }\end{array}$ & $\underset{\text { (feet) }}{\text { Depth }}$ & $\begin{array}{l}\text { Velocity } \\
\text { (feet per } \\
\text { second) }\end{array}$ & $\underset{\text { (feet) }}{\text { Depth }}$ & $\begin{array}{l}\text { Velocity } \\
\text { (feet per } \\
\text { second) }\end{array}$ & $\underset{\text { (feot) }}{\text { Depth }}$ & $\begin{array}{l}\text { Velocity } \\
\text { (feet per } \\
\text { second) }\end{array}$ \\
\hline $\begin{array}{l}0 \\
25 \\
38 \\
39 \\
42 \\
55 \\
75 \\
105 \\
130 \\
155 \\
180 \\
235\end{array}$ & $\begin{array}{l}0 \\
0 \\
0 \\
1.24 \\
6.54 \\
6.71 \\
6.71 \\
6.54 \\
6.54 \\
6.37 \\
6.71 \\
6.71 \\
6.88\end{array}$ & $\begin{array}{l}260 \\
285 \\
310 \\
340 \\
365 \\
390 \\
415 \\
440 \\
465 \\
490 \\
520 \\
545 \\
570\end{array}$ & $\begin{array}{l}6.37 \\
6.37 \\
6.20 \\
5.86 \\
6.37 \\
6.54 \\
6.37 \\
6.20 \\
6.20 \\
6.54 \\
6.37 \\
6.03 \\
6.37\end{array}$ & $\begin{array}{l}600 \\
625 \\
650 \\
675 \\
700 \\
725 \\
752 \\
763 \\
775 \\
805 \\
830 \\
855 \\
880\end{array}$ & $\begin{array}{r}6.20 \\
6.20 \\
6.37 \\
6.37 \\
6.88 \\
6.54 \\
7.05 \\
12.65 \\
13.16 \\
11.87 \\
11.87 \\
11.87 \\
13.33\end{array}$ & $\begin{array}{l}903 \\
908 \\
913 \\
922 \\
925 \\
934 \\
945 \\
985 \\
1,000 \\
1,100\end{array}$ & $\begin{array}{r}12.48 \\
11.87 \\
10.78 \\
11.87 \\
5.86 \\
1.59 \\
.06 \\
.07 \\
.05 \\
.00\end{array}$ \\
\hline
\end{tabular}

A marked increase in velocity occurred between the depths of 38 and 42 feet. A computation of the discharge at the 42 -foot level, using the area of an 8-inch casing, showed a discharge of about 1,000 gallons per minute. This corresponds to the discharge from the hole around the casing and indicates that practically all the water was finding its way to the surface through the hole. During the examination of the well it was interesting to note that whenever the meter passed the 42-foot level about 400 to 500 gallons per minute flowed out of the casing, probably because the meter would temporarily span the leak and partly close it. Minor variations in velocity were noted from the 55-foot level to the 725-foot level, but the average was consistently the same, showing that there was no other leak. A marked increase occurred between 752 and 763 feet, a depth at which according to the driller's log, the well had been reduced to 6 inches in diameter by means of a perforated liner. As a means of checking this the following computations were made:

8-inch portion:

Cross-section area of casing, 0.35 square foot.

Velocity at 725-foot level, 6.54 feet per second.

Discharge, $0.35 \times 6.54=2.29$ second-feet.

6-inch portion:

Cross-section area of casing, 0.19 square foot.

Velocity at 763-foot level, 12.65 feet per second.

Discharge, $0.19 \times 12.65=2.40$ second-feet. 
Thus the computed discharges check within 0.11 second-foot, or 50 gallons per minute, which is as near as could reasonably be expected. The recorded log gives the bottom of the liner at a depth of 917 feet. It will be noted that from 922 to 945 feet the velocity decreases almost to zero, showing that this is the horizon of the principal water-bearing strata. Only a little water enters the well from lower levels.

Well 3 at the time the examination was made had been only recently completed, and therefore accurate information was available concerning the size and depth of the hole and the casing that was inserted. The well was drilled 10 inches in diameter to a depth of 304 feet, and 10-inch casing was set to this depth. Drilling was continued with an 8-inch bit to a depth of 710 feet, and the hole was then reamed 10 inches in diameter to 650 feet. Before the hole was reamed the water level in the well was several feet below the ground surface, but after reaming the well flowed several hundred gallons per minute. As the depth of the hole had not been changed and no additional casing had been set, it is believed that the flow was caused by the reamings filling the interstices of open strata into which the artesian water was leaking. A study of the logs of other wells in this vicinity also indicates that there was insufficient casing in the well. To determine the location of the open strata and the approximate amount of the leakage the well was examined with the meter.

Record of velocity in well 3

\begin{tabular}{|c|c|c|c|c|c|c|c|}
\hline $\begin{array}{l}\text { Depth } \\
\text { (feet) }\end{array}$ & $\begin{array}{l}\text { Velocity } \\
\text { (feet per } \\
\text { second) }\end{array}$ & $\begin{array}{l}\text { Depth } \\
\text { (feet) }\end{array}$ & $\begin{array}{l}\text { Velocity } \\
\text { (feet per } \\
\text { second) }\end{array}$ & $\begin{array}{l}\text { Depth } \\
\text { (feet) }\end{array}$ & $\begin{array}{l}\text { Velocity } \\
\text { (feet per } \\
\text { second) }\end{array}$ & $\begin{array}{l}\text { Depth } \\
\text { (feet) }\end{array}$ & $\begin{array}{l}\text { Velocity } \\
\text { (feet per } \\
\text { second) }\end{array}$ \\
\hline $\begin{array}{l}0 \\
100 \\
285 \\
320 \\
360 \\
390\end{array}$ & $\begin{array}{r}1.38 \\
1.42 \\
1.46 \\
.82 \\
.82 \\
.88\end{array}$ & $\begin{array}{l}415 \\
440 \\
470 \\
4950 \\
530\end{array}$ & $\begin{array}{r}0.82 \\
.82 \\
.92 \\
.88 \\
.78 \\
1.00\end{array}$ & $\begin{array}{l}545 \\
555 \\
5700 \\
625 \\
650\end{array}$ & $\begin{array}{l}1.64 \\
2.09 \\
2.09 \\
3.05 \\
2.62 \\
4.80\end{array}$ & $\begin{array}{l}675 \\
685 \\
700 \\
706 \\
711\end{array}$ & $\begin{array}{r}4.25 \\
3.92 \\
1.54 \\
.25 \\
.00\end{array}$ \\
\hline
\end{tabular}

The observations to a depth of 285 feet were within the cased part of the hole. Below the end of the casing the velocity decreased, doubtless because the uncased hole was somewhat larger than the 10-inch casing. The velocity remained comparatively uniform from 320 to 520 feet, indicating that the size of the uncased hole remained fairly uniform and that there was no appreciable leakage. From 520 to 625 feet, however, there was in general a progressive increase in velocity until at 625 feet it was nearly twice that in the cased part of the hole and about three times that in the part between 320 and 520 feet. As this part of the hole was drilled to the same diameter as the uncased hole above 520 feet, the increase in velocity was almost certainly due to water wasting into permeable strata between 520 and 
625 feet. The increase in velocity between 625 and 650 feet was evidently caused by a reduction in the diameter of the hole to 8 inches.

Computations checking this interpretation of the velocity readings are as follows:

Cross-section area of 10-inch casing, 0.54 square foot.

Average velocity in casing, 1.40 feet per second.

Flow in casing, $0.54 \times 1.40=0.76$ second-foot, or 340 gallons per minute.

The hole below the casing to 650 feet was reamed to a diameter of 10 inches, but it had evidently been enlarged by erosion and caving. A coefficient was applied to express this enlargement and also other differences that may exist between the character of the flow in the cased and uncased parts of the hole.

The average velocity between 320 and 520 feet was about 0.85 foot per second. If the flow remained the same, as is altogether probable, the coefficient to be applied is the ratio of the two velocities-that is, $1.40 \div 0.85=1.65$.

Using this coefficient, the flow below the leak, near the bottom of the 10 -inch hole ( 625 feet), is computed as $0.54 \times 2.62 \times 1.65=2.33$ second-feet.

At the depth of 650 feet the hole was reduced to a diameter of 8 inches. Using the same coefficient the flow at this level is computed as $0.35 \times 4.80 \times 1.65=2.77$ second-feet.

The computed flows agree within 0.44 second-foot, which is as near as can be expected in view of the fact that the enlargement of the hole is doubtless irregular, differing with the character of the strata penetrated and with the original diameter. The velocity decreased at or above the 675-foot level and continued to decrease to the bottom, indicating the passing of the water-bearing strata.

It is estimated that with proper casing the discharge of this well could be increased from 340 to 800 or 900 gallons per minute. 


\title{
QUALITY OF WATER OF COLORADO RIVER IN 1925-1926
}

\author{
By W. D. Collins and C. S. Howard
}

\section{SAMPLES}

Most of the analyses given in this report represent composites of daily samples collected by the observers at United States Geological Survey gaging stations on Colorado River at Grand Canyon and Topock, Ariz. These stations are operated under the direction of W. E. Dickinson, district engineer of the Geological Survey at Tucson, Ariz., who personally collected some of the samples at other points and arranged for the collection of others.

At Grand Canyon samples from August 18, 1925, to September 30, 1926, were taken by B. S. Barnes; from October 25, 1925, to September 3, 1926, by D. H. Barber; and from September 4 to September 30, 1926, by Kenneth C. McCarter. At Topock samples from August 14, 1925, to July 13, 1926, were taken by James E. Klohr; from July 14 to July 27, 1926, by Kenneth C. McCarter; and from July 28 to September 30, 1926, by James E. Klohr. The samples for the single composite from Yuma were taken by P. J. Preston, superintendent of the irrigation project of the United States Bureau of Reclamation at Yuma. Other samples were taken by D. A. Dudley in connection with measurements of discharge at points in the river system. The points at which samples were taken are shown in Figure 6.

All the samples were collected in 4-ounce bottles, which were sent to the laboratory in Washington for analysis. For the composites a single bottle was filled each day, and the date and point of collection were marked on the bottle. Every effort was made to take samples that would truly represent the river water as to its content of dissolved mineral matter. Single samples for analysis consisted of four or eight bottles collected at one time. The continuity of collection of samples and the completeness of the analyses make the information in this report more comprehensive than that given in previous reports. ${ }^{1}$

1 Forbes, R. H., The river irrigating waters of Arizona, their character and effects: Arizona Agr. Exper. Sta. Bull. 44, 1902. Stabler, Herman, Some stream waters of the western United States, with chepters on sediment carried by the Rio Grande and the industrial application of water analyses: U. S. Geol. Survey Water-Supply Paper 274, 1911. Scofleld, C. 8., Salt content of Colorado River: Eng. News Record, vol. 97, pp. 131-132, 1926. 


\section{METHODS OF ANALYSIS}

C. S. Howard made all the analyses by the methods regularly used in the United States Geological Survey, which agree essentially with those recommended in "Standard methods of water analysis" published by the American Public Health Association.

The 4-ounce samples were allowed to stand in the laboratory till the suspended matter settled, leaving the liquid above apparently free from even traces of silt. Composite samples for 7-day periods

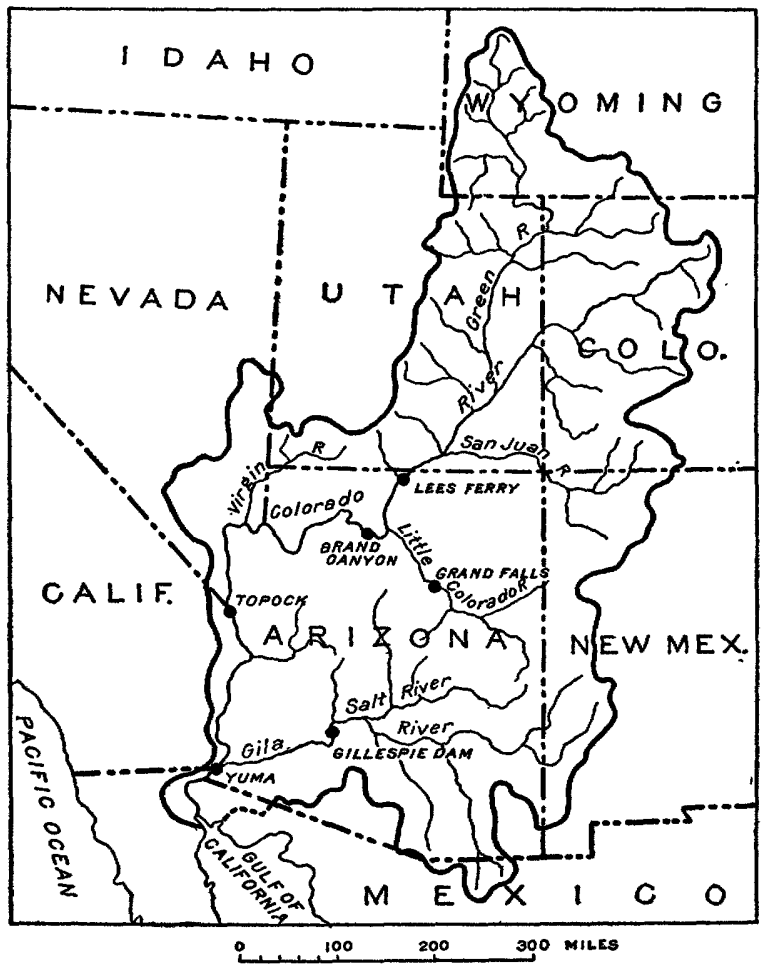

Figure 6.-Map of Colorado River drainage basin showing sampling points

were collected in flasks by drawing the clear liquid from the individual bottles through a siphon, without disturbing the sediment.

A sample of 5 cubic centimeters was taken from each small bottle for a chloride determination, but the results are not given in the table. They served as a check on the result obtained in the examination of the composite.

In the early part of the work the silt was washed from all the bottles of a set into an evaporating dish, which was placed on the steam bath. After the residue was dry it was heated in the oven at $180^{\circ} \mathrm{C}$. for one or two hours. This heating made no significant change 
in the weight of the residue, and later the heating in the oven was discontinued. For most of the samples the weight of the suspended material in each bottle was found after drying on the steam bath. Correction was made for the weight of the soluble salts in the original water (usually 5 to 8 cubic centimeters) transferred from the bottle to the evaporating dish with the silt. The silt was washed from the bottle into the dish with distilled water. The quantities of silt reported in the table for composite samples are nearly all averages of the determinations for the daily samples.

A sample of 500 cubic centimeters of the clear composite was evaporated to dryness in platinum, and the residue was weighed after heating 12 or 18 hours at $180^{\circ} \mathrm{C}$. Silica was determined, and the filtrate was divided into two parts. Iron was precipitated from one part and determined colorimetrically as thiocyanate, calcium was determined by titration of the oxalate with permanganate, and magnesium was weighed as pyrophosphate. From the other part sulphate was precipitated and weighed as barium sulphate, the mixed chlorides were weighed, and for most of the samples potassium was determined by weighing the platinum resulting from reduction of the potassium platinic chloride. If potassium was not determined, the total weight of mixed chlorides was calculated to sodium. Bicarbonate, chloride, and nitrate were determined by standard methods. No carbonate was found in any sample.

The percentage error of each analysis was calculated by dividing the difference between the sums of the equivalents of the bases and acids by the total sum. The calculations showed all the analyses to be well within the limits that are found for careful analytical work.

The weight reported as "residue on evaporation" is consistently higher than the sum of the determined constituents. This difference is commonly found in the analysis of waters that carry comparatively large quantities of calcium and sulphate.

\section{COMPOSITION OF WATER OF COLORADO RIVER} AND TRIBUTARIES

The accompanying table gives all the individual analyses made for this report and two averages for Colorado River at Grand Canyon, which are shown with some of the analyses in Plate 6 . The dates show the number of daily samples in each composite. Samples were collected each day at Grand Canyon and at Topock, but some samples were lost in transit. A few that contained hydrogen sulphide when received were rejected, because the hydrogen sulphide suggested decomposition of sulphate and possible change in the bicarbonate. The results for dissolved solids are sums of the constituents determined, with the bicarbonate divided by 2.03 to obtain the equivalent carbonate. The total hardness is the calcium carbonate equivalent 
to the calcium and magnesium together. The noncarbonate hardness is the total hardness minus the quantity of calcium carbonate equivalent to the bicarbonate. The mean discharge is that for the 7-day period represented by each analysis for Grand Canyon and Topock. The quantity of dissolved solids in tons per day is obtained by multiplying the dissolved solids in parts per million by the discharge in second-feet and the factor 0.002697 . In other publications the quantity of dissolved material in the river has been calculated from the results of determinations of the residue on evaporation, which is always greater than the anhydrous dissolved mineral matter.

Analysis 65 in the table, which is shown as diagram 7 of Plate 6, is the average of the 51 analyses for Colorado River at Grand Canyon from October 9, 1925, to September 30, 1926. Analysis 65 and diagram 7 represent accurately the composition of water that would be contained in a vessel or reservoir that had received equal quantities of water from the river each day of the period covered by the analyses.

Analysis 66 is a weighted average of analyses 14 to 64 . The quantities of the different constituents in each analysis were multiplied by the mean discharge for the period represented by the analysis. The sum of the 51 products for each constituent was divided by the sum of the discharges to obtain the weighted average given as analysis 66 . This analysis and diagram 8 represent approximately the composition of water that would be found in a reservoir containing all the water that had reached Grand Canyon during the period considered, after thorough mixing in the reservoir. This shows obviously better water than that represented by analysis 65 and diagram 7 , because at times of high discharge the river carries the least amount of dissolved solids. In analysis 65 and diagram 7 the waters represented by diagrams 5 and 6 have equal weight; in analysis 66 and diagram 8 the water represented by diagram 6 has over three times the weight of that represented by diagram 5 . Because the composite samples for analysis were made from equal daily samples, the analyses themselves do not represent accurately the water that would be found in a reservoir containing the whole flow of the river for the period covered by an individual analysis. The error due to this effect is not great, but its tendency is to make analysis 66 and diagram 8 show more dissolved mineral matter than would be found in the water of a reservoir storing the whole flow of the river for a year.

The analyses for Topock show the water to have about the same content of dissolved mineral matter there as at Grand Canyon. This is brought out in Figure 7, which shows the dissolved mineral matter at Grand Canyon and Topock, with the discharge at Grand Canyon. The discharge at Topock is so near that at Grand Canyor that it is omitted to avoid confusion. The dissolved mineral matter shown in Figure 7 is not the residue on evaporation, but the sum of 


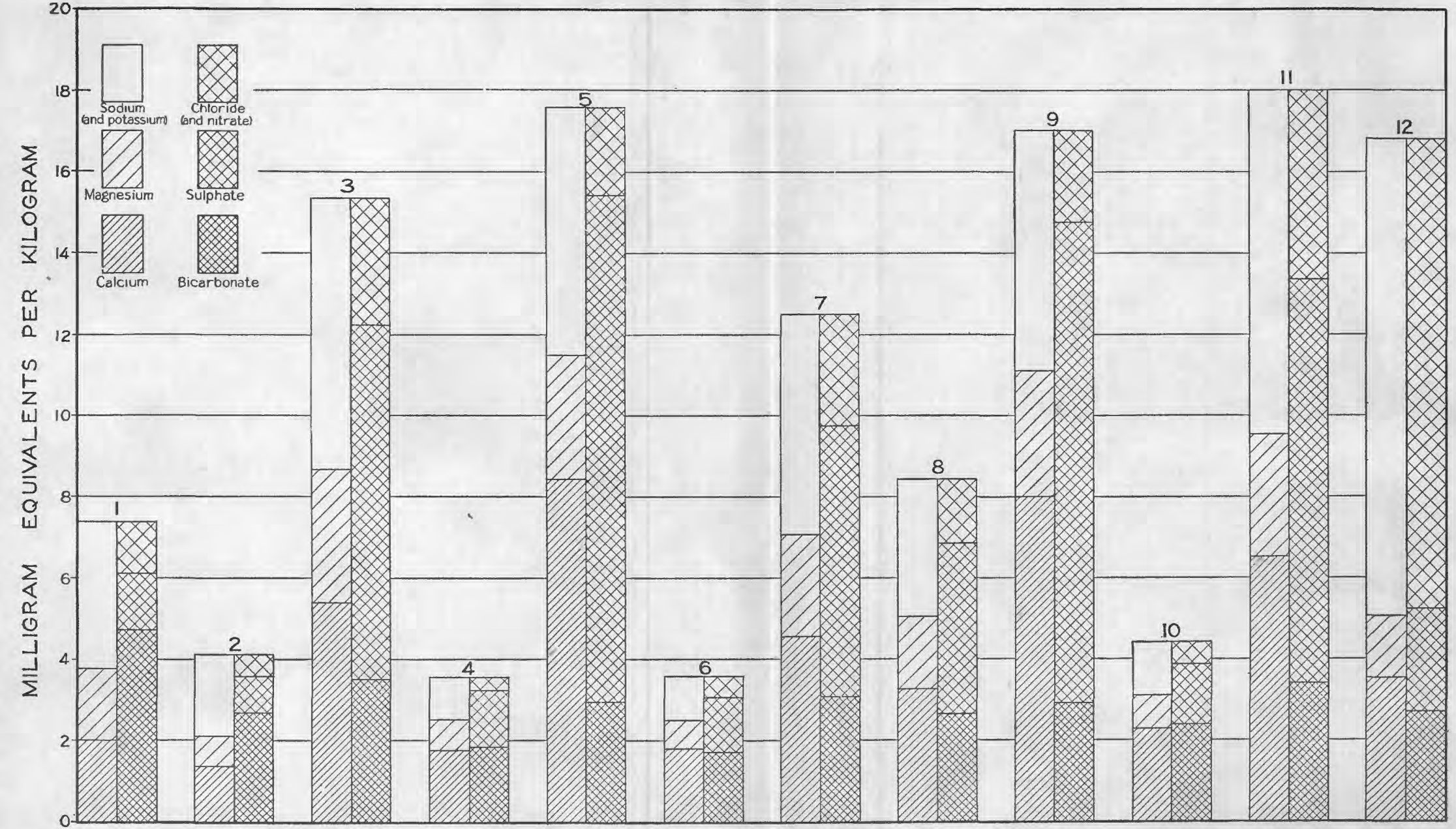

COMPOSITION OF RIVER WATERS IN ARIZONA AND CALIFORNIA

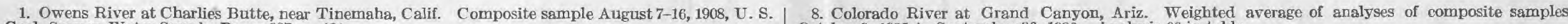
Geol. Survey Water-Supply Paper 237, p. 121 . 2. Owens River at. Charlies Butte, near Tinemaha, Calif. Composite sample April 29 to May 8, 3. Colorado River at Lees Ferry, Ariz. January 11, 1926. Analysis 1 in table.

4. Colorado River at Iees Ferry, Ariz. Composite sample June 13-19, 1926. Analysis 7 in table.

5. Colorado River at Grand Canyon, Ariz. Composite sample October 9-15, 1925. Analysis 14 in table-

6. Colorado River at Grand Canyon, Ariz. Composite sample June 11-17, 1926. Analysis 49 in tahle. 9. Colorado River at Topock, Ariz. Composite sample October 16-22, 1925. Analysis 76 in table. 10. Colorado River at Topock, Ariz. Composite sample June 18-24, 1926. Analysis 112 in table. 12. Little Colorado River at Grand Falls, Ariz. Composite sample December 7-9, 1925. Analysis 128 in table. 1925 to Septo River at Grand Canyon, Ariz. Average of 51 analyses of composite samples October $9_{s}$ 

Whot

QUALTTY OF WATER OF COLORADO RIVER IN 1925-1926

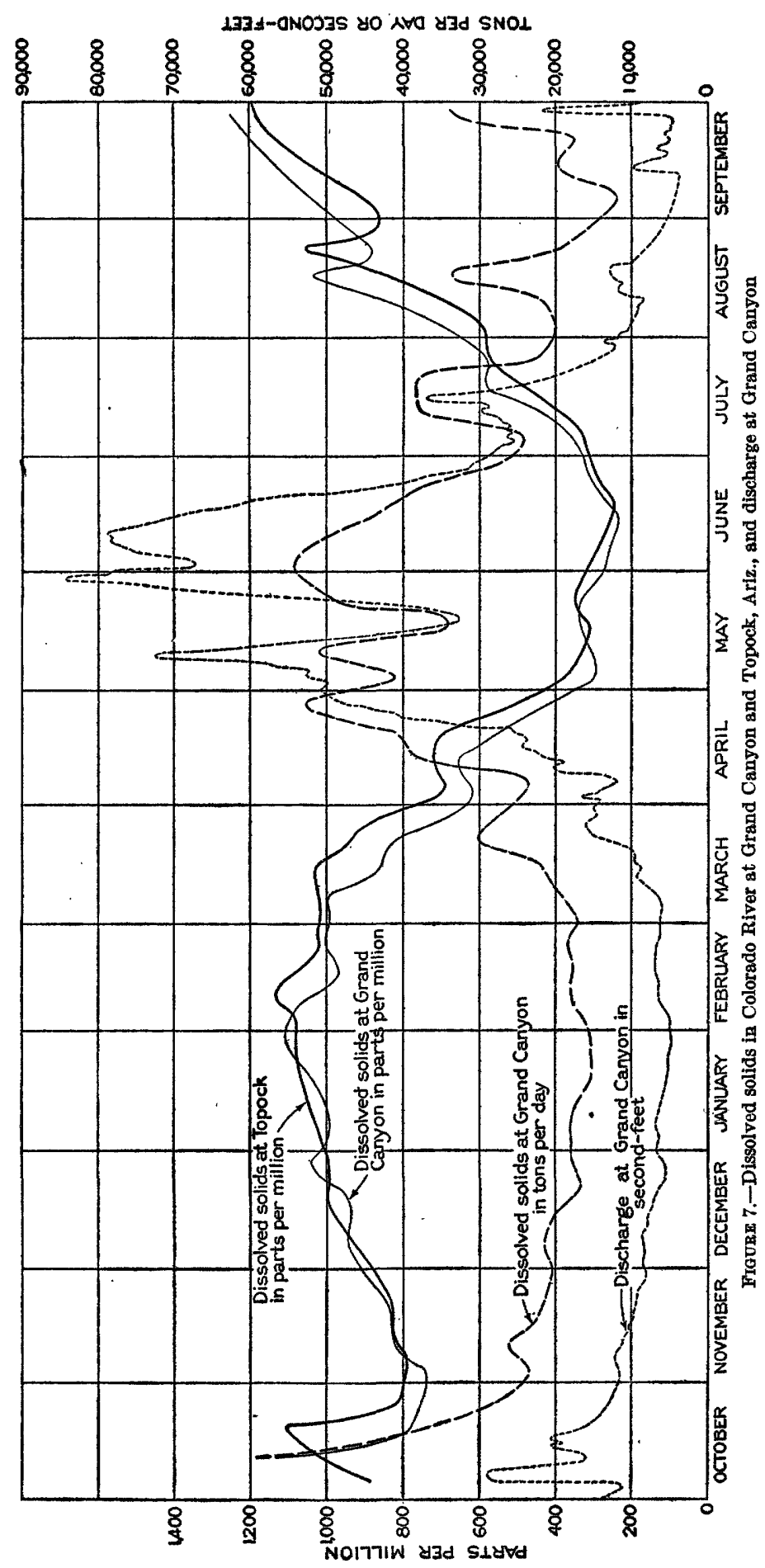


the determined constituents with the bicarbonate calculated to carbonate.

Of the 137 analyses in the table, 113 represent samples from Grand Canyon and Topock. The samples from other points have only the value of occasional samples and can not serve for calculation of the quantities of material carried by the river. Consideration of the discharge at the time of collection in comparison with the discharge throughout the year will give some basis for an opinion as to whether a given analysis may represent average or extreme concentration of dissolved mineral matter.

\section{SUSPENDED MATTER}

The figures given for suspended matter are accurate for the samples as received. The samples were, however, taken without any special precautions to make them represent accurately the silt being carried by the river. It is possible, therefore, that the use of these results in computations may lead to incorrect conclusions. Work on the silt problem, which is still under way, may make it possible to use the results published in this paper, either with or without corrections, as a reliable basis for calculations. 


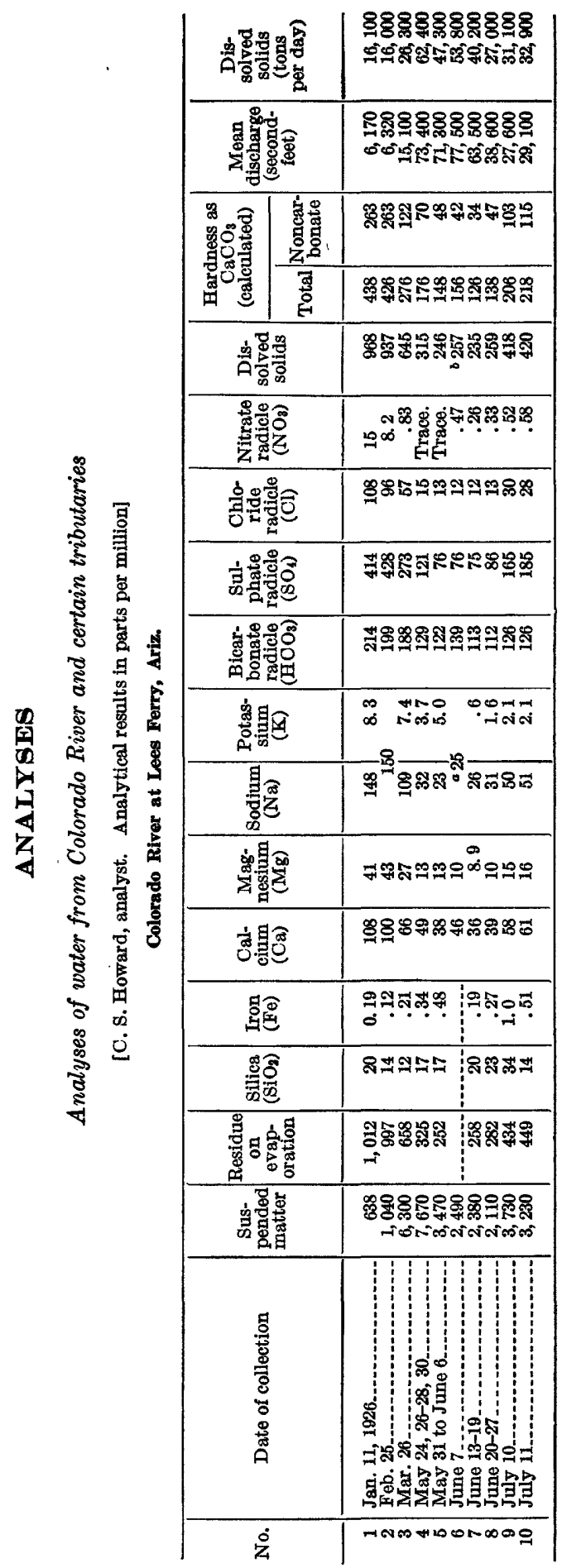

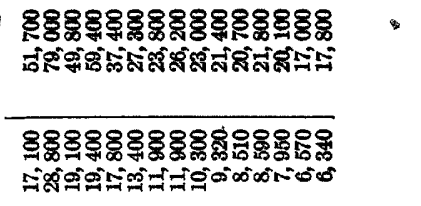

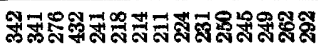

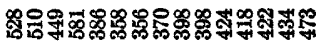

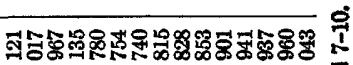
int $\rightarrow$

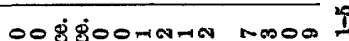
un स्वृ

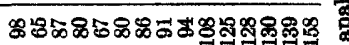

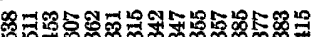

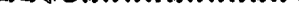

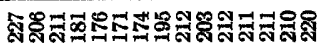

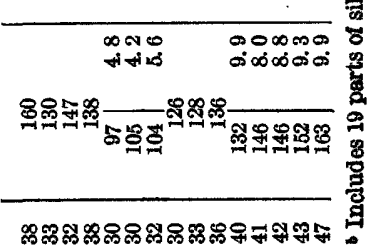

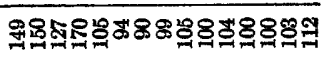

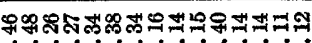
(2)

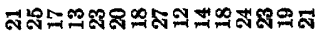

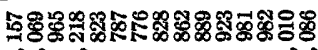
$\rightarrow-i \quad$ तi

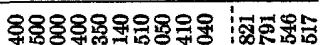

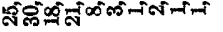

क्ष कิ 10 สำ

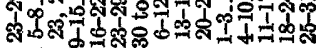

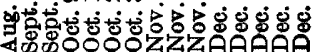

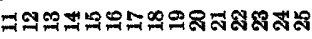




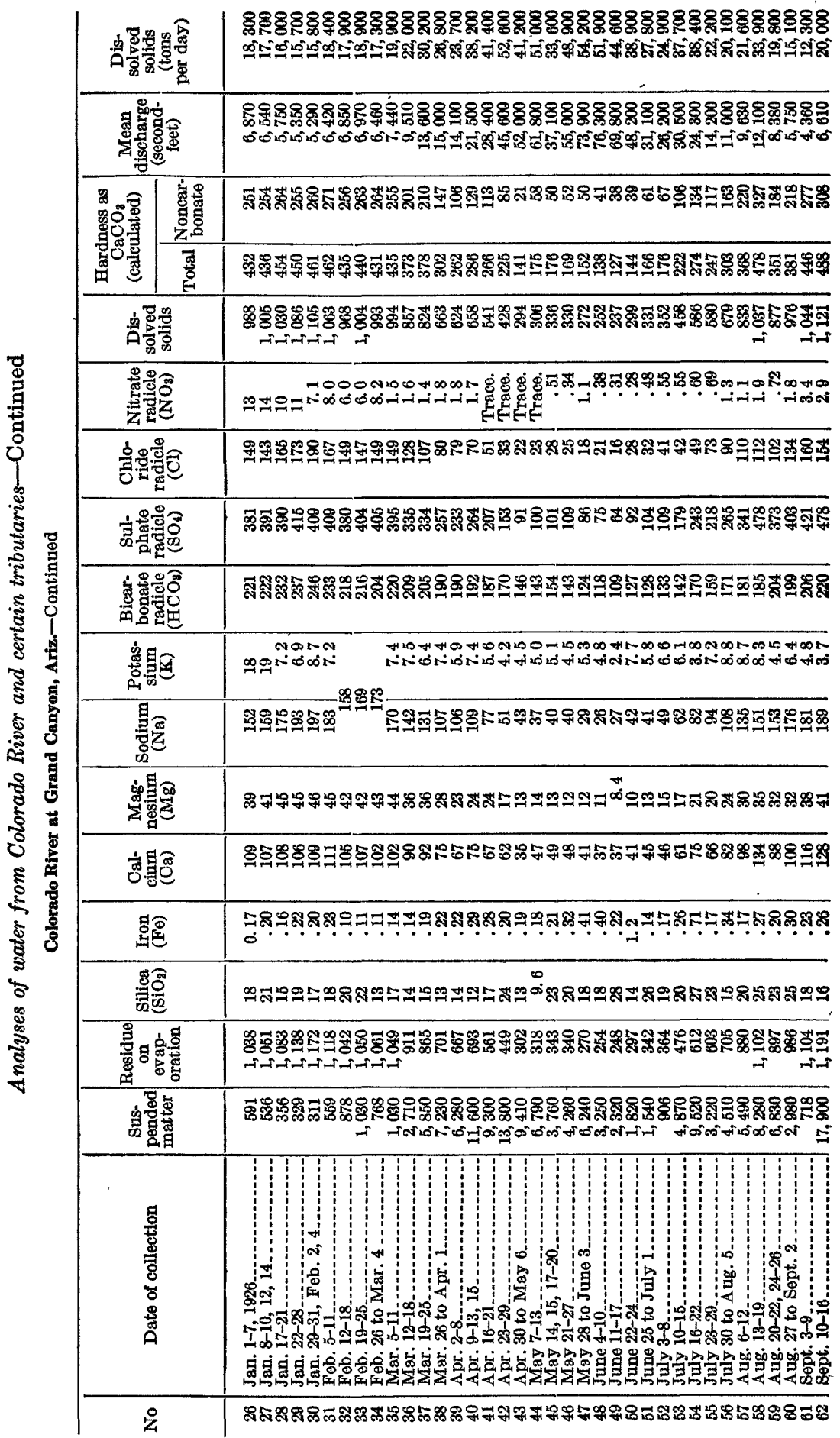


QUALITY OF WATER OF COLORADO RIVER IN 1925-1926:

\begin{tabular}{|c|c|}
\hline 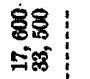 & 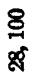 \\
\hline 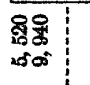 & $\begin{array}{l}8 \\
8 \\
9 \\
9\end{array}$ \\
\hline శ్ి్ㅇ్ & $\overline{9}$ \\
\hline 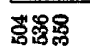 & สี \\
\hline 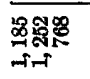 & ฉูต \\
\hline 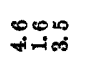 & $\stackrel{0}{\because}$ \\
\hline 뭉్ㅇ8 & 88 \\
\hline 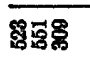 & รี \\
\hline สีส & 兽. \\
\hline $\begin{array}{l}\text { sino } \\
\text { tion }\end{array}$ & is \\
\hline 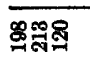 & ? \\
\hline 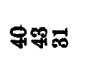 & $\ddot{\pi}$ \\
\hline
\end{tabular}

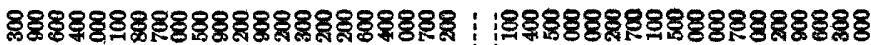

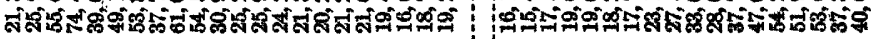

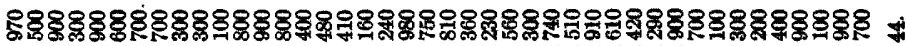
की

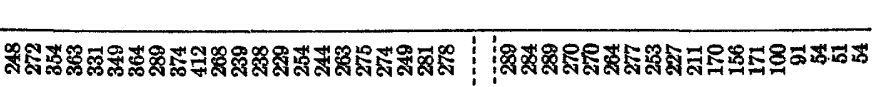
(1)

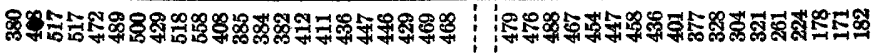

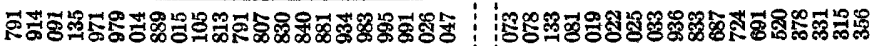

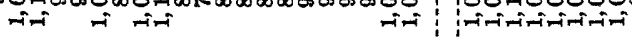

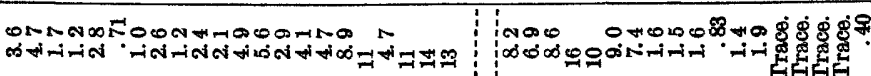

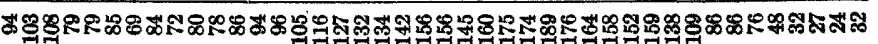

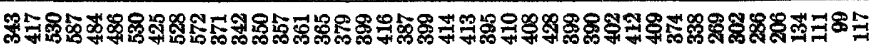

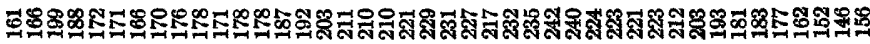

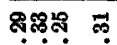

유요요 9

졍켱 용

-i

88

$\infty$

1.

迸

速

蓶:

的高

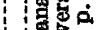

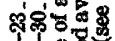

is

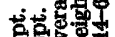

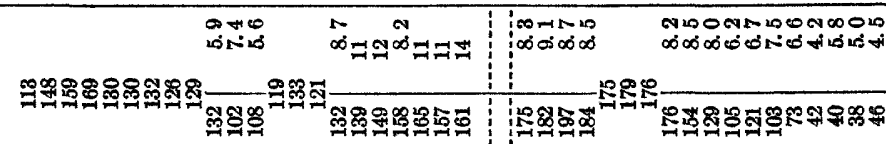

४

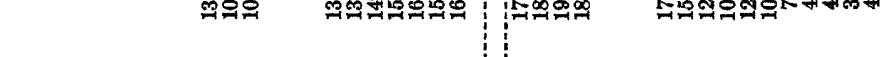

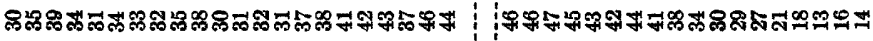

西

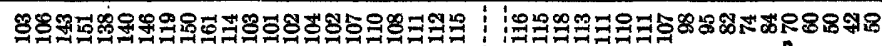

సสำผ

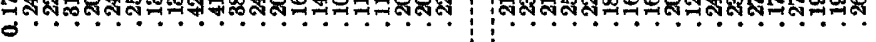

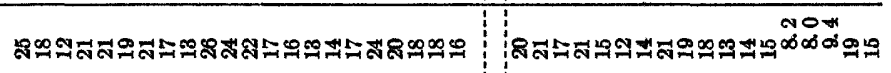

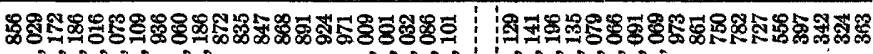
iniminiti-i $\rightarrow$

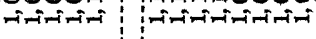

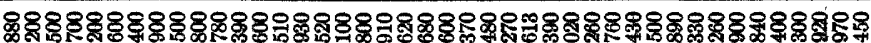

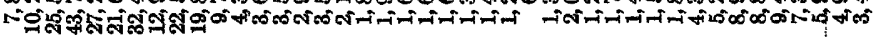

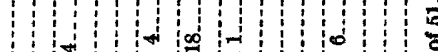

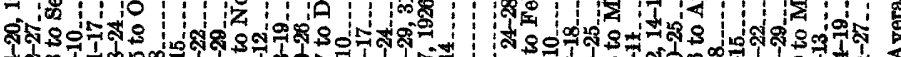
İส 1

ن

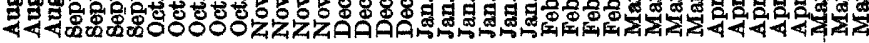

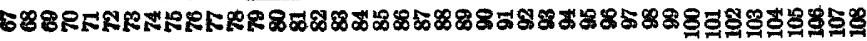


CONTRIBUTIONS TO HYDROLOGY OF UNTTED STATES, 1927

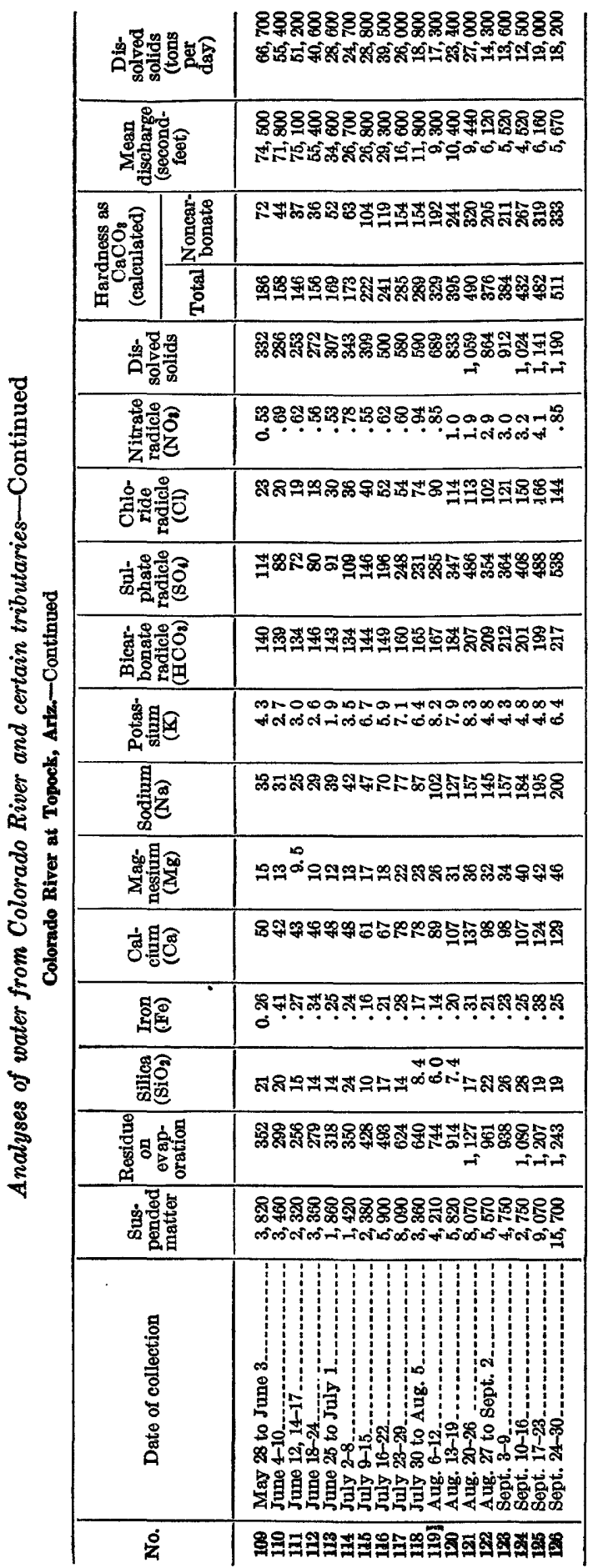

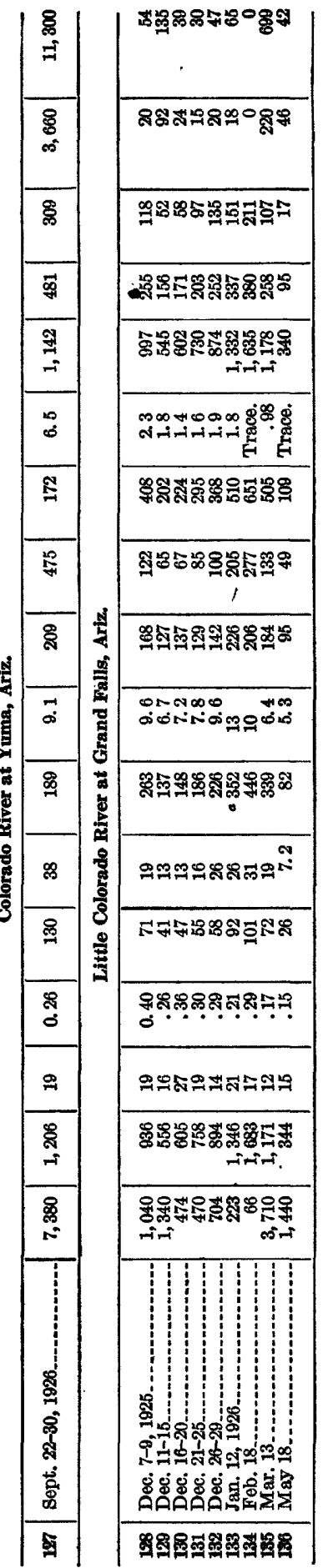


QUALTTY OF WATER OF COLORADO RIVER IN 1925-1926

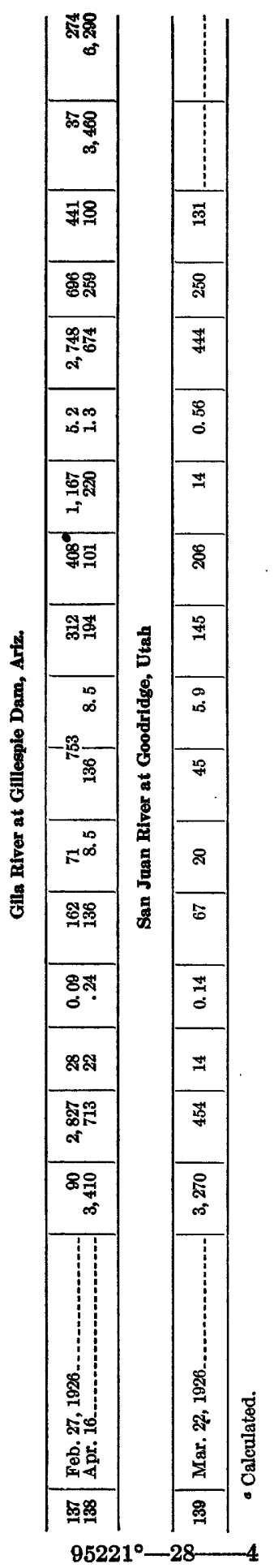





\title{
GROUND WATER IN THE ORDOVICIAN ROCKS NEAR WOODSTOCK, VIRGINIA
}

\author{
By George M. HaLl
}

\section{INTRODUCTION}

Woodstock, the county seat of Shenandoah County, Va., is one of the many prosperous towns in the Valley of Virginia. It is situated on the Southern Railway about 30 miles south-southwest of Winchester, at an altitude of 820 feet above sea level. The population of the town is 1,580, according to the United States Census of 1920. The position of the town is shown in Plate 7. The main highway in the valley passes through Woodstock, and the tourist traffic is heavy. Many automobilists use this route to and from the South and in local tours to the scenic attractions of the area. Numerous picturesque caverns occur in the limestone of the area and are visited by thousands annually. The Valley of Virginia was a battle ground throughout the Civil War and contains many famous spots where the conflicting forces clashed.

The surrounding region is a rich agricultural country devoted largely to orchards and dairy farms, and it annually produces large and valuable crops. Most of the business for a radius of a dozen miles or more is transacted in Woodstock, making the town prosperous. The town is essentially a residential and merchandising community and not an industrial center. The creamery of the Chapin-Sack Corporation ${ }^{1}$ and a flour mill are the only important industrial plants in Woodstock.

The United States Geological Survey has received numerous inquiries concerning the occurrence of water in the Cambrian and Ordovician limestones of the Valley of Virginia. Small supplies sufficient for an ordinary farm are usually available at relatively shallow depths, and a few wells yield large quantities, but in many places supplies adequate for industrial or municipal purposes are difficult to obtain. The question is frequently asked whether deep wells will yield large supplies. Recently the Chapin-Sacks Corporation drilled a well at Woodstock to a depth of 1,550 feet and encountered no water below the 250 -foot level. The information obtained from this

1 Now operated by Southern Dairies (Inc.). 
deep well, together with other data collected during two brief visits-one in July and the other in October, 1924-form the basis for this brief contribution. This deep well afforded a valuable opportunity to study the possibility of obtaining water supplies from considerable depths. The results of this study are applicable not only to the immediate vicinity of Woodstock but in some degree to other parts of the Valley of Virginia. Only a few analyses of water from the Ordovician rocks in these valleys have heretofore been published, and therefore six samples were taken and analyzed in the laboratory of the Geological Survey. (See pp. 63-65.)

The writer acknowledges the kindness of Mr. J. B. Eckhardt, formerly manager of the Chapin-Sacks Corporation, and of Mr. -Harvey Kessler, manager of the Woodstock Creamery, and is appreciative of the valuable information supplied by Mr. William $\mathbf{J}$. Gochenour, driller of the deep well.

\section{CLIMATE AND ITS EFFECT ON THE WATER TABLE}

The climate of Woodstock is relatively mild, and usually 180 days or more intervenes between the last killing frost in spring and the first in autumn. The mean annual temperature is $53.4^{\circ} \mathrm{F}$; t temperatures of more than $100^{\circ}$ or less than $0^{\circ}$ are uncommon. The mean annual precipitation during a period of 27 years, from 1897 to ' 1923, was 33.55 inches. There is considerable variation from year to year in the amount of precipitation, as is shown in Figure 8. The maximum during the period was 44.37 inches, in 1901, and the minimum was 25.19 inches, in 1914. During the 10 years ending 1923 the average annual precipitation was lower than that of the preceding decade. As shown in Figure 9, the summer months May to August have an excess over the remainder of the year, and each month of that period averages more than any one of the remaining eight months. The three years 1921 to 1923 were relatively dry, with an average precipitation of only 27.44 inches, or 6.11 inches below the annual mean. As shown in Plate 8, during this period only 9 of the 36 months had an excess of precipitation over the monthly average for the period from 1897 to 1923 , and 16 months had a total precipitation of less than 2 inches. This unprecedented period of drought resulted in a small discharge of the streams and in a low level of the water table.

The deficiency in precipitation in these three years amounted to more than 18 per cent of the annual mean, and many of the wells and springs failed. During this period the 185-foot drilled well in the Gravely orchard, west of Woodstock, in which the water usually stands within 40 feet of the top, went dry, apparently indicating a drop of as much as 140 feet in the water table. The water 

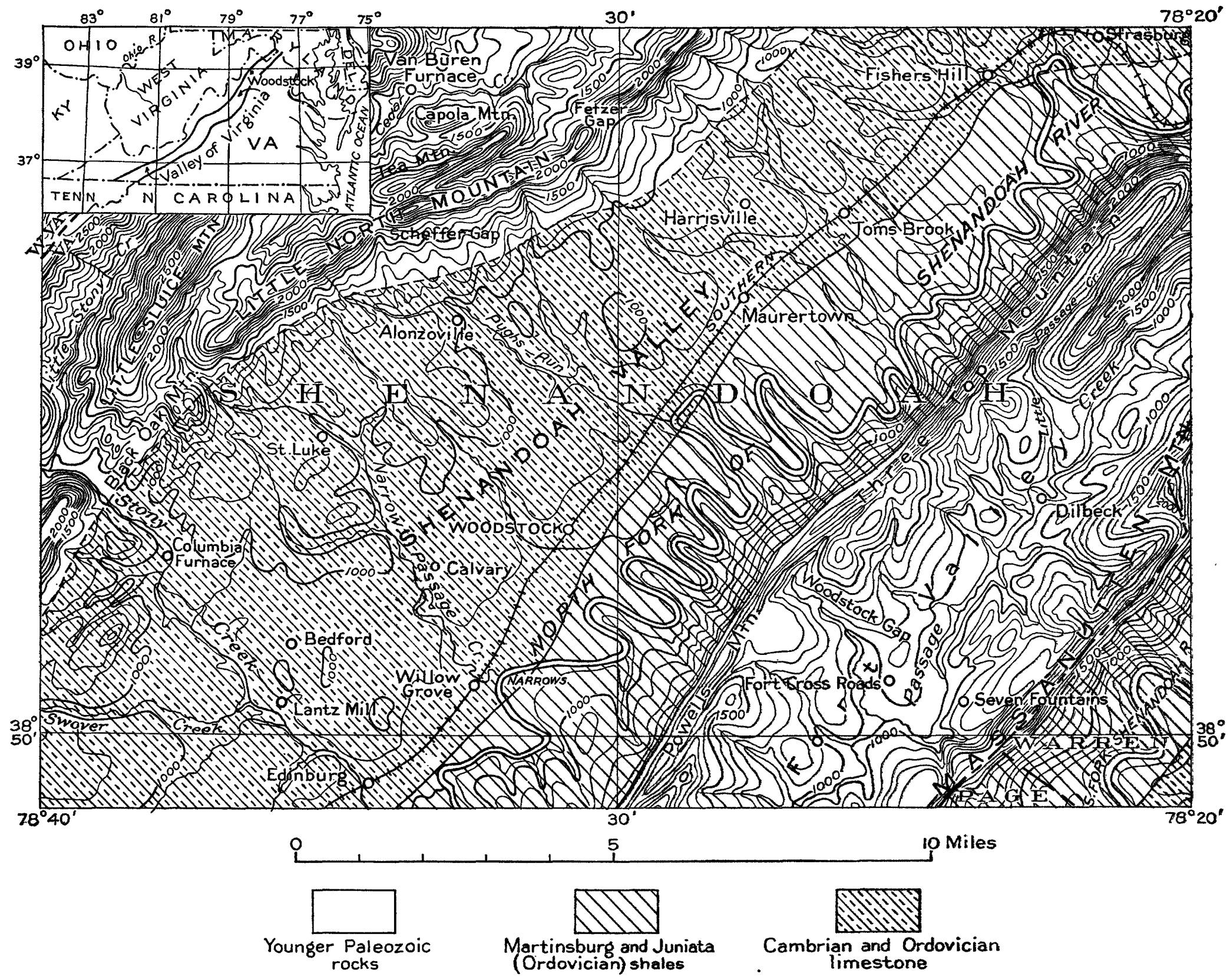

GENERALIZED GEOLOGIC MAP OF THE VICINITY OF WOODSTOCK, VA. 




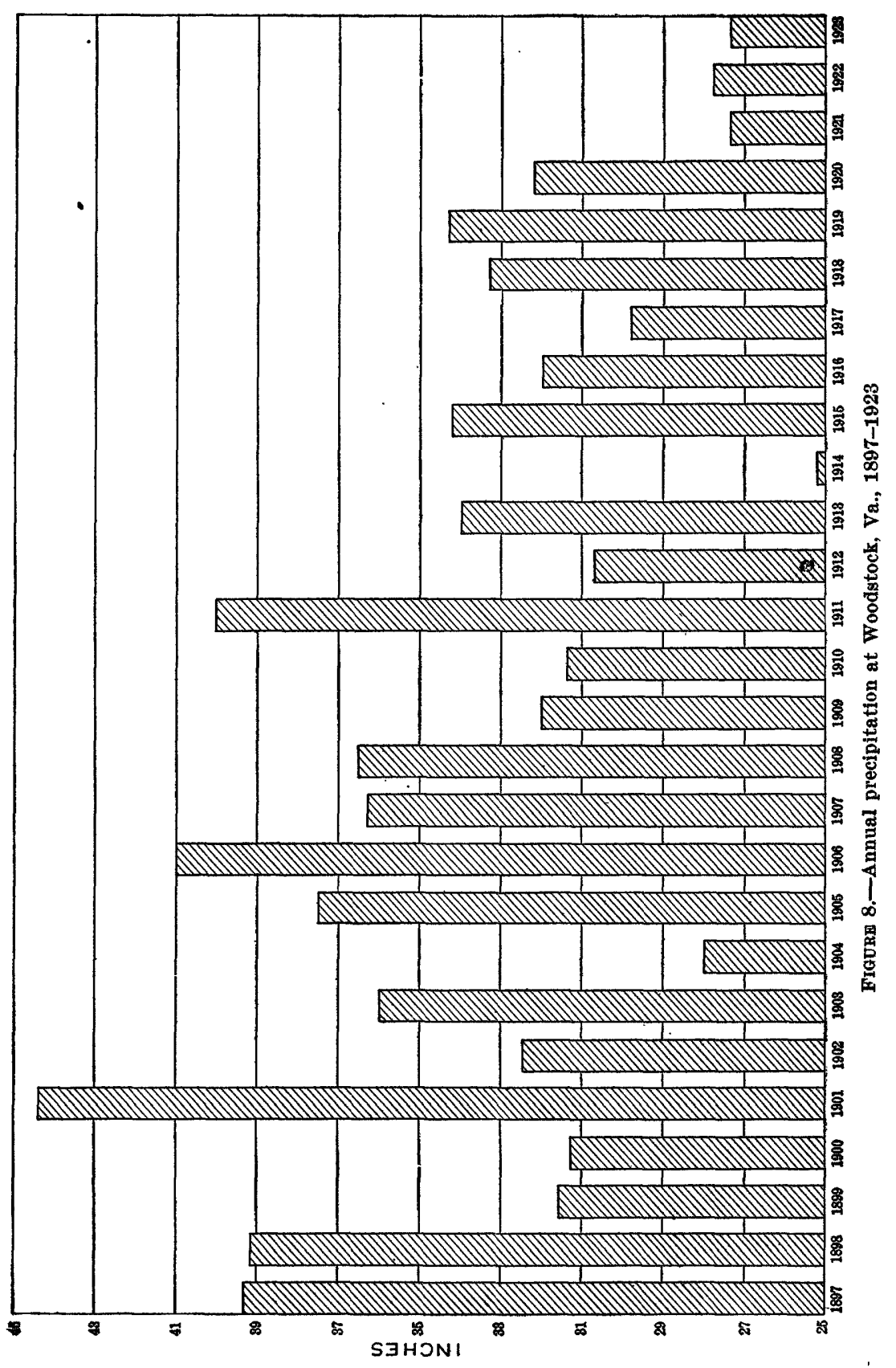




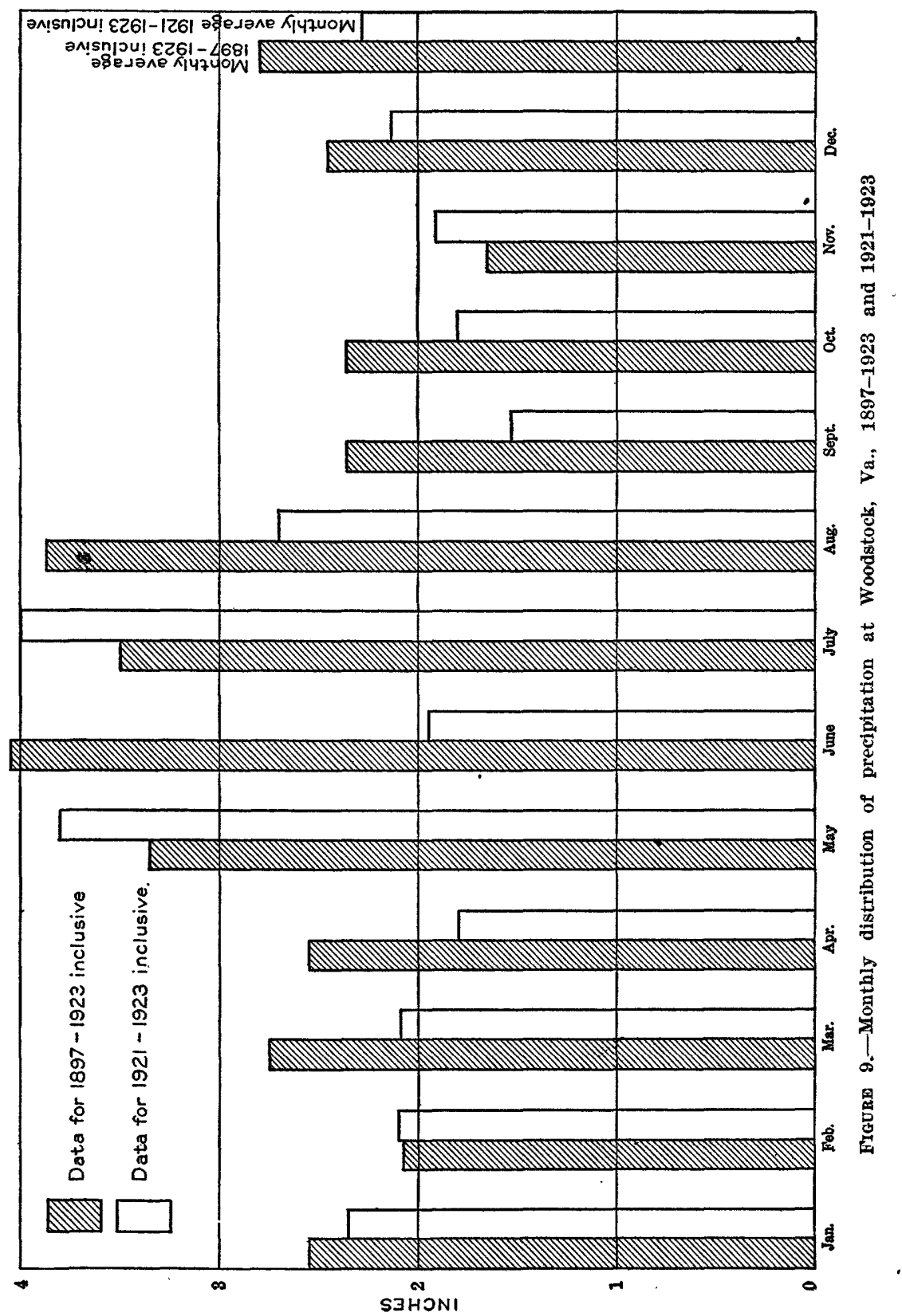


in the dug well on Spring Street, which now overflows and is reported to have overflowed for a number of years prior to the dry summer of 1923, dropped to a level 40 feet below the surface. This very considerable drop in the level of the water table caused the failure of many wells that had been considered permanent, and a serious water shortage resulted in both town and country.

The first six months of 1924 were decidedly wetter than the three preceding years, and a precipitation of 26.01 inches was recorded for that period, compared with 27.44 inches for all of 1923. At the beginning of the winter of 1923-24 the level of the water in the wells rose. By the end of July, 1924, the water table was not only back at its normal level but was slightly higher than normal. Numerous small hillside springs that had been dry began to flow. According to local observers these springs flow only in wet years. The Gravely orchard well and the dug well in Spring Street completely recovered.

On the writer's second visit to the region, October 10-12, 1924, although the rainfall in July and August had been only 1.90 and 2.65 inches, respectively, the Spring Street well was still overflowing at apparently the same rate as in July, and there was no reported shortage of water, although the temporary springs mentioned above had ceased to flow. Apparently the heavy rains of the first half of 1924 had raised the water table and had completely replenished the ground-water supply, so that the deficient rainfall of July and August had no serious effect.

\section{STREAMS}

The region is drained by the North Fork of Shenandoah River. With the exception of this river and a few tributaries that rise in the mountains to the west and flow across the valley the region is almost without streams. In a few places, however, large springs form branches that join the larger streams. Most of the run-off drains into sink holes, which are very numerous, and thus a large part of the precipitation becomes ground water. Most of the sink holes are dry throughout the year or hold water for only a few hours after a storm, but some always contain water, and these form the only ponds in the region.

The North Fork of the Shenandoah flows northeastward through the valley in a series of deeply intrenched meanders to meet the South Fork at the north end of Massanutten Mountain. It is a fastflowing stream that is used to generate electric power. The river flows within a mile of Woodstock but is not visible from the town. To appreciate the full beauty of this stream one must see it from Massanutten Mountain. 
A gaging station was maintained from 1899 to 1906 by the United States Geological Survey on the North Fork of the Shenandoah at a point near Riverton, about 25 miles below Woodstock. The maximum discharge recorded ${ }^{1}$ at this station is 21,630 cubic feet a second, in April, 1901, and the minimum 90 cubic feet a second, in August, 1900, and October, 1904. Passage Creek and several other tributaries enter the river between Woodstock and Riverton.

Analyses ${ }^{2}$ were made of a series of samples of water taken from the Shenandoah at Millville, W. Va., in 10-day periods extending from September 12, 1906, to September 9, 1907. The average of these analyses is given below:

\section{Analysis of Shenandoah River water}

[Mean of series of samples September 12, 1906, to September 9, 1907. Parts per million]

\begin{tabular}{|c|c|}
\hline Turbidity & 31 \\
\hline Suspended matter. & 39 \\
\hline Coefficient of fineness & 1.64 \\
\hline Total iron-_- & .9 \\
\hline Silica & 15 \\
\hline Iron & .08 \\
\hline Calcium & 32 \\
\hline Magnesium & 8.2 \\
\hline Sodium and potassium & 6. 7 \\
\hline Carbonate radicle & 1.3 \\
\hline Bicarbonate radicle & 132 \\
\hline Sulphate radicle & 6.2 \\
\hline Nitrate radicle & 2.6 \\
\hline Chloride radicle__-__- & 3 \\
\hline
\end{tabular}

Although Millville is more than 50 miles downstream from Woodstock and is below the junction of the North and South Forks, the figures are doubtless representative of the North Fork, because both forks of the river flow almost continuously over rocks like those surrounding Woodstock.

\section{SURFACE FEATURES}

The Woodstock area is in the Appalachian Valley province. The large expanse of valley which lies between the Blue Ridge and the Appalachian Valley Ridges and which is commonly called the Valley of Virginia extends in a general northeasterly direction from the southern to the northern boundary of the State, a distance of more than 300 miles, and ranges in width from $1 \frac{1}{2}$ to 20 miles. At Potomac River the floor of the valley is less than 500 feet above sea

\footnotetext{
${ }^{2}$ Stevens, G. C., Surface water supply of Virginia : Virginia Geol. Survey Bull. 10, 1916.

2 Dole, R. B., Quality of surface waters in the United States, Part I : U. S. Geol. Survey Water-Supply Paper 236, 1909.
} 
level, but in the southern part of the State it is much higher and reaches in places 2,500 feet. From Harrisonburg to Strasburg, a distance of 45 miles, the valley is divided lengthwise into two parts by Massanutten Mountain. The town of Woodstock is situated in the part that lies northwest of this mountain and is drained by the North Fork of Shenandoah River. This part of the Valley of Virginia is called the Shenandoah Valley.

From the lookout tower on Massanutten Mountain, just east of Woodstock, an excellent view of the physical features of the vicinity can be obtained. The tower is easily accessible, as a fair automobile road ascends the mountain and passes within 200 yards of it. From this vantage point on clear days the Blue Ridge and North Mountains are distinctly visible, and the observer can see for miles up and down the valley. The tower not only affords a magnificent view of the mountains and of the beautiful valley through which the North Fork of the Shenandoah flows but is also an excellent place to get a general idea of the physiography and the geology of the region.

In a general view the bounding mountains rise to a common level, which represents an ancient erosion surface. In addition to this upper surface of erosion several others can be discerned at successively lower altitudes. These were produced as the region was uplifted step by step and the streams cut deeper after each uplift. In a recent report Stose ${ }^{3}$ has applied the name Summit peneplain to the highest erosion surface and the names Upland, Intermediate, and Valley Floor peneplains to the successively lower ones. He also describes a former flood plain of the river that is far below the Valley Floor peneplain but has been dissected by the river and now forms a series of terraces that stand about 20 feet above the normal river level.

The Valley Floor peneplain is the most conspicuous of the erosion surfaces in the vicinity of Woodstock. When viewed from a high point, such as the lookout tower mentioned above, the so-called Valley Floor appears to be a gently undulating plain that rises gradually toward the west from the river to the foot of the mountains. When the observer comes down into the valley, however, the illusion of a plain is lost, for the river and its tributaries have cut into this ancient valley floor and have converted it into a hilly country. All that remains of the original valley floor are the flat tops of some of the hills. It was upon this plain that the great meanders of the Shenandoah were developed. The river now flows at a level fully 200 feet below the Valley Floor peneplain, and its meanders are deeply

\footnotetext{
Stose, G. W., and Miser, H. D., Manganese deposits of western Virginia : Virginia Geol. Survey Bull. 23, 1922.
} 
intrenched. The intrenched meanders are a most interesting feature of the scenery and are commented on by all visitors to the lookout tower. They are so intricate that in one locality the river flows 8 miles between points which are only 1 mile apart. The harder beds in the Martinsburg shale, over which the river flows in most of its course through the region, form small but conspicuous riffles.

\section{GEOLOGIC FORMATIONS}

The rock formations exposed near the town of Woodstock range in age from Lower Cambrian to Silurian. They are listed in the table below and discussed briefly in succeeding pages. The names of formations used are those given by Stose and Miser. ${ }^{4}$ The formations will be described from the youngest downward, which is the order in which they are encountered in drilling.

Rock formations underlying the vicinity of Woodstock, Va.

\begin{tabular}{|c|c|c|}
\hline Age & Name & $\begin{array}{c}\text { Estimated } \\
\text { thickness a } \\
\end{array}$ \\
\hline Silurian. & Tuscarora quartzite ${ }^{b}$ & Feet 300 \\
\hline \multirow{2}{*}{ Upper Ordovician. } & Juniata formationb & 200 \\
\hline & Martinsburg shale_.....- & 1,800 \\
\hline Middle Ordovician. & Chambersburg limestone......... & $40 \%$ \\
\hline Lower Ordovician. & $\begin{array}{l}\text { Stones River limestone } \\
\text { Beekmantown limestone }\end{array}$ & $\begin{array}{r}90 \% \\
2,301\end{array}$ \\
\hline Upper Cambrian. & Conocheague limestone . . . . & $1,50 n$ \\
\hline Middle Cambrian. & Elbrook formation........... & 3,000 \\
\hline Lower Cambrian. & $\begin{array}{l}\text { Waynesboro formation. } \\
\text { Tomstown limestone } \\
\text { Antietam sandstone }{ }^{\circ} \text { Harpers shale }{ }^{c} \text { - } \\
\text { Weverton sandstone }{ }^{\circ}- \\
\text { Loudonn formation }{ }^{\circ}\end{array}$ & $\begin{array}{r}1,257 \\
1,007 \\
507 \\
1,007 \\
100-907 \\
0-307\end{array}$ \\
\hline
\end{tabular}

Thicknesses are from Virginia Geol. Survey Bull. II-A, Cement resources of Virginia, and Geologi? map of Virginia.

bThe Tuscarora and Juniata are equivalent to the "Massanutten sandstone" as described by A. C. Spencer (The geology of the Massanutten Mountain in Virginia, 1896).

- Not exposed near Woodstock.

The Tuscarora quartzite is about 300 feet thick and consists chiefly of well-washed and sorted quartz grains. The sand is coarse and usually cross-bedded, and there are numerous layers of pebbles. Although this formation is usually called a sandstone it is so well cemented as to be a quartzite. Owing to its resistance to erosion it

I Șţose, G. W., and Mișer, H. D., op. cit. 
forms cliffs and steep slopes. It occurs on the top of Massanutten Mountain, and to its presence this mountain is due.

The Juniata formation, composed of shale and sandstone of Upper Ordovician age, lies immediately beneath the Tuscarora quartzite. In this locality the formation reaches a total thickness of about 200 feet. It consists at the top of sandstone and conglomerate which grade downward into micaceous sandy beds and then into yellow and gray shales. This lithology is in striking contrast to that exhibited farther north, where the rocks are red and about 400 feet thick. The Juniata formation is exposed on the flanks of Massanutten Mountain high above the valley.

The Martinsburg shale is a conspicuous formation in the Shenandoah Valley, being exposed on the flanks of the mountain as well as occupying a large area in the valley. Its generally gray to black color and fissile character suggested the local name "black slate." It weathers to rounded hills and gentle slopes and forms a subdued topography. The cedars that are so conspicuous on the limestone are absent on the shale. The soil of the hillsides underlain by this formation is everywhere full of small fragments of the shale, but except in steep-sided ravines and artificial excavations good exposures are uncommon. The intricate folds and the lack of exposures make it difficult to measure accurately the thickness of this shale, and estimates of its thickness range from 1,000 to 2,800 feet. It probably averages about 1,800 feet.

The Chambersburg limestone is a shaly limestone that probably does not exceed 400 feet in thickness. The conditions under which this formation was deposited were apparently transitional from those that produced the underlying pure limestone to those in which the overlying Martinsburg shale was formed. However, Bassler ${ }^{5}$ has shown by careful study that the Chambersburg represents a distinct interval of time and is not a transitional phase of the Martinsburg shale. Because of its narrow outcrop it is of little importance as a source of water.

The Stones River limestone is the rock that crops out in the immediate vicinity of Woodstock, and the town is built largely upon it. It is about 900 feet thick in most of northern Virginia, but only about 600 feet on Pughs Run, a few miles north of Woodstock. The formation consists of relatively pure dove-colored limestone alternating with heavy-bedded dolomitic rocks. Cedars are generally common on the outcrops of this limestone, but they are not abundant in the immediate vicinity of the town:

The Beekmantown limestone, approximately 2,300 feet thick, lies beneath the Stones River limestone and consists chiefly of beds of

\footnotetext{
•Bassler, R. S., Maryland Geol. Survey : Cambrian and Ordovician, 1919.
} 
pure limestone. It forms a very fertile soil, and areas which it underlies are largely cultivated. The complete and rapid weathering: of the formation produces a continuous soil mantle, and good exposures are rare except in artificial cuts. A distinctive rock called "edgewise conglomerate" occurs in the upper half of the lower 500 feet of the formation, but is more common in the lower part of the underlying Conococheague limestone. "Edgewise conglomerate" 6 is composed of slender fragments of limestone tilted at all angles ir. a matrix of limestone distinctly different in composition. This peculiar rock has received considerable study, but its origin is not yet, well understood. ${ }^{7}$

The Conococheague limestone, about 1,500 feet thick in this vicinity, consists almost entirely of massive dark-blue closely banded limestone. The banding is usually half an inch to 1 inch in thickness and consists of thin, wavy laminae of alternately pure and sandy limestone. On fresh fracture the banding is inconspicuous, but it weathers in relief and forms yellow' raised streaks separating bands of light-blue or gray rock. Chert occurs in the lower beds and weathers out in scoriaceous masses that are much used in making stone fences.

The Elbrook formation, about 3,000 feet thick, is composed in large, part of shaly limestone and calcareous shale. It weathers easily and affords few natural outcrops. The shale ranges in color from red to yellow, and the more highly colored beds occur in the lower third of the formation.

The Waynesboro formation, equivalent to the Watauga shale of southern Virginia, consists of a lower member of siliceous gray lime. stone and calcareous sandstone, a middle member of purer limestone, and an upper member of red and purple siliceous shale. The total thickness is estimated to be about 1,250 feet. The basal siliceous limestone weathers in such a manner that it appears to be a porous sandstone, and only in fresh cuts can its limy character be detected.

The Tomstown limestone is the oldest of the so-called "Valler limestones." It is composed largely of dolomite and limestone, in massive and thin beds, and near the base of the formation includes considerable interbedded shale. It undoubtedly underlies the Waynesboro formation in this vicinity, though it apparently does $\mathrm{no}^{+}$ crop out west of Woodstock owing to faulting.

\footnotetext{
6 Bassler, R. S., op. cit., pp. 86-88.

7 Nason, F. L., The geological relations and the age of the St. Joseph and Potosi limt: stones of St. Francois County, Mo.: Am. Jour. Sči., 4th ser., vol. 12, p. 360, 1901. Bair. H. F., and Ulrich, E. O., The copper deposits of Missouri : U. S. Geol. Survey Bull. 26T, p. 23, 1905. Stase, G. W. U. S. Geol. Survey, Geol. Atlas, Mercersburg-Chambersbur? folio (No. 170), 1909. Brown, T. C., Notes on the origin of certain Paleozoic sediments; Jour. Geology, vol. 21, pp. 233-244, 1913. Grabau, A. W., Principles of stratigraphy, pp. 530, 784, New York, 1924.
} 
The Antietam sandstone, Harpers shale, Weverton sandstone, and Loudoun formation, which are exposed in the Blue Ridge to the east of the area here discussed, probably underlie the area.

\section{STRUCTURE}

The rocks in this part of the Shenandoah Valley form a huge syncline that is limited on the east by the Blue Ridge and on the west by North Mountain. The syncline is cut off from the mountains by a fault of large throw, which in general parallels the axis of the valley. The simple synclinal structure is somewhat complicated by the presence of folds ranging in size from very small ones in the Martinsburg shale to large ones like those that can be seen in Massanutten Mountain. In this mountain, which extends 45 miles in a general southwesterly direction, the downfolding of the major syncline was so deep that the hard Tuscarora quartzite, which forms the resistant top of the mountain, has been preserved, though the same formation was removed from the northern part of the Shenandoah Valley, where it was more ex-

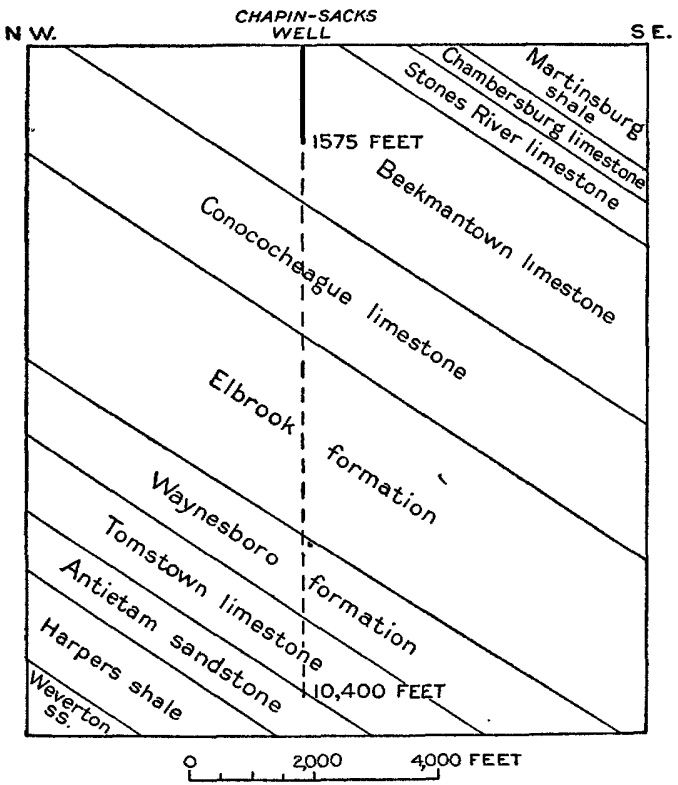

Figurig 10.-Diagrammatic cross section of the rocks in the vicinity of the Chapin-Sacks well, Woodstock, Va. posed. Geologic sections of this region are given in the reports by Bassler and Spencer previously cited. Figure 10 is a generalized, cross section to show diagrammatically the conditions at the deep well drilled at the creamery in Woodstock and is not intended to show the details of the structure.

The regional strike is $\mathrm{N} .40^{\circ}-60^{\circ} \mathrm{E}$., and the dip averages between $40^{\circ}$ and $45^{\circ} \mathrm{SE}$. Locally, however, there is considerable variation in both strike and dip, particularly in the dip, which ranges from $0^{\circ}$ to $90^{\circ}$. In a few localities the beds are overturned. The greatest changes in dip within a short distance are observable in the Martinsburg shale. 
One major fault lies along the western edge of the valley, approximately parallel with the regional strike, but there are some minor faults that trend almost at right angles to it. The major fault has a throw of several thousand feet, but as a rule the minor faults have throws not exceeding a few hundred feet. As a whole the rocks in the vicinity of Woodstock appear to be less complexly faulted than the rocks of similar age and type in areas both to the north and to the south.

\section{WATER-BEARING PROPERTIES OF THE ROCKS}

Ground water occurs in the vicinity of Woodstock chiefly in shale and limestone of Ordovician age, and the following discussion will be divided into two parts, based on the type of rock in which the water occurs. The shale formations are the Juniata and Martinsburg, and the limestone formations are the Chambersburg, Stones River, and Beekmantown.

\section{SHALE FORMATIONS}

The Martinsburg shale, locally called the "black slate," forms a strip of variable width along the east side of the valley, as shown in Plate 7. Although the shale itself is alomst impermeable, it contains numerous open bedding planes and joints in which is stored much water that is available to wells. In dry seasons, however, the amount of stored water is very much reduced, so that wells and springs diminish in their yield and frequently go dry during prolonged droughts. This is especially true of many of the shallow dug wells.

The municipal water supply of Woodstock is in part ${ }^{7 a}$ derived from five hillside springs that are fed by the water stored in the joints of the Martinsburg shale. During periods of dry weather, when this store of water is not replenished, the flow of these springs is always reduced, and one or two of them are reported to cease flowing during prolonged droughts. In the dry year 1920 an effort was made to augment the quantity of water by drilling a well 217 feet into the shale. Water was encountered at 100 and 150 feet below the surface and rose to a level 30 feet below the surface. When the well had been completed by the driller it yielded on test between 40 and 50 gallons a minute. In order to avoid the cost of pumping a tunnel was driven from the lower reservoir, a distance of 80 feet, to the well at a level low enough to divert the water as it rose in the well. When the writer visited the locality on July 22, 1924, the flow through the tunnel was about 5 gallons a minute. It is reported that the flow was considerably less than that during the summer of 1923 , although it did not cease entirely.

\footnotetext{
${ }^{7 a}$ Since this was written Woodstock has obtalned an additional supply from Little stony Creek.
} 
Drilled.wells in the Martinsburg shale usually have small but satisfactory yields, as shown in the examples herewith described. A drilled well on the property of Mrs. W. E. McInturff, a quarter of a mile east of Maurertown, is 75 feet deep and yields 5 gallons a minute. The water, which rises within 25 feet of the surface, is used for domestic purposes. The well on the property of Mr. W. E. Boyer, also near Maurertown, is 105 feet deep and yields 4 gallons a minute; the water in the well rises within 11 feet of the surface. The owner uses the well only as a reserve supply, preferring cistern water because it is softer, but he reports that the well water has no objectionable features except that it is hard. As shown in the analysis on page 65, the water contains 508 parts per million of total dissolved solids, and its hardness is 380 parts per million. Its temperature on October 11,1924 , was $56^{\circ} \mathrm{F}$. The well of $\mathrm{Mr}$. C. Brenner, 1 mile east of Woodstock, is 103 feet deep, ends in the Martinsburg shale, and yields several gallons of water a minute. The water is used for domestic purposes.

Wells in the Martinsburg shale rarely exceed 150 feet in depth. They generally obtain yields of a few gallons a minute but rarely more than 15 gallons a minute. The well water is generally used for drinking and is considered by the users as good but hard. Many well owners supplement their hard well water supply with rain water that is collected on the roofs of the buildings and is stored in cisterns. The soft cistern water is used chiefly for washing.

\section{ITMESTONE FORMATIONS}

The limestones of the area were formerly grouped as the Shenandoah limestone, but recent detailed work has made it possible to recognize a number of different formations distinguishable on both paleontologic and lithologic grounds, and these formations are listed on page 52. However, the differences in lithology among the limestone formations are not great enough to produce much difference in their water-bearing properties, and hence for the purposes of this report they can all be considered under one heading. The available data on ground water in this area pertain largely to the Stones River and Beekmantown limestones, but these data can be applied to all the limestones. Although the Elbrook and Waynesboro formations contain considerable shale and sandstone, they are, when unweathered, fairly calcareous and doubtless closely resemble the other limestone formations in their water-bearing properties. The Lower Cambrian sandstone and shale are not exposed in this area and their water-bearing characteristics are not discussed.

Compact limestone, such as occurs in the Shenandoah Valley, is a nearly impervious rocks. Water can not flow freely through the 
solid rock nor be stored in it. However, where the rock is fractured or creviced wells in it may have large yields. The openings in the limestone consist of joints and partings along bedding planes and of much larger openings due to solution along the joints and partings. The joints in limestone, like those in other rocks, are largely the result of breaking under pressure, probably during the folding of the rocks of the region. Solution channels are characteristic only of limestone, gypsum, and salt and are due to the dissolving of the rock material by ground water. In humid regions, such as the Shenandoah Valley, there is in normal years sufficient precipitation to furnish plenty of ground water, which, when charged with carbon dioxide, dissolves limestone. A very small percentage $\partial \mathbf{f}$ carbon dioxide is absorbed from the air by the rain, but the amount is sufficient to make the water a solvent for limestone. Additional carbon dioxide is doubtless absorbed in the passage of rain water through the soil where vegetation is decaying. The process of solution of limestone is open to inspection in the many caves in the valley. The rooms and passages in caves are solution channels once occupied by ground water but now generally above the water table, though in wet seasons small quantities of water find their way through the caves. The channels vary greatly in length and size. Some give rise to springs, but others are dry or partly filled with mud. Most of the successful limestone wells obtain their water from solution channels that are encountered at about the level of the North Fork of Shenandoah River, but in some wells the water rises above the level at which it is encountered, indicating that the water circulates in these channels under some pressure.

$\pi \dot{\mathrm{i}}$

In this region the solution channels probably do not extend to gregt depths below the water table. The solution of limestone depends on the circulation of water containing carbon dioxide. As the ground water passes along the solution channels it dissolves some rock, but this process continues only so long as there is carbon dioxide in the water. As the total amount of carbon dioxide in solution is generally small, most of it is used up before the water percolates very far. A short distance below the water table the water is nearly, devoid of carbon dioxide, and, moreover, it circulates only very slowly, and therefore the rock is not dissolved away or is dissolved at a slow rate. Not only is the solution of rock arrested below the water table but deposition of mineral matter may take place, as is attested by the innumerable tiny veins that occur throughout the limestones.

There has been intense folding and faulting in the Appalachian province, as a result of which the rocks were broken and in places more or less crushed, but these fissures may have generally been recemented with calcite below the water table. Careful examination of outcrops reveals many calcite veins, most of which fill openings caused 
by earth movements. These veins vary in size from half an inch down to microscopic width and are present in all the limestones, although most conspicuous in the darker ones on account of the difference in color. In some places, however, fault and joint planes are probably still open, and some solution channels may occur at considerable depths below the water table. However, the Chapin-Sacks well, which was drilled to a depth of 1,550 feet and obtained little or no water below 200 feet, evidently did not encounter such deep openings.

Although the greater part of the foregoing discussion has concerned itself with the large openings, small ones also occur, and when encountered in sufficient number they yield fairly large quantities of water, like the small openings in the Martinsburg shale. The formation of only small openings at any place is due either to the short time that water has circulated at that place or to the existence of less soluble portions of the limestone beds between the numerous small openings.

The physiographic history of the region is one of periodic uplift with intervals of erosion. At no time does there appear to have been any appreciable subsidence that would have submerged the solution channels far below the water table. The general regional movement has always been upward, resulting in rejuvenation of the streams and erosion of the uplands. Thus there has been a constant lowering of the solution channels and of the water table. The height of the water table varies considerably with the season and from year to year, as is shown by the difference in level of water "in wells in 1923 and 1924, but this range in level is a matter of only a few feet, whereas the changes in altitude of the water table due to the uplifts of the region are measured in hundreds of feet.

In pioneer days, when settlers first entered this fertile limestone valley, streams and springs furnished an adequate supply of pure water, but the streams soon became polluted, and as settlement increased there were not enough springs to furnish water for every household, nor were they all conveniently located. Consequently shallow wells were dug, many of them more than a century ago. At present dug wells are largely out of favor, and many have been replaced by drilled wells. Dug wells are being abandoned partly because they are more likely than drilled wells to go dry during a drought and also because it is difficult to keep them from becoming contaminated. Most dug wells do not reach far below the water table, and when the water table is lowered by a drought the well becomes dry. At such times a well may have to be dug deeper, but the deepening of a dug well is an expensive and hazardous task. Dug wells are usually not carefully cased, and surface filth and small bur$95221^{\circ}-28-5$ 
rowing animals are not excluded. Even where care is taken to cover the wells, the platforms may not be tight, and water spilt on them carries the accumulated filth into the well. Polluted drinking water may cause serious illness, involving loss of time and expensive medical attention. Consequently dug wells, though low in initial outlay, may prove to be very costly in the end. In Woodstock, where a municipal water supply has been available for more than a quarter of a century, nearly all the dug wells have wisely been abandoned, but in the surrounding country many dug wells are still in use.

The dug well in Spring Street, just east of Main Street, differs from most dug wells in that it normally overflows at the surface. It had been little used for a number of years. During the drought in 1923 this well ceased flowing, but on account of the need for water that year the Chapin-Sacks Corporation had the well cleaned out, installed a centrifugal pump direct connected with a 25 -horsepower electric motor, and laid about half a mile of 6 -inch pipe to the creamery. When the rubbish that had accumulated in the well was removed the workmen found that the well is about 48 feet deep and that two natural tunnels at the bottom lead off to the west and northwest. These tunnels are solution channels in the limestone and through them the water enters the well. During the summer of 1923 the yield was small, and the water did not rise at any time more than 6 feet above the bottom of the well. The yield was so small that on pumping at the rate of 200 gallons a minute the supply was soon exhausted, and it was necessary to wait several hours before the water again reached the depth of 6 feet. In the winter of 1923 the water level in the well rose rapidly, and by May, 1924, the well again. overflowed. Since May the well has overflowed at the rate of 25 gal-lons a minute, and the water level inside the well is about 18 inches above the overflow pipe. It is reported that on pumping with the equipment previously used the drawdown after a period of several hours of pumping is less than 6 inches and the natural overflow is not greatly decreased. The water from this well is polluted, and the State health department has forbidden its use for human consumption, but as its temperature is only $55^{\circ} \mathrm{F}$. it is useful for cooling. As shown in the analysis on page 65 , the water contains 381 parts per million of total dissolved solids, and its hardness is 342 parts per million.

Drilled wells are numerous throughout the area and reliable information concerning them is available. Information concerning 30 drilled wells was obtained. These wells range in depth from 111 to 1,550 feet, the depth at which water was encountered from 40 to 565 feet, the level of the water below the surface from 11 to 80 feet, and the yield from 5 to 60 gallons a minute. All these wells are within 
5 miles of Woodstock, except the well at Stephens City, approximately 20 miles northeast of Woodstock.

The new well at the Chapin-Sacks creamery, at the northwestern edge of Woodstock, is 1,550 feet deep and is one of the deepest if not the deepest well in this part of the Shenandoah Valley. This well yields about 60 gallons a minute with a 300 -foot draw down. It starts near the top of the Beekmantown limestone and ends in the same formation, as shown in Figure 10. The well obtains all of its water in the first 250 feet. The first water was encountered at 188 feet and rose to a level 55 . feet below the surface; the second was found at about 250 feet and rose to a level 42 feet below the surface. The drillers report that they did not encounter any large openings while drilling this well and that below the 250 -foot level there was no indication of any additional water. This water contains 339 parts per million of total dissolved solids, and its hardness is 314 parts per million. In the same lot are two drilled wells, 180 feet and 240 feet. The 180-foot well yielded only 15 to 20 gallons a minute, mostly from a depth of 80 feet, and is now abandoned. The 240foot well yields about 35 gallons a minute, and most of the water also comes from a depth of approximately 80 feet. This water contains 397 parts per million of total dissolved solids, and its hardness is 316 parts per million. When these wells are pumped simultaneously the yield of each is decreased, and this fact is taken to mean that they draw from the same source, but in neither well were any large openings in the rock reported by the drillers.

The other wells in the vicinity of Woodstock are similar in that they penetrate rather solid limestone with few if any large openings. The abandoned well at the foundry, drilled about 1880, is reported to have been 112 feet deep and to have had a small yield. The well on the property of the Standard Oil Co. is 153 feet deep. The water enters the well about 75 feet below the surface and rises to a level 40 feet below the surface. The well of M. B. Wonder, about a quarter of a mile north of the Standard Oil Co. well, is 220 feet deep and yields about 5 gallons a minute. The water enters the well about 180 feet below the surface. The two wells at the abandoned creamery on the east side of the town were 158 and 300 feet deep, and both were in the Stones River limestone. The 300 -foot well yielded on test about 12.5 gallons a minute and the 158 -foot well somewhat less. Both wells are reported to obtain most of their water about 100 feet below the surface. The drillers did not encounter any large openings in the rock.

To the south and west of Woodstock, in the general neighborhood of the fair grounds, there are several wells drilled into the Beekmantown limestone. The: well on the fair grounds is 165 feet deep and 
the water stands 60 feet below the surface. The drillers report that they found an opening in the rock from 160 to 165 feet below the surface. A large quantity of water can probably be obtained from this opening, but the well has never been thoroughly tested. The pump now installed obtains about 10 gallons a minute with a small draw down. The well of M. L. Walton is 215 feet deep and yields approximately 14 gallons a minute. The water enters the well in three places between 80 and 215 feet. The well of $\mathrm{H}$. C. Stauffer is 120 feet deep and encountered water at 85, 95, and 115 feet. The drillers do not report any large openings but mention small crevices. The water rises within 70 feet of the surface and the well yields about 15 gallons a minute. The well of J. G. Gravely, some distance from the fair grounds, is discussed on pages 46 to 49 . The water contains 360 parts per million total dissolved solids and its hardness is 251 parts per million. The well of E. Homer Artz, just south of the town, is 123 feet deep and yields about 16 gallons a minute.

In sharp contrast to the uniformly compact rock encountered in wells at the creamery the well drilled in the Stones River limestone by William J. Gochenour for his filling station at Maurertown encountered a large opening at a depth of 103 feet. The drill tools dropped into this hole a distance of 5 feet, and water rushed into the well and rose within 27 feet of the surface. During a three-hour test the well was pumped at the rate of 17 gallons a minute, and the draw down was only 7 feet. The same owner has another well in the Stones River limestone about a mile farther south, which is 209 feet deep, obtains most of its water from a depth of 80 feet, and yields about 4 gallons a minute. The water level is 79 feet below the surface, and therefore the water is under almost no artesian pressure. Another well near by penetrates first the Martinsburg shale, but obtains its water from the Chambersburg limestone at a lower level. The well is 163 feet deep, has a water level within 50 feet of the surface, and yields only a few gallons a minute. Near these three wells, on the farm of William J. Gochenour, is a well in which several water horizons in the Stones River limestone were encountered, but no large openings were reported. The total depth of this well is 365 feet, but all the water was obtained in the first 250 feet. The water stands within 60 feet of the surface, but during a 65-minute test when 20 gallons a minute was pumped the drawdown was 170 feet.

From the detailed description of wells in limestone given in the foregoing paragraphs and a consideration of the general principles underlying the formation of solution channels in limestone (p. 58), the conclusion can be reached that the success or failure of a well is dependent on striking crevices that carry water. Underground channels filled with mud, which flows into the hole and delays the drilling, 
ane found in some wells, but most of these channels are either above the water table and dry or below it and full of water. They are distributed in a most irregular manner throughout the body of rock, and, it is a matter of chance whether in a particular locality one will be encountered. Those wells that strike one large channel with a large volume of water or several smaller ones containing in the aggregate a considerable volume will yield large quantities of water; those which encounter only a few small openings will yield only a small supply. Wells drilled into solid rock without cavities are usually failures. The limestone has an enormous number of small openings, and wells usually encounter enough of them to yield sufficient water for ordinary farm use. Channels of large volume, however, are not numerous and are found so seldom that wells yielding more than 50 gallons a minute are uncommon. All but one of the wells near Woodstock encounter water above a depth of 300 feet, and the only well drilled to a greater depth was dry below 300 feet. It is therefore recommended that in drilling wells a dry hole be abandoned when it has reached a depth of 300 feet and another well be put down at a new location.

The cost of reaching the underlying sandstones that might contain water is prohibitive in this locality because of the great depth at which they occur. As shown in Figure 10, the depth to the Antietam sandstone is probably not less than 8,000 feet anywhere in the immediate vicinity of Woodstock. Not only would an attempt to obtain water from this formation be excessively costly, but it might end in failure, both because of the difficulties of drilling so deep a well and because the pores of the sandstone may be filled with mineral matter at so great a depth and the rock may therefore be dry.

\section{CHEMICAL CHARACTER OF THE GROUND WATER}

Six samples of water from wells in or near Woodstock were analyzed and show a range in total dissolved solids of 223 to 508 parts per million, and a range in hardness from 186 to 380 parts per million. These waters, which may be considered characteristic of the area, are thus relatively high in total dissolved solids and have a rather high hardness. However, this hardness is almost entirely carbonate hardness except in the sample of water from the Martinsburg shale, in which the noncarbonate hardness is rather large compared to that in the samples from the limestone, being eleven times greater than in No. 2 and six and one-half times greater than the average of Nos. 2 to 6 .

As shown by the table of analyses on page 65 and more graphically by Figure 11, calcium is the preponderant base in all but one sample, magnesium is next in amount, and the contents of sodium and potas. 
sium are relatively small. The four analyses given last in Figure 11 represent waters derived from the more dolomitic rocks. Larger amounts of magnesium should be expected in water from such rocks, and in sample No. 6 magnesium is the chief base. This water also

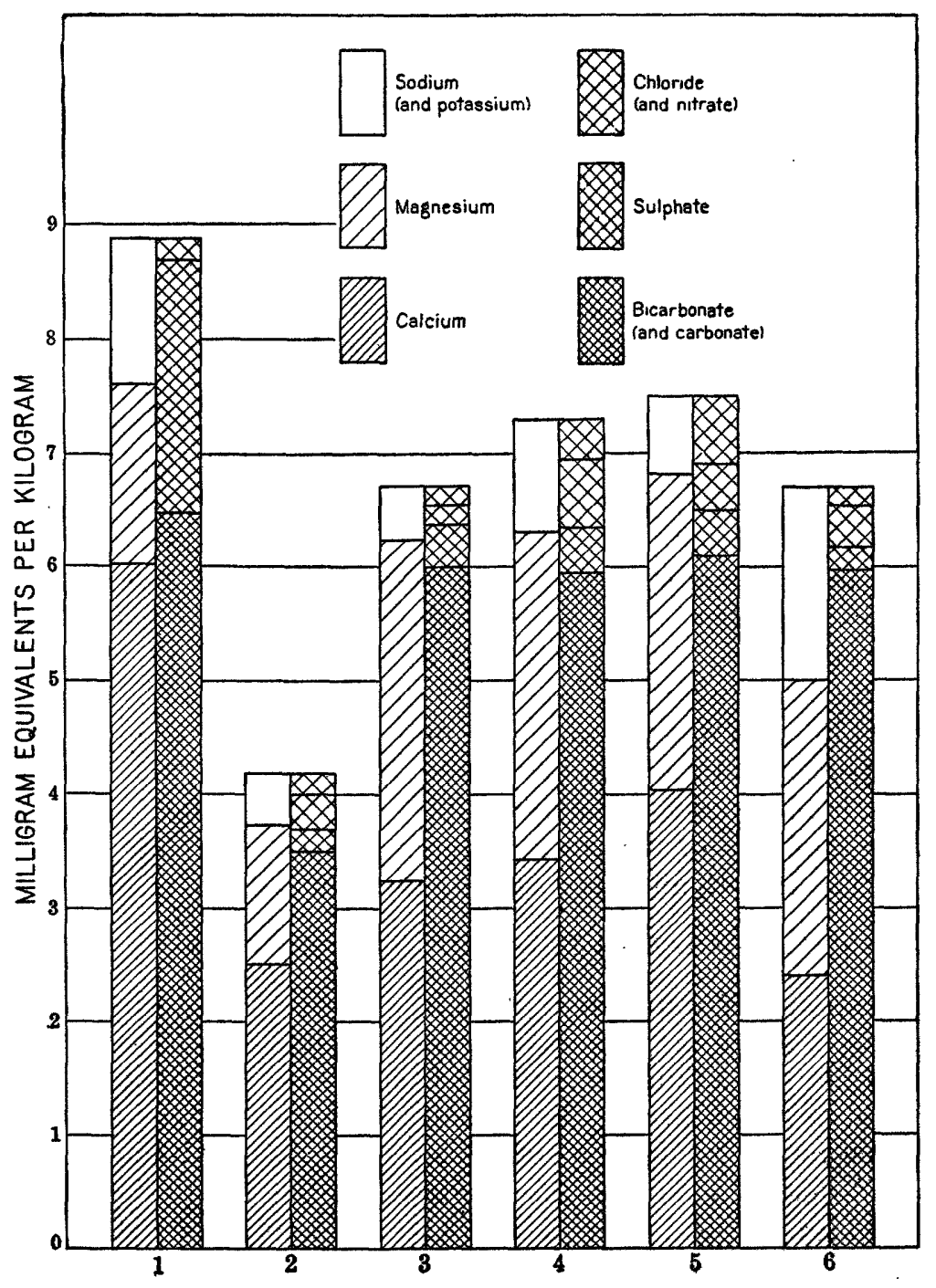

FIGUR 11.-Graphic representation of analyses of well waters from vicinity of Woodstock, Va.

has a sodium and potassium content exceeding that of any other sample.

The bicarbonate radicle is the preponderant radicle in these samples. The quantity of sulphate is small in all samples except in the water from the Martinsburg shale. Both chloride and nitrate are 
small in amount, though nitrate is rather high as compared to the amount in many other waters.

These waters are suitable for all domestic purposes except that they are rather hard for washing. On many of the farms there are cisterns for catching rain water for laundry and toilet uses. Cisterns are much more common on the Martinsburg shale areas than on the limestone, probably owing to the greater permanent hardness of the well water.

The value of the ground water in this area for industrial use is greatly lessened by the presence of the relatively large amounts of scale-forming constituents. However, where it is necessary to use these waters in boilers, they can be treated successfully by softening systems or with suitable boiler compounds. The ground water, when obtainable in sufficient quantities, is valuable for use in cooling, as it has an average temperature of only about $55^{\circ} \mathrm{F}$.

Analyses of well waters near Woodstock, Va.

[Collected October 10-12, 1924. Analyzed.by H. B. Riffenburg. Parts per million]

\begin{tabular}{|c|c|c|c|c|c|c|}
\hline & 1 & 2 & 3 & 4 & 5 & 6 \\
\hline 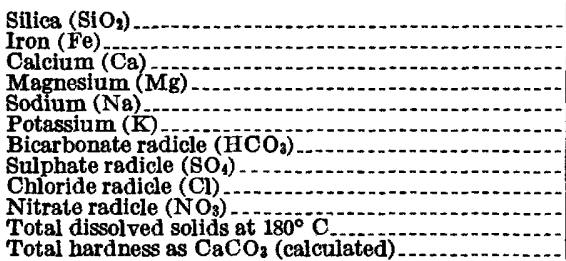 & $\begin{array}{c}18 \\
1.2 \\
121 \\
19 \\
28 \\
1.4 \\
395 \\
107 \\
7.0 \\
\text { Trace. } \\
508 \\
380\end{array}$ & $\begin{array}{c}4.8 \\
3.6 \\
50 \\
15 \\
9.4 \\
1.8 \\
215 \\
10 \\
9.0 \\
12 \\
223 \\
186\end{array}$ & \begin{tabular}{l|l}
12 \\
1.3 \\
65 \\
37 \\
8.9 \\
2.2 \\
366 \\
18 \\
5.0 \\
11 \\
339 \\
314
\end{tabular} & $\begin{array}{l}11 \\
69^{-60} \\
35 \\
19 \\
6.0 \\
361 \\
19 \\
18 \\
22 \\
397 \\
316\end{array}$ & $\begin{array}{l}9.4 \\
81 \\
34 \\
13 \\
5.2 \\
354 \\
20 \\
16 \\
36 \\
381 \\
342\end{array}$ & $\begin{array}{c}10 \\
4^{.40} \\
32 \\
40 \\
3.1 \\
359 \\
11 \\
13 \\
9.6 \\
360 \\
251\end{array}$ \\
\hline
\end{tabular}

1. Drilled well 105 feet deep; water from Martinsburg shale; owned by J. E. Boyer, Maurertown, Va. 2. Drilled well 108 feet deep; water from Stones River limestone; owned by Wm. J. Gochenour, Maurertown $\mathrm{Va}$.

3. Drilled well 1,550 feet deep; water from upper 250 feet, from Beekmantown limestone; owned by Chapin-Sacks Corporation, Woodstock, Va.

4. Drilled well 240 feet deep; water from Beekmantown limestone; owned by Chapin-Sacks Corporation, Woodstock, Va.

5. Dug well 48 feet deep; water from Stones River limestone; owned by town of Woodstock, Va.

6. Drilled well 181 feet deep; water from Beekmantown (?) limestone; owned by J. G. Gravely, 1 mile west of Woodstock, Va.

\section{POLLUTION OF THE GROUND WATER}

The large number of sink holes in this vicinity is a feature immediately noticed by even the casual visitor. A single field may contain several of them. Streams are scarce, the run-off is small; and much of the surface drainage leads into the sink holes; hence a large part of the precipitation becomes ground water. These sink holes are the starting points of the numerous solution channels that furnish the supplies to the wells and springs. That some springs and wells are closely connected with sink holes is shown by the fact that their water becomes muddy during a rainy period, in some of them within a few hours after a heavy shower. Obviously, wells 
and springs so directly connected with the surface may easily becomie polluted, especially where the sink holes are used as dumping grounds for refuse and where abandoned wells are used as cesspools.

The Chapin-Sacks Corporation had been turning its creamery waste into an open ditch, which became very foul. To get rid of this waste a sewer line about half a mile long was constructed, which ended in a sink hole in a field opposite the Standard Oil Go.'s plant. The first sewage was dumped in the sink hole in July, 1919, and within less than 48 hours afterwards milky water began to issue from the spring of Carl Gill, near the mouth of Pughs Run, about 1.5 miles away. The surrounding rocks soon turned black, the water had a foul odor, and the spring was ruined. To get rid of this objectionable water the spring was inclosed and the foul water was piped to the river. This spring is reported to have muddied up quickly during rainy periods, showing its close connection with the sink hole. A well was drilled within 100 yards of this spring to supply the property owner with water. This well is 234 feet deep and yields 10 gallons a minute. The water was encountered at 120 and 220 feet and rises within 80 feet of the surface. Although relatively close to the spring, this well apparently did not encounter the solution channels that supply the spring.

\section{CONCLUSTONS}

1. In the vicinity of Woodstock drilled wells are preferable to dug wells, because they are more sanitary and less likely to go dry.

2 . In the shale area drilled wells less than $200^{\circ}$ feet deep will generally yield supplies of hard water sufficient in quantity for farm use, but large supplies can rarely be obtained from the shale.

3. The yield of wells in the limestone area is variable and depends on the size and number of water-bearing crevices that are encountered in drilling.

4. In general it is not advisable to drill deeper than about 300 feet in either shale or limestone. If a drill hole is still dry at this depth it should be abandoned and a new location should be sought.

5. Wells in limestone are subject to pollution not only from near-by sources but also from contamination that enters the ground water through distant sink holes. On the other hand, wells in the Martinsburg shale are not likely to be contaminated except by near-by filth. The practice of dumping waste into sink holes and discharging sewage into abandoned wells or holes drilled into cavernous limestone should be discontinued. 


\title{
QUALI'Y OF WATER OF PECOS RIVER IN TEXAS
}

\author{
By W. D. Coluins and H. B. RIFFenbukg
}

\section{INTRODUCTION}

Water from Pecos River, although generally recognized as not of the highest quality, is nevertheless used for the irrigation of considerable areas in western Texas. The quality of the water varies so much from time to time and from one point to another that it seemed desirable to take advantage of the opportunity afforded by studies of discharge to make analyses of the water at different stages of the river. During the period covered by the analyses the river water below Barstow was rarely suitable for irrigation, and most of the time the water from Angeles to Barstow would ordinarily be classed as poor to fair in quality as reggards its use for irrigation.

\section{ACKNOWLEDGMENTS}

The samples analyzed for this report were collected under the direction of C. E. Ellsworth, district engineer of the United States Geological Survey. Data relating to Pecos River and irrigation in the Pecos Valley are taken largely from three manuscript reports of the Bureau of Reclamation:

Memorandum on the Pecos drainage basin in New Mexico and Texas; by C. T. Pease, October, 1923.

Report on preliminary investigations for Pecos River storage at the Red Bluff reservoir site, N. Mex.-Tex., by E. E. Teeter and Willis T. Lee, 1924.

-The Pecos River compact, report by C. T. Pease, February, 1925.

Stream-flow data for the period covered by the analyses were furnished by C. E. Ellsworth; those for earlier years are taken from published water-supply papers.

Analyses 1-5 are taken from United States Geological Survey Water-supply Paper 274; Nos. 20, 56, 100, 132, 172, and 212 were made by Miss Margaret D. Foster; the other analyses for this report were all made by H. B. Riffenburg. 


\section{PECOS RIVER BASIN}

\section{The Pecos River basin is described by Follansbee and Dean ${ }^{1}$ as follows:}

Pecos River, one of the most important tributaries of the lower Rio Grande, drains an area comprising approximately 32,000 square miles and extending from the Taos Mountains in northern New Mexico to the southern edge of the western Panhandle region in Texas. Its source is on the eastern slope of the Santa Fe Range in the extreme western corner of Mora County, at an elevation of 11,000 feet, and its course is southward nearly to Punta Pajarita, thence southeastward to the southeast corner of Guadalupe County, thence southward again to Carlsbad, and then once more southeastward to its junction with the Rio Grande at Moorhead, Valverde County, Tex. Except for some of the upper tributaries the branches of the Pecos are intermittent, though at times they carry large floods. The chief tributaries are Rio de la Vaca, Rio Tecolote, Gallinas River, Canyon Blanco, Pentado [Pintada] Canyon, Alamo Gordo Creek, Salt Creek, Felix, Penasco,' Seven -Rivers, Delaware, Toyah, and Comanche Creeks. Below Fort Sumner there are no important tributaries from the east, as the boundary of effective surface drainage of the Pecos parallels the river at a distance of 50 miles. The few streams in this section rise in the edge of the high plains but lose their waters in the porous soil within a few miles. Many of the streams in the western portion of the basin sink before reaching the Pecos, and it is probable that the streams actually reaching the Pecos lose much water by seepage after leaving the mountains.

The upper Pecos flows through narrow valleys and deeply cut gorges nearly down to Fort Sumner, and in this portion of the basin the elevations range from 4,500 feet to 11,000 feet above sea level. Below Fort Sumner the canyonlike walls of the Pecos are replaced by low rolling hills and at Roswell the gradation from the flood plains to the rolling prairie of the lower part of the drainage basin is imperceptible. Arroyos and gulches are rare, and canyons are practically unknown. Elevations in the lower section of the basin range. from 1,000 feet at the mouth to 4,500 feet near the foothills.

The distribution of precipitation throughout the Pecos basin is somewhat peculiar. Near the source of the river there is a very small area in which the mean annual precipitation is 20 inches or more, but $* * *$ the rate: drops to 15 inches at Anton Chico and less than '13 inches at Santa Rosa. From this point to Carlsbad there is a narrow strip coinciding practically with the immediate valley of the Pecos where the precipitation is between 15 . and 13 inches, and east and west of this narrow area it increases to 15 inches or more. Below Carlsbad the increase is fairly uniform to 19 inches at the mouth. Except on the mountains in the upper section of the basin, where much of it occurs as snow, by far the greater part of the precipitation is the rain of the summer storms.

In reports to the Bureau of Reclamation and in the proposed Pecos River compact the river basin is divided into three parts, defined in the compact as follows:

The term "upper basin" means that part of the Pecos River basin abov? and north from a due east and west line crossing the Pecos River on th? boundary between Tps. 6 and 7 N., R. 22 E. New Mexico principal meridian.

\footnotetext{
1 Follansbee, Robert, and Dean, H. J., Water resources of the Rio Grande basin, 1888 .. 1913 : U. S. Geol. Survey Water-Supply Paper 358, pp. 452-453, 1915.
} 
The term "middle basin" mean that part of the Pecos River basin below and south from a prolongation of the boundary line between Tps. 6 and $7 \mathrm{~N}$., R. 22 E. New Mexico principal meridian, to the Texas-New Mexico State line.

The term "lower basin" means that part of the Pecos River basin within the State of Texas lying above and northwest of the Kansas City, Mexico \& Orient Railroad.

The analyses made for this report relate only to the lower basin, but the composition of the water in the river at the sampling points is affected by regulation of the discharge and use of the water in the upper and middle basins.

\section{CONSTITUENTS OF NATURAL WATERS}

The mineral matter dissolved in natural waters is derived from the rocks and soils. The main constituents of most fresh waters are the bicarbonates of calcium and magnesium. Such waters contain minor quantities of sulphate, chloride, and sodium. Small quantities of potassium and nitrate are generally present, but the quantities of these substances are so small that in discussions of analyses potassium is usually included with the sodium, and sometimes the nitrate is included with the chloride.

Waters that pass over or through beds of gypsum dissolve comparatively large quantities of calcium and sulphate, the constituents of gypsum. When normal water evaporates from the soil the carbonates of calcium and magnesium become insoluble; calcium sulphate is slightly soluble; but sodium chloride and sodium sulphate are easily soluble and will be taken up at once by water which may chance to flow where the concentration by evaporation has taken place. Thus the waters flowing through regions where rainfall is slight and evaporation is rapid will carry much larger proportions of sodium chloride and sodium sulphate than the waters of humid, cool regions.

\section{USES OF WATER}

\section{DOMESTIC AND INDUSTRIAT}

The water of Pecos River at the points in Texas represented by analyses in this report contains so much dissolved mineral matter that it would generally be classed as unfit for domestic or industrial use.

\section{IRRIGATION}

A memorandum by C. T. Pease on the Pecos drainage basin in New Mexico and Texas, prepared in October, 1923, gives on page 51 a tabulation of areas irrigated from Pecos River in Texas, which shows a total of 33,577 acres. The figures are stated to be only approximate, but it is evident that large use in irrigation is now 
made or is planned for the water of Pecos River. The water generally carries more dissolved mineral matter than is considered desirable in irrigation, but this condition is offset by the porous character of the soil, which favors prompt drainage after the use of large volumes of water, and by the high proportion of calcium in the water, which helps the physical condition of the soil.

In a paper on the movement of water in irrigated soils Scofield ${ }^{2}$ notes chemical reactions between soils and waters as determining factors in the movement of the waters. These reactions are also referred to by Harris ${ }^{3}$ in his discussion of soil alkali. Both of the authors named emphasize the importance of drainage as a primary requisite for successful irrigation, regardless of the quality of the water used. Natural drainage may be sufficient to prevent the accumulation of harmful quantities of alkali, but many irrigated areas require artificial drainage. Scofield and Harris give many references to articles dealing with specific instances of irrigation practice and with laboratory experiments.

It is not possible to set any close limits for permissible concentration of salts in water to be used for irrigation. Reports of experiences on irrigation projects referred to by Scofield and by Harris suggest that 1,000 parts per million of dissolved solids is near the limit for satisfactory irrigation water and that water with 3,000 parts per million of dissolved solids requires the greatest care in its use to prevent accumulation of alkali in the soil. Scofield ${ }^{4}$ states:

While many crop plants may obtain water from a soil solution which contains more than 1 per cent of dissolved mineral matter, it would appear to be advisable generally to keep the solution below that degree of concentration. In order to do this it follows that in applying irrigation water it should be the aim to use enough so that the proportion lost by percolation is large enough to offset the concentration due to evaporation and transpiration. Thus if the irrigation water contains 1,000 parts per million of sait, enough should be used so that 10 per cent of the quantity applied may percolate below the root zone.

On this principle a water with 3,000 parts per million of dissolved solids should be used in sufficient quantity to permit 30 per cent to percolate below the root zone, and with water containing 5,000 parts per million 50 per cent should be drained away.

The effect of the proportions of the different basic constituents in irrigation waters has been noted by many writers and has been emphasized by Scofield in his discussion of the permeability of soils. From field studies and experiments and from the results reported by other workers he concludes: ${ }^{5}$

\footnotetext{
${ }^{2}$ Scofield, C. S., Jour. Agr. Research, vol. 27, pp. 617-694, 1924.

${ }^{8}$ Harris, F. S., Soil alkali, its origin, nature, and treatment., New York, John Wiley \& Sons, 1920.

Op. cit., pp. 681-682.

5 Op. cit., p. 692.
} 
The injurious effects that have been ascribed to sodium carbonate, or "black alkali," in irrigated soils appear to be due to the sodium rather than to the carbonate, and sodium in solution, even when associated with the stronger acids, combines with the soil and ultimately causes deflocculation and impermeability.

The readjustment of the relative proportions of sodium and other bases in an impermeable soil, to the end of improving the physical condition, depends upon replacing the sodium with another base, such as calcium or aluminum, which when combined with the soil brings about a flocculated and permeable condition.

Gypsum has long been recognized as beneficial in the treatment of soils injured or likely to be injured by alkali. Its application has not been so generally recognized as serving to prevent the replacement of calcium in the soil by sodium in the applied water that occurs when the ratio of calcium to sodium in the soil solution drops too low. Obviously the prevention of this reaction in the soil is much easier than its reversal, because before the replacement the soil is permeable, whereas after it the soil is relatively impermeable and therefore not so easily acted on by solutions that will give up calcium for the sodium. There is so much gypsum in the soil throughout the Pecos River basin that most of the ground and surface waters carry practically all they can hold in solution with the other salts they contain. Thus they generally have little tendency to make the soils impermeable through replacement of calcium by sodium.

\section{COLLECTION OF SAMPLES}

The samples analyzed for this report were nearly all collected from Pecos River at gaging stations maintained by the United States Geological Survey and the Board of Water Engineers of Texas at Angeles, Porterville, Barstow, Grandfalls, Buenavista, and Sheffield. The collections were made by the engineers who were making measurements of discharge of the river at the gaging stations. A few samples were collected from tributaries, from drainage ditches, and from Pecos River in New Mexico.

On account of the high mineral content of the waters it was possible to make a satisfactory examination of a small sample. Two 4-ounce bottles of water were used for most of the samples. When a more complete analysis was to be made, four or eight bottles were used for each sample.

\section{METHODS OF ANALYSIS}

The analyses of some samples included determinations of total solids, silica, iron, calcium, magnesium, sodium and potassium, bicarbonate, sulphate, chloride, and nitrate. These analyses were made by methods practically the same as are described in "Standard methods of water analysis," published by the American Public Health 
Association. In some of the otherwise complete analyses the potassium was not separated and the total quantity of mixed chlorides was calculated to sodium; in others sodium and potassium were not determined, but sodium was reported in sufficient quantity to balance the analysis. Such results are indicated as "calculated" in the table of analyses.

The quantities of silica, iron, and nitrate found made up so small a proportion of the total quantity of salts that their determination was omitted from most of the analyses. In the partial analyses a small portion of the water, usually 50 cubic centimeters, was evaporated for the determination of total solids. The residue was heated to approximately constant weight at $180^{\circ} \mathrm{C}$. A second portion of 50 cubic centimeters or less was diluted and used for the determination of sulphate by the usual gravimetric method. Another portion of 50 cubic centimeters or less was diluted and used for the determination of calcium and magnesium without evaporation. Bicarbonate and chloride were determined by titration.

Most of the samples contained so much calcium and sulphate that. the weight of the residue after long heating at $180^{\circ} \mathrm{C}$. was somewhat greater than the sum of the constituents as determined by analysis. In general this excess was 1 to 5 per cent of the sum.

The analyses are reported as radicles in parts per million. The errors involved in reporting as parts per million the results obtained with measured portions of the sample are well within the probable inevitable errors of analysis.

\section{QUALITY OF WATER}

\section{UPPER BASIN}

No samples of water from the upper basin of Pecos River were collected for this report. Published analyses ${ }^{\circ}$ of samples from Gallinas River near Las Vegas, N. Mex., and from Pecos River at Santa Rosa, N. Mex., have been used.

Gallinas River at the sampling point drains an area of 89 square miles. The mean weekly discharge from March 19, 1905, to March 31,1906 , was from 2 to 327 second-feet. The mean discharge for the years 1905 to 1908 was 35 second-feet. The average of analyses of monthly composite samples is given in Table 1 (No. 1). The total dissolved solids in weekly composite samples ranged from 120 to 386 parts per million. This water is rather better than the average hard water found over the greater part of the United States. On the basis of its dissolved mineral constituents it would be classed as good for all ordinary uses. It is probable that other headwaters of Pecos River are of the same quality.

\footnotetext{
' U. S. Geol. Survey Water-Supply Paper 274, pp. 139, 140.
} 
TẢBLE 1.-Analyses of water from Pecos River and tributaries in New Mexico, 1905-1907

[Averages of analyses of monthly composites of daily samples in parts per million (milligrams per liter). From U. S. Geological Survey Water-Supply Paper 274, pp. 139-140]

\begin{tabular}{|c|c|c|c|c|c|c|c|c|c|}
\hline No. & Source & 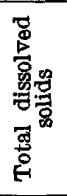 & 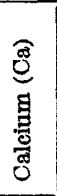 & 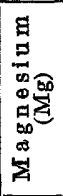 & 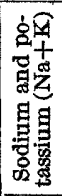 & 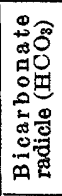 & 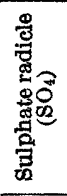 & 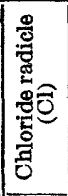 & 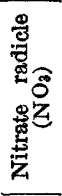 \\
\hline $\begin{array}{l}1 \\
2 \\
3 \\
4 \\
5 \\
5\end{array}$ & 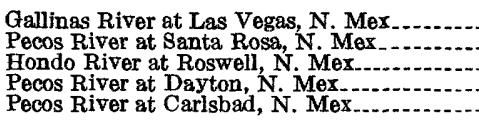 & $\begin{array}{r}204 \\
1,220 \\
762 \\
3,110 \\
2,720\end{array}$ & $\begin{array}{r}41 \\
270 \\
150 \\
440 \\
380\end{array}$ & $\begin{array}{c}5.9 \\
37 \\
30 \\
100 \\
95\end{array}$ & $\begin{array}{r}29 \\
45 \\
39 \\
400 \\
300\end{array}$ & $\begin{array}{l}150 \\
180 \\
150 \\
170 \\
160\end{array}$ & $\begin{array}{r}24 \\
620 \\
350 \\
1,200 \\
1,200\end{array}$ & $\begin{array}{r}22 \\
43 \\
39 \\
620 \\
460\end{array}$ & $\begin{array}{l}0.12 \\
.28 \\
.06 \\
.08\end{array}$ \\
\hline
\end{tabular}

Pecos River at Santa Rosa, N. Mex., drains an area of 2,780 square miles. The mean monthly discharge was 181 second-feet in 1906 and 32 second-feet in the year ending September 30, 1913. The daily discharge ranged from 5 to 2,930 second-feet between 1910 and 1913.

The average of analyses of monthly composites of samples taken daily from October 6, 1905, to December 29, 1906, is given in Table 1 (No. 2). The total dissolved solids in weekly composite samples ranged from 174 to 2,320 parts per million. Most of the time this water would be classed as suitable for irrigation but not wholly satisfactory for domestic use. The outstanding difference between the water of Gallinas River at Las Vegas and Pecos River at Santa Rosa is in the increased content of calcium and sulphate-the constituents of gypsum. The increase in these two constituents is 825 parts per million out of the total of 1,016 parts per million increase in total solids. The water changes from a typical calcium bicarbonate water to a calcium sulphate water.

\section{MIDDIE BASIN}

An attempt was made in September, 1924, to collect a series of samples from Pecos River and its tributaries in the middle and lower basins, from Carlsbad, N. Mex., to Sheffield, Tex. The series was not completed because rains on the drainage basin changed the character of the water so that the later samples were not comparable with those taken earlier. Analyses of samples collected at this time from points other than the regular gaging stations in Texas are given in Table 2 (Nos. 7-11). In January, 1925, a series of samples was completed without rain, so that the analyses are comparable; these analyses are given in Table 2 (Nos. 12-238). Six of these samples (Nos. 55, 99, 131, 171, 211, 238) were the final samples at the regular stations in Texas, and their analyses are given also in Table 3 under the same numbers. 


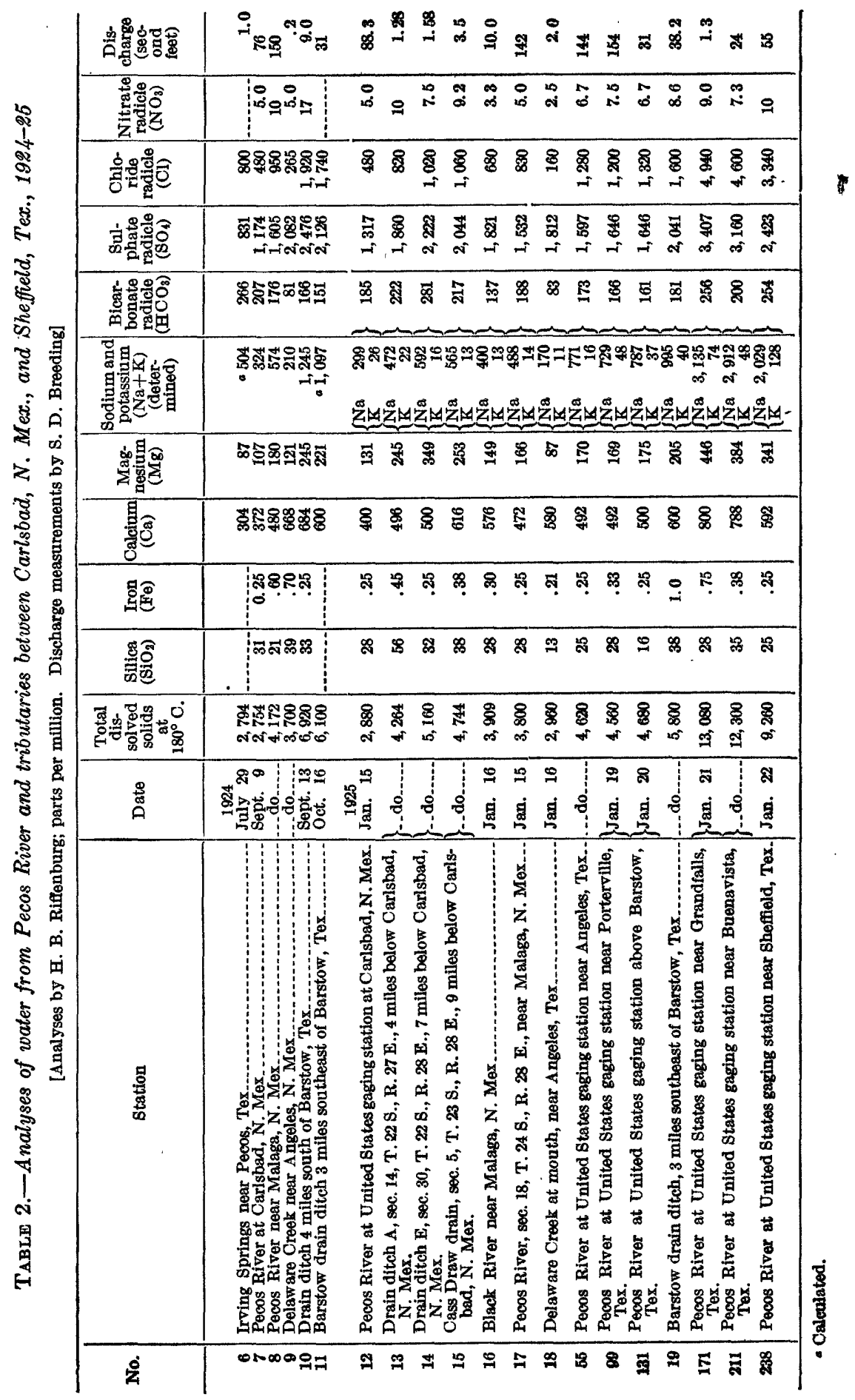


In 1905-6 samples were collected from Hondo River at Roswell, N. Mex., and from Pecos River at Dayton and Carlsbad, N. Mex. Averages of analyses of samples from these points are given in Table 1 (Nos. 3-5).

Hondo River near Roswell has a drainage area of 1,040 square miles. In 1906 the river was dry for about one-third of the time and flowed 200 second-feet for one day in January. The average discharge was about 13 second-feet. The quantity of dissolved : solids in weekly composite samples from March 26 to August 4, 1905, ranged from 546 to 986 parts per million. The predominating mineral constituents are calcium and sulphate, as in Pecos River at Santa Rosa.

Pecos River near Dayton has a drainage area of about 22,000 square miles. The yearly average discharge from 1905-6 to 1912-13

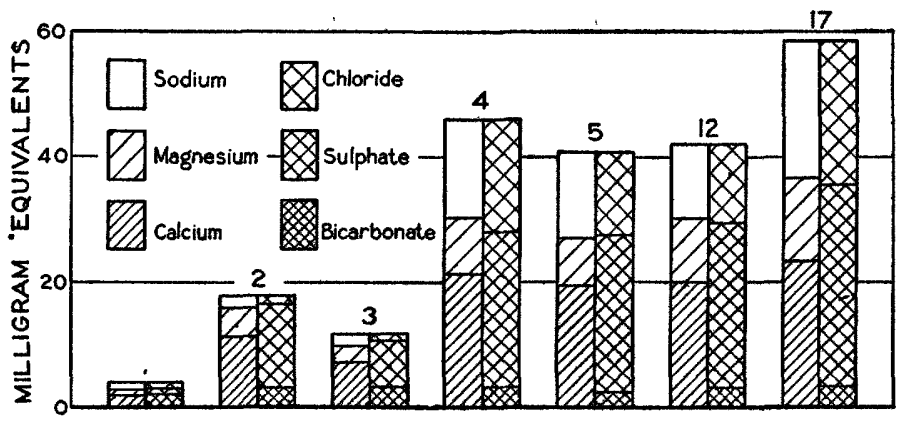

Fradn 12.-Composition of water from Pecos River and tributaries in New Mexico. Numbers refer to analyses in Tables 1 and 2

ranged from 276 to 416 second-feet and the daily discharge from 32 to 50,000 second-feet. Samples were collected for analysis in 1905-6 below the Rio Penasco near Dayton.

The average of analyses of monthly composites of daily samples from October 6, 1905, to December 29, 1906, is given in Table 1 (No. 4) and is shown graphically in Figure 12. The quantity of total dissolved solids in weekly composites ranged from 748 to 5,120 parts per million. As compared with the river water at Santa Rosa there is an increase in calcium and sulphate and a much greater increase in sodium and chloride.

Samples were collected from Pecos River at Carlsbad, N. Mex., from May 22, 1905, to April 30, 1907. The average of analyses of monthly composites of daily samples is given in Table 1 (No. 5) and is shown graphically in Figure 12. The quantity of total dissolved solids in weekly composites ranged from 1,240 to 3,810 parts per million.

$95221^{\circ}-28-6$ 
Other samples were collected from Pecos River at Carlsbad, N. Mex., September 9, 1924, and January 15, 1925. Analyses of these samples are given in Table 2 (Nos. 7 and 12). Analysis 12 is shown graphically in Figure 12. These analyses are not very different from the average of the analyses for 1905-1907.

Samples were collected January 15, 1925, from drain ditch A, 4 miles below Carlsbad; drain ditch E, 7 miles below Carlsbad; and Cass Draw drain, 9 miles below Carlsbad. Analyses of these samples are given in Table 2 (Nos. 13, 14, 15). These waters are somewhat like the river water at Carlsbad as shown by analysis 12, Table 2 , but they contain nearly twice as much dissolved mineral matter. The increase is chiefly in the more easily soluble constituents-sulphate and chloride of sodium and magnesium. The proportional increase in calcium is much less.

The analysis of a sample collected January 16, 1925, from Black River near Malaga, N. Mex., is given in Table 2 (No. 16). This sample was better than the samples from the drain ditches but poorer than the river water at Carlsbad. Its general characteristics are the same as those of the drain waters.

Samples were collected from Pecos River near Malaga, N. Mex., September 9, 1924, and January 15, 1925. Analyses of these samples are given in Table 2 (Nos. 8 and 17). Analysis 17 is shown graphically in Figure 12. The sample collected in 1925 was similar to the sample from Black River, but it contained more sodium and chloride and less calcium and sulphate. The sample collected in 1924 differed from that collected in 1925 chiefly in concentration; the proportions of the different salts were about the same.

The changes in composition of the water of Pecos River and its tributaries are shown graphically in Figure 12. The heights of the different sections are proportional to the number of milligram equivalents of the different constituents in 1 kilogram of water. The number of milligram equivalents is calculated from the parts per million by dividing by the combining weights of the different radicles as follows: Calcium 20, magnesium 12.16, sodium 23, bicarbonate 61 , sulphate 48 , chloride 35.45 .

The diagrams make plain the almost constant quantity of bicarbonate from the headwaters to the Texas line, and the preponderance of calcium, magnesium, and sulphate in all the analyses except No. 1. Nos. 4, 5, 12, and 17 show the results of the solution from the soil of sodium chloride and sulphates of calcium and magnesium beyond the quantities in the water of Pecos River at Santa Rosa (No. 2) and Hondo River at Roswell (No. 3). 


\section{LOWER BASIN}

Practically all the work done for this report relates to the lower basin of Pecos River, and nearly all the samples analyzed were collected at six stations where gages were maintained and frequent discharge measurements made. Analyses for these stations are given in Table 3, with discharge data corresponding to the analyses. The series of samples mentioned in the section on the middle basin includes several from the lower basin. Six of these (Nos. 55, 99, 131, $171,211,238)$ are given in Table 2 and also at their proper places in Table 3.

Samples were collected September 9, 1924, and January 16, 1925, from Delaware Creek near Angeles, Tex. Analyses are given in Table 2 (Nos. 9 and 18). The two analyses differ considerably in their quantities of dissolved solids, but the proportions of the constituents are about the same. The water is decidedly better than the river water at Malaga, $\mathrm{N}_{\xi}$ Mex., or at Angeles, as shown by analysis 55 in Table 2 and analysi 51 in Table 3, which is comparable with analysis 9 in Table 2. The water of Delaware Creek is not only lower in total solids than the Pecos River water, but it has a much higher ratio of calcium to sodium, which is possibly of more value in irrigation than the smaller total quantity of dissolved material.

Analyses of samples from Pecos River at Angeles, Tex., September 9, 1924, and January 16, 1925, are given in Table 3 (Nos. 51 and 55) and Table 2 (No. 55). Analysis 55 is shown graphically in Figure 13. Analyses of samples collected January 19, 1925, from Pecos River at Porterville, Tex., and January 20, 1925, from the river above Barstow, Tex., ane given in Table 2 (Nos. 99 and 131) and are shown graphically in Figure 13 . These analyses show comparatively little change in c $\phi$ mposition of the river water from Angeles to Barstow. Analysis in Table 2 represents a sample collected July 7, 1924, from Irving Springs, near Pecos, Tex. The composition of the water is similar to that of Pecos River at Carlsbad, N. Mex., but the ratio of calcium to sodium is lower. : The water is much better than samples collected from the river at Angeles and at Porterville in July, 1924.

Analyses 10, 11, and 19 in Table 2 represent samples collected from the Barstow drain ditch September 13 and October 16, 1924, and January 20, 1925. These samples all contained more dissolved mineral matter than the river water at Barstow at corresponding times. The increase is mainly in sodium, sulphate, and chloride, although some calcium has also been taken up from the soil.

Analyses of samples from Pecos River collected January 21, 1925, near Grandfalls, Buenavista, and Sheffield, Tex., are given in Tables 
2 and 3 (Nos. 171, 211, 238). These analyses are shown graphically in Figure 13. The waters are much more concentrated than any of the samples from stations farther upstream. The increase in dissolved solids is mainly in the sodium, sulphate, and chloride.

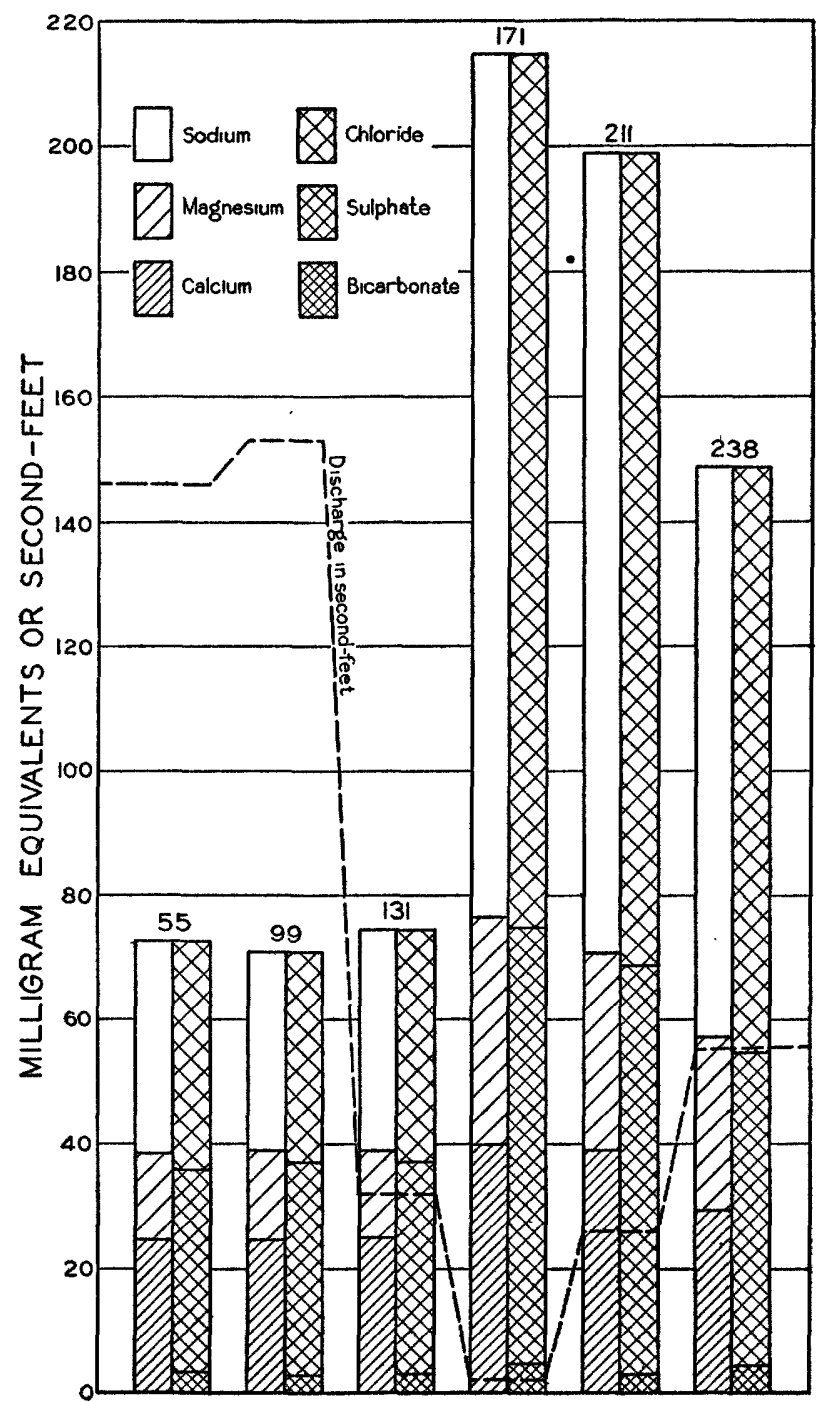

Fiquan 13.-Composition of water from Pecos River in Texas. Numbers refer to analyses in Tables 2 and 3

\section{ANGELES}

From March 23, 1922, to January 16, 1925, 36 samples of water were collected from Pecos River at the gaging station near Angeles, Tex. Analyses of these samples are given in Table 3 (Nos. 20-55). 
These analyses are shown graphically in Figure 14, and No. 55 is shown also in Figure 13.

The total dissolved material for these analyses is shown along with the discharge of the river in Plate 9. On account of the great difficulty of making satisfactory determinations of total dissolved solids in waters of such concentration the sum of the determined constituents has been plotted rather than the determined solids.

The results given in the table and shown in Figure 14 make plain the considerable range in. concentration of the dissolved solids. The most concentrated sample contained somewhat less than twice the quantity of dissolved solids found in the least concentrated sample. Figure 2 shows that the changes in composition of the water are almost entirely in the amounts of sodium, sulphate, and chloride. Plate 9 shows a general tendency toward greater concentration of dissolved material with lower discharges, but the changes are not very marked.

\section{PORTERVILLE}

From March 24, 1922, to January 19, 1925, 44 samples of water were collected from Pecos River at the gaging station near Porterville, Tex. Analyses of these samples are given in Table 3 (Nos. 56-99). No. 99 is shown graphically in Figure 13. The table shows that the samples collected at Porterville covered a wider range of concentration than those for Angeles. Both lower and higher concentrations were found at Porterville, and the most concentrated sample contained over three times the quantity of total solids found at Angeles. All the changes in composition were, however, almost wholly in the content of sodium, sulphate, and chloride.

\section{BARSTOW}

From March 25, 1922, to January 20, 1925, 32 samples of water were collected from Pecos

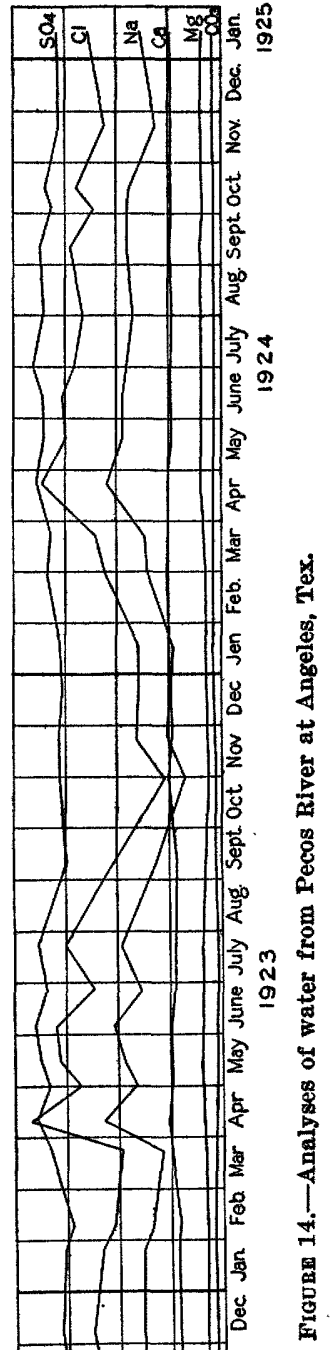


River at the gaging station above Barstow, Tex. Analyses of these samples are given in Table 3 (Nos. 100-131). No. 131 is shown graphically in Figure 13.

The analyses are similar to those for Angeles and Porterville, but the range in composition is more like that at Porterville. Both low and high limits of concentration are around 200 parts per million less than at Porterville; the highest quantity of total solids is more than three times the lowest.

\section{GRANDFALTS}

From April 4, 1922, to January 21, 1925, 40 samples of water were collected from Pecos River at the gaging station near Grandfalls, Tex. Analyses of these samples are given in Table 3 (Nos. 132-171) and are plotted in Figure 15. Analysis 171 is shown graphically in Figure 13. The sums of the determined constituents are shown with daily discharges in Plate 9.

The analyses show that the character of the water changes greatly between Barstow and Grandfalls. Discharge measurements indicate that nearly the whole flow of the river is diverted at Barstow. The small flow at Grandfalls must consist largely of return water from irrigation projects. This water naturally brings in large quantities of soluble salts from the soil, where they have been concentrated by evaporation of the irrigation water. Most of the time the concentration of dissolved solids at Grandfalls is about double the quantity at Barstow. The range in the samples examined was from about one and one-half times the minimum at Barstow to over two and onehalf times the maximum. The maximum at Grandfalls was over six times the minimum.

Figure 15 and Table 3 show that the variation in concentration at Grandfalls was almost entirely in the sodium, sulphate, and chloride, as at the other stations. The bicarbonate is the most constant constituent; its quantity is practically the same throughout the river in Texas. The calcium and magnesium vary slightly in concentration with the sodium, but they are fairly uniform all the time throughout the length of the river.

\section{BUENAVISTA}

From April 5, 1922, to January 21, 1925, 40 samples of water were collected from Pecos River at the gaging station near Buenavista, Tex. Analyses of these samples are given in Table 3 (Nos. 172-211). Analysis 211 is shown graphically in Figure 13. The analyses for Buenavista show the same characteristics as those for Grandfalls. The range in concentration of dissolved solids is from about the same 



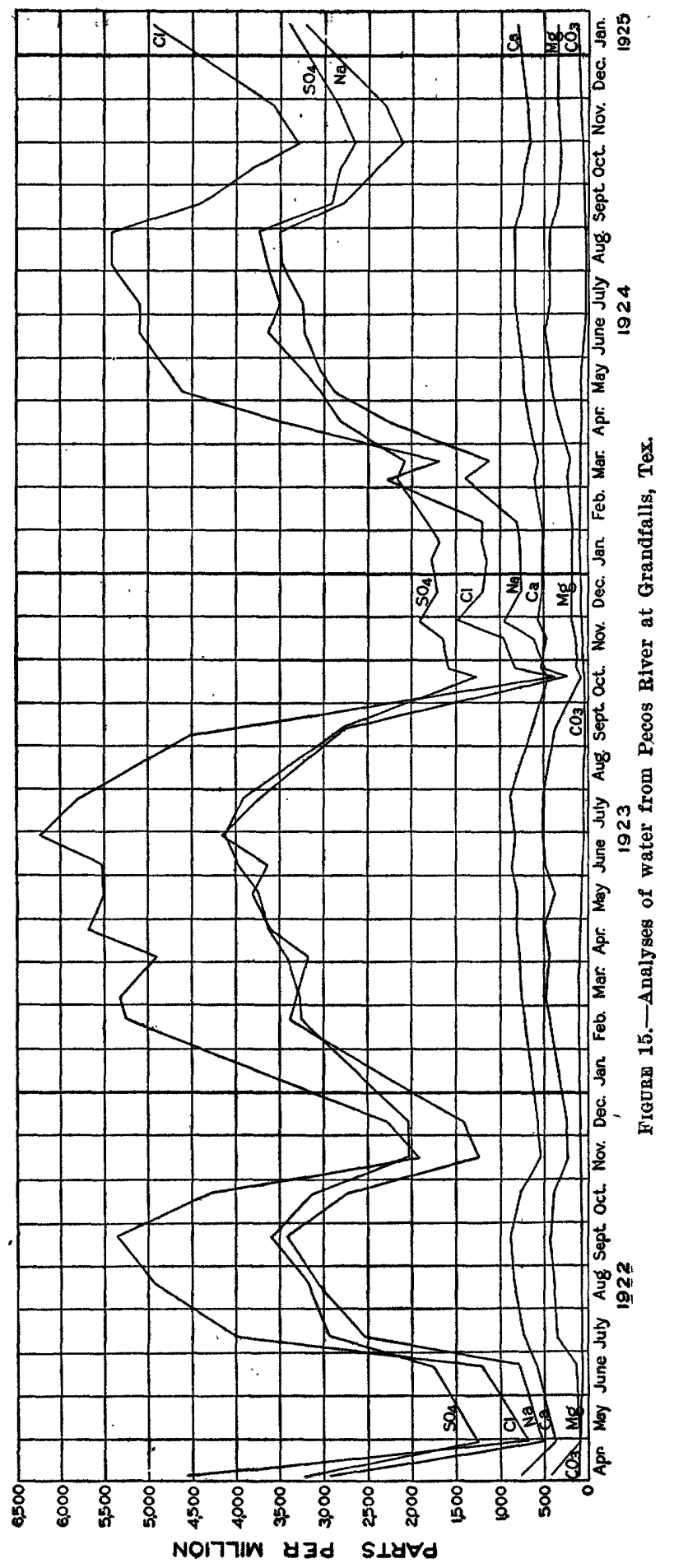


minimum to a maximum about 2,600 parts less than the maximum for Grandfalls. The discharge is usually greater at Buenavista. The water reaching the river between Grandfalls and Buenavista must be slightly better than the river water at Grandfalls but still highly concentrated and carrying much larger quantities of sodium salts than of calcium and magnesium salts.

\section{SHEFFIELD}

From April 6, 1922, to January 22, 1925, 27 samples of water were collected from Pecos River at the gaging station near Sheffield, Tex. Analyses of these samples are given in Table 3 (Nos. 212-238). No. 238 is shown graphically in Figure 13. The concentration of salts in the water is generally less than at Buenavista, but the character of the water is essentially the same as at Buenavista and Grandfalls. The range in quantity of dissolved solids is from a minimum practically the same as at the two stations above to a maximum 2,300 parts per million less than at Buenavista and 4,900 parts per million less than the maximum at Grandfalls. The maximum at Sheffield is about four and one-half times the minimum. The discharge at Sheffield is usually greater than at Buenavista but still considerably lower than at Barstow. It is evident that the water reaching the river between Buenavista and Sheffield is less concentrated than the river water at Buenavista, but that it nevertheless carries large quantities of sodium, sulphate, and chloride.

\section{SUMMARY}

The extreme headwaters of Pecos River in New Mexico are shown by older analyses to be originally normal calcium carbonate waters. Early in the course of the river it receives large quantities of calcium and sulphate through the solution of gypsum from the soil. Sodium and chloride (common salt) appear in increasing quantities to the Texas line, but the alkaline earth (calcium and magnesium) salts are appreciably in excess over the alkali (sodium) salts.

In Texas the river water carries about equal quantities of alkali (sodium) salts and alkaline earth (calcium and magnesium) salts, as far as Barstow. From Grandfalls down the quantity of alkali salts is generally double the quantity of alkaline earth salts. The total quantity of dissolved solids from Grandfalls down is usually two or three times the quantity carried above Barstow, which is in turn from one and one-half to two times the quantity at Carlsbad, N. Mex.

In times of high water the quantity of dissolved solids at all points in Texas drops to about the average quantity in the water at Carlsbad, N. Mex. 
Tabux 3.-Anatuses: of water from Pecós River at gaging stations in Texas, 1922-1925

[Analyses by H. B. Riffenburg, except Nos. 20, $56,100,132,172$, and 212, by Margaret D. Foster; parts per million. Samples collected at United States gaging stations by engineers making discharge measurements]

Angeles

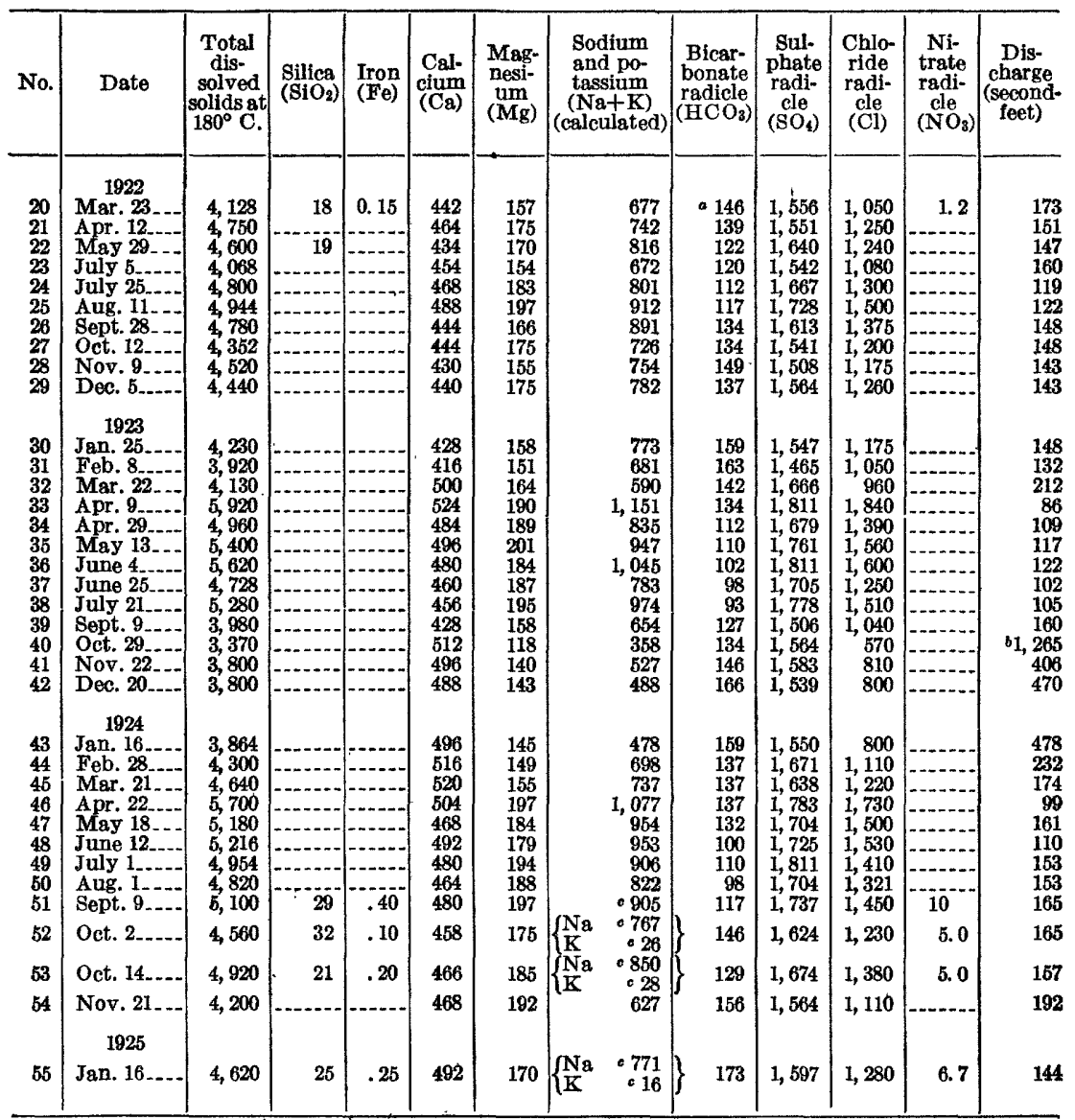

a Includes equivalent of a small amount of carbonate $\left(\mathrm{CO}_{8}\right)$.

b Flood of several days.

- Determined. 
TABLE 3.-Analyses of water from Pecos River at gaging stations in Texas, 1928-1925-Continued

Porterville

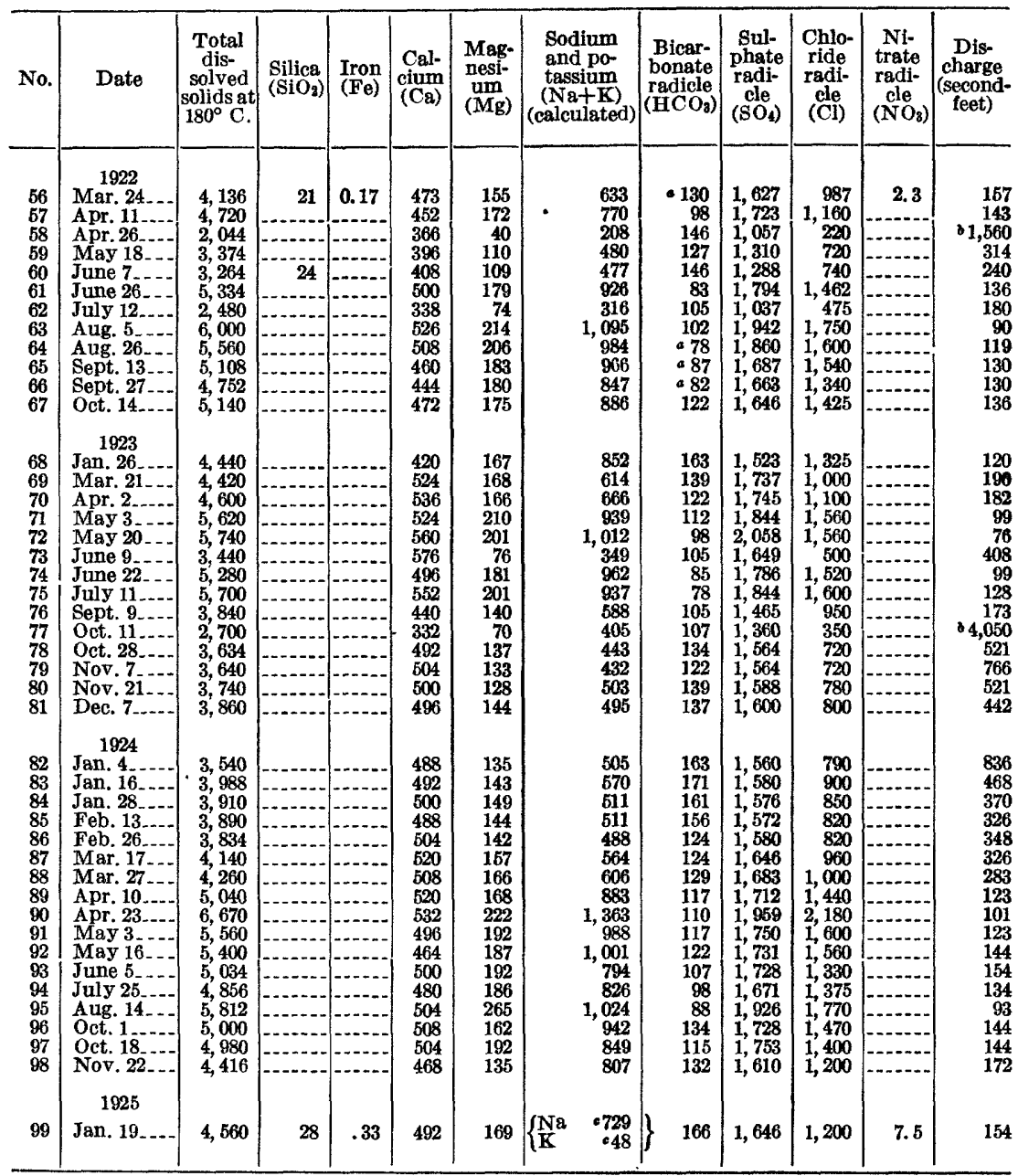

a Includes equivalent of a small amount of carbonate $\left(\mathrm{CO}_{3}\right)$.

b Flood of several days.

- Determined. 
Tabrw 3.-Analyses of vater from Pecos River at gaging stations in Tesas, 1922-1925-Continued

Barstow

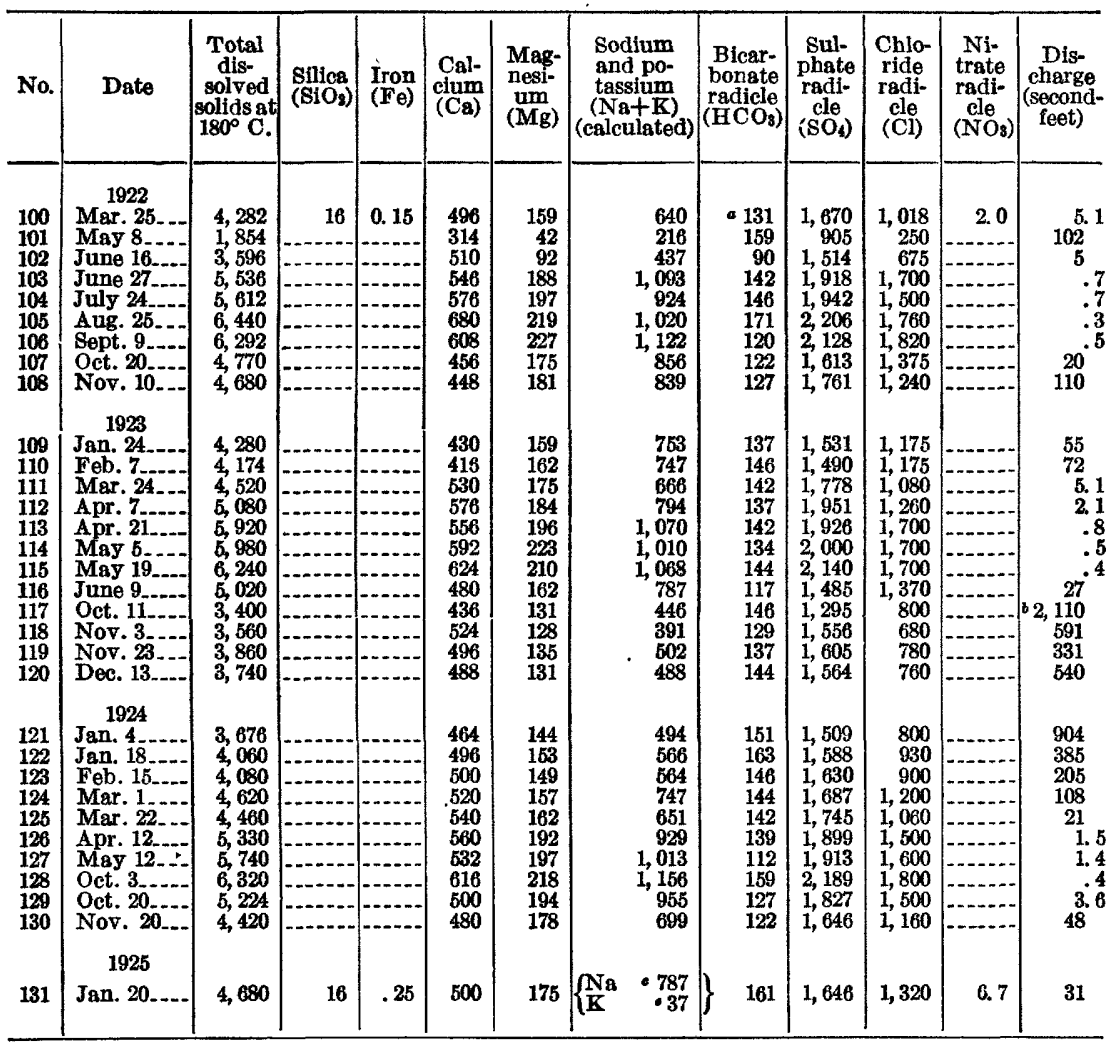

- Includes equivalent of small amount of carbonate (COs).

- Flood of several days.

- Detarmined. 
TABLE 3.-Analyses of water from Pecos River at gaging stations in Tewas, 1922-1925-Continued

Grandfalls

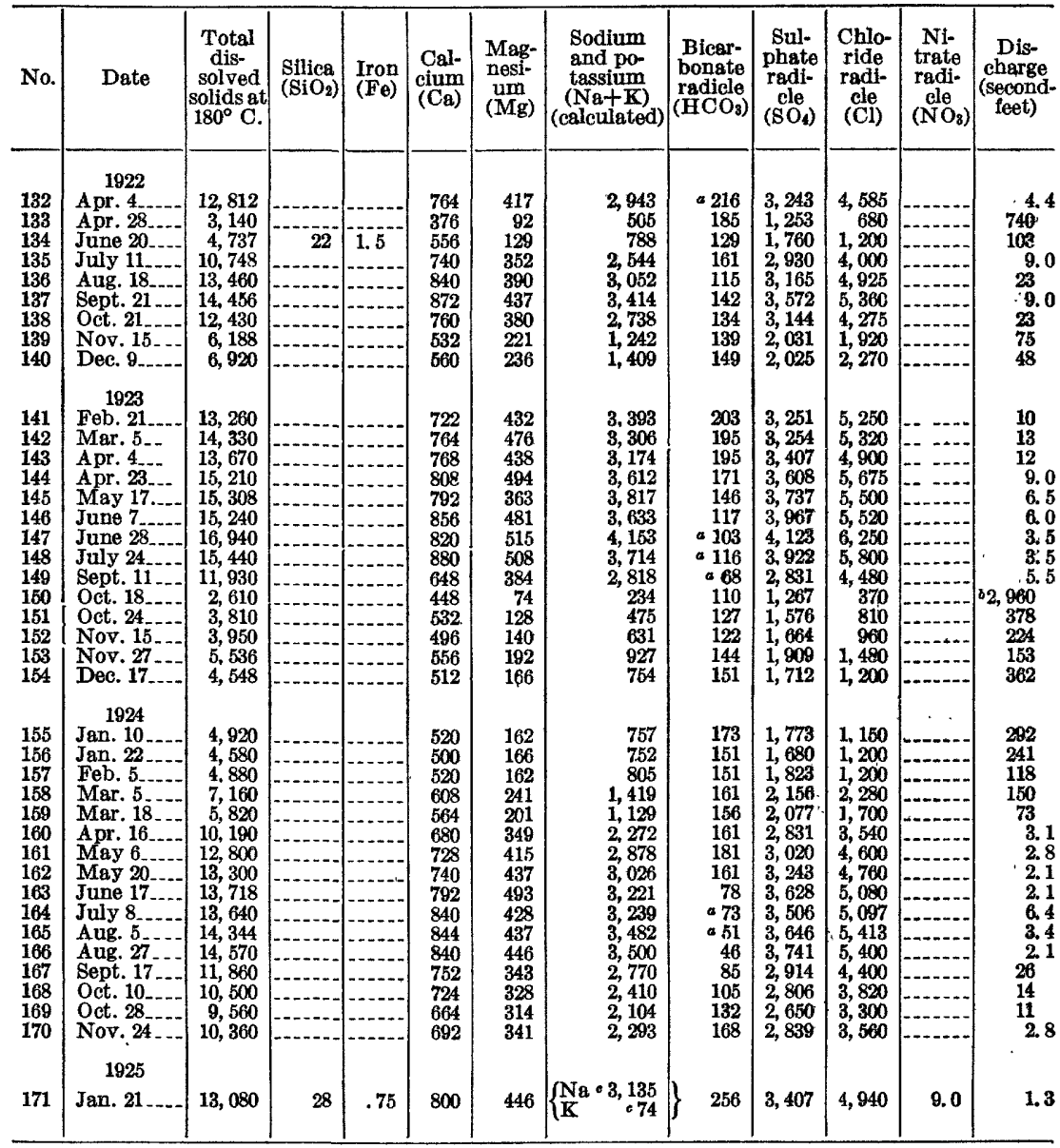

a Includes equivalent of small amount of carbonate $\left(\mathrm{CO}_{3}\right)$.

b Flood of several days.

- Determined. 
QUATITY OF WATER OF PECOS RIVER IN TEXas

TaBLw 3.-Analyses of water from Pecos River at gaging stations in Tewas, 19\%2-1925-Continued.

\section{Buenavista}

\begin{tabular}{|c|c|c|c|c|c|c|c|c|c|c|c|c|}
\hline No. & Date & $\begin{array}{c}\text { Total } \\
\text { dis- } \\
\text { solved } \\
\text { solids at } \\
\text { 180 C. }\end{array}$ & $\begin{array}{l}\text { Silica } \\
\left(\mathrm{SiO}_{2}\right)\end{array}$ & $\begin{array}{l}\text { Iron } \\
(\mathrm{Fe})\end{array}$ & $\begin{array}{l}\text { Cal- } \\
\text { cium } \\
\text { (Ca) }\end{array}$ & $\begin{array}{l}\text { Mag. } \\
\text { nesi- } \\
\text { um } \\
(\mathrm{Mg})\end{array}$ & $\begin{array}{l}\text { Sodium } \\
\text { and po- } \\
\text { tassium } \\
\text { (Na+-K) } \\
\text { (calculated) }\end{array}$ & $\begin{array}{l}\text { Bicar- } \\
\text { bonate } \\
\text { radicle } \\
\left.\text { ( } \mathrm{HCO}_{8}\right)\end{array}$ & $\begin{array}{l}\text { Sul- } \\
\text { phate } \\
\text { radi- } \\
\text { clo } \\
\left(\mathrm{BO}_{4}\right)\end{array}$ & $\begin{array}{l}\text { Chlo- } \\
\text { ride } \\
\text { radi- } \\
\text { cle } \\
\text { (Cl) }\end{array}$ & $\begin{array}{l}\mathrm{Ni-} \\
\text { trate } \\
\text { radi- } \\
\text { cle } \\
\left(\mathrm{NO}_{3}\right)\end{array}$ & $\begin{array}{l}\text { Dis- } \\
\text { charge } \\
\text { (second- } \\
\text { feet) }\end{array}$ \\
\hline $\begin{array}{l}172 \\
173 \\
174 \\
175 \\
176 \\
177 \\
178 \\
179\end{array}$ & $\begin{array}{l}1922 \\
\text { Apr. } 5 \\
\text { Apr. 28} \\
\text { June 19. } \\
\text { July 10. } \\
\text { July } 29 \\
\text { Aug. 17. } \\
\text { Sept. 6. } \\
\text { Sept. 21... }\end{array}$ & $\begin{array}{r}11,736 \\
5,724 \\
9,020 \\
12,004 \\
12,080 \\
13,460 \\
13,580 \\
13,296\end{array}$ & 29 & 0.16 & $\begin{array}{l}782 \\
484 \\
604 \\
810 \\
826 \\
824 \\
832 \\
812\end{array}$ & $\begin{array}{l}356 \\
178 \\
280 \\
374 \\
400 \\
420 \\
382 \\
407\end{array}$ & $\begin{array}{l}2,663 \\
1,140 \\
2,032 \\
2,907 \\
2,900 \\
3,027 \\
3,094 \\
3,108\end{array}$ & $\begin{array}{r}184 \\
156 \\
154 \\
178 \\
178 \\
137 \\
148 \\
161\end{array}$ & $\begin{array}{l}2,968 \\
1,872 \\
2,561 \\
3,118 \\
3,243 \\
3,243 \\
3,350 \\
3,251\end{array}$ & $\begin{array}{l}4,230 \\
1,660 \\
3,038 \\
4,600 \\
4,600 \\
4,875 \\
4,800 \\
4,920\end{array}$ & & $\begin{array}{r}64 \\
682 \\
116 \\
46 \\
38 \\
34 \\
31 \\
30\end{array}$ \\
\hline $\begin{array}{l}180 \\
181 \\
182 \\
183 \\
184 \\
185 \\
186 \\
187 \\
188 \\
189 \\
190 \\
191 \\
192 \\
193\end{array}$ & 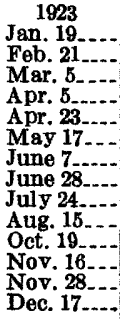 & $\begin{array}{r}12,320 \\
12,680 \\
13,120 \\
11,280 \\
13,120 \\
13,200 \\
13,920 \\
14,260 \\
14,230 \\
14,350 \\
2,640 \\
4,760 \\
6,780 \\
4,740\end{array}$ & - & & $\begin{array}{l}764 \\
770 \\
800 \\
754 \\
840 \\
800 \\
836 \\
828 \\
832 \\
824 \\
468 \\
544 \\
612 \\
480\end{array}$ & $\begin{array}{r}389 \\
400 \\
415 \\
361 \\
415 \\
411 \\
437 \\
428 \\
437 \\
460 \\
73 \\
163 \\
218 \\
163\end{array}$ & $\begin{array}{r}2,893 \\
3,051 \\
3,101 \\
2,520 \\
3,035 \\
2,996 \\
3,372 \\
3,316 \\
3,297 \\
3,423 \\
253 \\
738 \\
1,289 \\
843\end{array}$ & $\begin{array}{l}185 \\
195 \\
195 \\
185 \\
195 \\
188 \\
190 \\
154 \\
115 \\
151 \\
102 \\
142 \\
161 \\
146\end{array}$ & $\begin{array}{l}3,134 \\
3,209 \\
3,350 \\
2,830 \\
3,267 \\
3,309 \\
3,523 \\
3,536 \\
3,572 \\
3,613 \\
1,317 \\
1,751 \\
2,129 \\
1,761\end{array}$ & $\begin{array}{l}4,525 \\
4,750 \\
4,820 \\
4,000 \\
4,850 \\
4,680 \\
5,240 \\
5,125 \\
5,125 \\
5,320 \\
400 \\
1,200 \\
2,040 \\
1,240\end{array}$ & & $\begin{array}{r}34 \\
34 \\
39 \\
31 \\
37 \\
30 \\
28 \\
24 \\
18 \\
20 \\
62.000 \\
231 \\
98 \\
400\end{array}$ \\
\hline $\begin{array}{l}194 \\
195 \\
196 \\
197 \\
198 \\
199 \\
200 \\
201 \\
202 \\
203 \\
204 \\
205 \\
206 \\
207 \\
208 \\
209 \\
210\end{array}$ & 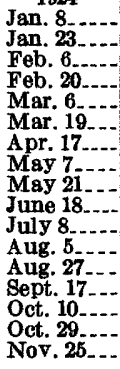 & $\begin{array}{r}4,544 \\
5,800 \\
6,580 \\
8,580 \\
7,420 \\
7,660 \\
11,600 \\
12,030 \\
12,150 \\
12,468 \\
12,256 \\
12,812 \\
13,028 \\
12,620 \\
12,024 \\
11,960 \\
8,220\end{array}$ & & & $\begin{array}{l}512 \\
572 \\
588 \\
648 \\
628 \\
632 \\
784 \\
744 \\
760 \\
784 \\
784 \\
800 \\
808 \\
772 \\
760 \\
780 \\
636\end{array}$ & $\begin{array}{l}161 \\
192 \\
218 \\
280 \\
247 \\
253 \\
354 \\
369 \\
370 \\
406 \\
402 \\
382 \\
419 \\
402 \\
379 \\
376 \\
271\end{array}$ & $\begin{array}{r}725 \\
1,041 \\
1,277 \\
1,853 \\
1,505 \\
1,584 \\
2,708 \\
2,724 \\
2,739 \\
2,978 \\
2,852 \\
3,062 \\
3,070 \\
2,877 \\
2,835 \\
2,721 \\
1,767\end{array}$ & $\begin{array}{r}176 \\
171 \\
166 \\
183 \\
163 \\
171 \\
181 \\
176 \\
181 \\
144 \\
107 \\
100 \\
98 \\
100 \\
124 \\
171 \\
146\end{array}$ & $\begin{array}{l}1,680 \\
1,934 \\
2,070 \\
2,428 \\
2,325 \\
2,354 \\
2,991 \\
2,992 \\
3,062 \\
3,276 \\
3,160 \\
3,328 \\
3,425 \\
3,190 \\
3,099 \\
3,103 \\
2,403\end{array}$ & $\begin{array}{l}1,150 \\
1,650 \\
2,020 \\
2,920 \\
2,340 \\
2,460 \\
4,280 \\
4,280 \\
4,280 \\
4,660 \\
4,560 \\
4,735 \\
4,800 \\
4,560 \\
4,460 \\
4,280 \\
2,780\end{array}$ & - & $\begin{array}{r}386 \\
227 \\
97 \\
77 \\
197 \\
119 \\
62 \\
51 \\
49 \\
26 \\
27 \\
27 \\
22 \\
27 \\
26\end{array}$ \\
\hline 211 & $\begin{array}{c}1925 \\
\text { Jan. 21 . . . }\end{array}$ & 12,300 & 35 & .38 & 788 & 384 & $\begin{cases}\mathrm{Na} & \bullet 2,912 \\
\mathrm{~K} & \bullet 48\end{cases}$ & 200 & 3,160 & 4,600 & 7.3 & 24 \\
\hline
\end{tabular}

- Includes equivalent of small amount of carbonate ( $\left.\mathrm{CO}_{3}\right)$.

- Flood of several days.

- Determined. 
TABLE 3.-Analyses of water from Pecos River at gaging stations in Texas, 1922-1925-Continued

Sheffield

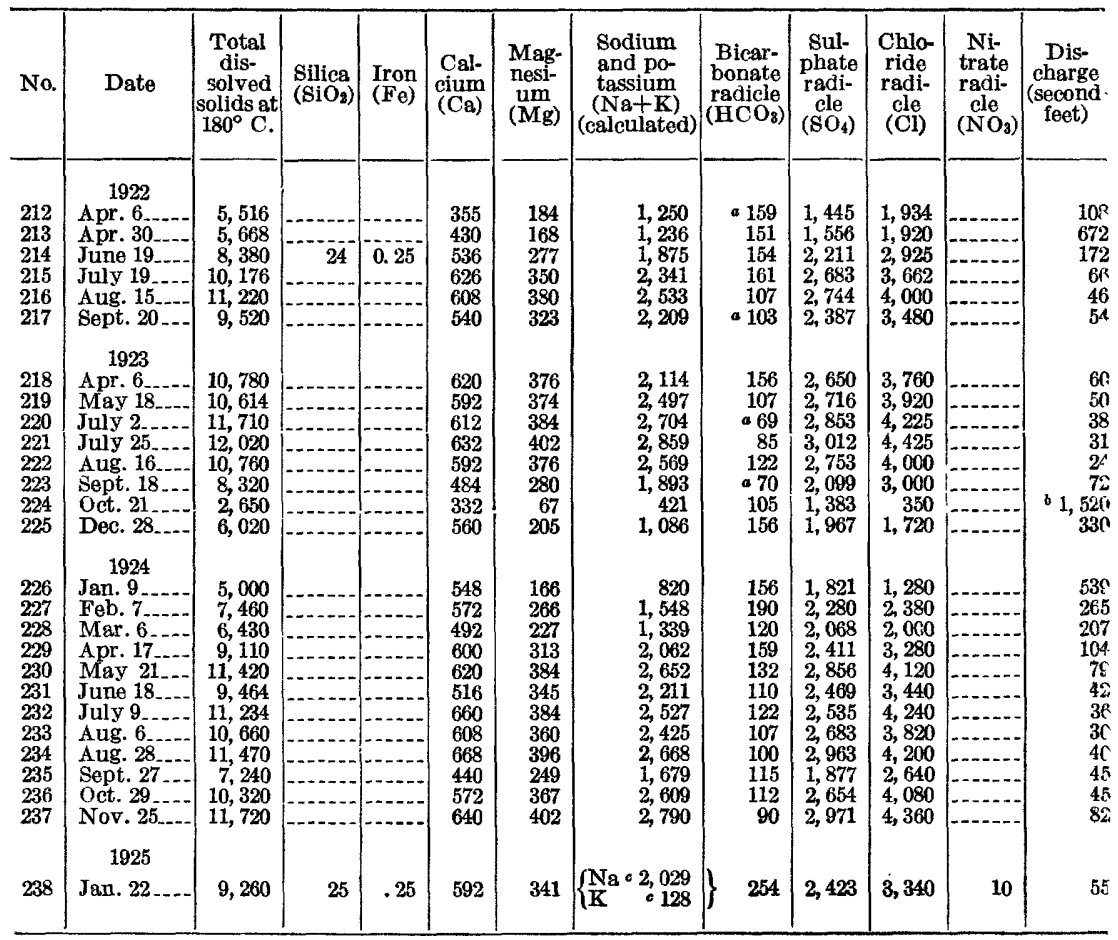

a Includes equivalent of small amount of carbonate $\left(\mathrm{CO}_{3}\right)$.

b Flood of several days.

c Determined. 


\title{
QUALITY OF THE SURFACE WATERS OF NEW JERSEY
}

\author{
By W. D. Coluins and C. S. Howard
}

\section{INTRODUCTION}

New Jersey is one of the leading industrial States. In volume of manufacturing the State is well up among the leaders, and its industrial activity to the square mile measured by the value added by manufacture as stated in the report on manufactures of the Fourteenth Census is greater than that of any other State except Massachusetts and Rhode Island. In the industrial development of the State the excellent quality of its surface waters has played no small part. Formerly the quantity of water was ample, but in recent years manufacturing has been halted for brief periods on account of shortage of water.

The New Jersey Department of Conservation and Development, in cooperation with the United States Geological Survey, has been making extensive studies of the quantity of ground and surface water available in certain parts of the State. In connection with the measurements that have been made of the discharge of the larger streams samples of water have been collected from time to time for chemical analysis. (See pl. 10.) The analyses given in the table on pages 116-119 show the chemical character of the surface waters of the State and indicate their suitability for different kinds of industrial use.

The material relating to surface features and drainage that is presented herein is abstracted in the main from the following reports :

Lewis, J. V., and Kümmel, H. B., The geology of New Jersey; a summary to accompany the geologic map (1910-1912) on the scale of $1: 250,000$, or approximately 4 miles to 1 inch: New Jersey Geol. Survey Bull. 14, 1915.

Salisbury, R. D.; The physical geography of New Jersey: New Jersey State Geologist Final Rept., vol. 4, 1898.

Vermeule, C. C., Report on water supply, water power, the flow of streams, and attendant phenomena: New Jersey State Geologist Final Rept., vol. 3, 1894.

Hazen, Whipple \& Fuller, Report on water resources of the State and their development, made to the Department of Conservation and Development, State of New Jersey, 1922.

The discussion of economic features is based on reports of the United States Census Bureau. Data in regard to climate are taken 
from publications of the United States Weather Bureau. Most of the figures for density of population in the drainage basins are from the report of Hazen, Whipple \& Fuller named above. The material relating to geographic features of the individual drainage basins is taken from the report of Vermeule, water-supply papers of the United States Geological Survey, and reports of the.Corps of Engineers, United States Army.

\section{NATURAL FEATURES}

Surface features.-New Jersey, which is a part of the Atlantic slope, has an area of 8,224 square miles, 710 square miles of which is covered with water in bays, harbors, lakes, etc. Two major physiographic divisions are recognized in the Atlantic slope-the Appalachian Highlands and the Atlantic Plain. The boundary between these divisions in New Jersey is a line running through Trenton and New Brunswick.

The Appalachian Highlands in New Jersey include parts of three provinces-the Appalachian Valley, the New England province, and the Piedmont province. The Appalachian Valley is a belt of valleys and ridges crossing the extreme northwest corner of the State. This region includes about one-twelfth of the area of the State and is occupied by the upper valley of Delaware River and the Kittatinny Valley. The part of the New England province lying in New Jersey occupies a highland belt of strong relief 10 to 25 miles wide, which covers about one-eighth the area of the State. The maximum altitude is about 1,400 feet and the average about 1,000 feet. The Piedmont province in New Jersey is an extension of the plateau of the Southern States but is lower and more nearly a plain here than it is farther south. It is a region of rolling lowland with scattered ridges and hills. The altitude ranges from a few feet above sea level in the vicinity of Newark to 200 feet in the valleys of Passaic and Raritan Rivers, 300 feet north of Paterson and Hackensack, and 913 feet in the Hunterdon Plateau.

The Coastal Plain of New Jersey contains about three-fifths of the area of the State. It is a region of low relief, one-third of it having an altitude of less than 50 feet. About 4 per cent of the plain is tidal marsh. A few areas rise higher than 200 feet, but most of them are isolated hills.

Drainage.-The drainage of the western part of the State goes chiefly to Delaware River, but a few streams in the northwestern part, notably Wallkill River, are tributary to Hudson River. The northeastern and central parts of the New England province are drained by tributaries of Passaic and Raritan Rivers, which empty into Newark and Raritan Bays. The southwestern part of the State 
is drained by tributaries to Delaware River and Delaware Bay, and the southeastern part by streams flowing to the ocean. The divide separating the Delaware River drainage basin from the drainage to the ocean is in general about 15 miles east of the river, but Rancocas Creek has its headwaters about 30 miles from the river. More detailed descriptions of the individual drainage systems of the State are given on pages $99-114$.

Climate.-The following description of the climate of New Jersey is based on reports by G. Harold Noyes, meteorologist at the United States Weather Bureau station at Trenton, N. J., published as sections 99 and 100 of a summary of climatologic data for the United States by sections, covering the periods from the establishment of the several stations through the year 1920. For consideration of the climate the State is divided into northern and southern parts. The northern part is described in two natural divisions-the highlands and Kittatinny Valley. district, comprising about 1,650 square miles, and the red sandstone plain (Piedmont province), comprising about 1,500 square miles. The area of the southern part is about 4,400 square miles.

The annual rainfall in New Jersey is generally uniform throughout the State, but there are seasonal and daily variations between different sections. The heavier local showers occur on the shore in summer. In the highlands and Kittatinny Valley the storms are less severe and longer.

The normal annual precipitation for the State, based on observations for about 40 years, is 46.54 inches and has ranged from a minimum of 37.29 inches in 1895 to a maximum of 63.33 inches in 1889. The precipitation has been below the average each year since 1920, when it was 51.87 inches. In 1923 it was 40.38 inches; in $1924,44.17$ inches. It is probable, therefore, that the river discharges have been slightly below normal in the period during which analyses were made for this report.

The temperature of the northern part of the State has a normal range from $100^{\circ}$ above to $20^{\circ}$ below zero, and that of the southern part from $100^{\circ}$ to zero. The higher altitude of the northern part of the State accounts for the lower temperature. In the southern part along the shores, owing to the modifying influence of the Atlantic Ocean and Delaware Bay, the ranges of daily, monthly, and annual temperatures are much less than in the interior, although the mean temperatures are much the same. The mean monthly temperatures for the State for July and August are 73.2 and 71.9; from December to February the mean monthly temperature is near the freezing point.

$95221^{\circ}-28-7$ 


\section{ECONOMIC FEATURES}

- Population.-New Jersey is one of the most densely populated States, having 420 inhabitants to the square mile at the time of the Fourteenth Census in 1920. Only Massachusetts and Rhode Island were more densely populated. The northern part of the State has more population than the southern part. Mercer and Monmouth Counties and those north of them have 51 per cent of the land area of the State and 83 per cent of the population.

The rate of increase of population of the State has been greater than the average rate for the United States since 1860. The increase from 1910 to 1920 was 24.4 per cent for New Jersey and 14.9 per cent for the whole United States. The increase for the northern half of the State was 24.6 per cent and for the southern half 23.2 per cent. This increase of population has made it imperative to study the conservation of both surface and ground waters for use as public supplies as well as for manufacturing.

Agrioulture.-New Jersey is not one of the leading agricultura] States, but the gross value of all agricultural products per square. mile of land area in 1919 was exceeded in only four other States. Thus it appears that agriculture is not an unimportant economic factor in the State. The total gross value of agricultural products in 1919, however, it was only about one twenty-seventh the value of the products manufactured in the State in the same year. The percentage of the land area of the State reported as farm land decreased from 53.5 in 1910 to 47.5 in 1920.

Mining.-Although the value of the products of the mining industry in New Jersey in 1919 was only 0.3 per cent of the total for the United States, the State ranked high in the production of zinc ore and was second in the quarrying of basalt or trap rock and in the mining of clay. The greensands of New Jersey are finding a rapidly increasing use in water treatment. After suitable preparation the sands have valuable properties of base exchange, rapid regeneration, and long life. The mining and quarrying industries make no unusual demands on the water resources and do not affect; the quality of water in the streams to any great extent.

Manufacturing.-New Jersey is primarily a manufacturing State. At the time of the Fourteenth Census it ranked sixth among the States in the value of manufactured products. This value was more than twenty-seven times the gross value of all farm products of the State and nearly four hundred times the value of the products of its mines and quarries.

As a measure of industrial activity the figures given in censur reports as "value added by manufacture" are more useful thar those given for "value of products." The latter may include the 
value of a given raw material several times as the product of one manufacturing process is passed along to serve as material for another. The value added by manufacture is the difference between the value of the finished products and the cost of materials and thus involves no duplication. The further discussion of industrial activity in this report is based on the value added by manufacture for the different commodities considered. ${ }^{1}$

In 1919 New Jersey ranked second among the States in the production of chemicals, the dyeing and finishing of textiles, petroleum refining, and silk manufactures. It was third in the production of rubber goods and fourth in canning and preserving, the production of jewelry, and the production of leather, tanned, curried, and finished. In silk products the value added by manufacture in New Jersey was 30.6 per cent of the total for the United States, and in the dyeing and finishing of textiles 23.5 per cent of the total. The leading industries of the State in 1919 were shipbuilding; steel; silk goods; foundry and machine-shop products; electrical apparatus, machinery, and supplies; petroleum refining; worsted goods; iron and steel works and rolling mills; rubber tires, tubes, and rubber goods not elsewhere specified; and dyeing and finishing textiles, exclusive of that done in textile mills. As reported in the Fourteenth Census, the 10 industries just named represented 41.6 per cent of the total industrial activity of the State.

Several of the industries named above are not dependent on the quality of water except as it is used in boilers for the generation of steam. Other industries, particularly the manufacture and dyeing of textiles, are greatly affected by the chemical character of the waters available. The study of industrial development cited above showed that these industries have largely remained in regions where soft waters are found, and that other industries have grown up in places where the natural waters are generally hard. The industrial plants of the State have seriously polluted some of the streams. Most of the polluting material is organic matter, and its presence is not shown by the analyses given in this report.

\section{SURFACE WATERS}

\section{SAMPLES}

The chemical composition of a surface water usually changes with variations in the discharge. In most streams the water shows the greatest concentration of dissolved material at low stages and the least at high stages. Sometimes, however, a stream fed by tributaries draining areas of different geologic character may have an

, ${ }^{1}$ See Collins, W. D., Relations between quality of water and industrial development in the United States: U. S. Geol. Survey Water-Supply Paper 559. 1926. 
increase in dissolved solids in time of a flood coming from an area that supplies much larger quantities of soluble salts than are supplied by the average soil of the whole drainage basin. The mineral matter dissolved in a given quantity of water taken from a river at low water may easily be twice as great as that in the same quantity taken at high water. Therefore a single sample from a river may give a decidedly misleading impression of the content of dissolved material generally to be found in the water.

The most reliable way to learn the chemical character of water to be obtained from a stream is to make analyses of composites of daily samples taken over a period of at least a year. The composites may represent long or short periods. If the periods are too long, the variations in composition are smoothed out too much; on the other hand, the cost of analyses makes it desirable to keep the number as small as possible. In general, composites of either 7 or 10 daily samples give the most information for the amount of money spent for the analyses. If the composition of a water does not change rapidly, a 30-day composite may be satisfactory.

The river waters of New Jersey do not change in composition so much as many other surface waters in the United States. During the time covered by the collection of the samples for which analyses are given in this report the discharge of most of the rivers was known for each day. It is possible, therefore, to use a few analyses representing different stages of the streams to show the probable character of the water at any other stage. Single samples have been collected at all the gaging stations maintained by the State Departmeinof Conservation and Development in cooperation with the United States Geological Survey. (See pl. 10.) The collections made at most stations cover the usual range of discharge. In addition several samples have been taken from streams on which there are no gaging stations. The samples were all collected by or under the direction of $O$. W. Hartwell, district engineer of the Geological Survey, in charge of the stream gaging in New Jersey.

\section{CONSTITUENTS OF NATURAI WATERS}

The surface waters of New Jersey are fairly clear, but they generally carry small quantities of suspended matter. Most of this is finely divided rock material. The waters in the northern part of the State are usually not highly colored, except as they may be polluted with wastes that contain coloring material. Some so-called "natural" color is obtained from decaying leaves and other organic matter. In the southern part of the State the waters are highly colored.

The surface waters carry also mineral matter in solution, whicl is dissolved from the rocks and soils. The greater part of tha 


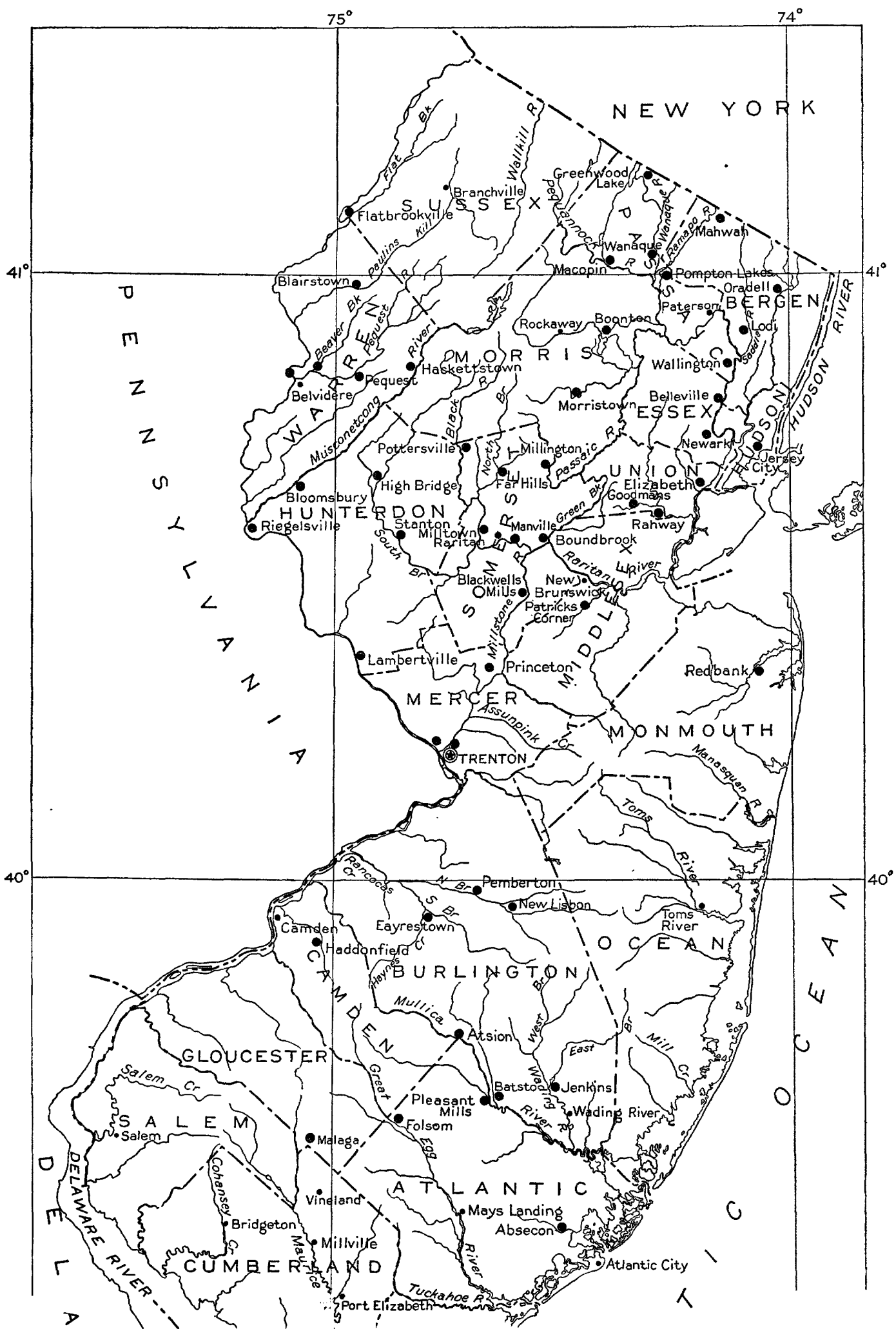


. 


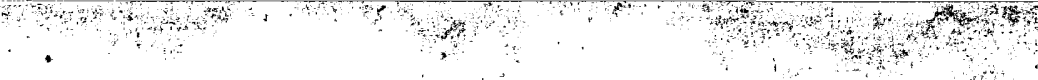

dissolved material in most waters consists of bicarbonates of calcium and magnesium, which are obtained most easily by the solution of limestone and dolomite but are also taken up from other rocks. Sodium and potassium are present in comparatively small quantities in most of the waters. Sulphate, chloride, and nitrate are also usually minor constituents. Silica and iron are present in nprmal amounts in most of the New Jersey waters. The silica may make up from 10 to 30 per cent of the total mineral matter; the quantity of iron is generally much less than 1 part per million. Iron dissolved in stream waters that are not acid is quickly oxidized by the air and precipitated. This freshly precipitated iron oxide or hydroxide is as harmful as dissolved iron in some uses of the water. The iron in the suspended material of the waters is therefore reported for a good many of the analyses.

\section{METHODS OF ANAIYSIS}

The samples collected for this report were analyzed by methods that involve only minor departures from the standard methods of the American Public Health Association. The results given in the table are reported in parts per million.

Many of the samples were clear when collected and when analyzed. Others carried appreciable amounts of suspended matter, and these were filtered through asbestos in a Gooch crucible, and the weight of the suspended matter was determined after drying at $180^{\circ} \mathrm{C}$. The filtered sample was used for analysis of the dissolved mineral matter. Some samples that were clear when collected contained precipitated iron at the time of analysis. The quantity of iron precipitated was determined and added to the quantity found in solution to give the result reported under the heading "Total iron." Some of the iron so reported may have been in solution when the samples were collected, but some undoubtedly came from the material suspended in the samples at the time of collection.

A convenient quantity of the water, usually 1 liter, was evaporated to dryness in platinum; the residue was heated to constant weight at $180^{\circ}$ C. and weighed to determine the total dissolved solids. Silica was separated by evaporation with hydrochloric acid and after. ignition was volatilized with hydrofluoric acid. Sulphate was determined as barium sulphate in the filtrate from the silica. Sodium and potassium in the filtrate from the barium sulphate were purified and weighed as mixed chlorides. In most of the analyses this weight was calculated to the equivalent sodium. In a few analyses potassium was determined by weighing the reduced platinum from potassium platinic chloride. In most of the analyses a second portion, usually 1 liter, was slightly acidified and then concentrated in a 
resistant glass beaker, and the iron was precipitated as hydroxide and determined colorimetrically. In the filtrate from the iron the calcium was determined by titrating the oxalate. with permanganate; magnesium was weighed as the pyrophosphate. Chloride, carbonate, and bicarbonate were determined by the usual titrations, and nitrate by the phenoldisulphonic acid method. The calculated hardness is reported as the calcium carbonate equivalent to the calcium and magnesium together.

\section{USES OF WATER}

Public suipply.-The most important use of water is to furnish a public supply, and the essential requirement for such use is that the water be safe to drink. This quality does not depend on the mineral content in New Jersey-in fact, there are few places where it does. The studies made for this report take no account of pollution that may make water unfit for drinking, but the processes employed to purify polluted water may affect its composition to the advantage or disadvantage of the industrial user. Although the water used for drinking sets the standard of purity for the whole of a public supply, the quantity so used is relatively small-generally between 0.5 and 1 per cent of the total. A large proportion of the water of public supplies in New Jersey is used by industrial establishments for the generation of steam in power plants and for various manufacturing processes.

The purification of a surface water to make it safe to drink generally involves treatment that also removes turbidity and color. Hence a surface water treated for a public supply may be much more desirable for industrial use than untreated water from the same source. Unless the plant requires very large quantities of water, it is usually cheaper to buy treated water from a public waterworks system than to undertake' purification for one plant:

Power plants.-The most common industrial use of water is in boilers used to generate steam for power or heating. The surface waters of New Jersey are among the best in the United States for boiler use. Most of them can be used with little treatment. In steam plants using large quantities of "make-up water" and operating above their rated capacity it is found profitable to treat the waters. Constituents that are undesirable in a feed water are acidity, high chloride or sulphate with much calcium and magnesium, calcium and magnesium; and suspended matter. At many plants large quantities of cooling water are used, principally for the condensers of steam turbines or other engines. A low temperature is, of course, the most essential characteristic for this cooling water.

Textile mills.-Silk; wool, and cotton manufacturing plants generally require large quantities of pure water. For the best results in 
mast of the processes in which water is used it should be free from color, suspended matter, calcium and magnesium (hardness), iron, and any unusual constituents such as acids or free caustic alkali;, which are rarely found in natural waters but are present in some waters that are polluted or have been treated chemically. Some of the New Jersey surface waters can be used in the textile industries without treatment, but many plants in New Jersey find it necessary or profitable to treat the water for the removal of color, suspended matter, iron, and hardness.

\section{TREATMENT OF WATER}

The treatment of water is discussed briefly in two previous publications of the Geological Survey ${ }^{2}$ and is described in detail in several well-known texts, ${ }^{3}$ In connection with discussions of the quality of surface waters of New Jersey it will suffice to mention several processes of treatment that relate to the chemical character of the waters.

Surface waters are generally filtered for public supplies. As the possibilities for pollution increase and higher standards with respect to color and turbidity are demanded the exceptions to thîs practice will become much fewer. The common procedure in filtration includes coagulation with an aluminum or iron salt, followed by sedimentation and rapid filtration through sand. Most of the surface waters of New Jersey have so little alkalinity that either lime or soda ash or both must be added to obtain proper coagulation with the aluminum salt.

In some parts of the country natural waters are softened for public supplies. The softening generally leaves a residual hardness of about 100 parts per million. The limit of the softening regularly accomplished by a lime-soda softener operating in the cold is close to 50 parts per million of hardness. Most of the surface waters in New Jersey have less hardness, and therefore the lime-soda process, which is extensively used in places where the natural waters are very hard, is not generally applicable to the New Jersey surface waters.

The exchange-silicate process, which softens water almost completely by an exchange of sodium for the calcium and magnesium, finds a particularly inviting field where the natural waters are comparatively soft. The softened water does not have the large quantity

${ }^{2}$ Collins, W. D., The industrial utility of public water supplies in the United States: V. S. Geol. Survey Water-Supply Paper 496, pp. 18-27, 1923 ; Relations between quality of water and industrial development in the United States: U. S. Geol. Survey WaterSupply Paper 559, pp. 22-27, 1926.

s vllms, J. W., Water purification, MeGraw-Hill Co., 1917. Mason. W. P.. Water supply, John Wiley \& Sons, 1916. Stein, M. F., Water-purification plants and their operation, John Wiley \& Sons, 1920. Turneaure, F. E., and Rusisell, H. L., Public water supplies, John Wiley \& Sons, 1924. 
of sodium salts that will be found in a very hard water softened by an exchange silicate; the costs of installation and of operation of an exchange-silicate softener to deliver a given number of gallons of softened water per day are much less for the soft water than for the hard water.

Some waters require treatment to render them noncorrosive. The surface waters of New Jersey are practically free from unneutralized acid, such as is found in streams that drain coal fields. They are therefore not intensely corrosive like the waters that destroy iron and steel structures exposed to their action. It is the general experience, however, that soft waters like those of New Jersey are much more active than very hard waters in the relatively mild attack on the interior of iron or steel pipes used in streets and buildings. At many purification plants, where soft waters are treated, it is necessary to take special precautions to avoid making the filtered water more corrosive than the water before filtration.

\section{TEMPERATURE}

Where water is used for cooling, as at an ice plant or for condensers, its initial temperature governs the economy of the operation. The higher the temperature the more water must be pumped for a given amount of cooling, and in summer the temperature of a surface water may be so high that the plant must be run at low efficiency, even with greatly increased pumpage.

A recent publication of the Geological Survey ${ }^{4}$ supplies a basis for estimating the probable temperature of surface waters throughout the United States. Charts of water temperatures and the figures for air temperatures obtained from reports of the United States Weather Bureau indicate that the temperature of surface water in New Jersey during the months of July and August is not far from $75^{\circ} \mathrm{F}$. This is much warmer than the ground water at depths of 60 to 100 feet, where the temperature is from $52^{\circ}$ to $57^{\circ} \mathrm{F}$. the year around. From June to September surface waters in New Jersey are decidedly warmer than ground water from the depths mentioned, from November to April they are colder, and in May and October there is usually little difference.

Several writers have pointed out that where lakes or reservoirs are deep enough cool water can be obtained in summer by drawing it from depths of more than 20 or 25 feet below the surface. This water may be cooler than the ground water that has the mean annual air temperature.

4 Collins, W. D., Temperature of water avaliable for industrial use in the United States: U. S. Geol. Survey Water-Supply Paper 520, pp. 97-104, 1924. 


\section{CHEMICAL CEARACTER}

The chemical character of the surface waters of New Jersey is shown by the analyses in the table. Typical analyses for some drainage basins are shown graphically in Figures 16 and 17.

In general, the waters are fairly clear, not highly colored, and of low mineral content. The predominating.constituents are calcium, magnesium, and bicarbonate. Sodium, chloride, and sulphate occur in relatively small quantities in nearly all the unpolluted waters. Sewage pollution increases the sodium chloride; industrial wastes may increase the sulphate also.

The range in concentration shown in Figure 16 for Passaic River and for North Branch of Raritan River is about the same as for Delaware River, although the samples for the first two were selected single samples, and the analyses for Delaware River were made on a series of composites of daily samples covering a period of a year.

In the following pages the characteristics of the surface waters of the State are taken up by drainage basins. Streams for which no analyses are available yield water of about the same composition as is found in other streams that drain areas of similar geologic character.

\section{HACKENSACK RIVER}

Hackensack River rises near Haverstraw, N. Y., and empties into Newark Bay. Its drainage area is about 202 square miles, of which 64 square miles is in New York. The watershed on the east along its whole course extends within half a mile of the west bank of the Hudson. The drainage basin above New Milford has an area of 115 square miles and is covered with glacial drift, sand, and gravel. The river is navigable and tidal to New Milford, and a large part of the basin below New Milford is tidal meadow. Pascack Creek, with a drainage area of 28 square miles, is the largest tributary to the Hackensack.

The population of the basin is about 325 per square mile. The principal large places are Hackensack and Rutherford, which in 1920 had populations of 17,627 and 9,497 , respectively.

The Hackensack Water Co. has a storage reservoir at Oradell, 1 mile north of New Milford, which supplies water to several municipalities of northeastern New Jersey. The total population supplied in 1920 was about 256,000 . The flow of the river is so nearly all used for these supplies that for several days in the summer no water goes over the dam at New Milford. The maximum discharge for the year ending September 30, 1924, was 1,800 second-feet.

Analysis 1 shows the composition of a sample collected at the Oradell reservoir. The filtered water used for the public supplies 
is free from suspended matter and low in color. It contains slightly more sulphate and less bicarbonate than the unfiltered water represented by the analysis.

Analyses made at the filtration works by G. R. Spalding indicate that the sample analyzed for this report had slightly more dissolved mineral matter than the average over a period of several years. Its hardness and total dissolved solids are less than the maximum and considerably greater than the minimum found by Mr. Spalding,

\section{PASSAIC RIVER BASIN}

\section{PASSAIC RIVER}

Passaic River rises in Morris County. a short distance from the headwaters of the North Branch of Raritan River and flows into Newark Bay. The distance by direct line from the source of the Passaic to its mouth is not more than 25 miles, but its course is very rambling and is about 80 miles long. The river heads in the highlands, but most of its drainage area is in the Piedmont province, where the principal tributaries, except Saddle River, join the main river. The area of the whole drainage basin is about 949 square miles; the part above Millington covers 55 square miles, and its population is 102 to the square mile. The maximum and minimum discharges at Millington for the year ending September 30, 1924, were 1,100 and 2.5 second-feet.

Analyses of five samples from Passaic River at Millington (Nos. 2-6) show that the water is soft and low in mineral content. A sample collected in October, 1924, was highly colored. The tur. bidity was determined on two of the samples and was not very high. although one of these samples (No. 2) was taken at a high stage (discharge 980 second-feet). Analyses 2 and 6 are shown graphically in Figure 16 to illustrate the change in concentration of the river water with a changing rate of discharge. Analysis 6 is shown in Figure 17 also, for comparison with analyses of other waters from the Passaic Basin.

Analyses of two other samples of the water of Passaic River, onf collected at Wallington (No. 7) and one at Belleville (No. 8), show that the water is more concentrated at these points, which are nearer the mouth of the river, than at Millington.

\section{TRIBUTARIES OF PASSAIC RIVER}

Rockaway River.-Rockaway River rises and has most of its drainage area of 140 square miles in the highlands. The river is 40 miles long and flows into the Passaic about 2 miles below Beaufort. The drainage aréa'above Boonton covers 119 square miles and has $f$ 
population of 210 to the square mile. A dam on the river at Boonton stores water for the supply of Jersey City. The mean discharge including diversion and allowing for storage for the year ending September 30, 1924, was 223 second-feet.

An analysis of a sample collected for this report in November, 1923, at the intake of the Jersey City waterworks (No. 10) shows hardness about the same as the average hardness that was reported by the city waterworks for 1923 , but the water was a little more concentrated than the sample represented by an analysis made in 1922 . (No. 9). Analysis 10 is shown graphically in Figure 17.

Whippany River.-Whippany River rises in the highlands and enters Rockaway River just above the junction of the Rockaway and the Passaic. The Whippany has a drainage area of 71 square miles,

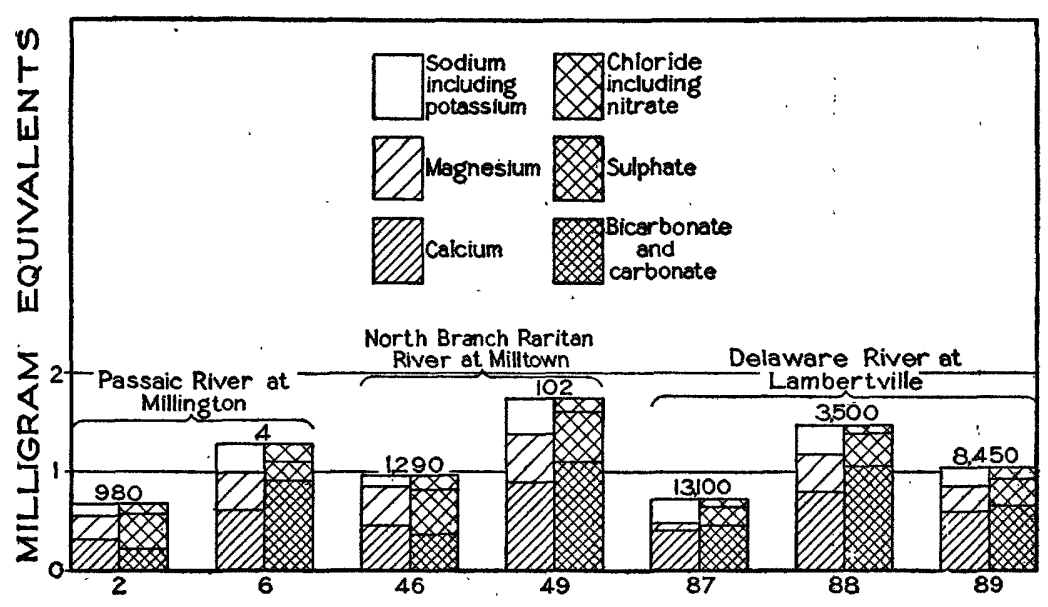

Figurb 16.-Range in composition of samples of water from rivers in New Jersey. Numbers below diagrams refer to analyses in table on pages 116-119. Figures above diagrams indicate discharge in second-feet.

of which 46 square miles is in the Piedmont province. The drainage area, including Morristown, the largest incorporated place in the basin, is 29 square miles, and the maximum and minimum discharges below Morristown for the year ending September 30, 1924, were 830 and 8 second-feet. Effluent from the sewage plant of Morristown flows into the river below the town and below the gaging station where samples of the river water were collected.

Analyses of three samples collected at Morristown (Nos. 11-13), representing water from the highlands drainage area, show that the water is slightly hard but low in total mineral content. There is no great change in composition within the range of discharge covered by the three samples. Analysis 13 is shown graphically in Figure 17. 
Pompton River.-Pompton River, formed by. the junction of Ramapo and Pequannock Rivers, flows through the Piedmont province into the Passaic. The composition of its water is within the

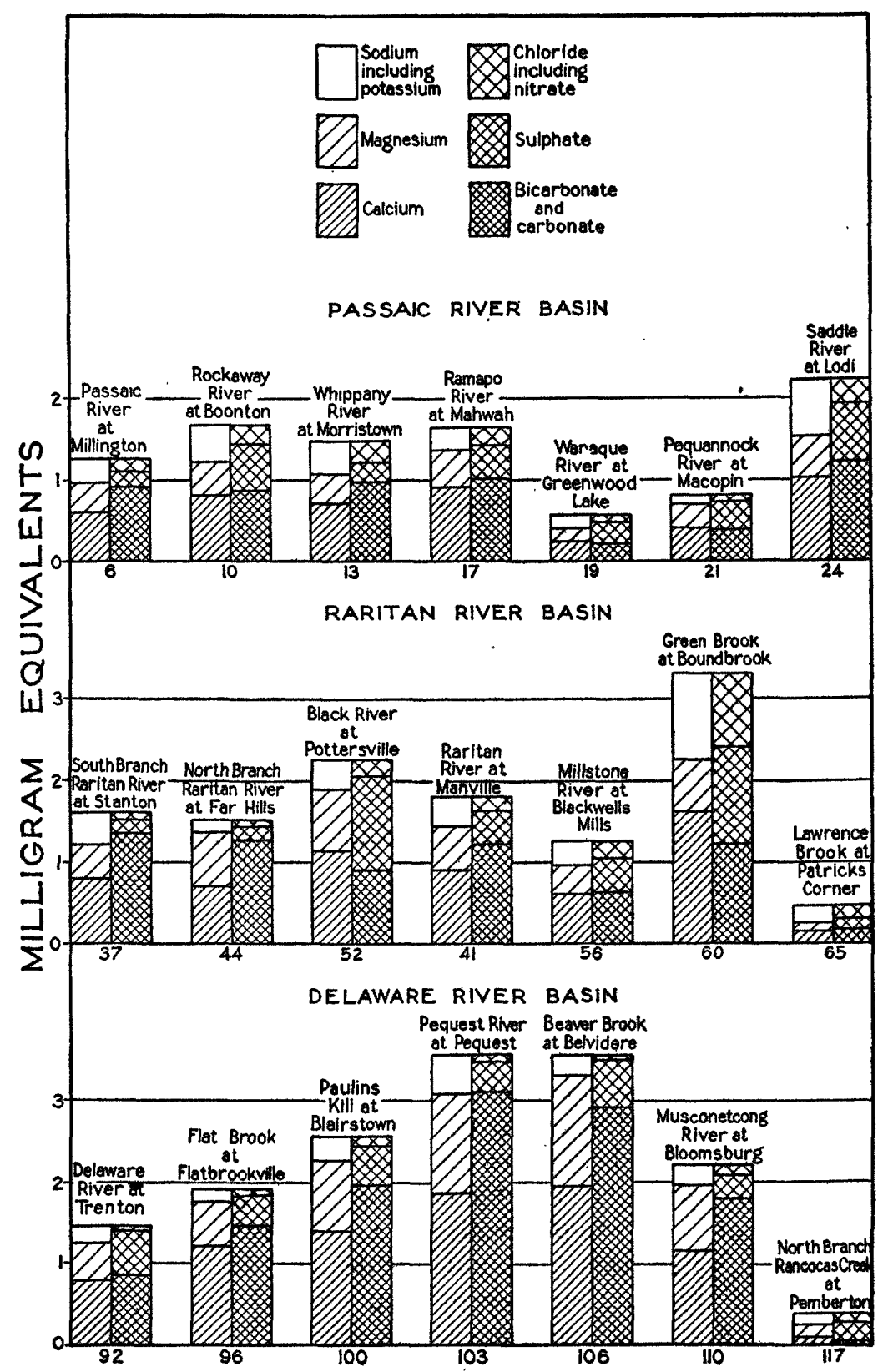

FIGUBm 17.-Analyses of surface waters of New Jersey. Numbers below diagrams refer to analyses in table on pages 116-119 
range of composition of the Ramapo, Wanaque, and Pequannock, as shown by analyses 14 to 21 .

Ramapo River.-Ramapo River rises in New York, and about 70 per cent of its total drainage area of 160 square miles is in that State. In New Jersey the river may be considered a highland stream. A dam at Pompton stores water for generating power, and below Pompton the Ramapo joins the Pequannock and Wanaque to form Pompton River. At the gaging station near Mahwah the maximum and minimum discharges for the year ending September 30,1925 , were 2,400 and 15 second-feet.

Four samples taken from Ramapo River near Mahwah (Nos. 14-17) show that the water is low in mineral content and slightly hard. One sample from the river at Pompton Lakes (No. 18) had a similar composition. Analysis 17 is shown graphically in Figure 17.

Wanaque River.-Wanaque River has its source in Greenwood Lake, at an altitude of 621 feet. The lake has a surface of 3 square miles and receives drainage from an area of 27 square miles, part of which, is in New York. The river flows 18 miles and empties into Pequannock River, at Pompton. Most of its drainage area is in the highlands.

Wanaque River above Wanaque has a drainage area of 91 square miles; the population in this area is about 25 to the square mile. In the year ending September 30, 1924, the maximum discharge at Wanaque was 5,050 second-feet and the minimum 1.4 second-feet. This river is now being developed as a source of water supply by the North Jersey District Water Supply Commission. A report of the commission for the period May 5, 1916, to June 30, 1925, gives a full account of the development, with reports by the consulting engineers, Weston \& Sampson, on the bacterial and chemical character of surface waters in the district. The chemical analyses are not complete analyses of the mineral content but give the results of the determinations usually made in a sanitary chemical analysis.

Analyses 19 and 20 represent samples from Wanaque River, taken at Greenwood Lake and at Wanaque at comparatively low stages. Analysis 19 is shown graphically in Figure 17. Both of these analyses represent waters that would be classed as soft and of low mineral content. It is probable that the water to be stored in the reservoir is represented much better by No. 19 than by No. 20. Results obtained by the North Jersey District Water Supply Commission indicate that No. 20 shows an extremely high concentration, which is not likely to be reached when the reservoir is filled and water of average composition is let down to maintain the low-water flow. 
Pequannock River.-Pequannock River rises in the highlands, at an altitude of nearly 1,500 feet. It flows in a general southeasterly direction for 31 miles to its junction with the Ramapo at Pompton, where the altitude is $\mathbf{1 7 0}$ feet. The water is impounded at Macopin for the public supply of Newark. The drainage area above Macopin is 64 square miles.

Analysis 21, which is shown graphically in Figure 17, represents a sample collected in November, 1923. This analysis agrees well with results obtained over a period of several years by Justus Goslau for the city of Newark and sent to the United States Geological Survey by John A. Foulks, chief engineer of the division of water of that city. The analyses made by Mr. Goslau show generally a somewhat lower mineral content, although some samples had slightly greater concentration.

Saddle River.-Saddle River rises in New York and flows into Passaic River about 12 miles from Newark Bay. Of its drainage area of 61 square miles, 52 square miles is in New Jersey. Above Lodi the drainage area is 55 square miles. The maximum and minimum discharges for the year ending September 30, 1924, were 1,280 and 5.3 second-feet.

Analyses 22-24 represent different stages of the river at Lodi. Analysis 24 is shown graphically in Figure 17. The water of Saddle River is appreciably harder than most of the other waters tributary to the Passaic. The samples collected in November, 1923 (No. 24), and November, 1925 (No. 23), are much more concentrated than the sample collected during high water in February, 1924.

\section{SUMMARY}

The analyses for the Passaic Basin shown in Figure 17 are those of the most concentrated samples collected at the different points. They may not represent the highest concentrations reached over a long period, but most of them can be taken as showing approximately the greatest concentration likely to persist for any considerable time. Study of the analyses in the table, with consideration of the discharge corresponding to the analyses and those reported throughout the year, indicates that in general the waters are not greatly diluted for any long period. The concentration is not likely ever to be much less than half the maximum and is generally well over half the maximum.

\section{ELIZABETH RIVER}

Elizabeth River rises in the city of East Orange and flows into Newark Bay through Arthur Kill. Above Elizabeth, at the head of tidewater, it has a drainage area of 20 square miles, most of 
which is covered thickly with glacial drift. The maximum and minimum discharges of the river at a point below the intake of the Elizabethtown Water Co. for the year ending September 30, 1924, were 890 second-feet and zero. The drainage area has a large population and considerable manufacturing.

Analysis 25 represents a sample collected above the reservoir of the water company, while rain was falling and the water was much more turbid than usual and probably less concentrated than the water generally held in the reservoir. Analyses 26 and 27 represent samples collected at the gaging station below the reservoir, $21 / 2$ miles above the mouth of the river.

The analyses show that the water is hard and moderately high in mineral content. Its hardness is several times that of most of the other river waters in the northeastern part of New Jersey. The water also contains much more sodium and chloride than the other river waters of the State.

\section{RAHWAY RIVER BASIN}

Rahuray River.-Rahway River is a small stream rising in a valley in the Watchung Mountains, west of Orange. The river flows south across the plain of glacial drift and empties into Arthur Kill a short distance from Newark Bay. The drainage area above Rahway, at the head of tidewater, is 41 square miles, most of which is covered with glacial drift. The river basin is densely populated and has considerable manufacturing. The maximum and minimum discharges at Rahway for the year ending September 30, 1924, were 1,100 and 2 second-feet. Ground water is withdrawn above Rahway by wells of the Orange Water Co. and the Short Hills Water Co., and water is also taken directly from the river by the Rahway Water Co.

Analyses of two samples taken from the river at Rahway (Nos. 28 and 29) indicate that the river water changes considerably in hardness and in mineral content with changing discharge.

Robinsons Branch.-The drainage area of Robinsons Branch of Rahway River above Goodmans is 12.7 square miles, and the maximum and minimum discharges at that point in the year ending September 30, 1924, were about 130 and 2 second-feet. The analysis of a sample collected in August, 1923 (No. 30), shows the water to be less concentrated than the water of the main stream at the same stage.

\section{RARITAN RIVER BASIN}

The Raritan River system is the largest in New Jersey, except the Delaware, but it is not economically as important as the Passaic, 
because the tributaries do not combine until they reach points within about 7 miles of tidewater. The whole Raritan drainage area is 1,105 square miles. The river is tidal to a point about 2 miles above New Brunswick and is navigable to that city.

South Branch of Raritan River.-The South Branch of Raritan River rises in Budd Lake, southwest of Lake Hopatcong. It is 42 miles long and drains 277 square miles. About 100 square miles of its drainage area is in the highlands, and the remainder is in the Piedmont province. At High Bridge the South Branch has a drainage area of 65 square miles. The maximum and minimum discharges at this point in the year ending September 30, 1924, were 2,500 and 19 second-feet. At Stanton the South Branch has a drainage area of 147 square miles, and the maximum and minimum discharges there for the year ending September 30, 1924, were 5,200 and 26 secondfeet.

Analyses of three samples collected at High Bridge (Nos. 31-33) and of four samples collected at Stanton (Nos. 34-37) show that the river water is slightly hard but is low in mineral content. Analysis 37 is shown graphically in Figure 17.

Raritan River.- Raritan River is formed by the union of the North Branch and South Branch near Raritan. At Manville the drainage area is 490 square miles; the maximum and minimum discharges at this point for the year ending September 30, 1924, were 20,000 and 38 second-feet. Analyses 38 to 41 , which represent samples collected at Manville, show the water to be slightly hard and of low mineral content. Analysis 41 is shown graphically in Figure 17.

North Branch of Raritan River.-The North Branch of Raritan River rises west of Morristown and unites with the South Branch near Raritan. It has a drainage area of 192 square miles, practically all of which is in the Piedmont province. At Far Hills this branch has a drainage area of 26 square miles and the maximum and minimum discharges for the year ending September 30, 1924, were 652 and 6 second-feet.

Analyses of samples taken at Far Hills (Nos. 42-45) indicate that in general the water is soft and of low mineral content. Analysis 44 is shown graphically in Figure 17.

At Milltown the drainage area of the North Branch is 190 square miles, and the maximum and minimum discharges for the year ending September 30, 1924, were 5,570 and 26 second-feet. Analyses of four samples collected at Milltown (Nos. 46-49) are similar to the analyses for Far Hills but show a larger quantity of sulphate. This sulphate probably is brought in by Black River. Analyses 46 and 49 are shown graphically in Figure 16 to illustrate the variation in concentration with the discharge. 
Black River,-Black River is the main tributary to the North Branch. Above Pottersville it has a drainage area of 33 square miles, most of which is in the highlands. The drainage basin includes a marsh from which the color of the river water is derived. The maximum and minimum discharges at Pottersville for the year ending September 30, 1924, were 740 and 4 second-feet.

Analyses of samples collected at Pottersville (Nos. 50-52) show considerable variation in composition with the discharge. The unusually large proportion of sulphate in the water of Black River may come from iron mines along the river. The relatively high sulphate is evident from Figure 17, in which analysis 52 is plotted with others for the Raritan Basin.

Analyses 37 and 44, shown in Figure 17, for the South and North branches of Raritan River, represent bicarbonate waters with little sulphate; No. 52 shows more sulphate than bicarbonate; and No. 41 , which represents the river below the junction of the South Branch, the North Branch, and the Black, has an intermediate quantity of sulphate.

Millstone River.-Millstone River rises southeast of Hightstown and flows into the Raritan below Manville. The Millstone is 35 miles long and has a drainage area of about 300 square miles. The larger part of the basin is in the Piedmont province. At Blackwells Mills the drainage area is 258 square miles and the maximum and minimum discharges for the year ending September, 1924, were 6,200 and 62 second-feet. The basin is rather densely populated. Analyses of four samples collected at Blackwells Mills (Nos. 53-56) indicate that the water is generally soft and low in mineral content. Analysis 56 is shown graphically in Figure 17.

Stony Brook.-A single analysis of water from Stony Brook at Princeton (No. 57) shows it to have about the average composition of Millstone River, which this brook enters near Princeton.

Green Brook.-Green Brook rises in the First and Second Watchung Mountains and flows into Raritan River at Boundbrook. Green Brook has a drainage area of 49 square miles, and the maximum and minimum discharges for the period from June 12 to September 30 , 1924, were 800 and 10 second-feet. Analyses of four samples collected at Boundbrook (Nos. 58-61) indicate, that at high stages of the stream the water is only slightly hard, but at low stages the water is hard and moderately high in mineral content. Plainfield sewage empties into Green Brook, and its effect is shown in the great increase in chloride at low stages of the stream when the diluting water is decreased while the volume of sewage keeps about the same. Analysis 60 is shown graphically in Figure 17.

$95221^{\circ}-28-8$ 
Lawrence Brook.-Lawrence Brook rises near Monmouth Junction and flows into the Raritan just below New Brunswick. It has a drainage area of 45 square miles, part of which is in the Piedmont province and part in the Coastal Plain. The drainage area above Patricks Corner is 29 square miles, and the maximum and minimum discharges at this point for the year ending September 30, 1924, were over 600 second-feet and 0.4 second-foot. Water is pumped from this stream at Weston Mills, below Patricks Corner, for the city supply of New Brunswick. Analyses of four samples taken at Patricks Corner (Nos. 62-65) show that the water is soft and low in mineral content. It is probably the least mineralized river water of northern New Jersey. Analysis 65 is shown graphically in Figure 17.

Summary. - The diagrams for Raritan River Basin in Figure 17 show a wide range in composition of the waters of the basin. The water of Lawrence Brook (No. 65) is one of the least mineralized surface waters of the northern part of the State, and that of Bound Brook one of the most highly mineralized. In general, however, the waters of the Raritan Basin are about the same in composition as those of the Passaic Basin. Their comparative softness and low mineral content place them definitely among the better waters of the United States for industrial use.

\section{SWIMMING RIVER}

Swimming River is formed by the junction of Hop and Yellow Creeks and joins Navesink River below tidewater. The maximum and minimum discharges of Swimming River at Redbank for the year ending September 30, 1924, were 2,000 and 13 second-feet.

Analyses of three samples from Swimming River at Redbank (Nos. 66-68) show changes in concentration with discharge, but the water is always low in dissolved solids and fairly soft. The sample collected February 6, 1924 (No. 66), carried an unusually large quantity of suspended matter for a surface water in New Jersey. Water from Swimming River is used after filtration by the Tintern Manor Water Co. for a public supply.

\section{MULIICA RIVER BASIN}

Mullica River.-Mullica River, which rises near Atco and empties into Great Bay, north of Atlantic City, 32 miles from its source, has a drainage area of 412 square miles, all in the Coastal Plain. The river is tidal and navigable for 20 miles. The main river and its tributaries flow through cedar swamps, and the water is colored by organic matter in the swamps. Above Pleasant Mills Mullica River has a drainage area of 126 square miles. 
Analyses of samples from Mullica River at Atsion and at Pleasant Mills (Nos. 69 and 70) show the water to be a typical soft, highly colored swamp water. It is not likely that the water changes much in composition throughout the year.

Batsto River.-Batsto River rises near the headwaters of the South Branch of Rancocas Creek, a tributary to the Delaware, and flows into Mullica River below Batsto. Above the dam at Batsto it has a drainage area of 70 square miles. Analysis 71 shows the water of Batsto River at Batsto to have much the same composition as that of Mullica River at Pleasant Mills.

Woding River.-Wading River rises west of Woodmansie and after flowing 22 miles, largely through swamp land, empties into Mullica River. The river is navigable for 8 miles from its mouth. Its drainage area is 189 square miles. The population in the drainage area of Wading River is only 7 to the square mile; in the rest of the basin of the Mullica the density is 46 to the square mile. Analysis 72 shows the water of East Branch of Wading River near Jenkins to have the same composition as the other waters sampled in the Mullica River Basin.

\section{ABSECON CREEK}

Absecon Creek rises northwest of Absecon and flows into the Atlantic Ocean. Its drainage area above the bridge at Absecon is 18 square miles and above the lower mill pond at the head of tidewater 12 square miles. Water from this creek is used as a part of the city supply for Atlantic City.

Analyses of four samples collected at the storage ponds of the Atlantic City Water Co. (Nos. 73-76) indicate that the water is soft and low in mineral content. It is, however, often highly colored. The color is bleached somewhat after long storage, so that the greatest color is likely to be present just after rains have washed into the pond water that has been in contact with organic matter in swamps for a long time.

\section{GREAT EGG RIVER}

Great Egg River rises west of Berlin and flows into the Atlantic Ocean. It is 38 miles long and above Mays Landing (at the head of tidewater) has a drainage area of 216 square miles. Above Folsom the drainage area is about 51 square miles. The area drained is all in the Coastal Plain, and some of it is swamp land.

An analysis of a sample from Great Egg River at Folsom (No. 77) shows that the water is soft and of low mineral content but noticeably colored. 


\section{MAURICE RIVER}

Maurice River rises near Glassboro and empties into Delaware Bay 33 miles from its source. Above Millville, at the head of tidewater, it has a drainage area of 218 square miles. The entire drainage area is in the Coastal Plain, and the river is a characteristic southern New Jersey stream. The analysis of a sample taken at Malaga (No. 78) shows that the water is soft, low in mineral content, and colored like the other river waters of the southern part of the State.

\section{SUMMARY FOR SOUTHERN NEW JERSEY}

The samples collected for this report from the southern part of the State are remarkably similar in composition. They are soft, colored, and generally clear, and they carry only small quantities of dissolved mineral matter. Because of the similarity of conditions in the other drainage basins it is to be expected that similar water will be found in practically all the streams of southern New Jersey above the influence of salt water from the ocean or bay.

\section{DELAWARE RIVER BASIN}

\section{DELAWARE RIVER}

Delaware River rises on the west side of the Catskill Mountains in New York at an altitude of about 1,900 feet; at the mouth of Neversink Creek, at the extreme north tip of New Jersey, its altitude is 411 feet. The Delaware is 360 miles long and flows into Delaware Bay; the river and bay form the western boundary of New Jersey. About 45 per cent of the State is drained by streams tributary to the river or to the bay.

Water from Delaware River is used for public supply at several places, of which Trenton is the largest in New Jersey. A number of cities also make use of the river to carry their sewage away. Large volumes of water are taken for industrial use by plants situated on the river. A commission is now working out plans for the equitable and economical use of the river in the States of New York, New Jersey, and Peninsylvania.

At Belvidere Delaware River has a drainage area of 4,540 square miles, and the maximum and minimum discharges for the year end-. ing September 30,1924, were 102,000 and 1,010 second-feet. Analyses 79-82 probably cover almost the whole range in concentration of the river water at Belvidere. The water has a low mineral content and is generally fairly clear and soft. The hardness shown in analysis 80 is sufficient to be objectionable for many uses.

At Riegelsville Delaware River has a drainage area of 6,190 square miles, and the maximum and minimum discharges for the year end- 
ing September 30, 1924, were 122,000 and 1,360 second-feet. Analyses 83-86, show the composition of the river water at Riegelsville to be practically the same as at Belvidere.

At Lambertville daily samples of river water were collected from September 8, 1906, to September 12, 1907. These were united in sets of 10 to make composites which were analyzed in the laboratory of the Geological Survey at Washington. The analyses were published in Water-Supply Paper 236. Three analyses (Nos. 87-89) representing composite samples are given in the table and are shown graphically in Figure 16. The range in composition of the river water at Lambertville in 1906 and 1907 is about the same as is shown by the analyses of samples collected occasionally at other points from 1923 to 1925 .

Delaware River above Trenton has a drainage area of 6,800 square miles. The maximum discharge at Trenton for the period 1913-1922 was 160,000 second-feet, in March, 1913; the minimum for the same period was 1,240 second-feet, for several days in 1914. Analyses 90-92 show about the same composition for the water at Trenton as the analyses of samples from other points. Analysis 92 is shown graphically in Figure 17.

\section{TRIBUTARIES OF DFLAWARE RIVER}

Flat Brook.-Flat Brook rises near High Point, in the Kittatinny. Mountains, and after flowing for 21 miles through the Appalachian Valley empties into the Delaware below Flatbrookville. The stream becomes swollen very quickly in time of flood. The total drainage area is 66 square miles, of which 65 square miles is above Flatbrookville. The maximum and minimum discharges at Flatbrookville in the year ending September 30,1924, were 4,400 and 4 second-feet. Analyses of samples taken at Flatbrookville (Nos. 93-96) show the water to be low in mineral content, though at low stages it is slightly hard. Analysis 96 is shown graphically in Figure 17.

Paulins Kill.-Paulins Kill rises in the Kittatinny Mountains east of the head of Flat Brook and flows 36 miles to the Delaware. Above Blairstown Paulins Kill has a drainage area of 128 square miles. The maximum and minimum discharges at Blairstown in the year ending September 30, 1924, were 1,680 and 6 second-feet. Analyses of four samples collected at Blairstown (Nos. 97-100) indicate that at average stages the river water is slightly hard but low in mineral content. Analysis 100 is shown graphically in Figure 17. The slightly greater content of calcium and magnesium in Paulins Kill as compared with Flat Brook is accounted for by limestone in the lower drainage basin of Paulins Kill.

Pequest River.-Pequest River rises near Pinkeyville and flows about 32 miles in a general southwesterly direction to its junction 
with Delaware River at Belvidere. It has a drainage area of 158 square miles. The southern and eastern edges of its basin are on gneiss, but the major portion of the basin is on limestone. Above Pequest the drainage area is 108 square miles; at this point the maximum and minimum discharges for the year ending September 30, 1924, were 593 and 17 second-feet. Analyses of samples collected at Pequest (Nos. 101-103) indicate that the river water is hard and moderately high in mineral content. Analysis 103 is shown graphically in Figure 17. The effect of the limestone in the drainage basin is clearly shown by the larger quantities of calcium and magnesium as compared with the quantities found in the waters from Flat Brook and Paulins Kill.

Beaver Brook.-Beaver Brook rises east of Blairstown and flows into Pequest River near Belvidere. It has a drainage area of 36 square miles. Near Belvidiere the maximum and minimum discharges for the year ending September 30, 1924, were 579 and 3.1 secondfeet. Analyses of samples collected near Belvidere (Nos. 104-106) indicate that the water of Beaver Brook is similar in composition to the water of the Pequest. (Compare analyses 106 and 103, fig. 17).

Musconetcong River.-Musconetcong River rises in the Sparta Mountains and flows 52 miles southwest to its junction with the Delaware. The Musconetcong has a long, narrow basin with an area of 156 square miles in the highlands. Above Hackettstown the drainage area of the river is 70 square miles, and at this point the maximum and minimum discharges in the year ending September 30 , 1924, were 750 and 6 second-feet. Above Bloomsbury the drainage area is 143 square miles, and the maximum and minimum discharges for the year ending September 30, 1924, were 1,300 and 25 secondfeet. The population in the basin of the Musconetcong is about 80 to the square mile, and the principal industry is agriculture. Analyses of three samples collected at Hackettstown (Nos. 107-109) indicate that the water is soft and is low in mineral content. The analysis of one sample collected at Bloomsbury at a rather low stage of the river (No.110) shows that at this stage the water is hard and somewhat more concentrated than the water at Hackettstown. This analysis is shown graphically in Figure 17. The quantity of calcium and magnesium bicarbonate is not so great as in the water of Pequest River and Beaver Brook but is greater than in waters from drainage basins with smaller proportions of their area underlain by limestone.

Assunpink Creek.-Assunpink Creek rises near Clarksburg, Monmouth County, and flows nearly due west into the Delaware at Trenton. The drainage area above Trenton is 89 square miles, of which 27 square miles is in the Piedmont province and the remainder in the 
Coastal Plain. The maximum and minimum discharges at Trenton during the year ending September 30,1924 , were 2,400 and 13 second-feet. Analyses of four samples collected at Trenton (Nos. 111114) indicate that the water is soft at high stages but is slightly hard and moderately high in mineral content at lower stages. The samples taken at the higher stages show considerable sediment. Sulphate is comparatively high in all the samples.

Rancocas Creek.-Rancocas Creek is the next to the largest tributary to the Delaware from New Jersey. Its drainage area is 301 square miles. The main stream is formed below Mount Holly by the union of the North Branch and the South Branch, both of which rise in the Coastal Plain. The North Branch of Rancocas Creek has a drainage area of 111 square miles above Pemberton. Some of the drainage area is swamp land, and the population in the basin is small. The maximum discharge at Pemberton for the year ending September 30, 1.924, was not recorded but was over 900 second-feet; the minimum was 46 second-feet. The water supplies of Mount Holly and Pemberton are taken from the North Branch; the supply for Camp Dix is taken from Mount Misery. Branch, which joins the North Branch at New Lisbon.

Analyses of three samples from the North Branch at Pemberton (Nos. 115-117) and of one sample from Mount Misery Branch at Camp Dix (No. 118) show the water of these streams to be soft; of low mineral content, and slightly colored. They are quite like the stream waters in the eastern part of southern New Jersey. Analysis 117 is shown graphically in Figure 17 for comparison with the analyses of the northern tributaries to Delaware River. The low bicarbonate of the samples from the North Branch and Mount Misery Branch suggests that at times the waters of these streams may be actually acid. Whether so or not, they are likely to corrode pipes. The South Branch of Rancocas Creek above Eayrestown has a drainage area of 62 square miles. Haynes Creek flows into the South Branch near Eayrestown. The population in the basins of these two streams is small. Vermeule ${ }^{5}$ estimated that Mount Misery Branch and the North Branch could supply $17,800,000$ gallons a day, and that the South Branch above Vincenttown could supply $9,000,000$ gallons a day in the driest years without storage.

Analyses of samples from the South Branch (No. 119) and from Haynes Creek (No. 120) collected near Eayrestown indicate that the water of these streams is soft and of low mineral content but is a little more concentrated than the water of the North Branch.

\footnotetext{
5 Vermeule, C. C., Report on water supply, water power, the flow of streams, and attendant phenomena: New Jexpey State Geologist Final Rept., vol. 3, p. 254, 1894.
} 


\section{CONTRIBUTTONS TO HYDROLOGY OF UNITED STATES, 1927}

Coopers Creek.-Coopers Creek rises in gravel hills and flows in a northwesterly direction to Camden, where it empties into the Delaware. The creek is tidal to the forks at Haddonfield. Above Haddonfield the branches flow through wooded areas having some outcrops of marl. The North Branch has a drainage area of 12 square miles. Vermeule ${ }^{B}$ estimated that with storage this branch would yield 5,660,000 gallons a day. Analysis 121 indicates that the water of Coopers Creek at Haddonfield is soft, low in mineral content, and similar in composition to that of other streams in southern New Jersey.

\section{SUMMARY}

The surface waters of New Jersey are one of the most valuable natural resources of the State. They are used for public water supplies of nearly all the larger cities, and they furnish the great quantities of water required for some of the leading industries. Where unpolluted, these waters are generally clear and contain only moderate quantities of dissolved mineral constituents. The waters in the southern part of the State are softer but more highly colored than the waters in the northern part.

\section{ANALYSES OF SURFACE WATERS}

The following table gives analyses of typical samples of surface waters of New Jersey. The usual constituents are reported in parts per million. In addition to the determined constituents of the dissolved mineral matter the table gives the calculated hardness, and for some samples, the quantity of suspended matter and the total iron. Nearly all the analyses were made by C. S. Howard; exceptions are indicated in footnotes.

The analyses are arranged in the order in which the drainage basins and streams are given in reports of stream measurements published by the United States Geological Survey. The following list of streams in alphabetic order shows the numbers of the analyses in the table for each stream.

\begin{tabular}{|c|c|c|}
\hline Absecon Creek_ & 73-76 & Green Brook - \\
\hline Assunpink Creek & $111-114$ & Hackensack River - \\
\hline Batsto River-_. & $\mathbf{7 1}$ & Haynes Creek \\
\hline Beaver Brook & $104-108$ & Lawrence Brook \\
\hline Black Ríver-_. & $50-52$ & Maurice River.... \\
\hline Coopers Creek & 121 & Millstone River \\
\hline Delaware River. & $79-92$ & Mount Misery Branch \\
\hline Elizabeth River & 25-27 & Mullica River-_. \\
\hline Flat Brook & $93-96$ & Musconetcong River \\
\hline Great Egg River._. & 77 & River \\
\hline
\end{tabular}

Idem, p. 256. 
Paulins KII

Pequannock River

Pequest River

Rahway River

Ramapo River.

Rancocas Creek:

North Branch

South Branch

Raritan River

North Branch

South Branch

97-100| Robinsons Branch (of Rahway

21

101-103

28,29

14-18

115-117

119

$38-41$

42-49

31-37
River)

Rockaway River

Saddle River.

Stony Brook

Swimming River

Wading River

Wanaque River

Whippany River
30

9, 10

22-24

57

66-68

72

19,20

11-13 
116 CONTRIBUTIONS TO HYDROLOGY OF UNITED 'sTATES, 1927

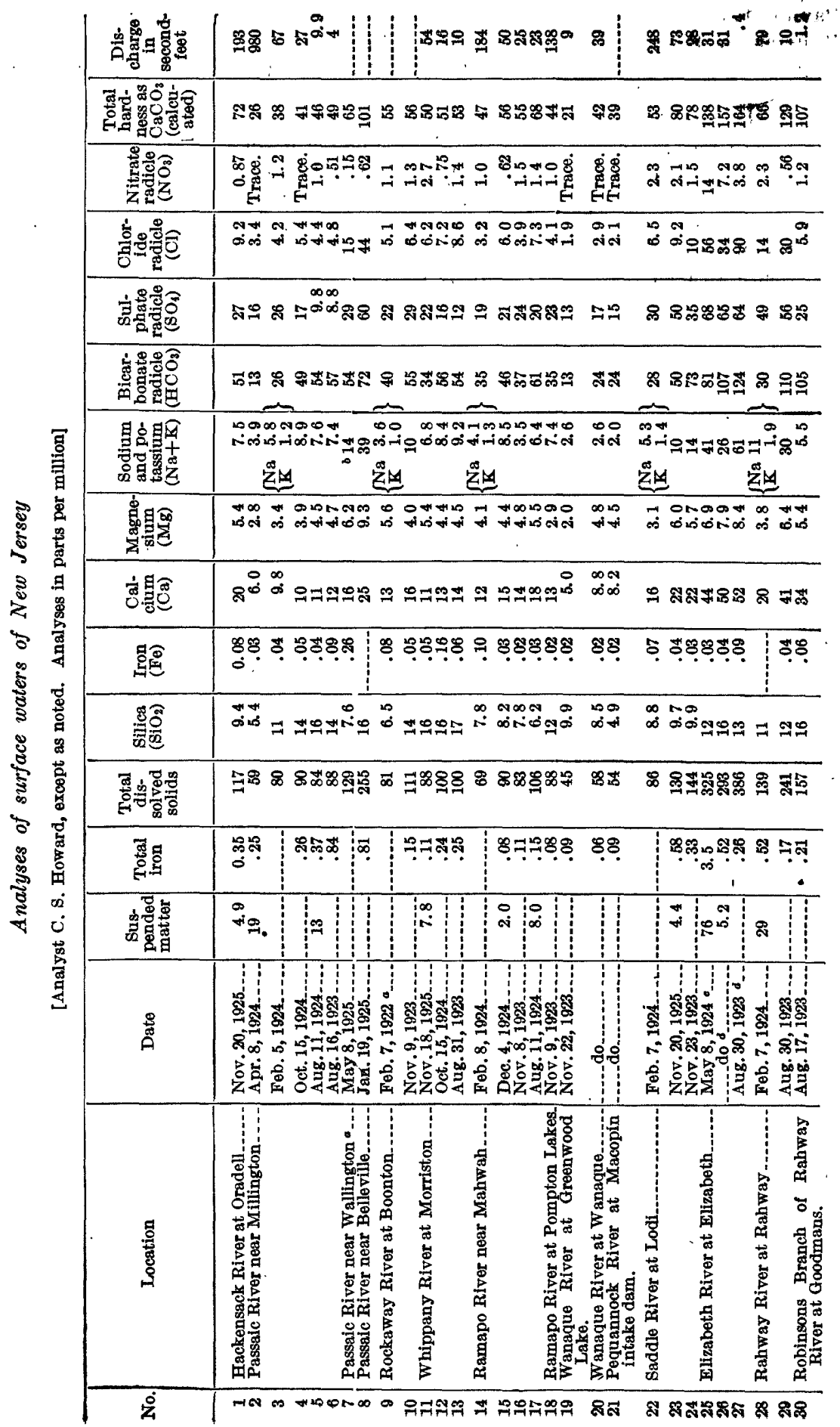




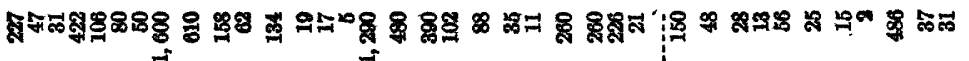

م.

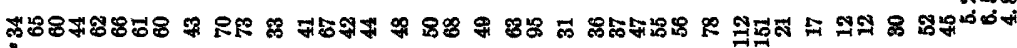

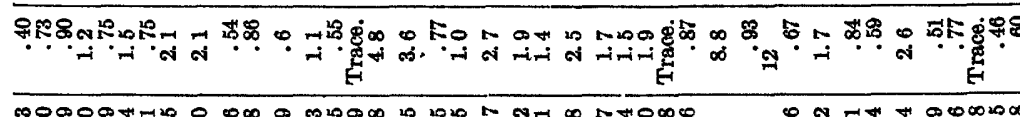

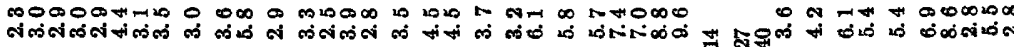

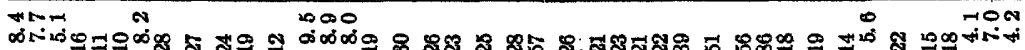

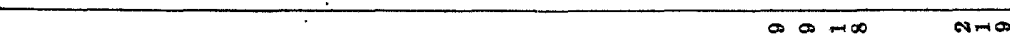

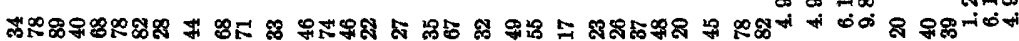

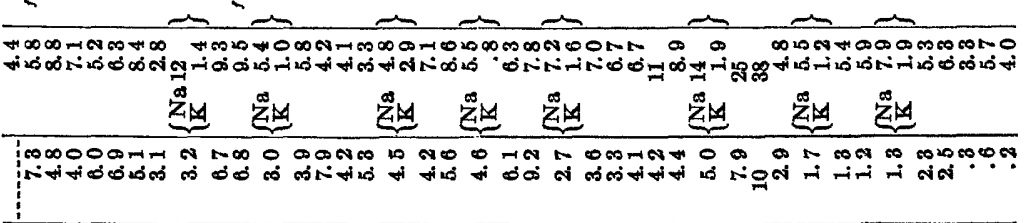

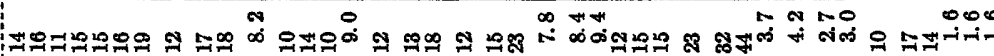

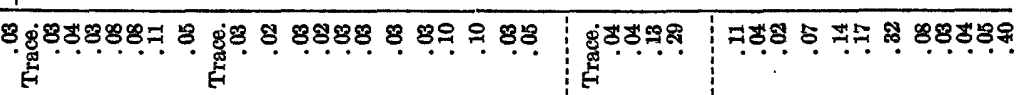

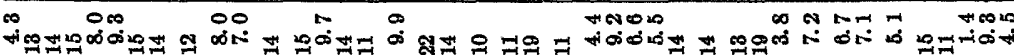

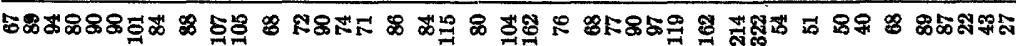

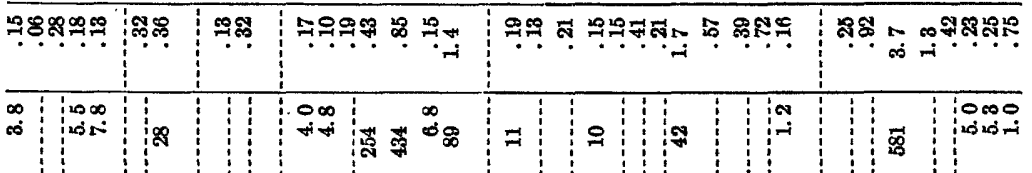

\$્心 तิ

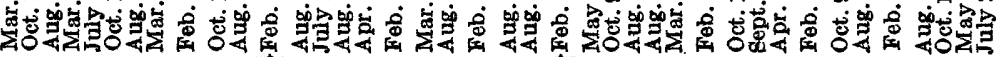

\begin{tabular}{|c|c|c|c|c|c|c|c|c|c|c|}
\hline 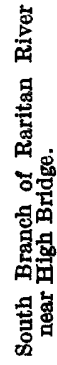 & 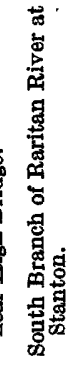 & 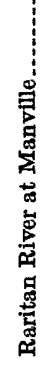 & 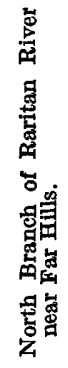 & 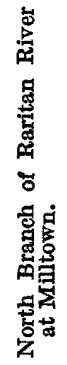 & 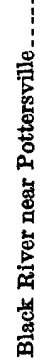 & 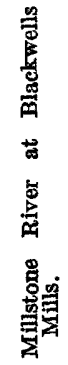 & 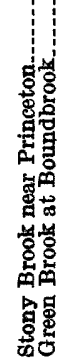 & 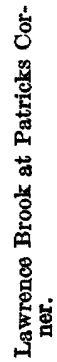 & 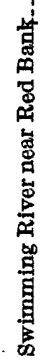 & \\
\hline
\end{tabular}




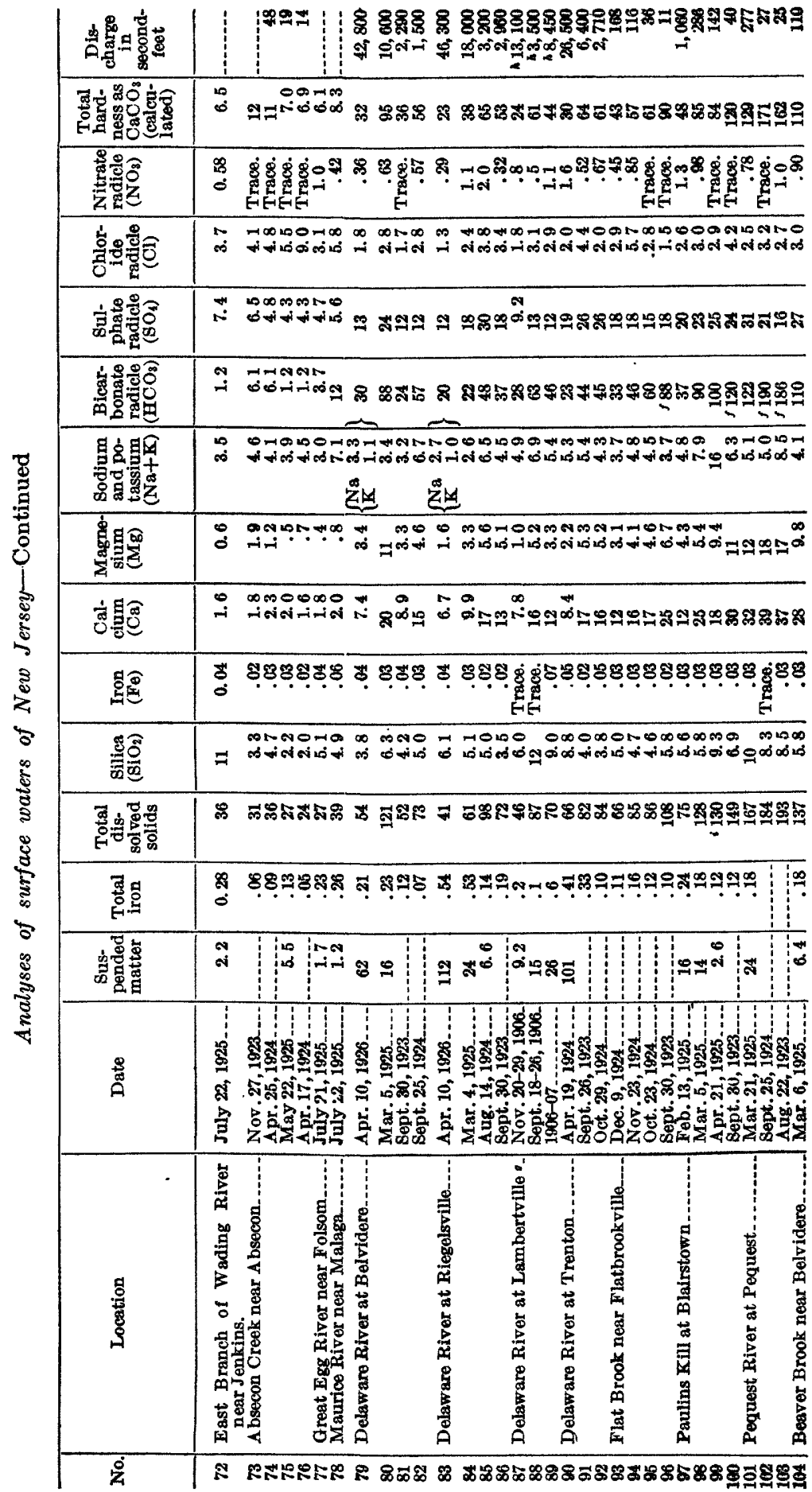




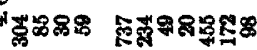

\begin{tabular}{|c|c|c|c|}
\hline 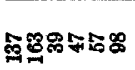 & 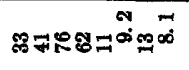 & 9 & 思品 \\
\hline 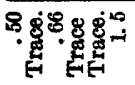 & 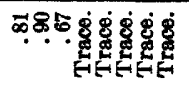 & $\stackrel{8}{8}$ & 象車 \\
\hline $\begin{array}{l}\text { n- } \\
\text { जी }\end{array}$ & 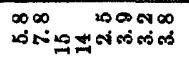 & + & $\infty \infty$ \\
\hline 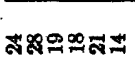 & 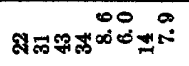 & 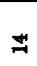 & $\approx=$ \\
\hline 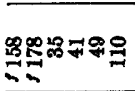 & 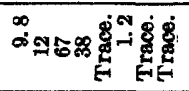 & 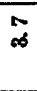 & 요 \\
\hline 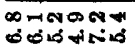 & 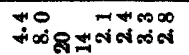 & $\infty$ & $\begin{array}{l}\infty \\
\infty\end{array}$ \\
\hline
\end{tabular}

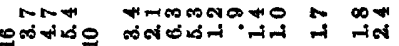

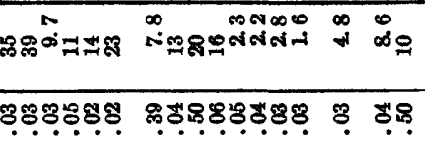

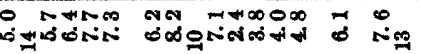

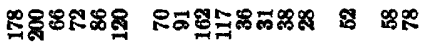

ทำำ.

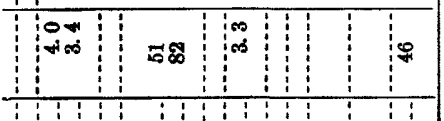

ริ

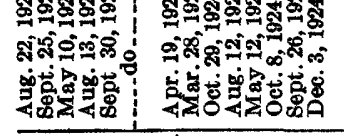

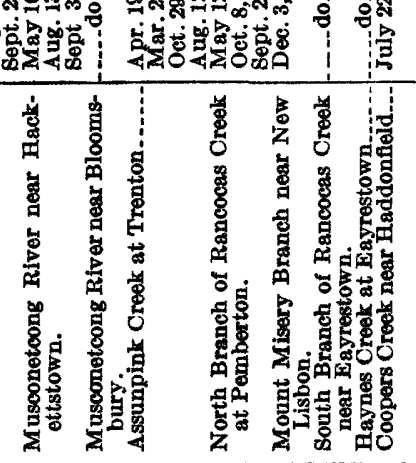

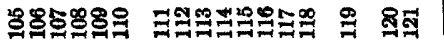





\title{
LABORATORY TESTS ON PHYSICAL PROPERTIES OF WATER-BEARING MATERIALS
}

\author{
By Norah Dowell Stearns
}

\section{INTRODUCTION}

The need of more definite quantitative data in regard to the hydrologic properties of water-bearing materials has long been recognized by geologists and engineers engaged in investigations of ground water. With the increase in importance of quantitative field studies, has come a demand for definite and accurate methods of testing samples of water-bearing sands and rocks. Until recently the classic researches of Hazen, ${ }^{1}$ King, ${ }^{2}$ and Slichter ${ }^{3}$ have been the chief basis of any quantitative estimates in this field in this country.

In 1923 an intensive investigation of the ground-water supplies in New Jersey was undertaken by David G. Thompson, of the United States Geological Survey, in cooperation with the New Jersey Department of Conservation and Development. The need for laboratory tests in connection with this investigation afforded the opportunity for establishing a small hydrologic laboratory in the Geological Survey. This paper describes briefly the apparatus and methods used in making tests of mechanical composition, porosity, moisture equivalent, and permeability, gives the data obtained from the first 97 samples that were tested, and discusses to some extent the interpretation and use of these data.

The samples for which results are given in this paper were obtained in 1923 by geologists who were making ground-water studies. The samples from New Jersey are all unconsolidated sand and gravel and range in age from Cretaceous to Recent. Those from Montana comprise unconsolidated sand, silt, and gravel and consolidated rocks,

\footnotetext{
1 Hazen, Allen, Experiments upon the purification of sewage and water at the Lawrence Experiment Station, Mass. : Massachusetts State Board of Health Twenty-third Ann. Rept., pp. 425-434, 1891 . Some physical properties of sands and gravels, with special reference to their use in filtration: Massachusetts State Board of Health Twenty-fourth Ann. Rept., pp. 541-556, 1892.

${ }^{2}$ King, F. H., Principles and conditions of the movements of ground water : U. S. Geol. Survey Nineteenth Ann. Rept., pt. 2, pp. 59-294, 1899.

Slichter, C. S., Field measurements of the rate of movement of underground water : v. S. Geol. Survey Water-Supply Paper 140, 1905.
} 
chiefly sandstone and shale, ranging in age from Lower Cretaceous to Recent. The samples from Idaho are chiefly surface silt and loess that mantle certain reservoir sites.

The primary object of the laboratory tests is to obtain quantitative data on permeability and on specific yield as defined on page 144 . The results of mechanical analysis and tests of porosity together give a nearly complete definition of the texture of unconsolidated materials, which chiefly controls both their permeability and specific yield. The porosity test supplies an essential factor in certain indirect methods of obtaining both permeability and specific yield. The moisture equivalent gives an approximation of the specific retention (p. 137) and hence of the specific yield. The permeability test gives a direct measurement of permeability to water. The four tests give at least fairly reliable comparative data on the water-bearing characteristics of the materials investigated, but much work is yet to be done before the results can be confidently applied in quantitative field problems.

\section{ACKNOWLEDGMENTS}

The hydrologic laboratory of the United States Geological Survey was started by $\mathrm{O}$. E. Meinzer, geologist in charge of the division of ground water, and the laboratory work has been organized and carried on under his supervision. Mr. Meinzer devised the methods and apparatus for taking volumetric samples and for determining permeability as described in this report. Throughout the work his counsel and the results of his long experience in the study of ground-water problems were available. Acknowledgments are due to C. E. Van Orstrand and D. G. Thompson for advice and criticism; to A. F. Melcher and C. S. Howard for aid in the laboratory procedure; and to Prof. J. H. Griffith, of Iowa State College, and Dean C. S. Slichter, of the University of Wisconsin, for criticism of the manuscript.

\section{METHODS OF TAKING SAMPLES}

Samples of unconsolidated material are taken volumetrically if possible. The apparatus devised by Mr. Meinzer for taking volumetric samples consists of a sampler and a gage rod. (Fig. 18.) The sampler is a heavy brass cylinder, 3 inches in diameter and about 1 foot long, closed at one end and having a cutting edge at the other. The gage rod is a steel rod about 2 feet long, sharpened at the front end and having a definite reference mark near the rear end. In taking a sample with this apparatus a smooth surface is first made on the exposed face of the material to be sampled. Then the gage rod is driven far into the bank at right angles to the smoothed surface, and the cylinder is pushed or driven in parallel 
to the rod, generally not more than 6 inches. By means of the gage rod the distance that the cylinder is inserted and hence the volume of the sample are readily determined. The material around the cylinder is carefully excavated, and the sample is cut off flush with the front of the cylinder with a knife or trowel. The sample is then dumped into a tin can about 4 inches in diameter and 6 inches high. A strip of soft adhesive tape is wrapped around the junction of cover and can to prevent any loss of material. The cans are shipped to the laboratory in wooden cases that hold eight cans each. Under some conditions it is practicable to obtain volumetric samples from auger holes of known diameter, care being taken to save all the material within certain limits of depth and to keep out all other material. If the deposit to be sampled has a tendency to

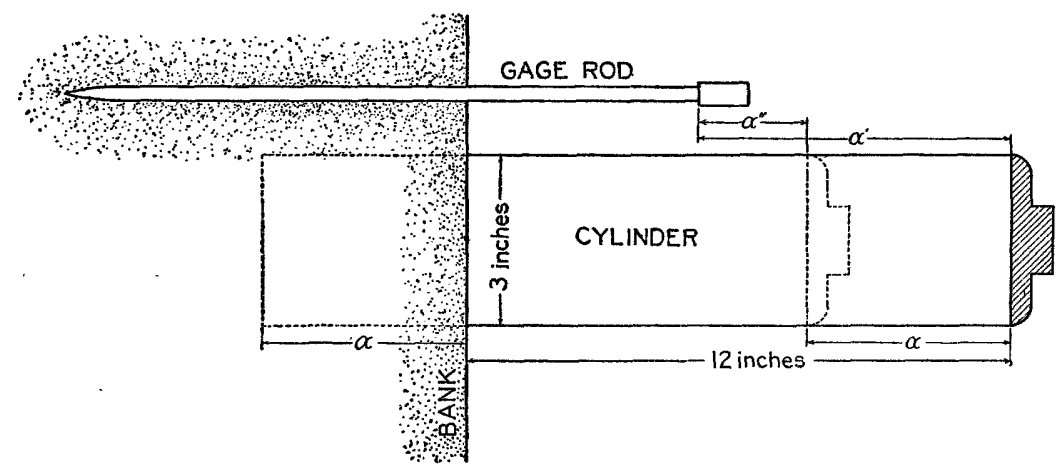

FIGURR 18.-Apparatus used for obtaining volumetric samples in the field. The length of the cylindrical sample is $a=a^{\prime}-a^{\prime \prime}$. The diameter is 3 inches. Hence the volume, in cubic inches, is $\frac{9_{\pi} a}{4}$ or $7.07 a$

cave the auger method can obviously not be used; if it contains very coarse material, neither of these volumetric methods can be used. Volumetric samples can rarely be obtained from drilled wells.

\section{APPARENT SPECIFIC GRAVITY}

When a sample of unconsolidated material is received in the laboratory it is placed in a tray and left to dry in air from one to several days, according to the wetness of the sample, until it reaches a nearly constant weight. Small samples for the several tests are obtained by quartering. If the sample is lumpy, it is first put on a glass plate and rolled with a wooden rolling pin, care being taken not to crush the grains.

Throughout this paper the term "apparent specific gravity" is used to designate the weight per unit volume of the material tested, including the pore space, in distinction from the specific gravity of the mineral matter that composes the material. From the volume $95221^{\circ}-28-9$ 
and weight the apparent specific gravity of the air-dry sample is obtained and recorded in grams per cubic centimeter. If the sample is unconsolidated and its volume was not determined in the field, a laboratory method is used to approximate the true volume. (See pp. 131-132.) The method of determining the volume and apparent specific gravity of consolidated samples is explained on page 132. In connection with the mechanical analysis (see below) the weight of an oven-dried sample is obtained and is used in computing the apparent specific gravity as given in the table on pages 164-169.

In general gravel and shale are heavier per unit volume than sand, and silt and loess are lighter. The materials from Rosebud County, Mont., have apparent specific gravities ranging from 1.33 to 2.50 and averaging 1.75. The gravel and the shales, which contain considerable clay, are heavy per unit volume; the sandstones of about average weight; and the alluvial silts, which contain a little clay, are light, ranging from only about 1.33 to 1.37 . The materials from Fergus County, Mont., have apparent specific gravities ranging from 1.89 to 2.09. The shales and sandstones that include considerable clay and silt have apparent specific gravities of $2.06,2.07$, and 2.09 ; the sandstones that are massive and fairly tight, 1.93, 1.96, and 1.98; and the gravel 1.89. The Idaho samples, which are all soils, have apparent specific gravities ranging from only 0.80 to 1.52 . The loess sample has the lowest of the group. Silty loess soils that look light and fluffy have an apparent specific gravity of 1.01 ; a loam soil, 1.27; and a fine red uniform clay, 1.52. The New Jersey samples, which consist largely of assorted sands, have apparent specific gravities that average about 1.50. The gravels, however, range from 1.68 to 1.81 , and a few silts are relatively light and fluffy and have apparent specific. gravities of only 1.01 to 1.15 .

\section{MECHANICAL ANALYSIS}

\section{METHOD OF ANALYSIS}

The mechanical analysis consists of sorting the particles of a sample by sizes. The procedure followed is in general that of the United States Bureau of Soils, ${ }^{4}$ because it is applicable to water-bearing materials, and its use makes all the mechanical analyses of the $\mathrm{Bu}$ reau of Soils available for comparison. As much water-bearing material is coarser than the common soils, however, it is desirable to have a few sieves with larger openings than 2 millimeters.

About 5 grams of the air-dry sample is put into a small dish and weighed and is then dried in an electric oven at about $110^{\circ} \mathrm{C}$. for at

4 Fletcher, C. C., and Bryan, H., Modification of the method of mechanical soll analysis: U. S. Dept. Agr. Bur. Solls Bull. 84, 1912 . 


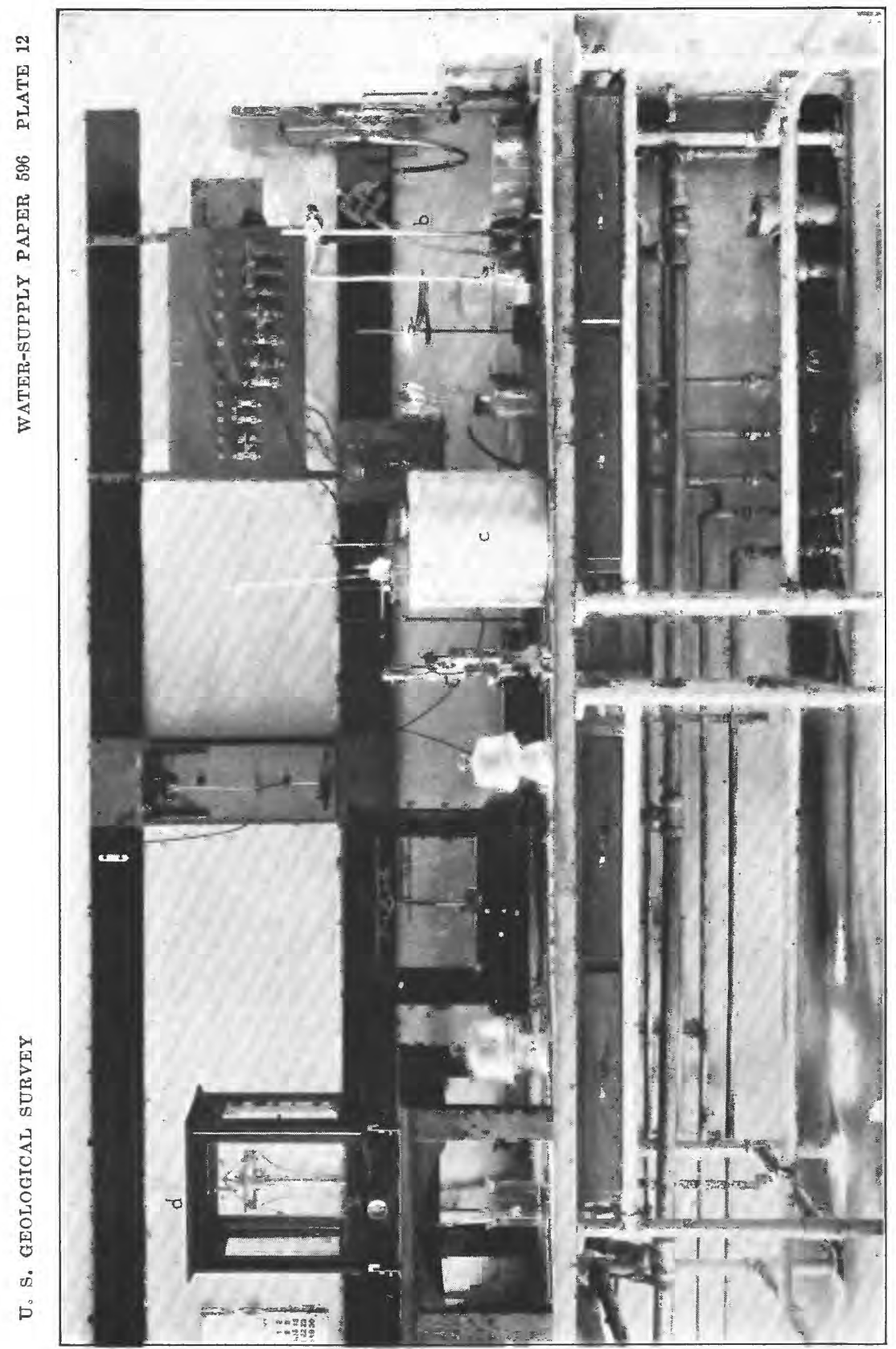

 


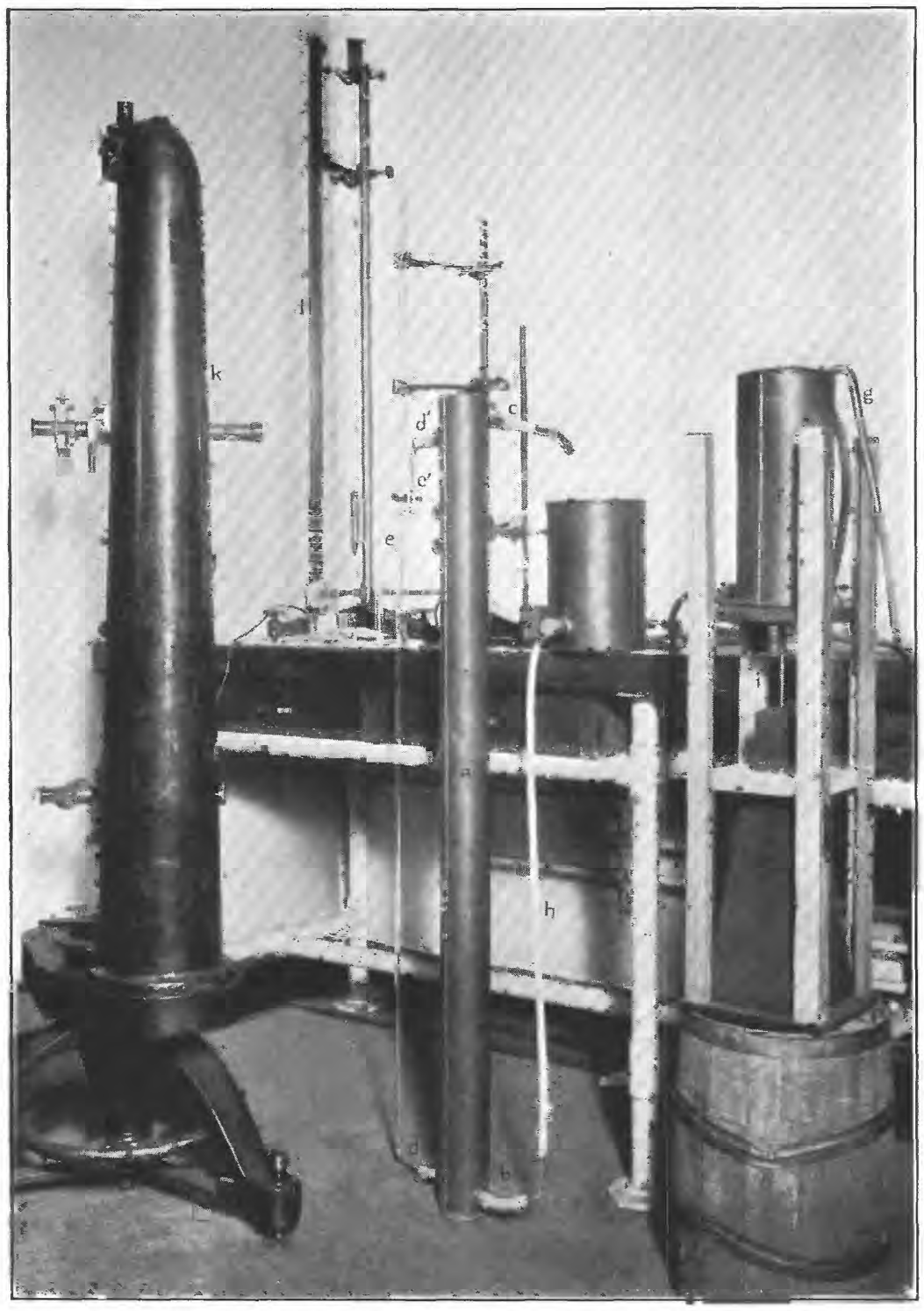

PERMEABILITY APPARATUS, INCLUDING THE LONG CYIINDER USED IN THE EXPERIMENT WITH SAND FROM FORT CASWELL, N. C.

$a$, Percolation cylinder; $b$, inflow opening; $c$, discharge opening; $d, d^{\prime}$, pressure-gage openings; $e, e^{\prime}$, pressure gages; $f$, supply tank; $g$, inflow to supply tank; $h$, tube leading frorn supply tank to percolation cylinder; $i$, screw jack; $k$, cathetometer with telescope; 1 , meter rod 

least two hours. It is then cooled in a desiccator and again weighed. The sample is then put into an 8-ounce sterilizer bottle with 4 ounces of water and about 5 cubic centimeters of ammonia, one-third strength, to deflocculate the particles. It is said that 5 drops of ammonia has been shown to be sufficient. However, in the process of analysis the soil is washed again and again, and each time the amount of ammonia left in the bottle is reduced. Hence it has been found advisable to put in several cubic centimeters at first, and thus enough is successively left to keep the particles deflocculated until all the silt and clay is washed from the sand.

The bottles containing the soil, water, and ammonia are put on the shaking machine (pl. 11, $A$ ) and shaken for at least seven hours. More time usually does no harm to the soil, but if left too long the rubber stoppers may be eroded to an appreciable extent.

Eight samples are usually tested at one time.

The bottles containing the samples are removed from the shaking machine and placed upright in a rack. The rubber stoppers are removed and examined for erosion. If the stoppers are badly eroded it may be necessary to repeat the analysis, as the eroded rubber may cause considerable error in the result. Any material adhering to the stopper is washed back into the bottle with the jet from a wash bottle. Each of the eight samples is in turn brought into suspension by the use of the compressed water jet, and then sufficient time is allowed for all the sand to settle. This time is determined by inspection and can be checked by an examination under the microscope. Usually, if the contents of the eight bottles are stirred up in order, by the time the last bottle is reached the first is ready to decant.

The liquid in each of the bottles is decanted into a separate dish. The residue is again washed and the liquid is again decanted, and this process is repeated until the liquid is clear. The sands remaining in the bottles are washed into porcelain dishes and dried on the steam bath. They are then transferred to small dishes and dried in the electric oven at about $110^{\circ} \mathrm{C}$. After being cooled in a desiccator they are weighed, then allowed to take moisture from the atmosphere, and again weighed. The sands are then ready for sieving.

The decanted liquids are placed in centrifuge tubes, and the centrifuge is run until there are no silt particles left in suspension. This is determined by inspection and by use of the microscope. The liquid, which is the clay suspension, is decanted. The silt at the bottom of the tubes is brought into suspension by the water jet. After centrifuging again another examination is made to determine the absence of silt particles in suspension and the liquid is decanted as before. This procedure is continued until the separation is virtually complete. As a rule, in the earlier processes of separation the larger particles 
are held up by smaller ones, and, consequently, as the separation nears completion it is possible to reduce the time of centrifuging.

The length of time for centrifuging will differ with the soil and with the speed of the centrifuge. Thus clayey samples are almost invariably more difficult to separate than sandy samples.. They require a longer period of centrifuging and must be centrifuged more times before the separation is complete. The centrifuge used is run at a speed of 500 revolutions a minute, the time run ranges from 5 minutes or less to about 10 minutes, and the number of times from about 5 to 15 or more.

The silts in the bottom of the tubes are washed into dishes and dried on a steam bath. They are then transferred to small dishes and dried in an electric oven at about $110^{\circ} \mathrm{C}$., cooled in a desiccator, and weighed.

The clay content may be determined directly by drying and weighing or by difference. In the first method the clay water is evaporated and the residue weighed. Because of the large amount of clayey water to be reduced by evaporation and hence the large container that is required, a heavy balance must be used in weighing, with corresponding loss in accuracy, or else the dry clay must be transferred to a smaller dish. A transfer of the dried clay, however, requires much time and involves great possibilities of loss of material. In the second method the total initial weight minus the weight of the sand and silt gives the weight of the clay. The error thus introduced is believed to be no greater than that involved in the separation of the clay and silt, and all errors due to loss by transfer and change in the state of hydration of the clay are eliminated.

There is usually little or no organic matter in the water-bearing materials, and hence organic matter is disregarded in the mechanical analysis made in the hydrologic laboratory. If the sample contains material that is much larger than 2 millimeters, a larger sample is taken and is put through the coarser sieves in the air-dry condition. The 5-gram sample is then taken from the material that passed through the 2-millimeter sieve.

The air-dry sand is placed in the top of a nest of sieves 2 inches in diameter and the sieves are agitated on a shaker $(p l .11, B)$ for about three minutes. The portions of sand remaining on each of the sieves and that which went through all the sieves to the bottom pan are weighed. Two of the sieves consist of brass plates with perforations about 1 and 0.5 millimeter in diameter. The other two are made of bolting cloth, the meshes of which give openings of about 0.25 and 0.1 millimeter. If the sample is very coarse sieves with perforations 2 and 5 millimeters in diameter are also used. The silt particles are regarded as 0.05 to 0.005 millimeter in diameter and the clay as 
less than 0.005 millimeter. Thus the separations ordinarily made are as follows, expressed in millimeters:

Gravel, greater than 5.

Gravel, $\mathbf{5}$ to 2.

Fine gravel, 2 to 1.

Coarse sand, 1 to 0.5 .

Medium sand, 0.5 to 0.25 .
Fine sand, 0.25 to 0.1 .

Very fine sand, 0.1 to 0.05 .

Silt, 0.05 to 0.005 .

Clay, less than 0.005 .

A calibration by the United States Bureau of Standards of the sjeves used indicates that the exact sizes of the openings are slightly different from the sizes stated above. The 0.5 is 0.59 , the 0.25 is 0.26 , the 0.1 is 0.09 . These exact sizes are used in the graphs and table. A summary of the classifications of materials according to size of grain used in different countries is given in a brief paper by Von Greyerz. ${ }^{5}$

\section{METHODS OF EXPRESSING RESULTS}

The weights of the materials of the several sizes are computed into percentages of the total weight. 'These percentages are given in the table on pages 164-169. They show that whereas some of the water-bearing materials investigated are more nearly uniform than others, each comprises several sizes. Some have large percentages of one or two sizes and small percentages of others; some have small percentages of all the sizes. The materials are, in general, coarser and more heterogeneous than the soils analyzed by the Bureau of Soils and not so well assorted as the sands used for filters. In Figures 19 and 20 are shown two methods of representing the mechanical composition graphically. As the terms are ordinarily used, No. 60 shows a clay, No. 47 a silt, No. 33 a fine sand, No. 72 a medium sand, No. 73 a coarse sand, and No. 65 a gravel.

The effective size of grain of a soil or rock is defined as the diameter of the grains in an assumed material that has the same transmission constant, or permeability, as the soil or rock under consideration and is composed of spherical grains of equal size arranged in a specified manner as indicated by the porosity. This is the general definition given by Meinzer ${ }^{6}$ and is substantially the meaning of the term as used by Slichter (p. 171). In correspondence Slichter has explained that in his use of the term the assumed soil or rock has the same porosity as the actual sample, except in materials to which this definition can not be applied. He states: "This definition can not be applied to a sandstone or to a mass of crystalline or angular particles. For such material I define effective size, but at stated porosity,

\footnotetext{
- Von Greyerz, Walo (captain, Royal Swedish Engineers), Nomenklatur för lösa jor. darter; Teknisk Tidskrift, Häft 52, 1925.

Meinzer, O. E., Outline of ground-water hydrology, with definit:ons : U. S. Geol. Survey Water-Supply Paper 494, p. 45, 1923.
} 


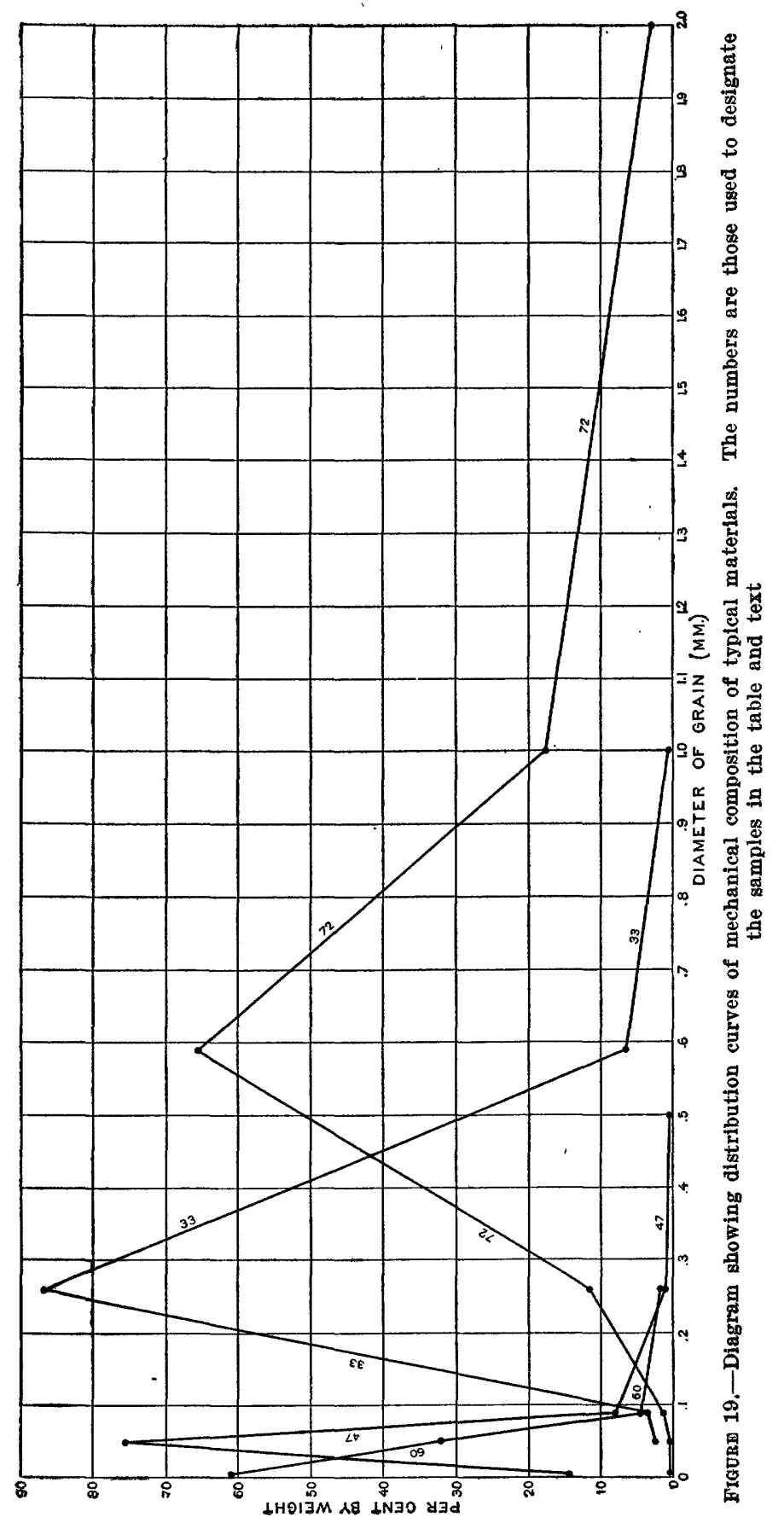




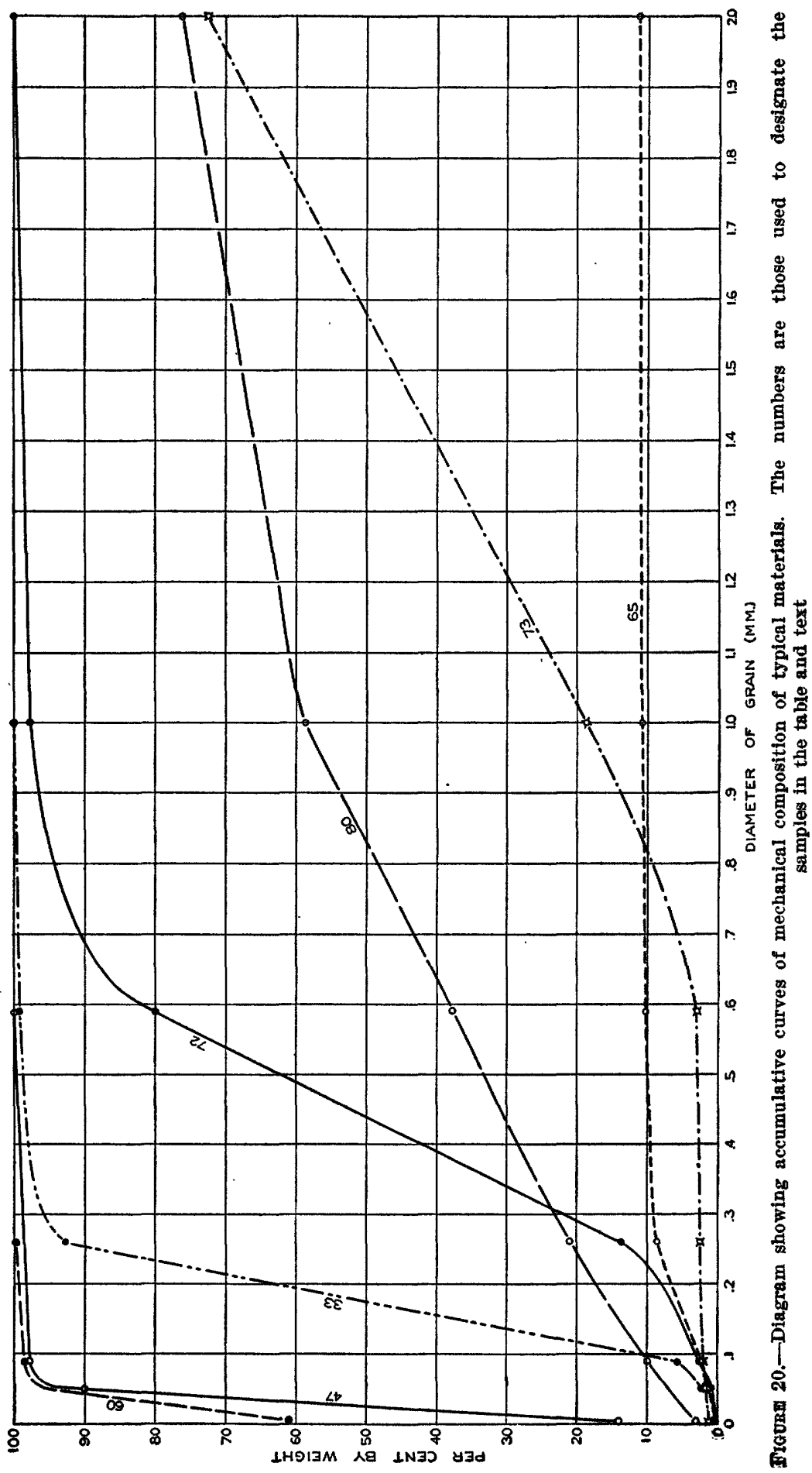


26 per cent. The definition needs must be very artificial, as sandstone of 15 per cent porosity can not be replaced by a uniform sand of that porosity." King, however, used the term "effective size" with the meaning of size of grain having average surface (p. 171), and Hazen used it in the sense of the size of grain that is larger than 10 per cent of the material and smaller than 90 per cent of the material (p. 170). The 10 per cent sizes of the samples tested, as obtained from accumulative curves of the mechanical analyses, are given in the table on pages 164-169.

The uniformity coefficient was used by Hazen ${ }^{7}$ to compare granular materials with respect to their degree of assortment. It is an expression of the variety of the sizes of the grains that constitute the material. As the term has been used, it is defined as the quotient of the diameter of the grain that is just too large to pass through a sieve that allows 60 per cent of the material by weight to pass through, divided by the diameter of a grain that is just too large to pass through a sieve that allows 10 per cent to pass through. The 60 per cent size, as well as the 10 per cent size, can be taken from the accumulative curves of the mechanical analyses. The more nearly uniform the grains of a material the steeper will be the curve and the smaller will be the uniformity coefficient. The uniformity coefficient of a material whose grains are all of the same size is 1.

The computed uniformity coefficients of the samples tested are given in the table on pages 164-169. This coefficient is obviously only a rough expression of the degree of uniformity of a material, and in some samples it is rather misleading. Thus in sample 19 the 60 per cent line cuts the 0.155 millimeter size, and the 10 per cent line cuts the 0.005 millimeter size, giving a uniformity coefficient of 31 . Nevertheless, the material is relatively uniform, as is shown by the fact that 63 per cent is between 0.10 and 0.25 millimeter and 15 per cent between 0.05 and 0.10 millimeter, which gives 78 per cent of the size about 0.10 millimeter. In contrast, the coefficient of uniformity of No. 80, a typically heterogeneous material, is only 12, the 10 per cent line being at 0.09 millimeter and the 60 per cent line at 1.07 .

Van Orstrand $^{8}$ has suggested a method by which three essential quantities computed from a mechanical analysis define the material in a comparative scale. The computation of these quantities involves higher mathematics and is laborious, but on the basis of his work it may be possible to devise a more simple formula which will give approximate results and can be more widely used. Such quantities

\footnotetext{
${ }^{7}$ Hazen, Allen, Experiments upon the purification of sewage and water at the Lawrence Experiment Station, Nov. 1, 1889, to Dec. 31, 1891 : Massachusetts State Board of Health, Twenty-third Ann. Rept., p. 431, 1892. See also Meinzer, O. E., op. cit., p. 45.

${ }^{8}$ Van Orstrand, C. E., On the empirical representation of certain production curves : Washington Acad. Sci. Jour., vol. 15, pp. 19-39, 1925.
} 
would express briefly the important features now shown in a mechanical analysis. Attempts have also been made to express the mechanical analyses by means of a "fineness modulus" or a " surface modulus."

\section{POROSITY}

\section{GENERAL METHOD}

The porosity of a sample is the percentage of pore space in the total volume of the sample-that is, the space not occupied by solid mineral matter. This percentage expresses practically the volume that can be occupied by water. The method used in the hydrologic laboratory for determining the porosity is that used by Melcher, ${ }^{10}$ with modifications for unconsolidated and coarse materials. There are two parts to the test-one to obtain the volume of the sample and the other to obtain the aggregate volume of the grains. The total volume of the sample minus the aggregate volume of the grains gives the volume of the pore space. The porosity is computed by the formula $P=100 \frac{V-v}{V}$, in which $P$ is the porosity in percentage, $V$ is the volume of the sample, and $v$ is the aggregate volume of the grains.

\section{METHOD OF DETERMINING THE VOLUME OF THE SAMPLE}

If the sample is unconsolidated and its volume was determined in the field, the volume of the small sample used for the porosity test is computed from its air-dry weight as compared with the airdry weight of the entire sample.

If the sample is unconsolidated and its volume was not determined in the field (see pp. 123-124), some of the air-dry material of the ample is put into a beaker or small-mouthed bottle of known cazacity and weight and is jarred and tamped to make it as compact is possible. After a certain amount of compacting any further "arring and tamping does not appreciably decrease the volume. The ressel filled with the material is then weighed, and the apparent pecific gravity of the air-dry material is computed in grams per "xbic centimeter.

The compacting in the laboratory may be either greater or less ithan that in nature. The compacting of fine, well-assorted materials is likely to be greater. For instance, a very tight packing in the Jaboratory of sample 78, a light fluffy loess, gave an apparent specific

- Tyler, R. G., A fineness modulus for filter sands: New England Waterworks Ass. "nur., vol. 39, pp. $239-253$, 1925; vol. 40, pp. 24-28, 1926. See also reference to the rork of A. N. Talbot, on page 253 of Tyler's paper.

${ }^{10}$ Melcher, A. F., Determination of pore space of oil and gas sands: Mining and 1. stallurgy, No. 160, sec. 5, April; 1920. 
gravity of 1.00 , but the apparent specific gravity computed from the volume of the sample as determined in the field is only 0.80 , showing that the compacting was much greater in the laboratory than in nature. On the other hand, it is difficult to pack gravel tightly. The rather heterogeneous sample of sand No. 102 had an apparent specific gravity of 1.85 in nature but only 1.66 in a laboratory test.

If the material is consolidated, the volume is obtained by coating it with paraffin and weighing it in air and in water. The fragment is cleaned of foreign material and loose particles are brushed off. It is weighed and then dipped in paraffin heated to a temperature a little above the melting point. The layer of paraffin is examined for air bubbles and pin holes, and these are removed by remelting the paraffin around them with the end of a hot wire. In dipping the fragments it is best to hold them with the fingers, first dipping one half of the fragment and then the other half. The samples are immersed for very short periods, two to three seconds or less, as tho paraffin should not enter the pores. If there is any doubt about the paraffin entering the pores, the specimen is broken and, examined after the test has been made. When the paraffin cools the sample with its coating is weighed to determine the weight of the paraffin.

The sample with the coating of paraffin is suspended in distilled water by a fine wire and weighed. (See $d$ in pl. 12.) A fine wire is used so that the error due to surface tension will be as small as possible. The temperature of the water is taken at the time of the weighing. The sample is then removed from the water, dried by pressing the surface against bibulous paper or a small towel, and weighed in air. The purpose of this weighing is to see whether the sample absorbed any water. If an appreciable quantity of water was absorbed, its weight, determined from the difference between the last weighing and the former weighing of the sample plus the paraffin in air, is added to the weight of the water displaced.

From the weight of the water displaced, its temperature, and its density the volume of the sample plus the paraffin is obtained. Fron a previous determination of the density of paraffin and the weight of the paraffin covering the sample the volume of the paraffin is computed. This volume subtracted from the total volume gives th? volume of the fragment of rock used.

\section{METHOD OF DETERMINING THE VOLUME OF THE GRAINS}

A sample weighing about 5 grams is dried in an electric oven s.t $110^{\circ} \mathrm{C}$. for 30 minutes to 1 hour, cooled in a desiccator, and weighed. It is then exposed to the air and allowed to take up moisture. Aftrr the sample has reached a nearly constant weight, it is transferred to 
a pycnometer of known weight by means of glazed paper. The pycnometer containing the sample is then weighed to correct for any loss in transfer.

The pycnometer used is of the type designed by Johnston and Adams, ${ }^{11}$ of the Carnegie Institution. The essential feature of this type is the plane-ground joint between the stopper and the bottle. The neck is made fairly thick, partly for strength and partly to minimize heat transfer when the bottle is held by the neck between the fingers. It is made in such a manner that there is no recess on the outside from which water can not readily be wiped away.

The pycnometer is attached to an aspirator (b in pl. 12), the air is evacuated from the sample, and distilled water is added under a vacuum. The pycnometer is placed in a constant-temperature thermostat ( $\mathrm{c}$ in pl. 12) regulated to $0.1^{\circ} \mathrm{C}$. Filling of the pycnometer is completed with distilled water taken from another vessel in the thermostat. After half an hour the pycnometer is removed from the thermostat, the outside surface is carefully dried with a towel, and the pycnometer is weighed. From a previous calibration of the pycnometer, which gives the weight of water necessary to fill it, the weight of water that the sample displaced is found. The volume of the particles of the sample in the pycnometer is computed from the weight of the water displaced and the table of densities of water at the temperature of the thermostat.

Although this method was used in determining the porosities given in this report, a study of the subject shows that the refinements of the method are not essential, because the experimental errors involved in determining the volume of unconsolidated samples are unavoidably great.

The pycnometer described is not adapted for use with coarse material. If the sample is a clean gravel a larger sample is taken, and a larger wide-mouthed bottle of known capacity and weight is used instead of the pycnometer. The aspirator is not used. If the sample contains both fine and coarse material the material larger than 2 millimeters is separated from the rest of the sample and is tested by the method used for gravel. The rest of the sample is then tested by the ordinary method.

\section{POROSITY DATA}

The porosity of a granular material depends largely upon the degree of assortment and the manner of packing of the grains. As

\footnotetext{
11 Johnston, John, and Adams, L. H., On the density of solid substances with espectal reference to permanent changes produced by high pressures: Am. Chem. Soc. Jour., vol. 34, p. 566, 1812 .
} 
is explained by Slichter, ${ }^{12}$ spheres of the same size can be packed so as to give porosities ranging from 25.95 to 47.64 per cent. In fact, even less compact arrangements are possible and occur, especially in soils. Angular grains of various sizes can be packed either more closely or more loosely than spherical grains, and hence they have an even wider range of possible porosities. The size of the grains is not important with respect to porosity. If other conditions are the same a material will have the same porosity whether it consists of large or small grains. On the whole, silt and clay are about as porous as sand and gravel. A sample composed of large grains of uniform size has a high porosity, and a sample composed of small grains of uniform size has an equally high porosity, but a sample composed of a mixture of grains of these two sizes has a much lower porosity.

Of the materials tested (see table on pp. 164-169), the heterogeneous gravels have low porosities; the consolidated samples have the next lowest; the medium-grained, fairly well assorted sands have rather high porosities, usually between 30 and 50 per cent; and the fine-grained, well-assorted materials, such as the loess and silt from Idaho, the shales and silt from Montana, and the fine silty materials from New Jersey, have the highest porosities-between 50 and 60 per cent.

Figure 21 shows that in a very general way the porosity of the samples tested increases with the uniformity coefficient, but that in many of the samples there are wide digressions from this rule. These digressions may be due partly to the fact that the so-called uniformity coefficient does not always express the actual degree of uniformity and partly to the fact that heterogeneous materials may be arranged in nature in a manner that gives high porosity, as is the case in many soils.

\section{MOISTURE EQUIVALENT}

\section{METHOD OF DETERMINING MOISTURE EQUIVALENT}

The term "moisture equivalent" was introduced by Briggs and McLane ${ }^{13}$ to denote the quantity of water retained by a sample of soil or other material when it is saturated and then subjected to a constant centrifugal force. ${ }^{14}$ As originally defined it is the ratio of the weight of water retained to the weight of the dry sample.

12 Slichter, C. S., Theoretical investigation of the motion of ground waters: U. S. Geol. Survey Nineteenth Ann. Rept., pt. 2, pp. 306 et seq., 1899.

${ }_{13}$ Briggs, L. J., and McLane, J. W., The moisture equivalents of soils : U. S. Dept. Agr. Bur. Soils Bull. 45, 1907.

1 For a summary of the work done by Briggs, McLane, Israelsen, and others on moisture equivalents see Meinzer, 0 . E., 'The occurrence of ground water in the United States, with a discussion of principles: U. S. Geol. Survey Water-Supply Paper 489, pp. 50-76, 1923 


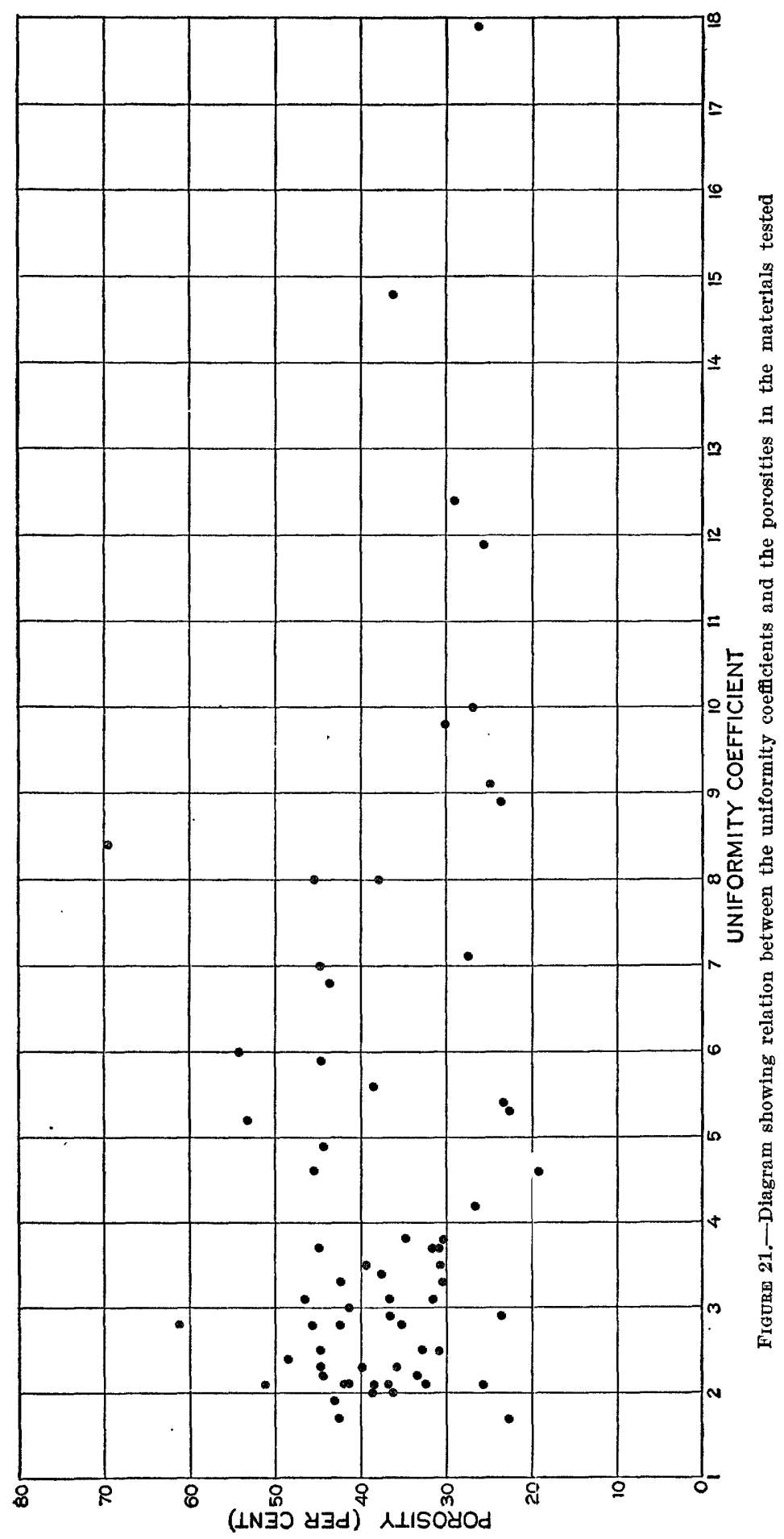


The moisture equivalent is computed by the formula

$$
M_{w}=100 \frac{w}{W}
$$

in which $M_{w}$ is the moisture equivalent in percentage by weight, $w$ is the weight of the moisture, and $W$ is the weight of the dry sample. The formula for the moisture equivalent by volume is

$$
M_{v}=100 \frac{w}{W} S,
$$

in which $M_{v}$ is the moisture equivalent in percentage by volume and $S$ is the apparent specific gravity of the dry sample.

The test for moisture equivalent is made practically according to the method used by Boyd ${ }^{15}$ in the laboratory of the United States Bureau of Public Roads and is not essentially different from the method used by the Bureau of Soils. A small piece of filter paper is placed in the bottom of a Gooch crucible to prevent the material to be tested from sifting through. A 5-gram sample is placed in the crucible and the crucible is set in a pan of water to allow the sample to take up water by capillarity until it is saturated. The crucible with the saturated sample is placed in a moist chamber overnight to insure an even distribution of moisture throughout the sample. It is then placed in a Babcock cup with a perforated rubber stopper at. the bottom, which serves as a cushion. This stopper is provided with a hole sufficiently large to hold the water that is thrown out during the centrifuging, without allowing any moisture to be drawn back into the crucible by capillarity after centrifuging. The Babcock cup is provided with a brass cover to prevent evaporation. The sample is centrifuged for an hour at a speed which for the diameter of head used will exert a centrifugal force approximately 1,000 times the force of gravity.

As a check on the results duplicate samples are placed opposite each other in the centrifuge. The centrifuge may vibrate badly if the cups do not exactly balance, but as about the same quantity of water is thrown out from equal weights of the same material the cups opposite each other generally continue to balance throughout the centrifuging. If the cups do not balance, fine shot is put in the bottom of one until it balances the other exactly.

After centrifuging the samples are weighed at once, before appreciable evaporation can take place. They are then dried in an electric oven at $110^{\circ} \mathrm{C}$., cooled in a desiccator, and weighed. The weight of the moist soil minus the weight of the dry soil gives the weight of the moisture which was retained after centrifuging. The moisture

${ }^{15}$ Boyd, J. R., Physical properties of subgrade materials : Am. Soc. Testing Materials Proc., vol. 22, pt. 2, Technical papers, pp. 337 et seg., 1922. 
equivalent, by weight, is this moisture expressed as a percentage of the weight of the dry soil. The moisture equivalent by volume is computed by multiplying the percentage by weight of the apparent specific gravity. (See formulas, p. 136.)

In some samples, especially in those consisting of clayey material, the moisture equivalent by volume is greater than the porosity. When the samples are saturated they usually show an excess of moisture on the top. In clayey samples the centrifuging often allows this excess to remain or to accumulate on top because the material is too impervious to allow it to pass through and be thrown out. It is possible that the centrifuging compacts the clay particles and squeezes out moisture, which accumulates on top. This excess moisture gives the sample a high apparent moisture content. Briggs and McLane ${ }^{16}$ state that they encountered this difficulty in some of the more retentive materials when large quantities of soil were used, and they therefore used samples with a depth of only 5 millimeters. Some samples of clay that contain considerable colloidal material may absorb large amounts of water, and the moisture equivalent may be greater than the porosity. Such absorbed water is actually retained in the material against the pull of the centrifugal force and can properly be considered a part of the moisture equivalent.

Tests of moisture equivalent can not be made by this method on coarse materials. The conditions of the test require a sample weighing not more than about 5 grams, in order not to have too great a thickness of material, and only material with particles less than 2 millimeters in diameter is used. It is found that fine uniform materials give close checks in results, and that coarse, heterogeneous materials differ rather widely. In heterogeneous materials the proportions of coarse and fine in the small samples used may not be the same. The method of quartering is evidently not sufficiently refined for a 5-gram sample, and it is probably impossible by any feasible method to obtain two 5-gram samples of heterogeneous material that do not differ considerably in their proportions of large and small grains.

\section{RELATION OF MOISTURE EQUIVALENT TO SPECIFIC RETENTION}

The moisture-equivalent test is made to obtain a value for the specific retention. The term "specific retention" ${ }^{17}$ is used to express the quantity of water which a soil or rock will retain against the pull of gravity if it is drained after having been saturated. The ratio

${ }^{16}$ Op. cit., p. 15.

${ }^{17}$ Meinzer, O. E., The occurrence of ground water in the United States, with a discussion of principles: U. S. Geol. Survey Water-Supply Paper 489, pp. 50 et seq., 1923; Outline of ground-water hydrology, with definitions: U. S. Geol. Survey Water-Supply Paper 494, p. 28, 1923. 
of the volume of this retained water to the total volume of the material, expressed as a percentage, is the specific retention. The specific retention of the formation is invariably less than the percentage of water retained by small isolated samples of the same material that are saturated and then allowed to drain. The communicating interstices of a soil or rock commonly form irregular capillary tubes. In a small sample these tubes may be short enough to hold all of their water, but in nature many of the tubes are indefinitely long and hence are drained down to a certain level above the water table determined by their diameters. Obviously, in any direct test, whether made in the laboratory or in the field, the true specific retention of the material can be ascertained only by using a high column of the material and disregarding the lower part that lies within the capillary fringe. A good summary of the measurements of the water-retaining capacity of soils, made chiefly in the field and beginning with King in 1889, is given by Israelsen and West. ${ }^{18}$

The moisture-equivalent method of determining the specific retention is based on the theory of applying a centrifugal force great enough to reduce the capillary fringe so much that this fringe can be ignored without introducing much error, even in small samples, and yet not great enough to withdraw a large proportion of the water that is held more securely above the capillary fringe. Thus, if a material will lift water 100 inches by capillarity acting against gravity, it will theoretically be able to hold it only 0.1 inch against a centrifugal force that is 1,000 times as great as the force of gravity.

Experimental work indicates that for at least some materials the moisture equivalent approximates the specific retention. Israelsen, ${ }^{19}$ who has made extensive field experiments on water-retaining capacities, states:

Correlations between the moisture equivalent and the maximum amounts of water found after irrigation show a gratifying agreement and suggest that the moisture equivalent might be made a basis of judging maximum capillary capacities [essentially specific retentions].

F. H. Veihmeyer, of the University of California, who has done much work on this subject, wrote on February 8, 1924: "All of the results we have obtained so far indicate that the moisture equivalent is a fairly accurate measure of the moisture-holding capacity of our agricultural soils." Veihmeyer's method is similar to that used by Israelsen. He determines the moisture content of samples of a soil 24 hours after an irrigation sufficient to wet the soil 6 feet in

\footnotetext{
${ }^{18}$ Israelsen, O. W., and West, F. L., Water-holding capacity of irrigated soils : Utah Agr. Coll. Exper. Sta. Bull. 183, p. 18, 1922.

${ }^{19}$ Israelsen, 0 . W., Studies on capacities of soils for irrigation water, and on a new method of determining volume weight: Jour. Agr. Research, vol. 13, p. 34, 1918.
} 
depth and also the moisture equivalents of the same samples. Veihmeyer ${ }^{20}$ found that the percentage of moisture retained by a sample that is centrifuged at 1,000 times the force of gravity varies inversely with the size of the sample. Thus a 60-gram sample of a certain sandy loam gave a moisture equivalent of 21 per cent, whereas a 10-gram sample of the same soil gave a result of 32 per cent. Similarly a 60-gram sample of a certain clay loam gave a moisture equivalent of 22 per cent and a 10 -gram sample 38 per cent. He says that with samples in excess of 60 grams in standard centrifuge cups the moisture equivalent is fairly constant. These experimental data obtained by Veihmeyer seem to verify the theoretical conclusions reached by Meinzer ${ }^{21}$ that each centrifuged sample retains at the bottom a capillary fringe the height of which is inversely proportional to the centrifugal force. As the height of the capillary fringe is independent of the height of the sample, it follows that the shallower the sample the larger the proportion of it that remains in the capillary fringe and hence the higher the percentage of moisture it retains against the centrifugal force. By using large samples this error becomes negligible. It seems desirable, therefore, that a test should be devised in which a relatively large sample can be used.

Bates $^{22}$ attempted to make moisture-equivalent tests on coarse heterogeneous forest soils and suggested centrifuging large samples of soil under a force of only one hundred times gravity. The large sample is obviously an advantage, but the reduction of the force exerted seems of doubtful value, because it will result in higher capillary fringes in the samples while they are being centrifuged. If the moisture-equivalent test is to be used to determine the specific retention of water-bearing materials, there is urgent need of adapting the test to materials that are coarse and heterogeneous.

\section{RELATION OF MECHANICAL ANALYSIS TO MOISTURE EQUIVAIENT AND SPECIFIC RETENTION}

The moisture equivalents of the samples tested range from 1.34 per cent to more than 100 per cent. (See table, pp. 164-169.) The samples that have extremely high moisture equivalents contain large amounts of clay or silt; those that have small moisture equivalents consist largely of coarse material. Figure 22 shows a general relation between the moisture equivalents of the samples tested and their 10 per cent sizes.

${ }^{20}$ Correspondence Feb. 8, 1924. See also Veihmeyer, F. J., Israelsen, O. W., and Conrad, J. "P., The moisture equivalent as influenced by the amount of soil used in its determination : California Univ. Agr. Exper. Sta. Tech. Paper 16, 1924.

21 Meinzer, O. E., op. cit. (Water-Supply Paper 489), p. 72.

22 Bates, C. G., and Zon, Raphael, Research methods in the study of forest environment: U. S. Dept. Agr. Bull. 1059, May 19, 1922. 


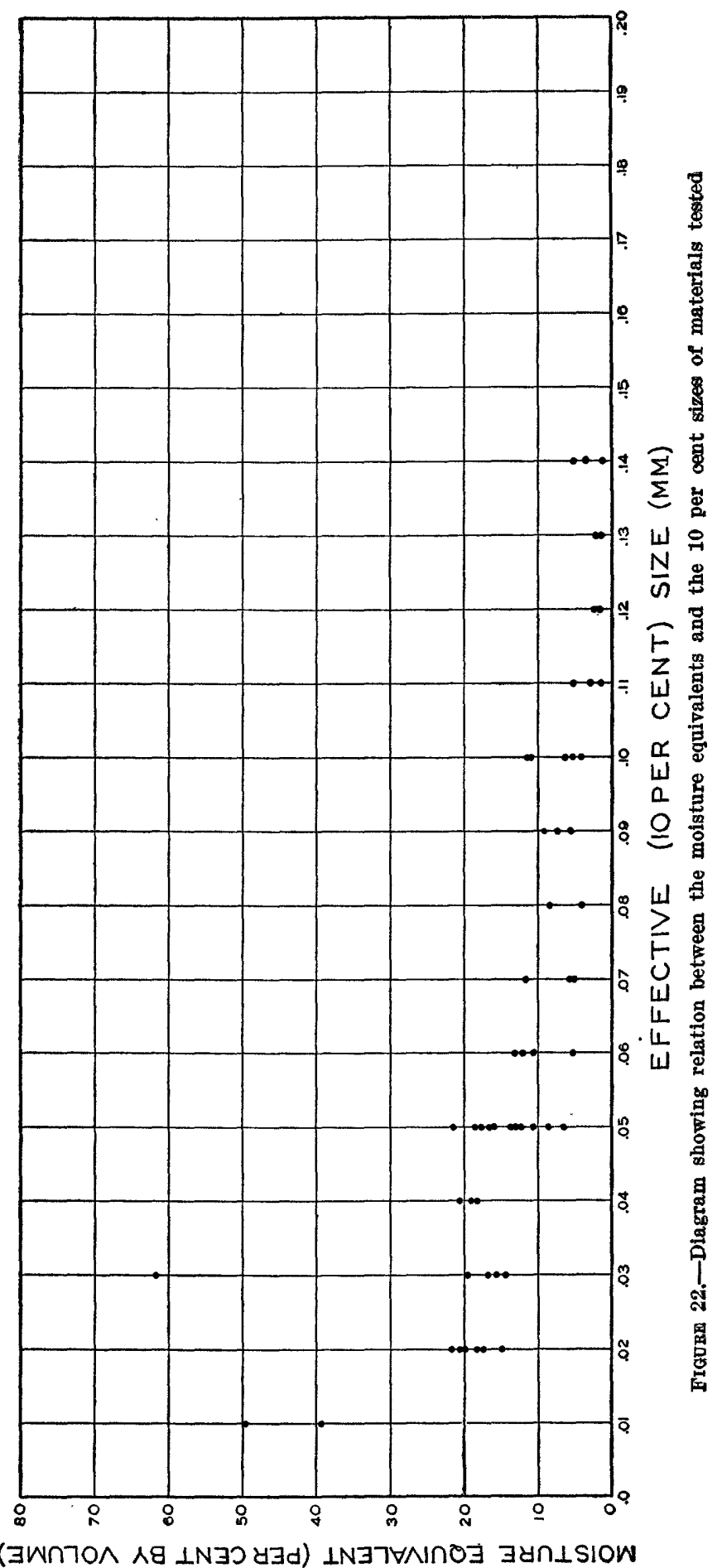


Briggs, Martin, and Pearce ${ }^{23}$ make the following statement in regard to the relation of the mechanical composition of a material to its moisture retentiveness:

Soil texture has been used for the quantitative description of soils more extensively than any other physical property, and unfortunately it has been one of the most difficult to interpret from the standpoint of moisture retentiveness. Texture is quantitatively expressed by means of the mechanical analysis, which shows the composition of the soil when the particles are separated into groups according to size. The accuracy with which the texture of the soil can be expressed by this means is dependent on the number of groups into which the particles are separated. But the difficulty of effecting a complete separation of the finer particles into the desired groups places a practical limit upon the number of groups, which is usually limited to seven.

The use of mechanical analysis as a basis for determining the moisture retentiveness of a soil is further complicated by the fact that solls having a high clay content will show great differences in the amount of colloidal material, which greatly affects the moisture retentiveness. Furthermore, the particles constituting a given group may lie much nearer one limit of the group than the other, so that a given group does not always have the same properties. Consequently, the particles constituting a given group in the mechanical analysis do not always have the same moisture retentiveness per unit mass. It is also possible that the specific retentivity of a group when measured alone is modified to some extent by admixture with particles from other groups.

Several formulas for obtaining the moisture equivalent from the mechanical analysis of a soil have been developed. The first work of this kind was done by Briggs and McLane, ${ }^{24}$ who used a moisture equivalent based on a force three thousand times that of gravity. Later Briggs and Shantz ${ }^{25}$ developed a number of formulas among which is the following, based on a centrifugal force of 1,000 times gravity:

Moisture equivalent $=0.02$ sand +0.22 silt +1.05 clay.

In this formula the sand, silt, and clay are expressed in percentages of the weight of the dry sample, and the moisture equivalent is, of course, also expressed by weight.

Alway and Russel ${ }^{26}$ compiled a table in which are compared moisture equivalents (1) determined by experiment, (2) computed by the formula of Briggs and Shantz, and (3) computed by a modified formula. They make the following statement:

It will be seen that the formula of Briggs and Shantz gives values too low for the coarsest-textured members of the series and too high for the finest

\footnotetext{
2 Briggs, L. J., Martin, O. F., and Pearce, J. R., The centrifugal method of mechanical soil analysis : U. S. Dept. Agr. Bur. Soils Bull. 24, p. 33, 1904.

24 Briggs, L. J., and McLane, J. W., The moisture equivalents of soils: U. S. Dept. Agr. Bur. Solls Bull. 45, pp. 17 et seq., 1907.

${ }_{25}$ Briggs, L. J., and Shantz, H. L., The wilting coefficient for different plants and its indirect determination: U. S. Dept. Agr. Bur. Plant Industry Bull. 230, p. 72, 1912.

${ }^{20}$ Alway, F. J., and Russel, J. C., Use of the moisture equivalent for the indirect determination of the hygroscopic coefficient : Jour. Agr. Research, vol. 6, p. 843, 1916.
} 
textured. In the modified formula the value assigned to the clay is lowered, that to the sands much increased, and that to the silt slightly raised.

This modified formula gave results in close concordance with the directly determined values. The authors summarize the matter thus:

For the calculation of the moisture equivalent from the mechanical analysis no general formula appears universally applicable, the formula needing modification according to the soil type to which it is to be applied.

The moisture equivalent has also been used by Middleton ${ }^{27}$ to interpret the mechanical analyses of soils. Middleton summarizes his paper as follows:

There is a direct relationship between the moisture equivalent and the percentages of sand, silt, and clay in the soil as determined by mechanical analysis. This relationship may be expressed as

Moisture equivalent $=0.063$ sand +0.291 silt +0.426 clay.

The presence of considerable amounts of organic matter in the soils tends to increase the moisture equivalent and to disturb the relation between the moisture equivalent and the mechanical analysis.

For samples containing less than 20 per cent of silt and clay Middleton recommends the following formula:

Moisture equivalent $=0.02$ sand +0.40 silt +0.53 clay.

In the following table are given the moisture equivalents of the samples tested in the present investigation as determined in the hydrologic laboratory and as computed from the mechanical analysis by means of the formula of Briggs and Shantz and the two formulas of Middleton. In each column the moisture equivalent by volume is given. To compute this the results obtained from the formulas by Briggs and Shantz and by Middleton were multplied by the apparent specific gravity. The samples are arranged in the order of their experimental moisture equivalents.

${ }^{27}$ Middleton, H. E., The moisture equivalent in relation to the mechanical analysis of: soils : Soil Sci., vol. 9, No. 2, pp. 159-167, February, 1920. 
Experimental moisture equivalents and moisture equivalents computed from formulas of Briggs and shantz and of Middleton ${ }^{a}$

[All moisture equivalents are expressed by volume]

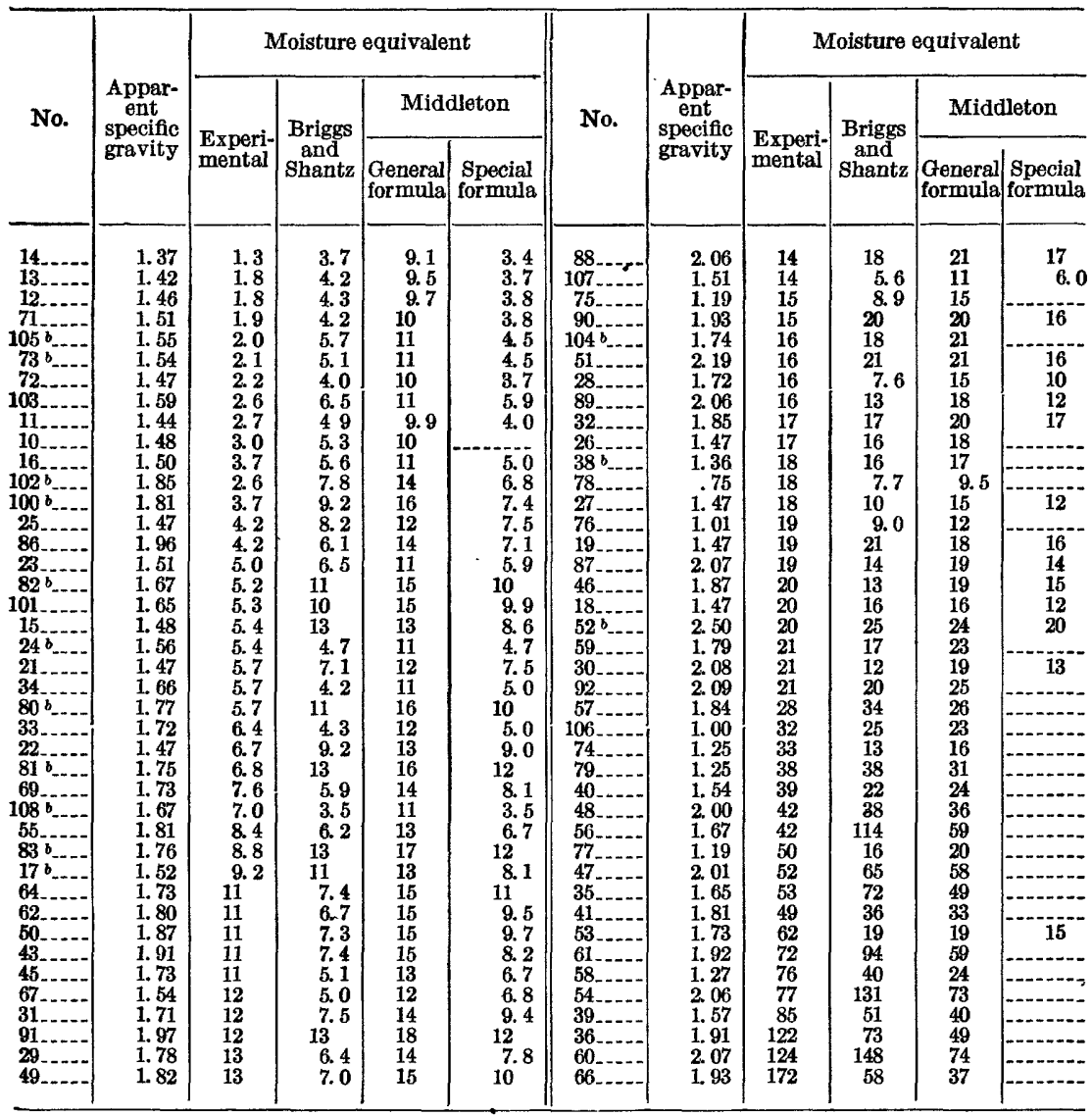

a The formulas used to compute the moisture equivalents by weight are as follows: Briggs and Shantz, 0.02 sand +0.22 silt +1.05 clay; Middleton, general formula, 0.063 sand +0.291 silt +0.426 clay; Middleton, special formula for samples that contain less than 20 per cent of silt and clay, 0.02 sand +0.40 silt +0.53 clay. All results were multiplied by the apparent specific gravity to obtain moisture equivalents by volume.

b Some grains greater than 2 millimeters in diameter.

For the samples that contain less than 2 per cent of silt and clay all the formulas give results that are much higher than the experimental moisture equivalents. The results obtained by use of the Middleton general formula are the most erratic. For the samples that contain 2 to 10 per cent of the silt and clay the Middleton general formula is likely to give results that are much higher than the experimental; the Briggs and Shantz formula and the Middleton special formula give fairly good results for many of the samples but results that are much too high or much too low for a considerable proportion. On the average the Middleton special formula gives somewhat 
the best results. For the samples that contain 10 to 20 per cent of silt and clay all three of the formulas give results that agree fairly well with the experimental results for most samples but with wide departures for some. For the samples that contain 20 to 30 per cent of silt and clay both the Briggs and Shantz formula and the Middleton general formula give fairly good results for most samples but with wide departures for some. For a large part of the samples that contain more than 30 per cent of silt and clay the results computed by either formula give results that vary widely from the experimental results.

\section{RELATION OF MOISTURE EQUIVALENT TO SPECIFIC YIELD}

The term "specific yield" is used to express the quantity of water that a formation will yield under the pull of gravity if it is first saturated and then allowed to drain. The ratio, expressed in percentage, of the volume of this water to the total volume of the formation that is drained is the specific yield. It is the porosity minus the specific retention.

In the table on pages $164-169$ is given the porosity minus the moisture equivalent by volume of the samples tested. The difference represents the percentage of pore space that is empty when a sample comes out of the centrifuge. For a material that has a low or moderate moisture equivalent the difference between the porosity and the moisture equivalent gives an approximation of the specific yield, but for a material that has a high moisture equivalent this computation is likely to give erratic results. The moisture equivalents computed from mechanical analyses of materials that contain less than 30 per cent of silt and clay apparently have some value in computing the specific yield. For materials with very low content of silt and clay the computed moisture equivalent is likely to have a large percentage of error, but as the moisture equivalents of these samples are low the resulting percentages of error in the computed specific yields are not correspondingly large.

\section{PERMEABILITY}

\section{APPARATUS}

The permeability test was devised by O. E. Meinzer to measure the rate of flow of water through columns of water-bearing materials under low heads, such as are found in nature. The method is to allow inflow of water at the bottom of a column of the material of known height and outflow at the top. The difference in head of water at the bottom and the top is regulated by an adjustable supply tank and is indicated by two pressure gages. Observations are made on the rate of discharge and the temperature of the water. 
In view of the difficulties King ${ }^{28}$ found in running water through samples and his subsequent use of air instead of water, it was believed that the permeability test would necessarily be one of permeability to air, the results of which would be computed into permeability to water. Therefore the air-permeability apparatus of Karr and Sager, of the Bureau of Standards, used in work on molding sands, was at first seriously considered. However, a little study into the subject showed that, although the viscosities of both air and water have been accurately determined, serious uncertainties are involved in converting permeabilities to air into permeabilities to water, chiefly because of notable effects of hygroscopic or other moisture in the sample on the air permeability, as determined by Karr and Sager. A few preliminary tests of permeability were made with water in the apparatus devised by Mr. Meinzer. The results were very satisfactory, and a more careful and extended series of tests were then made on a sand obtained from Fort Caswell, N. C. (pp. 152-159). The results of this series of tests were so good that this apparatus was used in all the work on permeability. It is, however, Mr. Meinzer's opinion that before a final decision can be reached as to the relative merits of the air and water methods further research is necessary, in which tests by the two methods shall be made on duplicate samples of the same material with the same compacting and in which tests shall also be made with the water apparatus on a series of samples of the same material and with the same compacting.

The permeability apparatus shown in Plate 13 and Figure 23 is known as the long-cylinder apparatus. It differs from the shortcylinder apparatus, which is used in most of the tests, only in the length of the cylindrical copper vessel that holds the sample and in the length of the pressure gages. The cylindrical vessel $a$, which is called the percolation cylinder, is closed at the lower end and has four openings, two at the bottom and two at the top. It is 3 .inches in diameter. In the long-cylinder apparatus this vessel is 48 inches high; in the apparatus that is ordinarily used it is only 8 inches high. There is one opening, $b$, near the bottom for inflow of water; one near the top, $c$, for discharge of water that has percolated up through the sample; and two, $d$ and $d^{\prime}$, for pressure gages. The pressure gages consist of two glass tubes, $e$ and $e^{\prime}$, each about half an inch in diameter. They indicate the difference in head at the bottom and top of the column of material that is being tested. The glass tubes must be of large enough diameter to make capillarity in them negligible. Another cylindrical copper vessel, $f$, about 12 inches high and 5 inches in diameter, is used as a water-supply tank.

\footnotetext{
${ }_{28}$ King, F. H., Principles and conditions of the movements of ground water: U. S. Geol. Survey Nineteenth Ann. Rept., pt. 2, pp. 107-206, 1899.
} 
Water from an ordinary faucet enters the supply tank slowly through a glass tube, $g$, which extends below the water level in the tank to prevent splashing. A rubber tube, $h$, leads water from the supply tank to the percolation cylinder. The surplus water is discharged from the supply tank through an opening $1 \frac{1}{2}$ inches in diameter

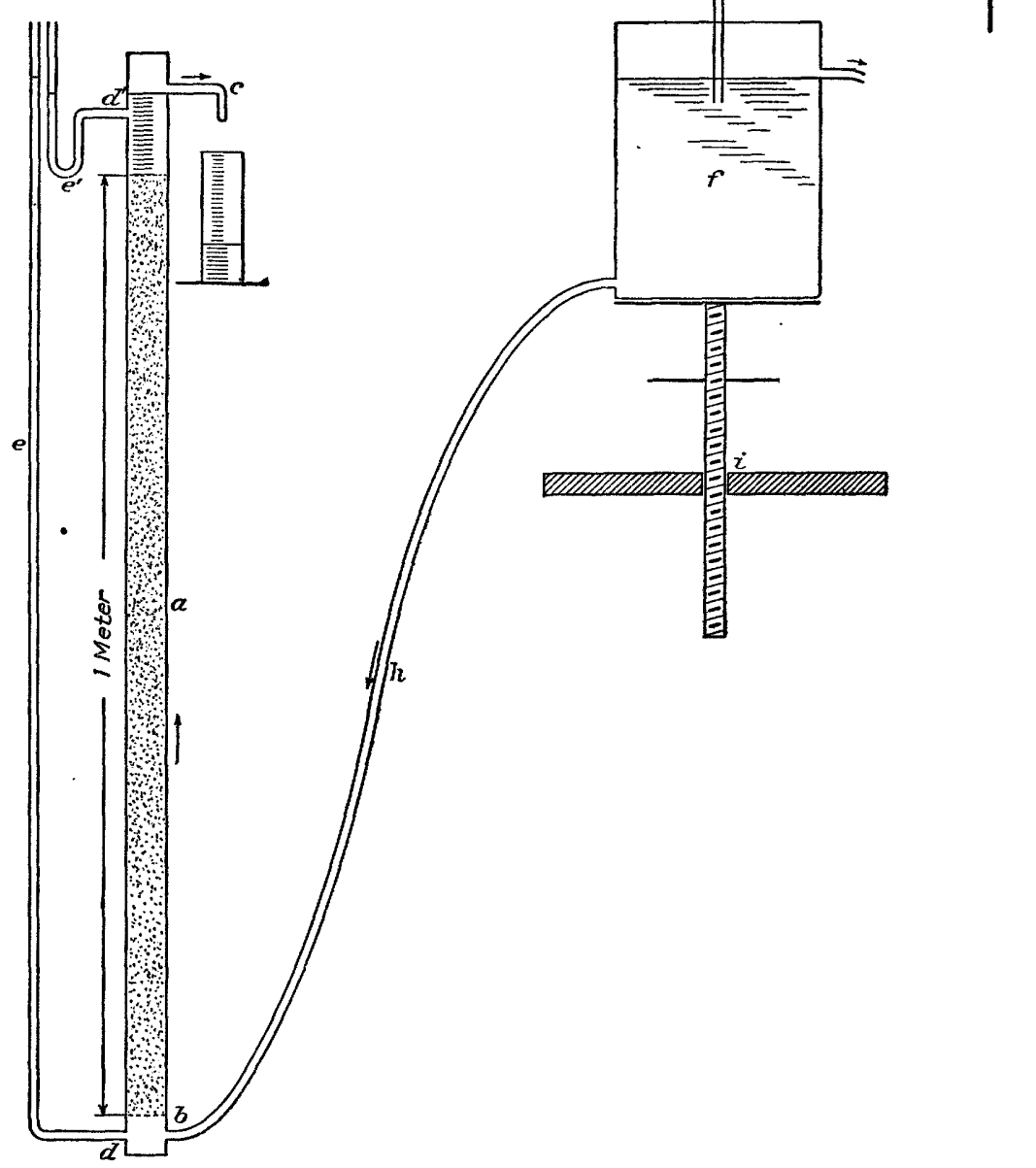

FIGURE 23.-Diagram of long-cylinder permeability apparatus

near the top, not visible in Plate 13. This overflow outlet keeps the water level in the tank nearly constant. Its accuracy as a regulator of the water level increases with the size of the outlet opening. The tank is raised or lowered by means of a screw jack, $i$, with which very fine adjustments of head are possible. Half a turn of the handle in the jack gives about 1 millimeter difference in the head. 
A cathetometer, $k$, in Plate 13 , is used to read the difference in level in the pressure gages when this difference is small. It consists of a telescope, mounted on a vertical rod on which it can be raised and lowered and swung in a $90^{\circ}$ arc. The telescope has an eyepiece with movable cross hair and micrometer adjustment. The telescope is focused on a meter rod, $l$, and calibrated. It is then swung to the pressure gages, and the distances between the levels are determined by means of the micrometer adjustment. By use of this cathetometer heads can be read down to less than a hundredth of a millimeter.

\section{METHOD OF PUTTING SAMPLE INTO THE APPARATUS}

Several rubber stoppers are put in the bottom of the percolation cylinder. On these is placed a circular piece of fine copper gauze to keep the sand from sifting through. If the material to be tested is very fine, a piece of fine-mesh bolting cloth is placed on the copper gauze.

In the short-cylinder apparatus the column of material to be tested is as nearly as possible 10 centimeters high. If the sample was taken volumetrically, the requisite weight of sand to make a column 10 centimeters high, based on the air-dry apparent specific gravity, is put into the percolation cylinder. The sample is shaken, tamped, and jarred in order to make it occupy practically the volume it had in nature. A sample may occupy more space than its computed volume in nature, and further jarring and tamping may not compact it further. Another sample, however, may occupy less than the computed volume, and there is no practicable method of increasing its volume to that which it occupied in nature. If the height of the column was greater or less than 10 centimeters, this fact is recorded in the footnotes of the table (pp. 164-169). If the sample is not volumetric, the material is packed into the cylinder until a column 10 centimeters high is obtained. It is jarred and tamped so as to make it as compact as possible, and this maximum compacting is assumed to be that of the natural sample. Serious errors may be involved in applying the coefficient of permeability in field problems because of irregularities in the natural packing of the formation that was sampled and especially because of local assortment and stratification even within the material that furnished the sample, which could not be restored in the laboratory. The assortment in nature generally increases the average permeability in the direction of the stratification. On the other hand, any assortment produced by shaking and jarring the sample in the percolation cylinder is likely to decrease the permeability. It is obviously desirable that a method should be developed for obtaining undisturbed samples of unconsolidated materials for 
the permeability tests. Permeability tests have not yet been made in this laboratory on consolidated samples.

After the percolation cylinder has been filled with the material to be tested, water is allowed to enter very slowly at the bottom, the head being kept very low so as not to roil the material. It may require only a few minutes or as much as several hours to saturate the sample, according as the material is coarse or fine.

\section{METHOD OF MAKING THE TEST}

When the water is discharging uniformly from the outlet at the top of the cylinder the test is begun. The temperature of the water is taken in degrees Fahrenheit. The head, as shown by the difference in the water levels in the pressure gages, is measured in millimeters by means of a metric rule or the cathetometer. The rate of discharge is observed with a graduated cylinder and a stop watch, usually in cubic centimeters in a period of either 30 or 60 seconds. If the discharge is very slow, however, it has been found convenient to count drops, the weight of one drop being determined. After a test has been made at a given head, the supply tank is raised or lowered, and a new test with a different head is made. Generally three to five tests are made, covering a considerable range in head.

\section{METHOD OF COMPUTING THE RESULTS}

The results of the tests are expressed as a coefficient of permeability, which is based on Darcy's law that the rate of flow varies in direct proportion as the hydraulic gradient. The coefficient of permeability of a material is the rate of flow, in gallons a day, through a square foot of its cross section, under a hydraulic gradient of 100 per cent, at a temperature of $60^{\circ} \mathrm{F}$. In field terms the coefficient of permeability may be expressed as the number of gallons of water a day, at $60^{\circ} \mathrm{F}$., that is conducted laterally through each mile of the water-bearing bed under investigation (measured at right angles to the direction of flow), for each foot of thickness of the bed and for each foot per mile of hydraulic gradient.

The general formula for permeability may be written as follows:

$$
P=\frac{q l t}{T a h}
$$

in which $P$ is the coefficient of permeability, $q$ the quantity of water, $l$ the length of column of sample, $t$ the correction for temperature. $T$ the time, $a$ the cross-section area of sample, and $h$ the head.

If the percolation cylinder has a diameter of 3 inches and the column of material is 100 millimeters high, the formula becomes

$$
P=\frac{46.56 f t}{h}
$$


in which $P$ is the coefficient of permeability, as above defined; $f$ is the rate of flow $\frac{(q)}{T}$ expressed in milligrams per second; $h$ is the head in millimeters; and $t$ is the correction for temperature which gives the rate of flow at $60^{\circ} \mathrm{F}$., based on the viscosity of water, as given in the Smithsonian Physical Tables (7th ed., p. 155) and in Water-Supply Paper 140 (p. 13).

Slichter's transmission constant ${ }^{29}$ is defined as the quantity of water, measured in cubic feet, that is transmitted in one minute through a cylinder of the soil 1 foot in length and 1 square foot in cross section under a difference in head at the ends of 1 foot of water. He computed the transmission constants for water at $60^{\circ} \mathrm{F}$. The difference between Slichter's transmission constant and Meinzer's coefficient of permeability is that the former gives the flow in cubic feet a minute and the latter gives it in gallons a day. To convert the transmission constant into a coefficient of permeability it is only necessary to multiply it by 10,770 .

\section{PERMEABIIITY DATA}

In the table on pages $160-163$ are given the data on the permeability of the samples tested. Details regarding the samples are given in the table on pages 164-169. On the assumption that Darcy's law holds exactly, the differences between the several coefficients of permeability for a given sample, recorded in the next to the last column, represent the experimental errors. The average of the results obtained by the several tests on a given sample is recorded in the last column as the average coefficient of permeability of the material. The differences are due largely to maladjustments of the apparatus and to inaccuracies in reading the head. It was found that after a few changes in the apparatus the coefficients checked more closely. The use of the cathetometer for small heads and of the metric rule for larger heads has probably caused a few discrepancies.

The hydraulic gradients used in the tests range from 0.64 to 91.3 per cent and are usually below 50 per cent. In other words, they range from about 35 to about 4,800 feet to the mile and are usually less than 2,650 feet. The high gradients were used only on the nearly impermeable materials in order to get a measurable flow. The lower gradients were used whenever practicable both to prevent roiling and to approximate natural hydraulic gradients.

The coefficients of permeability range from 0.26 to 20,663 . The ine silty samples and those with a considerable clay content yield mly a few gallons a day or even less than 1 gallon. The coarse,

20 Slichter, C. S., Fleld measurements of the rate of movement of underground waters: T. S. Geol. Survey Water-Supply Paper 140, p. 11, 1805. 
relatively clean gravels yield several thousand gallons a day. The medium-grained, relatively uniform sands yield about 400 to 600 gallons a day.

Slichter's work on the relation of porosity to rate of flow shows that a difference in packing may make a large difference in the permeability. For instance, in sample 22 the sand was packed in the cylinder into a space 10 per cent smaller than it had occupied in nature. Therefore its porosity was reduced from 42 to 32 per cent, and according to Slichter's table (Water-Supply Paper 67, p. 25), the observed rate of flow was 2.5 times slower than it would have been if the sample had been in its natural condition. In other words, the conclusion is reached that the true coefficient of permeability of the formation that was sampled is 68 instead of 27 , as determined in the laboratory. According to Slichter's data, if two samples of the same sand are packed, one so that it has a porosity of 26 per cent and the other so that it has a porosity of 47 per cent, the flow through the latter sample will be more than seven times the flow through the former sample, showing how important it is to obtain volumetric samples.

\section{COMPUTED AND EXPERIMENTAL COEFFICIENTS OF PERMEABILITY COMPARED}

In the table on page 163 are given the coefficients of permeability as computed by Slichter's graphic scale ${ }^{30}$ from the effective size and porosity, the 10 per cent size being taken as the effective size. Only samples having porosities that fall within the range of Slichter's graphic scale or close to it were used.

The table shows that for only a few of the samples is there a close agreement between the computed and the experimental coefficients and that for most of them the differences are large. In 26 of the 34 samples included in the table the experimental coefficient, of permeability is greater than the computed coefficient. Some of the data also seem to suggest that for some kinds of material the variatior of permeability with porosity is not so great as Slichter's formule. indicates.

In many of the volumetric samples the material was packed more closely into the percolation cylinder than it had been in its natural state. If corrections were made on these samples, the experimental coefficients, most of which are already larger than those computed, would be larger still, and the difference between the experimental and computed coefficients would generally be greater. In the nonvolumetric samples the maximum packing was used in obtaining the porosity and hence in the computed coefficients of permeability. A.

${ }^{30}$ Slichter, C. S., op. cit. (Water-Supply Paper 140), pl. 2. 
maximum packing was also used in obtaining the experimental coefficients of permeability. Hence, in these samples the experimental and computed coefficients are comparable.

A number of investigators have found that experimental rates of flow are larger as a rule than those computed from porosity and mechanical analyses. Smith ${ }^{31}$ found this true in his study of flow of ground water in the Rillito Valley, Ariz. Melcher ${ }^{32}$ states that actual rates of discharge of oil wells are invariably greater than those computed. King found that the observed rates of flow were usually larger than those computed. (See p. 173.)

An unsuccessful attempt was made to discover a law for effective size by using Slichter's formula to compute the effective size from the known porosity and experimental coefficient of permeability. Thus both No. 14 and No. 16 have a 10 per cent size of 0.14 millimeter; their porosities are 48 and 31 per cent, respectively; their uniformity coefficients, which do not enter into the formula, are 2.4 and 3.1; their computed coefficients of permeability 350 and 75; and their experimental coefficients 518 and 284 . The effective sizes obtained by Slichter's graph are 0.16 and 0.24 millimeter, respectively, and on the accumulative curves these sizes are found to be about at 15 and 31 per cent instead of 10 per cent. Further, both No. 10 and No. 15 have a 10 per cent size of 0.11 millimeter; their porosities are 45 and 44 per cent, respectively; their uniformity coefficients are 2.3 and 4.9 ; their computed coefficients of permeability are 165 and 150 ; and their experimental coefficients are 495 and 1,095. By means of Slichter's graph an effective size of 0.17 millimeter was obtained for No. 10 and 0.26 millimeter for No. 15 . The character of the grains in these two samples was entirely different. No. 15 contained numerous flakes of mica and angular grains and when wet it acted much like quicksand. No. 10 was a wellassorted quartz sand with rounded grains. The true effective size is, of course, affected by differences in texture; and the differences mentioned probably played an important part in determining the rate of flow of water through these samples. This case is cited because it shows the difficulty of expressing the characteristics of a complex natural material by the quantitative determination of a few properties such as porosity and 10 per cent size.

Further study of this subject may develop new factors which will express more adequately and completely the physical character of the naterials than those hitherto used and may lead to a revised formula Thich will give a closer approximation to the true permeability of rater-bearing materials. In the present state of knowledge the most

: Smith, G. E. P., Ground-water supply and irrigation in the Rilhto Valley : Ariz. Agr. Exper. Sta. Bull. 64, p. 127, 1910.

3 Melcher, A. F., personal communication. 
reliable results are to be obtained from either field or laboratory tests of rate of flow through a given cross section under a known hydraulic gradient.

\section{EXPERIMENT WITH SAND FROM FORT CASWELL TO INVESTI- GATE FLOW UNDER LOW FYDRAULIC GRADIENTS}

\section{PURPOSE OF EXPERIMENT}

King found that the rate of flow may increase either somewhat faster or somewhat slower than the increase in head. In a recent publication Miller-Brownlie ${ }^{38}$ stated that with certain low gradients there is no apparent motion of ground water. He says:

Observations made during the past few years of the subsoil of the Punjab have shown that the slopes necessary to cause water motion have varied from 1 in 260 in moderately coarse sand to 1 in $\mathbf{1 7 5}$ in fairly fine sand. In gradiente flatter than this in each type of sand there is no apparent motion. Capillary attraction interferes with the true flow and investigation into the forward motion becomes greatly involved. Observations indicate that any lateral or forward motion of the water, where the hydraulic gradients are slightly less than those mentioned, is so slow that for practical purposes it may be neglected. the actual velocity probably not exceeding a few inches per day.

Miller-Brownlie's limiting gradients of 1 in 260 and 1 in 175 equal about 0.4 and 0.6 per cent or about 20 and 30 feet to the mile. The gradients found in the water-bearing sand and sandstone formations: in the United States are very generally less than 20 feet to the. mile, hence it appeared to be imperative to investigate the law of flow for low gradients before adopting any laboratory method based on the use of higher gradients. For if Darcy's law does not hold through a range of hydraulic gradients that includes those found ir nature, the results of laboratory tests made with higher gradientr can obviously not be used in computing by this law the rates of flow in nature, and either a new law that is applicable to low heads must be discovered, or else laboratory tests must be made with the low heads found in nature. Tests with such low heads are necessarily difficult and laborious. In order to find out whether the results of: the tests made with relatively high gradients could be used for lower natural gradients a series of tests with low gradients was made by means of the specially devised long-cylinder apparatus. Sand of the same kind was also used with high gradients in the shortcylinder apparatus, and the results of both series of tests were compared. These results were further compared with the permeability computed by Slichter's formula and by field experiments with dye. These comparisons gave such reassuring results that the convenient short-cylinder apparatus was used in obtaining permeabilities of all the unconsolidated samples.

ss Miller-Brownlie, T, A., Subsoil water in relation to tube wells: Indian and Eastern Engineer, December, 1919, pp. 191-193. 
The sand used was obtained in connection with a field investigation at Fort Caswell, N. C., made by C. W. Stiles and H. R. Crohurst, ${ }^{34}$ of the United States Public Health Service, in regard to the pollution of ground water. It is a reddish-brown, fairly uniform finegrained beach sand. The writer had spent a month studying the ground-water phase of the experiment and had made physical tests on the sand and sent a large sample to the laboratory for future study. The field experiment was made to determine the distance, rate, and conditions of movement of Bacillus coli through ground water from a dosed pit. Uranin dye, which is similar to fluorescein, was put into the pit with the dose of fecal material, and from a series of pipe wells surrounding the pit water samples were obtained and tested for the dye and for Bacillus coli. The dye and the bacteria were both carried by the ground water, but the spread of the dye was taken to indicate the movement of ground water. Data were obtained on the rate of movement of ground water under the hydraulic gradients existing in the sand underlying the experiment field.

The field data obtained related to the so-called "500 trench" area, and the sample used in the laboratory came from the "600 trench" area, a few hundred feet away. However, the physical tests on the sands from both areas show a close agreement.

The mechanical composition of the sand from the "600 trench," determined by sieving, is given below. The nest of sieves was put on a shaking machine and shaken for 15 minutes. Because the samples contained relatively small quantities of very fine materials, the samples were not washed.

Mechanical composition of sand from Fort Caswell, N. $O$.

\begin{tabular}{|c|r|}
\hline $\begin{array}{c}\text { Diameter of grains in } \\
\text { millimeters }\end{array}$ & Per cent \\
\hline More than 2 & \\
\hline 2 to 1 & 0.04 \\
1 to 0.5 & .11 \\
0.5 to 0.25 & 4.33 \\
0.25 to 0.125 & 36.75 \\
0.125 to 0.074 & 56.36 \\
Less than 0.074 & 1.35 \\
& 1.06 \\
\hline & 100.00 \\
\hline
\end{tabular}

Effective size (10 per cent size), 0.14 millimeter.

Uniformity coefficient, 1.9 .

as Stiles, C. W., and Crohurst, H. R., The principles underlying the movement of Bacillus coll in ground water with resulting pollution of wells : Public Health Repts., vol. 38, No. 24, p. 1350, June 15, 1922. Stiles, C. W., Crohurst, H. R., and Thomson, G. E., Experimental bacterial and chemical pollution of wells via ground water and the factors involved : U. S. Public Health Service Hygientc Lab. Bull. 147, 1927. 
The porosity of the sand, as determined from a known volume obtained in the field, is 49 per cent.

PERMEABILITY EXPERIMENT WITH 1,000-MILLIMETER COLUMN OF SAND

For the permeability experiment with a 1,000 -millimeter column of sand the long-cylinder apparatus was used. As the hydraulic gradient varies directly as the head and inversely as the length of

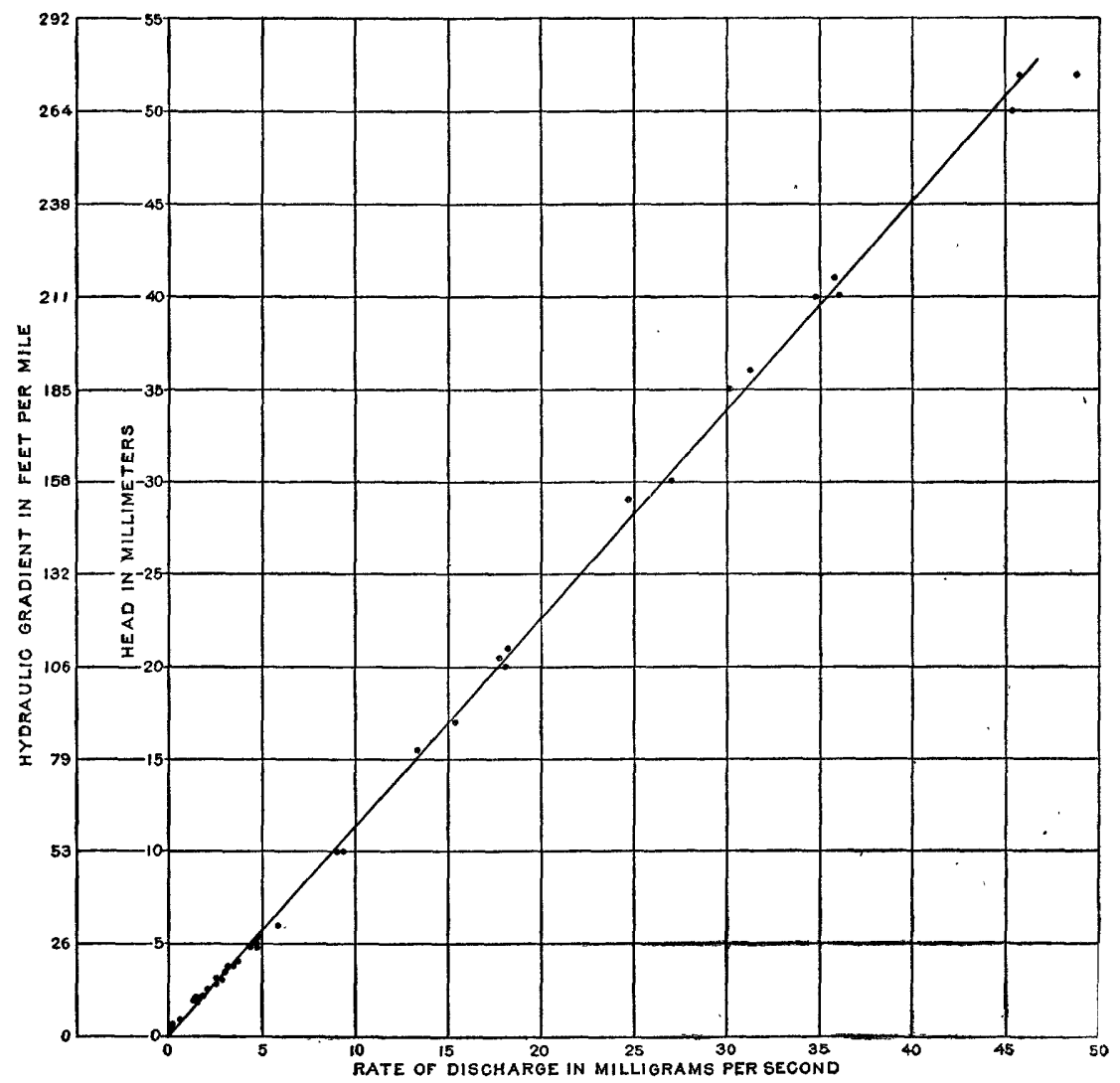

Figurg 24.-Diagram showing relation of rate of flow to hydraulic gradient in the experi ment in which a 1,000-millimeter column of sand from Fort Caswell, N. C., was used. (See also fig. 25)

column through which the water percolates, it was obviously necessary in order to obtain a low gradient to use a low head and a high column of sand. Hence the cathetometer was used to obtain the differences in head, which were read down to hundredths of a millimeter, and a column of sand 1,000 millimeters high was used insteac? of the 100-millimeter column used in the short-cylinder apparatus The apparatus as used is shown in Plate 13. 
A series of tests was made using heads ranging from 52 millimeters down to about 0.2 millimeter. The head of 0.2 millimeter gave a hydraulic gradient of 0.02 per cent or about 1 foot to the mile. In the following table are given the coefficients of permeability for 68 tests with heads ranging from 0.95 millimeter to 52 millimeters. A weighted average gives a coefficient of permeability of 415 . To obtain this weighted average, the average coefficients of permeability

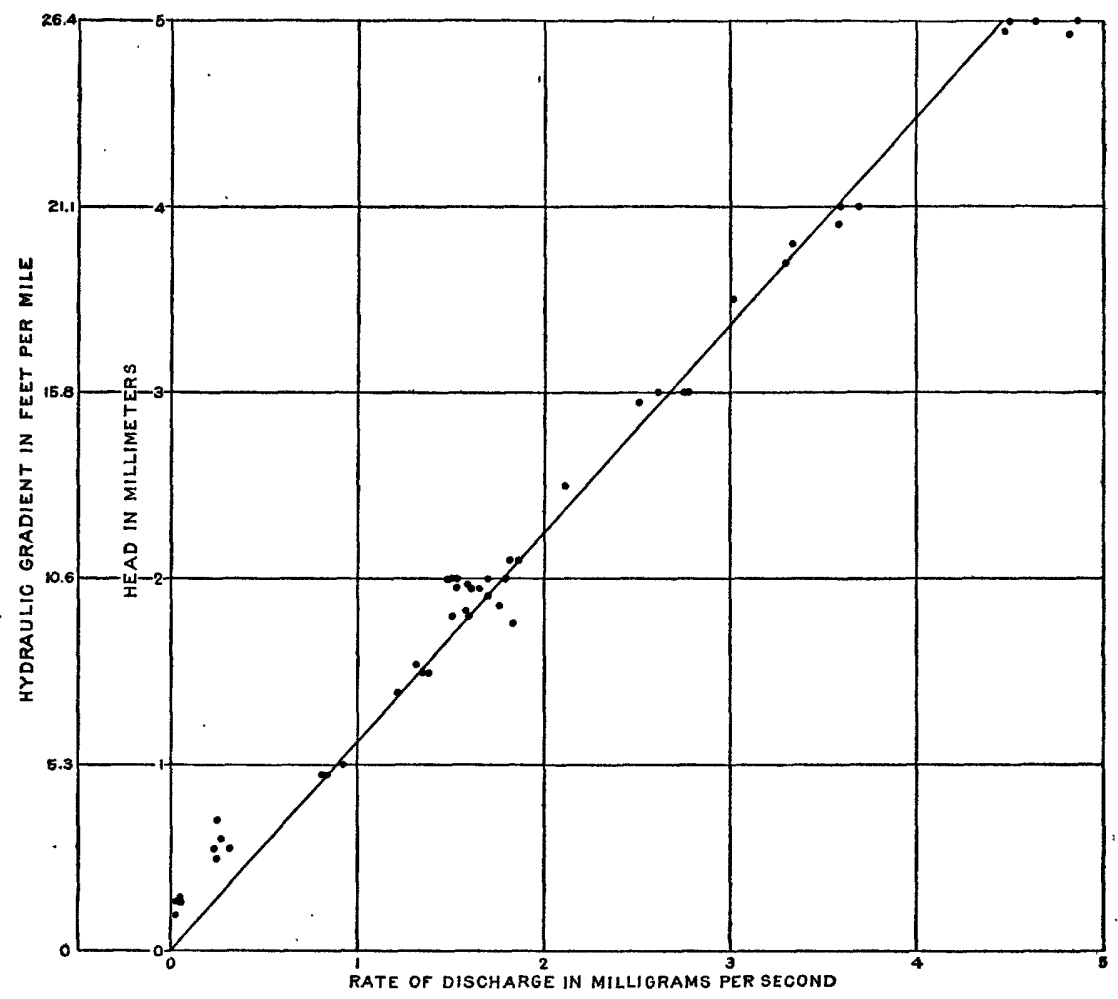

Figure 25.-Diagram showing on an enlarged scale a part of the data shown in Figure 24

with heads of 0.95 to 2,2 to 4,4 to 8,8 to 16,16 to 32 , and 32 to 52 millimeters were successively taken, and an average of these averages was used as the weighted average.

In the diagrams in Figures 24 and 25 the coefficients of per-. meability are plotted against the pressure heads and hydraulic gradients. The resulting curve down to a gradient of 5 feet to the mile approximates a straight line and supports Darcy's law for this sand for hydraulic gradients ranging from about 5.20 to 0.1 per cent, or from about 270 feet to about 5 feet to the mile. 
Permeability tests on a 1,000-millimeter column of sand from Fort Caswell, N. C.

[The results are given in the order in which the tests were made]

\begin{tabular}{|c|c|c|c|c|c|c|c|c|c|c|c|}
\hline No. & $\begin{array}{l}\text { Head } \\
\text { (milli- } \\
\text { meter) }\end{array}$ & $\begin{array}{c}\text { Hy. } \\
\text { draulic } \\
\text { gradient } \\
\text { (per } \\
\text { cent) }\end{array}$ & $\begin{array}{c}\text { Rate of } \\
\text { flow } \\
\text { (milli- } \\
\text { grams } \\
\text { per } \\
\text { second) }\end{array}$ & $\begin{array}{l}\text { Tem- } \\
\text { pera- } \\
\text { ture } \\
\left({ }^{\circ} \mathrm{F} .\right)\end{array}$ & $\begin{array}{c}\text { Coef- } \\
\text { flcient } \\
\text { of } \\
\text { perme- } \\
\text { ability }\end{array}$ & No. & $\begin{array}{l}\text { Head } \\
\text { (milli- } \\
\text { meter) }\end{array}$ & $\begin{array}{c}\text { Hy- } \\
\text { draulic } \\
\text { gradient } \\
\text { (per } \\
\text { cent) }\end{array}$ & $\begin{array}{c}\text { Rate of } \\
\text { flow } \\
\text { (milli- } \\
\text { grams } \\
\text { per } \\
\text { second) }\end{array}$ & $\begin{array}{l}\text { Tem- } \\
\text { pera- } \\
\text { ture } \\
\text { ('F.) }\end{array}$ & $\begin{array}{l}\text { Coef- } \\
\text { flcient } \\
\text { of } \\
\text { perme- } \\
\text { ability }\end{array}$ \\
\hline 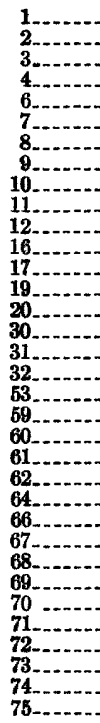 & $\begin{array}{r}52.00 \\
35.00 \\
36.00 \\
29.00 \\
21.00 \\
20.50 \\
15.50 \\
15.50 \\
5.10 \\
3.80 \\
3.70 \\
2.10 \\
2.10 \\
.95 \\
.95 \\
4.94 \\
5.00 \\
4.88 \\
1.00 \\
1.50 \\
1.38 \\
1.54 \\
1.50 \\
2.00 \\
1.76 \\
1.87 \\
1.91 \\
1.95 \\
1.97 \\
1.95 \\
2.00 \\
2.00 \\
2.00 \\
1.80\end{array}$ & $\begin{array}{l}5.20 \\
3.50 \\
3.60 \\
2.90 \\
2.10 \\
2.05 \\
1.55 \\
1.55 \\
.51 \\
.38 \\
.37 \\
.21 \\
.21 \\
.095 \\
.095 \\
.49 \\
50 \\
.49 \\
.10 \\
.15 \\
.14 \\
.15 \\
.15 \\
.20 \\
.18 \\
.19 \\
.19 \\
.20 \\
.20 \\
.20 \\
.20 \\
.20 \\
.20 \\
.18\end{array}$ & $\begin{array}{r}58.82 \\
36.32 \\
37.65 \\
29.87 \\
22.05 \\
21.49 \\
16.16 \\
16.10 \\
5.72 \\
4.07 \\
4.04 \\
2.23 \\
2.28 \\
1.03 \\
1.01 \\
5.46 \\
5.49 \\
5.88 \\
1.14 \\
1.68 \\
1.49 \\
1.61 \\
1.65 \\
2.20 \\
2.24 \\
2.16 \\
2.08 \\
1.97 \\
1.96 \\
1.88 \\
1.88 \\
1.82 \\
1.84 \\
1.84\end{array}$ & $\begin{array}{l}78.8 \\
73.4 \\
73.4 \\
73.4 \\
73.4 \\
73.4 \\
73.4 \\
73.4 \\
74.3 \\
74.3 \\
74.3 \\
74.3 \\
74.3 \\
74.3 \\
74.3 \\
74.3 \\
74.3 \\
74.3 \\
74.3 \\
74.3 \\
74.3 \\
74.3 \\
74.3 \\
74.3 \\
71.6 \\
71.6 \\
71.6 \\
71.6 \\
71.6 \\
71.6 \\
71.6 \\
71.6 \\
71.6 \\
74.3\end{array}$ & $\begin{array}{l}411 \\
401 \\
404 \\
398 \\
406 \\
405 \\
403 \\
401 \\
428 \\
409 \\
416 \\
406 \\
415 \\
412 \\
407 \\
422 \\
419 \\
460 \\
433 \\
428 \\
412 \\
399 \\
419 \\
419 \\
487 \\
441 \\
417 \\
387 \\
381 \\
368 \\
359 \\
347 \\
352 \\
391\end{array}$ & 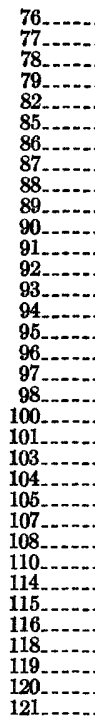 & $\begin{array}{r}1.83 \\
1.88 \\
1.95 \\
1.95 \\
2.00 \\
2.50 \\
2.95 \\
3.00 \\
3.50 \\
4.00 \\
4.00 \\
3.90 \\
4.00 \\
5.00 \\
6.00 \\
6.20 \\
6.00 \\
10.00 \\
20.00 \\
30.00 \\
40.00 \\
50.00 \\
3.00 \\
52.00 \\
40.00 \\
41.00 \\
30.00 \\
20.00 \\
10.00 \\
5.40 \\
5.00 \\
4.00 \\
3.00 \\
2.00\end{array}$ & $\begin{array}{l}0.18 \\
.19 \\
.20 \\
.20 \\
.20 \\
.25 \\
.30 \\
.30 \\
.35 \\
.40 \\
.40 \\
.39 \\
.40 \\
.50 \\
.60 \\
.62 \\
.60 \\
1.00 \\
2.00 \\
3.00 \\
4.00 \\
5.00 \\
.30 \\
5.20 \\
4.00 \\
4.10 \\
3.00 \\
2.00 \\
1.00 \\
.54 \\
.60 \\
.40 \\
.30 \\
.20\end{array}$ & $\begin{array}{r}1.93 \\
1.95 \\
1.98 \\
2.02 \\
2.07 \\
2.59 \\
3.07 \\
3.19 \\
3.69 \\
4.37 \\
4.49 \\
4.37 \\
4.49 \\
5.93 \\
7.22 \\
7.22 \\
7.22 \\
11.45 \\
22.23 \\
33.20 \\
44.17 \\
55.31 \\
3.33 \\
59.00 \\
42.11 \\
43.23 \\
32.79 \\
21.86 \\
11.03 \\
5.93 \\
5.59 \\
4.44 \\
3.33 \\
2.05\end{array}$ & $\begin{array}{l}74.3 \\
74.3 \\
74.3 \\
74.3 \\
74.3 \\
74.3 \\
74.3 \\
74.3 \\
74.3 \\
74.3 \\
74.3 \\
74.3 \\
74.3 \\
74.3 \\
74.3 \\
74.3 \\
74.3 \\
74.3 \\
74.3 \\
74.3 \\
74.3 \\
74.3 \\
72.5 \\
72.5 \\
72.5 \\
72.5 \\
72.5 \\
72.5 \\
72.5 \\
72.5 \\
72.5 \\
72.5 \\
72.5 \\
72.5\end{array}$ & $\begin{array}{l}402 \\
396 \\
387 \\
396 \\
396 \\
395 \\
398 \\
407 \\
403 \\
417 \\
428 \\
427 \\
428 \\
453 \\
469 \\
445 \\
469 \\
437 \\
424 \\
422 \\
422 \\
422 \\
430 \\
438 \\
407 \\
407 \\
422 \\
422 \\
426 \\
424 \\
432 \\
430 \\
428 \\
396\end{array}$ \\
\hline
\end{tabular}

A verage coefficient of permeability, 408; weighted average, 415 .

The results obtained with heads lower than 1 millimeter, or hydraulic gradients lower than 0.1 per cent, were erratic on account of losses through evaporation and differences in temperature that could not be adequately controlled with the apparatus that was used. It is planned to construct a constant-temperature apparatus that will not allow appreciable evaporation and to obtain reliable results down to a gradient of 1 foot to the mile.

In carrying on this experiment the apparatus was kept in operation for five days under a head, according to the cathetometer readings, of only about 0.2 millimeter, or an apparent hydraulic gradient of only about 1 foot to the mile. The rate of discharge under this low head was very slow, but was continuous for the entire period of five days, showing that movement continues under gradients that are much less than 5 feet to the mile. 
Another experiment was performed which showed in a still more impressive manner that movement under hydrostatic pressure may be continuous even though the velocity is extremely slow. A column 50 millimeters high of fine silty material, which is nearly impervious but has a porosity of 54 per cent, was put in one side of a $U$-shaped glass tube 15 millimeters in diameter, and enough water was placed in the other side to give a hydraulic gradient of 100 per cent. Evaporation was prevented. The experiment was started August 13,1924 . At the end of a week the 50-millimeter column of the material to be tested was just wetted throughout, and by December 31 the column of water that had come through was only 7 millimeters high. This result indicates that water percolates through the material used at a rate of about 0.04 foot in 133 days, or about 1 foot in 10 years. At this rate it would take about 50,000 years for the water to move a mile through the sand. This experiment proves the extremely slow but continuous movement of water through dense material. It indicates that water behaves as a typical fluid.

The tests made in the course of this investigation have led to the conclusion that movement of ground water continues in water-bearing formations even under exceedingly low hydraulic gradients and that Darcy's law is probably reliable, even in fine sands, for gradients down to 5 feet to the mile or less, and certainly for gradients of much less than 30 feet to the mile.

\section{PERMEABILITY EXPERIMENT WITH 100-MILLIMETER COLUMN OF SAND}

Next a series of 31 tests was made on the sand from Fort Caswell in the short cylinder, using a column of sand 100 millimeters in height, in order to determine whether the results with this apparatus checked with those of the 1,000-millimeter column. In the following table are given the results of these tests. The heads used ranged from 5 millimeters to 0.5 millimeter, giving hydraulic gradients that ranged from 5 to 0.5 per cent, or from about 265 feet down to about 25 feet to the mile. The average coefficient of permeability is 389 . A weighted average similar to that obtained with the 1,000-millimeter column (p. 155) is 379 . The coefficients of permeability were plotted against the pressure heads as shown in Figure 26, and a straight-line curve was obtained, which also supports Darcy's law. 
Permeability tests on the sand from Fort Caswell, N. O., with 100-millimeter column

[The results are given in the order in which the tests were made]

\begin{tabular}{|c|c|c|c|c|c|c|c|c|c|c|c|}
\hline No. & $\begin{array}{l}\text { Head } \\
\text { (milli- } \\
\text { moter) }\end{array}$ & $\begin{array}{c}\text { Hy- } \\
\text { draulic } \\
\text { gradient } \\
\text { (per } \\
\text { cent) }\end{array}$ & $\begin{array}{c}\text { Rate of } \\
\text { flow } \\
\text { (milli- } \\
\text { grams } \\
\text { per } \\
\text { second) }\end{array}$ & $\begin{array}{l}\text { Tem- } \\
\text { pera- } \\
\text { ture } \\
\left({ }^{\circ} \mathrm{F} .\right)\end{array}$ & $\begin{array}{l}\text { Coef- } \\
\text { fleient } \\
\text { of } \\
\text { perme- } \\
\text { ability }\end{array}$ & No. & $\begin{array}{l}\text { Head } \\
\text { (milli- } \\
\text { meter) }\end{array}$ & $\begin{array}{l}\text { Hy- } \\
\text { draulic } \\
\text { gradient } \\
\text { (per } \\
\text { cent) }\end{array}$ & $\begin{array}{l}\text { Rate of } \\
\text { flow } \\
\text { (milli- } \\
\text { grams } \\
\text { per } \\
\text { second) }\end{array}$ & $\begin{array}{l}\text { Tem- } \\
\text { pera- } \\
\text { ture } \\
\text { (F.) }\end{array}$ & $\begin{array}{l}\text { Coef- } \\
\text { ficient } \\
\text { of } \\
\text { perme- } \\
\text { ability }\end{array}$ \\
\hline $\begin{array}{r}1 \\
2 \\
4 \\
5 \\
6 \\
7 \\
7 \\
9\end{array}$ & $\begin{array}{l}1.54 \\
1.50 \\
1.50 \\
5.00 \\
4.50 \\
4.00 \\
4.00 \\
3.50 \\
3.00 \\
2.50 \\
2.10 \\
2.10 \\
2.00 \\
1.50 \\
1.30 \\
1.50\end{array}$ & $\begin{array}{l}1.54 \\
1.50 \\
1.50 \\
5.00 \\
4.50 \\
4.00 \\
4.00 \\
3.50 \\
3.00 \\
2.50 \\
2.10 \\
2.10 \\
2.00 \\
1.50 \\
1.30 \\
1.50\end{array}$ & $\begin{array}{l}17.24 \\
16.67 \\
16.67 \\
53.60 \\
49.00 \\
39.20 \\
39.20 \\
32.70 \\
26.60 \\
24.50 \\
20.60 \\
19.40 \\
18.70 \\
14.00 \\
13.10 \\
14.00\end{array}$ & $\begin{array}{l}73.8 \\
73.8 \\
73.8 \\
73.4 \\
73.4 \\
73.4 \\
73.4 \\
73.4 \\
73.4 \\
73.4 \\
73.4 \\
73.4 \\
73.4 \\
73.4 \\
73.4\end{array}$ & $\begin{array}{l}428 \\
424 \\
424 \\
414 \\
421 \\
378 \\
378 \\
361 \\
343 \\
378 \\
379 \\
357 \\
361 \\
360 \\
390 \\
360\end{array}$ & $\begin{array}{l}19 \\
20 \\
21 \\
22 \\
23 \\
24 \\
26 \\
27 \\
31 \\
32 \\
33 \\
34 \\
35 \\
36 \\
37\end{array}$ & $\begin{array}{l}1.50 \\
1.00 \\
1.00 \\
.88 \\
1.00 \\
.50 \\
1.10 \\
1.20 \\
2.50 \\
3.00 \\
3.50 \\
3.50 \\
4.00 \\
4.50 \\
5.00\end{array}$ & $\begin{array}{l}1.50 \\
1.00 \\
1.00 \\
.88 \\
1.00 \\
.50 \\
1.10 \\
1.20 \\
2.50 \\
3.00 \\
3.50 \\
3.50 \\
4.00 \\
4.50 \\
5.00\end{array}$ & $\begin{array}{r}15.10 \\
11.10 \\
8.90 \\
8.90 \\
8.90 \\
4.50 \\
10.40 \\
11.50 \\
30.00 \\
34.40 \\
34.40 \\
33.70 \\
40.40 \\
45.50 \\
52.00\end{array}$ & $\begin{array}{l}73.4 \\
73.4 \\
73.4 \\
73.4 \\
73.4 \\
73.4 \\
71.6 \\
71.6 \\
71.6 \\
71.6 \\
71.6 \\
71.6 \\
71.6 \\
71.6 \\
71.6\end{array}$ & $\begin{array}{l}388 \\
428 \\
345 \\
392 \\
345 \\
345 \\
372 \\
380 \\
475 \\
453 \\
388 \\
380 \\
390 \\
400 \\
412\end{array}$ \\
\hline
\end{tabular}

A verage coefficient, 389; weighted average, 379.

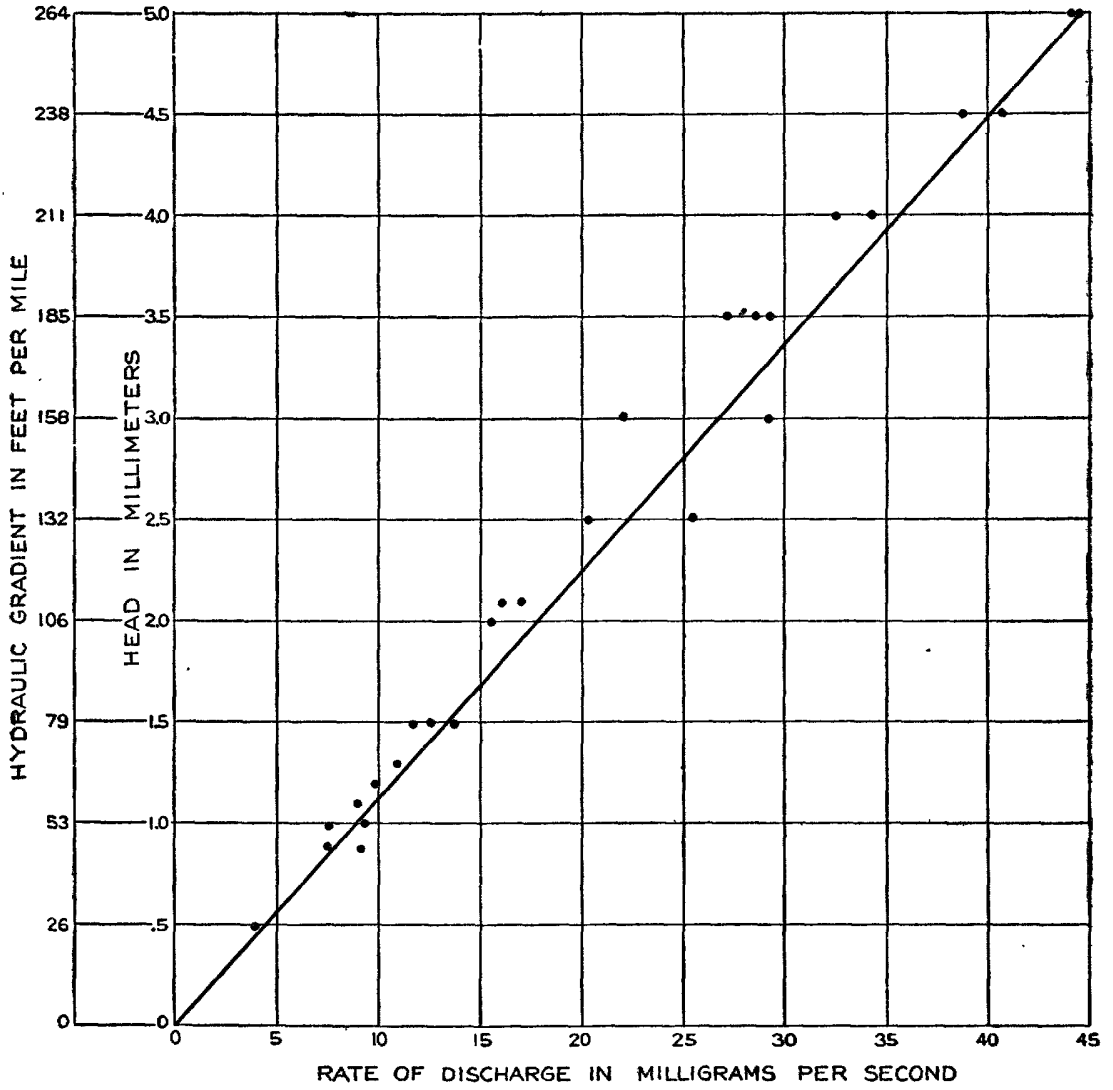

FIGOR 26.-Diagram showing relation of rate of flow to hydraulic gradient in the experiment in which a 100-millimeter column of sand from Fort Caswell, N. C., was used 


\section{PERMEABILITY OF SAND AS CALCULATED BY SLICHTER'S FORMULA}

The effective size (that is, the 10 per cent size) of the sand from Fort Caswell is 0.14 millimeter, and the porosity is 49 per cent. From field data ${ }^{35}$ the hydraulic gradient during the month of May, 1922, was found to be about 0.9 per cent. By using these figures in Slichter's formula, or graphic scale, the discharge is computed to be 0.468 cubic foot in 24 hours. Computing this at 100 per cent gradient and $60^{\circ} \mathrm{F}$. into gallons a day gives a coefficient of permeability of 389. This figure compares very well with the coefficients 415 and 379 obtained by the two permeability tests (pp. 155, 157). The close agreement is believed to be partly accidental and partly due to the fact that this sand is somewhat similar in size of grain and assortment to the sand studied by Hazen.

PERMEABILITY OF SAND AS DETERMINED IN THE FIELD WITH DYE

The uranin dye used in the experiment reached a known distance of 23 feet in 30 days at trench 500 . It is possible that the dye had gone farther, but for the distance of 23 feet there is positive evidence. Using the 0.9 per cent hydraulic gradient and the rate of 23 feet in 30 days gives a coefficient of permeability of 306 .

\section{SUMMARY OF EXPERTMENTS WITH SAND FROM FORT CASWELL}

The experiments made on the sand from Fort Caswell gave consistent results and support Darcy's law for hydraulic gradients ranging from 270 feet down to 5 feet to the mile. The tests made with the long column checked closely with those made with the short column and indicated that tests with the more convenient shortcolumn apparatus are trustworthy. The field determination of rate of movement by means of dye showed a permeability that agreed. substantially with that obtained in the laboratory tests. Moreover, the permeability as computed by Slichter's formula agreed closely' with the permeability derived by the laboratory and field tests. After these preliminary determinations and checks, the short-cylinder apparatus was adopted for making permeability tests on the regular samples.

${ }^{35}$ Stearns, N. D., Report on the geology and ground-water hydrology of the experimental area of the United States Public Health Service at Fort Caswell, N. C.: U. S. Pub. Health Service Hygienic Lab. Bull. 147, pp. 137-168, 1927. 


\section{TABLES}

\section{Permeability tests}

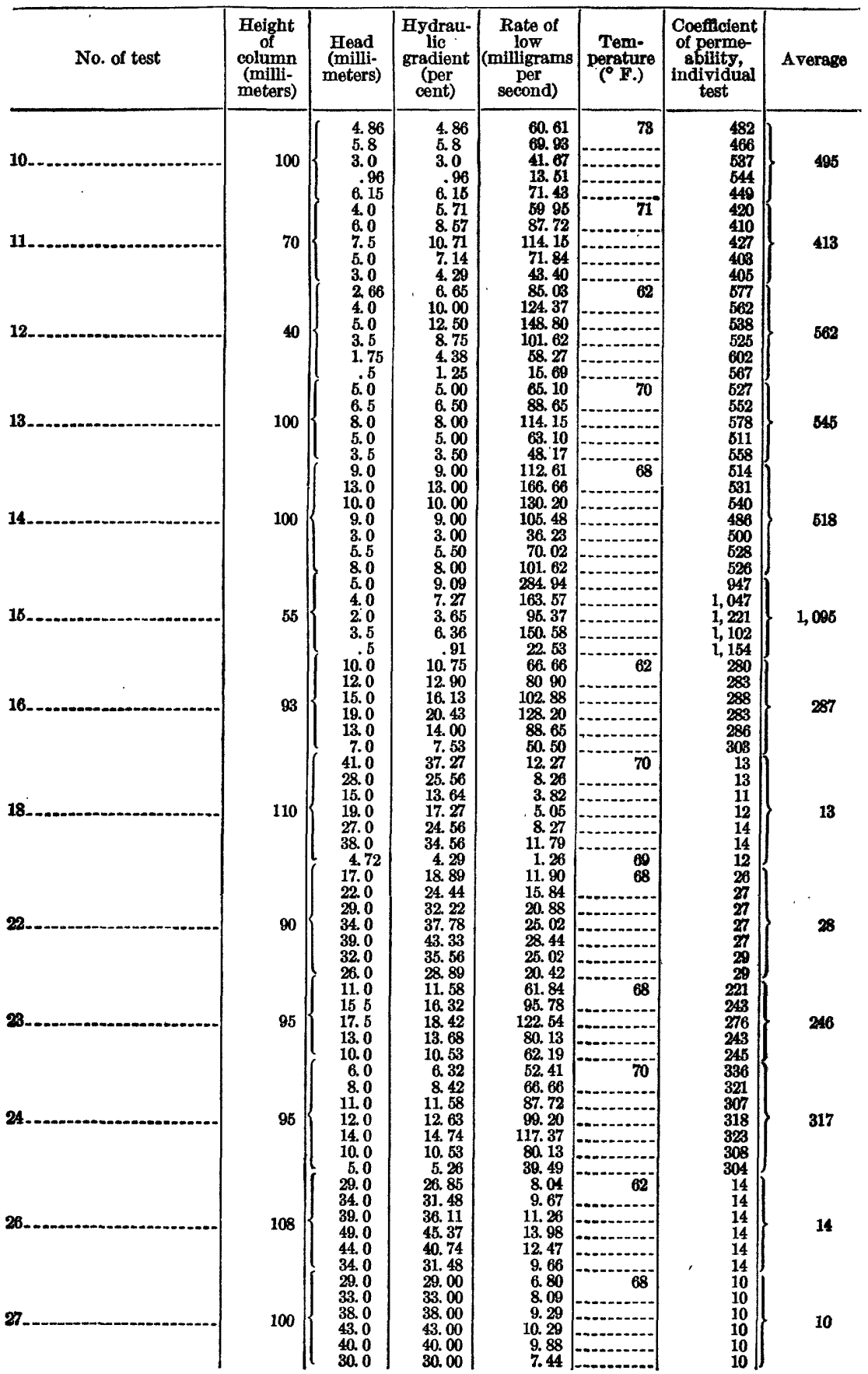


PHYSICAL PROPERTIES OF WATER-BEARING MATERIAIS 161

Permeability tests-Continued

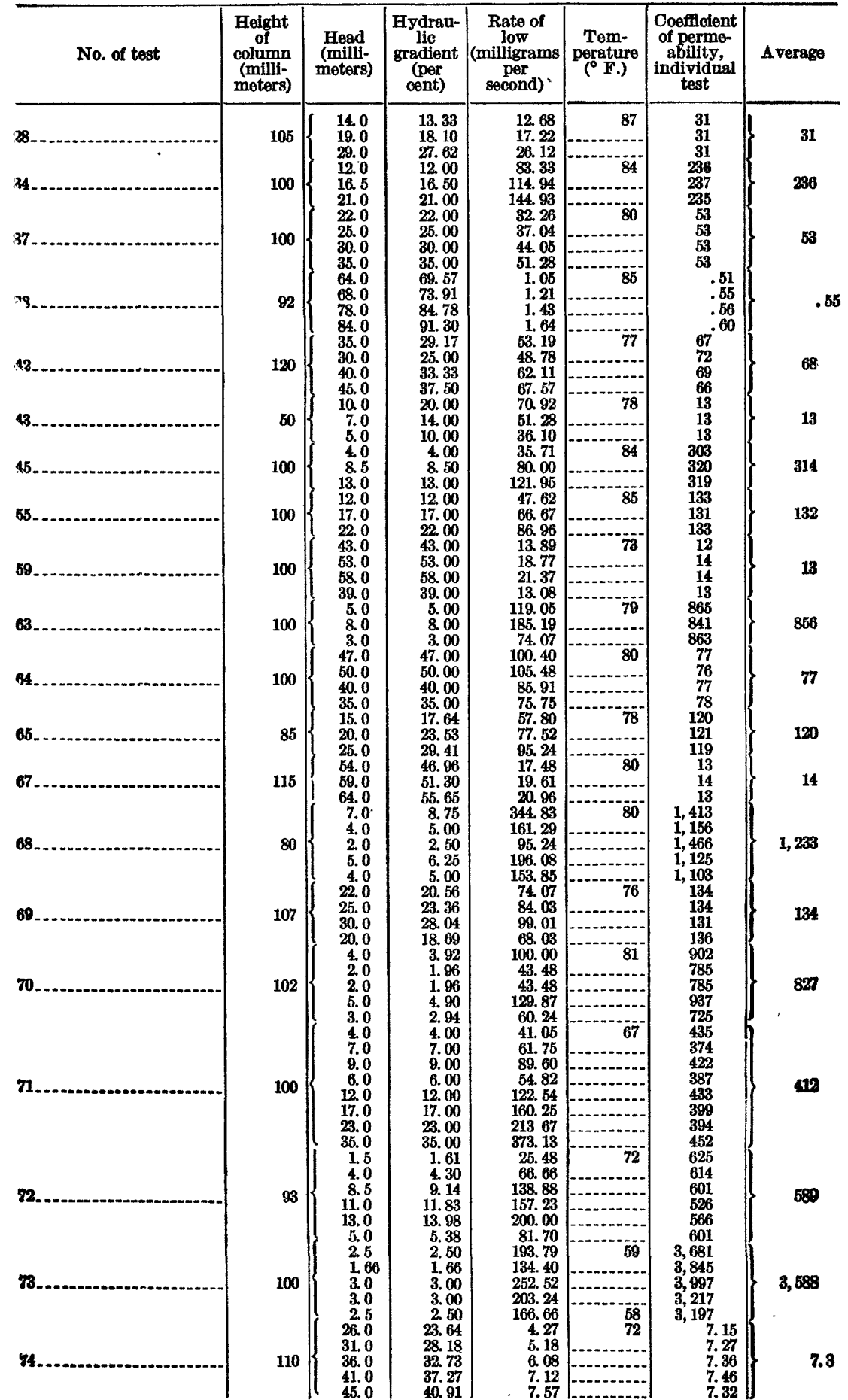


Permeability tests-Continued

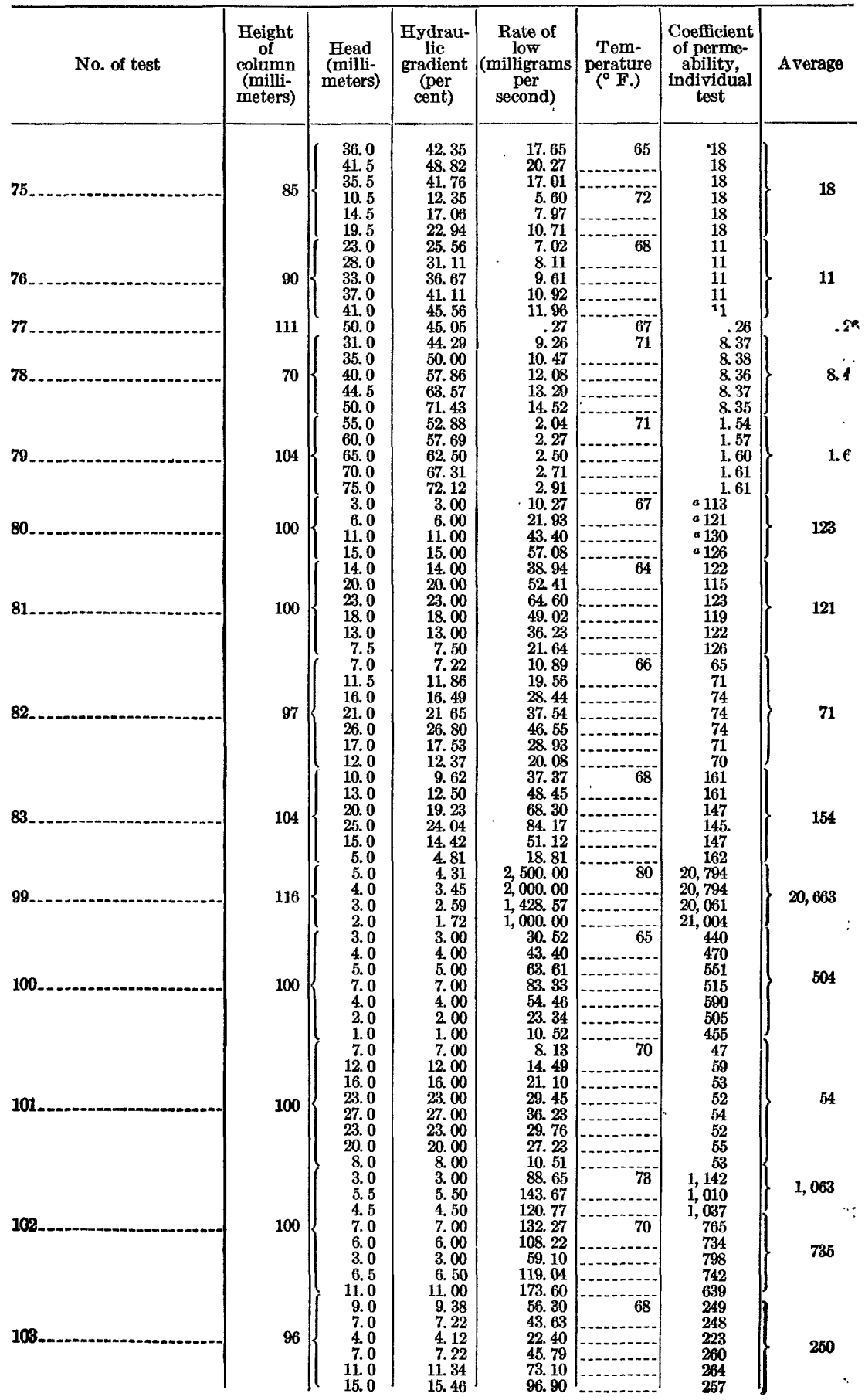

- Corrected for 22 per cent large sand disearded. 
Permeability tests-Continued

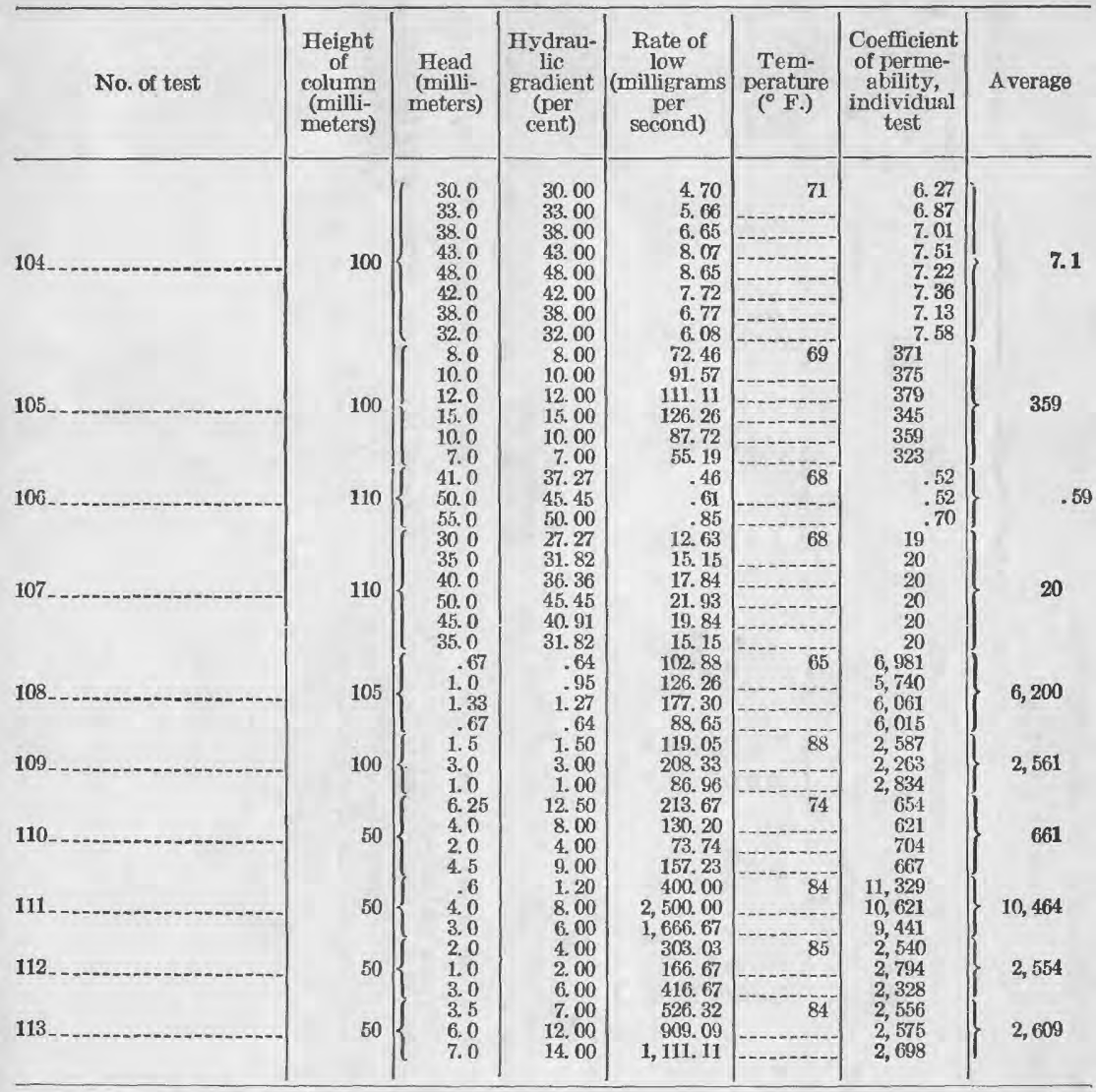

Computed and experimental coefficients of permeability of some of the samples that were tested

\begin{tabular}{|c|c|c|c|c|c|c|c|c|c|c|c|}
\hline \multirow{2}{*}{$\begin{array}{c}\text { No. } \\
\text { of } \\
\text { sample }\end{array}$} & \multirow{2}{*}{$\begin{array}{l}\text { Effec- } \\
\text { tive } \\
\text { size } \\
\text { (10 per } \\
\text { cent } \\
\text { size) } \\
\text { (milli- } \\
\text { meter) }\end{array}$} & \multirow{2}{*}{$\begin{array}{c}\text { Uni- } \\
\text { form- } \\
\text { ity } \\
\text { coeffi- } \\
\text { cient }\end{array}$} & \multirow{2}{*}{$\begin{array}{c}\text { Poros- } \\
\text { ity } \\
\text { (per } \\
\text { cent) }\end{array}$} & \multicolumn{2}{|c|}{$\begin{array}{l}\text { Coefficient of } \\
\text { permeability }\end{array}$} & \multirow{2}{*}{$\begin{array}{c}\text { No. } \\
\text { of } \\
\text { sample }\end{array}$} & \multirow{2}{*}{$\begin{array}{c}\text { Effec- } \\
\text { tive } \\
\text { size } \\
\text { (10 per } \\
\text { cent } \\
\text { size) } \\
\text { (milli- } \\
\text { meter) }\end{array}$} & \multirow{2}{*}{$\begin{array}{l}\text { Uni- } \\
\text { form- } \\
\text { ity } \\
\text { coeffi- } \\
\text { cient }\end{array}$} & \multirow{2}{*}{$\begin{array}{c}\text { Poros- } \\
\text { ity } \\
\text { (per } \\
\text { cent) }\end{array}$} & \multicolumn{2}{|c|}{$\begin{array}{l}\text { Coefficient of } \\
\text { permeability }\end{array}$} \\
\hline & & & & $\begin{array}{l}\text { Com- } \\
\text { puted }\end{array}$ & $\begin{array}{l}\text { Experi- } \\
\text { mental }\end{array}$ & & & & & $\begin{array}{l}\text { Com- } \\
\text { puted }\end{array}$ & $\begin{array}{l}\text { Experi- } \\
\text { mental }\end{array}$ \\
\hline & 0.02 & 3.8 & 35 & 2. 3 & 13 & 15. & 0.11 & 4.9 & 44 & 150 & 1,095 \\
\hline & .02 & 5.9 & 44 & 5.2 & 013 & 71. & .11 & & 40 & 105 & - 412 \\
\hline 104 & .03 & 20 & 31 & 3. 5 & b. 7.1 & 110 & .11 & 2. 2 & 44 & 150 & 661 \\
\hline & .05 & 18 & 26 & 5. & - 154 & 12. & .12 & 2. & 45 & 210 & 562 \\
\hline & .05 & 12 & 29 & 7. 5 & a 121 & 103 & .12 & 3. & 38 & 11 & ${ }^{b} 250$ \\
\hline & .05 & 2. 1 & 37 & 17 & 31 & 11 . & 1 & 2. & 46 & 270 & 413 \\
\hline & .05 & 4. & 45 & 32 & b 27 & & .1 & 3 . & 46 & 2 & 545 \\
\hline 107 & .05 & 1. & 42 & 29 & 20 & 24 & .14 & 3. & 3 & it & в 297 \\
\hline 101 & .06 & 8. & 38 & 28 & b 54 & 14 & .14 & 2. & 4 & 350 & 518 \\
\hline & .07 & 1. & 43 & 58 & c 14 & 16 . & 1 & 3. & 31 & 75 & $b 284$ \\
\hline & .07 & 9.8 & 30 & 17 & 671 & 42. & .2 & 25 & 2 & 130 & 68 \\
\hline 55 & .08 & 2. 5 & 33 & 30 & a 132 & 72. & .2 & 2. & 4 & 5 & - 589 \\
\hline 69. & .09 & 2. 2 & 33 & 39 & 134 & 105 & .2 & 8. & 40 & 530 & a 359 \\
\hline & .09 & 2. 1 & 38 & 58 & 236 & 109 & .4 & 3. & 41 & 2,000 & 2,561 \\
\hline & .10 & 2.8 & 35 & 61 & 314 & 65. & 5 & 9. & 2 & 560 & 120 \\
\hline & .10 & 2.8 & 43 & 120 & b 243 & 108 & .8 & 2. & 32 & 2,700 & 6,200 \\
\hline & .11 & 2.3 & 45 & 16.5 & 495 & 73 & .83 & 2.1 & 41 & 7,500 & a 3,788 \\
\hline
\end{tabular}

- Volumetric sample packed into correct volume; hence, coefficient of permeability probably correct. - Volumetric sample more compacted than in nature; hence, coefficient of permeability probably too small.

c Volumetric sample less compacted than in nature; hence, coefficient of permeability probably too large. 


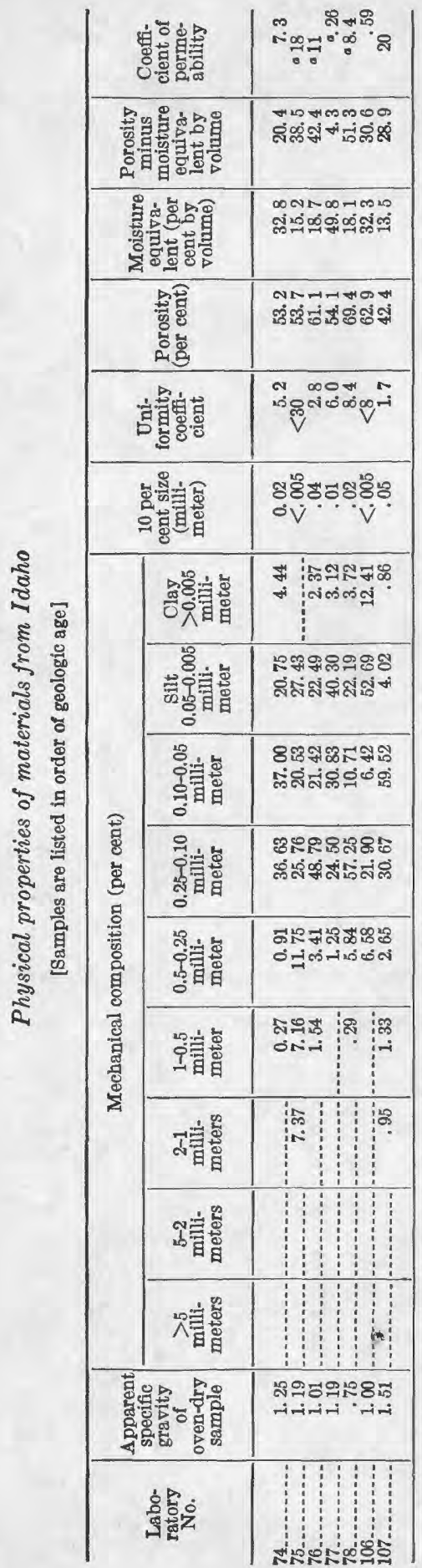

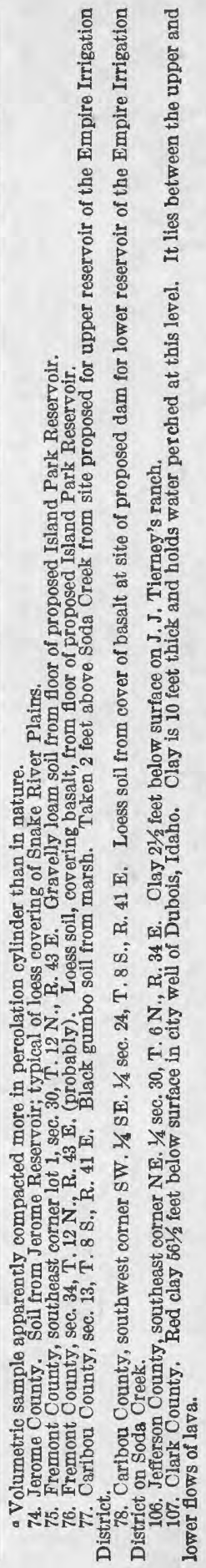


PHYSICAL PROPERTIES OF WATER-BEARING MATERIALS 165

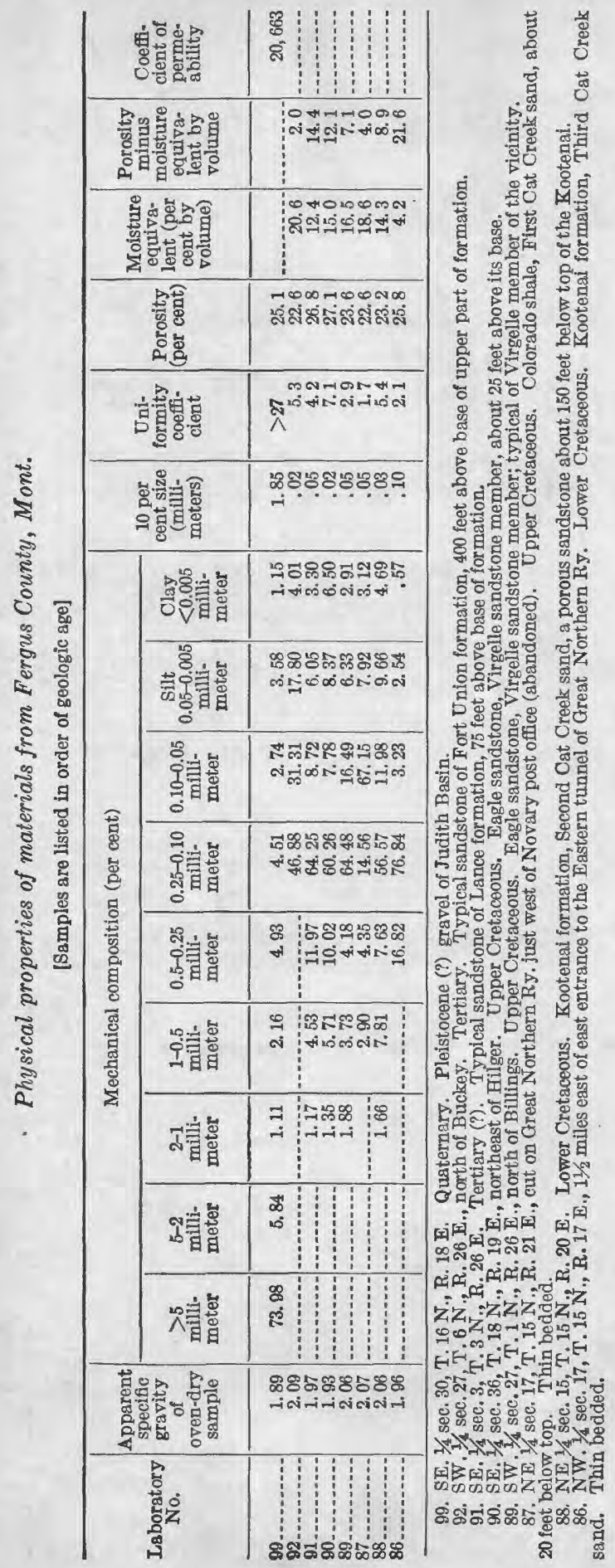




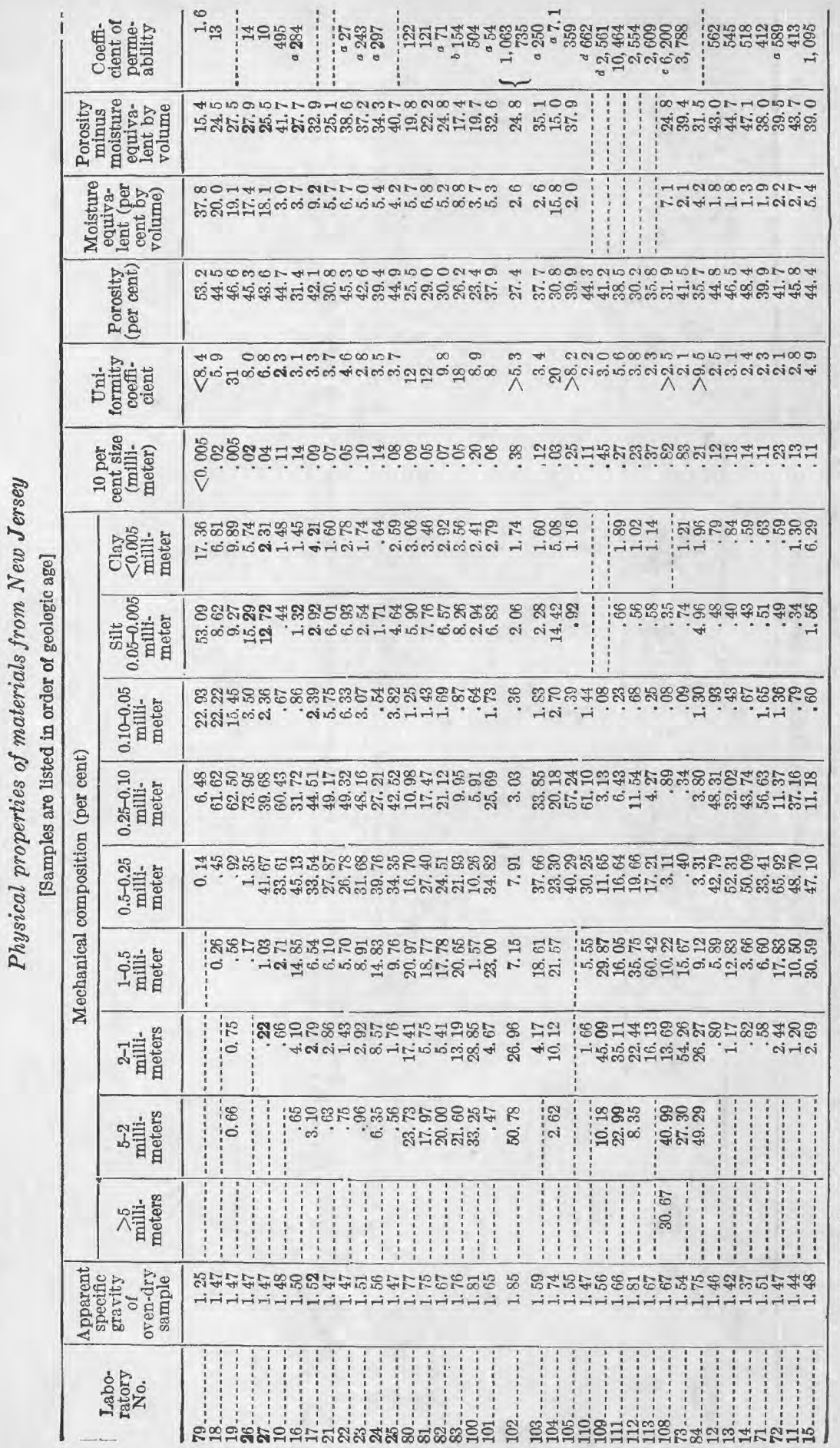




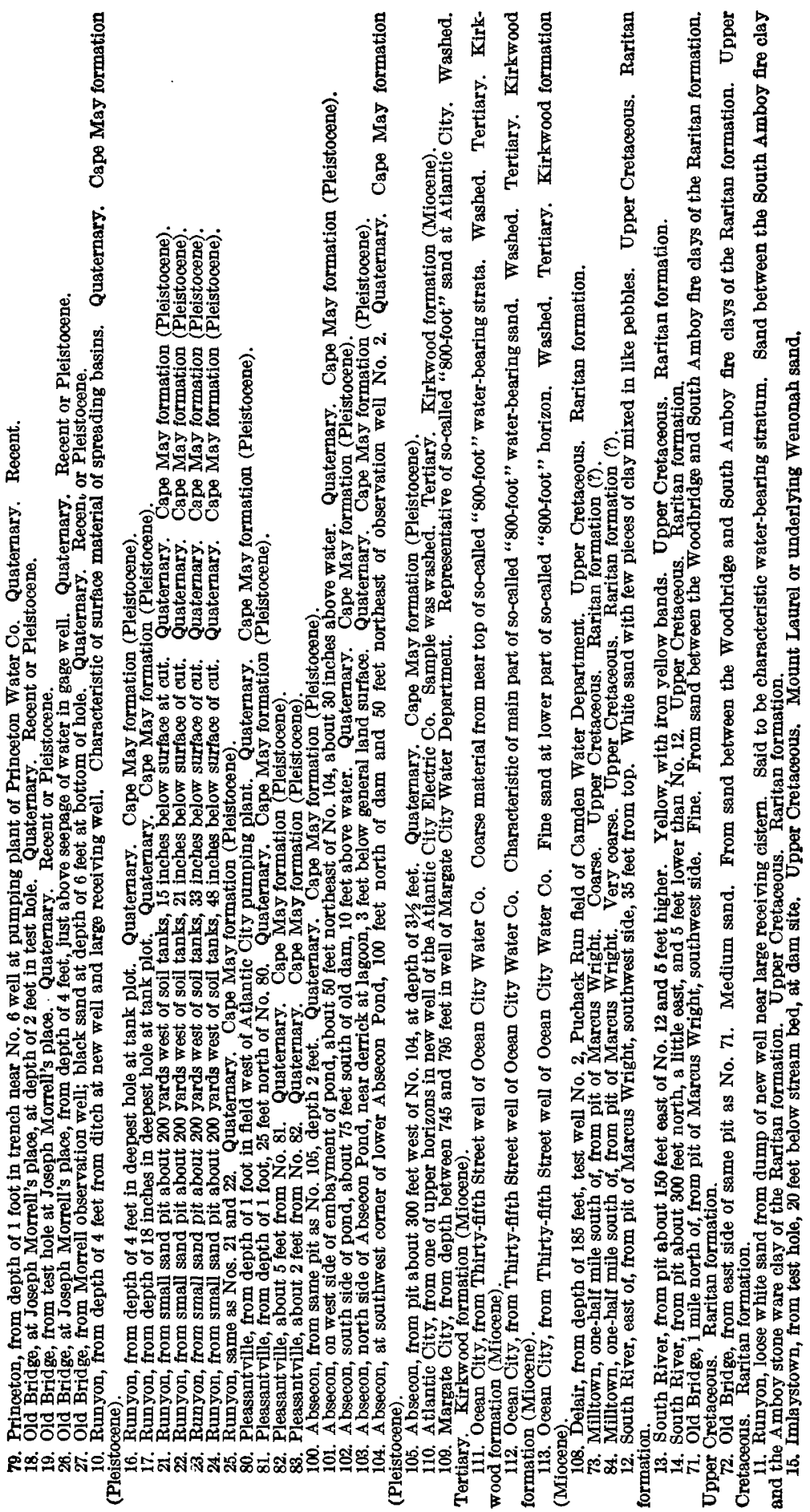




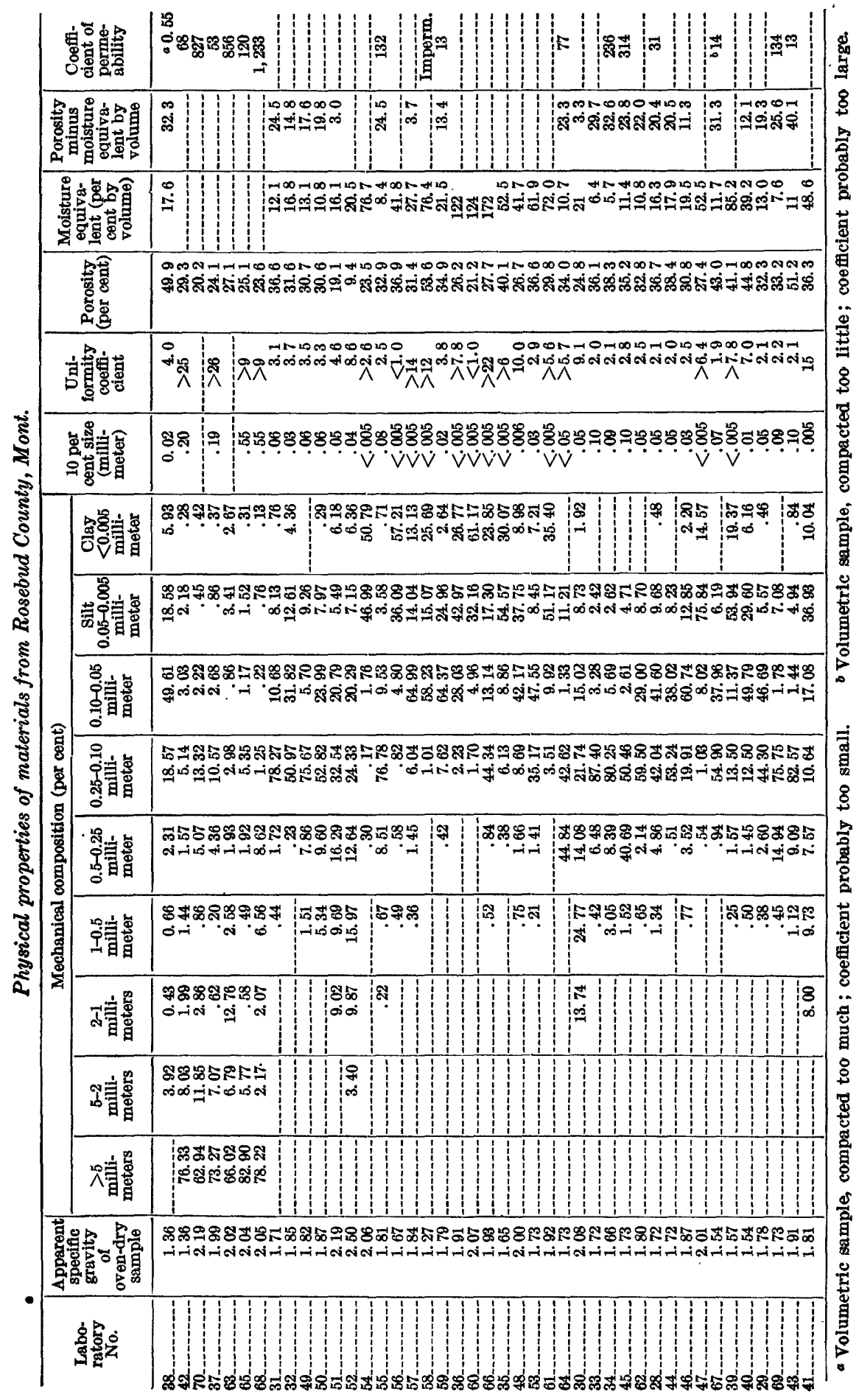




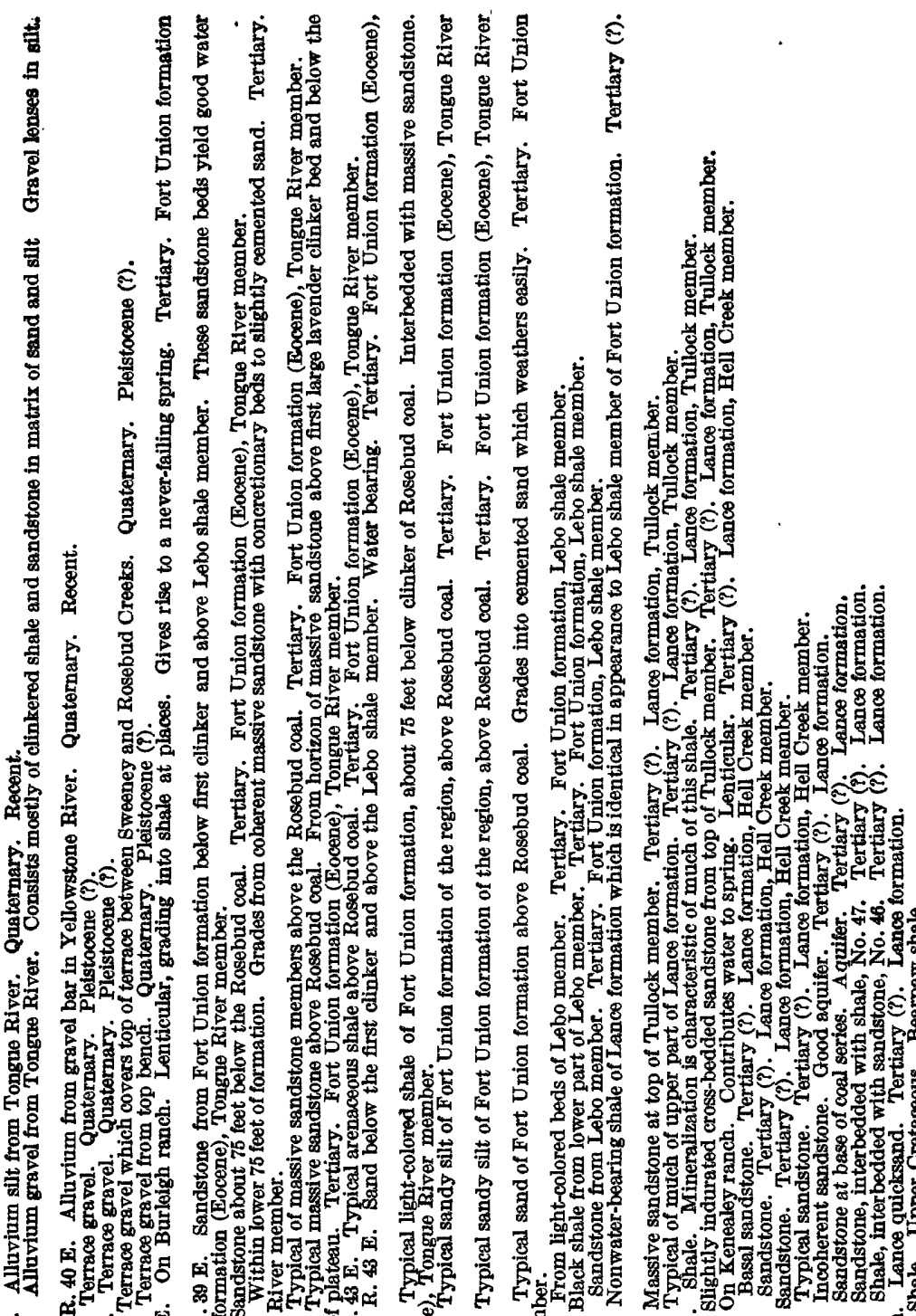




\section{OUTLINE OF WORK BY HAZEN, KING, AND SLICHTER ON EFFECTIVE SIZE IN RELATION TO PERMEA- BILITY}

There has been considerable misunderstanding on the part of some geologists and engineers in regard to the significance of the term "effective size" as used by Hazen, King, and Slichter. It seems desirable, therefore, to give an outline of their work on this subject in so far as it has a bearing on methods of computing permeability.

The term "effective size" was apparently first used by Hazen ${ }^{36}$ in connection with his study of water filters. He made mechanical analyses of the sands by sieves and plotted the results in accumulative curves based on percentages by weight of the several sizes. He says:

It has been found as a result of a careful study that the points where the curves in the diagram cut the 10 per cent line give the best idea of the total effect of the various materials. *** This gives as good an idea of the relative effective sizes of the materials as can be condensed into a single figure for each.

\section{In another report ${ }^{37}$ Hazen says:}

As a provisional basis which best agrees with the known facts, the size of grain where the curve cuts the 10 per cent line is considered to be the "effective size" of the material. This size is such that 10 per cent of the material is of smaller grains and 90 per cent is of larger grains than the size given. The results obtained at Lawrence indicate that the finer 10 per cent have as much influence upon the action of a material in filtration as the coarser 90 per cent. This is explained by the fact that in a mixed material containing particles of various sizes the water is forced to go around the larger particles and through the finer portions which occupy the intervening spaces, and so it is this finest portion which mainly determines the frictional resistance, the capillary attraction, and, in fact, the action of the sand in almost every way.

Hazen used the effective size in his formula for permeability, or "frictional resistance," but limited the effective sizes that could be used in this way. He says : ${ }^{38}$

The frictional resistance of sand to water within certain limits of size of grain and rate of fiow varies directly as the rate and as the depth of sand. This is given by Piefke as Darcy's law. I have found that the friction also varies with the temperature *** and also that with different sands the resistance varies universally as the square of the effective size of the sand grain. It probably varies also somewhat with the uniformity coefficient, but no satisfactory data are at hand upon that point.

\footnotetext{
${ }^{36}$ Hazen, Allen, Experiments upon the purification of sewage and water at the Lawrence Experiment Station, Nov. 1, 1889, to Dec. 31, 1891 : Massachusetts State Board of Health Twenty-third Ann. Rept., p. 431, 1892.

${ }^{37}$ Hazen, Allen, Some physical properties of sands and gravels with special reference to their use in filtration : Massachusetts State Board of Health Twenty-fourth Ann. Rept., p. 541, 1893.

${ }^{38}$ Idem, p. 552.
} 
Putting the available data in the shape of a formula, we have

$$
V=c d^{2} \frac{h}{l}(0.70+0.03 t)
$$

where $V$ is the velocity of the water in meters daily in a solid column of the same area as that of the sand,

$o$ is the constant factor which present experiments indicate to be approximately 1,000 ,

$d$ is the effective size of sand grain,

$h$ is the loss of head,

$l$ is the thickness of sand through which water passes, and

$t$ is the temperature on the centigrade scale.

The data at hand only justify the application of this formula to sands having a uniformity coefficient below 5 and effective size of grain 0.10 to 3 millimeters.

Hazen ${ }^{39}$ found that for gravel with effective sizes of about 3 millimeters the permeability varied in such a way as to make the application of a general formula very difficult. He says:

As the size increases beyond this point the velocity with a given head does not increase as rapidly as the square of the effective size; and with coarse gravels the velocity varies as the square root of the head instead of directly with the head, as in sands. The influence of temperature also becomes less marked with the coarse gravels.

He gives a table showing the rate at which water will pass through gravel of different sizes under various heads. Regarding this table he says:

The available data for materials about 3 millimeters, which are far less complete than could be desired, have been obtained entirely from screened gravels with uniformity coefficients from 1.4 to 2 , and at a temperature of $10^{\circ} \mathrm{C}$. or a little above. The results obtained were plotted, making a diagram from which the table has been prepared. The figures given in the table must be taken as provisional, and for use only until more extended results are obtained.

Both King and Slichter used the term "effective size"-King in the sense of mean grain with average surface, and Slichter in the sense of grain of such diameter that if all grains were of that diameter the soil would have the same transmission capacity or permeability that it actually possesses.

King ${ }^{40}$ in 1898 described his new method for the mechanical analysis of soils, the primary object of which was to determine the effective size of soil grains, chiefly in connection with soil studies. $\mathrm{He}$ states:

We are greatly in need of a method of soil examination which shall give definite data regarding the effective surface of a unit volume of soil, both for the holding of soil moisture and for the solution of plant food; one which will give the effective diameter of the soil grains or grouping of soil grains which determines the water-holding power or saturation capacity of a soil, and which determines the rate of percolation and of air movement through it.

\footnotetext{
Idem, p. 554 .

40 King, F. H., Wisconsin Univ. Agr. Exper. Sta. Fifteenth Ann. Rept., p. 123, 1898.
}

$95221^{\circ}-28-12$ 
Two methods of obtaining effective sizes or mean diameters of soil grains were in use and are mentioned by King."1 One method consisted of measuring with a micrometer the diameters of all the grain in a sample of soil; the other consisted of counting the grains in a sample of known weight and computing the diameter of the mean grain from the number of grains, the weight of the sample, and the specific gravity. In order to get results that were even approximately accurate a large number of measurements in three dimensions of the grains had to be made by the first method, and a large number of grains had to be counted by the second method. King found that the labor involved in these methods was great and, moreover, that the results obtained by the two methods did not agree very well. Hence? he tried to find a less laborious method of obtaining the effective sizis by means of the flow of water through sands. However, he encountcred such difficulties in duplicating results that he resorted to the flow of air through the sand. The use of air was found so much easier and more expeditious, and the results could be duplicated so much more closely that King and Slichter put the method on a quantitative basis. King ${ }^{42}$ says:

After considering the subject, it appeared to him [Slichter] that in view of the accepted laws of flow of air and of water through capillary tubes and the extensive experiments which had been made to determine the viscosity of botl air and water, it ought to be possible to compute the effective diameter of the soil grains from a knowledge of the observed pore space and the rate at whicl air would flow through the specimens under known conditions.

The result was Slichter's first formula. This formula ${ }^{43}$ for determining the effective diameter of the grain is as follows:

$$
d^{2}=K \frac{h}{s p t}[8.9434-10]
$$

where $d$ is the diameter of grain in centimeters, $h$ the length of sand columr in centimeters, $s$ the area of cross section of sand column in square centimeters, $p$ the pressure in centimeters of water at $20^{\circ} \mathrm{C}$., $t$ the time in seconds for 5,000 cubic centimeters of air to flow through at a temperature of $20^{\circ} \mathrm{C},[8.9434-10]$ a logarithm of a constant, and $K$ a constant taken from a table that takes account of the factor of porosity.

At this stage of King's work he undertook for the United Stater Geological Survey an investigation of the movement of ground water, and Slichter collaborated with him in developing certair theoretical phases of the subject.44 In connection with this work Slichter's second formula was devised. Both formulas, and con-

42 King, F. H., op, cit., p. 124.

42 Idem, p. 126.

«s Idem, p. 133.

th King, F. H., Principles and conditions of the movements of ground water: U. S Geol. Survey Nineteenth Ann. Rept., pt. 2, p. 67, 1899. 
sequently King's aspirator method were tested and checked by King's experimental data on the rate of flow of water through sand. King ${ }^{45}$ says :

The most rigid test yet found for the method is that furnished by comparing the observed flows of water through a series of sands with those which would be computed on theoretical considerations from the diameters as determined by the aspirator. To make such a test as this, and in order also to test the general accuracy of his two formulas, one for determining the diameter of soil grains by means of the aspirator and the other for computing the flow of water through sands, Professor Slichter has, upon request, computed the effective sizes and flows of 10 samples of sand through which the flow of water and air were carefully measured under low pressures and uniform conditions of temperature.

However, as King noted, the observed flows, both for air and for water, were slower than the computed flows through the coarsegrained soils and faster through the fine-grained soils, indicating that the formulas did not exactly meet the demands of the test or that there was some systematic error in the observations or in the operation of the apparatus. Slichter, in recent correspondence, has stated that the small departures noted by King were due to the growth of an organism in the sand.

Regarding this formula, Slichter ${ }^{46}$ says:

In Chapter I an attempt is made to derive from purely theoretical considerations an expression for the flow of water or other fluid through a column of soil made up of grains of nearly uniform size and of approximately spherical form. For the purpose of constructing this formula a study is made of the pores of the ideal spherical-grained soil, and the relation of porosity to the average arrangement of the grains is shown and made a factor in the resulting formula. I derive as the formula for the quantity of water per second transmitted by a column of soil the following expression:

$$
q=1.0094 \frac{p d^{2} s}{u h K} \text { cubic centimeters per second; }
$$

in which $\bar{q}$ is the quantity in cubic centimeters, $p$ is the difference in pressure at the ends of the cylinder in centimeters of water at $4^{\circ} \mathrm{C}$, $d$ is the mean diameter of soil grains in centimeters, $s$ is the area of cross section of the cylinder in square centimeters, $h$ is the height of the column of sand in centimeters, $u$ is the coefficient of viscosity of the fluid, $K$ is a constant taken from Table II [table of constants for various porosities of an ideal soil], and [1.0094] is the logarithm of a factor.

\section{Regarding the experiments, King ${ }^{471}$ states :}

The general conclusion which appears to be indicated by this series is that with the smaller sizes, where the grains give a minimum pore having diameters of $0.0117,0.01361,0.01619$, and 0.01809 millimeter, and under pressures not

45 Idem, p. 225.

ts Slichter, C. S., Theoretical investigation of the motion of ground waters: U. S. Geol. Survey Nineteenth Ann. Rept., pt. 2, p. 301, 1899.

t7 King, F. H., op. cit., p. 241. 
exceeding a gradient of about 3 to 5 , the flow increases faster than the prex. sure; but when the diameters of the pores are $0.02756,0.0248,0.03249,0.04094$, and 0.05821 millimeter, the fiow does not increase so rapidly as the pressur?, even when the gradient is no steeper than 1 to 5 in the three coarsest.

Details regarding the apparatus used and the results obtained are given in King's article. ${ }^{8}$ The material used was a series of 10 grades of quartz sand, thoroughly washed and screened. The pressures that were used ranged from 0.5 centimeter to 18 centimeters The length of the sand column was 12 inches, or about 30.5 centimeters. Therefore, the hydraulic gradients ranged from 1.64 to 59.11 per cent, or from 87 to 3,168 feet to the mile.

The experimental basis of the work of King and Slichter, ther, consists of the results obtained from observed flows of water through artificially screened and washed sands under relatively high hydraulic gradients. The observed flows did not check very closely with thos? computed by the formulas using the mean diameters of grain as determined with the aspirator.

Later Slichter made both field and laboratory experiments on th9 rates of flow of water, and the results obtained were published in water-supply papers of the United States Geological Survey.99 In Water-Supply Paper 67, pages 18-21, he summarizes the work done on laws of flow, including his own work and that of King. In this paper he makes the following definite statement regarding the effective size (pp. 22, 23) :

In order to compare one soil with another as to its capacity to transmit water, it is necessary to have some way of arriving at a mean or average-sized grain which it is appropriate to associate with each sample. This mean diameter is known as the effective size and is such that if all grains were of that diameter the soil would have the same transmission capacity that it actually has. Hazen's method of determining the effective size consists in first separating or analyzing the sand or soil into several grades by use of sieves of knowr mesh. The effective size is determined from the dimensions of the mesh of $\varepsilon$. sieve which will permit 10 per cent of the sample to pass through it but wil: retain the other 90 per cent-that is, in any soil 10 per cent of the grains are smaller than the effective size and 90 per cent are larger. ** * Hazer concludes from his experimental work that the 10 per cent of small grains in a sample of a natural sand or soil has the same influence on the rate of: flow of water as the 90 per cent of large grains, provided the uniformity coefficient does not exceed 5. ***

The most promising method of soil analysis for the purpose of determining its transmission capacity is that devised by Professor King. The analysis is accomplished without the use of sieves, by means of an apparatus known as King's aspirator. In this method the effective size is determined by measuring

${ }^{48}$ King, F. H., op. cit., pp. 222 et seq.

40 The following are of especial interest in this connection: Slichter, C. S., The motions of underground waters: U. S. Geol. Survey Water-Supply Paper 67, 1902; Field measurements of the rate of movement of underground waters: U. S. Geol. Survey WaterSupply Paper 140, 1905. 
the time required for the flow of a known amount of air through the sample, the measurements being made under a known pressure. It seems that the results yielded by this method are much more concordant than those given by other methods, and the apparatus deserves a thorough test by engineers interested in soil analysis.

Slichter then summarizes his formula for determining flow and gives a table of velocities of water in sands of different effective sizes of grain and the maximum flow or transmission constant for each sand-that is, the flow with a hydraulic gradient of 100 per cent.

In Water-Supply Paper 140 Slichter discusses the general laws of flow, presents again his formula and tables, and gives a scale for estimating graphically the transmission constant of a sand or gravel. He also gives an account of laboratory experiments upon the flow of water through sand and gravel contained in tanks. These experiments were designed primarily to supplement his electrolytic method used in the field, but also to verify the law of flow of water through sand and gravel under hydraulic gradients similar to those found in the field. The gradients used in the horizontal-tank experiments ranged from 0.33 to 2.04 per cent, or about 17 to 108 feet to the mile. Experiments were also made in a vertical tank with hydraulic gradients of 1 to 11.91 per cent, or about 53 to 630 feet to the mile. Mechanical analyses made by screening are given for each of the materials used in the tests, but their relation to the observed permeabilities is not discussed. The conclusion was reached that "the law of direct variation of the flow of ground waters with the head under which the flow takes place are verified by the experiments in the tank."

Hazen's effective size has been used in Slichter's formula with varying results. Smith, ${ }^{50}$ in his studies in Rillito Valley, Ariz., found a velocity computed in this manner of 3 feet a day, whereas the velocities which he obtained by field experiments with Slichter's electrolytic method ranged from 25 to 400 feet a day. He states that Hazen's effective size was perhaps applicable to deposits of sand and gravel in Massachusetts, but should not be adopted elsewhere without, special investigation as to its applicability. He concludes:

It is not likely that any formula for velocity of underflow can be safely published for widespread use until the problem of analyzing the soils has been most comprehensively studied in its relation to transmission of water. The effects of the sharpness or roundness of grain, of the various crystalline constituents, as, for example, mica, and especially of the peculiar stratification of sand in situ due to its sorting by running water, seem quite incapable of mathematical expression.

${ }^{50}$ Smith, G. E. P., op. cit., p. 126. 
Lee, ${ }^{51}$ in his studies of ground waters in the Gila and Salt River Valleys, Ariz., attempted estimates of the amount of underflow, using Slichter's formula with Hazen's effective size. He reached the conclusion that "an application of Slichter's formula to the underflow of Salt River Valley, using the effective size thus obtained, gives results which are obviously erroneous, since the quantity of underflow thus indicated is notably less than the quantity known to return to the surface and measured as water actually diverted for irrigation purposes." Slichter advised Lee that 10 per cent size is not applicable to the gravel in these localities and that the 50 per cent size gives a value of grain nearer the true mean.

It is obvious from the foregoing discussion that an indiscriminate use of the 10 per cent size for the effective size in Slichter's formula is not warranted. Such extensive use was doubtless not contemplated by Hazen, who merely found the 10 per cent size useful in estimating the permeability of the filter materials with which he worked. Nor did Slichter authorize the use of the 10 per cent size for the effective size in his formulas. Further methods of obtaining a correct value for the effective size need to be devised if permeability is to be estimated from the mechanical analysis. King's aspirator does not seem to have been widely used, probably because students of soil have required information as to the full range of sizes and not merely as to the effective size, and because hydrologists have commonly made field determinations of rate of flow by means of the fluorescein or the electrolytic method. The process of computing the effective size from results obtained with the aspirator and then using this effective size in Slichter's formula is, of course, only a roundabout method of converting permeability to air into permeability to water.

51 Lee, W. T., The underground waters of Gila Valley, Ariz. : U. S. Geol. Survey WaterSupply Paper 104, p. 40, 1904 ; Underground waters of Salt River Valley; Ariz.: U. S. Geol. Survey Water-Supply Paper 136, p. 153, 1905. 


\title{
CHEMICAL CHARACTER OF WATERS OF FLORIDA
}

\author{
By W. D. Collins and C. S. Howard
}

\section{INTRODUCTION}

The chemical character of waters in Florida has been discussed briefly in several publications, but the subject has not been treated comprehensively hitherto. A few field assays and many general statoments regarding quality of water are given in United States Geological Survey Water-Supply Paper 319, "Geology and ground waters of Florida," by G. C. Matson and Samuel Sanford, published in 1913. In connection with field work in 1908 samples of ground water were collected for analysis in the water resources laboratory of the Geological Survey. Some of these analyses were published in 1908 in Bulletin 1 of the Florida Geological Survey, "A preliminary report on the underground water supply of central Florida," by E. H. Sellards. Other analyses are given in the third, fourth, and fifth annual reports of the State Survey.

Systematic collection of the samples whose analyses are given in the present report was begun in June, 1923. The collection was made by agents of the State board of health under the direction of George W. Simons, jr., chief sanitary engineer, and the samples were sent to Washington with information in regard to the sources and treatment of the waters. The United States Geological Survey supplied the containers to the State board of health and analyzed the samples. The analyses were made by C. S. Howard, Margaret D. Foster, and H. B. Riffenburg in the water resources laboratory. Some of the analyses that were made in 1908 are also included in this report.

Samples have been obtained especially from the public water supplies of the State. Sources not now used for public supplies but likely to be used in the future are also represented. In each county other samples have been taken to indicate the quality of water available at different depths in the ground. Samples have been taken from lakes and rivers thoughout the State, from large springs and from wells or springs supplying water that is bottled and sold. Thus the analyses give a reasonably complete picture of the chemical character of the waters of Florida. 
Correlations of analyses with geologic formations have been made by C.S. Howard on the basis of data given in Water-Supply Paper 319, with modifications from later geologic work referred to in the section on geology.

\section{SURFACE FEATURES}

The State of Florida is an area of low relief. A topographic map prepared by Matson, Clapp, and Sanford ${ }^{1}$ shows that about twothirds of the State is less than 50 feet above sea level, and only small areas are more than 200 feet above sea level.

Agassiz, Dall, Vaughan, ${ }^{2}$ and others have pointed out that the mainland of Florida is but the top of a larger plateau, most of which is submerged. Sanford ${ }^{3}$ says that a depression of 50 feet would submerge all southern Florida but a few ridges. An uplift of 50 feet would extend the shore line only a little on the east but 20 or 30 miles on the west. Such an uplift ${ }^{4}$ would add an area equal to about one-third of the present land area of the entire State.

The portion of the State lying west of Aucilla River is part of the main continental mass. Parts of its surface reach higher altitudes and larger areas lie more than 250 feet above sea level than in the peninsula.

The peninsula of Florida consists of an upland or lake region and a lowland region. The upland region extends through the central part of the State from the Georgia line to about the latitude of the north end of Lake Okeechobee. The surface features of this region are similar to those of other areas that are underlain by limestone. Sinks, underground channels, and natural bridges have been formed as a result of the solution of the limestone. There are many springs in this region.

The lowland region consists of the areas along the coast and the southern portion of the peninsula; the Everglades and their environs make up a large part of this region. The lowland region contains many ponds and shallow lakes that have formed in the depressions of the surficial deposits. Ridges, sand dunes, and terraces are found throughout this area.

\section{GEOLOGY}

Matson and Sanford summarized previous geologic work in Florida in the paper already cited. Other detailed information is given in the annual reports of the State Geological Survey. A report by

1 Matson, G. C., and Sanford, Samuel, Geology and ground waters of Florida: U. S. Geol. Survey WaterSupply Paper 319, p1. 1, 1913.

2 Agassiz, Alezander, The elevated reef of Floride: Harvard Coll. Mus. Comp. Zoolog Bull., vol. 28, Na. 2, pp. 29-51, 1896. Dall, W. H., and Harris, G. D., Correlation papers-Neocene: U. S. Geol. Survey Bull. 84, 1892, Vaughan, T. W., A contribution to the geologic history of the Floridian plateau: Carnegie Inst. Washington Pub.133, pp. 107 et seq., 1910.

Matson, G. C., and Sanford, Samuel, op. cit., p. 44 and pl. 1.

4 Vaughan, T. W., op. cit., p. 117. 
Matson ${ }^{5}$ contains geologic information relating to the phosphate deposits of the State. The following discussion is a summary drawn from these publications and from other published and unpublished reports. It has been reviewed and revised by $\mathrm{C}$. Wythe Cooke.

The rocks exposed at the surface or penetrated by wells in Florida are of Tertiary or Quaternary age and include formations of all the series of both those systems.

\section{EOCENE}

The Eocene series is represented in Florida by the Ocala limestone, which is exposed in several quarries near Ocala, in phosphate mines throughout north-central Florida, and at many natural outcrops. The Ocala limestone underlies the Vicksburg group in western and peninsular Florida and in large part is identical with the "Peninsular" limestone described by Dall. ${ }^{6}$ The Ocala and "Peninsular" limestones were considered by Matson and Sanford ${ }^{7}$ parts of the Vicksburg group. Cooke, ${ }^{8}$ however, has shown that the Ocala limestone is equivalent in age to the Jackson formation of Mississippi and Alabama. The Ocala limestone in some localities is close grained and compact, but as a rule it is porous and granular and yields large quantities of water.

\section{OLTGOCENE}

The Oligocene series in Florida is represented by the Marianna limestone and the Glendon formation of the Vicksburg group. The Byram marl, which forms the upper formation of the Vicksburg group in Alabama, has not been definitely recognized in Florida but may be exposed in the western part of the State. A large part of what was formerly classed as Chattahoochee limestone is now placed in the Glendon formation. ${ }^{9}$

The Eocene and Oligocene formations are the chief sources of water in Florida, supplying nearly all the large springs and many flowing wells and yielding large supplies to nonflowing wells. These formations contain many solution cavities, and their materials are, as a rule, very porous. (See p. 191.)

Water from the Eocene and Oligocene formations is generally hard and may contain hydrogen sulphide. It is moderately mineralized, containing about 250 to 350 parts per million of dissolved solids, except in certain localities where it is highly mineralized and salty.

\section{MIOCENE}

The Miocene formations are of less importance as aquifers than the Eocene and Oligocene formations, chiefly because they are less porous and less widely distributed.

Satson, G. C., The phosphate deposits of Florida: U. S. Geol. Survey Bull. 604, pp. 11-23, 1916.

- Dall, W. H., Tertiary fauna of Florida: Wagner Free Inst. Sci. Trans., vol. 3, pt. 6, p. 1534, 1003.

7 Op. cit., pp. 71 et seq.

Cooke, C. W., The age of the Ocala limestone: U. S. Geol. Survey Prof. Paper 95, pp. 107-117, 1915.

- Cooke, C. W., The correlation of the Vicksburg group: U. S. Geol. Survey Prof. Paper 133, p. 3, 1923. 
The Chattahoochee formation and the contemporaneous Tampa formation yield water to shallow wells in localities where they lie at or close to the surface. The Chattahoochee crops out along Apalachicola and Chipola Rivers and the Tampa along Hillsboro and Manatee Rivers.

The formations of the Alum Bluff group, which overlie the Chattahoochee formation, consist chiefly of sand, clay, and marl but at some places include impure limestone. The formations of this group are thin but are widely spread and are sources of water for many shallow wells in north-central Florida.

The Choctawhatchee marl, which overlies the Alum Bluff group, and the contemporaneous Jacksonville formation yield water to a - few shallow wells.

Water from the Miocene formations is usually hard but of moderate mineral content. Shallow wells and springs in these formations may yield soft waters of low mineral content in localities where the water comes from the sandy portions of the formations. The older Miocene formations, the Chattahoochee and some others, may yield water containing hydrogen sulphide.

\section{PIIOCENE}

The Pliocene formations in Florida do not yield large quantities of water, and most of the water drawn from them is hard, although in some localities soft water may be obtained from sandy deposits of Pliocene age.

\section{PLEISTOCENE}

The Pleistocene deposits are partly of marine and partly of nonmarine origin. These deposits differ in thickness and in value as water-bearing formations. In some localities they yield large supplies of water some of which is soft, but much of it is hard because of the shells and other calcareous materials that are found in the deposits. In lowland areas flowing wells may be obtained from these formations, but the yields are usually small. Some waters from these formations contain hydrogen sulphide.

\section{QUALITY OF WATER}

Throughout this report discussions of quality of water relate only to the characteristics due to mineral constituents. Analyses showing the mineral content of waters give little indication of their sanitary condition. Such analyses serve to show the suitability of the waters for industrial use, for use in steam boilers, and for commercial or home laundry work, and they also indicate the few waters of the State that are not suitable for drinking on account of excessive mineral content. 
The treatment of a water to make it safer for drinking may affect its chemical character so as to make it decidedly better or worse for industrial use. This phase of the purification of waters is taken up briefly in the present report.

\section{CONSTITUENTS OF NATURAL WATERS}

The mineral constituents of natural waters reflect the composition and solubility of the rock materials with which the waters have been in contact. The waters of Florida have a wide range in composition, but all the types of waters encountered here are to be found in greater or less abundance in many other localities. The following notes relate to the different items listed in the table of analyses.

\section{TOTAL DISSOLVED SOLIDS}

The residue on evaporation of a water consists mainly of the rock materials listed below. A small quantity of organic material and a little water of crystallization are sometimes included. The range in quantity of dissolved solids in the waters of Florida is from less than 50 parts to several thousand parts per million. Waters with less than 500 parts per million of dissolved solids are generally entirely satisfactory for domestic use, except for the difficulties resulting from their hardness. The waters with more than 1,000 parts per million are likely to contain enough of certain constituents to produce a noticeable taste or to make the water unsuitable in some other respects. Some satisfactory waters contain over 1,000 parts per million of dissolved solids.

\section{SILICA}

Silica $\left(\mathrm{SiO}_{2}\right)$ is dissolved from practically all rocks. In the waters of Florida the quantity found is generally from 10 to 30 parts per million. The silica in a water may go with the other scale-forming materials when they are deposited as hard scale in a steam boiler. Otherwise it is of no significance as regards the use of the water.

\section{IRON}

Iron $(\mathrm{Fe})$ is dissolved from many rock materials. The quantity in the ground water is not so uniform over large areas as the quantity of calcium and other ingredients. Wells near together may differ considerably in the quantity of iron in their waters.

If a water contains much more than 0.1 part per million of iron the excess may separate out and settle as the reddish sediment common in spring and well waters of certain regions. The excess iron may be removed by simple aeration and filtration from most waters, but a few require the addition of lime or some other substance. 


\section{CALCIUM}

Calcium (Ca) is dissolved in large quantities from limestone, which is essentially calcium carbonate. Corals and shells are also nearly all calcium carbonate. Calcium is therefore found in considerable quantities in the ground waters of Florida.

Calcium carbonate is not very soluble in pure water, but when enough carbon dioxide is available large quantities of the calcium carbonate go into solution as the bicarbonate.

Many of the waters in lakes and rivers of Florida carry less than 10 parts per million of calcium. Some spring waters are also low in calcium. The calcium in potable waters from wells is generally from 40 to 100 parts per million. A few waters have more than 200 parts per million. Calcium is the main cause of the hardness of waters in Florida.

\section{MAGNESIUM}

Magnesium $(\mathrm{Mg})$ is dissolved from practically all rocks but mainly from dolomite and dolomitic limestones. As the limestones of Florida contain little magnesium, the waters of the State also generally carry only small quantities. Magnesium is one of the abundant constituents of sea water and therefore will be found in large quantity in ground water contaminated with sea water or with salts embedded in the deposits laid down in the sea ages ago.

Magnesium is the only element besides calcium that causes any appreciable amount of hardness in most natural waters.

\section{SODIUM AND POTASSIUM}

Sodium ( $\mathrm{Na}$ ) and potassium (K) are dissolved from practically all rocks, but they make up only a small part of the dissolved mineral matter in most of the waters of Florida. As sea water is essentially a solution of common salt (sodium chloride), considerable quantities of sodium are found in waters contaminated with sea water or with salts inclosed in the older marine deposits. The quantity of sodium may be 5 to 20 parts per million in an ordinary well water or several hundred parts per million in a highly mineralized water. The quantity of potassium is generally comparatively small.

Moderate quantities of sodium have little effect on the suitability of a water for ordinary household use. If the quantity of sodium is much more than 100 parts per million, foaming may occur in steam boilers unless special precautions are taken to prevent it. In some parts of the country natural waters contain so large quantities of sodium salts that crops are injured by application of the waters. The quantity that will be injurious depends on the crop, the composition and condition of the soil, and the drainage, and so no definite limit can be set, but at most places the limit will be in the thousands 
f parts per million. The only waters in Florida that come in this 'lass are those contaminated with sea water.

\section{CARBONATE AND BICARBONATE}

The carbonate $\left(\mathrm{CO}_{3}\right)$ and bicarbonate $\left(\mathrm{HCO}_{3}\right)$ in natural waters j'ssult from the solution of carbonate rocks through the action of carbon dioxide dissolved in the waters. Carbonate is not present in appreciable quantities in many natural waters; it is found in rome treated waters. Surface waters and ground waters that have not been in contact with limestone may have less than 10 parts per nillion of bicarbonate. The ordinary ground waters in Florida have "rom 100 to 300 parts per million of bicarbonate. The bicarbonate s such has little effect on the use of a water.

\section{SULPHATE}

Sulphate $\left(\mathrm{SO}_{4}\right)$ is dissolved in large quantities from gypsum (calcium sulphate) in the rocks and soil. It is also formed by the oxida"ion of sulphides of iron, and sulphate from this source causes serious Tollution of streams in parts of the country where the opening of vines has exposed large quantities of iron sulphide to the action of $\therefore$ ir and water. The waters in Florida that have large quantities of rlphate appear to have obtained it from sea water, from sea salts " vid down with sedimentary rocks, or from solution of concentrated Aeposits of sodium or calcium sulphate.

Sulphate itself has little effect on the general use of a water. Mag"esium sulphate and sodium sulphate may be present in suficient quantity to give a bitter taste. Sulphate in a hard water may inrease the cost of softening and will make the scale formed in a team boiler much more troublesome.

About half the waters analyzed for this report had less than 10 varts per million of sulphate. Less than a quarter had more than :0 parts per million, and only a little more than one-tenth had more 'han 200 parts per million. On the whole, the sulphate in waters of ?lorida is of little significance.

\section{CHLORIDE}

Chloride $(\mathrm{Cl})$ is an abundant constituent of sea water and is disolyed in small quantities from rock materials throughout the country. "he rain water brings down much more chloride near the ocean han in the interior, as the finely divided salt spray from the ocean is carried with dust particles by the wind and precipitated with the "ain. This difference is shown in the so-called "normal chlorine" naps that have been prepared for some regions. Such maps are vlotted from analyses of normal unpolluted waters and show quantities of chloride ranging from less than 1 part per million far from the 
ocean up to 5 or 6 parts per million near the coast. As chloride is a characteristic constituent of sewage, the content of chloride in a water when compared with the normal content shown on the normal chlorine map was formerly thought to be an indication of pollution. So many other sources besides sewage supply chloride to natural waters, however, that its presence in more than "normal" quantities is no longer taken as a definite indication of pollution.

Many of the surface waters of Florida have less than 15 parts per million of chloride, but well waters with 100 parts per million or more are not uncommon. Chloride, like sodium, with which it form a sodium chloride (common salt), comes largely from present or anciert sea water. Chloride has little effect on the suitability of water for ordinary use unless there is enough to give the taste of salt. Waters high in chloride may be corrosive when used in steam boilers.

\section{NITRATE}

Nitrate $\left(\mathrm{NO}_{3}\right)$ in water is considered a final oxidation product of nitrogenous organic material. Most waters in Florida carry lers than 1 part per million of nitrate. This small quantity has no effect on the value of the water for ordinary uses.

\section{HARDNESS}

Hardness of a water is most commonly recognized by its effects when soap is used with the water in washing. The figures for harcness given in the table of analyses are calculated from the determined quantities of calcium and magnesium, which cause practically all the hardness of ordinary waters. In addition to causing trouble in the use of soap, the constituents that cause hardness are also the active agents in the formation of the greater part of all the scale formed in steam boilers and in other vessels in which water is heated or evaporated.

Water with a hardness of less than 50 parts per million is generallrated as soft, and its treatment for the removal of hardness is rarel-r justified. Hardness between 50 and 150 parts per million does nct. seriously interfere with the use of water for most purposes, but it does slightly increase the consumption of soap, and its removal by a softening process is profitable for laundries or other industrie that use large quantities of soap. Treatment for the prevention of scale is necessary for the successful operation of steam boiler? using water in the upper part of this range of hardness. Hardners above 150 parts per million is noticed by anyone, and where the harc ness is 200 or 300 parts per million it is common practice to soften water for household use or to install cisterns to collect rain water. Where municipal water supplies are softened an attempt is generallmade to reduce the hardness to about 100 parts per million. The 
-dditional improvement from further softening of a whole public upply is not deemed worth the additional cost.

Waters of widely differing hardness are found in Florida. The urface waters are practically all soft; a large proportion of the well raters are decidedly hard. A number of the public supplies from $\pi$ ells are softened.

\section{HYDROGEN SULPHIDE}

Hydrogen sulphide $\left(\mathrm{H}_{2} \mathrm{~S}\right)$ was not detected in many samples of Tater from Florida when they were received in the laboratory, and therefore this constituent is not shown in the tables of analysis. Tydrogen sulphide is a gas which gives the characteristic odor to sulphur waters. It is formed during the decomposition of eggs and ther organic materials that contain considerable sulphur. Hydrogen sulphide in ground waters is commonly believed to be formed by the reduction of sulphates.

Many ground waters in Florida carry small quantities of hydrogen sulphide. It usually disappears quickly when the water is allowed to stand in an open vessel. Treatment for the removal of iron will insure the removal of hydrogen sulphide from most of these waters.

COLOR

Ground waters are generally colorless; surface waters are likely to be noticeably colored even when quite free from suspended matter. The color is taken up from decaying leaves and other organic matter. Swamp waters are much more highly colored than waters that have ieen in contact only with rocks, sand, and gravel or, than waters of streams and lakes fed almost entirely by springs from limestone. The vaters of a few shallow wells and springs are colored, but these are practically surface waters from swamps. In some parts of the country highly colored waters are obtained from deep wells that penetrate beds of lignite or other deeply buried organic matter.

Color is measured in terms of an arbitrary color standard, which has been used in nearly all studies of natural waters for the last 20 years. The color standard is made from potassium chloroplatinate, cobalt chloride, and hydrochloric acid. The unit color corresponds to 1 milligram of platinum in 1 liter of water.

Color less than 10 according to this standard is not objectionable to those who have not been accustomed to colorless water, but in some communities it is necessary to keep the color of a filtered water well below 10 in order to avoid complaints. The color of some stream waters in Florida is well over 100. The materials that color swamp waters are of themselves harmless, but the removal of color is one of the first considerations in any plant for the purification of water for a public supply. Consumers are generally more concerned over the slight color that they can see than over the invisible bacteria, which may be the cause of disease or death. 


\section{SUSPENDED MATTER}

Ground water is generally free from suspended matter. Some waters contain enough iron in solution to give on exposure to the air a precipitate, which is usually red or brown but in sulphur water: may be black iron sulphide. Sulphur waters may become turbid from separation of sulphur.

Most of the surface waters of Florida are practically free from suspended matter. The samples analyzed for this report were so clear that no determinations of suspended matter were made. The single sample from Apalachicola River was exceptionally clear, although this river is usually rather muddy. Analyses of water from Chattahoochee and Flint Rivers, published in $1909,{ }^{10}$ gave averages of 136 and 58 parts per million, respectively, for the suspended matter. Some large rivers in the United States carry over 500 parts per millior. of suspended matter. It has been estimated ${ }^{11}$ that from the whole United States the quantity of mineral matter carried to the oceans ir. suspension in the rivers is nearly twice the quantity carried in solution.

Suspended matter in a water may be harmless, but its removal is necessary to make the water satisfactory as a public supply or suitable for most industrial uses.

\section{METHODS OF ANALYSIS}

The methods used in the analyses made for this report are described. in detail in another paper. ${ }^{12}$

A suitable volume of the water was evaporated to dryness in platinum and weighed after heating one hour at $180^{\circ} \mathrm{C}$. Silica was separated after evaporation with hydrochloric acid. The filtrate from the silica was made to a definite volume and divided into twc equal parts, unless the composition of the water made it desirable to divide differently in order to have more suitable quantities for the determination of the several constituents. Iron and aluminum were precipitated in one part of the filtrate. The precipitate was dis. solved in hydrochloric acid, and the iron was determined colorimetrically as thiocyanate. Calcium was precipitated as oxalate in the filtrate from the iron and aluminum; the precipitate was filtered out, dissolved in dilute sulphuric acid, and titrated with permanganate. Magnesium was determined as pyrophosphate in the filtrate from the calcium.

10 Dole, R. B., The quality of surface waters in the United States: U. S. Geol. Survey Water-Supply Paper 236, pp. 54, 62, 1909.

II Dole, R. B., and Stabler, Herman, Denudation: U. S. Geol. Survey Water-Supply Paper 234, pp. 78-93, 1909.

${ }^{12}$ Collins, W. D., Notes on practical water analysis: U. S. Geol. Survey Water-Supply Paper 596, pp. 235-261, 1927. 
Sulphate was determined as barium sulphate in the second portion of the filtrate from the silica. Sodium and potassium were weighed together as chlorides after removal of magnesium, barium, and calcium from the sulphate filtrate. Usually the whole weight of mixed chlorides was calculated to sodium. In a few samples potassium was determined in the mixed chlorides by the use of platinic chloride and reduction by magnesium, as described by Hicks. ${ }^{13}$ For a number of the samples the determination of sodium was omitted and the sodium necessary to balance the analysis was calculated.

\section{EXPRESSION OF RESULTS}

Units.-In accordance with the long-established custom of the United States Geological Survey the radicles determined are reported in parts per million. Results given in parts per million can be converted to grains per United States gallon by dividing by 17.12.

Hypothetical combinations.-A natural water or solution of rock materials is a balanced chemical system and not a mere collection of random quantities of the several radicles. In practically all waters the quantities of the basic radicles calcium, magnesium, sodium, and potassium are together chemically equivalent to the sum of the acid radicles-bicarbonate, sulphate, chloride, and nitrate. It is not possible to set down a list of salts that actually exist in a water, but a number of combinations of salts can be given each of which would make up a solution chemically identical with the water. This is the meaning of the tables of hypothetical combinations in which analyses are sometimes reported.

The outstanding characteristics of many waters can be indicated by the name of a single compound. A water from limestone is likely to be a calcium bicarbonate or calcium carbonate water. Calcium and bicarbonate together may make up 70 to 90 per cent of the dissolved mineral matter. A brine is a sodium chloride water.

Palmer ${ }^{14}$ worked out a plan for the classification of waters by their chemical properties without using the names of compounds. $\mathrm{He}$ used the term "primary" for sodium and the other alkali metals and "secondary" for the alkaline-earth metals. The weak acid radicles (carbonate and bicarbonate) give "alkalinity," and the strong acid radicles (sulphate, chloride, and nitrate) give "salinity." Thus a limestone water has secondary alkalinity and a brine has primary salinity. This classification with the properties expressed in percentages of the whole, has been used widely in studies of geochemical relations of waters, particularly those found in oil fields.

\footnotetext{
18 Hicks, W. B., A rapid modified chloroplatinate method for the estimation of potassium: Ind. and Eng. Chemistry, vol. 5, pp. 650-653, 1913.

14 Palmer, Chase, The geochemical interpretation of water analyses: U. S. Gẹol, Survey Bull. 479, 1911. $95221^{\circ}-28-13$
} 
Graphic representation of analyses. ${ }^{15}$-For more than 50 years different writers have represented water analyses by diagrams similar to those shown below. The heights of the several sections correspond to the quantities of the radicles, expressed in terms of combining weights rather than in parts per million. One unit of height corresponds to 20 parts per million of calcium, 12 of magnesium, 23 of sodium, 39 of potassium, 61 of bicarbonate, 48 of sulphate, 35.5 of chloride, 62 of nitrate, or 50 of hardness as calcium carbonate. The total hardness is measured to the top of the magnesium; the carbonate hardness is measured to the top of the bicarbonate, if this is lower than the top of the magnesium. If the bicarbonate extends above the magnesium all the hardness is carbonate hardness.

Calculations from analyses.-Stabler ${ }^{16}$ gave in 1908 a series of formulas for calculating from water analyses the probable quantities of scale-forming constituents and several other characteristics.

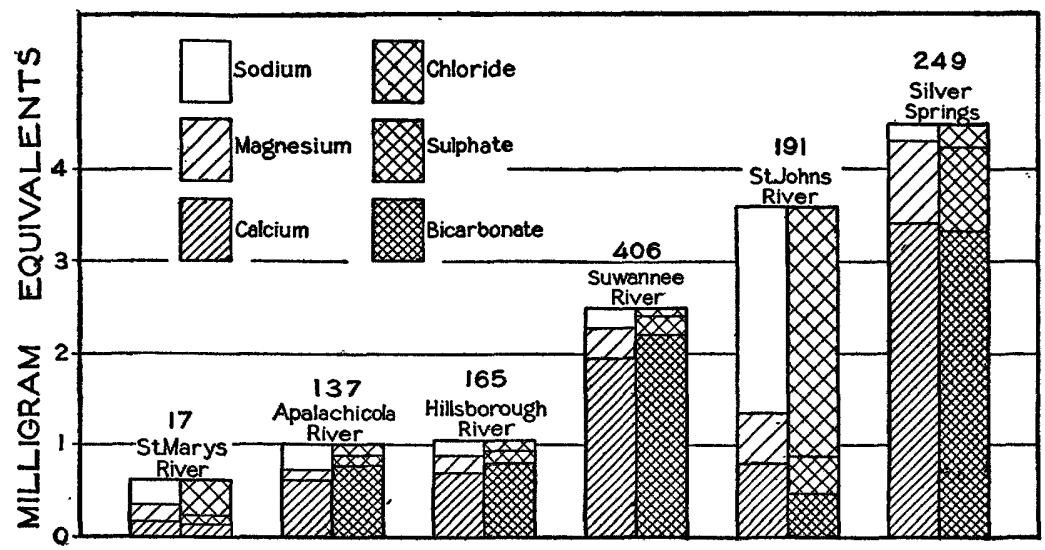

Figure 27.-Analyses of river waters in Florida. Numbers refer to analyses in the table

His calculations are based on analyses expressed in terms of combining weights in milligrams per kilogram, to which he gave the name "reacting values."

\section{QUALITY OF SURFACE WATERS}

Surface waters of Florida differ widely in composition. In general, however, the rivers and smaller streams carry only small quantities of dissolved mineral matter-not much more than 100 parts per million. Some streams that originate as large springs in limestone have 200 or 300 parts per million of dissolved solids. All the rivers become brackish toward their mouths, where ocean or Gulf water is mixed with the river water by the tide.

15 Collins, W. D., Graphic representation of water analyses: Ind. and Eng. Chemistry, vol. 15, p. 394, 1923. ${ }^{10}$ Stabler, Herman, The mineral analysis of water for industrial purposes and its interpretations by the engineer: Eng. News, vol.60, p. 355, 1908; Some stream waters of the western United States, with chapters on sediment carried by the Rio Grande and the industrial application of water analyses: U. S. Geol. Survey Water-Supply Paper 274, pp. 165-181, 1911. 
The waters of many small lakes have less than 50 parts per million of dissolved solids; other lake waters have 100 or 200 parts per million. The water of Lake Okeechobee is not the same throughout the lake, but at nearly all points the mineral content ranges from 250 to 300 parts per million. Waters of some small lakes are salty-for example, Salt Lake in Brevard County. Nearly all the surface waters are noticeably colored, and the larger lakes and streams generally have more color than the smaller ones.

The composition of typical lake and river waters is shown graphically in Figures 27 and 28.

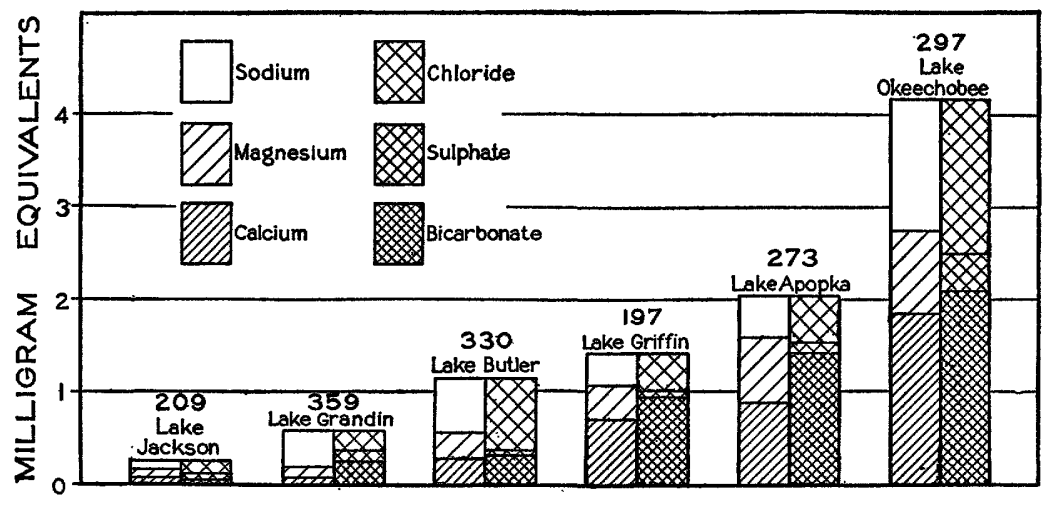

FrGuRe 28.-Analyses of lake waters in Florida. Numbers refer to analyses in the table

\section{QUALITY OF GROUND WATERS}

The chemical composition of individual ground waters is shown in the accompanying table, in which a brief statement is made regarding the character of the waters of each county. For a more general discussion of ground waters the State is considered in three geographic divisions called western Florida, northern and central Florida, and southern Florida.

\section{WESTERN FLORIDA}

As used in this paper, western Florida comprises the counties west of Aucilla River-Jefferson, Leon, Wakulla, Gadsden, Liberty, Franklin, Jackson, Calhoun, Gulf, Holmes, Washington, Bay, Walton, Okaloosa, Santa Rosa, and Escambia. These counties are underlain by the Chattahoochee formation and the limestones of Oligocene and Eocene age. The Marianna and Ocala limestones are at the surface in the northern part of Jackson County. The Chattahoochee formation is at the surface along Aucilla River and in the northern part of Holmes County and southern part of Jackson County. These formations yield large quantities of hard water of moderate mineral content to many wells in this area; in some places 
they yield sulphur water, and along the coast they yield salty water to many wells. In Walton, Okaloosa, Santa Rosa, and Escambia Counties few wells have been drilled to these older formations.

Along the Gulf coast in the area west of Liberty and Franklin Counties, including all of Escambia and Santa Rosa Counties and the major portion of Okaloosa County, the surface deposits are Miocene to Recent undifferentiated. These deposits yield good quanti-

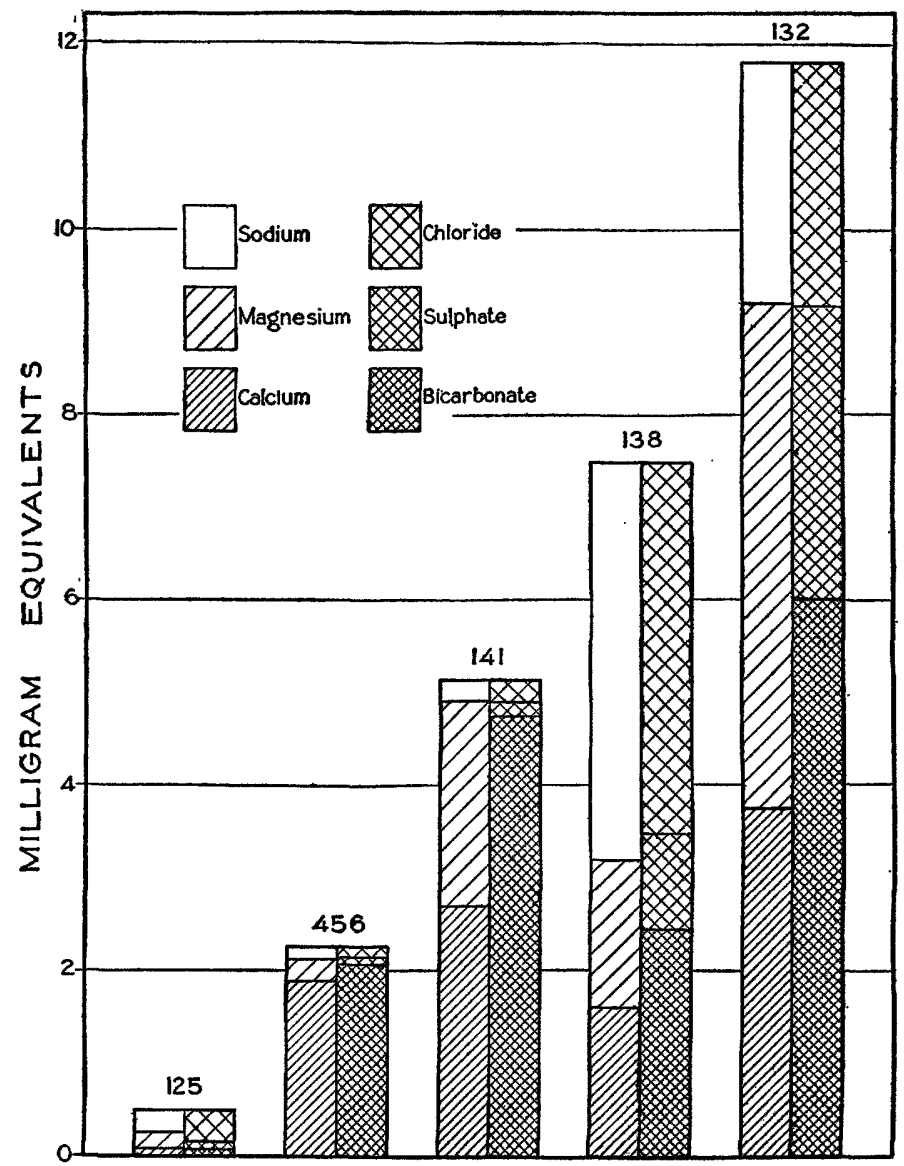

Fradre 29.-Analyses of ground waters in western Florida. Numbers refer to analyses in the table

ties of soft water to shallow wells. In some localities where a larger supply of water is needed wells have been drilled into the older formations, but the water from these formations is as a rule harder than that obtained from shallow wells.

The Choctawhatchee marl, Jacksonville formation, and formations of the Alum Bluff group underlie the northern part of the coastal area just described and are the surface deposits in the region between the coastal area and the area where the Chattahoochee formation is at 
the surface. The Choctawhatchee marl and other Miocene formations are the source of water for many shallow wells but do not contain as much water as the older formations. Water from the Miocene formations is as a rule hard, although locally it is reported to be soft.

Soft water with a low mineral content is found in Escambia, Santa Rosa, and Walton Counties in wells as deep as 300 feet. This water probably has its source in the formations that overlie the Oligocene and Eocene limestones and contain practically no limestone or other calcareous material. Analyses of waters of western Florida are shown graphically in Figure 29. No. 125 is typical of the very soft waters found in a small area in Escambia County, No. 456 is a typical limestone water of moderate hardness, and No. 141 is similar except for its greater hardness. Waters like Nos. 456 and 141 are found at many places throughout the State. Nos. 138 and 132 are typical of waters from deep wells in different parts of the State. They contain larger proportions of magnesium than the simple limestone waters; chloride and sulphate make up the greater part of the acid radicles. The constituents other than those found in limestone waters are not in the proportions in which they occur in sea water, and their source is not evident.

\section{NORTHERN AND CENTRAL FLORIDA}

Northern and central Florida includes the counties east of Aucilla River and north of Lee, Hendry, and Palm Beach Counties. The Oligocene and Eocene limestones underlie this entire region and crop out in a large portion of the central part of the peninsula. These limestones are very porous and contain large quantities of water, much of it in solution channels in the limestone. Water from these limestones is hard and of moderate mineral content and in many places contains hydrogen sulphide. Wells sunk to these formations yield water under considerable pressure. Flowing wells occur on the east coast near Jacksonville, in central Florida near Sanford, and on the west coast near Bradentown and St. Petersburg. Practically all the large springs of the region flow from these formations, and therefore the spring waters are hard.

The Glendon formation, of Oligocene age, and the formations of the Alum Bluff group, the Jacksonville formation, and the Choctawhatchee marl, all of Miocene age, yield water to many shallow wells but only in moderate quantities. As a rule the water from these formations is of moderate mineral content and hard, although in some places soft water is obtained from them.

The Pliocene deposits consist of marl, clay, and gravel. The marl and clay do not yield much water, and the area where the gravel is most widely distributed has many deep wells sunk to the older 


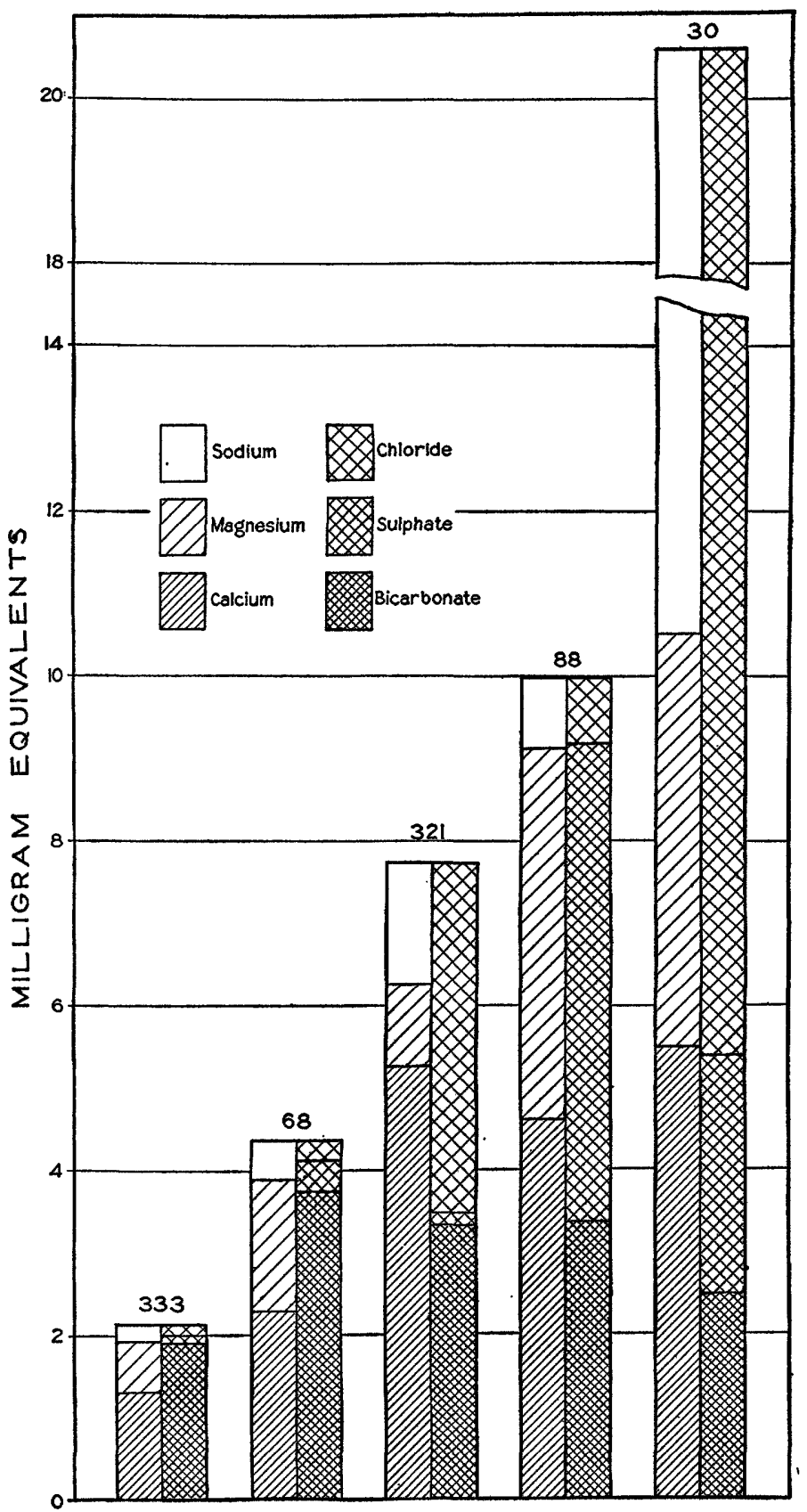

FIGURE 30.-Analyses of ground waters in northern and central Florida. Numbers refer to analyses in the table 
formations in order to get large quantities of water under a good head. The gravel yields moderate quantities of water.

The Pleistocene and Recent deposits occur especially along the coast and yield good supplies of water to shallow wells. The waters are usually not so hard as those from the older formations, although coquina and other calcareous materials in the deposits cause some hardness.

More than 60 per cent of the ground waters of northern and central Florida analyzed for this report have a hardness of 150 to 400 parts per million and total solids less than 400 parts per million. The waters having a hardness greater than 400 parts per million and total solids greater than 400 parts per million have considerably more chloride or sulphate or both than the normal ground waters. Analyses of characteristic waters of the region are shown in Figure 30. Nos. 333 and 68 are typical limestone waters such as are found throughout the State. They may be called slightly and moderately hard, respectively. Nos. 321 and 88 are decidedly hard waters, which in addition to constituents dissolved from limestone contain considerable quantities of chloride and sulphate, respectively, with correspondingly larger quantities of sodium or magnesium. No. 30 is primarily a sodium chloride water. It represents in a general way the composition of a ground water contaminated with sea water. In the diagram for No. 30 sodium chloride to the amount of 3 milligram equivalents has been omitted, as indicated by the numbers on the margin.

\section{SOUTHERN FLORIDA}

In this report southern Florida comprises Martin, Palm Beach, Broward, Dade, Hendry, Collier, Monroe, and Lee Counties. The Everglades cover a large part of this region.

The Oligocene and older formations are deeply buried in southern Florida. Wells, some flowing, that reach these formations yield large quantities of hard water, which is sulphureted and nearly everywhere salty. The Miocene and Pliocene beds yield a little water; on the west coast some wells obtain flows from these formations. The water is hard, and as large quantities can not be obtained, wells usually are sunk to the older formations. The Pleistocene formations are in some localities 125 feet thick and throughout this region are the chief sources of water. The water is usually hard because it comes from limestone and other calcareous materials. The public supply at Olympia, Martin County (No. 255, fig. 31) is obtained from shallow wells and is the only soft water from the Pleistocene deposits in southern Florida among those analyzed for this report. The Pleistocene formations generally yield the best water in this region, and unless the quantity is insufficient it is unnecessary 
194 CONTRIBUTIONS TO HYDROLOGY OF UNITED STATES, 1927

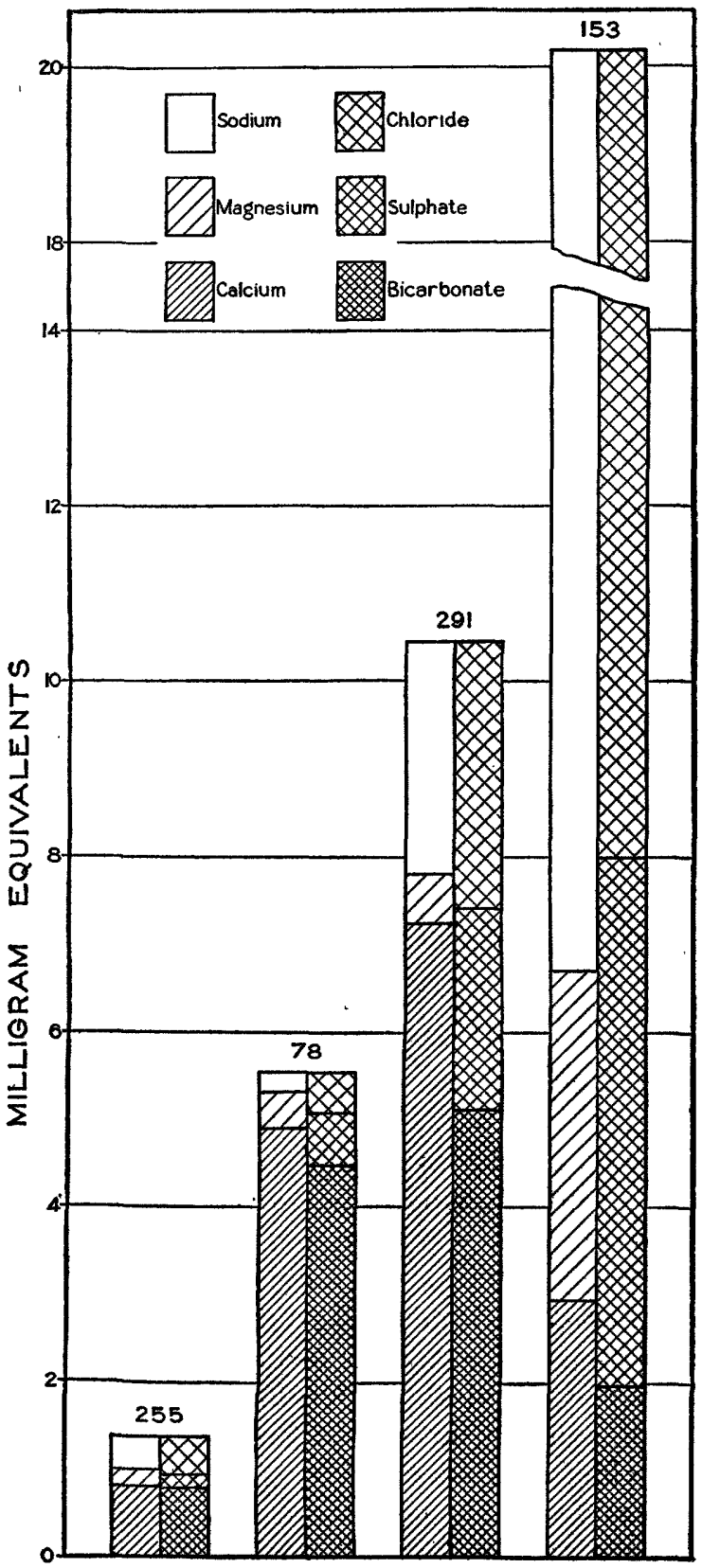

IreoRH 31.-Analyses of ground water in southern Florida. Numbers refer to analyses in the table 
to drill to the deeper formations. Some of the ground waters.in this area are colored, as the surface waters are.

Typical analyses are shown in Figure 31. Although fairly soft, No. 255 has in general the composition of a limestone water. Calcium and bicarbonate are its chief constituents. No. 78 is a characteristic hard limestone water. A large number of wells in many parts of the State supply water almost identical with that represented by diagram No. 78. Nos. 291 and 153 represent common types of water containing large quantities of chloride and sulphate in addition to the bicarbonate that is characteristic of limestone waters.

\section{UTILIzation OF WATERs FOR PRIVATE AND PUBLIC SUPPLIES}

\section{REQUIREMENTS}

The primary requirement for a water for ordinary private or public supply is that it shall be safe to drink. It must come from a source known to be free from possibility of pollution with bacteria that may cause disease, or it must be so treated as to kill any such bacteria that may be in it. For many industrial uses the sanitary condition of a water is of no importance.

The requirement that is second in real importance, though put first in the demands of most customers, is that a water shall have a pleasing appearance and be free from objectionable taste or odor. These qualities are not so important industrially, although clear, colorless water is essential for certain processes.

It is desirable that water for domestic use be soft. Hardness probably has no effect on the value of a water for drinking and certrinly is of no consequence for the uses which consume most of the water required by a household. As soon as soap is used with water the ill effects of hardness appear. On the score of economy the softening of hard water may be justified for a single family. The money saving will depend on the quantity of soap used. It does not take a commercial laundry long to save enough in soap to pay for a water softener, but a much larger proportion of the total water used in a laundry is used with soap. In the home the use of a water softener is comparable with the use of a water heater. One can wash, after a fashion, with cold water just as one can wash, also after a fashion, with hard water.

In the industrial use of water freedom from hardness is in general the most important feature. Hardness must be removed for the proper operation of steam boilers to supply power for manufacturing or hot water for industrial processes. In addition to laundry work other textile operations, like bleaching and dyeing, are affected by the hardness of the water used. 
Some waters are objectionable because of their corrosive properties. Soft waters that contain large quantities of carbon dioxide often attack iron pipes so vigorously that the water is rendered turbid and red by the dissolved iron, and in time the pipes are almost closed by the accumulation of iron oxide in them. Hard waters are usually less corrosive than naturally soft waters.

\section{SOURCES}

Throughout much of the State abundant supplies of potable ground water can be obtained for individual homes or for small communities. Some of the cities, however, have found it difficult to obtain a sufficient supply of ground water, and others have found the quality of the water deteriorating as wells were drawn upon for ever-increasing demands. Moreover, the surface waters at most places are decidedly softer than the ground waters, and hence the utilization of surface waters for public supplies in Florida is likely to increase.

\section{TREATMENT OF GROUND WATER}

Some natural ground waters are perfectly satisfactory for all ordinary uses, but many can be decidedly improved by treatment for the removal of iron or hydrogen sulphide or by softening. So many caverns and solution channels have been formed in the limestones of Florida that ground waters there are less safe from pollution than they are in regions where the water-bearing strata consist of sandstone, shale, sand, and gravel. Where the possibility of pollution exists a water that is otherwise acceptable may require chlorination to insure its safety.

\section{REMOVAL OF IRON AND HYDROGEN SULPHIDE}

Aeration, with or without filtration, generally serves to remove the iron and hydrogen sulphide from the ground waters of Florida. The purification of some waters is aided by the addition of small quantities of lime or some other agent that will make the separation of the undesirable constituents more rapid and more complete. The condition in which the iron exists in a water and the quantities of the other constituents determine the treatment for removal of the iron and affect the result. Thus each new installation is a separate problem, which may not yield to treatment that has been successful under apparently similar conditions.

\section{SOFTENING WITH LIME AND SODA}

The lime-soda process for softening water has been used so long that it need not be described in detail. Theoretically lime equivalent to the free carbon dioxide, the carbonate hardness, and the magnesium is added to the water, also soda ash or sodium carbonate 
equivalent to the noncarbonate hardness. In practice the quantities of chemicals to be added are often determined by tests of the softened water. If the softening is conducted at a high temperature, there is a saving of chemicals and the softening is more nearly complete than at ordinary temperatures.

The lime-soda process works best with water of constant composition. Changes in the mineral content of the water make it necessary to alter the rate of addition of the chemicals and may make it necessary to alter their relative proportions. Well waters and waters obtained from large lakes or other sources of constant composition are more easily treated than waters from rivers, whose content of dissolved mineral matter may fluctuate from 50 to 150 per cent of the average. Municipal softening of a public supply is a help to the operation of a plant using the lime-soda process for further softening in that it tends to keep the hardness of the water more uniform.

Lime-soda softening properly conducted always decreases the total quantity of dissolved material in the water. The carbonate hardness is nearly all removed, and the dissolved solids are correspondingly decreased. The calcium and magnesium of the noncarbonate hardness are replaced by sodium, so that this part of the process makes little difference in the quantity of dissolved solids. Some waters have so much noncarbonate hardness that after treatment they are likely to cause foaming in steam boilers because of the great increase in the concentration of sodium salts.

\section{SOFTENING WITH EXCHANGE SILICATES}

A newer process for softening water depends on the property of some insoluble silicates of exchanging sodium for calcium or magnesium. When used in treating ordinary hard water these silicates take from it practically all its calcium and magnesium and give $\theta$ in exchange sodium. Water thus treated is for all practical purposes free from hardness, although analyses may show that it still contains a few parts per million of calcium and magnesium.

When the silicate in a softener begins to lose its exchange capacity it is regenerated by passing a strong solution of common salt through the layer of silicate, which now takes sodium from the salt solution in exchange for the calcium and magnesium that it had removed from the hard water. The salt solution must be completely washed out before water is again taken from the softener for use in steam boilers.

Whatever may be the composition of a water it can not be overtreated in an exchange-silicate softener, and unless the capacity of the apparatus is overtaxed the water will not be undertreated. The size of the softener required for a given output between regenerations depends, however, on the hardness of the water. The exchange- 
silicate process makes practically no change in the total quantity of dissolved solids in a water. This is a disadvantage that is sometimes overcome by first treating the water with lime to remove most of the carbonate hardness and filtering out the precipitated calcium carbonate before passing the water through the bed of silicate.

Some waters contain so much sodium that they are not softened satisfactorily by exchange silicates. Other waters are so hard that they can not be softened in this way. Such waters are uncommon, and their use is not often considered even for private supplies.,

\section{TREATMENT WITH HEAT AND WITHIN THE BOILER}

Systems are in use for removing scale-forming substances by heating feed water to boiler temperature before it enters the boiler. These systems serve for boiler feed water but have not the universal applicability of the lime-soda or exchange-silicate systems, which are used to supply soft water for all purposes.

Treatment within the boiler is under many conditions the best method of preventing scale and is the only method of preventing foaming. At small plants waters of moderate hardness can generally be treated more satisfactorily in the boiler than in an outside softening apparatus. Some large plants have obtained the best results by treatment within the boiler, but the large plants also offer the best field for the softening of water outside the boiler.

\section{RESULTS OF WATER SOFTENING}

The changes in composition of waters that result from softening are shown in Figure 32. Diagrams A and B represent respectively untreated and softened water of part of the public supply at Daytona Beach. The treatment when the samples were taken involved the addition of 24 pounds of lime and 7 pounds of soda ash to 10,000 gallons of water. The waters represented by diagrams A and B may have been slightly different before the treatment, but the sulphate and nitrate did not differ more than could be attributed to unavoidable errors of analysis, and the chloride was exactly the same. The diagrams show the reduction in bicarbonate, calcium, and magnesium that is accomplished by the addition of lime. Diagram A shows an excess of calcium and magnesium together over the bicarbonate. This excess is the noncarbonate hardness. The large content of chloride suggests that the water would be corrosive if heated in a steam boiler. The addition of sodium carbonate (soda ash) helped the precipitation of calcium carbonate and magnesium hydroxide and served to balance more of the chloride. Thus not only is the noncarbonate hardness decreased, but the probability of corrosive action is also reduced. 
Diagrams $C$ and $D$ represent corresponding analyses for another part of the Daytona Beach public water supply. When the samples were collected the water was being treated with 24 pounds of lime to 10,000 gallons. The noncarbonate hardness in $\mathrm{C}$ is much less than in

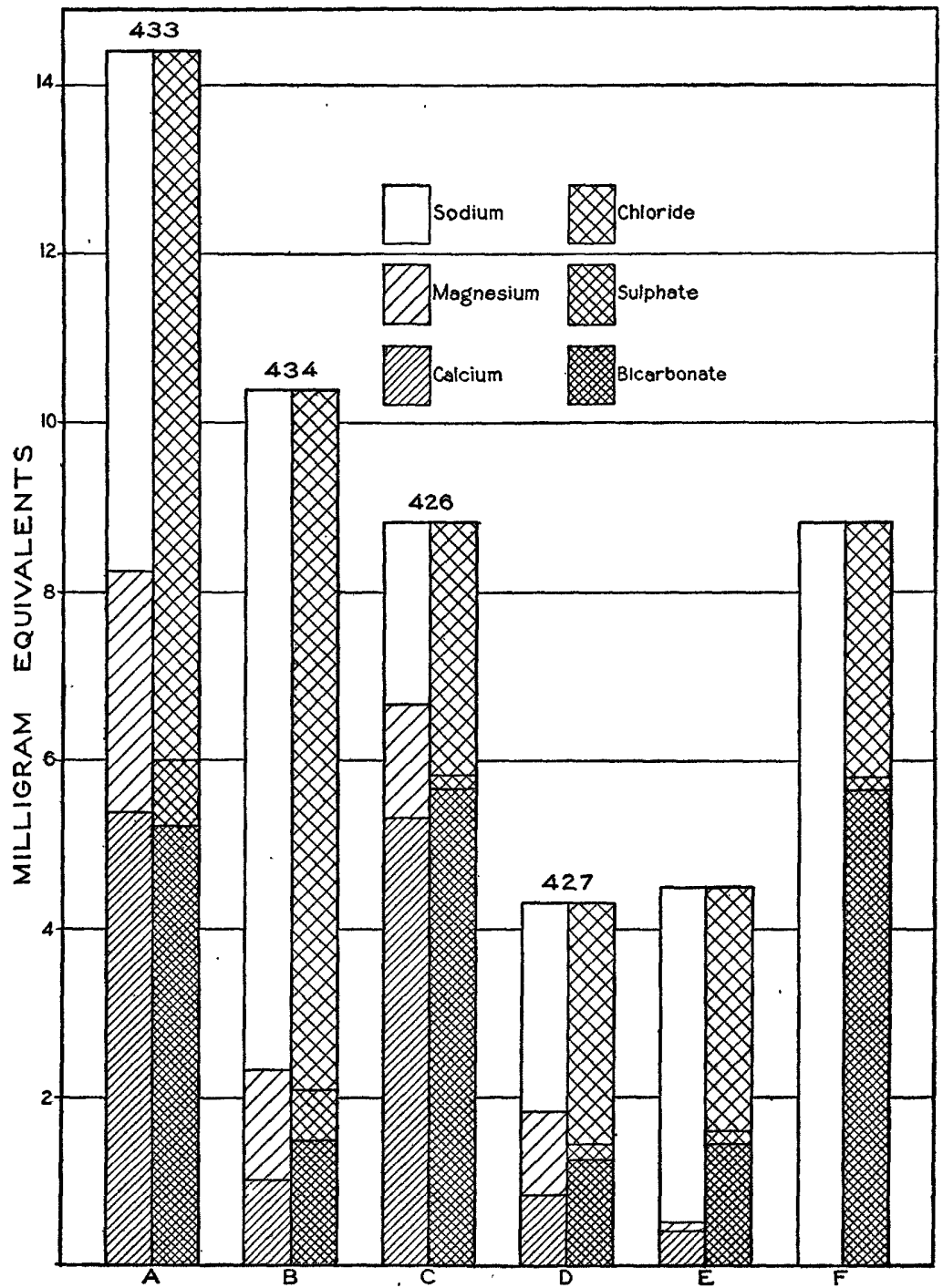

Figure 32.-Analyses of natural and softened waters in Florida. A, C, Natural water; B, D, E, F, softened water. Numbers refer to analyses in the table

A and therefore there is less need for the use of soda ash in the treatment. The probability of corrosion is also less in $\mathrm{C}$ than in A. The results of treatment at the two places are practically the same as regards hardness. The use of soda ash at Daytona Beach makes a noticeable increase in the rather large quantity of sodium already in the water. 
Diagram E represents the probable result of treating the Daytona water (C) in a hot-process lime-soda softener, so as to attain the

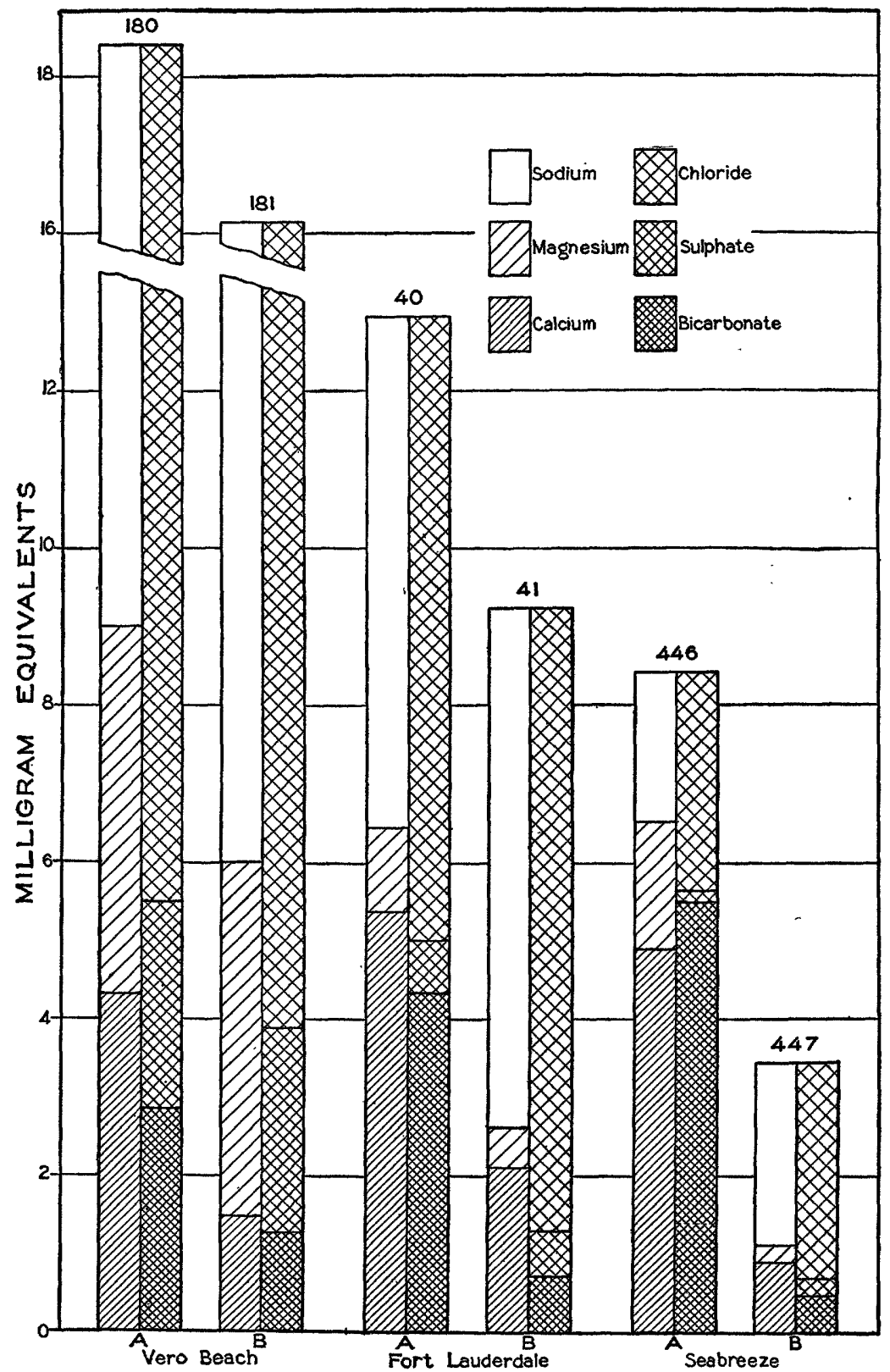

Figure 33.-Analyses of waters from public supplies in Florida before and after treatment. A, Before treatment; B, after treatment. Numbers refer to analyses in the table

greatest practicable softening. It is necessary to add a decided excess of soda ash to accomplish the greatest softening by this process. 
The total quantity of mineral matter remaining in solution may be a little greater than in the less thorov.rhly softened water represented by diagram $\mathrm{D}$, but the water is much superior for boiler or laundry use.

Diagram $\mathrm{F}$ represents water $\mathrm{C}$ softened by an exchange-silicate softener. For all practical purposes the hardness is completely removed. The total quantity of dissolved mineral matter is, however, almost the same as before treatment; the rucid radicles are unchanged, and the calcium and magnesium are replaced by sodium. This water is ideal for laundry work or other processes in which soap is used. It is not the best for boiler use. Waters like $\mathrm{C}$ are sometimes treated with lime to give practically the composition shown in diagram $\mathbf{D}$ and then with an exchange silicate to remove the remaining calcium and magnesium.

Sodium, chloride, and sulphate remain in the waters throughout the treatments shown. Changes in these constituents are increases. It is possible to decrease the sulphate by the use of barium salts, and this means is occasionally resorted to in treating very bad waters. There is no practical way to remove sodium and chloride except by distillation of the water.

Figure 33 shows the changes resulting from treatment of public water supplies at Vero Beach, Fort Lauderdale, and Seabreeze. Sodium chloride to the amount of 2 milligram equivalents is omitted from each of the diagrams for Vero Beach, as indicated by the numbers at the margin. These waters are all greatly improved by the treatment.

\section{TREATMENT OF SURFACE WATER}

Practically all surface waters are exposed to pollution and therefore require treatment to render them safe to drink. The surface waters of Florida are nearly all too highly colored also to be satisfactory for domestic use. The necessity for the removal of color determines the type of treatment to be applied for purification of the waters.

Surface waters are treated with aluminum sulphate to produce a flocculent precipitate, which will remove the coloring matter. It is necessary to add lime or soda to some waters in order to obtain a satisfactory precipitate. After the precipitate has settled, the water is filtered rapidly through sand until the accumulation of precipitate on top of the sand bed has reduced the rate of filtration a predetermined amount. The flow is then reversed and the accumulation of precipitate and mud is washed away from the sand bed into a sewer by filtered water. The precipitate that removes the color and aids the filter in removing suspended mud or silt also removes most of the harmful bacteria that may have been in the water. As an added precaution a small quantity of chlorine is added to nearly all filtered waters just before they enter the mains. 
The proper proportioning of the materials used in water purification calls for careful chemical control. If the composition of the water to be treated does not change greatly from day to day, a filter plant may possibly. be operated by set rules, but changes in composition of the water must be met promptly by corresponding changes in the treatment.

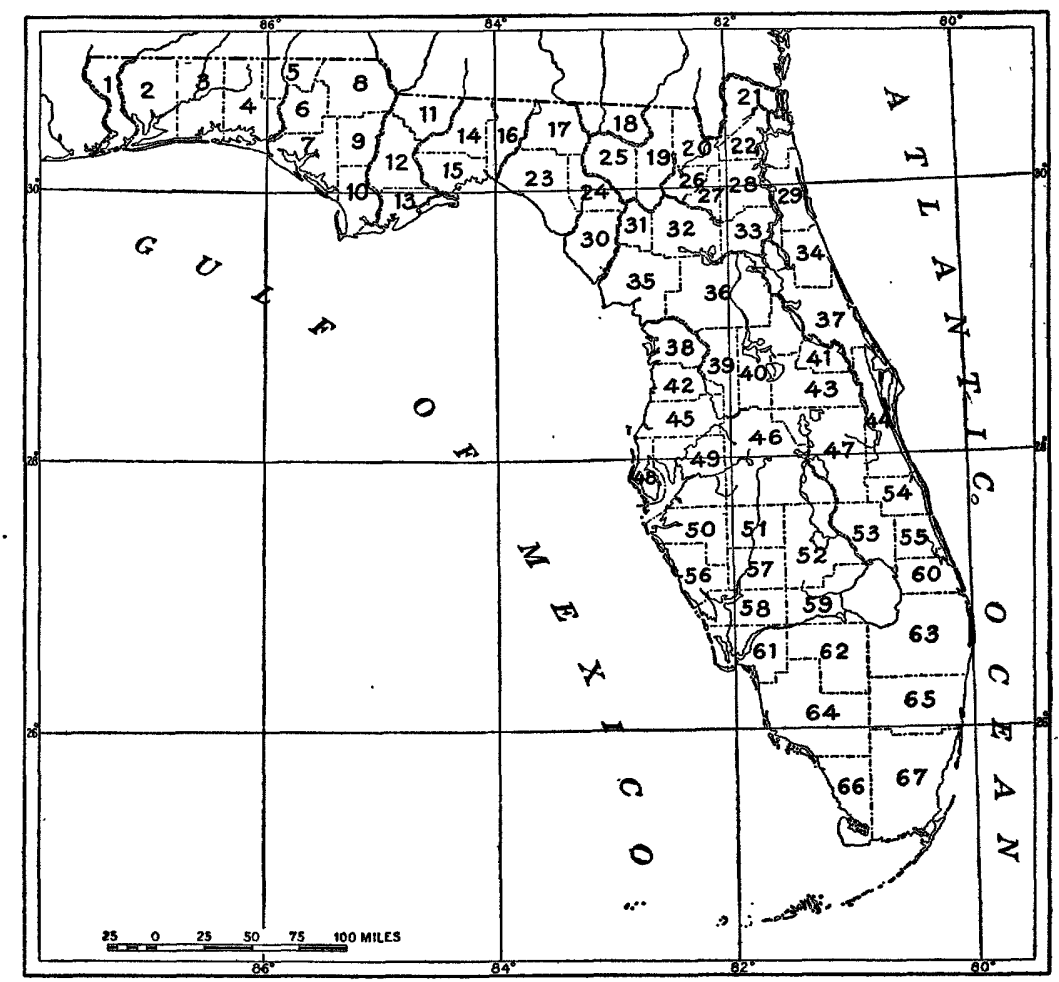

Figure 34.-County lines in Florida at time of compilation of table of analyses

1. Escambia.
2. Santa Rosa.
3. Okaloosa.
4. Walton.
5. Holmes.
6. Washington.
7. Bay.
8. Jackson.
9. Calhoun.
10. Gulf.
11. Gadsden.
12. Liberty.
13. Franklin.
14. Leon.
15. Wakulla.
16. Jefferson.
17. Madison.

18. Hamilton.
19. Columbia.
20. Baker.
21. Nassau.
22. Duval.
23. Taylor.
24. Lafayette.
25. Suwannee.
26. Union.
27. Bradford.
28. Clay.
29. Saint Johns.
30. Dixie.
31. Gilchrist.
32. Alachua.
33. Putnam.
34. Flagler.

35. Levy.

36. Marion.

37. Volusis.

38. Citrus.

39. Sumter.

40. Lake.

41. Seminole.

42. Hernando.

43. Orange.

44. Brevard.

45. Paseo.

46. Polk.

47. Osceole.

48. Pinellas.

49. Hillsborough.

50. Manateo.

51. Hardee.
52. Highlands.
53. Okeechobee.
54. Indian River.
55. Saint Lucie.
56. Sarasota.
57. De Soto.
58. Charlotte.
59. Glades.
60. Martin.
61. Lee.
62. Hendry.
63. Palm Beach.
64. Collier.
65. Broward.
66. Monroe.
67. Dade.

\section{ANALYSES OF WATERS IN FLORIDA}

The following table contains analyses of waters from Florida, arranged by counties. Figure 34 shows the boundaries of the counties as they were at the time of compilation of the table. Nearly all the samples were collected for this report by or under the direction of 
George W. Simons, jr., sanitary engineer of the State board of health. The chemists who analyzed these samples are indicated in the table by initials-Margaret D. Foster (F), C. S. Howard (H), and H. B. Riffenburg (R). The table includes a few analyses of samples collected in connection with the field work for Water-Supply Paper 319. These were made by or under the direction of R. B. Dole (D). Practically all the analyses in the table were made in the water-resources laboratory of the United States Geological Survey.

The table contains several partial analyses, in which sulphate and calcium were determined by comparison of turbidity produced by the appropriate reagents. Such determinations are indicated by a footnote. In these partial analyses the hardness was usually determined and is so indicated.

Some samples contained carbonate $\left(\mathrm{CO}_{3}\right)$ when analyzed. It is probable that only bicarbonate was present in most of the samples when collected; accordingly the equivalent of the carbonate found was calculated and added to the bicarbonate. In the analyses of treated waters, some of which undoubtedly contained carbonate when sampled, the amount of carbonate found is given in a footnote; in the other analyses the actual amount found is not given.

Iron was precipitated from many samples when they were analyzed. If the samples were marked "clear" by the collectors, the amount of iron precipitated at the time of analysis is not given separately but is included with the amount found in solution, and this fact is stated in a footnote.

Hydrogen sulphide was determined in a few samples and was reported by the collectors as present in others. Failure to report hydrogen sulphide in any analysis does not necessarily mean that it is absent from the water. Several samples from sources previously reported to yield sulphur water gave no evidence of the presence of hydrogen sulphide when received in the laboratory, and its presence was not reported by the collectors.

$95221^{\circ}-28-14$ 


\section{For convenience of reference an alphabetic list of the towns repre-} sented by the analyses is given below with the names of some of the larger lakes, rivers, and springs. Numbers refer to analyses.

Alachua, 1, 2.

Altamonte Springs, 393.

Alton, 190.

- Apalachicola, 132, 133.

Apalachicola River, 137.

Apopka, 272.

Aquavite Springs, 151.

Arcadia, 88-92.

Ariana Lake, 334.

Astor, 191.

Auburndale, 333, 334.

A von Park, 156.

Bagdad, 381-383.

Bartow, 335-337.

Bayard, 93.

Belleair, 310, 311.

Big Pine, 257.

Black Creek, North Fork, 60-62.

Blountstown, 46, 47.

Blue Springs, 2448.

Bonifay, 179.

Bowling Green, 149.

Boyd, 415.

Boynton, 287-291.

Bradentown, 230-240.

Branford, 406.

Brewster, 338.

Bristol, 223, 224.

Brooksville, 154, 155.

Bunnell, 131.

Bushnell, 401-403.

Butler, Lake, 330.

Callahan, 260, 261.

Camp Walton, 266.

Carbur, 416.

Carrabelle, 134, 135.

Caryville, 455 .

Cedar Keys, 212-218.

Century, 122.

Chattahoochee, 136, 137.

Chipley, 456-458.

Clearwater, 312-315.

Clermont, 192, 193.

Clinch Lake, 343.

Crestview, 267.

Cocoa, 26-28.

Coronet, 158.

Cottondale, 182.

Crawfordsville, 449.

Crescent City, 357.

Crystal Lake, 193.

Crystal River, 51.

Crystal springs, 305.

Dade City, 306, 307.

Dania, 39.

Daytons Beach, 426-436.

De Funiak Springs, 452.

De Land, 437.

Deleon Springs, 438.

Delray, 292-294

Dunedin, 316.

Wastport, 94, 85.
Eau Gallie, 29, 30.

Ellaville, 226.

Espiritu Santo Springs, 318.

Eustis, 194, 195.

Everglades, 65.

Falmouth, 407.

Fenholloway, 417.

Fernandina, 262-264.

Florahome, 358.

Fort Barrancas, 123.

Fort George, 96.

Fort Lauderdale, 40-44.

Fort Meade, 339-341.

Fort Myers, 202-208.

Fort Pierce, 375-380.

Freeport, 453, 454.

Frost Proof, 342, 343.

Gainesville, 3-8.

Glen St. Mary, 15.

Grandin, 359.

Grand Ridge, 183.

Green Cove Springs, 53-56.

Greenville, 227.

Griffin, Lake, 197.

Haines City, 344-346.

Hampton Springs, 418.

Harris, Lake, 198.

Hastings, 368, 369 .

Heilbronn Springs, 25.

Hialeah, 72, 73.

High Springs, 9-12.

Hillsboro River, 166-7.

Hollywood, 45.

Homestead, 74, 75.

Hosford, 225.

Interlachen, $\mathbf{3 6 0}$.

Inverness, 52.

Jacksonville, 98-109.

Jasper, 144, 145.

Jennings, 146.

Jensen, 254.

Jupiter, 295.

Ivanhoe, Lake, 274.

Kelsey City, 296.

Keystone Heights, 57, 58.

Key West, 258, 259.

Kingsley, Lake, 63.

Kissimmee, 284, 285.

Kissimmee River, 271.

La Belle, 152, 153.

Lake Alfred, 347.

Lake City, 68-70.

Lake Helen, 439.

Lake Jackson, 209.

Lakeland, 348, 349.

Lake Mary, 394.

Lake Monroe, 395.

Lake Wales, 350.

Laurel Hill, 268.

Leesburg, 196-198.

Lemon City, 76.

Lithis, 150.
Live Oak, 408-412.

MacClenny, 16-18.

McGirts Creek, 97.

Madison, 228, 229.

Magnolia Springs, 70.

Mandarin, 110.

Manatee, 241, 242.

Marco, 66.

Marianna, 184-186.

Martha, Lake, 356.

Mayport, 111.

Melbourne, 31-33.

Melbourne Beach, 34, 85.

Miami, 77-86.

Miami Beach, 87.

Middleburg, 59-62.

Millville, 19.

Milton, 384.

Mirror Lake, 349.

Molino, 124.

Monticello, 188, 189.

Moore Haven, 142, 143.

Mount Dora, 199.

Mulberry, 351, 352.

Murdock, 48.

Newberry, 13.

Newland's Spring, 407.

Newport, 450.

New Smyrna, 440-442.

Nichols, 353.

Norwalk, 251-253.

Oakland, 273.

Ocala, 245-250.

Okeechobee, 269, 270.

Okeechobee, Lake, 297, 298.

Olsmar, 317.

Olympia, 255.

Orange City, 443, 444,

Orienda, Lake, 393.

Orlando, 273-276.

Ormond, 445.

Ortega, 112, 113.

Otter Creek, 219.

Pablo Beach, 114.

Pahokee, 297, 298.

Palatka, 361-366.

Palma Ceis Springs, 172.

Palmetto, 243.

Panama City, 20.

Parish, 244.

Peace River, 341.

Pensacola, 125-130.

Perry, 419-423.

Pierce, 354.

Plant City, 160-162.

Poe Springs, 11.

Ponce de Leon Springs, 179a.

Port Dupont, 67.

Port Tampa, 163.

Punta Gorda, 49, 50.

Quincy, 138-140.

Qui-S1-Sane Spring, 56. 
Raiford, 424.

River Junction, 141.

Riverview, 115.

Safety Harbor, 318, 319.

St. Andrews, 21.

St. Augustine, 370-374.

St. Cloud, 286.

St. Johns River, 112, 191, 361.

St. Marys River, 17, 18.

St. Nicholas Spring, 109.

St. Petersburg, 320-328.

Sanford, 306-400.

Sal Taylor Creek, 98.

Salt Springs, 251-253.

Santa Fe River, 12.

Sarasota, 385-390.

Satsuma, 367.

Seabreeze, 446-448.

Seabring, 157.

Silver Springs, 249, 250.

Sneads, 187.

South Jacksonville, 116-119.
Starke, 22-25, 63.

Stuart, 256.

Sulphur Springs, 164.

Sumner, 220, 221.

Sumterville, 404, 405.

Su-No-Wa Spring, 265.

Suwannee River, 406.

Suwannee Springs, 413, 414.

Tallahassee, 210, 211.

Tampa, 165-175.

Tarpon Springs, 329-331.

Tavares, 200.

Taylor Creek, 379.

Tiger Lake, 238.

Titusville, 36-38.

Trilby, 308.

Trout Creek, 115.

Turkey Creek, 176.

Umatilla, 201.

Venice, 391, 392.

Verdie, 265.

Vero Beach, 180, 181.
Wadesboro Spring, 64.

Wakulla, 451.

Waldo, 14.

Wall Springs, 332.

Watertown, 71.

Wauchula, 150.

Weekewachee Spring, 155.

Wekiwa springs, 277.

West Palm Beach, 290-304.

West Tampa, 177.

Whitehouse, 120.

White Springs, 147, 148.

Williston, 222.

Winter Garden, 278-280.

Winterhaven, 355, 356 .

Winter Park, 281-283.

Wi-Wachula Spring, 107.

Worthington, 425.

Ybor City, 178.

Yukon, 121.

Zephyrhills, 309.

Zolfo, 151. 


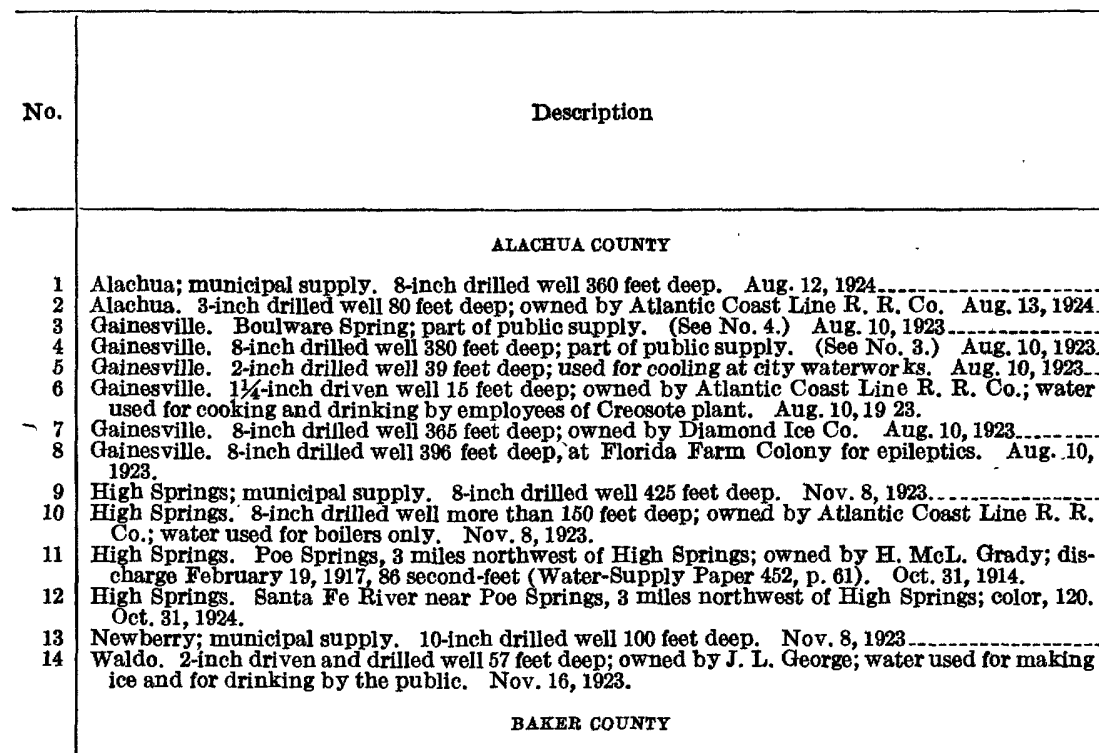

Few deep wells have been drilled in Baker County, but it is probable that wells from 250 to 500 feet deep will obtain water from the Ocala limestone. The head is not likely to be sufficient to give a flow. The water will be similar in composition and concentration to that found in the deeper welis in Bradford, Columbia, and Duval Counties and will probably be more concentrated than water from shallow wells. 1924

MacClenny. Public well; $1 \frac{1}{4} 4$ inches in diameter and 23 feet deep. Dec. 23, 1907

MacClenny, 6 miles north of. St. Marys River. Color, 180. Feb. 13, 1924.

MacClenny; South Prong of St. Marys River at bridge between MacClenny and Glen st. Mary across State road No. 1. Color, 180. Feb. 26, 1924.

\section{BAY COUNTY}

Millville. 6-inch drilled well 227 feet deep; owned by St. Andrews Bay Lumber Co. Apr. 17, 1924.Panama City; municipal supply. 8-inch drilled well 710 feet deep. Apr. 17, 1924

St. Andrews. Driven well $11 / 4$ inches in diameter and 22 feet deep; owned by $\mathrm{I}$. A. Comstock; supply of Villa Hotel. Most wells in the locality are about 22 feet deep. Apr. 18, 1924.

\section{BRADFORD COUNTY}

Shallow wells in Bradford County will probably yield hard water, similar to No. 25.

Starke; municipal supply. 6-inch drilled well 529 feet deep, known as "Old well." Nov. 16, 1923.

Starke; municipal supply when collected. 6-inch drilled well 529 feet deep, known as "OId well." Nov. $9,1907$.

Starke; municipal supply. 10-inch well 400 feet deep, drilled in 1923; known as "New well." Aug. 12, 1924 .

Starke, 5 miles west of; Heilbronn Springs; owned by Heilbronn Mineral Water Co., Starke. Nov. 7,1924 .

\section{BREVARD COUNTY}

Cocoa; municipal supply. 12-inch well 30 feet deep, drilled in 1924; color, 62 . July 29, 1925 .

Cocoa. Flowing well 6 inches in diameter and 265 feet deep; owned by Brevard County Power $\mathrm{Co}$ Oct. 31, 1923.

Cocoa. 2-inch driven well 27 feet deep; owned by M. B. Pruitt. Oct. 31, 1923.

Eau Galke. Flowing well 2 inches in diameter and 325 feet deep; owned by Dixje Garage. July 9,1923 .

Eau Calile. Flowing well 6 inches in diameter and 500 feet deep; owned by East Coast Lumber Co. Estimated flow 1,000 gallons a minute. July 9, 1923.

Melbourne, Front Street. Driven well 11/4 inches in diameter and 28 feet deep; owned by E. R. Hedges. July 10, 1923.

Melbourne. Drilled well $11 / 4$ inches in diameter and 42 feet deep; owned by Sam Martin. Sept. 20,1924 .

- Calculated.

- Includes iron precipitated at time of analysis. 


\begin{tabular}{|c|c|c|c|c|c|c|c|c|c|c|c|c|}
\hline \multicolumn{12}{|c|}{ Analyses (parts per million) } & \multirow[b]{2}{*}{ No. } \\
\hline $\begin{array}{l}\text { Ang- } \\
\text { lyst }\end{array}$ & $\begin{array}{c}\text { Total } \\
\text { dis- } \\
\text { solved } \\
\text { solids at } \\
180^{\circ} \mathrm{C} \text {. }\end{array}$ & $\begin{array}{l}\text { Silica } \\
\left(\mathrm{SiO}_{2}\right)\end{array}$ & $\begin{array}{l}\text { Iron } \\
(\mathrm{F} \dot{\theta})\end{array}$ & $\begin{array}{c}\text { Cal- } \\
\text { cium } \\
\text { (Ca) }\end{array}$ & $\begin{array}{c}\text { Mag- } \\
\text { ne- } \\
\text { sium } \\
(\mathrm{Mg})\end{array}$ & $\begin{array}{l}\text { Sodium } \\
\text { and po- } \\
\text { tassium } \\
(\mathrm{Na}+\mathrm{K})\end{array}$ & $\begin{array}{l}\text { Bicar- } \\
\text { bonate } \\
\text { radicle } \\
\text { (स्HCO }\end{array}$ & $\begin{array}{c}\text { Sul- } \\
\text { phate } \\
\text { radiclo } \\
\left(\mathrm{SO}_{4}\right)\end{array}$ & $\begin{array}{l}\text { Chloride } \\
\text { radicle } \\
\text { (CI) }\end{array}$ & $\begin{array}{c}\text { Nitrate } \\
\text { radicle } \\
\left(\mathrm{NO}_{3}\right)\end{array}$ & $\mid \begin{array}{c}\text { Total } \\
\text { hard- } \\
\text { ness as } \\
\mathrm{CaCO}_{3}\end{array}$ & \\
\hline $\begin{array}{l}\text { H. } \\
\text { H. } \\
\text { F. } \\
\text { F. } \\
\text { F. } \\
\text { F. }\end{array}$ & $\begin{array}{r}487 \\
255 \\
94 \\
273 \\
299 \\
27\end{array}$ & $\begin{array}{c}17 \\
6.4 \\
24 \\
16 \\
3.1\end{array}$ & $\begin{array}{r}0.20 \\
.14 \\
.06 \\
.07 \\
6.6 \\
.18\end{array}$ & $\begin{array}{l}99 \\
72 \\
17 \\
57 \\
41 \\
.8\end{array}$ & $\begin{array}{l}24 \\
6.4 \\
11 \\
20 \\
21 \\
1.0\end{array}$ & $\begin{array}{r}9.4 \\
07.1 \\
2.8 \\
6.3 \\
15 \\
6.6\end{array}$ & $\begin{array}{c}206 \\
207 \\
89 \\
218 \\
126 \\
7.3\end{array}$ & $\begin{array}{c}164 \\
27 \\
2.4 \\
43 \\
9.9 \\
3.0\end{array}$ & $\begin{array}{c}16 . \\
16 \\
8.8 \\
9.6 \\
74 \\
9.6\end{array}$ & $\begin{array}{l}\text { Tr. } \\
1.5 \\
\mathbf{5 . 4} \\
\operatorname{Tr} . \\
\operatorname{Tr} . \\
\operatorname{Tr} .\end{array}$ & $\begin{array}{r}346 \\
206 \\
88 \\
224 \\
189 \\
6\end{array}$ & $\begin{array}{l}1 \\
2 \\
3 \\
4 \\
5 \\
6\end{array}$ \\
\hline F. & $\begin{array}{l}209 \\
220\end{array}$ & $\begin{array}{l}14 \\
32\end{array}$ & $\begin{array}{r}.06 \\
. .34\end{array}$ & $\begin{array}{l}52 \\
41\end{array}$ & $\begin{array}{l}11 \\
19\end{array}$ & $\begin{array}{l}6.5 \\
8.2\end{array}$ & $\begin{array}{l}202 \\
219\end{array}$ & $\begin{array}{l}7.3 \\
7.6\end{array}$ & $\begin{array}{l}8.2 \\
9.0\end{array}$ & Tr. & $\begin{array}{l}175 \\
180\end{array}$ & $\begin{array}{l}7 \\
8\end{array}$ \\
\hline F. & $\begin{array}{r}-212 \\
204\end{array}$ & 11 & .02 & $\begin{array}{l}62 \\
57\end{array}$ & $\begin{array}{l}8.4 \\
7.0\end{array}$ & $\left.{ }^{(c)}\right)_{5.5}$ & $\begin{array}{l}183 \\
174\end{array}$ & $\begin{array}{l}25 \\
26\end{array}$ & $\begin{array}{l}9.4 \\
7.6\end{array}$ & $\begin{array}{l}1.8 \\
.25\end{array}$ & $\begin{array}{l}189 \\
171\end{array}$ & $\begin{array}{r}9 \\
10\end{array}$ \\
\hline H. & 204 & 8.7 & .05 & 64 & 4.7 & 5.7 & 201 & 10 & 7.0 & Tr. & 179 & 11 \\
\hline H. & 190 & 9.7 & b. 27 & 41. & 7.0 & 8.6 & 122 & 85 & 10 & Tr. & 131 & 12 \\
\hline F. & $\begin{array}{r}-174 \\
264\end{array}$ & 18 & .07 & $\begin{array}{l}53 \\
47\end{array}$ & $\begin{array}{c}6.7 \\
26\end{array}$ & (c) & $\begin{array}{l}181 \\
227\end{array}$ & $\begin{array}{l}6.1 \\
5.9\end{array}$ & $2^{2.9}$ & $1_{17}^{1.1}$ & $\begin{array}{l}160 \\
224\end{array}$ & $\begin{array}{l}13 \\
14\end{array}$ \\
\hline H. & 188 & 24 & Tr. & 34 & 19 & $\begin{cases}\mathrm{Na} & 7,7\end{cases}$ & 194 & 4.7 & 10 & Tr. & 163 & 15 \\
\hline D. & 127 & 15 & 1.0 & 2.1 & 1.8 & 31 & 10 & 10 & 32 & 18 & 13 & 16 \\
\hline H. & 74 & 7.3 & .03 & 3.8 & 2.4 & $\begin{cases}\mathrm{Na} & 5.8 \\
\mathrm{~K} & 1.2\end{cases}$ & 8.5 & 3.4 & 12 & Tr. & 19 & 17 \\
\hline H. & 80 & 9.4 & .02 & 3.4 & 1.7 & $\begin{cases}N a & 7.5 \\
K & 1.6\end{cases}$ & 7.3 & 2.1 & 12 & Tr. & 15 & 18 \\
\hline H. & 214 & 18 & .15 & 46 & 14 & $\begin{cases}\mathrm{Na} & 12 \\
\mathrm{~K} & 1.6\end{cases}$ & 189 & 4.2 & 20 & Tr. & 172 & 10 \\
\hline ㅍ. & 264 & 17 & 1.5 & 66 & 11 & $\begin{cases}N a & 14 \\
K & 1.8\end{cases}$ & 233 & 6.0 & 26 & Tr. & 210 & 20 \\
\hline 五. & 53 & 15 & .09 & 13 & .6 & $\begin{cases}\mathrm{Na} & 3.2 \\
\mathrm{~K} & .6\end{cases}$ & 39 & 4.2 & 4.0 & 1.5 & $\mathbf{3 5}$ & 21 \\
\hline H. & 187 & 23 & Tr. & 40 & 12 & 12 & 188 & 8.1 & 13 & Tr. & 149 & 22 \\
\hline D. & 198 & 26 & .11 & 38 & 16 & 15 & d 188 & 11 & 16 & Tr. & 161 & 28 \\
\hline H. & 255 & 46 & .98 & 42 & 22 & 15 & 244 & 2.3 & 19 & Tr. & 195 & 24 \\
\hline H. & 197 & 23 & .03 & 38 & 19 & 8.7 & 206 & 2.5 & 14 & Tr. & 173 & 25 \\
\hline H. & $\begin{array}{r}311 \\
2,630\end{array}$ & 16.6 & $\begin{array}{r}6.31 \\
.12\end{array}$ & $\begin{array}{r}23 \\
177\end{array}$ & $101^{9.9}$ & $\begin{array}{r}54 \\
643\end{array}$ & $\begin{array}{r}40 \\
144\end{array}$ & $\begin{array}{r}24 \\
253\end{array}$ & $\begin{array}{r}114 \\
1,342\end{array}$ & $\begin{array}{l}\operatorname{Tr} . \\
1.7\end{array}$ & $\begin{array}{r}98 \\
857\end{array}$ & $\begin{array}{l}26 \\
27\end{array}$ \\
\hline F. & $\begin{array}{r}466 \\
1,262\end{array}$ & 24.8 & $\begin{array}{r}\text { b. } 65 \\
.27\end{array}$ & $\begin{array}{r}99 \\
115\end{array}$ & $\begin{array}{l}13 \\
61\end{array}$ & $\begin{array}{r}51 \\
206\end{array}$ & $\begin{array}{l}320 \\
154\end{array}$ & $\begin{array}{r}21 \\
129\end{array}$ & $\begin{array}{r}83 \\
504\end{array}$ & $\stackrel{.14}{3.2}$ & $\begin{array}{l}301 \\
538\end{array}$ & $\begin{array}{l}28 \\
29\end{array}$ \\
\hline $\mathbf{R}$. & 1,312 & 22 & .20 & 110 & 61 & 232 & 144 & 147 & 536 & 1.0 & 525 & 30 \\
\hline R. & 500 & 24 & .24 & 113 & 9.6 & 88 & 298 & 1.8 & 100 & .30 & 322 & 31 \\
\hline H. & 582 & 14 & .04 & 152 & 5.1 & - 38 & 293 & 6.6 & 168 & Tr. & 401 & 32 \\
\hline
\end{tabular}

\footnotetext{
- Less than 10 parts per million. \& Includes equivalent of small quantity of carbonate $\left(\mathrm{CO}_{3}\right)$.
} 
Ground and surface

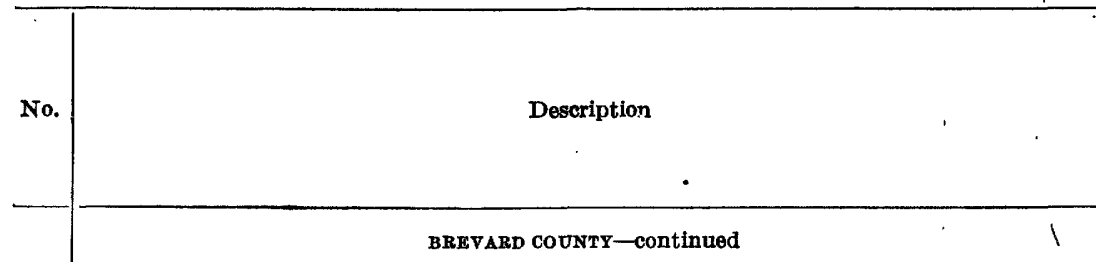

Melbourne. Flowing (in 1908) well $1 \frac{1}{4}$ inches in diameter and 45 feet deep; owned by M. D. Rhodes. Jan. 30,1908 .

Melbourne Beach. Flowing well 4 inches in diameter and 250 feet deep; owned by L. T. Hunt and C. E. Farrington. Oct. 31, 1923 .

Melbourne Beach. Flowing well 4 inches in diameter and 350 feet deep; 100 yards north of bridge approach; owned by Richard O. Fishers. July 10, 1923

Titusville. 2-inch driven well 20 feet deep; one of 8 wells furnishing city supply. July 9, 1923

Titusville. 4-inch drilled well 400 feet deep at Dixie Hotel; owned by C. Fielden. Bromide $(\mathrm{Br}), 50$ parts per million. July 9,1923

Titusville, 8 miles west of; a typical salt lake. Jan. 31, 1908

\section{BROWARD COUNTY}

Dania; municipal supply. 6-inch drilled well 75 feet doep in $\mathrm{SW} .1 / 4$ sec. 34, T. 51 S., R. 42 E.; water level 3 feet above surface; yield 500 gallons a minute. Oct. 25, 1924 .

Fort Lauderdale. 8-inch drilled well 70 feet deep; owned by municipality; the water after softening is used for municipal supply (No. 41); color, 70. June 24, 1924

Fort Lauderdale; municipal supply. Water from No. 40 after softening and filtration. June 24, 1924.

Fort Lauderdale. 2-inch drilled well 62 feet deep; owned by Crown Bottling Works. July 12, 1923.

Fort Lauderdale. 2-inch driven well 30 feet deep; owned by Southern Utilities Co. July 12, 1923.

Fort Lauderdale, 6 miles above. North New River Canal in T. 50 S., R. 41 E.; color, 32. June 24, 1913.

Hollywood; municipal supply. 7 driven wells 2 inches in diameter and 50 feet deep; color, 100. Nov. $3,1923$.

\section{CALHOUN COUNTY}

Blountstown. Public well 6 inches in diameter and 428 feet deep. Apr. 10, 1924

Blountstown. Driven well 11/4 inches in diameter and 27 feet deep; owned by S. A. Leonard; used by public school. May 29, 1924.

\section{CHARLOTTE COUNTY}

Shallow wells in Charlotte County may yield hard water of moderate mineral content that will be much better than the deep-well water represented by analysis 50 .

Murdock. Large spring locally known as Salt Spring. Feb. 10, 1927

Punta Gorda; municipal supply. Drilled wëll 92 feet deep. June 1, 1925......

Punta Gorda. 8-inch drilled well 680 feet deep; owned by Southern Utilities Co. Water level 20 feet above surface. Feb. 21, 1924.

\section{CITRUS COUNTY}

Crystal River. Spring supplying water for drinking at the municjpal tourist camp; one of many springs that feed Crystal River; discharge of group of springs estimated at 445 second-feet, 1907 (Water-Supply Paper 319, p. 281). Nov. 9, 1923 .

Inverness. 10-inch drilled well 187 feet deep; owned by the city. Sept. 7,1923

\section{CLAY COUNTY}

Green Cove Springs; municipal supply. 6-inch drilled well 753 feet deep. Feb. 16, 1924

Green Cove Springs. Flowing well 4 inches in diameter and 400 feet deep on Walkill Stock Farms; owned by Grant Van Sant, St. Paul, Minn. Water level 6 feet above surface; yield 300 gallons a minute. Jan. 12, 1925 .

Green Cove Springs. Qui-Si-Sana Spring, owned by Qui-Si-Sana Co.; yield 3,000 gallons a minute. Feb. 16, 1924.

treen Cove Springs. Flowing well 4 inches in diameter and about 500 feet deep; owned by N. B. Ivey. Dec. $24,1907$.

Keystone Heights. Drilled well $2 \frac{1}{2}$ inches in diameter and 50 feet deep at schoolhouse; owned by Clay County. Jan. 10, 1925 .

Middleburg, 31\% miles south of. South Fork of Black Croek at Dowling Bridge; color, 180 . Mar. 6, 1924.

Middleburg, 21/2 miles northwest of. North Fork of Black Creek at Tritt Bridge; color, 200. The color of a sample collected Mar. 24, 1924, was 240. The other constituents were about the same as in the earlier sample. Mar. $5,1924$.

61 Middleburg, 5 miles northwest of. North Fork of Black Creek 100 feet below mouth of Yellow Water Creek; color, 180. Feb. 21, 1924.

- Calculated.

Includes iron precipitated at time of analysis. 


\begin{tabular}{|c|c|c|c|c|c|c|c|c|c|c|c|c|}
\hline \multicolumn{12}{|c|}{ Analyses (parts per million) } & \multirow[b]{2}{*}{ No. } \\
\hline $\begin{array}{l}\text { Ana- } \\
\text { lyst }\end{array}$ & $\begin{array}{c}\text { Total } \\
\text { dis- } \\
\text { solved } \\
\text { solids at } \\
180^{\circ} \mathrm{C} .\end{array}$ & $\begin{array}{l}\text { Silices } \\
\left(\mathrm{SiO}_{2}\right)\end{array}$ & $\begin{array}{l}\text { Iron } \\
(\mathrm{Fe})\end{array}$ & $\begin{array}{l}\text { Cal- } \\
\text { cium } \\
\text { (Ca) }\end{array}$ & $\begin{array}{l}\text { Mag- } \\
\text { ne- } \\
\text { sium } \\
(\mathrm{Mg})\end{array}$ & $\begin{array}{l}\text { Sodium } \\
\text { and po- } \\
\text { tassium } \\
(\mathrm{Na}+\mathrm{K})\end{array}$ & $\begin{array}{l}\text { Bicar- } \\
\text { bonate } \\
\text { radicle } \\
\left(\mathrm{HCO}_{3}\right)\end{array}$ & $\begin{array}{c}\text { Sul- } \\
\text { phate } \\
\text { radicle } \\
\left(\mathrm{SO}_{4}\right)\end{array}$ & $\begin{array}{l}\text { Chloride } \\
\text { radicle } \\
\text { (Cl) }\end{array}$ & $\mid \begin{array}{l}\text { Nitrate } \\
\text { radicle } \\
\left(\mathrm{NO}_{3}\right)\end{array}$ & $\begin{array}{c}\text { Total } \\
\text { hard- } \\
\text { ness as } \\
\mathrm{CaCO}_{3} a\end{array}$ & \\
\hline D. & 370 & & Tr. & 105 & 3.0 & a 27 & d. 349 & 2 & 34 & $\cdots$ & 276 & 33 \\
\hline F. & 1,079 & & $-\cdots$ & 103 & 61 & 196 & 158 & 116 & 490 & Tr. & 508 & 34 \\
\hline $\mathbf{R}$. & 1,208 & 24 & 0.20 & 111 & 62 & 230 & 154 & 124 & 540 & 3.0 & 532 & .35 \\
\hline $\begin{array}{l}\mathbf{R} \\
\mathbf{R}\end{array}$ & $\begin{array}{r}263 \\
26,334\end{array}$ & $\begin{array}{l}12 \\
24\end{array}$ & $\begin{array}{l}1.0 \\
2.0\end{array}$ & $\begin{array}{r}89 \\
688\end{array}$ & $859^{2.3}$ & $7,739^{4.7}$ & $\begin{array}{l}261 \\
170\end{array}$ & $2,111^{4.6}$ & $\begin{array}{r}16 \\
14,276\end{array}$ & $\begin{array}{l}\text { Tr. } \\
\text { Tr. }\end{array}$ & $\begin{array}{r}232 \\
5,242\end{array}$ & $\begin{array}{l}36 \\
37\end{array}$ \\
\hline D. & 7,114 & -..-.- & 1.3 & 358 & 148 & a 2,051 & d 102 & 642 & 3,700 & & 1,502 & 38 \\
\hline H. & 336 & 5.8 & .18 & 101 & 17 & a 11 & 281 & 28 & 16 & $\operatorname{Tr}$. & 322 & 39 \\
\hline H. & 910 & 7.2 & b1.2 & 122 & 19 & 167 & 293 & 35 & 338 & Tr. & 383 & 40 \\
\hline H. & 673 & 5.0 & b. 10 & 46 & 7.2 & 179 & - 48 & 31 & 329 & Tr. & 145 & 41 \\
\hline H. & 336 & 6.0 & 1.5 & 104 & 1.1 & 20 & 311 & 8.1 & 36 & Tr. & 264 & 42 \\
\hline H. & 372 & 24 & Tr. & 88 & 1.5 & 41 & 256 & 2.6 & 68 & 2.7 & 222 & 43 \\
\hline D. & 130 & 8.2 & .03 & 26 & 6.7 & $\left\{\begin{array}{cc}\mathrm{Na} & 19 \\
\mathrm{~K} & 2.0\end{array}\right.$ & 94 & 4.1 & 26 & .1 & 92 & 44 \\
\hline F. & 253 & 8.1 & .60 & 77 & 3.6 & 8 & $240^{\circ}$ & 4.0 & 12 & 2.0 & 207 & 45 \\
\hline H. & 168 & 19 & .11 & 37 & 11 & $\left\{\begin{array}{ll}\mathrm{Na} & 8.7 \\
\mathrm{~K} & .4\end{array} \mid\right.$ & 200 & .6 .1 & 2.3 & Tr. & 138 & 46 \\
\hline H. & 56 & 12 & $b 1.0$ & 2.1 & 1.6 & 9.8 & 16 & 7.5 & 11 & $\operatorname{Tr}$. & 12 & 47 \\
\hline $\begin{array}{l}\mathbf{F} \\
\mathbf{H}\end{array}$ & $\begin{array}{r}17,812 \\
1,678\end{array}$ & $\begin{array}{l}18 \\
27\end{array}$ & b... & $\begin{array}{l}766 \\
247\end{array}$ & $\begin{array}{r}471 \\
41\end{array}$ & $\begin{array}{r}5,124 \\
268\end{array}$ & $\begin{array}{l}167 \\
259\end{array}$ & $\begin{array}{r}1,704 \\
83\end{array}$ & $\begin{array}{r}9,350 \\
761\end{array}$ & 6.7 & $\begin{array}{r}3,846 \\
786\end{array}$ & $\begin{array}{l}48 \\
49\end{array}$ \\
\hline H. & 3,899 & 16 & .08 & 238 & 159 & $\begin{cases}\mathrm{Na895} \\
\mathrm{K} & 14\end{cases}$ & 127 & 502 & 1,800 & Tr. & 1,247 & 50 \\
\hline H. & 134 & 13 & .08 & 28 & 6.7 & 6.5 & 99 & 13 & 8.0 & Tr. & 97 & 51 \\
\hline F. & 130 & P. 5 & .15 & 34 & 3.5 & 3.7 & 111 & 4.0 & 8.4 & Tr. & 99 & 52 \\
\hline F. & $\begin{array}{l}212 \\
111\end{array}$ & 10 & 1.6 & $\begin{array}{l}30 \\
21\end{array}$ & $\begin{array}{l}22 \\
11\end{array}$ & $\begin{array}{r}1.2 \\
6.0\end{array}$ & $\begin{array}{r}93 \\
106\end{array}$ & $\stackrel{80}{9.4}$ & $\begin{array}{l}6.0 \\
5.0\end{array}$ & Tr. & $\begin{array}{r}165 \\
98\end{array}$ & $\begin{array}{l}53 \\
54\end{array}$ \\
\hline F. & 170 & 15 & .08 & 28 & 16 & $\left\{\begin{array}{ll}\mathrm{Na} & 2.4 \\
\mathrm{~K} & 1.8\end{array} \mid\right.$ & 100 & 49 & 5. 7 & Tr. & 136 & 55 \\
\hline D. & 332 & -...... & .2 & 46 & 26 & $\ln a 13^{\circ}$ & d 122 & 132 & 8 & & 222 & 56 \\
\hline H. & 66 & 4.1 & .07 & 13 & 6.9 & 3. 7 & 61 & 5.5 & 6.4 & Tr. & 61 & 57 \\
\hline H. & 18 & 1.0 & .03 & 1.2 & .9 & 4.6 & 4. 9 & 3.7 & 6.0 & Tr. & 6 & 58 \\
\hline H. & 53 & 4.0 & Tr. & 3.1 & 1.3 & $\left\{\begin{array}{ll}\mathrm{Na} & 6.9 \\
\mathrm{~K} & 1.6\end{array} \mid\right.$ & 10 & 25 & 10 & Tr. & 13 & 59 \\
\hline H. & 66 & 6.0 & .01 & 5. 2 & 1.7 & $\begin{cases}\mathrm{Na} & 5.7 \\
\mathrm{~K} & 1.4\end{cases}$ & 13 & 2.3 & 10 & Tr. & 20 & 60 \\
\hline H. & 59 & 6. 3 & Tr. & 3.6 & 2.6 & $\left|\begin{array}{ll}\mathrm{Na} & 5.5 \\
\mathrm{~K} & .8\end{array}\right|$ & |\} 21 & 1.8 & 10 & Tr. & 20 & 61 \\
\hline
\end{tabular}

d Includes equivalent of small quantity of carbonate $\left(\mathrm{CO}_{3}\right)$

- Includes equivalent of 11 parts per million of carbonate $\left(\mathrm{CO}_{3}\right)$. 
Ground and surface

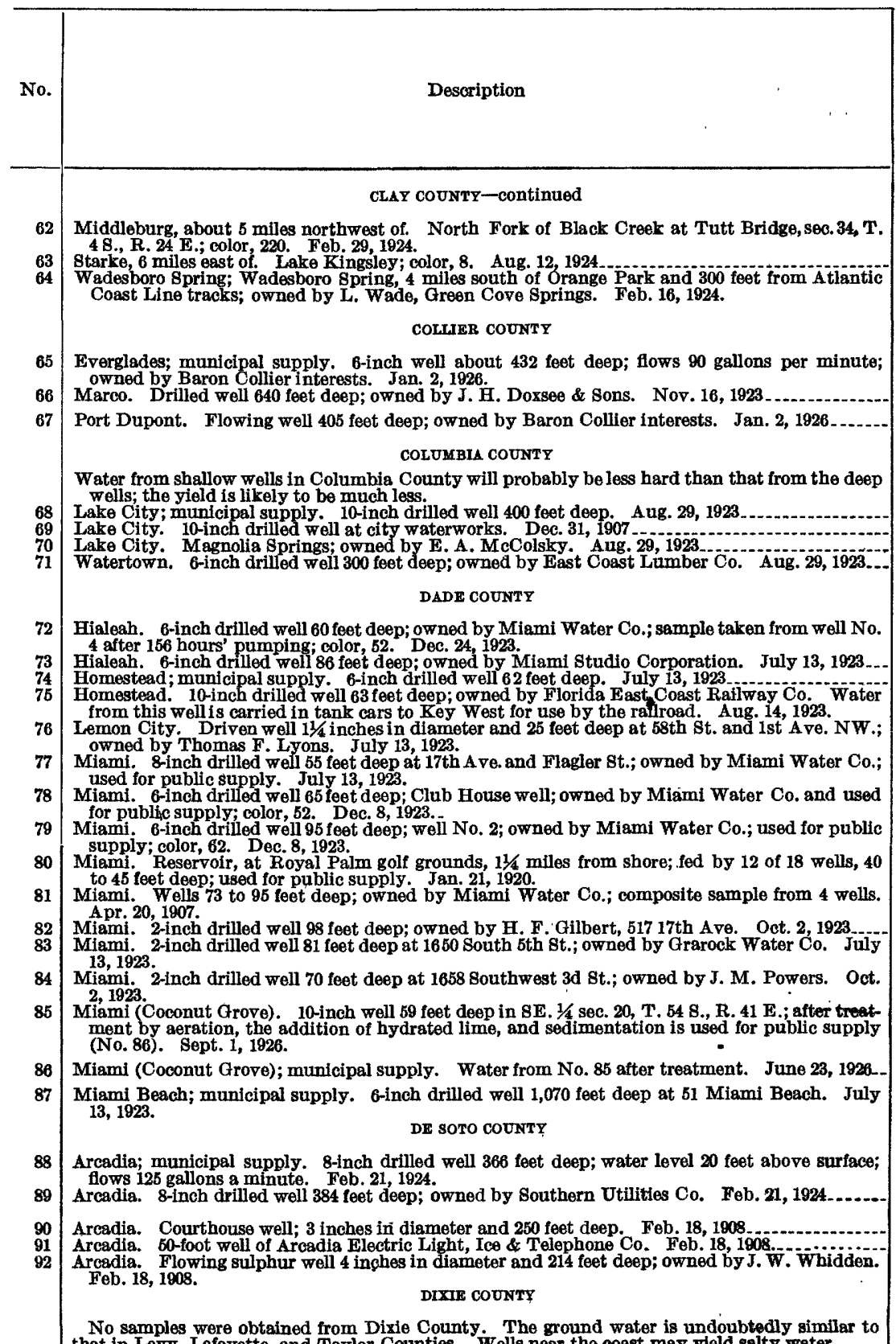

that in Levy, Lafayette, and Taylor Counties. Wells near the coast may yield salty water.

- Calculated.

b Includes iron precipitated at time of analyeis. 


\begin{tabular}{|c|c|c|c|c|c|c|c|c|c|c|c|c|}
\hline \multicolumn{12}{|c|}{ Analyses (parts per million) } & \multirow[b]{2}{*}{ No. } \\
\hline $\begin{array}{l}\text { Ana- } \\
\text { lyst }\end{array}$ & $\begin{array}{c}\text { Total } \\
\text { dis- } \\
\text { solved } \\
\text { solids at } \\
180^{\circ} \mathrm{C} .\end{array}$ & $\begin{array}{l}\text { Silica } \\
\left(\mathrm{SiO}_{2}\right)\end{array}$ & $\underset{(\mathrm{F} \theta)}{\text { Iron }}$ & $\begin{array}{c}\text { Cal- } \\
\text { cium } \\
(\mathrm{Ca})\end{array}$ & $\begin{array}{c}\text { Mag- } \\
\text { ne- } \\
\text { sium } \\
(\mathbf{M g})\end{array}$ & $\begin{array}{l}\text { Sodium } \\
\text { and po- } \\
\text { tassium } \\
(\mathrm{Na}+\mathrm{K})\end{array}$ & $\begin{array}{l}\text { Bicar- } \\
\text { bonate } \\
\text { radicle } \\
\text { (HCOs) }\end{array}$ & $\begin{array}{c}\text { Sul- } \\
\text { phate } \\
\text { radicle } \\
\left(\mathrm{SO}_{4}\right)\end{array}$ & $\begin{array}{l}\text { Chloride } \\
\text { radicle } \\
\text { (C1) }\end{array}$ & $\begin{array}{c}\text { Nitrate } \\
\text { radicle } \\
\left(\mathrm{NO}_{3}\right)\end{array}$ & $\begin{array}{c}\text { Total } \\
\text { hard- } \\
\text { ness as } \\
\mathrm{CaCO}_{3}^{\circ}\end{array}$ & \\
\hline $\mathbf{H}$. & 70 & 4.6 & Tr. & 3. 5 & 0.8 & $\begin{cases}\mathrm{Na} & 7.5 \\
\mathrm{~K} & 1.6\end{cases}$ & 11 & 2.1 & 11 & Tr. & 12 & 62 \\
\hline H. & 22 & 1.0 & Tr. & 2.2 & 1.0 & 3.5 & 3.7 & 2.9 & 8.0 & Tr. & 9.6 & 63 \\
\hline H. & 110 & 6.3 & Tr. & 33 & 1.7 & $\begin{cases}\mathrm{Na} & 5.0 \\
\mathrm{~K} & .7\end{cases}$ & 104 & 3. 6 & 11 & Tr. & 89 & 64 \\
\hline $\mathbf{H}$. & 579 & 14 & 0.26 & 29 & 40 & $\begin{cases}\mathrm{Na} 124 \\
\mathrm{~K} & 8.0\end{cases}$ & 294 & 80 & 133 & Tr. & 236 & 65 \\
\hline H. & 7,350 & 44 & $b 105$ & 220 & 266 & 2,085 & 131 & $\pi 19$ & 3,764 & Tr. & 1,641 & 66 \\
\hline H. & 629 & 16 & .17 & 29 & 38 & $\begin{cases}\mathbf{N a 1 4 6} \\
\mathbf{K} & 11\end{cases}$ & 296 & 77 & 166 & Tr. & 228 & 67 \\
\hline $\begin{array}{l}\text { H. } \\
\text { D. } \\
\text { H. }\end{array}$ & $\begin{array}{r}248 \\
256 \\
97 \\
235\end{array}$ & $\begin{array}{l}25 \\
36 \\
3.2 \\
\mathbf{2 1}\end{array}$ & $\begin{array}{l}.12 \\
.0 \\
.11 \\
.12\end{array}$ & $\begin{array}{c}48 \\
47 \\
6.0 \\
47\end{array}$ & $\begin{array}{l}20 \\
18 \\
1.3 \\
16\end{array}$ & $\begin{array}{l}11 \\
14 \\
18 \\
10\end{array}$ & $\begin{array}{c}223 \\
{ }_{223} \\
\text { Tr. } \\
221\end{array}$ & $\begin{array}{c}16 \\
10 \\
2.9 \\
6.8\end{array}$ & $\begin{array}{c}9.0 \\
9.8 \\
22 \\
10\end{array}$ & $\begin{array}{r}\text { Tr. } \\
26.20 \\
.44\end{array}$ & $\begin{array}{r}202 \\
191 \\
20 \\
183\end{array}$ & $\begin{array}{l}68 \\
69 \\
70 \\
71\end{array}$ \\
\hline H. & 308 & & ${ }^{b} 2.3$ & 96 & 3.5 & $\cdot 7.1$ & 264 & 28 & 17 & Tr. & 254 & 72 \\
\hline$\underset{\mathrm{H}}{\mathrm{H}}$. & $\begin{array}{l}329 \\
208 \\
211\end{array}$ & $\begin{array}{l}15 \\
7.2 \\
6.5\end{array}$ & $\begin{array}{l}1.0 \\
\mathrm{Tr} . \\
.12\end{array}$ & $\begin{array}{l}94 \\
72 \\
70\end{array}$ & $\begin{array}{l}7.0 \\
2.8 \\
4.0\end{array}$ & $\begin{array}{l}22 \\
7.2 \\
7.7\end{array}$ & $\begin{array}{l}300 \\
218 \\
222\end{array}$ & $\begin{array}{l}4.4 \\
3.0 \\
4.3\end{array}$ & $\begin{array}{l}29 \\
11 \\
12\end{array}$ & $\begin{array}{l}\mathbf{T r} . \\
\mathbf{T r} \\
. \theta 1\end{array}$ & $\begin{array}{l}264 \\
191 \\
191\end{array}$ & $\begin{array}{l}73 \\
74 \\
75\end{array}$ \\
\hline H. & 227 & 5.4 & Tr. & 65 & 2.4 & 16 & 189 & 15 & 13 & 3. 5 & 172 & 76 \\
\hline H. & 461 & 9.2 & Tr. & 108 & 2.8 & 48 & 262 & 16 & 102 & .67 & 259 & 77 \\
\hline H. & 340 & & b. 50 & 98 & 5.1 & .5 .4 & 272 & 28 & 17 & 1.6 & 266 & 78 \\
\hline H. & 318 & $\ldots$ & b. 79 & 91 & 6.9 & a8. 2 & 290 & 4.5 & 22 & Tr. & 256 & 79 \\
\hline F. & 772 & 12 & .64 & 116 & 18 & a 141 & 282 & 56 & 269 & Tr. & 364 & 80 \\
\hline D. & 315 & 2.8 & Tr. & 90 & 7.2 & 18 & 285 & 16 & 28 & .10 & 254 & 81 \\
\hline $\begin{array}{l}\text { F. } \\
\text { H. }\end{array}$ & $\begin{array}{l}298 \\
286\end{array}$ & $\begin{array}{l}6.5 \\
7.2\end{array}$ & $\begin{array}{l}{ }_{\mathrm{T}}^{15} \\
\text {. }\end{array}$ & $\begin{array}{l}93 \\
93\end{array}$ & $\begin{array}{l}4.7 \\
1.1\end{array}$ & $\begin{array}{l}11 \\
12\end{array}$ & $\begin{array}{l}272 \\
257\end{array}$ & $\begin{array}{l}26 \\
19\end{array}$ & $\begin{array}{l}\mathbf{1 3} \\
\mathbf{1 7}\end{array}$ & $\begin{array}{l}\text { Tr. } \\
\text { Tr. }\end{array}$ & $\begin{array}{l}252 \\
237\end{array}$ & $\begin{array}{l}82 \\
83\end{array}$ \\
\hline F. & 283 & 7.4 & .29 & 88 & 4.0 & 13 & 251 & 20 & 23 & Tr. & 236 & 84 \\
\hline H. & 258 & 13 & .49 & 80 & 2.2 & $\begin{cases}\mathrm{Na} & 9.4 \\
\mathrm{~K} & 1.8\end{cases}$ & 243 & 8.4 & 18 & .28 & 209 & 85 \\
\hline H. & 79 & 4.2 & .15 & 15 & 1.9 & $\begin{cases}\mathrm{Na} & 9.6 \\
\mathrm{~K} & 1.8\end{cases}$ & $d 48$ & 11 & 14 & Tr. & 45 & 86 \\
\hline H. & 3, 376 & 13 & $\mathbf{T r}$ & 121 & 120 & ${ }^{5-4} 895$ & 145 & 819 & 1,485 & 16 & 819 & 87 \\
\hline H. & 670 & 27 & .10 & 94 & $\mathbf{B 5}$ & $\begin{cases}\mathrm{Na} & 18 \\
\mathrm{~K} & 3,7\end{cases}$ & 205 & 276 & 30 & $\mathbf{T r}$ & 460 & 88 \\
\hline H. & 451 & 23 & .28 & 86 & 22 & $\begin{cases}\mathrm{Na} & 28 \\
\mathrm{~K} & 2.6\end{cases}$ & 250 & 103 & 28 & .75 & 305 & 89 \\
\hline $\begin{array}{l}\text { D. } \\
\text { D. } \\
\text { D. }\end{array}$ & $\begin{array}{l}360 \\
314 \\
382\end{array}$ & 25 & $\begin{array}{l}.60 \\
\therefore .86 \\
.05\end{array}$ & $\begin{array}{l}52 \\
84 \\
47\end{array}$ & $\begin{array}{l}29 \\
8.0 \\
28\end{array}$ & $\begin{array}{l}\text { a } 20^{\circ} \\
21 \\
.29\end{array}$ & $\begin{array}{l}\text { d } 295 \\
\text { d } 307 \\
\text { d } 264\end{array}$ & $\begin{array}{c}4 \\
3.4 \\
11\end{array}$ & $\begin{array}{l}34 \\
17 \\
48\end{array}$ & .48 & $\begin{array}{l}249 \\
243 \\
232\end{array}$ & $\begin{array}{l}90 \\
91 \\
92\end{array}$ \\
\hline
\end{tabular}

- Includes equivalent of small quantity of carbonate $\left(\mathrm{CO}_{3}\right)$. 
Ground and surface

\begin{tabular}{|c|c|}
\hline No & Description \\
\hline & DUVAL COUNTY \\
\hline 93 & $\begin{array}{l}\text { Bayard. Flowing well } 4 \frac{1}{2} \text { inches in diameter and } 353 \text { feet deep; owned by W. W. Powell. June } \\
16,1925 \text {. }\end{array}$ \\
\hline 94 & $\begin{array}{l}\text { Eastport. 8-inch drilled well 1,100 feet deep; owned by Brooks-Scanlon Corporation; water level } \\
6 \text { feet above surface. Dec. 11, } 1923 \text {. }\end{array}$ \\
\hline 95 & $\begin{array}{l}\text { Eastport. 10-inch drilled well } 350 \text { feet deep; owned by Brooks-Scanlon Corporation. Dec. 11, } \\
\text { 1923. }\end{array}$ \\
\hline 96 & $\begin{array}{l}\text { Fort George. 8-inch drilled well } 450 \text { feet deep; owned by Rear ÂAmiral Victor Blue; sulphur } \\
\text { water, hydrogen sulphide }\left(\mathrm{H}_{2} \mathrm{~S}\right), 15 \text { parts per million. May } 27,1924 .\end{array}$ \\
\hline 98 & $\begin{array}{l}\text { Jacksonville, about } 15 \text { miles southwest of. Sal Taylor Crek just above junction with Yellow } \\
\text { Water Creek, sec. } 35, \text { T. } 3 \text { S., R. } 24 \text { E.; color, } 180 \text {. Feb. 22, } 1924 \text {. }\end{array}$ \\
\hline 99 & $\begin{array}{l}\text { Jacksonville. City tap water. Aug. 7, 1922. 'Published in Water-Supply Paper 496, p. 32, No. } \\
36,1923 \text {. }\end{array}$ \\
\hline 100 & $\begin{array}{l}\text { Jacksonville. 8-inch drilled well } 750 \text { feet deep at Municipal Docks on Talleyrand A venue; owned } \\
\text { by municipality. Aug. } 24,1923 \text {. }\end{array}$ \\
\hline 101 & $\begin{array}{l}\text { Jacksonville (Brentwood), 8-inch drilled well } 750 \text { feet deep near north city limits of Jacksonville; } \\
\text { owned by J. E. Lee; leased to city of Jacksonville for public supply. Mar. 10, } 1924 \text {. }\end{array}$ \\
\hline 102 & $\begin{array}{l}\text { Jacksonville. 12-inch drilled well, 1,210 feet deep; owned by Atlantic Ice \& Coal Corporation. } \\
\text { Aug. } 24,1923 \text {. }\end{array}$ \\
\hline 103 & $\begin{array}{l}\text { Jacksonville. 4-inch drilled well } 86 \text { feet deep; owned by J. C. De Bevoise, route 4, box 700. Nov. } \\
23,1923 \text {. }\end{array}$ \\
\hline 104 & $\begin{array}{l}\text { Jacksonville. 11-inch drilled well } 1,690 \text { feet deep; cased to about } 800 \text { feet; owned by J. I. Daniels, } \\
\text { route 4, box 252-B. May } 30,1924 \text {. }\end{array}$ \\
\hline 105 & $\begin{array}{l}\text { Jacksonville. 4-inch drilled well } 500 \text { feet deep; owned by Elixir Water Co.; water level } 6 \text { feet above } \\
\text { surface. Aug. } 24,1923 \text {. }\end{array}$ \\
\hline 106 & $\begin{array}{l}\text { Jacksonville. 6-inch drilled well 1,000 feet deep; owned by Good Hope Water Co.; water level } \\
12 \text { feet above surface. Aug. } 23,1923 \text {. }\end{array}$ \\
\hline $\begin{array}{l}107 \\
108\end{array}$ & $\begin{array}{l}\text { Jacksonville. Wi-Wachula Spring; owned by Wi-Wachula Water Co. Aug. 24, 1923... } \\
\text { Jacksonville. 8-inch drilled well 1,026 feet deep; owned by Jacksonville Terminal Co.; water level } \\
25 \text { feet above surface. Aug. 24, } 1923 \text {. }\end{array}$ \\
\hline 109 & $\begin{array}{l}\text { Jacksonville (St. Nicholas.) St. Nicholas Spring; owned by St. Nicholas Spring Water Co., Jack- } \\
\text { sonville. Oct. } 31,1923 \text {. }\end{array}$ \\
\hline $\begin{array}{l}110 \\
111\end{array}$ & $\begin{array}{l}\text { Mandarin. } 2 \text {-inch drilled well } 193 \text { feet deep; owned by Thomas M. Loucks. June 16, } 1925 . \\
\text { Mayport. Flowing well } 8 \text { inches in diameter and } 780 \text { feet deep; owned by Capt. John Daniels. } \\
\text { July 28, 1925. }\end{array}$ \\
\hline 112 & $\begin{array}{l}\text { Ortega. St. Johns River at foot of River Street on Ortega Boulevard. Color, } 128 \text {. Jan. } 26,1925 . \\
\text { Ortega. 8-inch drilled well } 700 \text { feet deep; owned by Florida Country Club; flows } 400 \text { gallons a min- } \\
\text { ute. July } 30 \text {, 1925. } \\
\text { Water of practically the same composition was obtained from an 8-inch well } 500 \text { feet deep at } \\
\text { Ortega; owned by the Ortega Co., and from an } 8 \text {-inch well } 690 \text { feet deep, } 1 \text { mile south of Ortega } \\
\text { in the Venetia development; owned by the Consolidated Development \& Engineering Corpo- } \\
\text { ration of Jacksonville. }\end{array}$ \\
\hline 114 & $\begin{array}{l}\text { Pablo Beach; public supply. Flowing well } 6 \text { inches in diameter and } 650 \text { feet deep on sand dunes } \\
\text { about } 300 \text { feet west of beach; owned by J. G. Christopher, Jackson ville. June 8, } 1925 \text {. }\end{array}$ \\
\hline 115 & $\begin{array}{l}\text { Riverview. Trout Creek at Trout Creek Bridge on Lem Turner Rosd; color, 152. Feb. 2, } 1925 \\
\text { South Jacksonville. 8-inch drilled well } 900 \text { feet deep; owned by city and used for public supply. } \\
\text { Oct. 22, 1923. }\end{array}$ \\
\hline$\cdot 117$ & $\begin{array}{l}\text { South Jacksonville. 4-inch drilled well } 500 \text { feet deep; owned by city; water level, } 10 \text { feet above } \\
\text { surface; flows } 300 \text { gallons a minute; used for public supply. Nov. } 13,1923 \text {. }\end{array}$ \\
\hline 118 & $\begin{array}{l}\text { South Jacksonville. 6-inch drilled well 640 feet deep; owned by eity; water level } 10 \text { feet above sur- } \\
\text { face; flows } 250 \text { gallons a minute; used for public supply. Nov. } 13,1923 \text {. }\end{array}$ \\
\hline 119 & $\begin{array}{l}\text { South Jacksonville. 8-inch drilled well } 780 \text { feet deep; owned by city; water level, } 40 \text { feet above } \\
\text { surface; flows 1,150 gallons a minute; used for public supply. Nov. 13, 1923. }\end{array}$ \\
\hline $\begin{array}{l}120 \\
121\end{array}$ & $\begin{array}{l}\text { Whitehouse. 2-inch drilled well } 200 \text { feet deep; owned by Chas. F. Cox. Oct. 20, } 1923 \\
\text { Yukon. Artesian well; supply for Camp Johnston; owned by military department of the State } \\
\text { of Florida, St. Augustine. June 8, 1925. }\end{array}$ \\
\hline & ESCAMBIA COUNTY \\
\hline $\begin{array}{l}122 \\
123 \\
124\end{array}$ & 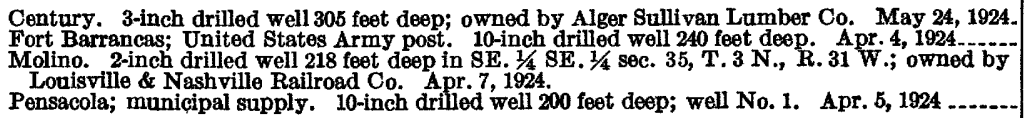 \\
\hline $\begin{array}{l}126 \\
127 \\
128\end{array}$ & $\begin{array}{l}\text { Pensacola; municipal supply } 10 \text {-inch drilled well } 200 \text { feet deep; well No. } 2 . \text { Apr. 5, } 1924 \\
\text { Pensacola. Composite sample from group of } 136 \text {-inch wells } 112 \text { to } 150 \text { feet deep. Dec, 16, } 1007 \\
\text { Pensacola; naval air station. Well No. } 3 ; 6 \text { inches in diameter, } 40 \text { feet deep; one of six wells in } \\
\text { series on the same line. May 16, 1924. }\end{array}$ \\
\hline 129 & $\begin{array}{l}\text { Pensacola; naval air station. 12-inch drilled well } 150 \text { feet deep. May } 16,1924, \\
\text { Pensacola; naval air station supply. Mixture of water from wells } 128 \text { and } 129 \text {, which has been } \\
\text { aerated, treated with lime and alum, filtered, and chlorinated. Sample taken froma tap. Apr. } \\
\text { 4, 1924. }\end{array}$ \\
\hline
\end{tabular}

- Calculated.

Includes iron precipitated at time of analysis.

- Less then 10 parts per million. 


\begin{tabular}{|c|c|c|c|c|c|c|c|c|c|c|c|c|}
\hline \multicolumn{12}{|c|}{ Analyses (parts per million) } & \multirow[b]{2}{*}{ No. } \\
\hline $\begin{array}{l}\text { Ans- } \\
\text { lyst }\end{array}$ & $\begin{array}{c}\text { Total } \\
\text { dis- } \\
\text { solved } \\
\text { solidsat } \\
180^{\circ} \mathrm{C} \text {. }\end{array}$ & $\begin{array}{l}\text { Silica } \\
\left(\mathrm{SiO}_{2}\right)\end{array}$ & $\begin{array}{l}\text { Iron } \\
\text { (F.e) }\end{array}$ & $\begin{array}{c}\text { Cal- } \\
\text { clum } \\
(\mathrm{Ca})\end{array}$ & $\begin{array}{l}\text { Mag- } \\
\text { ne- } \\
\text { sium } \\
(\mathbf{M g})\end{array}$ & $\begin{array}{l}\text { Sodium } \\
\text { and po- } \\
\text { tassium } \\
(\mathrm{Na}+\mathrm{K})\end{array}$ & $\begin{array}{l}\text { Bicar- } \\
\text { bonate } \\
\text { radicle } \\
\left(\mathrm{HCO}_{3}\right)\end{array}$ & $\begin{array}{c}\text { Sul- } \\
\text { phate } \\
\text { radicle } \\
\left(\mathrm{SO}_{4}\right)\end{array}$ & $\begin{array}{c}\text { Chloride } \\
\text { radicle } \\
\text { (CI) }\end{array}$ & $\begin{array}{l}\text { Nitrate } \\
\text { radicle } \\
\left(\mathrm{NO}_{3}\right)\end{array}$ & $\mid \begin{array}{c}\text { Total } \\
\text { hard- } \\
\text { ness as } \\
\text { CaCOs }\end{array}$ & \\
\hline H. & 478 & 28 & 0.19 & & 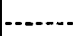 & 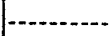 & 172 & 187 & 15 & & .336 & 93 \\
\hline F. & 323 & 29 & .16 & 54 & 26 & 13 & 188 & 81 & 17 & Tr. & 242 & 94 \\
\hline F. & 249 & 29 & .17 & 35 & 18 & 24 & 176 & 41 & 17 & 0.38 & 161 & 95 \\
\hline H. & 445 & 38 & b. 35 & 62 & 24 & 37 & 212 & 98 & 48 & Tr. & 253 & 96 \\
\hline $\mathbf{F}$ & 343 & 6.0 & .21 & 12 & 12 & 83 & 22 & 24 & 151 & .61 & 79 & 97 \\
\hline H. & 71 & 7. 6 & .01 & 5.2 & 2.6 & $\begin{cases}\mathrm{Na} & 7.9 \\
\mathrm{~K} & 3.4\end{cases}$ & 21 & 2.1 & 12 & Tr. & 24 & 98 \\
\hline F. & 420 & 24 & .15 & 76 & 28 & $\begin{cases}\mathrm{Na} & 12 \\
\mathrm{~K} & 2.1\end{cases}$ & 163 & 165 & 15 & .42 & 305 & 99 \\
\hline $\mathbf{F}$ & 410 & 25 & 1.2 & 70 & 28 & 11 & 166 & 149 & 16 & Tr. & 290 & 100 \\
\hline H. & 410 & 19 & .17 & 74 & 27 & 14 & 168 & 156 & 15 & Tr. & 296 & 101 \\
\hline F. & 399 & 22 & .15 & 66 & 29 & 10 & 152 & 165 & 13 & Tr. & 284 & 102 \\
\hline F. & 394 & 26 & .08 & 63 & 32 & 14 & 166 & 151 & 11 & Tr. & 289 & 103 \\
\hline H. & 200 & 18 & .04 & 35 & 14 & 12 & 133 & $\$ 1$ & 8.0 & Tr. & 145 & 104 \\
\hline F. & 114 & 13 & .08 & 20 & 11 & 4.4 & d 94 & 16 & 4. 9 & Tr. & 95 & 105 \\
\hline F. & 387 & 27 & .14 & 68 & 26 & 12 & 167 & 136 & 15 & Tr. & 277 & 106 \\
\hline F. & $\begin{array}{r}46 \\
436\end{array}$ & ${ }_{24}^{3.9}$ & .21 & $7^{3.0}$ & $32^{2.2}$ & $\begin{array}{l}6.1 \\
9.9\end{array}$ & $\begin{array}{r}8.1 \\
155\end{array}$ & $\begin{array}{r}5.6 \\
184\end{array}$ & ${ }_{13}^{5.6}$ & ${ }^{14} \mathrm{Tr}$. & $\begin{array}{r}17 \\
321\end{array}$ & $\begin{array}{l}107 \\
108\end{array}$ \\
\hline F. & 86 & 12 & b 1.4 & 12 & 3. 5 & 11 & 39 & 8. 6 & 16 & 1.5 & 44 & 109 \\
\hline H. & $\begin{array}{l}272 \\
352\end{array}$ & $\begin{array}{l}20 \\
31\end{array}$ & $\begin{array}{l}.22 \\
.05\end{array}$ & 56 & 26 & 17 & $\begin{array}{l}162 \\
183\end{array}$ & $\begin{array}{l}63 \\
93\end{array}$ & $\begin{array}{l}11 \\
20\end{array}$ & $T r$. & $\begin{array}{r}\cdot 202 \\
247\end{array}$ & $\begin{array}{l}110 \\
111\end{array}$ \\
\hline H. & $\begin{array}{l}448 \\
292\end{array}$ & ${ }_{22}^{8.0}$ & $\begin{array}{l}\text { b. } .45 \\
.28\end{array}$ & $\begin{array}{l}28 \\
44\end{array}$ & $\begin{array}{l}16 \\
24\end{array}$ & $\begin{array}{r}103 \\
13\end{array}$ & $\begin{array}{r}48 \\
149\end{array}$ & $\begin{array}{l}48 \\
86\end{array}$ & $\begin{array}{r}198 \\
14\end{array}$ & $\begin{array}{l}\text { Tr. } \\
.52\end{array}$ & $\begin{array}{l}136 \\
208\end{array}$ & $\begin{array}{l}112 \\
113\end{array}$ \\
\hline H. & 469 & 28 & .36 & & & 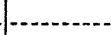 & 139 & 202 & 14 & & • 336 & 114 \\
\hline$\frac{\text { H. }}{\text { F. }}$ & 732 & 8.0 & b. 34 & $\begin{array}{l}20 \\
73\end{array}$ & $\begin{array}{l}29 \\
34\end{array}$ & $\begin{array}{l}193 \\
(c)\end{array}$ & $\begin{array}{r}22 \\
151\end{array}$ & $\begin{array}{r}58 \\
176\end{array}$ & $\begin{array}{r}360 \\
9.6\end{array}$ & $\begin{array}{l}\text { Tr. } \\
.50\end{array}$ & $\begin{array}{l}169 \\
322\end{array}$ & 1116 \\
\hline $\mathbf{F}$. & & & 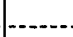 & 71 & 33 & - 7.1 & 151 & 180 & 12 & .33 & 313 & 117 \\
\hline F. & - & & & 69 & 45 & (c) & 157 & 202 & 13 & .38 & 357 & 118 \\
\hline F. & & & $\ldots$ & 70 & 33 & - 9.0 & 155 & 180 & 11 & Tr. & 310 & 119 \\
\hline $\begin{array}{l}\mathbf{F} \\
\text { H. }\end{array}$ & $\begin{array}{l}319 \\
271\end{array}$ & $\begin{array}{l}33 \\
26\end{array}$ & $\begin{array}{l}.16 \\
.17\end{array}$ & 83 & 14 & 11 & $\begin{array}{l}325 \\
142\end{array}$ & $\begin{array}{l}3.0 \\
76\end{array}$ & $\begin{array}{l}10 \\
12\end{array}$ & Tr. & $\begin{array}{r}265 \\
\cdot 202\end{array}$ & $\begin{array}{l}120 \\
121\end{array}$ \\
\hline $\begin{array}{l}\text { H. } \\
\text { H. }\end{array}$ & $\begin{array}{r}111 \\
57 \\
131\end{array}$ & $\begin{array}{l}14 \\
12 \\
34\end{array}$ & $\begin{array}{r}61.2 \\
62.2 \\
1.0\end{array}$ & $\begin{array}{l}16 \\
2.6\end{array}$ & $\begin{array}{r}3.1 \\
.8 \\
3.1\end{array}$ & $\begin{array}{l}19 \\
8.7 \\
13\end{array}$ & $\begin{array}{l}94 \\
21 \\
95\end{array}$ & $\begin{array}{l}8.5 \\
3.1 \\
9.0\end{array}$ & $\begin{array}{c}2.7 \\
10 \\
3.5\end{array}$ & $\begin{array}{l}\text { Tr. } \\
\text { Tr. } \\
\text { Tr. }\end{array}$ & $\begin{array}{l}53 \\
15 \\
63\end{array}$ & $\begin{array}{l}122 \\
123 \\
124\end{array}$ \\
\hline $\mathbf{F}$ & 41 & 9. 4 & .06 & 1.1 & 2.3 & $\begin{cases}\mathrm{Na} & 5.3 \\
\mathbf{K} & .6\end{cases}$ & 2.9 & 4. 1 & 7.8 & 7.2 & 12 & 125 \\
\hline $\begin{array}{l}\text { F. } \\
\text { D. }\end{array}$ & $\begin{array}{l}-22 \\
68\end{array}$ & $\begin{array}{l}8.8 \\
5.8\end{array}$ & Tr. & $\begin{array}{r}.7 \\
9.2\end{array}$ & 2.4 & $\begin{array}{r}6.6 \\
3.1 \\
12\end{array}$ & $\begin{array}{r}3.7 \\
3.7 \\
27\end{array}$ & $\begin{array}{l}12 \\
2.0 \\
10\end{array}$ & $\begin{array}{r}7.2 \\
4.8 \\
19\end{array}$ & $\begin{array}{c}7.2 \\
\dot{T} \\
\text { Tr. }\end{array}$ & $\begin{array}{r}-4.8 \\
3.4 \\
34\end{array}$ & $\begin{array}{l}126 \\
127 \\
128\end{array}$ \\
\hline H. & $\begin{array}{l}89 \\
80\end{array}$ & $\begin{array}{l}16 \\
6.8\end{array}$ & $\begin{array}{l}\text { b. } 87 \\
\text { b. } 94\end{array}$ & $\begin{array}{l}10 \\
12\end{array}$ & $\begin{array}{l}2.3 \\
1.0\end{array}$ & $-12^{8.2^{\circ}}$ & $\begin{array}{l}37 \\
37\end{array}$ & $12^{2.2}$ & $\begin{array}{l}17 \\
13\end{array}$ & $\begin{array}{l}\text { Tr. } \\
\text { Tr. }\end{array}$ & $\begin{array}{l}34 \\
34\end{array}$ & $\begin{array}{l}129 \\
130\end{array}$ \\
\hline
\end{tabular}

Includes equivalent of small quantity of carbonate $\left(\mathrm{CO}_{3}\right)$.

By turbidity.

- Determined. 


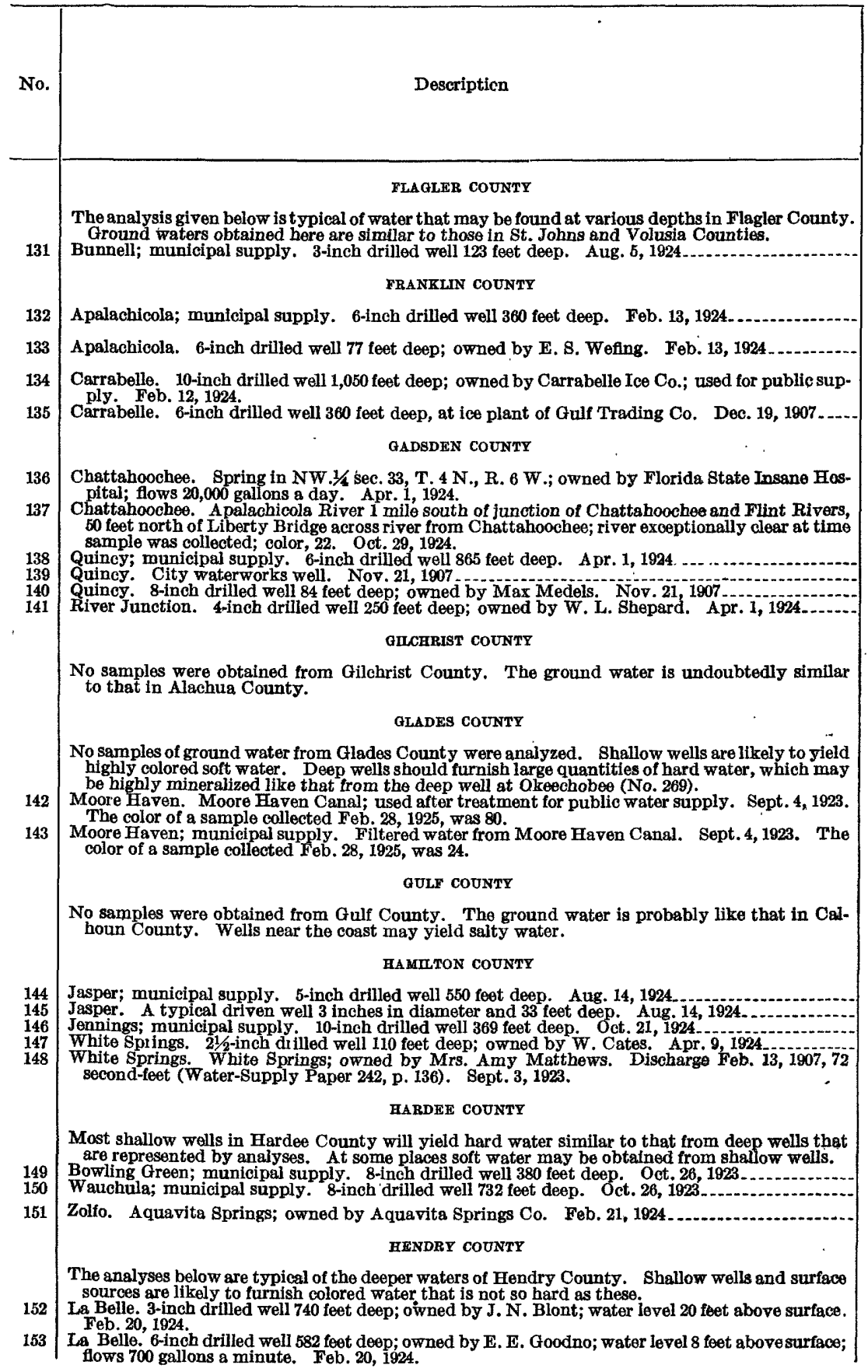

a Calculated.

b Includes iron precipitated at time of analysis. 


\begin{tabular}{|c|c|c|c|c|c|c|c|c|c|c|c|c|}
\hline \multicolumn{12}{|c|}{ Analyses (parts per million) } & \multirow[b]{2}{*}{ No. } \\
\hline $\begin{array}{l}\text { Ana- } \\
\text { 1yst }\end{array}$ & $\begin{array}{c}\text { Total } \\
\text { dis- } \\
\text { solved } \\
\text { solids at } \\
180^{\circ} \mathrm{C} \text {. }\end{array}$ & $\begin{array}{l}\text { Silica } \\
\left(\mathrm{SiO}_{2}\right)\end{array}$ & $\begin{array}{l}\text { Tron } \\
\text { (Fe) }\end{array}$ & $\begin{array}{l}\text { Cal- } \\
\text { cium } \\
\text { (Ca) }\end{array}$ & $\begin{array}{c}\text { Mag- } \\
\text { ne- } \\
\text { sium } \\
\text { (Mg) }\end{array}$ & $\begin{array}{l}\text { Sodium } \\
\text { and po- } \\
\text { tassium } \\
(\mathrm{Na}+\mathrm{K})\end{array}$ & $\begin{array}{c}\text { Bicar- } \\
\text { bonate } \\
\text { radicle } \\
\left(\mathrm{HCO}_{3}\right)\end{array}$ & $\begin{array}{c}\text { Sul- } \\
\text { phate } \\
\text { radicle } \\
\left(\mathrm{SO}_{4}\right)\end{array}$ & $\begin{array}{c}\text { Chloride } \\
\text { radicle } \\
\text { (Cl) }\end{array}$ & $\begin{array}{l}\text { Nitrate } \\
\text { radicle } \\
\left(\mathrm{NO}_{3}\right)\end{array}$ & $\begin{array}{c}\text { Total } \\
\text { hard- } \\
\text { ness as } \\
\mathrm{CaCO}_{3}^{a}\end{array}$ & \\
\hline H. & 1,610 & 18 & 0.08 & 150 & 66 & 315 & 287 & 62 & 735 & Tr. & 646 & 131 \\
\hline F. & 680 & 24 & .14 & 75 & 67 & $\begin{cases}\mathrm{Na} & 54 \\
\mathrm{~K} & 8,0\end{cases}$ & 358 & 154 & 93 & 1.3 & 462 & 132 \\
\hline F. & 249 & 11 & 3.1 & 48 & 5. 7 & $\begin{cases}\mathrm{Na} & 29 \\
\mathrm{~K} & 2.3\end{cases}$ & 133 & 2.9 & 66 & Tr. & 143 & 133 \\
\hline F. & 453 & 15 & .08 & 101 & 18 & $\begin{cases}\mathrm{Na} & 22 \\
\mathrm{~K} & 3.8\end{cases}$ & 247 & 93 & 53 & Tr. & 326 & 134 \\
\hline D. & 516 & $-\ldots$ & $\ldots$ & 106 & 14 & $443^{\circ}$ & $d 279$ & 105 & 55 & & 322 & 135 \\
\hline H. & 34 & 4.0 & .07 & 4. 2 & 1.3 & 1.5 & 2.4 & 1.7 & 3.8 & 14 & 16 & 136 \\
\hline H. & 66 & 10 & b. 50 & 13 & 1.5 & 6.3 & 46 & 4.5 & 4.0 & .67 & 39 & 137 \\
\hline $\begin{array}{l}\mathrm{H} . \\
\mathrm{D} . \\
\mathrm{D} . \\
\mathrm{H} .\end{array}$ & $\begin{array}{r}444 \\
480 \\
59 \\
265\end{array}$ & $\begin{array}{l}23 \\
21 \\
6.4 \\
13\end{array}$ & $\begin{array}{l}.35 \\
.06 \\
.13 \\
.12\end{array}$ & $\begin{array}{c}32 \\
33 \\
4.1 \\
54\end{array}$ & $\begin{array}{l}20 \\
18 \\
1.9 \\
27\end{array}$ & $\begin{array}{r}93 \\
113 \\
7.0 \\
5.5\end{array}$ & $\begin{array}{r}156 \\
d 160 \\
11 \\
288\end{array}$ & $\begin{array}{l}52 \\
56 \\
.3 \\
6.5\end{array}$ & $\begin{array}{r}145 \\
158 \\
7.3 \\
9.0\end{array}$ & ${ }_{\mathrm{Tr} .}^{\mathrm{Tr}}$ & $\begin{array}{r}162 \\
156 \\
18 \\
246\end{array}$ & $\begin{array}{l}138 \\
139 \\
140 \\
141\end{array}$ \\
\hline H. & 320 & 11 & 8.27 & 41 & 11 & $a 46$ & 182 & 13 & 60 & Tr. & 148 & 148 \\
\hline H. & 319 & 7.0 & b.42 & 41 & 12 & 45 & 148 & 37 & 56 & Tr. & 152 & 143 \\
\hline $\begin{array}{l}\text { H. } \\
\text { H. } \\
\text { H. } \\
\text { F. }\end{array}$ & $\begin{array}{l}465 \\
170 \\
173 \\
228 \\
203\end{array}$ & $\begin{array}{l}25 \\
14 \\
25 \\
29 \\
17\end{array}$ & $\begin{array}{l}.23 \\
.12 \\
.05 \\
\operatorname{Tr} . \\
.21\end{array}$ & $\begin{array}{l}84 \\
31 \\
36 \\
47 \\
43\end{array}$ & $\begin{array}{c}24 \\
9.7 \\
10 \\
14 \\
13\end{array}$ & $\begin{array}{c}29 \\
10 \\
3.9 \\
12 \\
5.6\end{array}$ & $\begin{array}{l}250 \\
154 \\
138 \\
228 \\
171\end{array}$ & $\begin{array}{c}146 \\
2.3 \\
18 \\
8.2 \\
19\end{array}$ & $\begin{array}{l}10 \\
16 \\
2.0 \\
8.0 \\
7.7\end{array}$ & $\begin{array}{l}\text { Tr. } \\
\text { Tr. } \\
\text { Tr. } \\
\text { Tr. } \\
\text { Tr. }\end{array}$ & $\begin{array}{l}308 \\
117 \\
131 \\
175 \\
161\end{array}$ & $\begin{array}{l}144 \\
145 \\
146 \\
147 \\
148\end{array}$ \\
\hline F. & $\begin{array}{l}242 \\
382\end{array}$ & $\begin{array}{l}29 \\
17\end{array}$ & $\begin{array}{l}.08 \\
.16\end{array}$ & $\begin{array}{l}39 \\
63\end{array}$ & $\begin{array}{l}19 \\
30\end{array}$ & $\stackrel{20}{7.9}$ & $\begin{array}{l}204 \\
156\end{array}$ & $\begin{array}{r}29 \\
147\end{array}$ & $\begin{array}{l}14 \\
10\end{array}$ & $\begin{array}{l}\text { Tr. } \\
.60\end{array}$ & $\begin{array}{l}175 \\
280\end{array}$ & $\begin{array}{l}149 \\
150\end{array}$ \\
\hline H. & 445 & 22 & .09 & 69 & 32 & $\begin{cases}\mathrm{Na} & 16 \\
\mathrm{~K} & 2.6\end{cases}$ & 177 & 153 & 17 & Tr. & 304 & 151 \\
\hline H. & 2,868 & 22 & 0.10 & 64 & 69 & $\begin{cases}\mathrm{Na} 999 \\
\mathrm{~K} & 12\end{cases}$ & 131 & 650 & 1,020 & Tr. & 443 & 162 \\
\hline H. & 1,274 & 12 & .08 & 59 & 46 & $\begin{cases}\mathrm{Na} & 310 \\
\mathrm{~K} & 3.2\end{cases}$ & 120 & 291 & 440 & Tr. & 336 & 153 \\
\hline
\end{tabular}

d Includes equivalent of small quantity of carbonate (COJ. 
Ground and surface

No.

In Hernando County shallow wells in sand yield soft water, which is liable to pollution. The deeper wells are represented by No. 154

Brooksville; municipal supply. 10-inch drilled well 205 feet deep. Oct. 5,1923

Brooksville (near), Weekewachee Spring, in sec. 2, T. 23 S., R. 17 E.; owned by M. M. Metcalt Co., Oberlin, Ohio; estimated discharge 220 second-feet. Oct. 4, 1923 .

\section{HIGHLANDS COUNTY}

Avon Park; public supply. 8-inch drilled well, 1,040 feet deep; owned by Florida Ice \& Power Co. Oct. 26, 1923.

Seabring; municipal supply. 13-inch drilled well 150 feet deep. Feb. 13, 1924

\section{HIISBOROUGH COUNTY}

Coronet. 12-inch drilled well 800 feet deep; owned by Coronet Phosphate Co. Feb. 14, 1924 Lithia. Spring owned by South Tampa Land Co.; yield 25,000 to 30,000 gallons a minute. July $\overline{1}$ 1923.

Plant City; part of municipal supply. 8-inch drilled well 360 feet deep. Feb. 14, 1924

Plant City; part of municipal supply. 12-inch drilled well 630 feet deep. Aug. 23, 1923

Plant City. 5-inch drilled well 584 feet deep; owned by Warnell Lumber Co. Feb. 14, $1924 \ldots \ldots$ Port Tampa; municipal supply. 5-inch drilled well 20 feet deep. Jan. 6, 1925 .

Sulphur Springs. Spring owned by Josiah Richardson; yield 5 gallons a minute. Oct. 9, 1923.... Tampa, 6 miles northeast of. Hillsboto River directly above Tampa Electric Co.'s dam. Color, 110. July $20,1923$.

Tampa; municipal supply in 1927. Hillsboro River, raw water at filtration plant; color, 20. Suspended matter 0.5. June 29,1927

Tampa; municipal supply in 1927 . Filtered water from main at Tampa waterworks; color, 6 . June 29, 1927.

Tampa; municipal supply in 1922. Composite of samples from Magbee Spring, 16-inch conduit, 20 -inch conduit, substation No. 2, substation No. 3, substation No. 4, and fire plug at Seventh and Twenty-second Streets. Each source was represented by a quantity of water that would make the composite represent the average composition of water supplied to the city at the date of collection. Sept. 25,1922 .

Tampa. Composite sample from 9 wells used for municipal supply in 1908 . Feb. 21, 1908.

Tampa. 10-inch drilled well 118 feet deep; owned by Tampa Electric Co. Aug. 26, 1923. Tampa; 4 miles from city, on highway to Palm River. DeShong Spring; owned by Joseph Hendry. Nov. 16, 1923.

Tampa. Palma Ceis Springs; owned by Thomas Palmer. Aug. 26, 1923

Tampa; north of city on Hillsboro River. Purity Springs; owned by Harry $\mathrm{G}$. Warner; yield 500 gallons a minute. July $20,1923$.

Tampa; north of eity on Hillsboro River. Sulphur Springs; owned by J. S. Richardson; discharge 35 second-feet Feb. 24, 1917 (Water-Supply Paper 452, p. 61). July, 1923.

Tampa, Seminole Heights, privately owned water system for suburb. 6 -inch drilled well 300 feet deep; owned by H. A. DeLoach. Oct. 10, 1923.

Turkey Creek. Turkey Creek. About 1907.

West Tampa; municipal supply. Drilled wells 400 feet deep. Feb. 21, 1908.

Ybor City. Drilled well 11/2 inches in diameter and 50 feet deep; owned by Reed \& Dorchester. Feb. 8, 1908.

HOLMES COUNTY

In Holmes County shallow wells in sand yield soft water, which is liable to pollution. The deeper waters are likely to be harder than No. 179.

Bonifay; municipal supply. 8-inch drilled well 450 feet deep. Apr. 2, 1924

Ponce De Leon. Ponce De Leon Springs. Feb. 21, 1927.

\section{INDIAN RIVER COUNTY}

Vero Beach. 8-inch drilled well 661 feet deep; owned by municipality; flows 1,500 gallons a minute; used for public supply after softening (No. 181). July 10, 1923.

Vero Beach; municipal supply. Water from No. 180 after treatment with lime and soda ash. Oct. 31, 1923.

\section{JACKSON COUNTY}

Cottondale. 2-inch drilled well 118 feet deep; owned by J. R. Showmaker. Dec. 2, 1907 Grand Ridge. 4 -inch drilled well 256 feet deep at Cohasset Sugar Plantation. Dec. 13, $1907 . .$. Marianna; municipal supply. 10-inch drilled well 255 feet deep. July $18,1923 \ldots \ldots \ldots$ Marianna, 6 miles east of. Spring in NE. $1 / 4 \mathrm{SW} .1 / 4$ sec. 33, T. 5 N., R. 9 W.; owned by Milton Land Co. Apr. 2, 1924.

Marianna. 6-inch drilled well 276 feet deep at State Reform School. Nov. 27, 1907

- Calculated.

- Includes iron precipitated at time of analysis. 


\begin{tabular}{|c|c|c|c|c|c|c|c|c|c|c|c|c|}
\hline \multicolumn{12}{|c|}{ Analyses (parts per million) } & \multirow[b]{2}{*}{ No. } \\
\hline $\begin{array}{l}\text { Ana- } \\
\text { lyst }\end{array}$ & $\begin{array}{c}\text { Total } \\
\text { dis- } \\
\text { solved } \\
\text { solids at } \\
180^{\circ} \mathrm{C} .\end{array}$ & $\begin{array}{l}\text { Silica } \\
\left(\mathrm{SiO}_{2}\right)\end{array}$ & $\underset{(\mathrm{Fe})}{\text { Iron }}$ & $\underset{\text { calum }}{\text { Cal- }}$ & $\begin{array}{l}\text { Mag- } \\
\text { ne- } \\
\text { sium } \\
(\mathrm{Mg})\end{array}$ & $\begin{array}{l}\text { Sodium } \\
\text { and po- } \\
\text { tassium } \\
(\mathrm{N} \mathbf{+}+\mathrm{K})\end{array}$ & $\begin{array}{l}\text { Bicar- } \\
\text { bonate } \\
\text { radicle } \\
\left(\mathrm{HCO}_{3}\right)\end{array}$ & $\begin{array}{c}\text { Sul- } \\
\text { phate } \\
\text { radicle } \\
\left(\mathrm{SO}_{4}\right)\end{array}$ & $\begin{array}{l}\text { Chloride } \\
\text { radicle } \\
\text { (C1) }\end{array}$ & $\begin{array}{c}\text { Nitrate } \\
\text { radicle } \\
\left(\mathrm{NO}_{3}\right)\end{array}$ & $\begin{array}{c}\text { Total } \\
\text { hard- } \\
\text { ness as } \\
\mathrm{CaCO}_{3}{ }^{a}\end{array}$ & \\
\hline$\frac{\mathrm{F}}{\mathrm{F}}$. & $\begin{array}{l}254 \\
173\end{array}$ & $\begin{array}{l}29 \\
14\end{array}$ & $\begin{array}{r}0.12 \\
.14\end{array}$ & $\begin{array}{l}72 \\
49\end{array}$ & $\begin{array}{l}7.7 \\
7.8\end{array}$ & $\begin{array}{l}9.3 \\
3.7\end{array}$ & $\begin{array}{l}251 \\
178\end{array}$ & $\begin{array}{l}4.7 \\
7.5\end{array}$ & $\begin{array}{l}11 \\
4.7\end{array}$ & Tr. & $\begin{array}{l}212 \\
154\end{array}$ & $\begin{array}{l}154 \\
155\end{array}$ \\
\hline F. & 152 & 28 & b1. 4 & 29 & 15 & 4.7 & 155 & 3.4 & 4.6 & .75 & 134 & 156 \\
\hline F. & 32 & 7.1 & .04 & .5 & 1.8 & $\left\{\begin{array}{lr}\mathrm{Na} & 4.1 \\
\mathrm{~K} & .7\end{array}\right.$ & 2.4 & 2.7 & 6. 0 & 7.5 & 8.6 & 157 \\
\hline F. & $\begin{array}{l}227 \\
331\end{array}$ & 19 & .15 & $\begin{array}{l}50 \\
65\end{array}$ & $\begin{array}{l}18 \\
14\end{array}$ & $\begin{array}{l}-3.6 \\
14\end{array}$ & $\begin{array}{l}221 \\
135\end{array}$ & $\begin{array}{l}11 \\
93\end{array}$ & $\begin{array}{l}10 \\
23\end{array}$ & .76 & $\begin{array}{l}199 \\
220\end{array}$ & $\begin{array}{l}158 \\
159\end{array}$ \\
\hline $\begin{array}{l}\text { F. } \\
\text { F. } \\
\text { F. } \\
\text { F. }\end{array}$ & $\begin{array}{r}208 \\
258 \\
224 \\
1,323 \\
8,454 \\
87\end{array}$ & $\begin{array}{l}28 \\
25 \\
14 \\
3.3\end{array}$ & $\begin{array}{r}.09 \\
.38 \\
.28 \\
.14\end{array}$ & $\begin{array}{r}44 \\
60 \\
47 \\
221 \\
391 \\
16\end{array}$ & $\begin{array}{c}15 \\
11 \\
22 \\
26 \\
254 \\
2.2\end{array}$ & $\begin{array}{c}4.1 \\
16 \\
22.2 \\
223 \\
2,386 \\
4.0\end{array}$ & $\begin{array}{r}195 \\
253 \\
233 \\
322 \\
162 \\
44\end{array}$ & $\begin{array}{r}6.9 \\
1.7 \\
5.8 \\
7.1 \\
820 \\
4.9\end{array}$ & $\begin{array}{c}8.8 \\
14 \\
11 \\
611 \\
4,405 \\
3.0\end{array}$ & $\begin{array}{c}\text { Tr. } \\
1.6 \\
\text { Tr. } \\
\text { Tr. }\end{array}$ & $\begin{array}{r}172 \\
195 \\
208 \\
659 \\
2,019 \\
49\end{array}$ & $\begin{array}{l}160 \\
161 \\
162 \\
163 \\
164 \\
165\end{array}$ \\
\hline F. & 186 & 11 & .10 & 48 & 5.8 & $\begin{cases}\mathrm{Na} & 5.6 \\
\mathrm{~K} & .8\end{cases}$ & 140 & 25 & 10 & .10 & 144 & 166 \\
\hline F. & 149 & 7.3 & .03 & 32 & 5.5 & $\left\{\begin{array}{lll}\mathrm{N} 2 & 7 & 3 \\
K & 7 & 0\end{array}\right.$ & 70 & 45 & . 10 & .10 & 103 & 167 \\
\hline F., & 1,273 & 22 & .48 & 113 & 33 & $\cdot 275$ & 176 & 92 & 548 & 2.8 & 418 & 168 \\
\hline $\begin{array}{l}\text { D. } \\
\text { F. } \\
\text { H. }\end{array}$ & $\begin{array}{r}645 \\
1,313 \\
5,902\end{array}$ & $\begin{array}{l}15 \\
14 \\
22\end{array}$ & $\begin{array}{l}.06 \\
.26 \\
\text { Tr. }\end{array}$ & $\begin{array}{r}76 \\
132 \\
236\end{array}$ & $\begin{array}{r}12 \\
33 \\
164\end{array}$ & $\begin{array}{r}126 \\
292 \\
1,671\end{array}$ & $\begin{array}{l}140 \\
200 \\
215\end{array}$ & $\begin{array}{r}40 \\
95 \\
513\end{array}$ & $\begin{array}{r}253 \\
588 \\
2,973\end{array}$ & $\begin{array}{l}\text { Tr. } \\
\text { Tr. }\end{array}$ & $\begin{array}{r}239 \\
465 \\
1,262\end{array}$ & $\begin{array}{l}169 \\
170 \\
171\end{array}$ \\
\hline F. & $\begin{array}{l}692 \\
157\end{array}$ & ${ }_{8.9}^{17}$ & $\begin{array}{l}.19 \\
.07\end{array}$ & $\begin{array}{r}109 \\
45\end{array}$ & $\begin{array}{l}15 \\
3.4\end{array}$ & $\begin{array}{l}100 \\
6.0\end{array}$ & $\begin{array}{l}249 \\
142\end{array}$ & $\stackrel{29}{3.6}$ & $\begin{array}{r}231 \\
11\end{array}$ & $\begin{array}{l}.58 \\
.26\end{array}$ & $\begin{array}{l}334 \\
126\end{array}$ & $\begin{array}{l}172 \\
178\end{array}$ \\
\hline F. & 619 & 15 & .21 & 63 & 15 & 110 & 103 & 77 & 209 & Tr. & 219 & 174 \\
\hline F. & 161 & 15 & .09 & 36 & 4.1 & 8.6 & 88 & 18 & 13 & 18 & 107 & 175 \\
\hline D. & $\begin{array}{r}33 \\
650 \\
208\end{array}$ & 21 & $\begin{array}{r}12.1 \\
1.9 \\
.4\end{array}$ & $\begin{array}{l}3.4 \\
94 \\
35\end{array}$ & $12^{.6}$ & $\begin{array}{r}4.0 \\
110 \\
a 1.8\end{array}$ & $\begin{array}{c}3.0 \\
195 \\
55\end{array}$ & $\begin{array}{l}8.2 \\
45 \\
32\end{array}$ & $\begin{array}{c}6.1 \\
228 \\
24\end{array}$ & .15 & $\begin{array}{r}11 \\
284 \\
108\end{array}$ & $\begin{array}{l}176 \\
177 \\
178\end{array}$ \\
\hline H. & 140 & 15 & .08 & 42 & 5.6 & 1.7 & ${ }^{d} 151$ & 3.6 & 7.0 & Tr. & 128 & 170 \\
\hline F. & 113 & 8.8 & .27 & 30 & 9.2 & $\left\{\begin{array}{lr}\mathrm{Na} & 1.9 \\
\mathrm{~K} & .4\end{array}\right.$ & \} 123 & 3.8 & 2.6 & .25 & 113 & $179 \mathrm{a}$ \\
\hline R. & 1,120 & 22 & .20 & 87 & 57 & 215 & 174 & 128 & 453 & 2.7 & 451 & 180 \\
\hline F. & 966 & 15 & .09 & 30 & 55 & 233 & $d 78$ & 125 & 440 & 1.2 & 300 & 181 \\
\hline $\begin{array}{l}\text { D. } \\
\text { D. } \\
\text { P. } \\
\text { H. }\end{array}$ & $\begin{array}{r}170 \\
-138 \\
238 \\
125\end{array}$ & 12 & $\begin{array}{l}.0 \\
\text { Tr. } \\
.12 \\
.09\end{array}$ & $\begin{array}{l}49 \\
27 \\
56 \\
43\end{array}$ & $\begin{array}{l}\text { Tr. } \\
13 \\
11 \\
1.0\end{array}$ & $\begin{array}{l}a 7.8 \\
33 \\
15 \\
2.3\end{array}$ & $\begin{array}{l}d 165 \\
d 151 \\
211 \\
126\end{array}$ & $\begin{array}{l}\mathrm{Tr} . \\
6.2 \\
2.4\end{array}$ & $\begin{array}{c}3 \\
2 \\
23 \\
2.0\end{array}$ & $\begin{array}{l}3.8 \\
1.6\end{array}$ & $\begin{array}{l}123 \\
121 \\
185 \\
112\end{array}$ & $\begin{array}{l}182 \\
183 \\
184 \\
185\end{array}$ \\
\hline D. & $\begin{array}{l}125 \\
126\end{array}$ & 17 & $\begin{array}{r}.07 \\
1.0\end{array}$ & $\begin{array}{l}34 \\
25\end{array}$ & 13.9 & ${ }^{4.9}$ & $\begin{array}{l}d 138 \\
d 140\end{array}$ & $\begin{array}{l}3.3 \\
5\end{array}$ & ${ }_{3}^{2.5}$ & .12 & $\begin{array}{l}105 \\
116\end{array}$ & $\begin{array}{l}186 \\
187\end{array}$ \\
\hline
\end{tabular}

d Ineludes equivalent of small quantity of carbonate $\left(\mathrm{CO}_{3}\right)$.

- Includes iron and aluminum oxides $\left(\mathrm{Feg}_{3}+\mathrm{Al}_{2} \mathrm{O}_{3}\right)$. 


No. $\left|\begin{array}{c}\text { Description } \\ 188\end{array}\right| \begin{gathered}\text { Monticello; municipal supply. 8-inch drilled well 500 feet deep. Mar. 1, 1924 } \\ \text { Monticello, 3 miles east of. Dug well } 4 \text { feet in diameter and 30 feet deep; owned by W. W. Bassett. } \\ \text { A typical shallow well for Jefferson County. Mar. 1, 1924. }\end{gathered}$

\section{LAFATETTE COUNTY}

In Lafayette County shallow wells in sand yield soft water; deeper wells are like No. 190 . They may yield sulphur water.

piped to all homes. Nov. 22, 1923.

\section{LAKE COUNTY}

Astor. St. Johns River 4 miles south of Lake George; color, 163. Oct. 25, 1924

Clermont; municipal supply. 4-inch drilled well 200 feet deep. Aug. 8, 1924.

Clermont. Crystal Lake; sample collected near the old pump house. Color, 11. Sept. 6, 1924.Eustis; public supply. Composite sample from two drilled wells 4 inches in diameter and 125 feet deep; owned by Florida Public Service Co. Aug. 8, 1924.

1924 .

Teeshurg; municipal supply. Compasite samplo from 3 drilled wolls about 150 feet deep; diameter of one well is 4 inches and that of the other two is 6 inches: Oct. 30, 1924. 1924.

Leesburg. Lake

, municipal supply. 8-inch drilled well 240 feet deep. Dec. 21, 1924

Umatilla; municipal supply. 3-inch drilled well 250 feet deep. Aug. 8, 1924

\section{LEE COUNTY}

Cedar Keys. 21/2-inch driven well 35 feet deep; owned by G. T. Lewis. Nov. 7, 1923

217 Cedar Keys. Dug well 6 feet in diameter and 25 feet deep 350 feet from the beach; owned by $\overline{M r}$. Toler. Water is served through pipes to about 20 families. April 24, 1920.

\section{LEON COUNTY}

Tallahassee; municipal supply. Composite sample from 12-inch drilled wells 250 and 700 feet deep. A sample collected in 1908 from "city well" had almost exactly the same composition. Feb. 27, 1924.

Tallahassee. 8-inch drilled well 375 feet deep; owned by Middle Florida Ico Co. May 26, 1908.

\section{LEVY COUNTY}

Cedar Keys. Driven well 11/4 inches in diameter and 20 feet deep; owned by Levy County. This water is used by sohool children from Cedar Keys, Sumner, and outlying districts. Nov. 7, 1923. 1923.

1edar Keys, near. Spring in NE. $1 / 4$ sec. 10, T. 15 S., R. 13 E,; owned by W. H. Hale. Nov. 12, 1923. level 47 foet above surface; flows 900 gallons a minute. Sept. 5,1923 .

Fort Myers. 2-inch drilled well 90 feet deep; owned by municipality; a typical shallow well for the ort Myers. Composite sample from two flowing wells 570 and 587 feet deep; used for municipal time of collection. Feb. 15, 1908 .

ort Myers. Drilled well 11/2 inches in diameter and 102 feet deep; owned by Gaý Laundry.

Fort Myers. 6-inch drilled well 1,050 feet deep; owned by Southern Utilities Co.; flows 300 gallons a minute. Sept. 5, 1923 . from tide either north or south. Well easily pumped dry; water used at a small factory mak. ing fiber product from pelmetto leaves. April 24, 1920 .

- Calculated. 


\begin{tabular}{|c|c|c|c|c|c|c|c|c|c|c|c|c|}
\hline \multicolumn{12}{|c|}{ Analyses (parts per million) } & \multirow[b]{2}{*}{ No. } \\
\hline $\begin{array}{l}\text { Ana- } \\
\text { lyst }\end{array}$ & $\begin{array}{c}\text { Total } \\
\text { dis- } \\
\text { solved } \\
30 \text { idds at } \\
180^{\circ} \mathrm{C} \text {. }\end{array}$ & $\begin{array}{l}\text { Silica } \\
\left(\mathrm{SiO}_{2}\right)\end{array}$ & $\begin{array}{l}\text { Iron } \\
(\mathrm{F} \theta)\end{array}$ & $\underset{(\mathrm{Ca})}{\text { cal- }}$ & $\begin{array}{c}\text { Mag- } \\
\text { ne- } \\
\text { sium } \\
(\mathrm{Mg})\end{array}$ & $\begin{array}{l}\text { Sodium } \\
\text { and po } \\
\text { tassium } \\
(\mathrm{Na}+\mathrm{K})\end{array}$ & $\begin{array}{c}\text { Bicar- } \\
\text { bonate } \\
\text { radicle } \\
\left(\mathrm{HCO}_{3}\right)\end{array}$ & $\begin{array}{c}\text { Sul- } \\
\text { phate } \\
\text { radicle } \\
\left(\mathrm{BO}_{4}\right)\end{array}$ & $\begin{array}{c}\text { Chloride } \\
\text { radicle } \\
\text { (Cl) }\end{array}$ & $\begin{array}{l}\text { Nitrate } \\
\text { radicle } \\
\left(\mathrm{NO}_{3}\right)\end{array}$ & $\begin{array}{c}\text { Total } \\
\text { hard- } \\
\text { ness as } \\
\mathrm{CaCO}_{3}^{\circ}\end{array}$ & \\
\hline H. & 164 & 13 & 0.04 & 46 & 7.3 & $\left\{\begin{array}{lr}\mathrm{Na} & 3.4 \\
\mathrm{~K} & .4\end{array}\right.$ & 167 & 4.7 & 6.0 & Tr. & 145 & 188 \\
\hline H. & 39 & 2.1 & .18 & 1.8 & .6 & $\begin{cases}\mathrm{Na} & 9.4 \\
\mathrm{~K} & .8\end{cases}$ & 18 & 1.3 & 4.7 & 7.1 & 7.0 & 189 \\
\hline H. & 260 & 12 & b 1.1 & 68 & 15 & 7.8 & 287 & 3.8 & 6.2 & 2.0 & 232 & 180 \\
\hline $\begin{array}{l}\mathbf{H} . \\
\text { H. } \\
\text { H. }\end{array}$ & $\begin{array}{r}238 \\
251 \\
33 \\
108\end{array}$ & $\begin{array}{c}3.6 \\
20 \\
1.1 \\
14\end{array}$ & $\begin{array}{l}\text { b. } 12 \\
1.0 \\
\text { b. } 12 \\
.04\end{array}$ & $\begin{array}{l}16 \\
68 \\
1.3 \\
23\end{array}$ & $\begin{array}{l}6.8 \\
6.3 \\
1.3 \\
4.8\end{array}$ & $\begin{array}{c}51 \\
9.9 \\
6.9 \\
8.2\end{array}$ & $\begin{array}{c}29 \\
239 \\
6.1 \\
86\end{array}$ & $\begin{array}{c}19 \\
3.7 \\
4.2 \\
1.7\end{array}$ & $\begin{array}{l}98 \\
12 \\
10 \\
8.0\end{array}$ & $\begin{array}{l}\text { Tr. } \\
\mathbf{T r} . \\
\mathbf{T r} \\
\mathbf{T r} .\end{array}$ & $\begin{array}{c}68 \\
196 \\
8.6 \\
77\end{array}$ & $\begin{array}{l}191 \\
192 \\
193 \\
194\end{array}$ \\
\hline H. & 68 & 1.7 & .16 & 4.0 & 2.3 & 22 & 18 & 3.7 & 18 & 34 & 19 & 195 \\
\hline H. & 174 & 18 & .05 & 48 & 6.4 & 6.5 & 144 & 4.1 & 15 & 2.1 & 134 & 198 \\
\hline H. & 102 & 5.6 & b. 12 & 14 & 4.4 & .7 .3 & 59 & 2.5 & 14 & 1.1 & 63 & 197 \\
\hline H. & 83 & 8.4 & b. 15 & 11 & 2.9 & 7.6 & 41 & 3.3 & 12 & 1.0 & 39 & 198 \\
\hline $\begin{array}{l}\text { H. } \\
\text { H. }\end{array}$ & $\begin{array}{l}176 \\
152 \\
247\end{array}$ & $\begin{array}{l}15 \\
12 \\
14\end{array}$ & $\begin{array}{r}.08 \\
6.37 \\
.12\end{array}$ & $\begin{array}{l}36 \\
34 \\
63\end{array}$ & $\begin{array}{l}4.4 \\
11 \\
10\end{array}$ & $\begin{array}{l}33 \\
7.8 \\
15\end{array}$ & $\begin{array}{l}170 . \\
151 \\
254\end{array}$ & $\begin{array}{l}7.9 \\
8.3 \\
8.4\end{array}$ & $\begin{array}{l}15 \\
10 \\
12\end{array}$ & $\begin{array}{l}\text { Tr. } \\
\text { Tr. } \\
\text { Tr. }\end{array}$ & $\begin{array}{l}108 \\
130 \\
198\end{array}$ & $\begin{array}{l}199 \\
200 \\
201\end{array}$ \\
\hline F. & 1,740 & 14 & .14 & 109 & 93 & 371 & 156 & 326 & 718 & Tr. & 654 & 202 \\
\hline F. & 1,986 & 14 & .27 & 128 & 103 & 414 & 163 & 331 & 832 & Tr. & 742 & 203 \\
\hline F. & 357 & 24 & .10 & 79 & 14 & 28 & 295 & 9.2 & 44 & .35 & 255 & 204 \\
\hline D. & 2,007 & 17 & .18 & 234 & 26 & 419 & 168 & 316 & 833 & Tr. & 682 & 208 \\
\hline F. & 460 & 15 & .06 & 46 & 35 & 75 & 238 & 25 & 143 & Tr. & 258 & 206 \\
\hline F. & 410 & 23 & .10 & 68 & 26 & 44 & 298 & 10 & 84 & Tr. & 277 & 207 \\
\hline F. & 1,895 & 12 & b3. 5 & 130 & 101 & 394 & 165 & 343 & 786 & Tr. & 739 & 208 \\
\hline H. & $\begin{array}{r}17 \\
155\end{array}$ & $11^{.8}$ & $\stackrel{07}{\text { Tr. }}$ & $36^{1.6}$ & $\begin{array}{r}.9 \\
9.8\end{array}$ & $\begin{array}{r}2.7 \\
-2.4\end{array}$ & $144^{3.7}$ & $\begin{array}{l}1.9 \\
4.9\end{array}$ & $\begin{array}{l}5.0 \\
8.0\end{array}$ & $\begin{array}{l}1.0 \\
1.2\end{array}$ & $\begin{array}{r}8 \\
130\end{array}$ & $\begin{array}{l}200 \\
210\end{array}$ \\
\hline D. & 200 & 18 & .09 & 48 & 10 & 8.5 & 174 & 2.5 & 20 & 9.6 & 161 & 211 \\
\hline F. & 358 & 12 & .18 & 83 & 10 & 31 & 277 & 14 & 47 & Tr. & 248 & 212 \\
\hline F. & 255 & 6.0 & b3. 7 & 80 & 5.2 & 8.6 & 258 & 2.2 & 16 & 1.1 & 221 & 213 \\
\hline F. & .... & -... & 2.3 & 92 & 14 & - 19 & 276 & 6.1 & 68 & .46 & 287 & 214 \\
\hline F. & 495 & 7.0 & b2.5 & 91 & 14 & 71 & 274 & 15 & 187 & .62 & 285 & 215 \\
\hline F. & $\begin{array}{l}506 \\
310\end{array}$ & $12^{7.6}$ & $\begin{array}{l}.08 \\
.11\end{array}$ & $\begin{array}{r}56 \\
.52\end{array}$ & $\begin{array}{l}14 \\
7.9\end{array}$ & $\begin{array}{r}102 \\
44\end{array}$ & $\begin{array}{l}174 \\
141\end{array}$ & $\begin{array}{l}43 \\
35\end{array}$ & $\begin{array}{r}143 \\
56\end{array}$ & 30 & $\begin{array}{l}197 \\
162\end{array}$ & $\begin{array}{l}216 \\
217\end{array}$ \\
\hline F. & 609 & 16 & .46 & 55 & 9.8 & 133 & 159 & 56 & 205 & 8.0 & 178 & 218 \\
\hline
\end{tabular}

- Includes iron precipitated at time of analybis. 
Description

\section{LEVY COUNTY - continued}

Otter Creek. 21/2-inch drilled well 70 feet deep; owned by Cummer Cypress Co.; supply for basket mill and for domestic use of employees. Nov. 7, 1923.

sumner. 11/4-inch driven well 30 feet deep; owned by Cummer Cypress Co.; water used by primary-school children at Sumner. Nov. 7, 1923.

Sumner. 6-inch drilled well 96 feet deep; owned by Cummer Cypress Co.; used for supply of mill and mill town. Nov. 6, 1923.

Williston; municipal supply. 9-inch drilled well 125 feet deep. Aug. 11, 1924.

\section{LRERTY COUNTY}

Bristol; public supply. Driven well 11/4 inches in diameter and 33 feet deep; owned by municipality. May 29, 1924.

Bristol. Driven well $11 /$ inches in diameter and 35 feet deep; owned by Mrs. S. G. Smith; supplies the Florida Hotel and several stores. April 15, 1924.

Hosford. 4-inch drilled well 492 feet deep; owned by Graver Bros. April 15, 1924.

\section{MADISON COUNTY}

Ellaville. 2-inch drilled well 72 feet deep in front of Seaboard Air Line station; owned by H. C. Noegel. Feb. 26, 1924 .

Greenville. 6-foot dug well 30 feet deep; owned by town. Nov. 21, 1923

Madison; municipal supply. 8-inch drilled well 400 feet deep. Nov. 21,1923

Madison. 4-inch drilled weil 240 feet deep; owned by municipality. April 11, 1008

\section{MaNATEE COUNTY}

Samples from 14 wells in Bradentown, from 45 to 250 feet deep, were of about the same composition as Nos. 292 and 235.

Bradentown; municipal supply. 4-inch drilled wells 85 feet deep; composite sample from four wells. Aug. 29, 1923.

Bradentown. 6-inch wells 410

Bradentown. 2-inch drilled well 75 feet deep; owned by R. M. Beall. Aug. 29, 1923.

233 Bradentown. 3-inch drilled well 64 feet deep; owned by William Kellar. Aug. 29, 1923

235 Bradentown. 2-inch drilled well 88 feet deep; owned by C. A. Morrow. Sept. 13, 1923 -t--...Bradentown. Drilled well $1 \frac{1}{2}$ inches in diameter and 64 feet deep; owned by A. Perrie. Aug. $29,1923$.

236 Bradentown. Dug well 25 feet deep; owned by Louise Richason. Oct. 29, 1923

237 Bradentown. Flowing well 3 inches in diameter and 400 feet deep; owned by $\mathbf{H}, \overline{\mathrm{L}}$. Wadham. Sept. 13, 1923.

238 Bradentown. Tiger Lake. Color, 44. Oct. 18, 1923

Bradentown, 2 miles west of. 4-inch drilled well 550 feet deep; owned by v. 1923.

Brádentown, 2 miles' west of. Spring owned by W. R. Brack. Aug. 29, 1923

241 Manatee; municipal supply. Flowing well 8 inches in diameter and 650 feet deep. $\mathrm{sept.} 13,1907$

242 Manatee. Spring; owned by S. C. Cates. Sept. 13, 1923

243 Palmetto; municipal supply. 8-inch drilled well 620 feet deep. Nov. 5,1923

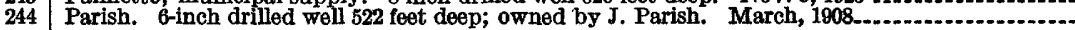

\section{MARION COUNTY}

Dunnellon, 2 miles northeast of. Blue Springs at Juliette, owned by Strohmeyer Realty Co., Sarasota. Mar. 4, 1927.

245 Ocala; municipal supply. 8-inch drilled well 350 feet deep. Aug. 13, 1923

246 Ocala; municipal supply. 12-inch drilled well 380 feet deep. Aug. 13, 1923

247 Ocala; municipal supply. 8-inch drilled well 1,220 feet deep. Aug. 13, 1923

248 Ocala. 8-inch drilled well 1,250 feet deep; owned by Ocala Water Co. Dec. 16, 100

Ocala. Silver Springs; sample collected from a point directly over the largest "boil"; discharge 545 second-feet on May 26, 1906 (Water-Supply Paper 204, p. 50). Aug. 14, 1923.

250 Ocala. Silver Springs. Dec. 16, 1907.

Ocala. Silver Springs. Dec. 16, 1907 ...

252 Norwalk, 3 miles west of. Salt Springs; sample from boiling spring. A Aug. 19,1924 many, 3 miles west of. Salt Sprited 187 sec 19,1924 .

Jensen. Indian River about 500 feet east of west shore line off Jensen bridge. Color, 60. Nov. $11,1924$.

256 Olympia; public supply. Composite sample from group of sixteen 2-inoh driven wells 33 feet deep; owned by the Olympia Corporation. Nov. 2, 1923.

256 Stuart. 4-inch drilled well 60 feet deep; owned by Southern Utilities Co. July 11, 1923

a Calculated.

b Includes iron precipitated at time of analysis.

- Less than 10 parts per million. 


\begin{tabular}{|c|c|c|c|c|c|c|c|c|c|c|c|c|}
\hline \multicolumn{12}{|c|}{ Analyses (parts per million) } & \multirow[b]{2}{*}{ No. } \\
\hline $\begin{array}{l}\text { Ang- } \\
\text { lyst }\end{array}$ & $\begin{array}{c}\text { Total } \\
\text { dis- } \\
\text { solved } \\
\text { solids at } \\
180^{\circ} \mathrm{C} \text {. }\end{array}$ & $\begin{array}{l}\text { Silica } \\
\left(\mathrm{SiO}_{2}\right)\end{array}$ & $\begin{array}{l}\text { Iron } \\
(\mathrm{Fe})\end{array}$ & $\begin{array}{l}\text { Oal- } \\
\text { cium } \\
\text { (Ca) }\end{array}$ & $\begin{array}{l}\text { Mag- } \\
\text { ne- } \\
\text { sium } \\
(\mathbf{M g})\end{array}$ & $\begin{array}{l}\text { Sodium } \\
\text { and po- } \\
\text { tassium } \\
(\mathrm{Na}+\mathrm{K})\end{array}$ & $\begin{array}{c}\text { Bicar- } \\
\text { bonate } \\
\text { radicle } \\
\left.\text { (HCO } \mathrm{CO}_{3}\right)\end{array}$ & $\begin{array}{c}\text { Sul- } \\
\text { phate } \\
\text { radicle } \\
\left(\mathrm{SO}_{4}\right)\end{array}$ & $\begin{array}{c}\text { Chloride } \\
\text { radicle } \\
\text { (CI) }\end{array}$ & $\begin{array}{l}\text { Nitrate } \\
\text { radicle } \\
(\mathrm{NO})^{2}\end{array}$ & $\mid \begin{array}{c}\text { Total } \\
\text { hard- } \\
\text { ness as } \\
\mathrm{CaCO}_{3}^{\circ}\end{array}$ & \\
\hline F. & 326 & 12 & b7.1 & 105 & 4.3 & 8.0 & 317 & 3.2 & 17 & 0.67 & 280 & 219 \\
\hline F. & & $\ldots$ & $\ldots$ & 73 & 6.5 & (o) & 229 & 6.3 & 11 & Tr. & 209 & 220 \\
\hline F. & 249 & 6.7 & $\diamond 3.5$ & 77 & 5.6 & 9.1 & 259 & 4.5 & 6.6 & .44 & 215 & 221 \\
\hline H. & 324 & 5.3 & .10 & 88 & 4.4 & 9.0 & 268 & 3.7 & 44 & 3.8 & 263 & 222 \\
\hline H. & 161 & $\mathbf{3 . 3}$ & .10 & 5.6 & 4.6 & 17 & 2.4 & 1.6 & 6.0 & 66 & $\mathbf{3 3}$ & 223 \\
\hline H. & 174 & 24 & .10 & 7.6 & 7.4 & - 23 & 1.2 & 2.0 & 26 & 74 & 49 & 224 \\
\hline H. & 221 & 23 & .19 & 41 & 11 & 24 & 227 & 15 & 3.9 & $\mathbf{T r}$. & 148 & 225 \\
\hline $\mathbf{H}$. & 246 & 8.0 & 2.0 & 60 & 18 & $\begin{cases}\mathrm{Na} & 5.1 \\
\mathrm{~K} & 6\end{cases}$ & 250 & 19 & 7.0 & Tr. & 224 & 226 \\
\hline $\begin{array}{l}\text { H. } \\
\text { H. }\end{array}$ & $\begin{array}{l}185 \\
167 \\
163\end{array}$ & $\begin{array}{l}6.0 \\
14 \\
15\end{array}$ & $\begin{array}{r}.10 \\
.24 \\
.03\end{array}$ & $\begin{array}{r}16 \\
45 \\
44\end{array}$ & $\begin{array}{l}\mathbf{5 . 2} \\
\mathbf{9 . 7} \\
8.7\end{array}$ & $\mid \begin{array}{r}29^{\circ} \\
3.6 \\
4.6 \\
4.6\end{array}$ & $\begin{array}{r}26 \\
173 \\
d 178\end{array}$ & $\begin{array}{l}21 \\
3.7 \\
2.8\end{array}$ & $\begin{array}{c}46 \\
5.0 \\
4.9\end{array}$ & ${ }^{27} \mathrm{Tr}$. & $\begin{array}{r}61 \\
152 \\
146\end{array}$ & $\begin{array}{l}227 . \\
228 \\
229\end{array}$ \\
\hline H. & 1,762 & 24 & .15 & 280 & 96 & 102 & 161 & 782 & 244 & Tr. & 1,094 & 230 \\
\hline D. & 1,163 & 30 & Tr. & 260 & 30 & 37 & 172 & 594 & 49 & Tr. & 773 & 231 \\
\hline $\begin{array}{l}\text { H. } \\
\text { H. } \\
\text { H. }\end{array}$ & $\begin{array}{l}338 \\
243 \\
472 \\
425\end{array}$ & $\begin{array}{l}43 \\
9.6 \\
42 \\
32\end{array}$ & $\begin{array}{r}.11 \\
.08 \\
.26\end{array}$ & $\begin{array}{l}57 \\
57 \\
75 \\
88\end{array}$ & $\begin{array}{l}18 \\
12 \\
20 \\
19\end{array}$ & $\begin{array}{r}21 \\
13 \\
\times 62 \\
30\end{array}$ & $\begin{array}{l}231 \\
223 \\
322 \\
334\end{array}$ & $\begin{array}{l}19 \\
9.1 \\
21 \\
14\end{array}$ & $\begin{array}{l}41 \\
14 \\
84 \\
50\end{array}$ & $\begin{array}{l}\mathbf{T r} . \\
\mathbf{T r} . \\
\mathbf{T r} .\end{array}$ & $\begin{array}{l}216 \\
192 \\
270 \\
298\end{array}$ & $\begin{array}{l}232 \\
2833 \\
234 \\
235\end{array}$ \\
\hline 惎. & 1,270 & 27 & ${ }^{1}{ }^{1.2}$ & 205 & 81 & 25 & $\begin{array}{r}24 \\
163\end{array}$ & $\begin{array}{l}810 \\
669\end{array}$ & $\begin{array}{l}26 \\
62\end{array}$ & $\mathrm{Tr}$. & $\begin{array}{l}\mathbf{4 4 1} \\
\mathbf{8 4 5}\end{array}$ & $\begin{array}{l}236 \\
237\end{array}$ \\
\hline 㫷. & $\begin{array}{r}37 \\
1,273\end{array}$ & ${ }_{10}^{2.1}$ & $\begin{array}{r}.02 \\
6.0\end{array}$ & $189^{3.0}$ & $\frac{1.2}{75}$ & $5^{6.3}$ & $102^{8.5}$ & 644 & $107^{7.7}$ & $\begin{array}{l}\mathbf{T r} . \\
\mathbf{T r} .\end{array}$ & $\begin{array}{r}12 \\
780\end{array}$ & $\begin{array}{l}238 \\
239\end{array}$ \\
\hline $\begin{array}{l}\text { H. } \\
\text { H. } \\
\text { H. } \\
\text { D. }\end{array}$ & $\begin{array}{r}71 \\
1,173 \\
1,020 \\
1,282 \\
494\end{array}$ & \begin{tabular}{c}
3.2 \\
22 \\
28 \\
\hdashline- \\
\hdashline
\end{tabular} & $\begin{array}{l}.04 \\
\text { Tr. } \\
8.67 \\
.17 \\
\text { Tr. }\end{array}$ & $\begin{array}{c}3.4 \\
193 \\
177 \\
214 \\
86\end{array}$ & $\begin{array}{l}1.9 \\
64 \\
60 \\
85 \\
37\end{array}$ & $\begin{array}{r}15 \\
33 \\
24 \\
\times 21 \\
\end{array}$ & $\begin{array}{l}2.4 \\
161 \\
185 \\
166 \\
195\end{array}$ & $\begin{array}{l}616 \\
616 \\
619 \\
691 \\
208\end{array}$ & $\begin{array}{l}25 \\
38 \\
30 \\
53 \\
19\end{array}$ & $\begin{array}{l}\mathbf{T r} . \\
\mathbf{T r} . \\
\mathbf{T r} . \\
\mathbf{T r} .\end{array}$ & $\begin{array}{r}16 \\
745 \\
688 \\
884 \\
168\end{array}$ & $\begin{array}{l}240 \\
241 \\
242 \\
243 \\
244\end{array}$ \\
\hline F. & 83 & 9.4 & .15 & 21 & 5.1 & $\left\{\begin{array}{cc}\mathrm{Na} & 1.4 \\
\mathrm{~K} & .5\end{array}\right.$ & 72 & 16 & 3.0 & .34 & 73 & $244 a$ \\
\hline $\begin{array}{l}\text { F. } \\
\text { F. } \\
\text { P. } \\
\text { F. }\end{array}$ & $\begin{array}{l}540 \\
652 \\
485 \\
659 \\
284\end{array}$ & $\begin{array}{l}27 \\
27 \\
63 \\
21 \\
32\end{array}$ & $\begin{array}{l}2.3 \\
.15 \\
.48 \\
.02 \\
.06\end{array}$ & $\begin{array}{r}116 \\
150 \\
89 \\
151 \\
70\end{array}$ & $\begin{array}{l}28 \\
29 \\
21 \\
25 \\
11\end{array}$ & \begin{tabular}{|cc}
$1.1^{\circ}$ \\
\\
14 \\
17 \\
18 \\
$\quad 4.4$
\end{tabular} & $\begin{array}{r}215 \\
259 \\
d 170 \\
d 256 \\
205\end{array}$ & $\begin{array}{r}213 \\
270 \\
174 \\
\mathbf{2 6 6} \\
\mathbf{4 3}\end{array}$ & $\begin{array}{c}17 \\
19 \\
14 \\
18 \\
7.6\end{array}$ & $\begin{array}{l}0.70 \\
\mathrm{Tr} . \\
.64 \\
.22 \\
.86\end{array}$ & $\begin{array}{l}405 \\
494 \\
309 \\
480 \\
220\end{array}$ & $\begin{array}{l}245 \\
246 \\
247 \\
248 \\
249\end{array}$ \\
\hline $\begin{array}{l}\mathbf{D} \\
\mathbf{H} . \\
\mathbf{H} \\
\text {. }\end{array}$ & $\begin{array}{r}274 \\
5,377 \\
4,800 \\
5,210\end{array}$ & $\begin{array}{c}13 \\
8.4 \\
\end{array}$ & $\begin{array}{r}\mathrm{Tr} . \\
.36\end{array}$ & $\begin{array}{r}73 \\
254 \\
213 \\
218\end{array}$ & $\begin{array}{l}9.2 \\
181 \\
134 \\
138\end{array}$ & $\begin{array}{r}9.8 \\
1,418 \\
a 1,238 \\
\cdot 1,362\end{array}$ & $\begin{array}{r}219 \\
85 \\
90 \\
84\end{array}$ & $\begin{array}{r}44 \\
580 \\
501 \\
542\end{array}$ & $\begin{array}{l}{ }^{7,662} \\
2,754 \\
2,439\end{array}$ & $\begin{array}{c}20 \\
\mathrm{Tr} .\end{array}$ & $\begin{array}{r}220 \\
1,377 \\
1,082 \\
1,111\end{array}$ & $\begin{array}{l}250 \\
251 \\
252 \\
253\end{array}$ \\
\hline H. & 11,432 & 2.4 & .30 & 166 & 412 & $\cdot 3,548$ & 93 & 894 & 6,249 & Tr. & 2,104 & 254 \\
\hline F. & 77 & 5.7 & .27 & 16 & 2.8 & 8.0 & 50 & 6.2 & 15 & .30 & 49. & 255 \\
\hline H. & 221 & 13 & 6.6 & 64 & .7 & 9.4 & 199 & 2.6 & 13 & Tr. & 163 & 256 \\
\hline
\end{tabular}

$d$ Includes equivalent of small quantity of carbonate $\left(\mathrm{CO}_{3}\right)$.

By turbidity.

- Determined. 


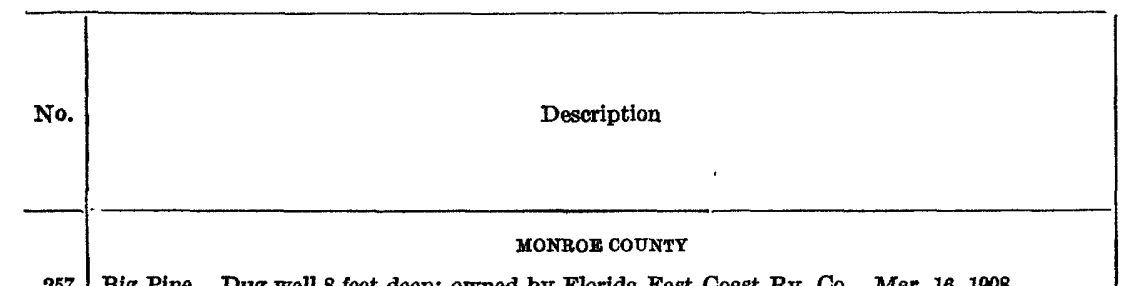

Calculated.

- Includes iron precipitated at time of analysis.

Includes equivalent of small quantity of carbonate $\left(\mathrm{CO}_{3}\right)$.

By turbidity. 


\begin{tabular}{|c|c|c|c|c|c|c|c|c|c|c|c|c|}
\hline \multicolumn{12}{|c|}{ Analyses (parts per million) } & \multirow[b]{2}{*}{ No. } \\
\hline $\begin{array}{l}\text { Ana- } \\
\text { lyst }\end{array}$ & \begin{tabular}{|} 
Total \\
dis- \\
solved \\
solds at \\
$180^{\circ} \mathrm{C}$.
\end{tabular} & $\begin{array}{l}\text { Silica } \\
\left(\mathrm{SiO}_{2}\right)\end{array}$ & $\begin{array}{l}\text { Iron } \\
(\mathbf{F} \text { ) }\end{array}$ & $\begin{array}{l}\text { Cal- } \\
\text { cium } \\
\text { (Ca) }\end{array}$ & $\begin{array}{c}\text { Mag- } \\
\text { ne- } \\
\text { sium } \\
\text { (Mg) }\end{array}$ & \begin{tabular}{|l} 
Sodium \\
and po- \\
tassium \\
(Na+K)
\end{tabular} & $\begin{array}{l}\text { Bicar- } \\
\text { bonate } \\
\text { radicle } \\
\left(\mathrm{HCO}_{3}\right)\end{array}$ & $\begin{array}{c}\text { Sul- } \\
\text { phate } \\
\text { radicle } \\
\text { (SO4) }\end{array}$ & $\begin{array}{c}\text { Chloride } \\
\text { radicle } \\
\text { (Cl) }\end{array}$ & $\begin{array}{l}\text { Nitrate } \\
\text { radicle } \\
\left(\mathrm{NO}_{3}\right)\end{array}$ & $\mid \begin{array}{c}\text { Total } \\
\text { hard- } \\
\text { ness as } \\
\mathrm{CaCO}_{3}{ }^{4}\end{array}$ & \\
\hline D. & $\begin{array}{l}1,042 \\
2,390\end{array}$ & 7.0 & Tr. & 84 & 23 & 269 & ${ }_{280}^{231}$ & 17 & 484 & 0.30 & 304 & 257 \\
\hline$\cdots$ & 30,450 & 36 & ${ }^{2} 0^{\circ}$ & 607 & 1,005 & $-89,344$ & 206 & 2,392 & 16,320 & $\cdots$ & 5,388 & 259 \\
\hline H. & 395 & 22 & Tr. & 73 & 23 & 21 & 234 & 79 & 28 & Tr. & 277 & 260 \\
\hline D. & $\begin{array}{l}414 \\
470\end{array}$ & 35 & .12 & $\begin{array}{l}65 \\
66\end{array}$ & $\begin{array}{l}29 \\
29\end{array}$ & $\begin{array}{r}23 \\
-41\end{array}$ & $\begin{array}{l}191 \\
193\end{array}$ & $\begin{array}{l}126 \\
167\end{array}$ & $\begin{array}{l}26 \\
29\end{array}$ & .32 & $\begin{array}{l}281 \\
284\end{array}$ & $\begin{array}{l}261 \\
262\end{array}$ \\
\hline F. & 496 & 37 & .06 & 73 & 40 & $\begin{cases}\mathrm{Na} & 19 \\
\mathrm{~K} & \mathbf{3 , 2}\end{cases}$ & 194 & 173 & 31 & Tr. & 346 & 263 \\
\hline D. & 286 & 27 & .08 & 62 & 9.5 & {$\left[\begin{array}{ll}10 & 2.2 \\
& 28\end{array}\right.$} & 220 & 18 & 29 & .20 & 194 & 264 \\
\hline F. & 49 & 6.4 & .38 & 7.6 & 4.0 . & $\begin{cases}\mathrm{Na} & \mathbf{2 . 7} \\
\mathbf{K} & .9\end{cases}$ & 35 & 3.4 & 6.5 & Tr. & 35 & 265 \\
\hline H. & 40 & 3.5 & .06 & 2.2 & .5 & 6.9 & 4.9 & 1.1 & 11 & Tr. & 7.6 & 286 \\
\hline H. & 42 & 4.2 & .14 & 1.6 & .5 & 9.4 & 7.3 & 6.7 & 9.0 & Tr. & 6. 2 & 267 \\
\hline D. & 48 & (.....- & .3 & 6 & 1 & • 3.7 & 27 & 3 & 2 & ...... & 10 & 268 \\
\hline F. & $\begin{array}{r}1,300 \\
114\end{array}$ & $\begin{array}{c}19 \\
6.1\end{array}$ & 6.10 & $\begin{array}{l}109 \\
3.2\end{array}$ & $\begin{array}{l}60 \\
3.0\end{array}$ & $\begin{array}{r}285 \\
16\end{array}$ & $\begin{array}{r}125 \\
17\end{array}$ & $\begin{array}{r}235 \\
12\end{array}$ & $\begin{array}{r}532 \\
13\end{array}$ & $\begin{array}{c}.77 \\
\text { Tr. }\end{array}$ & $\begin{array}{r}518 \\
20\end{array}$ & $\begin{array}{l}268 \\
270\end{array}$ \\
\hline D. & 57 & 1.0 & .05 & 4.5 & 2.7 & $\begin{cases}\mathrm{Na} & \mathbf{7 . 2} \\
\mathrm{K} & \mathbf{1 . 4}\end{cases}$ & 13 & 4.3 & 10 & .2 & 22 & 271 \\
\hline н. & 161 & 15 & $\mathbf{b} .39$ & 37 & 11 & 5.7 & 150 & 3.5 & 10 & Tr. & 138 & 272 \\
\hline $\begin{array}{l}\text { H. } \\
\text { H. }\end{array}$ & $\begin{array}{r}129 \\
56 \\
90\end{array}$ & $\begin{array}{r}6.7 \\
1.4 \\
.9\end{array}$ & $\begin{array}{r}6.17 \\
.08 \\
.11\end{array}$ & $\begin{array}{l}18 \\
4.6 \\
15\end{array}$ & $\begin{array}{l}8.3 \\
2.3 \\
2.4\end{array}$ & $\begin{array}{c}11 \\
8.9 \\
9.9\end{array}$ & $\begin{array}{r}89 \\
13 \\
i 35\end{array}$ & $\begin{array}{l}4.5 \\
10 \\
22\end{array}$ & $\begin{array}{l}17 \\
10 \\
9.0\end{array}$ & $\begin{array}{c}1.1 \\
\text { Tr. } \\
\text { Tr. }\end{array}$ & $\begin{array}{l}79 \\
21 \\
47\end{array}$ & $\begin{array}{r}273 \\
274 \\
.275\end{array}$ \\
\hline $\begin{array}{l}\text { H. } \\
\text { H. }\end{array}$ & $\begin{array}{l}178 \\
122 \\
217\end{array}$ & $\begin{array}{l}19 \\
8.0 \\
28\end{array}$ & $\begin{array}{l}.05 \\
.06 \\
\text { Tr. }\end{array}$ & $\begin{array}{l}40 \\
28 \\
43\end{array}$ & $\begin{array}{r}9.7 \\
7.1 \\
16\end{array}$ & $\begin{array}{l}13 \\
4.0 \\
13\end{array}$ & $\begin{array}{l}161 \\
117 \\
178\end{array}$ & $\begin{array}{l}2.3 \\
5.3 \\
2.3\end{array}$ & $\begin{array}{l}13 \\
8.0 \\
23\end{array}$ & $\begin{array}{l}1.0 \\
\text { Tr. } \\
1.5\end{array}$ & $\begin{array}{r}140 \\
99 \\
173\end{array}$ & $\begin{array}{l}276 \\
277 \\
278\end{array}$ \\
\hline н. & 132 & 17 & .06 & 31 & 8.2 & 4.0 & 122 & 1.7 & 7.0 & Tr. & 111 & 279 \\
\hline H. & 148 & 20 & .05 & 30 & 11 & 5.2 & 145 & 1.4 & 7.3 & Tr. & 120 & 280 \\
\hline D. & 40 & 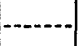 & 1.2 & 4 & 3 & a8.1 & 35 & 3 & 7 & & 22 & 281 \\
\hline D. & $\begin{array}{l}202 \\
181\end{array}$ & 18 & $\begin{array}{l}.3 \\
.05\end{array}$ & $\begin{array}{l}58 \\
45\end{array}$ & $\begin{array}{r}4 \\
12\end{array}$ & $\frac{11}{8.7}$ & $\begin{array}{r}209 \\
174\end{array}$ & $\begin{array}{l}3 \\
2.4\end{array}$ & $\begin{array}{r}8 \\
10\end{array}$ & Tr. & $\begin{array}{l}161 \\
162\end{array}$ & $\begin{array}{l}282 \\
283\end{array}$ \\
\hline H. & 123 & 14 & Tr. & 30 & 5. 9 & 5. 5 & 120 & 3.9 & 5.5 & Tr. & 99 & 284 \\
\hline D. & 131. & 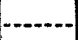 & .1 & 30 & 6 & 11 & $d 137$ & 2 & 6 & . & 100 & 285 \\
\hline H. & 242 & 23 & b 1.0 & 48 & 8.7 & 10 & 142 & 41 & 8.5 & Tr. & 156 & 286 \\
\hline H. & & & .39 & & & & 179 & $f 3$ & 16 & & 174 & 287 \\
\hline 蛋. & $\begin{array}{l}222 \\
560\end{array}$ & $\begin{array}{l}7.6 \\
9.6\end{array}$ & $\begin{array}{l}\text { b. } 1.1 \\
.19\end{array}$ & $\begin{array}{l}64 \\
84\end{array}$ & $1_{16}^{2.4}$ & $\begin{array}{l}11 \\
97\end{array}$ & $\begin{array}{l}189 \\
243\end{array}$ & $\begin{array}{l}14 \\
41\end{array}$ & $\begin{array}{r}16 \\
163\end{array}$ & $\stackrel{.60}{2.2}$ & $\begin{array}{l}170 \\
276\end{array}$ & $\begin{array}{l}288 \\
289\end{array}$ \\
\hline F. & 1,883 & 10 & b. 44 & 264 & 17 & 401 & 249 & 16 & 991 & .28 & 730 & 290 \\
\hline
\end{tabular}

- Determined.

Ineludes iron and aluminum oxides $\left(\mathrm{Fe}_{2} \mathrm{O}_{3}+\mathrm{Al}_{2} \mathrm{O}_{3}\right)$.

Includes equivalent of 12 parts per million of carbonate $\left(\mathrm{CO}_{3}\right)$. 
Ground and surface

\begin{tabular}{|c|c|}
\hline No. & Description \\
\hline & PALM BEACH COUNTY-continued \\
\hline 291 & Boynton. 2-inch drilled well 40 feet deep in $\mathrm{SW}, 1 / 4 \mathrm{sec}$. 34, T. $45 \mathrm{~S}$., R. $43 \mathrm{E}$.; owned by Ward B. \\
\hline 292 & $\begin{array}{l}\text { Delray; municipal supply. 6-inch drilled well } 45 \text { feet deep. Distinct odor of hydrogen sulphide. } \\
\text { Aug. } 23,1923 \text {. }\end{array}$ \\
\hline$\stackrel{293}{294}$ & $\begin{array}{l}\text { Delray; municipal supply. 6-inch drilled well } 63 \text { feet deep. July } 12,1923 \\
\text { Delray (Delray Beach); municipal supply. 2-inch drilled well } 42 \text { feet deep. Distinct odor of } \\
\text { hydrogen sulphide. Aug. 23, } 1923 \text {. }\end{array}$ \\
\hline 295 & 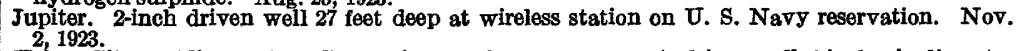 \\
\hline 296 & $\begin{array}{l}\text { Kelsey City; public supply. Composite sample from group of six driven wells } 2 \text { inches in diameter } \\
\text { and } 43 \text { feet deep. Nov, } 2,1923 \text {. }\end{array}$ \\
\hline $\begin{array}{l}297 \\
298\end{array}$ & Pahokee. Lake Okeechobee. Color, 48. Aug. 17, 1923. Lake Okeechobee 3 miles north of Ritter Island; sample taken i foot below surface; \\
\hline 299 & $\begin{array}{l}\text { West Palm Beach. 2-inch driven well } 39 \text { feet deep; owned by Baker Bros. Market, } 323 \text { Clematis } \\
\text { Avenue. Sept. } 7,1923 \text {. }\end{array}$ \\
\hline 300 & $\begin{array}{l}\text { West Palm Beach. } 10 \text {-inch drilled well } 1,080 \text { feet deep; owned by Southern Utilities Co.; flows } \\
1,000 \text { gallons a minute. July } 11,1923 \text {. }\end{array}$ \\
\hline 301 & $\begin{array}{l}\text { West Palm Beach. 2-inch drilled well } 186 \text { feet deep; owned by Deep Rock Mineral Co., Ohmar } \\
\text { Road. July 11, } 1923 \text {. }\end{array}$ \\
\hline $\begin{array}{l}302 \\
303\end{array}$ & $\begin{array}{l}\text { West Palm Beach. Ciear Lake; color, } 144 \text {. Nov. 11, 1924 } \\
\text { West Palm Beach; municipal supply. Lake Mangonea, near canali leading to Clear Lake; raw } \\
\text { water; color, 62. Suspended matter, 0.4. June 24, 1927. }\end{array}$ \\
\hline 304 & $\begin{array}{l}\text { West Palm Beach; municipal supply. Water from No. } 303 \text { after addition of alum and filtration; } \\
\text { color, } 6 \text {. June 25, } 1927 \text {. } \\
\text { PAsco coUNTY }\end{array}$ \\
\hline 305 & $\begin{array}{l}\text { Crystal Springs. Crystal Springs; northeast of Tampa. Flow } 25,000 \text { gallons a minute. July } \\
19,1923 \text {. }\end{array}$ \\
\hline $\begin{array}{l}306 \\
307\end{array}$ & $\begin{array}{l}\text { Dade City; municipal supply. 8-inch drilled well } 100 \text { feet deep. Oct. } 6,1923 \\
\text { Dade City. 6-inch drilled well } 45 \text { feet deep; owned by Muller \& Zinsser; used at ice plant in } 1907 . \\
\text { Nov. 27, } 1907 \text {. }\end{array}$ \\
\hline $\begin{array}{l}308 \\
309\end{array}$ & $\begin{array}{c}\text { Trilby. 10-inch drilled well 31 feet deep; owned by Atlantic Coast Line R. R. Co. Nov. 28, } 1907 . \\
\text { Zephyrhills; municipal supply. 2-inch drilled well } 260 \text { feet deep. Oct. 6, 1923.. } \\
\text { PINELLAs cooNTY }\end{array}$ \\
\hline $\mathbf{3 1 0}$ & $\begin{array}{l}\text { Belleair. 12-inch drilled well } 146 \text { feet deep; owned by Bellview Hotel Co.; test well No. 1. July } \\
28,1924 .\end{array}$ \\
\hline 311 & $\begin{array}{l}\text { Belleair. 2-inch drilled well } 43 \text { feet deep; owned by Bellview Hotel Co.; test well No. 2. July 28, } \\
\text { 1924. }\end{array}$ \\
\hline $\begin{array}{l}312 \\
313 \\
314\end{array}$ & $\begin{array}{l}\text { Clearwater; municipal supply. } 10 \text {-inch drilled well } 190 \text { feet deep; well No. } 6 . \text { Sept. 1, 1923.... } \\
\text { Clearwater; municipal supply. 10-inch drilled well } 165 \text { feet deep; well No. } 7 \text {. Sept } 11923 \\
\text { Clearwater. } 8 \text {-inch drilled well } 204 \text { feet deep; owned by muncipality; known as "Old well." } \\
\text { Sept. 1, 1923. }\end{array}$ \\
\hline $\begin{array}{l}315 \\
316 \\
317\end{array}$ & $\begin{array}{l}\text { Clearwater. 4-inch drilled well } 52 \text { feet deep, at ice plant. Feb. } 28,1908 \\
\text { Dunedin; municipal supply, } 18 \text {-inch drilled well 78 feet deep. Sept. } 1,1923 \\
\text { Olsmar. 6-inch drilled well } 196 \text { feet deep; owned by Olsmar Light \& Development Co. Aug. 19, } \\
\text { 1924. }\end{array}$ \\
\hline 318 & $\begin{array}{l}\text { Safety Harbor. Espiritu Santo Springs. A sample from flowing spring No. } 2 \text { had practically the } \\
\text { same composition. Oct. 16, } 1923 \text {. }\end{array}$ \\
\hline 319 & $\begin{array}{l}\text { Safety Harbor. Drilled well } 11 / 4 \text { inches in diameter and } 296 \text { feet deep in sec. 3, T. } 29 \text { N., R. } 16 \text { E.; } \\
\text { owned by D. M. Pipkin. Oct. 16, } 1923 \text {. }\end{array}$ \\
\hline $\begin{array}{l}320 \\
321 \\
322 \\
323\end{array}$ & $\begin{array}{l}\text { St. Petersburg; municipal supply. 12-inch drilled well } 200 \text { feet deep; well No. 1. Aug. 31, 1923. } \\
\text { St. Petersburg; municipal supply. 12-inch drilled well } 200 \text { feet deep; well No. 3. Aug. 31, 1923. } \\
\text { St. Petersburg; municipal supply, 12-inch drilled well } 200 \text { feet deep; well No. 5. Aug. 31, 1923.- } \\
\text { St. Petersburg. Flowing well 4, inches in diameter and } 216 \text { feet deep; owned by municipality; } \\
\text { known as "Fount of Youth." Nov. 3, 1923. }\end{array}$ \\
\hline $\begin{array}{l}324 \\
325 \\
326\end{array}$ & $\begin{array}{l}\text { St. Petersburg. 3-inch drilled well } 116 \text { feet deep; owned by A. P. Avery. Feb. 7, 1908. } \\
\text { St. Petersburg. 6-inch drilled well } 265 \text { feet deep; owned by Crystal Ice W orks. Feb. 7, 1908..... } \\
\text { St. Petersburg. Drilled well 11/2 inches in diameter and } 40 \text { feet deep in NE. 1/4 sec. 20, T.31 S., R.16 } \\
\text { E.; owred by Pasadena Estates. Jan. 11, 1924. }\end{array}$ \\
\hline 327 & $\begin{array}{l}\text { St. Petersburg. Flowing well } 8 \text { inches in diameter and } 162 \text { foet deep; owned by Pasadena Estates. } \\
\text { Aug. 21, 1923. }\end{array}$ \\
\hline 328 & $\begin{array}{l}\text { St. Petersburg. Flowing well } 8 \text { inches in diameter and } 162 \text { feet deep; owned by Pasadena Estates. } \\
\text { Same as No. 327. Jan. 16, 1925. A sample collected from this well Mar. 6, 1925, had the same } \\
\text { composition. }\end{array}$ \\
\hline 329 & $\begin{array}{l}\text { Tarpon Springs; municipal supply. Composite sample from three 6-inch and two 10-inch drilled } \\
\text { wells } 115 \text { to } 127 \text { feet deep. Sept. } 1,1923 \text {. }\end{array}$ \\
\hline $\begin{array}{l}330 \\
331 \\
332\end{array}$ & $\begin{array}{l}\text { Tarpon Springs. Iake Butler. Color, } 152 \text {. Aug. 19, } 1924 \\
\text { Tarpon Springs. } 6 \text {-inch drilled well } 105 \text { feet deep; well No. } 3 \text { at city waterworks. March, 1608. } \\
\text { Wall Springs. Spring owned by Edgar Wall, Tampa; flows } 800 \text { gallons a minute. Sept. 1, } 1923 .\end{array}$ \\
\hline
\end{tabular}




\begin{tabular}{|c|c|c|c|c|c|c|c|c|c|c|c|c|}
\hline \multicolumn{12}{|c|}{ Analyses (parts per million) } & \multirow[b]{2}{*}{ No. } \\
\hline $\begin{array}{l}\text { Ang- } \\
\text { lyst }\end{array}$ & $\begin{array}{c}\text { Total } \\
\text { dis- } \\
\text { solved } \\
\text { solids at } \\
180^{\circ} \mathrm{C} .\end{array}$ & $\begin{array}{l}\text { Silica } \\
\left(\mathrm{SiO}_{2}\right)\end{array}$ & $\underset{(\mathrm{F} \theta)}{\text { Iron }}$ & $\begin{array}{l}\text { Cal- } \\
\text { cium } \\
(\mathrm{Ca})\end{array}$ & $\begin{array}{c}\text { Mag- } \\
\text { ne- } \\
\text { sium } \\
(\mathrm{Mg})\end{array}$ & $\begin{array}{l}\text { Sodium } \\
\text { and po- } \\
\text { tassium } \\
(\mathrm{Na}+\mathrm{K})\end{array}$ & $\begin{array}{c}\text { Bicar- } \\
\text { bonate } \\
\text { radicle } \\
\left(\mathrm{HCO}_{3}\right)\end{array}$ & $\begin{array}{c}\text { Sul- } \\
\text { phate } \\
\text { radicle } \\
\left(\mathrm{SO}_{4}\right)\end{array}$ & $\begin{array}{c}\text { Chloride } \\
\text { radicle } \\
\text { (Cl) }\end{array}$ & $\begin{array}{l}\text { Nitrate } \\
\text { radicle } \\
\text { (NO3) }\end{array}$ & $\begin{array}{c}\text { Total } \\
\text { hard- } \\
\text { ness as } \\
\mathrm{CaCO}_{3} a\end{array}$ & \\
\hline H. & 644 & 14 & b 1.5 & 145 & 6.7 & 62 & 311 & 110 & 105 & 0.38 & 390 & 291 \\
\hline H. & 224 & 7.8 & B 3.0 & 64 & 2.0 & 15 & 184 & 9.4 & 20 & Tr. & 168 & 292 \\
\hline$\frac{\mathrm{H}}{\mathrm{F}}$ & $\begin{array}{l}235 \\
497\end{array}$ & $\underset{6.6}{23}$ & o. 1.36 & $\begin{array}{l}59 \\
99\end{array}$ & 11.9 & $\begin{array}{l}16 \\
60\end{array}$ & $\begin{array}{l}184 \\
273\end{array}$ & $57^{9.8}$ & $\begin{array}{r}17 \\
101\end{array}$ & $\begin{array}{l}\mathrm{Tr} . \\
.53\end{array}$ & $\begin{array}{l}155 \\
293\end{array}$ & $\begin{array}{l}293 \\
294\end{array}$ \\
\hline F. & 345 & 3.2 & .43 & 37 & 7.7 & 73 & 107 & 15 & 127 & 2.8 & 124 & 295 \\
\hline F. & 157 & 6.1 & .05 & 41 & 3.5 & 9.6 & 113 & 9.9 & 13 & 15 & 117 & 296 \\
\hline F. & 272 & 5.9 & .25 & 37 & 11 & 34 & 128 & 19 & 58 & Tr. & 138 & 297 \\
\hline D. & 183 & 8. 2 & .03 & 31 & 7.0 & $\begin{cases}\mathrm{Na} & 16 \\
\mathrm{~K} & \mathbf{2 . 0}\end{cases}$ & \}$^{d 114}$ & 7.3 & 28 & .1 & 106 & 298 \\
\hline H. & 199 & 6.3 & .08 & 44 & 6.3 & 12 & 93 & 43 & 23 & 2.5 & 136 & 299 \\
\hline H. & 4,740 & 23 & .17 & 140 & 175 & 1,343 & 187 & 449 & 2,345 & 13 & 1,068 & 300 \\
\hline H. & 180 & 13 & $\operatorname{Tr}$. & 41 & 2.3 & 14 & $d 110$ & 30 & 10 & 3. 0 & 112 & 301 \\
\hline H. & 66 & 1.3 & b. 10 & 6.5 & 1.4 & 9.6 & 29 & 2.9 & 13 & Tr. & 22 & 302 \\
\hline F. & 99 & 2.8 & .22 & 14 & 2.8 & $\begin{cases}\mathrm{Na} & 6.7 \\
\mathrm{~K} & 1.0\end{cases}$ & 34 & 6.9 & 18 & .12 & 46 & $303^{\circ}$ \\
\hline F. & 108 & 1.0 & .05 & 17 & 3.7 & $\begin{cases}\mathrm{Na} & 7.6 \\
\mathrm{~K} & 1.6\end{cases}$ & 3.7 & 43 & 18 & 1.0 & 58 & 304 \\
\hline F. & 177 & 14 & .08 & 53 & 5.0 & 3.8 & 168 & 9.3 & 5.5 & .42 & 153 & 305 \\
\hline $\begin{array}{l}\text { T. } \\
\text { D. }\end{array}$ & $\begin{array}{l}149 \\
204\end{array}$ & $\begin{array}{l}16 \\
20\end{array}$ & $\begin{array}{l}.08 \\
\text { Tr. }\end{array}$ & $\begin{array}{l}37 \\
58\end{array}$ & $\begin{array}{l}\text { 5. } 9 \\
4.2\end{array}$ & $\begin{array}{l}5.7 \\
9.1\end{array}$ & $\begin{array}{l}127 \\
191\end{array}$ & $\begin{array}{l}9.2 \\
2.2\end{array}$ & 13 & $\begin{array}{l}3.3 \\
.55\end{array}$ & $\begin{array}{l}117 \\
162\end{array}$ & $\begin{array}{l}306 \\
307\end{array}$ \\
\hline$\underset{\mathbf{F}}{\mathbf{D}}$ & $\begin{array}{l}136 \\
184\end{array}$ & $\begin{array}{l}16 \\
21\end{array}$ & $\begin{array}{l}.49 \\
.18\end{array}$ & $\begin{array}{l}39 \\
46\end{array}$ & $\begin{array}{l}1.2 \\
2.6\end{array}$ & $\begin{array}{l}6.6 \\
8.5\end{array}$ & $\begin{array}{l}113 \\
130\end{array}$ & $\begin{array}{l}2.3 \\
2.8\end{array}$ & 20.4 & $\begin{array}{l}1.6 \\
4.9\end{array}$ & $\begin{array}{l}102 \\
126\end{array}$ & $\begin{array}{l}308 \\
309\end{array}$ \\
\hline H. & 221 & 15 & .08 & 56 & 5.8 & 16 & 204 & 2.1 & 18 & Tr. & 164 & 310 \\
\hline H. & 190 & 40 & .05 & 20 & 7.4 & 9.2 & 67 & 7.4 & 22 & Tr. & 80 & 311 \\
\hline $\begin{array}{l}\text { H. } \\
\text { F. }\end{array}$ & $\begin{array}{r}229 \\
721 \\
1,763\end{array}$ & $\begin{array}{l}22 \\
27 \\
19\end{array}$ & $\begin{array}{l}.13 \\
0.1 .1 \\
b .18\end{array}$ & $\begin{array}{r}53 \\
86 \\
118\end{array}$ & $\begin{array}{l}5.3 \\
18 \\
53\end{array}$ & $\begin{array}{r}16 \\
140 \\
461\end{array}$ & $\begin{array}{l}170 \\
201 \\
178\end{array}$ & $\begin{array}{l}4.4 \\
28 \\
80\end{array}$ & $\begin{array}{r}30 \\
287 \\
915\end{array}$ & $\begin{array}{l}\mathrm{Tr} . \\
.44 \\
.96\end{array}$ & $\begin{array}{l}154 \\
289 \\
512\end{array}$ & $\begin{array}{l}312 \\
313 \\
314\end{array}$ \\
\hline $\begin{array}{l}\text { D. } \\
\text { H. }\end{array}$ & $\begin{array}{r}254 \\
210 \\
1,279\end{array}$ & 20 & $\begin{array}{l}1.3 \\
.12 \\
0.42\end{array}$ & $\begin{array}{r}52 \\
37 \\
155\end{array}$ & $\begin{array}{c}\underset{6}{7.0} \\
23\end{array}$ & $\begin{array}{r}\times 24 \\
16 \\
+246\end{array}$ & $\begin{array}{r}d 228 \\
137 \\
203\end{array}$ & $\begin{array}{r}2 \\
26 \\
54\end{array}$ & $\begin{array}{r}14 \\
19 \\
545\end{array}$ & $\begin{array}{l}2.1 \\
\text { Tr. }\end{array}$ & $\begin{array}{l}155 \\
121 \\
482\end{array}$ & $\begin{array}{l}315 \\
316 \\
317\end{array}$ \\
\hline H. & 3,473 & 14 & .09 & 176 & 108 & 960 & 261 & 232 & 1,775 & Tr. & 883 & 318 \\
\hline F. & 29,779 & 4.4 & b15 & 834 & 1,070 & 8,969 & 281 & 2,374 & 16,422 & 4.2 & 6,472 & 319 \\
\hline $\begin{array}{l}\text { H. } \\
\text { H. } \\
\text { F. }\end{array}$ & $\begin{array}{r}458 \\
483 \\
754 \\
1,086\end{array}$ & 20 & .06 & $\begin{array}{l}106 \\
108 \\
132 \\
215\end{array}$ & $\begin{array}{l}16 \\
11 \\
18 \\
37\end{array}$ & $\begin{array}{r}r 23 \\
34 \\
\times 100 \\
113\end{array}$ & $\begin{array}{l}200 \\
205 \\
214 \\
207\end{array}$ & $\begin{array}{c}f 6 \\
5.7 \\
+10 \\
107\end{array}$ & $\begin{array}{l}150 \\
148 \\
309 \\
458\end{array}$ & 2.9 & $\begin{array}{l}331 \\
315 \\
404 \\
689\end{array}$ & $\begin{array}{l}320 \\
321 \\
322 \\
323\end{array}$ \\
\hline $\begin{array}{l}\text { D. } \\
\text { D. } \\
\text { H. }\end{array}$ & $\begin{array}{l}314 \\
608 \\
684\end{array}$ & 30 & $\begin{array}{l}.2 \\
.05 \\
.59\end{array}$ & $\begin{array}{r}66 \\
112 \\
108\end{array}$ & $\begin{array}{r}8 \\
14 \\
21\end{array}$ & $\begin{array}{r}a 17 \\
a 42 \\
87\end{array}$ & $\begin{array}{r}d 201 \\
d 226 \\
207\end{array}$ & $\begin{array}{r}6 \\
13 \\
21\end{array}$ & $\begin{array}{r}46 \\
163 \\
262\end{array}$ & Tr. & $\begin{array}{l}198 \\
338 \\
356\end{array}$ & $\begin{array}{l}324 \\
325 \\
326\end{array}$ \\
\hline H. & 1,076 & 30 & .12 & 184 & 29 & 127 & 214 & 48 & 454 & 1.0 & 579 & 327 \\
\hline F. & 1,067 & 33 & .01 & 200 & 35 & 126 & 212 & 52 & 490 & & 644 & 328 \\
\hline H. & 854 & 9.0 & .15 & 68 & 25 & 190 & $d 99$ & 57 & 378 & 13 & 272 & 329 \\
\hline $\begin{array}{l}\text { H. } \\
\text { D. }\end{array}$ & $\begin{array}{r}90 \\
279 \\
564\end{array}$ & $\begin{array}{c}1.2 \\
6.1\end{array}$ & $\begin{array}{l}.11 \\
.9 \\
.06\end{array}$ & $\begin{array}{l}3^{5.6} 6 \\
33\end{array}$ & $\begin{array}{l}3.1 \\
7 \\
15\end{array}$ & $\begin{array}{r}14 \\
a 50 \\
148\end{array}$ & $\begin{array}{r}18 \\
886 \\
107\end{array}$ & $\begin{array}{l}3.7 \\
14 \\
38\end{array}$ & $\begin{array}{r}27 \\
91 \\
252\end{array}$ & $\begin{array}{r}\text { Tr. } \\
\text { Tr. }\end{array}$ & $\begin{array}{r}27 \\
104 \\
144\end{array}$ & $\begin{array}{l}330 \\
331 \\
332\end{array}$ \\
\hline
\end{tabular}




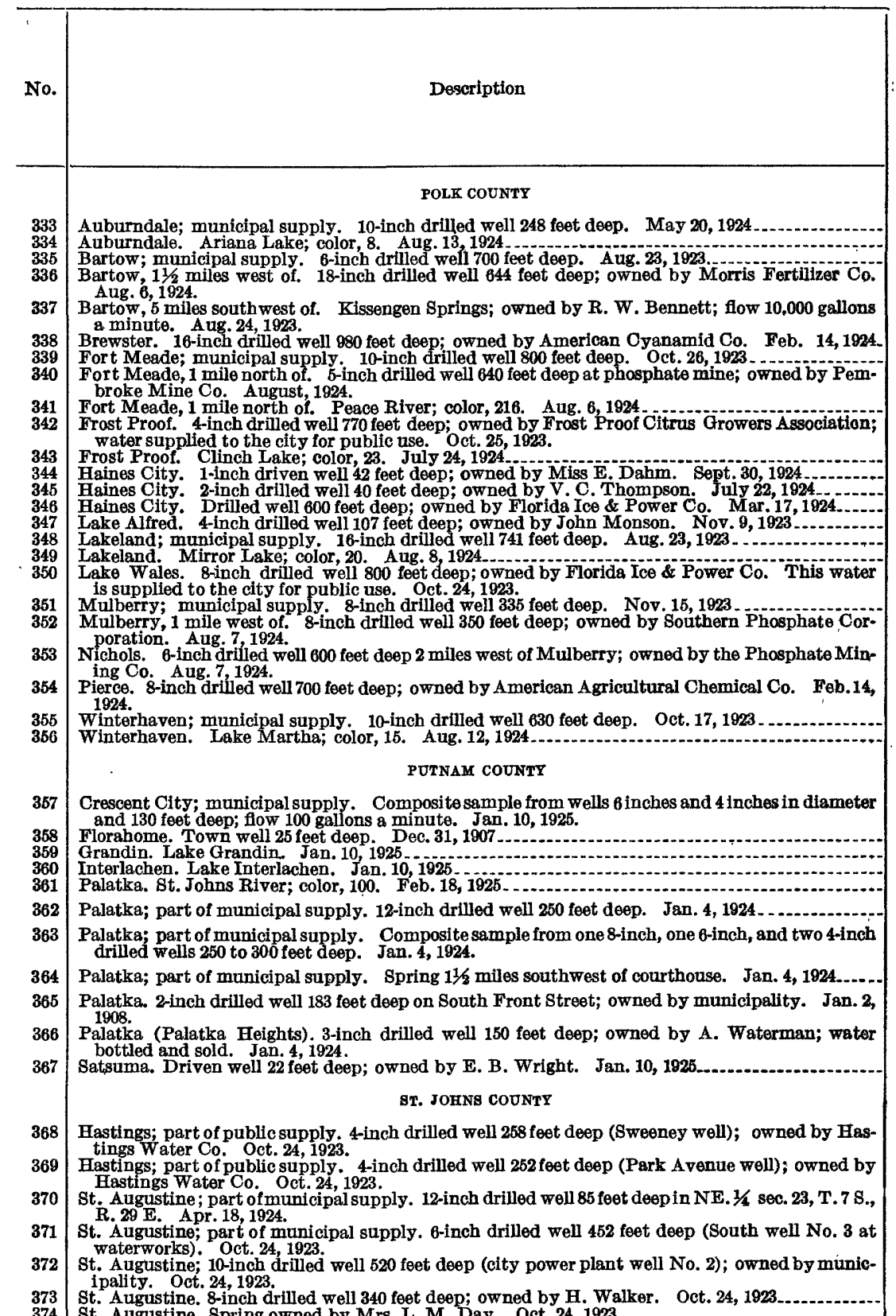

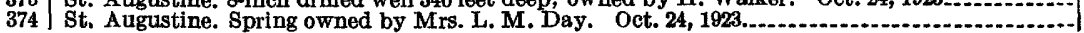

a Calculated.

- Includes fron precipitated at time of analysis.

- Less than 10 parts per million.

Includes equivalent of small quantity of carbonate (COs).

$f$ By turbidity. 
waters of Florida-Continued

\begin{tabular}{|c|c|c|c|c|c|c|c|c|c|c|c|c|}
\hline \multicolumn{12}{|c|}{ Analyses (parts per million) } & \multirow[b]{2}{*}{ No. } \\
\hline $\begin{array}{l}\text { Ans- } \\
\text { lyst }\end{array}$ & $\begin{array}{c}\text { Total } \\
\text { dis- } \\
\text { solved } \\
\text { solids at } \\
180^{\circ} \mathrm{C} .\end{array}$ & $\begin{array}{l}\text { Silica } \\
\left(\mathrm{SiO}_{2}\right)\end{array}$ & $\begin{array}{l}\text { Iron } \\
(\mathrm{Fe})\end{array}$ & $\begin{array}{l}\text { Cal- } \\
\text { cium } \\
\text { (Ca) }\end{array}$ & $\begin{array}{c}\text { Mag: } \\
\text { nes- } \\
\text { ium } \\
(\mathrm{Mg})\end{array}$ & $\begin{array}{l}\text { Sodium } \\
\text { and po- } \\
\text { tassium } \\
(\mathrm{Na}+\mathrm{K})\end{array}$ & $\begin{array}{l}\text { Bicar- } \\
\text { bonate } \\
\text { radicle } \\
\left(\mathrm{HCO}_{3}\right)\end{array}$ & $\begin{array}{c}\text { Sul- } \\
\text { phate } \\
\text { radicle } \\
\left(\mathrm{SO}_{4}\right)\end{array}$ & $\begin{array}{c}\text { Chloride } \\
\text { radicle } \\
\text { (Cl) }\end{array}$ & $\begin{array}{l}\text { Nitrate } \\
\text { radicle } \\
\left(\mathrm{NO}_{3}\right)\end{array}$ & $\begin{array}{c}\text { Total } \\
\text { hard- } \\
\text { ness as } \\
\mathrm{CaCO}^{\circ}\end{array}$ & \\
\hline $\begin{array}{l}\text { H. } \\
\text { H. } \\
\text { H. }\end{array}$ & $\begin{array}{r}132 \\
35 \\
234 \\
169\end{array}$ & $\begin{array}{l}24 \\
2.1 \\
13 \\
12\end{array}$ & $\begin{array}{l}0.06 \\
\text { Tr. } \\
.09 \\
.08\end{array}$ & $\begin{array}{l}26 \\
1.0 \\
51 \\
39\end{array}$ & $\begin{array}{l}7.8 \\
1.4 \\
14 \\
15\end{array}$ & $\begin{array}{r}3.5 \\
6.6 \\
3.6 \\
2.0\end{array}$ & $\begin{array}{l}124 \\
4.9 \\
143 \\
173\end{array}$ & $\begin{array}{c}1.4 \\
3.7 \\
60 \\
9.9\end{array}$ & $\begin{array}{c}6.0 \\
10 \\
8.0 \\
8.0\end{array}$ & $\begin{array}{l}\mathbf{T r} . \\
\mathbf{T r} . \\
\mathbf{T r} \\
\mathbf{T r} .\end{array}$ & $\begin{array}{c}97 \\
8.2 \\
185 \\
159\end{array}$ & $\begin{array}{l}333 \\
334 \\
335 \\
336\end{array}$ \\
\hline F. & 232 & 17 & .06 & 45 & 17 & 4.2 & 131 & 65 & 7.6 & .85 & 182 & 337 \\
\hline $\begin{array}{l}\text { F. } \\
\text { H. }\end{array}$ & $\begin{array}{l}178 \\
201 \\
267\end{array}$ & $\begin{array}{l}18 \\
34\end{array}$ & .15 & $\begin{array}{l}35 \\
40 \\
46\end{array}$ & $\begin{array}{l}17 \\
15 \\
21\end{array}$ & $\begin{array}{l}(c) \\
6.1 \\
\times 21\end{array}$ & $\begin{array}{l}149 \\
154 \\
255\end{array}$ & $\begin{array}{l}24 \\
35 \\
13\end{array}$ & $\begin{array}{r}8.4 \\
7.2 \\
17^{-2}\end{array}$ & Tr. & $\begin{array}{l}157 \\
162 \\
201\end{array}$ & $\begin{array}{l}338 \\
339 \\
340\end{array}$ \\
\hline$\frac{\mathrm{H}}{\mathrm{F}}$. & 80 & 7.8 & .00 & $\begin{array}{c}9.4 \\
44\end{array}$ & 16.2 & 6.3 & $\begin{array}{r}37 \\
193\end{array}$ & $\begin{array}{l}4.9 \\
2.1\end{array}$ & $\begin{array}{l}6.0 \\
8.8\end{array}$ & $\begin{array}{l}\mathrm{Tr} . \\
.75\end{array}$ & $\begin{array}{r}37 \\
176\end{array}$ & $\begin{array}{l}341 \\
342\end{array}$ \\
\hline $\begin{array}{l}\text { H. } \\
\text { H. }\end{array}$ & $\begin{array}{l}30 \\
99 \\
53\end{array}$ & $\begin{array}{l}1.0 \\
3.6\end{array}$ & $\begin{array}{l}.04 \\
.13\end{array}$ & $1_{11}^{2,6}$ & $\begin{array}{l}1.2 \\
2.8\end{array}$ & $1^{5.0}$ & $\begin{array}{r}8.5 \\
3.7 \\
17\end{array}$ & $\begin{array}{l}3.0 \\
4^{4}\end{array}$ & $\begin{array}{l}8.0 \\
8.0 \\
5.0\end{array}$ & $\begin{array}{l}\text { Tr. } \\
8.3 \\
4.6\end{array}$ & $\begin{array}{r}11 \\
39 \\
-10\end{array}$ & $\begin{array}{l}343 \\
344 \\
345\end{array}$ \\
\hline $\begin{array}{l}\text { H. } \\
\text { H. } \\
\text { H. } \\
\text { F. }\end{array}$ & $\begin{array}{r}192 \\
78 \\
199 \\
178 \\
160\end{array}$ & $\begin{array}{l}12 \\
16 \\
24 \\
1.0 \\
19\end{array}$ & $\begin{array}{r}.09 \\
.17 \\
.08 \\
.11 \\
.13\end{array}$ & $\begin{array}{l}51 \\
11 \\
41 \\
29 \\
38\end{array}$ & $\begin{array}{r}4 \\
5 \\
15 \\
9 \\
91 \\
12\end{array}$ & $\begin{array}{c}13 \\
5.9 \\
8.0 \\
24 \\
2.8\end{array}$ & $\begin{array}{r}189 \\
60 \\
199 \\
128 \\
160\end{array}$ & $\begin{array}{l}3.5 \\
2.9 \\
2.8 \\
4.8 \\
3.2\end{array}$ & $\begin{array}{c}12 \\
7.0 \\
7.0 \\
36 \\
6.2\end{array}$ & $\begin{array}{l}\text { Tr. } \\
\text { Tr. } \\
1,2 \\
\text { Tr. } \\
.71\end{array}$ & $\begin{array}{r}146 \\
49 \\
164 \\
110 \\
144\end{array}$ & $\begin{array}{l}346 \\
347 \\
348 \\
349 \\
\mathbf{3 5 0}\end{array}$ \\
\hline H. & $\begin{array}{l}191 \\
141\end{array}$ & $\begin{array}{l}22 \\
23\end{array}$ & $\begin{array}{l}.10 \\
.06\end{array}$ & $\begin{array}{l}43 \\
31\end{array}$ & $\begin{array}{l}12 ! \\
12\end{array}$ & $\stackrel{10}{10}$ & $\begin{array}{l}183 \\
142\end{array}$ & $\begin{array}{l}5.5 \\
2.6\end{array}$ & $\begin{array}{c}15 \\
7.0\end{array}$ & $\begin{array}{l}\text { Tr. } \\
\text { Tr. }\end{array}$ & $\begin{array}{l}157 \\
127\end{array}$ & $\begin{array}{l}351 \\
352\end{array}$ \\
\hline H. & 222 & 28 & .19 & 42 & $13^{k}$ & a 19 & 214 & 6.4 & 13 & Tr. & 158 & 363 \\
\hline F. & 187 & -5 & $\ldots$ & 41 & 134 & $\cdot 3.8$ & 149 & 33 & 5.4 & & 156 & 354 \\
\hline H. & $\begin{array}{r}148 \\
36\end{array}$ & $\stackrel{19}{1.6}$ & $\begin{array}{l}\text { b. } 70 \\
\text { Tr. }\end{array}$ & $\begin{array}{l}39 \\
1.4\end{array}$ & $\begin{array}{l}5.2 \\
1.4\end{array}$ & $\begin{array}{l}6.3 \\
7.9\end{array}$ & $\begin{array}{r}139 \\
8.5\end{array}$ & $\begin{array}{l}2.8 \\
\text { 5. } 1\end{array}$ & $11^{6.0}$ & $\begin{array}{l}\text { Tr. } \\
\text { Tr. }\end{array}$ & $\begin{array}{c}119 \\
9.2\end{array}$ & $\begin{array}{l}355 \\
356\end{array}$ \\
\hline H. & 171 & 11 & .08 & 40 & 6.8 & 14 & 150 & 3.4 & 24 & Tr. & 128 & 357 \\
\hline $\begin{array}{l}\mathbf{D} . \\
\text { H. } \\
\text { F. }\end{array}$ & \begin{tabular}{r|}
55 \\
35 \\
19 \\
394
\end{tabular} & $\begin{array}{r}1.1 \\
7.7\end{array}$ & $\begin{array}{l}3.3 \\
.03 \\
.03 \\
.21\end{array}$ & $\begin{array}{c}3 \\
1.5 \\
1.0 \\
30\end{array}$ & $\begin{array}{l}1 \\
1.4 \\
1.0 \\
13:\end{array}$ & $\begin{array}{c}\times 3 \\
8.3 \\
5.0 \\
85\end{array}$ & $\begin{array}{l}18 \\
15 \\
6.1 \\
52\end{array}$ & $\begin{array}{c}2 \\
5.5 \\
3.9 \\
39\end{array}$ & $\begin{array}{r}6 \\
7.8 \\
6.1 \\
165\end{array}$ & $\begin{array}{l}\mathrm{Tr} . \\
\mathrm{Tr} . \\
.64\end{array}$ & $\begin{array}{c}12 \\
9.5 \\
6.6 \\
128\end{array}$ & $\begin{array}{l}\mathbf{3 5 8} \\
\mathbf{3 5 9} \\
\mathbf{3 6 0} \\
\mathbf{3 6 1}\end{array}$ \\
\hline H. & 532 & 12 . & .07 & 62 & 28 & $\left\{\begin{array}{l}\mathrm{Na} \\
\mathrm{K}\end{array}\right.$ & 140 & 62 & 174 & Tr. & 270 & 362 \\
\hline ㅍ.ᅭ. & 526 & $-\ldots$ & .07 & 68 & 28 & a 68 & 132 & 69 & 162 & Tr. & 260 & 363 \\
\hline H. & 34 & 9.1 & .04 & 6. 2 & 1.6 & $\begin{cases}\mathrm{Na} & 3.3 \\
\mathrm{~K} & 1.8\end{cases}$ & 11 & 4.0 & 9.0 & $\mathrm{Tr}$. & 20 & 364 \\
\hline D. & 462 & 17 & .06 & 66 & 18 & 56 & $d 149$ & 54 & 136 & .40 & 239 & 365 \\
\hline H. & 111 & 11 & .06 & 27 & 2.0 & $\begin{cases}\mathrm{Na} & 6.5 \\
\mathbf{K} & 1.3\end{cases}$ & 85 & 14 & 7.0 & Tr. & 76 & 366 \\
\hline H. & 58 & 2.6 & 1.1 & 3.1 & 5. & 7.0 & 18 & 12 & 10 & 1.8 & 29 & 367 \\
\hline H. & 1,388 & 21 & 12.4 & 166 & $93:$ & 91 & 109 & 616 & 181 & Tr. & 794 & 308 \\
\hline H. & 1,422 & 21 & $k 26$ & 173 & $88^{i}$ & 106 & 117 & 651 & 205 & Tr. & 834 & 360 \\
\hline H. & 472 & 12 & .38 & 137 & 3.0 & 28 & 423 & 2.0 & 42 & Tr. & 355 & 370 \\
\hline H. & 987 & 28 & 1.48 & 116 & 62 & 69 & 152 & 351 & 154 & $\operatorname{Tr}$. & 544 & 371 \\
\hline H. & 1,780 & 27 & .11 & 143 & 87 & 302 & 162 & 361 & 635 & Tr. & 714 & 372 \\
\hline $\begin{array}{l}\text { H. } \\
\text { H. }\end{array}$ & $\begin{array}{l}791 \\
434\end{array}$ & $\begin{array}{l}27 \\
11\end{array}$ & $\begin{array}{l}.07 \\
.08\end{array}$ & $\begin{array}{l}103 \\
113\end{array}$ & $\begin{array}{l}57 \\
22\end{array}$ & $\begin{array}{l}47 \\
17\end{array}$ & $\begin{array}{l}150 \\
415\end{array}$ & $\begin{array}{r}347 \\
37\end{array}$ & $\begin{array}{l}70 \\
19\end{array}$ & $\begin{array}{l}\text { Tr. } \\
\text { Tr. }\end{array}$ & $\begin{array}{l}491 \\
373\end{array}$ & $\begin{array}{l}373 \\
374\end{array}$ \\
\hline
\end{tabular}

- Determined.

1 Includes 2.3 parts per million precipitat d as sulphide at time of analysis.

* Includes 0.1 part per million of tron in solution at time of analysis and 26 parts per million precipitated as iron sulphide.

IPrecipitated as iron sulphide at time of analysis. 


\begin{tabular}{|c|c|}
\hline No. & Description \\
\hline & ST. LUCIE COUNTY \\
\hline 375 & $\begin{array}{l}\text { Fort Pierce. Driven well } 2 \frac{1}{2} \text { inches in diameter and } 32 \text { feet deep; owned by municipality. July } \\
10,1923 \text {. }\end{array}$ \\
\hline 376 & $\begin{array}{l}\text { Fort Pierce; municipal supply. 8-inch drilled well } 800 \text { feet deep; flows } 200 \text { gallons a minute. July } \\
\text { 10, } 1923 \text {. }\end{array}$ \\
\hline 377 & Fort Pierce. 4-inch drilled well 750 feet deep; owned by S. H. Hale, Kansas City, Mo., flows 220 \\
\hline 378 & $\begin{array}{l}\text { Fort Pierce. Driven well } 11 / \text { inches in diameter and } 12 \text { feet deep; owned by Fee \& Stuart; typical } \\
\text { shallow well. Jan. 17, } 1908 \text {. }\end{array}$ \\
\hline $\begin{array}{l}379 \\
380\end{array}$ & $\begin{array}{l}\text { Fort Pierce. Taylor Creek. Slight yellow color. July 10, 1923. } \\
\text { Fort Pierce, } 3 \text { miles south of. Driven well } 1 \frac{1}{4} \text { inches in diameter and } 32 \text { feet deep; owned by Egret }\end{array}$ \\
\hline
\end{tabular}

\section{SANTA ROSA COUNTY}

Bagdad. 8-inch drilled well 168 feet deep in SE. 1/4 sec. 10, T. 1 N., R. 28 W., owned by Bagdad Land \& Lumber Co. Apr. 7, 1924.

Bagdad. Driven well $1 \frac{1}{2}$ inches in diameter and 30 feet deep; owned by J. C. McArthur. Dec. 14, 1907.

Bagdad. Drilled well 1\%1/4 inches in diameter and 74 feet deep; owned by Charles Summers. Dec. 14, 1907.

Milton; municipal supply. 4-inch drilled well 125 feet deep. Apr. 7, 1924.

\section{SARASOTA COUNTY}

Sarasota; municipal supply. Drilled wells, one 4-inch and two 6-inch, 400 feet deep; water level 8 feet above surface. Aug. 28, 1923 .

Sarasota. Flowing well 6 inches in diameter and 470 feet deepincenter of Banana Avenue; piped to side of road; owned by J. C. Brown. Aug. 28, 1923.

Sarasota. 4-inch drilled well 200 tyet deep; owned by S. H. Highsmith. Aug. 28, 1923.

Sarasota. 2-inch drilled well 80 feet deep; owned by L. W. Pickett; water level 3 feet above surface. Aug. 28, 1923 .

Sarasota. 8-inch drilled well 640 feet deep; owned by Sarasota Ice \& Cold Storage Co.; flows 450 gallons a minute; water used only for cooling. Aug. 28, 1923.

Sarasota. 4-inch drilled well 303 feet deep; owned by J. B. Turner; flows 200 gallons a minute. Aug. 28, 1923 .

Venice. 8-inch drilled well (No. 4) 405 feet deep in N. 1/2 SE. 1/4 sec. 7, T. 39 S., R. 19 E., owned by B. L. E. Realty Corporation. Mar. 5, 1927.

Venice. 6-inch drilled well about 460 feet deep in NW.1/4 sec. 10, T. 29 S., R. 19 E., owned by C. A. McKenney, Washington, D. C. Mar. 5, 1927.

\section{SEMTNOLE COUNTY}

Altamonte Springs. Lake Orienda in rear of residence of F. P. Waterhouse. Mar. 8, 1924

Lake Mary; public supply. 2-inch drilled well 125 feet deep; owned by A. E. Sjoblom. July 30, 1923 .

Lake Monroe. 4-inch drilled well 150 feet deep; owned by F. H. Black. Nov. 10, 1923

Sanford; part of public supply. 10-inch drilled well 435 feet deep; at small ice plant; owned by Southern Utilities Co.; flows 100 gallons a minute. July 30, 1923.

Sanford; part of public supply. 10-inch drilled well 452 feet deep; at ice and water plant; .owned by Southern Utilities Co.; flows 200 gallons a minute. July $30,1923$.

Sanford, 2 miles west of, on Dixie Highway. 2-inch drilled well 94 feet deep; owned by A. P. Connelly; water level 10 feet above ground. July 30, 1923.

Sanford, $51 / 2$ miles south of, on Oriando Road; spring owned by T. A. Frazer. July 30, 1923

Sanford, south of. 2-inch drilled well 194 feet deep at 7-mile post on Dixie Highway; owned by J. M. Scaucer. Nov, 10, 1923.

\section{SUMTER COUNTY}

Bushnell; public supply. 4-inch drilled well 540 feet deep. Apr. 25, 1924

Bushnell. Drilled well 11/2 inches in diameter and 70 feet deep; owned by Standard Oil Co., used by general public. Apr. 25, 1924.

Bushnell. Driven well $1 \frac{1}{2}$ Inches in diameter and 50 feet deep; owned by Mrs. S. M. Wall. Apr. 25, 1924.

Sumterville. Drilled well 45 feet deep; owned by F. T. Knight. Apr. 25, 1924

Sumterville. Driven well $11 / 4$ inches in diameter and 62 feet deep; owned by J. T. Williams. Apr. 25, 1924 .

- Calculated.

- Includes iron precipitated at time of analysis. 


\begin{tabular}{|c|c|c|c|c|c|c|c|c|c|c|c|c|}
\hline \multicolumn{12}{|c|}{ Analyses (parts per million) } & \multirow[b]{2}{*}{ No. } \\
\hline $\begin{array}{l}\text { Ang- } \\
\text { lyst }\end{array}$ & $\begin{array}{c}\text { Total } \\
\text { dis- } \\
\text { solved } \\
\text { solids at } \\
180^{\circ} \mathrm{C} .\end{array}$ & $\begin{array}{l}\text { Silica } \\
\left(\mathrm{SiO}_{2}\right)\end{array}$ & $\begin{array}{l}\text { Iron } \\
(\mathrm{Fe})\end{array}$ & $\begin{array}{c}\text { Cal- } \\
\text { cium } \\
\text { (Ca) }\end{array}$ & $\begin{array}{c}\text { Mag- } \\
\text { ner } \\
\text { sium } \\
(\mathrm{Mg})\end{array}$ & $\begin{array}{l}\text { Sodium } \\
\text { and po- } \\
\text { tassium } \\
\text { (Na+K) }\end{array}$ & $\begin{array}{l}\text { Bicar- } \\
\text { bonate } \\
\text { radicle } \\
\left(\mathrm{HCO}_{3}\right)\end{array}$ & $\begin{array}{c}\text { Sul- } \\
\text { phate } \\
\text { radicle } \\
\left(\mathrm{SO}_{4}\right)\end{array}$ & $\begin{array}{l}\text { Chloride } \\
\text { radicle } \\
\text { (Cl) }\end{array}$ & $\begin{array}{c}\text { Nitrate } \\
\text { radicle } \\
\left(\mathrm{NO}_{3}\right)\end{array}$ & $\begin{array}{c}\text { Total } \\
\text { hard- } \\
\text { noss as } \\
\text { CaCOQ }\end{array}$ & \\
\hline H. & 159 & 7.2 & 0.37 & 13 & 3.1 & 36 & 17 & 27 & 54 & 0.52 & 45 & 375 \\
\hline R. & 1,355 & 26 & .20 & 51 & 50 & 368 & 255 & 296 & 434 & 2.1 & 332 & 376 \\
\hline H. & 1,480 & 26 & .09 & 44 & 40 & 409 & 259 & 425 & 375 & Tr. & 274 & 377 \\
\hline D. & 362 & 4.0 & .12 & 18 & 5.6 & 91 & 18 & 58 & 94 & 40 & 68 & 378 \\
\hline 昔. & $\begin{array}{r}134 \\
63\end{array}$ & $\begin{array}{l}9.0 \\
3.2\end{array}$ & .14 & $\begin{array}{l}18 \\
4.6\end{array}$ & $\begin{array}{l}2.2 \\
1.8\end{array}$ & $\begin{array}{l}9.4 \\
9.1\end{array}$ & $\begin{array}{c}52 \\
4.9\end{array}$ & $\begin{array}{l}8.9 \\
8.9\end{array}$ & $\begin{array}{l}16 \\
12\end{array}$ & .50 & $\begin{array}{l}54 \\
19\end{array}$ & $\begin{array}{l}379 \\
380\end{array}$ \\
\hline H. & 26 & 6.3 & .08 & 1.8 & .4 & 4.9 & 2.4 & 2.8 & 6.0 & 1.0 & 6.1 & 381 \\
\hline D. & 84 & -..--. & 2.0 & 12 & 2 & $a 63$ & $₫ 200$ & 6 & B & 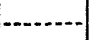 & 38 & 382 \\
\hline D. & 34 & ............ & Tr. & 5 & 2 & $a 2.8$ & 19 & 5 & 4 & $\ldots$ & 20 & 383 \\
\hline F. & 19 & 4.4 & .02 & .8 & .7 & $\left|\begin{array}{ll}\mathrm{Na} & 1.5 \\
\mathrm{~K} & .4\end{array}\right|$ & 4.4 & 1.0 & 2.4 & Tr. & 4.9 & 384 \\
\hline H. & 1,063 & 28 & .11 & 124 & 60 & 110 & 183 & 398 & 157 & .41 & 656 & 385 \\
\hline F. & 1,677 & 24 & .21 & 250 & 116 & 89 & 165 & 868 & 177 & Tr. & 1,101 & 386 \\
\hline F. & $\begin{array}{l}497 \\
478\end{array}$ & $\begin{array}{l}35 \\
22\end{array}$ & .10 & $\begin{array}{l}42 \\
72\end{array}$ & $\begin{array}{l}26 \\
27\end{array}$ & $\begin{array}{l}90 \\
56\end{array}$ & $\begin{array}{l}241 \\
282\end{array}$ & $\begin{array}{r}126 \\
52\end{array}$ & $\begin{array}{l}53 \\
86\end{array}$ & $\begin{array}{l}\operatorname{Tr} \\
.64\end{array}$ & $\begin{array}{l}212 \\
201\end{array}$ & $\begin{array}{l}387 \\
388\end{array}$ \\
\hline F. & 1,997 & 23 & .23 & 285 & 128 & 152 & $155^{\circ}$ & 924 & 341 & Tr. & 1,237 & 389 \\
\hline F. & 804 & 36 & .09 & 75 & 63 & 78 & 204 & 310 & 91 & Tr. & 446 & 300 \\
\hline F. & 2,436 & 24 & .13 & 389 & 151 & 98 & 154 & 1,321 & 194 & .12 & 1,592 & 391 \\
\hline F. & 2,464 & -...-. & 2.6 & 396 & 159 & $a 49$ & 162 & 1,340 & 157 & .10 & 1,642 & 302 \\
\hline ㅍ. & 47 & 1.6 & .02 & $\mathbf{3 . 0}$ & 1.6 & $\left\{\begin{array}{ll}\mathrm{Na} & 9.9 \\
\mathrm{~K} & .8\end{array} \mid\right.$ & 0.8 & 15 & 10 & Tr. & 14 & 393 \\
\hline F. & 129 & 19 & .18 & 33 & 5.7 & 3.1 & 122 & 1.9 & 4.4. & Tr. & 106 & 394 \\
\hline $\begin{array}{l}\text { H. } \\
\text { F. }\end{array}$ & $\begin{array}{r}286 \\
1,039\end{array}$ & 6.8 & .4 .8 & $\begin{array}{l}49 \\
40\end{array}$ & $\begin{array}{l}10 \\
45\end{array}$ & $\begin{array}{l}a 30 \\
289\end{array}$ & ${ }_{63}^{d 161}$ & $\begin{array}{l}12 \\
53\end{array}$ & $\begin{array}{r}59 \\
565\end{array}$ & $\begin{array}{l}\text { Tr. } \\
\text { Tr. }\end{array}$ & $\begin{array}{l}164 \\
224\end{array}$ & $\begin{array}{l}395 \\
396\end{array}$ \\
\hline F. & 990 & 16 & .12 & 80 & 39 & 226 & 142 & 104 & 448 & Tr. & 360 & 397 \\
\hline F. & 172 & 18 & .12 & 46 & 5.0 & 6.1 & 156 & 2.6 & 11 & Tr. & 136 & 398 \\
\hline F. & $\begin{array}{r}74 \\
194\end{array}$ & 15 & .05 & $\frac{11}{45}$ & $\begin{array}{l}2.4 \\
8.5\end{array}$ & $\begin{array}{r}5.0 \\
\times 6.7\end{array}$ & $\begin{array}{r}33 \\
167\end{array}$ & $\begin{array}{l}3.1 \\
6.3\end{array}$ & ${ }_{13}^{7.4}$ & Tr. & $\begin{array}{l}37 \\
147\end{array}$ & $\begin{array}{l}399 \\
400\end{array}$ \\
\hline Н. & 204 & 11 & .30 & 65 & .4 & $\begin{cases}\mathrm{Na} & 5.1 \\
\mathrm{~K} & .2\end{cases}$ & 212 & 1.9 & 2.4 & .73 & 164 & 401 \\
\hline H. & 197 & 7.8 & 3.0 & 61 & .7 & $\begin{cases}\mathrm{Na} & 6.2 \\
\mathrm{~K} & .3\end{cases}$ & 182 & 6.9 & 11 & 1.7 & 155 & 402 \\
\hline H. & 213 & 7.8 & .10 & 62 & .5 & $\begin{cases}\mathrm{Na} & 3.3 \\
\mathbf{K} & 1.1\end{cases}$ & 171 & 6.2 & 18 & 8.6 & 157 & 403 \\
\hline H. & 209 & 6.5 & .09 & 70 & .4 & $\left|\begin{array}{ll}\mathrm{Na} & 9.0 \\
\mathrm{~K} & 1.6\end{array}\right|$ & 216 & 4.1 & 9.0 & .38 & 177 & 404 \\
\hline H. & 186 & 7.2 & .80 & 69 & .3 & $\mid\left\{\begin{array}{ll}\mathrm{Na} & \mathbf{3 . 0} \\
\mathbf{K} & .6\end{array} \mid\right.$ & 204 & 1.8 & 8.0 & Tr. & 174 & 405 \\
\hline
\end{tabular}

d Inclqdes equivalent of small quantity of carbonate $\left(\mathrm{CO}_{3}\right)$. 


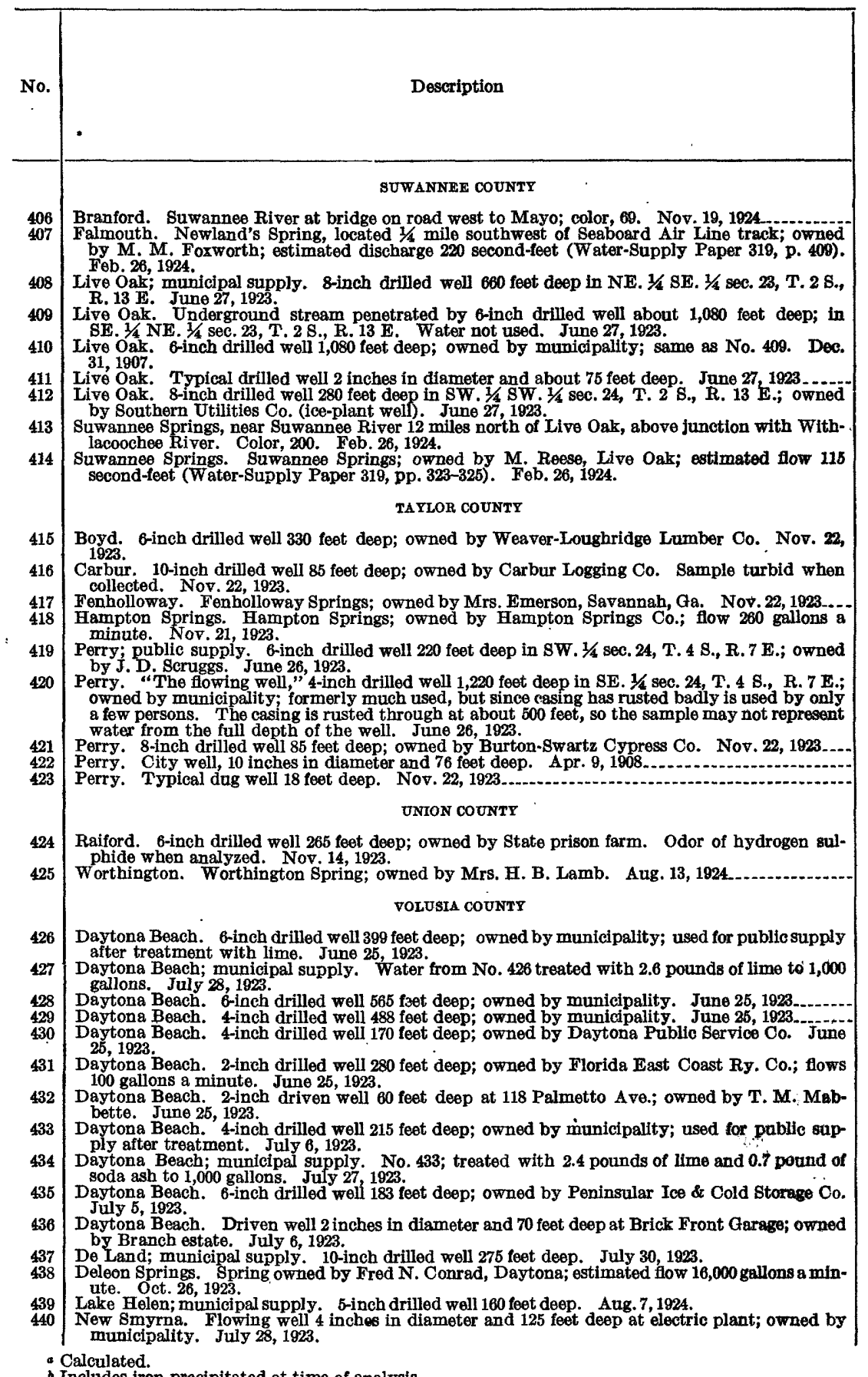

Includes iron precipitated at time of analysis. 


\begin{tabular}{|c|c|c|c|c|c|c|c|c|c|c|c|c|}
\hline \multicolumn{12}{|c|}{ Analyses (parts per million) } & \multirow[b]{2}{*}{ No. } \\
\hline $\begin{array}{l}\text { Ans- } \\
\text { lyst }\end{array}$ & $\begin{array}{c}\text { Total } \\
\text { dis- } \\
\text { solved } \\
\text { solids at } \\
180^{\circ} \mathrm{C} .\end{array}$ & $\begin{array}{l}\text { Silica } \\
\left(\mathrm{SiO}_{2}\right)\end{array}$ & $\begin{array}{l}\text { Iron } \\
(\mathrm{Fe})\end{array}$ & $\underset{\text { cium }}{\text { Cal- }}$ & $\begin{array}{c}\text { Mag- } \\
\text { ne- } \\
\text { sium } \\
(\mathrm{Mg})\end{array}$ & $\begin{array}{l}\text { Sodium } \\
\text { and po- } \\
\text { tassium } \\
(\mathrm{Na}+\mathrm{K})\end{array}$ & $\begin{array}{l}\text { Bicar- } \\
\text { bonate } \\
\text { radicle } \\
\left(\mathrm{HCO}_{3}\right)\end{array}$ & $\begin{array}{c}\text { Sul- } \\
\text { phate } \\
\text { radicle } \\
\left(\mathrm{SO}_{4}\right)\end{array}$ & $\begin{array}{l}\text { Chloride } \\
\text { radicle } \\
\text { (Cl) }\end{array}$ & $\begin{array}{l}\text { Nitrate } \\
\text { radicle } \\
(\mathrm{NO})\end{array}$ & $\begin{array}{c}\text { Total } \\
\text { hard- } \\
\text { ness as } \\
\text { CaCOaf }\end{array}$ & \\
\hline H. & 151 & 7.6 & 0.05 & 40 & 3. 9 & 4.7 & 129 & 10 & 3.0 & $\mathbf{T r}$ & 116 & 406 \\
\hline H. & 218 & 6.1 & .04 & 65 & 9.2 & $\left\{\begin{array}{lr}\mathrm{Na} & 3.1 \\
\mathrm{~K} & .4\end{array}\right.$ & 228 & 9.5 & 4.0 & Tr. & 200 & 407 \\
\hline H. & 220 & 16 & .20 & 68 & 6. 2 & 6.1 & 224 & 8.5 & 5.0 & Tr. & 195 & 408 \\
\hline H. & 257 & 16 & 3.0 & 75 & 6.4 & 9.2 & 234 & 8.5 & 10 & 2.4 & 214 & 400 \\
\hline D. & 219 & 17 & .04 & 68 & 5.7 & 7.2 & 224 & 8.9 & 3.9 & .6 & 198 & 410 \\
\hline $\begin{array}{l}\mathbf{R} . \\
\mathbf{R} \text {. }\end{array}$ & $\begin{array}{l}280 \\
338\end{array}$ & $\begin{array}{l}16 \\
18\end{array}$ & .24 & $\begin{array}{l}85 \\
84\end{array}$ & ${ }_{12}^{5.2}$ & $21^{6.3}$ & $\begin{array}{l}278 \\
239\end{array}$ & $\begin{array}{l}12 \\
12\end{array}$ & $\begin{array}{c}8.0 \\
60^{\circ}\end{array}$ & $\begin{array}{l}1.5 \\
\text { Tr. }\end{array}$ & $\begin{array}{l}284 \\
259\end{array}$ & $\begin{array}{l}411 \\
412\end{array}$ \\
\hline H. & 116 & 8.2 & .02 & 18 & 5.3 & 0.8 & 61 & 9.0 & 8.0 & Tr. & 67 & 413 \\
\hline $\mathbf{H}$. & 220 & 14 & .16 & 53 & 12 & $\begin{cases}\mathrm{Na} & 5.5 \\
\mathrm{~K} & .6\end{cases}$ & 185 & 27 & 7.0 & Tr. & 182 & 414 \\
\hline H. & 238 & 8.1 & $b 1.2$ & 59 & 20 & 4.6 & 272 & 2.8 & 5.0 & Tr. & 230 & 415 \\
\hline H. & 323 & 9.4 & $b 1.4$ & 76 & 17 & 19 & 285 & 7.5 & 35 & Tr. & 260 & 416 \\
\hline $\begin{array}{l}\text { F. } \\
\text { H. }\end{array}$ & $\begin{array}{l}348 \\
914\end{array}$ & 15.4 & $\begin{array}{l}.08 \\
.10\end{array}$ & $\begin{array}{r}81 \\
162\end{array}$ & $\begin{array}{l}29 \\
72\end{array}$ & $\begin{array}{l}1.4 \\
6.6\end{array}$ & $\begin{array}{l}289 \\
294\end{array}$ & $\begin{array}{r}72 \\
440\end{array}$ & $10^{6.0}$ & $\begin{array}{l}\text { Tr. } \\
\text { Tr. }\end{array}$ & $\begin{array}{l}321 \\
700\end{array}$ & $\begin{array}{l}417 \\
418\end{array}$ \\
\hline R. & 215 & 12 & .17 & 48 & 14 & 16 & 195 & 4.9 & 22 & 3. 0 & 177 & 419 \\
\hline R. & 1,074 & 19 & 3.0 & 166 & 75 & 67 & 315 & 418 & 96 & 1.7 & 722 & 420 \\
\hline $\begin{array}{l}\text { H. } \\
\text { D. }\end{array}$ & $\begin{array}{l}155 \\
158 \\
201\end{array}$ & $\begin{array}{l}11 \\
7.6 \\
3.6\end{array}$ & $\begin{array}{r}.10 \\
.06 \\
.41\end{array}$ & $\begin{array}{l}34 \\
36 \\
11\end{array}$ & $\begin{array}{l}15 \\
13 \\
7.1\end{array}$ & $\begin{array}{r}5.7 \\
9.4 \\
42\end{array}$ & $\begin{array}{r}173 \\
164 \\
11\end{array}$ & $\begin{array}{r}5.9 \\
3.8 \\
13\end{array}$ & $\begin{array}{r}3.8 \\
4.2 \\
17\end{array}$ & $110^{.45}$ & $\begin{array}{r}146 \\
143 \\
57\end{array}$ & $\begin{array}{l}421 \\
422 \\
423\end{array}$ \\
\hline H. & 247 & 43 & .00 & 52 & 18 & 6.5 & 246 & 3. 7 & $\mathbf{2 . 0}$ & Tr. & 204 & 424 \\
\hline H. & 189 & 24 & .04 & 40 & 7.9 & 12 & 166 & 8.8 & 10 & Tr. & 132 & 425 \\
\hline $\mathbf{R}$. & 520 & 27 & .30 & 107 & 16 & 55 & 346 & 6.1 & 102 & 2.4 & 333 & 426 \\
\hline R. & 270 & 23 & .40 & 17 & 12 & 55 & $m 77$ & 8.9 & 100 & 2.3 & 92 & 427 \\
\hline $\begin{array}{l}\mathbf{R} . \\
\mathbf{R} \\
\mathbf{R} .\end{array}$ & $\begin{array}{l}504 \\
523 \\
493\end{array}$ & $\begin{array}{l}26 \\
27 \\
29\end{array}$ & $\begin{array}{l}.27 \\
.2 \\
.24\end{array}$ & $\begin{array}{r}98 \\
106 \\
108\end{array}$ & $\begin{array}{l}17 \\
16 \\
14\end{array}$ & $\begin{array}{l}50 \\
47 \\
42\end{array}$ & $\begin{array}{l}320 \\
342 \\
349\end{array}$ & $\begin{array}{l}6.6 \\
5.9 \\
5.6\end{array}$ & $\begin{array}{r}104 \\
102 \\
84\end{array}$ & $\begin{array}{l}1.5 \\
1.5 \\
1.2\end{array}$ & $\begin{array}{l}315 \\
331 \\
327\end{array}$ & $\begin{array}{l}428 \\
429 \\
430\end{array}$ \\
\hline R. & 492 & 30 & .30 & 104 & 13 & 58 & 351 & 4.8 & 90 & 2.4 & $\mathbf{3 1 3}$ & $\mathbf{4 3 1}$ \\
\hline R. & 468 & 81 & .20 & 106 & 13 & 42 & 354 & 5. 6 & 76 & 1.0 & 318 & 432 \\
\hline R. & 833 & 30 & Tr. & 108 & 35 & 148 & 322 & 37 & 296 & 2.0 & 414 & 433 \\
\hline $\mathbf{R}$. & 640 & 42 & Tr. & 21 & 16 & 185 & $=91$ & 28 & 206 & 1.0 & 117 & 434 \\
\hline R. & 816 & 27 & .20 & 101 & 32 & 151 & 327 & 34 & 280 & 1.3 & 384 & 436 \\
\hline R. & 450 & 30 & Tr. & 93 & 24 & 30 & 332 & 7.6 & 76 & 2.0 & 331 & 436 \\
\hline F. & $\begin{array}{r}172 \\
1,256\end{array}$ & $\begin{array}{l}16 \\
19\end{array}$ & $\begin{array}{l}.07 \\
.15\end{array}$ & $\begin{array}{l}39 \\
64\end{array}$ & $\begin{array}{l}6.8 \\
44\end{array}$ & $332^{7.6}$ & $\begin{array}{l}140 \\
130\end{array}$ & $93^{9.0}$ & $\begin{array}{r}12 \\
622\end{array}$ & $\begin{array}{l}4.3 \\
1.1\end{array}$ & $\begin{array}{l}125 \\
340\end{array}$ & $\begin{array}{l}437 \\
438\end{array}$ \\
\hline H. & $\begin{array}{r}154 \\
2,941\end{array}$ & 18.4 & $\begin{array}{r}.09 \\
.18\end{array}$ & $\begin{array}{r}46 \\
159\end{array}$ & $100^{2.0}$ & ${ }_{777^{8}}^{8}$ & $\begin{array}{l}144 \\
\mathbf{3 0 7}\end{array}$ & $181^{2.4}$ & $\begin{array}{r}10 \\
1,510\end{array}$ & Tr. & $\begin{array}{l}123 \\
844\end{array}$ & $\begin{array}{l}499 \\
410\end{array}$ \\
\hline
\end{tabular}

Includes equivalent of 22 parts per million of carbonate $\left(\mathrm{CO}_{3}\right)$.

- Incliudes equivalent of 41 parts per million of carbonate (COs). 


\begin{tabular}{|c|c|}
\hline \multirow[t]{2}{*}{ No. } & \multirow[b]{2}{*}{ voLUSIA COUNTY-continued } \\
\hline & \\
\hline 441 & New Smyrna, 2 miles west of, on De Land Road. Flowing well 4 inches in diameter and 182 feet \\
\hline 442 & $\begin{array}{l}\text { New Smyrna, } 3 \text { miles west of, on De Land Road. Flowing well } 4 \text { inches in diameter and } 187 \text { teet } \\
\text { deep; owned by Mineral Well farm. July } 28,1923 \text {. }\end{array}$ \\
\hline 443 & Orange City. 10-inch drilled well 157 feet deep; owned by A. B. Granger. Mar. 8, 1924. \\
\hline $\begin{array}{l}444 \\
445 \\
446\end{array}$ & $\begin{array}{l}\text { Orange City. 3-inch drilled well } 167 \text { feet deep; owned by Wm. Laws, jr. June, } 1924 . \\
\text { Ormond. 4-inch drilled well } 183 \text { feet deep; owned by Ormond Supply Co. July } 8,1923 \text {. } \\
\text { Seabreeze. 6-inch drilled well } 181 \text { feet deep; owned by municipality; the water after treatment is } \\
\text { used for public supply. July } 5,1923 \text {. }\end{array}$ \\
\hline 447 & $\begin{array}{l}\text { Seabreeze; municipal supply. Water from No. } 446 \text { treated with } 2.35 \text { pounds of lime and } 0.18 \text { pound } \\
\text { of soda ash to 1,000 gallons. July } 28,1923 \text {. }\end{array}$ \\
\hline \multirow[t]{2}{*}{448} & $\begin{array}{l}\text { Seabreeze. Driven well } 11 / 2 \text { inches in diameter and } 55 \text { feet deep } 400 \text { yards from Halifax River; } \\
\text { owned by Geddes Long, Daytona Beach. July 6, } 1923 \text {. }\end{array}$ \\
\hline & WAKULLA COUNTY \\
\hline 449 & $\begin{array}{l}\text { Crawfordsville. 3-inch drilled well } 349 \text { feet deep in SW. } 1 / 4 \text { SW. } 1 / 4 \text { sec. 30, T. } 3 \text { S., R. } 1 \text { W.; owned } \\
\text { by Wakulla County. Apr. 14, } 1924 \text {. }\end{array}$ \\
\hline \multirow[t]{2}{*}{$\begin{array}{l}450 \\
451\end{array}$} & $\begin{array}{l}\text { Newport, } 1 \text { mile north of. Spring owned by Nathal Breun, jr., Tallahassee. Nov. 2, } 1924 . \\
\text { Wakulla. Wakulla Springs, at head; discharge } 3 \text { miles downstream on Feb. 13, 1917, was } 326 \\
\text { second-feet (Water-Supply Paper 452, p. 61). Feb. 28, 1924. }\end{array}$ \\
\hline & WALTON COUNTY \\
\hline $\begin{array}{l}452 \\
453\end{array}$ & $\begin{array}{l}\text { De Funiak Springs; municipal supply. } 8 \text {-inch drilled well } 525 \text { feet deep. July } 17,1923 . \\
\text { Freeport. 8-inch drilled well } 180 \text { feet deep; flowing city well; odor of hydrogen sulphide. Dec. } \\
\text { 7, 1907. }\end{array}$ \\
\hline 454 & $\begin{array}{l}\text { Freeport. Flowing well } 4 \text { inches in diameter and } 186 \text { feet deep; owned by Blackman \& MeLoan. } \\
\text { Dec. 6, 1907. } \\
\text { WASHINGTON coUNTY }\end{array}$ \\
\hline 455 & $\begin{array}{l}\text { Caryville. 5-inch drilled well } 726 \text { feet deep in SW. } 1 / 4 \text { sec. } 2, \text { T. } 4 \text { N., R. } 16 \text { W.; owned by Hender- } \\
\text { son Waite Lumber Co. April 9, 1924. }\end{array}$ \\
\hline $\begin{array}{l}456 \\
457 \\
458\end{array}$ & $\begin{array}{l}\text { Chipley; municipal supply. } 10 \text {-inch drilled well } 180 \text { feet deep. July } 18,1923 . \\
\text { Chipley. 10-inch drilled well } 160 \text { feet deep; owned by municipality. Dec. 5, } 1907 . \\
\text { Chipley. 3-inch drilled well } 390 \text { feet deep in NW.1/4 sec. 3, T. 4 N., R. } 13 \text { W.; owned by Chipley } \\
\text { Packing Co. Apr. 2, } 1924 \text {. }\end{array}$ \\
\hline
\end{tabular}

- Calculated.

d Includes equivalent of small quantity of carbonate $\left(\mathrm{CO}_{3}\right)$. 
waters of Florida-Continued

\begin{tabular}{|c|c|c|c|c|c|c|c|c|c|c|c|c|}
\hline \multicolumn{12}{|c|}{ Analyses (parts per million) } & \multirow[b]{2}{*}{ No. } \\
\hline $\begin{array}{l}\text { Ana- } \\
\text { lyst }\end{array}$ & $\mid \begin{array}{c}\text { Total } \\
\text { dis- } \\
\text { solved } \\
\text { solidds at } \\
180^{\circ} \mathrm{C} .\end{array}$ & $\begin{array}{l}\text { Silica } \\
\left(\mathrm{SiO}_{2}\right)\end{array}$ & $\begin{array}{l}\text { Iron } \\
(\mathrm{Fe})\end{array}$ & $\begin{array}{l}\text { Cal- } \\
\text { cium } \\
\text { (Ca) }\end{array}$ & $\begin{array}{l}\text { Mag- } \\
\text { ne- } \\
\text { sium } \\
\text { (Mg) }\end{array}$ & $\begin{array}{l}\text { Sodium } \\
\text { and po- } \\
\text { tassium } \\
\text { (Na+K) }\end{array}$ & $\begin{array}{c}\text { Bicar- } \\
\text { bonate } \\
\text { radicle } \\
\left(\mathrm{HCO}_{3}\right)\end{array}$ & $\begin{array}{c}\text { Sul- } \\
\text { phate } \\
\text { radicle } \\
\left(\mathrm{SO}_{4}\right)\end{array}$ & $\begin{array}{c}\text { Chloride } \\
\text { radicle } \\
\text { (Cl) }\end{array}$ & $\begin{array}{l}\text { Nitrate } \\
\text { radiele } \\
\left(\mathrm{NO}_{3}\right)\end{array}$ & $\begin{array}{c}\text { Total } \\
\text { hard- } \\
\text { ness as } \\
\text { CaCO }_{3^{\circ}}\end{array}$ & \\
\hline R. & 2,040 & 26 & 0.20 & 154 & 64 & 467 & 348 & 99 & 912 & Tr. & 647 & 441 \\
\hline F. & 777 & 29 & .07 & 138 & 25 & 125 & 354 & 22 & 272 & Tr. & 448 & 442 \\
\hline F. & 183 & 10 & Tr. & 55 & 5.0 & $\left\{\begin{array}{ll}\mathrm{Na} & 5.2 \\
\mathrm{~K} & 1.0\end{array} \mid\right.$ & 168 & 8.8 & 9.6 & 4. 1 & 158 & 443 \\
\hline $\begin{array}{l}\text { H. } \\
\text { R. } \\
\text { H. }\end{array}$ & $\begin{array}{l}128 \\
603 \\
494\end{array}$ & $\begin{array}{l}17 \\
26 \\
\mathbf{3 5}\end{array}$ & $\begin{array}{l}.08 \\
.17 \\
\text { Tr. }\end{array}$ & $\begin{array}{r}32 \\
115 \\
98\end{array}$ & $\begin{array}{l}4.4 \\
17 \\
20\end{array}$ & $\begin{array}{l}\text { (A } 4.0 \\
47 \\
57 \\
47\end{array}$ & $\begin{array}{l}104 \\
332 \\
337\end{array}$ & $\begin{array}{l}4.6 \\
9.2 \\
7.6\end{array}$ & $\begin{array}{r}10 \\
146 \\
94\end{array}$ & $\begin{array}{l}\text { Tr. } \\
\text { Tr. } \\
\text { Tr. }\end{array}$ & $\begin{array}{r}98 \\
\mathbf{3 5 7} \\
\mathbf{3 2 7}\end{array}$ & $\begin{array}{l}444 \\
445 \\
446\end{array}$ \\
\hline R. & 291 & 63 & .2 & 18 & 2.6 & 57 & 029 & 10 & 92 & 1.5 & 56 & 447 \\
\hline H. & 269 & 15 & .83 & 19 & 9.5 & 54 & 44 & 21 & 96 & 3.8 & 86 & 448 \\
\hline H. & 162' & 9.3 & .14 & 42 & 6.7 & 4. 8 & 152 & 1.9 & 9.0 & Tr. & 132 & 449 \\
\hline 㫷. & $\begin{array}{l}216 \\
167\end{array}$ & ${ }_{16}^{8.3}$ & $\begin{array}{l}\text {.03 } \\
\text { TT. }\end{array}$ & $\begin{array}{l}62 \\
39\end{array}$ & $\begin{array}{l}\mathbf{7 . 3} \\
\mathbf{9 . 6}\end{array}$ & $\begin{array}{l}4.8 \\
5.7\end{array}$ & $\begin{array}{l}205 \\
154\end{array}$ & $\begin{array}{l}18 \\
11\end{array}$ & $\begin{array}{l}7.0 \\
8.0\end{array}$ & $\begin{array}{l}\text { Tr. } \\
\text { Tr. }\end{array}$ & $\begin{array}{l}185 \\
137\end{array}$ & $\begin{array}{l}\mathbf{4 5 0} \\
\mathbf{4 5 1}\end{array}$ \\
\hline F. & $\begin{array}{r}94 \\
110\end{array}$ & $\begin{array}{l}17 \\
20\end{array}$ & $\begin{array}{l}.07 \\
.01\end{array}$ & $\begin{array}{l}18 \\
21\end{array}$ & $\begin{array}{l}8.6 \\
7.8\end{array}$ & $\begin{array}{r}2.7 \\
7.7\end{array}$ & $\begin{array}{l}d 91 \\
d 115\end{array}$ & $\begin{array}{l}6.2 \\
5.7\end{array}$ & $\begin{array}{l}2.2 \\
2.3\end{array}$ & .43 & $\begin{array}{l}80 \\
84\end{array}$ & $\begin{array}{l}452 \\
453\end{array}$ \\
\hline D. & 144 & $\ldots$ & .05 & 23 & 8 & 48.8 & ${ }^{d} 122$ & 7 & 2 & & 90 & 454 \\
\hline H. & 196 & 45 & .06 & 31 & 16 & 3.7 & 173 & 12 & 1.8 & Tr. & 143 & 455 \\
\hline $\begin{array}{l}\text { F. } \\
\text { D: }\end{array}$ & $\begin{array}{l}126 \\
123 \\
128\end{array}$ & $\begin{array}{l}15 \\
12 \\
14\end{array}$ & $\begin{array}{l}.08 \\
.17 \\
.11\end{array}$ & $\begin{array}{l}38 \\
38 \\
\mathbf{3 7}\end{array}$ & $\begin{array}{r}2.8 \\
.5 \\
.4\end{array}$ & $\begin{array}{l}2.4 \\
3.9 \\
7.4\end{array}$ & $\begin{array}{l}\$ 127 \\
d 132 \\
\quad 134\end{array}$ & $\begin{array}{l}2.8 \\
1.0 \\
1.8\end{array}$ & $\begin{array}{l}2.5 \\
2.4 \\
2.5\end{array}$ & $\begin{array}{l}.15 \\
.35 \\
\text { Tr. }\end{array}$ & $\begin{array}{r}106 \\
98 \\
94\end{array}$ & $\begin{array}{l}456 \\
457 \\
458\end{array}$ \\
\hline
\end{tabular}

- Includes equivalent of 9.6 parts per milion of carbonate ( $\left.\mathrm{CO}_{3}\right)$. 



\section{NOTES ON PRACTICAL WATER ANALYSIS}

\section{By W. D. Colunss}

The directions given below are intended to show the methods used in the United States Geological Survey for the analysis of waters of moderate mineral content in order to learn their suitability for industrial use. The analyses so made give little or no indication of the sanitary condition of the waters, and they do not involve the determination of some of the rarer constituents of natural waters. The methods must be modified for some waters of unusual composition.

The methods have been selected from long-established procedures for the different determinations, and their details have been chosen as best adapted for use in a laboratory which is planned and equipped to make such analyses and in which no other chemical work is done. Different details might be selected for use under other conditions. The selections necessarily agree closely with those made by organizations that have published standard ${ }^{1}$ or official $^{2}$ methods for water analysis.

These notes are intended for the use of those who have had experience in analytical work and may wish to know the methods used for the water analyses published by the United States Geological Survey. It is assumed that the reader is familiar with the standard procedures of volumetric and gravimetric analysis, and therefore it is not necessary to direct that a crucible shall be cooled in a desiccator before weighing or that the volumetric glassware and the weights used shall be calibrated. Some directions that may seem equally simple have been included because certain minor details that have a real effect on the reliability of a water analysis appear to be overlooked by some analysts.

Directions as to the volumes of solution in which the precipitations are made must be taken merely as suggestions for average conditions. For success the analyst must keep in mind the quantities of the substances dissolved in the solution at hand. A reagent added to produce a preeipitate must be in sufficient excess to make the precipitate properly insoluble. The excess must not be so great as to

1 am. Pub. Health Amsoc, Standard methods for the examination of water and mewage, Dth ed., 1928.

2 Assoc. Officlal Agricultural Chemists, Ofllal and tentative mathods of analyals, 2d eil., repited to July, 1824, pp. 88-112, 1926.

$95221^{\circ}-28-16$ 
interfere with subsequent treatment of the filtrate, and care is necessary to avoid the addition of undesirable quantities of impurities through the use of too great an excess of a reagent. If a solution is too concentrated the precipitate will retain undue amounts of the soluble substances that should be in the filtrate. If the volume is too great the solubility of the precipitate will introduce errors or else too large a quantity of the precipitant must be used to give the proper concentration for the best precipitation. By keeping these considerations in mind it is easy to tell whether a precipitation should be made in a volume of 200 cubic centimeters or 20 cubic centimeters. Considerations of the same kind govern the washing of precipitates, for which precise directions can not be given.

Analyses are reported in parts per million of the radicles determined. Portions of the samples for the different determinations are measured in cubic centimeters at room temperature. The error inrolved in the assumption that a cubic centimeter of water that contains less than 3,000 parts per million of dissolved solids weighs 1 gram is usually considerably less than the probable error of most of the determinations and is much too small to have any effect on the practical use of the analysis.

For practical use quantities of less than 1 part per million of the ordinary mineral constituents of a water have little or no significance, with the exception of iron. In general the error in the determination of a single constituent is likely to be about 1 per cent of the quantity determined. These considerations lead to the arbitrary rule that no decimals are reported for quantities of 10 parts per million or more, one decimal figure is given for quantities from 1 to 10 , and two decimal figures for quantities less than 1.

\section{SAMPLES}

The size of sample required may be from a gallon to a pint, according to the concentration of the water. Usually a gallon is most satisfactory. It is desirable that the samples be collected in bottles of resistant glass, ${ }^{3}$ and this precaution is necessary if more than a few days is to elapse between the collection and the analysis of the sample. Bottles sold for other uses may be good enough for water samples, but some may give up to a sample more mineral matter than was in the water at its source.

Analysis of the mineral content of a water should be started within a month of the collection of the sample, even if it is in a good bottle. Some waters will be apparently unchanged after three months in storage. Those containing sodium bicarbonate or else very little dis-

${ }^{8}$ Collins, W. D., and Riffenburg, H. B., Contamination of water samples with materia] dissolved from glass containers: Ind. and Eng. Chemistry, vol. 15, pp. 48-49, 1923. 
solved mineral matter are much more likely to attack the glass container than the waters high in calcium sulphate or sodium chloride.

It is essential that the condition of the water as regards precipitated iron be noted at the time of collection. Few surface waters carry much over 0.1 part per million of iron in solution unless they are acid. Ground waters may have several parts per million of iron that will be precipitated on contact with the oxygen of the air. This iron is in the water in the ground and must be reported with the dissolved material, even though it is precipitated when the analysis is made.

If the water contains hydrogen sulphide, precautions must be taken to permit a correct determination of sulphate in the laboratory. Usually the best way is to collect a small extra sample in a bottle or several bottles containing solid cadmium chloride free from sulphate. The cadmium sulphide remains unaffected and can be filtered out and treated by the method used in steel works for the determination of sulphur in steel when the steel is dissolved in acid and the evolved hydrogen sulphide is collected in a solution of a cadmium salt. The result for hydrogen sulphide will probably be less accurate than if the water were titrated with iodine at its source but will be better than if the determination were made on a sample as received without any treatment at the time of collection.

The filtrate from the cadmium sulphide will give a correct figure for the sulphate in the water at its source. All the other determinations may be made on the larger sample with the precautions mentioned in the directions for titration of chloride. Very rarely a sample contains alkaline sulphides, which make the determination of bicarbonate unreliable.

A sample may have a noticeable odor of hydrogen sulphide although it contains barely 1 part per million of the gas. The analysis of the mineral content of such a water is practically unaffected by the hydrogen sulphide, which may be completely oxidized by the time the sample reaches the laboratory.

\section{REAGENTS AND APPARATUS}

Reagents used in water analysis should be at least up to the standards proposed by the Committee on Analytical Reagents of the American Chemical Society. ${ }^{4}$ It is desirable to use better reagents in some of the work. All reagents must be tested with reference to the determinations in which they are to be used.

The main source of error from reagents is in the determination of the alkalies. Barium chloride and barium hydroxide may contain

4 Recommended specifications for analytical reagent chemicals : Ind. and Eng. Chemistry, vol. 17, p. 756, 1925 ; vol. 18, pp. $636,759,1926$; vol. 19, p. 645, 1927. 
more sodium than is permissible. Ammonium carbonate may have too much nonvolatile material, and ammonium hydroxide is likely to introduce alkali salts into the analysis. The impurities in ammonium hydroxide nearly all come from the action of the reagent on the glass of the container. Many laboratories are now preparing ammonium hydroxide by absorbing in cold water ammonia gas from cylinders of liquid ammonia. Where large quantities are used there may be some saving in cost by this procedure, but the greatest saving comes from the improved quality due to the shorter time for action on the glass container as compared with the time required for the shipment and storage of the reagent in bottles. Some laboratories prepare small quantities of the reagent by distillation of the commercial reagent ammonium hydroxide with absorption in cold water.

Distilled water for use in the analysis of the mineral content of waters does not have to be up to the standard of the ammonia-free water used in sanitary analyses, but care must be taken that it does not take up material from containers in which it may be kept.

Solutions of reagents should not be kept long. Many must be made up fresh for each set of analyses. Volumetric solutions must be checked from time to time.

Evaporations are best made in platinum unless enough nitrate and chloride are present in acid solutions to dissolve some of the metal. It is obvious that care must be taken to use resistant glass vessels throughout, and it is well to note that acid solutions usually attack glass much less than alkaline solutions.

Throughout the directions the acids and ammonium hydroxide used are to be of full strength unless dilution is specified. The customary convention is followed of indicating dilution of 1 volume of strong acid with 2 volumes of water as " $(1+2)$."

\section{PRELIMINARY EXAMINATION"}

Unless the composition of the water is known approximately it is worth while to make a preliminary examination so that the most advantageous quantity of water may be taken for evaporation. The preliminary examination includes the final determinations of alkalinity, chloride, and nitrate, with turbidimetric estimations of sulphate and calcium. A determination of hardness by the soap method may replace or supplement the determination of calcium.

\section{ALKALINITY (BICARBONATE, CARBONATE, HYDROXIDE, ACIDITY)}

The alkalinity should be determined promptly after the sample bottle is opened. Exposure to the air permits absorption of carbon

s Collins, W. D., and Foster, M. D., Preliminary examination of water samples: Ind. and Eng. Chemistry, vol. 15, p. 1078, 1923. 
dioxide; which changes the relations of hydroxide; carbonate, and bicarbonate. If an excess of carbon dioxide is present it may be lost, sometimes even to the precipitation of calcium carbonate. With some samples it is necessary to titrate the alkalinity and take out the sample to be evaporated for the determination of calcium and magnesium at the same time in order to avoid the error that would be introduced if time were given for precipitation of calcium carbonate. .

Titrate 50 cubic centimeters of the sample with 0.01639 normal sulphuric acid, using as indicators phenolphthalein and either methyl orange or methyl red. If methyl red is used air free from carbon dioxide must be bubbled through the water during the titration; the calculations are the same as with methyl orange.

Let $A$ represent the number of cubic centimeters of acid used in the pherolphthalein titration and $B$ the additional acid used in the methyl orange titration.

For most natural waters $A$ is zero, the total alkalinity is due to bicarbonate, and the quantity of bicarbonate $\left(\mathrm{HCO}_{3}\right)$ in parts per million is $20 \times B$.

If $A$ is greater than zero and less than $B$ the alkalinity is due to carbonate and bicarbonate, and the water contains no hydroxide. The carbonate $\left(\mathrm{CO}_{3}\right)$ is $19.67 \times \mathrm{A}$, and the bicarbonate $\left(\mathrm{HCO}_{3}\right)$ is $20 \times(B-A)$.

If $A$ is greater than $B$ the water contains no bicarbonate. The carbonate $\left(\mathrm{CO}_{3}\right)$ is $19.67 \times \mathrm{B}$, and the hycroxide is $5.574 \times(\mathrm{A}-\mathrm{B})$.

The strength of the acid was chosen to facilitate the calculation of bicarbonate without the use of tables or calculating instruments. The factors used for carbonate and hydroxide may well be rounded off to three or even two figures for most analyses.

For waters that contain only small quantities of dissolved mineral matter the estimation of alkalinity is likely to introduce the largest error in the analysis. It is possible to evaporate large volumes: of water for the main analysis and for the determination of chloride, but the alkalinity must be determined on about the same volume of sample regardless of the quantity of mineral matter in the water. After practice the analyst can check titrations with methyl orange and find twice as much bicarbonate in 100 cubic centimeters as in 50 cubic centimeters. It is worth while to try this, or to titrate a volume of about 50 cubic centimeters of water containing different quantities of sodium carbonate, in order to learn the exact shade that corresponds to the correct end point.

Some waters are acid to methyl orange. If the acidity is due to free mineral acids and the water contains little iron or aluminum the free acid may be titrated with sodium hydroxide, using methyl orange indicator, and reported as free sulphuric or hydrochloric acid. In practically all acid natural waters, however, the acidity is due to 
sulphates of iron and aluminum, and the titration is not so simple. Titration at boiling temperature with sodium hydroxide and phenolphthalein indicator will give approximately the sum of the acidity due to free mineral acids and that due to sulphates of iron and aluminum. The latter may be calculated from determinations of iron and aluminum.

Some colored waters seem to contain in equilibrium with the bases organic acids that do not appear as alkalinity in the titration with methyl orange and therefore leave the analysis out of balance.

\section{CHLORIDE}

For the chloride determination titrate 25 cubic centimeters with a silver nitrate solution of which 1 cubic centimeter corresponds to 0.5 milligram of chloride radicle, using potassium chromate indicator. The titration is best made in yellow light or with the use of yellow goggles. Each analyst must determine his own correction for the end point. An average correction is 0.1 cubic centimeter for a volume of 25 cubic centimeters. The accuracy of the figure for the end point may be estimated by making several successive titrations in the same solution, removing the red tint each time by the addition of 1 cubic centimeter of a standard sodium chloride solution. Such small increases in volume will not affect the quantity of silver nitrate needed to produce the end point, and the successive quantities of chloride should require the same volume of silver nitrate. The total volume at the end of three or four titrations will exceed three or four times the amount used in the successive titrations by the amount necessary to produce the tint adopted as the end point.

If the chloride is more than 100 parts per million take a smaller sample and dilute to 25 cubic centimeters; if less than 5 parts per million concentrate a larger volume to 25 cubic centimeters, taking care to avoid absorption of chloride by the sample during evaporation and washing down the sides of the vessel before titration.

If the sample contains hydroxide add standard sulphuric acid till it is just acid to phenolphthalein; if it is acid add sodium carbonate till it is slightly alkaline to methyl orange or litmus. If hydrogen sulphide is present remove it by passing pure air through the sample or by boiling. A small quantity of hydrogen sulphide may disappear on exposure to the air for a short time.

It is possible to buy silver nitrate sufficiently, pure to make the standard solution by weighing out 2.3955 grams of dry crystals and making up to a liter. It is well to crush the crystals before drying. The solution may be checked against a solution made from pure fused sodium chloride, but it is generally possible to get the silver nitrate purer than the sodium chloride. 
The indicator solution is made by dissolving 50 grams of potassium chromate in a liter of water, adding enough silver nitrate to precipitate a small amount of silver chromate, and filtering or decanting after the solution has stood in the dark for a day. The quantity of indicator solution used affects the sharpness of the end point, and the same quantity must be used for each titration and for the determination of the correction for the end point. From 0.25 to 0.50 cubic centimeter is satisfactory in titrating a volume of 25 cubic centimeters.

\section{- NITRATE}

Nitrate is best determined by the phenoldisulphonic acid method. ${ }^{\circ}$ To prepare the phenoldisulphonic acid solution dissolve 25 grams of pure white phenol in 150 cubic centimeters of concentrated sulphuric acid, add 75 cubic centimeters of fuming sulphuric acid (15 per cent $\mathrm{SO}_{3}$ ), stir well, and heat for two hours at about $100^{\circ} \mathrm{C}$.

Evaporate 50 cubic centimeters of the sample to dryness and at the same time evaporate measured volumes of a standard solution of potassium nitrate to make standards for comparison. These should have from 0.015 to 0.15 milligram of nitrate radicle, $\mathrm{NO}_{3}$. Remove the dishes from the bath as soon as dry, or better just before, so that the last few drops may evaporate as the dishes cool. When the sample and standards are cool add to each 1 cubic centimeter of the phenoldisulphonic acid and rub thoroughly with a glass rod. Dilute cautiously with water, allow to cool, and add an excess of ammonium hydroxide to develop the yellow color. Compare in Nessler tubes with or without a colorimeter. If the quantity of nitrate is less than 0.015 milligram the comparison may be made best in the porcelain dishes. If care is taken to have the treatment identical it is safe to prepare the standards after development of color in the samples. This practice saves the preparation of standards that are not needed. If the sample evaporated contains much over 0.15 milligram of nitrate evaporate a smaller sample and develop the color to compare with the standards.

Experience in the routine examination of several thousand samples and the results of many tests of the method have shown the necessity for the above directions as to the preparation of standards, and the use of a fresh smaller sample rather than dilution when too intense color is obtained. The relation of the intensity of color to the quantity of nitrate is not absolute over an indefinite range, and serious errors may be introduced in the determination of high nitrates by assuming strict proportionality.

\footnotetext{
- Chamot, E. M., and Pratt, D. S., A study on the phenolsulphonic acid method for the determination of nitrates in water: Am. Chem. Soc. Jour., vol. 31, pp. 922-928, 1909 ; yol. 32, pp. 630-637, 1910.
} 
In a laboratory where sanitary analyses are not made it is simplest to use ammonium hydroxide to develop the color. This helps keep the stock moving through the reagent bottles and does not call for an extra reagent, which must be kept if potassium hydroxide solution is used. The latter solution is not satisfactory to keep in stock on account of its rapid action on bottles.

\section{SULPHATE (BY TURBIDITY)}

For the turbidimetric estimation of sulphate take a clear sample of 10 cubic centimeters in a test tube and prepare in other test tubes standards made from distilled water and enough standard sulphuric acid solution to give from 0.1 to 0.3 milligram of $\mathrm{SO}_{4}$ in 10 cubic centimeters. Add to each tube 1 cubic centimeter of acidified barium chloride solution (10 grams of $\mathrm{BaCl}_{2} \cdot 2 \mathrm{H}_{2} \mathrm{O}$ and 5 cubic centimeters of hydrochloric acid of specific gravity 1.20 in 100 cubic centimeters), shake vigorously and compare after 10 minutes. The comparison is best made by looking down through the tubes against a dark background. If the sulphate is more than 30 or 35 parts per million take a smaller sample and dilute to 10 cubic centimeters.

\section{CAICIUM (BY TURBIDITY)}

For the turbidimetric estimation of calcium take a clear sample of 10 cubic centimeters in a test tube and prepare in other test tubes standards of equal volume. Add to each tube 1 cubic centimeter of dilute glacial acetic acid $(1+1)$ and shake well; add 1 cubic centimeter of potassium oxalate solution containing 0.2 gram of $\mathrm{K}_{2} \mathrm{C}_{2} \mathrm{O}_{4}$, shake, and compare after 10 minutes. The calcium chloride solution used for standardizing the soap solution for hardness determinations makes convenient standards. From 0.5 to 3.0 cubic centimeters of the calcium chloride solution will make standards of 10 cubic centimeters corresponding to 4 to 24 parts per million of calcium. If the sample contains more than 24 parts per million of calcium a smaller quantity is taken for the determination and diluted to 10 cubic centimeters.

\section{HARDNESS (BY SOAP)}

The determination of hardness by Clark's soap method " has been found satisfactory for ordinary waters ${ }^{8}$ if the directions are followed carefully in every detail.

Prepare the standard calcium chloride solution by dissolving 0.2 gram of pure calcite or other dry calcium carbonate in a little dilute

\footnotetext{
7 Clark, Thomas, The examination of water for towns for Its hardness and ior the Incrustation it deposits on bolling: Chem. Gazette, vol. 5, p. 100, 1847.

Collins, W. D., and Foster, M. D., Preliminary examination of water samples : Ind. and Eng. Chemistry, rol. 15, p. 1078, 1023.
} 
hydrochloric acid, taking care to avoid loss 'by spattering. Remove the excess of acid by several evaporations and make to 1 liter.'

Prepare a stock soap solution by dissolving 100 grams of shredded dry pure olive oil castile soap in 1 liter of 80 per cent ethyl alcohol or 50 per cent methyl alcohol. It is necessary to use alcohol that has not been denatured. Many soaps not made with olive oil can not be used for this solution. Potassium oleate for the solution may be made from potassium carbonate and lead plaster, or from the hydroxide and oleic acid.

Adjust the strength of the soap solution by the exact procedure that is to be used in titrating the waters. Dilute 20 cubic centimeters of the standard calcium chloride solution to 50 cubic centimeters with distilled water that has been freshly boiled and cooled. To the diluted solution in a bottle of about 250 cubic centimeters capacity add soap solution from a burette, 0.2 to 0.5 cubic centimeter at a time. A bottle of square cross section is most convenient for the test. Shake vigorously after each addition of soap solution. The titration is completed when a permanent lather persists for 5 minutes over the whole surface of the water when the bottle is on its side. Adjust the soap solution by the addition of alcohol till exactly 6.40 cubic centimeters is required to produce the permanent lather as described.

Table 1 gives the hardness as found by Clark for different volumes of soap solution. The figures for less than about 1.5 cubic centimeters of soap solution do not check with results obtained in tests of the method in the Geological Survey. Above this point the agreement. has been all that could be expected for such a method.

TARIE 1.-Total hardness, in parts per million of $\mathrm{CaCO}_{3}$, indicated by 0.0 to 7.9 cubic centimeters of soap solution when 50 cubic centimeters of the sample is titrated ${ }^{a}$

\begin{tabular}{|c|c|c|c|c|c|c|c|c|c|c|}
\hline $\begin{array}{l}\text { Cubic centimeters of } \\
\text { soap solution }\end{array}$ & 0.0 & 0.1 & 0.2 & 0.3 & 0.4 & 0.6 & 0.6 & 0.7 & 0.8 & 0.9 \\
\hline 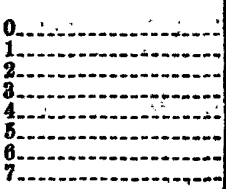 & $\begin{array}{r}4.8 \\
19.5 \\
32.5 \\
46.7 \\
60.0 \\
74.3 \\
88.6\end{array}$ & $\begin{array}{r}6.3 \\
20.8 \\
33.8 \\
47.1 \\
61.4 \\
75.7 \\
90.0\end{array}$ & $\begin{array}{r}7.9 \\
22.1 \\
35.1 \\
48.6 \\
62.9 \\
77.1 \\
91.4\end{array}$ & $\begin{array}{r}\vdots \\
9.5 \\
23.4 \\
36.4 \\
50.0 \\
64.3 \\
78.6 \\
92.0\end{array}$ & $\begin{array}{l}11.1 \\
24.7 \\
37.7 \\
51.4 \\
65.7 \\
80.0 \\
94.3\end{array}$ & $\begin{array}{r}12.7 \\
26.0 \\
39.0 \\
82.9 \\
67.1 \\
81.4 \\
95.7\end{array}$ & $\begin{array}{l} \\
14.3 \\
27.3 \\
40.3 \\
54.3 \\
68.6 \\
82.9 \\
97.1\end{array}$ & $\begin{array}{r}0.0 \\
16.6 \\
28.6 \\
41.6 \\
56.7 \\
70.0 \\
84.3 \\
98.6\end{array}$ & $\begin{array}{r}1.6 \\
16.9 \\
29.9 \\
42.9 \\
87.1 \\
71.4 \\
85.7 \\
100.0\end{array}$ & $\begin{array}{r}3.2 \\
18.2 \\
31.2 \\
44.3 \\
58.6 \\
72 . \\
87.1 \\
101.5\end{array}$ \\
\hline
\end{tabular}

- Recalculated in Button's "Valumatrle analysis" from the original table by Thomas Clark, painted in 8 circular and reprinted in Chem. Gazette, vol. 5 , pp. 100-106, 1847.

Titrate 50 cubic centimeters of the sample with the soap solution exactly as directed for the standardization." If the hardness of the sample is over 100 parts per million take a smaller volume and dilute to 50 cubic centimeters. Use the appropriate factor for multiplication of the hardness taken from the table. 
Hardness is not usually determined in the preliminary examingtion if an analysis is to be made.

\section{RESULTS OF PRELIMINARY EXAMINATION}

The preliminary examination may give all the information that is needed about a particular sample. The work outlined above will frequently satisfy the analyst that a sample is practically identical with another for which a complete analysis is at hand. If the water is known to come from a place where high-calcium limestone predominates, as in most parts of Florida, it is safe to assume that practically all the hardness is due to calcium, and if either the hardness or calcium has been determined the other is known approximately. If the water comes from typical dolomite half the hardness will be due to calcium and half to magnesium.

If hardness is determined a rough figure for sodium and potassium together may be calculated. It will be the quantity of sodium which . must be taken with the hardness to balance the acid radicles. The figure will be affected by any error in the determination of hardness and the estimation of sulphate.

The best quantity of water to take for evaporation is indicated by the preliminary examination. For most practical analyses a liter or half a liter is enough to evaporate for analysis of the residue. In order to obtain a convenient weight of silica it is generally well to evaporate the whole volume in one dish and divide the filtrate into two parts after separation of the silica. The most satisfactory quan-. tity of calcium for titration with permanganate is from 10 to 20 Inilligrams. As little as 1 or 2 milligrams can be determined by careful manipulation, and as much as 40 milligrams can be titrated easily. It is convenient to weigh as oxide 100 or 200 milligrams of calcium. Almost any quantity of sulphate from 2 or 3 to 400 milligrams can be handled easily. It is most satisfactory to have between 50 and 100 milligrams of mixed chlorides of sodium and potassium. More than 250 milligrams may give less accuracy on account of loss by occlusion with the precipitates removed in the purification and loss by decrepitation in heating. Less than 10 milligrams requires careful attention to prevent loss and is likely to have an undue percentage of contamination from the reagents used.

The preliminary determinations of sulphate and calcium or hardness may sometimes show errors in the regular analysis that come from incorrect calculation, a mistake as to the quantity of water taken, or some other accident that introduces an error much greater than possible normal errors of analysis. 


\section{TURBIDITY}

The commonly accepted standard for measurement of turbidity is that proposed by Hazen and Whipple, ${ }^{9}$ as follows:

The standard of turbidity shall be a water which contains 100 parts of silica per million in such a state of fineness that a bright platinum wire 1 millimeter in diameter can just be seen when the center of the wire is 100 millimeters below the surface of the water and the eye of the observer is 1.2 meters above the wire, the observation being made in the middle of the day, in the open air but not in sunlight, and in a vessel so large that the sides do not shut out the light so as to influence the results. The turbidity of such water shall be 100.

Practieally all measurements of slightly turbid waters are made by comparison with dilutions of a standard suspension. Pear's precipitated fuller's earth which has been dried and sifted through a 200-mesh sieve may be weighed out to make the standard suspension. One gram in 1,000 cubic centimeters of water will produce a turbidity of about 1,000. A 1 to 10 dilution of this standard should have a turbidity of 100 measured by the platinum-wire method. If slightly in error the suspension may be adjusted to the standard by the addition of water or fuller's earth as required.

The turbidity rod described by Hazen and Whipple may be used in the field. The Jackson turbidimeter or a similar instrument should be used in the laboratory for the measurement of turbidities greater than about 100. Each observer must calibrate the graduations on the tube of the turbidimeter by use of a standard suspension of silica or other insoluble material. If the turbidity to be measured is mueh over 500 the sample should be diluted with clear water for the measurement and the measured turbidity multiplied by the factor corresponding to the dilution.

- For the measurement of turbidity of filter effluents and other clear waters it is necessary to use a more sensitive method, such as that proposed by Baylis. ${ }^{10}$ The apparatus used can be purchased from dealers or may be made according to the directions given with the description of the method.

\section{SUSPENDED MATTER}

To determine suspended matter filter a measured volume of the well-shaken sample through asbestos in a Gooch crucible, dry at $180^{\circ} \mathrm{C}$, and weigh. If the suspended matter is so finely divided as to pass through any asbestos mat that permits water to pass at a

\footnotetext{
9 Measprement of turbidity and color: U. \$. Geol. Suryey Div. Hydrography Circ. 8, 1802.

10 Baylis, J. R., Turbidimeter for accurate measurement of low turbidities: Ind. and Eng. Chemistry, vol. 18, p. 311, 1926.
} 
reasonable rate, it is not possible to obtain a thoroughly satisfactory result for suspended matter. A part of the sample may be completely clarified by the use of a filter of the Berkfeldt type or by adding alumina cream and filtering through paper. The difference between the residue on evaporation of samples of the unfiltered and the clear water is sometimes taken as a measure of the suspended matter. This result is affected by the errors of drying and weighing the two residues, and the errors are likely to be different for the two determinations.

\section{COLOR}

The measurement of color is usually made by the method described by Hazen. ${ }^{11}$ The standard color of 500 is prepared by dissolving 1.245 grams of potassium chloroplatinate $\left(\mathrm{K}_{2} \mathrm{PtCl}_{6}\right)$, containing 0.5 gram of platinum, and 1 gram of crystallized cobalt chloride $\left(\mathrm{CoCl}_{2} \cdot \mathrm{H}_{2} \mathrm{O}\right)$, containing about 0.25 gram of cobalt, in water with 100 cubic cencimeters of concentrated hydrochloric acid, and diluting to 1 liter with distilled water. Comparison is made with dilutions of this standard or with colored disks that have been calibrated against standard color solutions.

\section{PRECIPITATED IRON}

When iron precipitates from a clear sample after exposure to the air make a separate determination of the precipitated iron. With some samples it is satisfactory to shake vigorously and then pour out quickly a definite quantity to be filtered. The iron often precipitates on the walls of the container and can not be distributed throughout the sample by shaking. In this event the whole sample must bo filtered and the iron dissolved from the glass with hydrochloric acid.

Dissolve the iron from the filter paper, add the solution of iron from the container, and make to a definite volume. Determine the iron colorimetrically as thiocyanate and calculate to parts per million from the volume of the sample filtered and the original volume in the container if solution from the walls is necessary.

\section{RESIDUE ON EVAPORATION (TOTAL DISSOLVED SOLIDS)}

For determination of the residue on evaporation, or total dissolved solids, measure out the volume of filtered sample required for the main analysis and evaporate to dryness in platinum on the steam bath. Silica or porcelain dishes may be used, but the results are less satisfactory than with platinum. Dry the dish and contents one hour

2 Hazen, Allen, Am. Chem. Jour., vol. 12, pp. 427-428, 1892. 
at $180^{\circ}$ C. and weigh. The weight obtained is often reported as "toigl dissolved solids," and for most waters of moderate mineral. content this is reasonably accurate.

Occasionally a sample will increase in weight while on the balance pan. It must then be dried again and weighed more quickly. Sometimes it is necessary to make the determination of total solids or residue by evaporating and drying in a small bottle with a glass stopper that can be inserted for the weighing.

\section{LOSS ON IGNITION}

Determine the loss on ignition by weighing the dish after heating 3 minutes in a "radiator," which consists of a nickel dish with cover and a triangle to support the platinum dish out of direct contact with the radiator. The full heat of a Bunsen burner is used. The residue may be ignited carefully over a small free flame, but it is more difficult to obtain consistent results without the use of the "radiator."

Some surface waters with high color require much more heating than is directed above in order to burn off all the carbon. For such water the loss on ignition may be a rough indication of the quantity of dissolved organic matter. The loss for other waters may be chiefly water that was not removed by the heating at $180^{\circ} \mathrm{C}$.

For most samples the only value of the determination of loss on ignition is to afford a check on the residue on evaporation and another reference point for comparison of the sum of the determined constituents, which obviously ought to come between the residue on evaporation and the residue on ignition.

\section{SILICA}

The first step in the separation of silica from the residue on evaporation in platinum of a sample that contained more than 2 milligrams of nitrate as $\mathrm{NO}_{3}$ is to transfer the residue to a porcelain or silica dish with water and a small quantity of dilute hydrochloric acid. If the sample was not evaporated in platinum or contained less than 2 milligrams of nitrate take up the residue with water and add cautiously 1 cubic centimeter of hydrochloric acid $(1+1)$. Evaporate to dryness. Moisten the residue with a few drops of hydrochloric acid and take up with hot water. If the sample contains much calcium and sulphate it may be difficult to dissolve all of the calcium sulphate from the dish. Sometimes the successive portions of hot water used amount to as much as the original volume of the sample, even with the addition of several cubic centimeters of hydrochloric acid. Filter and wash with hot water, collecting the filtrate and wash water in a volumetric flask (usually 100 or 200 centimeters). 
Ignite the precipitate in a platinum crucible and weigh. Add two or three drops of sulphuric acid and a few cubic centimeters of hydrofluoric acid, heat gently to volatilize the acids; then ignite and weigh. The loss is silica $\left(\mathrm{SiO}_{2}\right)$. The nonvolatile residue should not be as much as 0.0005 gram. A larger quantity may come from calcium sulphate that was not dissolved when the residue was taken up in water and acid, or from suspended silt that was not completely filtered out before the evaporation.

Mix the filtrate thoroughly and divide into two equal portions unless the preliminary examination has shown the desirability of some other division. One part will serve for the determination of iron, calcium, and magnesium; the other for sulphate and alkalies.

\section{IRON}

To determine iron heat to boiling one portion of the filtrate from the silica and add ammonium hydroxide in slight excess. If only a few drops of acid was used in taking up the residue on evaporation, add 1 cubic centimeter of hydrochloric acid $(1+1)$ to redissolve the precipitate and again make alkaline with ammonium hydroxide. Allow to stand on the steam bath for half an hour, filter, and wash. Dissolve the precipitate with hydrochloric acid and water, using the equivalent of 1 cubic centimeter of strong acid. Add 1 cubic centimeter of strong nitric acid, mix and make to a convenient volume of 50 to 100 cubic centimeters. Prepare standards of the same volume containing from 0.05 to 0.4 milligram of iron and the quantities of acid used for the sample. Add 5 cubic centimeters of 2 per cent ammonium thiocyanate to the sample and standards and compare at once. The color is affected by temperature and by the concentration of reagents in the solution.

\section{ALUMINUM}

The determination of aluminum is not worth while in the ordinary practical analysis. If it must be made one of the special methods for aluminum should be used. The practice of weighing the ammonium hydroxide precipitate and reporting as aluminum oxide the difference between this weight and the iron oxide calculated from the determination of iron generally gives incorrect results. This procedure is, however, satisfactory for the analysis of waters high in iron and aluminum, such as the seepage from shale beds and many mine waters. The quantity of iron may be large enough to make it desirable to determine the iron by titration with permanganate or dichromate after fusion of the ignited oxides with sodium bisulphate. 


\section{CALCIUM}

For the determination of calcium add to the filtrate from the iron precipitation an excess of ammonium oxalate or oxalic acid. From 5 to 10 cubic centimeters of saturated ammonium oxalate solution is usually enough. Too little will permit the precipitation of magnesium or even fail to precipitate all the calcium. Too much interferes with the subsequent precipitation of magnesium. If the amount of calcium is very small a considerable excess of the oxalate is necessary to start the precipitation. Add hydrochloric acid till the solution is clear and heat to boiling. Add ammonium hydroxide drop by drop with constant stirring till the calcium begins to precipitate. Allow to stand on the steam bath for about half an hour with the precipitate partly down and the solution still acid to methyl orange. Add ammonium hydroxide to make the solution alkaline to methyl orange and allow to stand on the steam bath two or three hours more. Filter, then wash by decantation three times with dilute ammonium hydroxide ( 0.2 to 0.5 per cent $\mathrm{NH}_{3}$ ) and twice with hot water. As much as possible of the precipitate should be kept in the beaker, because it is much more easily dissolved there than from the paper. Dissolve the precipitate from the paper into the beaker in about 20 cubic centimeters of hot sulphuric acid $(1+3)$ and hot water to make to about 75 cubic centimeters. Titrate hot with permanganate solution of such strength that 1 cubic centimeter corresponds to 1.0 milligram of calcium. The permanganate solution is best standardized against Bureau of Standards sodium oxalate.

Care is necessary to insure complete removal from the filter paper of the strong oxalate solution in which precipitation took place and at the same time to avoid dissolving too much calcium oxalate. If too much of the precipitate reaches the paper its complete solution is difficult.

The calcium oxalate precipitate may be ignited and weighed as oxide. If this is done the washing of the precipitate may all be done with water containing a little ammonium oxalate.

\section{MAGNESIUM}

To determine magnesium add to the filtrate from the calcium 5 to 10 cubic centimeters of a 10 per cent solution of ammonium phosphate or sodium and ammonium phosphate, clear the solution with hydrochloric acid, and cool in ice water. Add ammonium hydroxide slowly with stirring till the solution is alkaline to methyl orange. Stir occasionally during half an hour or an hour, add an excess of 10 or 20 cubic centimeters of ammonium hydroxide, and allow to stand overnight. Filter and wash with 2 to 3 per cent ammonium hydroxide. 
Ignite in a porcelain crucible and weigh as magnesium pyrophosphate. Report as magnesium $(\mathrm{Mg})$, which is 21.84 per cent of the precipitate.

If the quantity of magnesium is very small it is well to evaporate the filtrate from the calcium to dryness and remove the bulk of the ammonium salts by heating and gentle ignition. The residue is taken up with a little hydrochloric acid and hot water, the solution is filtered, and the magnesium is precipitated with phosphate and ammonium hydroxide in small volume. A small precipitate comes down much more promptly under these conditions.

\section{SULPHATE}

To determine the sulphate add, if necessary, enough hydrochloric acid to acidify slightly the portion of the filtrate from the silica reserved for the determination of sulphate and alkalies. Heat to boiling and slowly add 5 to 8 cubic centimeters of hot 10 per cent barium chloride solution, with constant stirring. Allow to stand overnight or till the precipitate settles rapidly after stirring. Filter, wash thoroughly, ignite the precipitate, and weigh. Report as sulphate $\left(\mathrm{SO}_{4}\right)$, which is 41.14 per cent of the weight of barium sulphate.

\section{SODIUM AND POTASSIUM}

To determine sodium and potassium heat the filtrate from the sulphate determination in a volume of 100 to 200 cubic centimeters, add an excess of ammonium hydroxide and an excess of a fresh solution of ammonium carbonate, and heat till the precipitate becomes crystalline and settles well. Slow clearing of the solution is often due to lack of sufficient ammonium carbonate or hydroxide. Filter. out, wash thoroughly, and reject the precipitated calcium and barium carbonates. With samples containing very large quantities of alkalies with much calcium and barium it may be worth while to dissolve the carbonates and reprecipitate them in order to avoid loss of alkalies, but the quantity held by the precipitate under normal conditions is negligible.

Evaporate the filtrate to dryness, then heat gently to drive off ammonium salts and just below redness to remove the last traces. Take up in a small volume of hot water, and add a slight excess of freshly prepared barium hydroxide solution. Heat to boiling, filter, and wash. Heat the filtrate, add an excess of ammonium hydroxide and ammonium carbonate, filter, and wash. Evaporate the filtrate to dryness, drive off the ammonium salts, take up in a little hot water, filter and add ammonium hydroxide and ammonium carbonate. If a precipitate appears, filter and repeat the treatment. When no precipitate is produced by the ammonium hydroxide and carbonate, 
filter into a small platinum, porcelain, or silica dish suitable for weighing, cautiously add an excess of hydrochloric acid, evaporate to dryness, drive off the ummonitu selts, heat.just below:redness, cool, and weigh. It is easy to volatilize potassium and sodium chlorides when small quantities are spread thinly over a dish. It is necessary to heat sufficiently to remove all the ammonium salts and water. Repeat the heating and weighing to constant weight, taking care not to volatilize any potassium or sodium chloride. Take up the mixed chlorides in a few cubic centimeters of water and filter through a small filter paper. Wash thoroughly and reserve the filtrate for the determination of potassium. Place the filter paper in the dish, dry, burn the paper carefully, gently ignite, and weigh. The difference between the last two weights is the weight of the sodium and potassium chlorides.

\section{POTASSIUM 2}

For the determination of potassium add to the solution of mixed chlorides in a small evaporating dish 1 drop of hydrochloric acid and a slight excess of platinic chloride over the amount needed to combine with the potassium. It is not necessary to add enough to combine with the sodium. For average waters it may be assumed that approximately one-fourth the weight of mixed chlorides is potassium chloride. The determination should be carried on in a place free from fumes of ammonia that might be absorbed by the solutions and be precipitated by the platinic chloride. Evaporate on the steam bath nearly to dryness. Remove from the bath and allow the last. few drops of water to evaporate as the dish is cooling to room temperature. When cool and dry add a few cubic centimeters of 80 per cent alcohol. Grind the residue in the alcohol with a flattened glass rod and allow to stand half an hour with occasional griniding to insure extraction of all the sodium platinic chloride from the insoluble potassium platinic chloride. Decant through a small filter paper and repeat the extraction two or three times till the alcohol in contact with the precipitate is no longer yellow. Transfer the precipitate to the filter paper and wash with 80 per cent alcohol. The yellow color of the solution shows that enough platinic chloride was added. If the solution is not yellow there is probably some potassium chloride still in solution, and it will be necessary to evaporate the filtrate to dryness to remove the alcohol and then repeat the treatment with platinic chloride. If the alcohol contains other organic matter it may be necessary to ignite the residue to prevent reduction

12 Hicks, W. B., A rapid modified chloroplatinate method for the estimation of potascium : Jour. Ind. Eng, Chemistry, vol. 5, p. 650, 1913. Wells, $\mathbf{R}$ C., Bailey, R. $\mathbf{K}$, and Fairchild, J. G., Note on the Hicks method of determining potassium: Ind. and Eng. Chemistry, vol. 16, p. 985, 1824.

$95221^{\circ}-28-17$ 
and precipitation of platinum by the organic matter. Dissolve the contents of the filter paper in hot water and make to a volume of about 50 cubic centimeters. Add one or two drops of hydrochloric acid and a piece of metallic magnesium weighing from 20 to 50 milligrams. Allow to stand covered on the steam bath for about two hours, adding a few drops more of acid if necessary to insure complete solution of the magnesium. Filter through a small paper, wash thoroughly, ignite, and weigh the reduced platinum. The filtrate with the excess of platinic chloride is saved in a platinum residue bottle. The ignited metallic platinum is saved in the same or another bottle, and when enough is collected the total residue is reworked into a solution of platinic chloride which is made to a known strength. Usually the strength is indicated on the label as the weight of potassium chloride corresponding to 1 cubic centimeter of the solution.

The weight of potassium is 40.05 per cent of the weight of the metallic platinum.

\section{SODIUM}

To determine sodium subtract from the weight of the mixed chlorides the weight of potassium chloride corresponding to the platinum from the potassium platinic chloride. This is 76.37 per cent of the weight of the platinum. The remainder is sodium chloride; of which 39.34 per cent is sodium.

Only a small error is introduced in most analyses by ignoring the potassium and calculating the sodium corresponding to the total weight of the chlorides. Report as sodium and potassium, although it would be more accurate to use the expression "sodium plus $3 / 4$ potassium."

\section{MANGANESE}

Manganese is rarely present in quantity sufficient to affect the balancing of the analysis or to interfere with any of the regular determinations. It may; however, be desirable to determine even a very small quantity on account of possible trouble it may. cause in the use of the water. It is most satisfactory to make the determination on a separate sample by the well-known bismuthate method, modified for use with water samples. ${ }^{13}$

To 100 cubic centimeters of water or a sample small enough to contain less than 1 milligram of manganese, add 10 cubic centimeters of dilute nitric acid $(1+3)$ and 1 cubic centimeter of concentrated sulphuric acid, and heat in a beaker on a hot plate until most of the sulphuric acid has been driven off. Cool and take up with about 50

\footnotetext{
ss Collins, W. D., and Foster, M. D., The determination of manganese in water by the sodium bismuthate method: Ind. and Eng. Chemistry, vol. 16, p. 586, 1924.
} 
ubic centimeters of water and 20 cubic centimeters of dilute nitric cid through which air has been bubbled to remove oxides of nitrogen. Add 0.10 gram of sodium bismuthate, stir for one or two minutes, -llow the excess of bismuthate to settle, and filter through an alundum rucible or a Gooch crucible with a mat of ignited asbestos which ias been washed with permanganate solution and water. Dilute the "Itrate to a definite volume and compare with standards. To prepare he standards measure out appropriate volumes of standard pernanganate solution, add to each the quantity of nitric acid used for he sample, and make to the same volume.

\section{CHECKS AND CALCULATIONS}

The reliability of an analysis may be checked by the calculations tescribed below.

\section{RESIDUE ON EVAPORATION AND SUM OF DETERIINED CONSTITUENTS}

For a calcium carbonate water of moderate concentration the "asidue on evaporation should be about the same as the sum of the determined constituents if the bicarbonate is divided by 2.03 to conrert it to the corresponding carbonate that remains on evaporation. if the water is high in calcium and sulphate the residue is likely to ' $\theta$ decidedly greater than the sum. If the water contains much aitrate and chloride with only a moderate quantity of sodium the "sidue may be less than the sum. Samples have been analyzed after they had stood in bottles so long that appreciable quantities of sili- ate were dissolved. Some of the alkalinity that was reported as arbonate and bicarbonate, or possibly hydroxide, was really silicate. All the silica was reported as such, and therefore the sum exceeded the weight of the residue by the amount of carbonate calculated as the quivalent of the alkalinity due to silicates.

\section{ERROR OF BATANCE OF BASES AND ACIDS}

The determinations described in the previous pages cover all the onstituents ordinarily found in natural waters in appreciable quan"ities. The titration of alkalinity which is reported as bicarbonate, arbonate, or hydroxide is really a measure of the excess of the bases "alcium, magnesium, sodium, and potassium over the amounts necesrury to balance the strong acid radicles sulphate, chloride, and nitrate. "Terefore, the accuracy of the analysis as a whole is indicated by the rrror of balance of the acids and bases.

In the calculation of the error of balance the silica and iron are "sually left out of consideration. The results in parts per million re divided by the combining weights of the respective radicles, giv- 
ing the milligram equivalents per kilogram, which are directly comparable. Instead of dividing by the combining weights it is generally more convenient to multiply by their reciprocals as given in the following list of factors for converting analyses in parts per million to milligram equivalents per kilogram:

Calcium 0.04991

Bicarbonate 0. 01639

Magnesium .08224

Sodium 04348

Potassium .02556

Carbonate

Sulphate .02082

Chloride 02821

The use of these factors is illustrated in Table 2, which shows a partial analysis as reported in parts per million and also in milligram equivalents per kilogram. The last column shows the analysis adjusted for graphic representation.

TABI\# 2.-Partial analysis of water from a publia supply

\begin{tabular}{|c|c|c|c|}
\hline \multirow[b]{2}{*}{ Constituents } & \multirow{2}{*}{$\begin{array}{c}\text { Parts per } \\
\text { million }\end{array}$} & \multicolumn{2}{|c|}{$\begin{array}{c}\text { Milligram equivalents } \\
\text { per kilogram }\end{array}$} \\
\hline & & Asreported & $\begin{array}{l}\text { Adjusted } \\
\text { to distrib- } \\
\text { ate error }\end{array}$ \\
\hline $\begin{array}{l}\text { Bases: } \\
\text { Calcium (Ca) } \\
\text { Magnesium }(\bar{M} \mathrm{M}) \\
\text { Sodium (Na) } \\
\text { Potassium (K) }\end{array}$ & $\begin{array}{c}23 \\
6.4 \\
3.0 \\
1.4 \\
\end{array}$ & $\begin{array}{r}1.1480 \\
.4441 \\
.1304 \\
.0358\end{array}$ & $\begin{array}{r}1.13 \\
.44 \\
.13 \\
.08 \\
\end{array}$ \\
\hline \multirow{3}{*}{$\begin{array}{l}\text { Acids: } \\
\text { Bicarbonate radicle }\left(\mathrm{HCO}_{3}\right) \\
\text { Sulphate radidele }\left(\mathrm{SO}_{4}\right) \\
\text { Chloride radicle }\left(\mathrm{Cl}_{1}\right) \\
\text { Nitrate radicle }\left(\mathrm{NO}_{3}\right)\end{array}$} & $\ldots \ldots \ldots \ldots$ & 1.7583 & 1.78 \\
\hline & $\begin{array}{l}70 \\
20 \\
3.3 \\
2.8\end{array}$ & $\begin{array}{r}1.1473 \\
.4164 \\
.0031 \\
.0452 \\
\end{array}$ & $\begin{array}{r}1.17 \\
. .42 \\
.09 \\
.00 \\
\end{array}$ \\
\hline & - & 1.7020 & 1.78 \\
\hline
\end{tabular}

- See p. 256.

As stated above, the sum of the equivalents of the bases should be equal to the sum for the acids. In the analysis shown in Table 2 the difference is 0.0563 , which is 1.6 per cent of the total 3.4603 . It is customary to report this error as +1.6 per cent and report as negative the errors of analyses in which the acids are in excess.

The error in this average analysis is seen to amount to more than the total potassium or nitrate and to be the equivalent of more than 1 part per million of calcium or sodium and about 2 parts of chloride or sulphate. It is not at all likely that this total error is concentrated in a single determination. An error up to 2 per cent may result from a summation of small unavoidable errors in the analysis of a water containing about 100 parts per million of dissolved solids. In careful work it is customary to have the error not over 1.0 per 
cent in analyses of water with much over 100 parts per million. of dissolved solids. The error may be 5 per cent for waters with as little as 25 or 30 parts per million of solids.

The general tendency is toward positive errors. The reagents and distilled water are more likely to introduce calcium, magnesium, and particularly sodium into the analysis than they are to introduce sulphate. The other determinations are made on separate samples to which reagents have not been added other than those used in the actual determination. When the error appears unduly large an examination of the analysis will frequently suggest the single determination that is responsible for most of the error.

\section{HARDNESS}

Report the hardness as the calcium carbonate corresponding to the total calcium and magnesium. Multiply the parts per million of calcium by 2.5 and the magnesium by 4.1 . If the milligram equivalents have been calculated the sum of the equivalents for calcium and magnesium may be multiplied by 50 to obtain the total hardness in parts per million.

It is sometimes desirable to show the noncarbonate hardness. This is most easily calculated from the milligram equivalents by subtracting the bicarbonate from the sum of the calcium and magnesium and multiplying the remainder by 50 . The noncarbonate hardness may be calculated by multiplying the bicarbonate in parts per million by 0.820 and subtracting the product from the total hardness.

The calculated hardness is generally considered more accurate than the hardness determined by the soap method. The two should, however, agree within about 10 per cent if the soap method has been followed with care. This check will occasionally indicate a gross error in the determination of calcium or magnesium.

\section{HYPOTHETICAL COMBINATIONS}

The disadvantages of expressing analyses in hypothetical combinations so outweigh the slight advantage of this form of expression that the use of such combinations was abandoned many years ago for reports of the United States Geological Survey.

The main advantage of hypothetical combinations as indicating the general character of a water may be had more simply by indicating the predominating basic and acid radicles if the analysis shows that the water contains chiefly the constituents of some one salt. This can best be seen from the equivalents but is not difficult to tell from the analysis in parts per million. If the hypothetical combinations must be reported they may be calculated from the equivalents as explained in the official methods of the Association of 
Official Agricultural Chemists. ${ }^{14}$ Stabler ${ }^{15}$ and Palmer ${ }^{18}$ hav? given methods for making calculations and classifications based on analyses expressed in milligram equivalents per kilogram, for which Stabler used the name " reacting values."

\section{GRAPHIC REPRESENTATION OF ANALYSES ${ }^{17}$}

In recent publications of the United States Geological Survey and for the study of analyses in the laboratory use has been made of diagrams to represent analyses, as shown in Plate 14. The heights of the sections are proportional to the quantities of the constituents a measured in equivalents. Only three patterns are used for each sida of the analysis. Unless the quantity of potassium, of nitrate, or of carbonate is exceptional no notice is taken of it. If the quantity $i$ r large a horizontal line is drawn through the area representing sodiun and potassium, chloride and nitrate, or bicarbonate and carbonate, to show the division, with the potassium, nitrate, or carbonate at tha top. Although the diagrams as shown with patterns are cheape: to print, it is easier to make them for laboratory study with colored crayons. A convenient color scheme is as follows: Calcium, red; magnesium, orange; sodium and potassium, yellow; chloride (and nitrate), light green; sulphate, blue; bicarbonate (and carbonate), violet.

Few analyses balance absolutely, and it is necessary to adjust the equivalents to make the two sides of the diagram come to the same height. This is illustrated in Table 2. Half the difference between. the totals of the equivalents for bases and for acids is divided pro. portionally and subtracted from the higher and added to the lnwer. This method of adjustment makes the greatest changes in the pre. dominating constituents and little change in those present in small quantities.

Since one equivalent of $\mathrm{CaCO}_{3}$ is 50 , the coordinates for equivalents represent hardness as $\mathrm{CaCO}_{3}$ in units of 50 parts per million. The total hardness is measured on the diagram to the top of the magnesium. The carbonate hardness is measured to the top of the bicarbonate if this is below the top of the magnesium. In such 8

\footnotetext{
${ }^{14}$ Assoc. Official Agricultural Chemists, Official and tentative methods of analysis, $\mathrm{r}$. 104, 1925.

${ }^{15}$ Stabler, Herman, The mineral analysis of water for industrial purposes and its interpretation by the engineer: Eng. News, vol. 60, p. 335, 1908; Some stream waters of th? western United States, with chapters on sediment carried by the Rio Grande and th? Industrial application of water analyses: U. S. Geol. Survey Water-Supply Paper 274, pr. 165-181, 1911.

${ }_{16}$ Palmer, Chase, The geochemical interpretation of water analyses : U. S. Geol. Surve" Bull. 479, 1911.

${ }^{17}$ Collins, W. D., Graphic representation of analyses: Ind. and Fng. Chemistry, vol, 16 p. 894, 1928.
} 
water the distance from the top of the bicarbonate to the top of the magnesium measures the noncarbonate hardness. If the bicarbonate extends above the magnesium there is no noncarbonate hardness; the water has more alkalinity than hardness and is commonly said to contain sodium bicarbonate or carbonate. Waters of this type are shown by diagrams 5, 10, and 11 in Plate 14, which represents the analyses in Table 3. 
258 CONTRIBUTIONS TO HYDROLOGY OF UNMTED STATES, 1027

\begin{tabular}{|c|c|c|c|}
\hline \multirow[t]{2}{*}{, } & \multirow{2}{*}{ 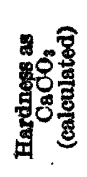 } & 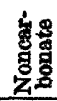 & 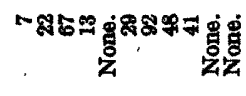 \\
\hline & & हึँّ & 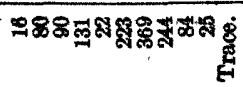 \\
\hline \multirow{13}{*}{ 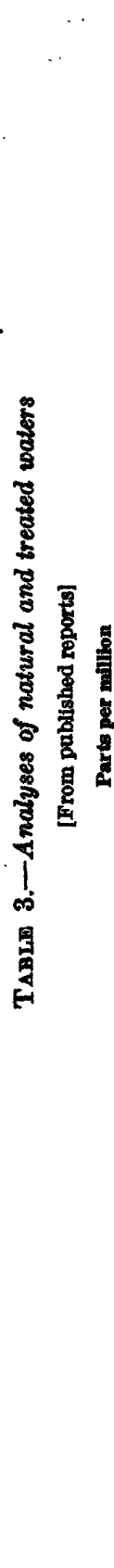 } & \multicolumn{2}{|c|}{ 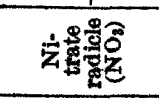 } & 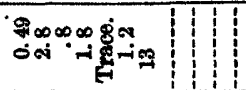 \\
\hline & \multicolumn{2}{|c|}{ 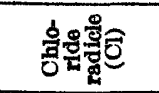 } & 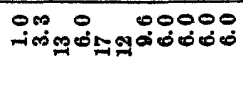 \\
\hline & \multicolumn{2}{|c|}{ 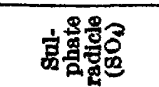 } & 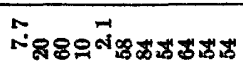 \\
\hline & \multicolumn{2}{|c|}{ 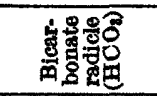 } & 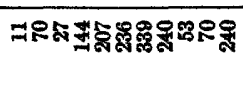 \\
\hline & \multicolumn{2}{|c|}{ 密最最 } & 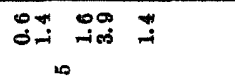 \\
\hline & \multicolumn{2}{|c|}{ 莺蛋 } & 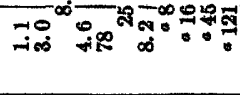 \\
\hline & \multicolumn{2}{|c|}{ 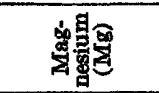 } & 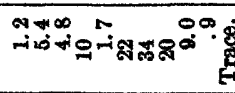 \\
\hline & \multicolumn{2}{|c|}{ ठ்륭ํํ } & 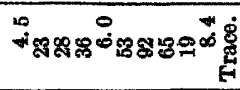 \\
\hline & \multicolumn{2}{|c|}{ 朂最 } & 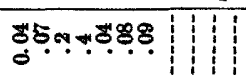 \\
\hline & \multicolumn{2}{|c|}{ 䟢递 } & 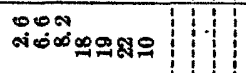 \\
\hline & \multicolumn{2}{|c|}{ 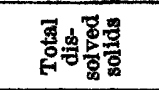 } & నిక్ష \\
\hline & \multicolumn{2}{|c|}{ 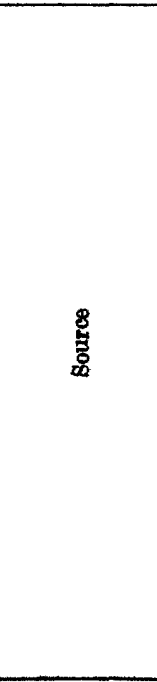 } & 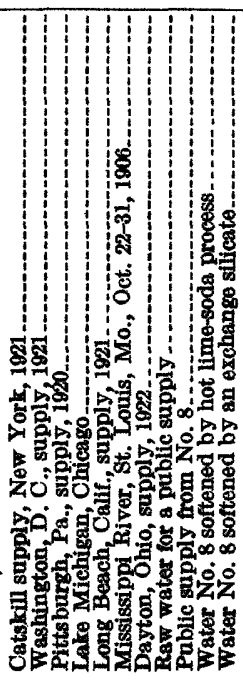 \\
\hline & & & 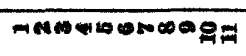 \\
\hline
\end{tabular}

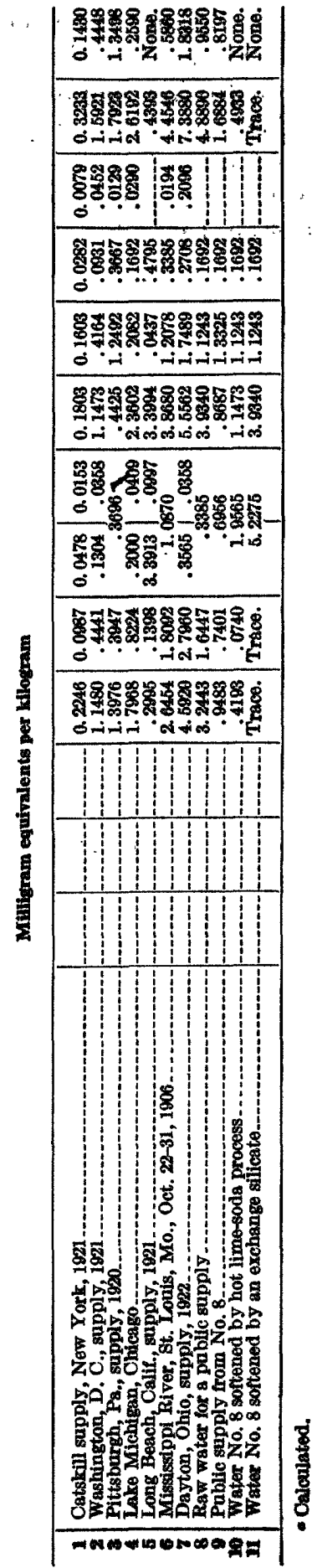




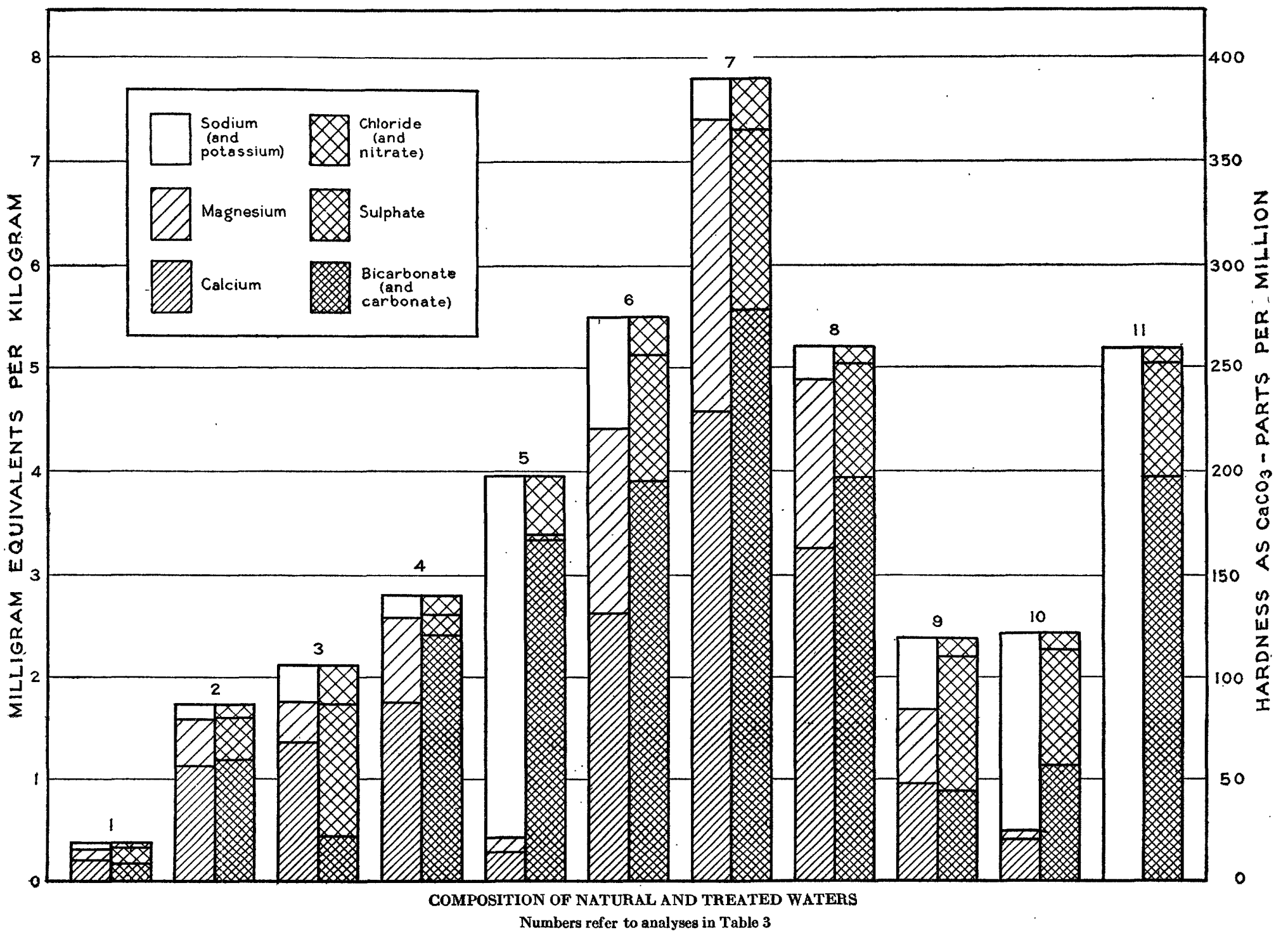




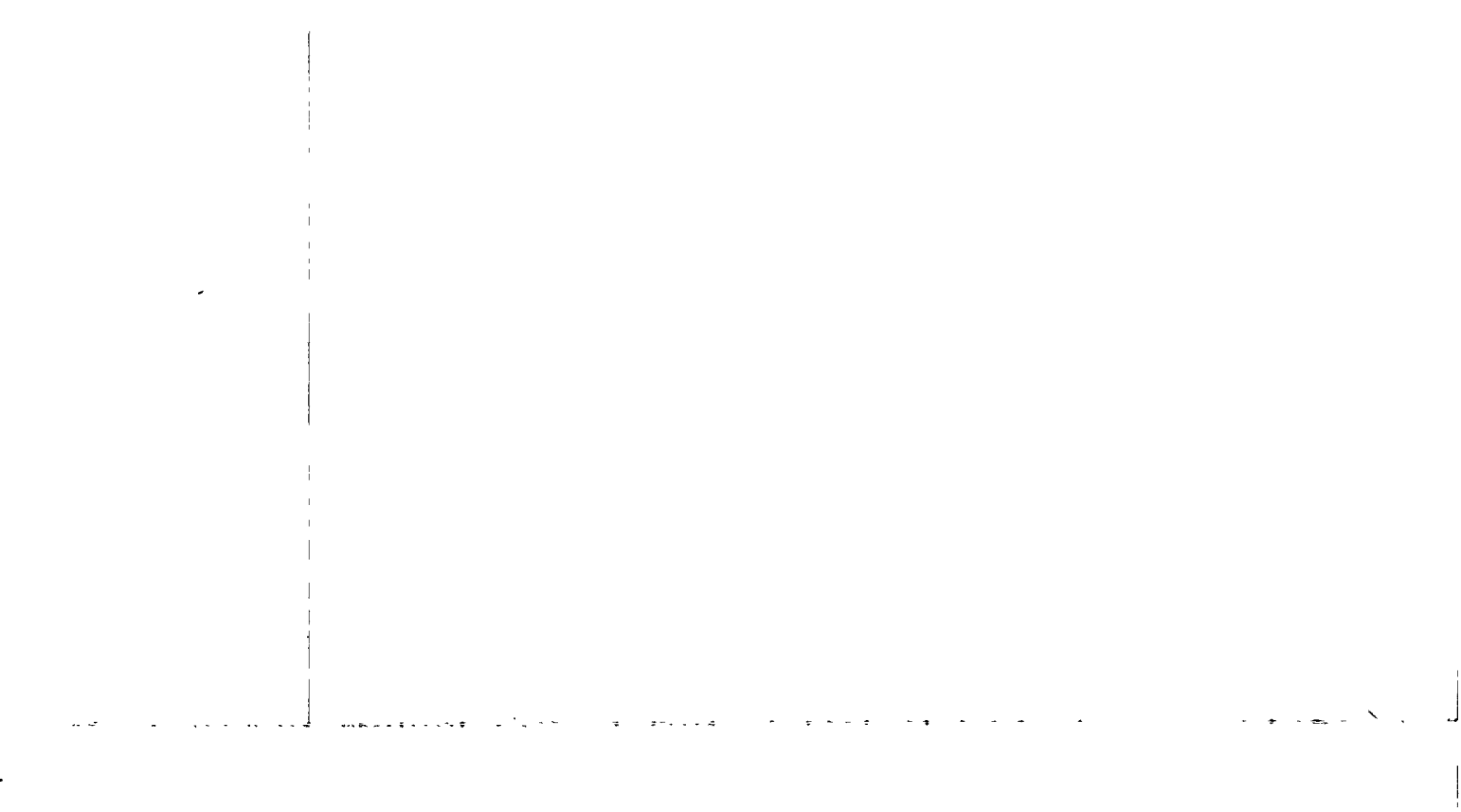




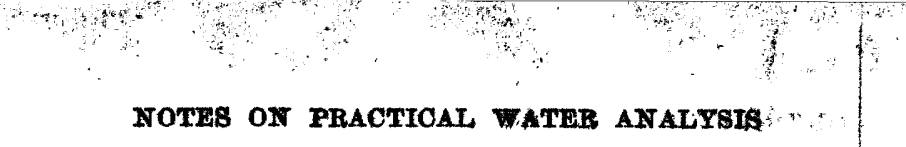

The type of water most widely used for public and private supplies in the United States is the calcium bicarbonate water in which calcium, magnesium, and bicarbonate make up the greater part of the dissolved mineral matter. Typical waters of this kind are shown in diagrams $2,4,6,7$, and 8 . Bicarbonate waters of very low mineral content like No. 1 are likely to have the other acid radicles together amount to more than the bicarbonate.

Many natural waters have dissolved enough gypsum to make calcium and sulphate the predominating radicles. The only calcium sulphate water shown in Plate 14 is No. 3, which owes most of its sulphate to contamination of river water with acid wastes from coal mines. The sulphuric acid has been neutralized by the water with reduction of alkalinity.

Here and there throughout the United States natural waters are found with high alkalinity and comparatively little calcium or magnesium. No. 5 is a typical sodium bicarbonate water, ${ }^{18}$ although many such waters contain more sodium bicarbonate and less calcium and magnesium. Some waters that have much more calcium and magnesium than sodium still have more bicarbonate than the combined calcium and magnesium and so may be said to contain sodium bicarbonate. They are, however, as much calcium bicarbonate waters as Nos. 4 or 6.

Diagram 9 shows the results obtained by treatment of water No. 8 for a public supply. The sulphate is increased because of the use of aluminum sulphate to produce a precipitate that will settle well and assist in clarification of the water. Lime is added to cause precipitation of calcium and magnesium as carbonate and hydroxide. The sulphate from the aluminum sulphate would increase the noncarbonate hardness but for the fact that soda ash (sodium carbonate) is added to decrease the noncarbonate hardness. The water as delivered has a total hardness of less than 100 parts per million and about the same noncarbonate hardness as before treatment. Complications in the treatment due to delayed precipitation of the calcium carbonate have led to adoption of recarbonation of waters treated by this process, as described recently by C. P. Hoover. ${ }^{19}$

Diagram 10 shows the result of treatment of a water like No. 8 by the hot lime-soda softening process. The hardness is reduced to about 25 parts per million, but the excess of sodium carbonate added brings the total quantity of dissolved material to about the same as in No. 9.

Diagram 11 shows the result of treating water No. 8 with an exchange silicate water softener. The calcium and magnesium are al-

3 Collins, W. D., and Howard, C. S., Natural sodium bicaxbonate water in the United Dtates: Ind. and Fing. Chemistry, vol. 19, p. 628, 1927.

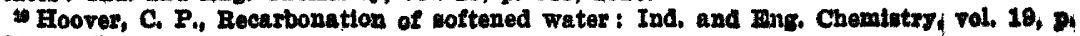
184, 1827. 
most entirely replaced by sodium, but the acid radicles are unaffected, and the total quantity of dissolved mineral matter is about the same as before treatment.

\section{SHORT METHODS AND PARTIAL ANALYSES}

It has been found in the Geological Survey and in some other laboratories where large numbers of analyses have been made that. most of the rapid methods are not generally superior in speed, reliability, or accuracy to the somewhat old-fashioned standard analytical procedures outlined above. Some of the shorter methods serve well for special routine work where the operator can acquire the necessary skill to obtain consistently accurate results, but for the ordinary laboratory it is usually more satisfactory to shorten the regulai methods.

As already stated, the preliminary examination will sometimes give all the information needed about a sample. The total hardness may be determined fairly accurately by the soap method and divided into carbonate and noncarbonate hardness from the determination of bicarbonate. A rough figure for sodium may be calculated, as noted on page 244 . The sum of the milligram equivalents of the acids minus the milligram equivalents of the total hardness gives the number of equivalents of alkalies, which may be multiplied by 23 to give the sodium. This figure includes any error in the hardness and the much greater probable error of the sulphate determined by turbidity. A rough figure for the dissolved solids may be calculated by adding the constituents as determined and calculated. assuming all the hardness to be due to calcium and converting tho bicarbonate to carbonate by dividing by 2.03 . About the same result can be obtained for an estimate of the total dissolved solids by the following equation, in which the formulas stand for the parts per million of the various acid radicles as determined.

Dissolved solids $=\mathrm{HCO}_{3}-1 / 6 \mathrm{HCO}_{3}+\mathrm{SO}_{4}+0.4 \mathrm{SO}_{4}+\mathrm{Cl}+0.6 \mathrm{Cl}$. $\mathrm{CO}_{3}+.7 \mathrm{CO}_{3}$

Starting from the complete practical analysis as outlined in thr text, the first and most common saving is the omission of the determination of potassium. The total weight of mixed chlorides ir calculated to sodium, and the error so introduced is not great in ar ordinary water with 100 to 500 parts per million of solids. If the quantity of sodium and potassium together is much less than 10 parts per million the percentage error introduced may be appreciable This shortening of the work still leaves available the check of balancing the analysis. 
The next step in saving is usually the entire omission of the determination of alkalies. This saves much time. It also leaves the analysis without a real check. A number can be calculated for alkalies as sodium. The sum of the milligram equivalents of the acid radicles minus the sum for calcium and magnesium gives a number which should give the sodium in parts per million when multiplied by 23. It includes, however, the algebraic sum of all the errors in the determination of acids and of calcium and magnesium. A rough check on the calcium and magnesium is furnished by the soap hardness, and a still more rough check on the whole analysis by comparison of the sum of the constituents with the residue on evaporation. The latter results may differ considerably in a very good analysis, so that the check is not very helpful.

If something more than a preliminary examination is desired and the time available or the value of the information to be obtained does not justify a complete analysis, the preliminary examination may be supplemented by determinations of calcium, magnesium, and sulphate, and the determinations of residue, silica, iron, sodium, and potassium may be omitted. A volume of 100 to 250 cubic centimeters of the sample is filtered if necessary, and the calcium is precipitated and determined as in the regular analysis. Magnesium is determined in the filtrate. In another portion of 100 to 250 cubic centimeters the sulphate is precipitated and determined as usual. Sodium is calculated. If time is important the calcium may be filtered about one hour after precipitation; the magnesium precipitate may be brought into condition for filtering within three or four hours after precipitation by vigorous stirring or shaking. Careful precipitation of the sulphate and sufficient heating after precipitation will make its filtration feasible after a few hours. Thus a sort of analysis can be completed the day it is started, and if no serious error is made the results may be of as much practical value as a complete accurate analysis. They will, however, be without any check except that made by comparing the hardness calculated from the calcium and magnesium with the hardness determined by the soap method.

In the hands of an experienced analyst the short cuts are often very useful, but the incomplete partial analyses can never give the confidence that goes with an analysis in which all the constituents present in appreciable quantities have been determined. 



\section{INDEX}

Page

Absecon Creek, N. J., basin and water of.. 109, 11 Acknowledgments for aid................. 4, 33, 67, 122 Alway, F. J., and Russel, J. C., cited....... 141-148 Angeles, Tex., water of Pecos River at....... 742

Assunpink Creek, N. J., basin and water $77,78-79,83$ of................................. 112-113, 119

Au deep-well current meter, apparatus for using, plates showing............. 14, 26

description of................................ 24-27

interpreting the readings of................ 28-29

plate ghowing ............................... 14

rating of........27-28

Badon Ghyben, W., theory of................ 6-7 Barstow, Tex., water of Pecos River above.- 74, $77,79-80,85$

Batsto River, N. J., course and water of... 109, 117 Beaver Brook, N. J., conrse and water of.... 112, 118-119

Beekmantown limestone, features of, near Woodstock, Va_..................... 53-54

Black River, N. J., besin and water of...... 107, 117

Briggs, L. J., Martin, O. F., and Pearce, J. R., cited.

141

Brown, J. 8., cited ........................... 6-7 Bucket, dump, old type of, plate showing..- 14 Buenavista, Tex., water of Pecos River at... 74 $77-78,80,82,87$

Caleium, presence of, in waters of Florida....

Carbonate and bicarbonate, presence of, in waters of Florida

182

Chambersburg limestone, features of, near Woodstock, $\mathrm{Va}$

Chapin-Sacks creamery, Woodstock, Va wells at.............................. 65,61

Chloxide, presence of, in waters of Florida. 183-184

Color of water, measurement of................. 185

Colorado River, water of, analyses of ........ $30-42$ water of, collection of samples............ 33

compasition of........................... 35-38 chart showing ................... 36

methods of analysis of ................ $34-35$ chart showing..................... 36

suspended matter in.................... $\quad 38$

Concrete, use of, in sealing wells.............. 17-21

Conococheague limestone, features of, near Woodstock, Va.

61

Coopers Creek, N. J., basin and waters of... 114, 119 Current meter, use of, in exploring wells..... 1-3

Delaware Creek, Tex., quality of water of ... 74,77 Delaware River; basin and waters of, in New Jersey 110-114, 118
Elbrook formation, features of, near Woodstock, Va.

Elizabeth River, N. J., basin and water of

Flat Brook, N. J., course and water of..... 111, 118

Florida, geology of............................... 178-180 quality of ground waters of, northern and central sections..................... 191-198

southern section........................ 198-195

western section............... 189-191

quality of surface waters of ................. 188

sources of water supplies in................ 196

surface features of.......................... 178

waters of, analyses of ....................... 206-283 analyses of, localities represented by ................................ 208-205

color of

field and laboratory work on.......... 177

hardness of ............................ 184-185

mineral constituents of ........... 181-186

suspended matter in................... 186

Follansbee, Robert, and Dean, H. J., cited.. 68

Fort Caswell, N. C., sand from, experiment on flow of water through....... 152-159

sand from, mechanical composition of.. 153 permeability as determined in the fleld. permeability calculated by Schlichter's formula..................... 159 permeability experiment with 100 millimeter column of ........... 167-168 with 1,000-millimeter column of .

Foster, Margaret D., analyses by _........... 67, 116

Gallinas River, Tex., quality of water of... 72,73

Gila River, Ariz., water of, anal yses of....... 43

Gochenour, William J., wells drilled by, near

Woodstock, Va................... 46, 62

Grandfalls, Tex., water of Pecos River at.... 74, $77-78,80,86$

Gravely, J. G., well of, at Woodstock, Va- 46,49, 62 Great Egg River, N. J., basin and water of 109, 118 Green Brook, N. J., basin and water of.... 107, 117 Greenwood Lake, N. J., features of............ 103 Gypsum, action of, in water used for irrige-

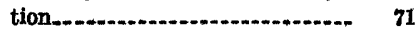

Hackensack River, N. J., basin and water of

Hawait, laws relating to artesian wells in.... 22-24 See also Oahu.

Haynes Creek, N. J., water of............... 113, 119 
Hazen, Allen, work of, on effective size of water-bearing materials......... 170-176 and Whipple, George C., cited .......... 245

Herzberg, Baurat, theory of Hondo River, N. Mex., quality of water of _._. 73,75 Honolulu district. See Oahu.

Howard, C. S., analyses by ....... 39-43, 116-119 Hydrogen sulphide, minute quantities of, in waters of Florida...................

Iron, presence of, in waters of Florida....... $\quad 181$ removal of, from water ................... 196

Iron turnings, use of, in plugging wells...... $\quad 19$

Irrigation, solids in water for ................. 70-71

Israelson, O. W., and West, F. L., cited.... 138

Juniata formation, features of, near Woodstock, Va...........................

King, F. H., work of, on effective size of waterbearing materials $170-176$

King, H. D., well of, near Roswell, N. Mex., plate showing.

Lawrence Brook, N. J., basin and water of_ 108, 117 Lead shot, use of, in plugging wells.

Little Colorado River, Ariz., water of, analyses of

water of, chart showing composition.-.-

Magnesium, small quantity in waters of Florida

Martinsburg shale, features of, near Woodstock, Va.

water in, near Woodstock, Va............. 56-57

Massanutten Mountain, Va., view from....- 49,51

Maurice River, N. J., basin and water of .. 110, 118

Meinzer, Oscar E., Preface on exploring wells 1-3

Middleton, H. E., citèd...................... 142

Miller-Brownlie, T. A., cited._-_...-...-... 152

Millstone River, N. J., basin and water

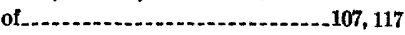

Mount Misery Branch, N. J., water of..... 113, 119

Mullica River, N. J., basin and water of.-108-109,

Musconetcong River, N. J., basin and water

of . $\ldots \ldots \ldots \ldots$ 112, 119

Now Jersey, climate of. . . . . . . drainage of . . . . . . economic features of . ....................... $92-93$ manufacturing in....................... 92-93 southern, waters of ...................... 110 surface features of . ....................... 90 surface waters of, analyses of . . ......... 114-119 analyses of, methods used in ......... 95-96 chemical character of ................. 99-119 collection of samples................... 93-94 features of . ........... 94-95, 114 map showing location of sampling points for................. quality of, sources of information.... 89-90 temperature of . . . ...................... 98 treatment of . . . . uses of ................................... 96-97

Nitrate, minute quantity of, in waters of Florida.
Oahu, artesian water on, rock in which it occurs

artesian water on, use and investigations of

investigation and improvement on........ 3,13

leaks in wells, causes of................... 13-14

measurement of . ..................... 11-14

water, fresh, behavior of, in contact with salt water. ....................... 7-11

wells, admixture of salt water in.......... 8-10

artesian, decline of head in .......... 8

plugging or sealing of . .

recasing of.................................. 15-17

Oasis Cotton Co., well of, plate showing..... 14

Owens River, Calif., chart showing composition of water of ..................... 36

Passaic River, N. J., basin and water of..... 100104,116

Paulins Kill, N. J., course and water of.... 111, 118

Pecos River, Texas, basin of.................. 68-69

discharge of, chart showing ................. $\quad 80$

lower basin of, quality of water of . ....... 77-82 middle basin of, quality of water of...... 73-76 upper basin of, quality of water of ........ 72-73 water of, analyses of ...................... 73, 74 collection of samples of .............. 67, 71 dissolved mineral matter in, chart showing ............ 80

irrigation with.......................... 69-71

methods used in analysis of........... 71-72 quality of, summary of report on .... 82 Pequannock River, N. J., course and water of . . . . .............................. 104, 116

Pequest River, N. J., basin and water of .... 111112,118

Pompton River, N. J., course and water of - 102-103 Porterville, Tex., water of Pecos River at.... 74, $77,79,84$

Price current meter, use of, in testing wells.. $\quad 12$

Rahway River, N. J., basin and water of _. 105, 116 Ramapo River, N. Y. and N. J., basin and water of . ........................ 103, 116 Rancocas Creek, N. J., basin and water of 113, 119 Raritan River, N. J., basin and water of.... 105108,117 Riffenburg, H. B., analyses by ............ 65, 67, 74 Rockaway River, N. J., basin and water of................................. 100-101, 116

Roswell artesian basin, N. Mex., meesurements of flow in................. 2-3 current meter used in investigation of.- 24-27 flowing wells in, plates showing.......... 14 tests of wells in............................ 29-32

Saddle River, N. Y. and N. J., basin and water of.......................... 104, 116

San Juan River, Utah, water of, analysis of.. $\quad 48$ Scofleld, C. S., cited............................. 70, 71 Sheffield, Tex., water of Pecos River at..... $\quad 74$, 77-78, 82,88

Shenandoah River, Va., water of, analysis of. $\quad 50$ Silica, presence of, in waters of Florida...... 181 Size of grain, effective, definition of...... 127, 130 slichter, C. S., work of, on effective size of water-bearing materials.......... 170-176 
Bodinm and potassium, presence of, in waters of Florida................ 182-183

Solution chanmels, formation of ............... 58 Stones River limestone, features of, near Woodstock, Va.

Stony Brook, N. J., water of.................. 107, 117 Sulphate, presence of, in waters of Florida.. 183 Swedge used in cleaning wells, plate showing.. 14 Swimming River, N. J., course and water of.

Tomstown limestone, features of, near Woodstock, Va....................

Tuscarora quartzite, features of, near Woodstoek, Va

Uniformity coefficient of granular materials, definition of

Veins, calcite, in limestone, occurrence of .... 58-59

Wading River, N. J., basin and water of... 109, 118 Waikiki district. See Oahu.

Wanaque River, N. J., basin and water of - 103, 116 Water, boiler-feed, treatment of.............. 108 calculation of hardness of .

tresh, behavior of, in contact with salt water.............................. 6-11 natural, constituents of ................. 69 natural and treated, analyses of............ $\quad 258$ composition of, plate showing......... 258 quality of, for domestic and for industrial use .................... 180-181 salt, floating of fresh water on.......... 6-7 softening of, results of ...................... 198-201 with exchange silicates............. 197-198 with lime and soda.................. 196-197 treatment of ground supplies........... 196-201 treatment of surface supplies ............. 201-202 Water analysis, balance of bases and acids in - 253-255 checking accuracy of ...................... 253-259 collection and care of sample............. 235-237 determination of alkalinity . ........ 238-240 aluminum.............................. 248 calcium -.................... 242, 249 chloride................................. 240-241 hardness_............................. 242-244 iron................... 246, 248 loss on ignition. ..................... 247 magnesium.......... 249-250 manganese............................ 252-253 nitrate_............... 241-242 potassium ....................... 250-252 residue on evaporation:.......... 246-247, 252 sillica . 247-248 sodium......................... 250-251, 252 sulphate.......................... 242, 250 suspended matter...................... 245-246 expression of results of ................... 187-188

in hypothetical combinations...... 255-256 general considerations.................... 235-236 graphic representation of . . . . ....... 256-257, 259 measurement of turbidity................. 245 methods of 186-18?
Water analysis, preliminary examination

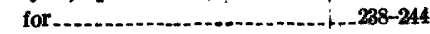

results of............................. 244

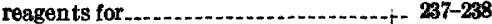

short methods of........................... 250-261

Water-bearing materials, apparent specific gravity of, determinations of - 123-124

from Forgus County, Mont., physical properties of ...................... 165

from Idaho, physical properties of ........ 164

from New Jersey, physical properties of ............... 166-167

from Rosebud County, Mont., physical properties of..................... 168-169

laboratory research on .................... 121-122 mechanical analysis of, expression of re-

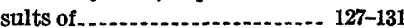

method followed...................... 124-127 relation to moisture equivalent and specific retention. ............... 189-144

shakers used in making, plate showing .............................. 124 methods of taking samples of .......... 122-123 moisture equivalent of, method of determining. .................... 134, 136-137

relation to mechanical analysis and specific retention. ................ 139-144

relation to speciflc retention....... 137-139

relation to specifie yield. . ............. 144

permeability of, apparatus used for testing - 144-147

apparatus used for testing, plate showing ........................... 144

comparison of computed and experimental coefficients................ 150-152

computing of results of tests. ....... 148-149

data concerning. ..................... 149-150

method of testing................... 147-148

tables of computed and experimental coefficients of...................... 163

tables of results of tests............. 160-163

porosity of, apparatus used in determin. ing, plate showing................ 124

conditions affecting ............ 133-134

method of determining. .............. 131-133 specific retention of, relation to mechanical analysis and moisture equivalent. . . . . . . 139-144

relation to moisture equivalent.... 137-139 specific yield of, relation to moisture equivalent............................

volume of grains in, method of determin-

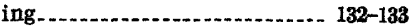
volume of samples of, method of determining . ....................... 131-132

Water supplies, requirements for.......... 195-196 Waynesboro formation, features of, sear Woodstock, Va.................... 54

Wells, artesian, laws of Hawail relating to. .. 22-24 artesian, methods of drilling.............. 11 deep, use of current meter in exploring... $1-3$ pump, future use of current meter in exploring -.................... 2 Whippany River, N.J., basin and water of - 101, 116 Whipple, George C., with Hazen, Allen, cited. 
Woodstock, Va., drilled wells near... Page dug wells near.............................. $59-60$ geologic formations underlying........... 52-55 geologic map of vicinity of ................. 46 ground water near, chemical character of 63-65 pollution of............................... $65-66$ limestone formations underlying, water in 67-63 location and activities of................... 45 municipal water supply of
Woodstock, Va., precipitation at........... $\begin{array}{r}\text { Page } \\ 46-59\end{array}$ precipitation at, chart showing........... 46 shale formations underlying, water in.... $56-87$ streams near................................ 49-80 surface features near........................ $80-52$ structure of rocks under................. $55-56$ uplifts of the region........................... 50 water at, sources of information........... 45-46 well on fair grounds at.................... 61-62 well on Spring Btreet in................... 49,60 wells near, conclusions concerning .... 62-68, 66 